Escola Politécnica da Universidade de São Paulo

Departamento de Engenharia de Telecomunicações e Controle

\title{
Otimização Multidimensional \\ Baseada em Heurísticas Aplicada aos Sistemas de Comunicação Sem Fio
}

Fernando Ciriaco Dias Neto 


\section{Escola Politécnica da Universidade de São Paulo}

Departamento de Engenharia de Telecomunicações e

Controle

\section{Otimização Multidimensional \\ Baseada em Heurísticas Aplicada aos Sistemas de Comunicação Sem Fio}

Tese orientada pelo Prof. Dr. Paul Jean Etienne Jeszensky intitulada Otimização Multidimensional Baseada em Heurísticas Aplicada aos Sistemas de Comunicação Sem Fio e apresentada à Escola Politécnica da Universidade de São Paulo, como parte dos requisitos necessários para a obtenção do Título de Doutor em Engenharia Elétrica.

Discente: Fernando Ciriaco Dias Neto 


\section{Escola Politécnica da Universidade de São Paulo}

Departamento de Engenharia de Telecomunicações e

Controle

\section{Otimização Multidimensional \\ Baseada em Heurísticas Aplicada aos Sistemas de Comunicação Sem Fio}

Tese orientada pelo Prof. Dr. Paul Jean Etienne Jeszensky intitulada Otimização Multidimensional Baseada em Heurísticas Aplicada aos Sistemas de Comunicação Sem Fio e apresentada à Escola Politécnica da Universidade de São Paulo, como parte dos requisitos necessários para a obtenção do Título de Doutor em Engenharia Elétrica.

Área de Concentração: Sistemas Eletrônicos

Discente: Fernando Ciriaco Dias Neto Orientador: Prof. Dr. Paul Jean Etienne Jeszensky 
Este exemplar foi revisado e alterado em relação à versão original, sob responsabilidade única do autor e com anuência de seu orientador.

São Paulo, 09 de Abril de 2012.

Fernando Ciriaco Dias Neto

Prof. Dr. Paul Jean Etienne Jeszensky

\section{Ficha Catalográfica}

Ciriaco Dias Neto, Fernando

Otimização Multidimensional Baseada em Heurísticas Aplicada aos Sistemas de Comunicação Sem Fio. São Paulo, 2012. 367 p.

Tese (Doutorado) - Escola Politécnica da Universidade de São Paulo. Departamento de Engenharia de Telecomunicações e Controle.

1. Algoritmos Heurísticos. 2. Otimização Multidimensional. 3. CDMA. 4. Estimativa de Parâmetros. 5. Deteç̧ão Multiusuário.

I. Escola Politécnica da Universidade de São Paulo. Departamento de Engenharia de Telecomunicações e Controle. II. Otimização Multidimensional Baseada em Heurísticas Aplicada aos Sistemas de Comunicação Sem Fio. 
"Pensar é o trabalho mais difícil que existe.

Talvez por isso tão poucos se dediquem a ele."

(Henry Ford)

"O único lugar aonde o sucesso vem antes do trabalho é no dicionário."

(Albert Einstein)

"O sucesso é ir de fracasso em fracasso sem perder entusiasmo."

(Winston Churchill)

"Eu acredito demais na sorte. E tenho constatado que, quanto mais duro eu trabalho, mais sorte eu tenho."

(Thomas Jefferson) 


\section{Agradecimentos}

Agradeço ao mestre e orientador, Prof. Dr. Paul Jean E. Jeszensky, pela sua compreensão e confiança, capacidade de orientação, pela sua generosidade em compartilhar e pelos mais de 8 anos de formação técnica que me foram concedidos. Mesmo à distância, acompanhou e participou da minha formação técnica desde a graduação, incentivando e direcionando as pesquisas realizadas.

Gostaria de registrar também meus agradecimentos ao amigo e orientador de graduação e mestrado, Prof. Dr. Taufik Abrão, pelo apoio, dedicação, capacidade de orientação, pelo companheirismo e por toda formação técnica disponibilizada, pois esta mostrou-se essencial para o exercício da profissão e pelo término de mais uma etapa.

Aos mestres, no mais amplo sentido da palavra, registro aqui meus agradecimentos.

À minha esposa, Janice, pelo carinho, paciência, companheirismo, incentivo e compreensão que me foram proporcionados nos últimos 12 anos. À minha filha, Letícia, que nasceu recentemente, pois trouxe um estado de felicidade que contagiou toda a família e me proporcionou uma motivação adicional.

Aos meus pais, Milson Antônio Ciriaco Dias e Marli Napoli Ciriaco Dias, pelo esforço e apoio incondicional que me ajudaram a chegar até aqui.

Aos meus familiares, ao meu irmão Thiago, meus avós e tios, pelo incentivo e compreensão.

À direção da Faculdade Pitágoras de Londrina, pela ajuda e compreensão ofertada nos momentos em que precisei, mostrando-se como uma instituição que apóia o aprimoramento técnico e obtenção de titulação dos seus colaboradores.

Aos meus amigos e colegas de profissão, Marcos Rambalducci e Roberson Fonte, pelo apoio irrestrito, pelas conversas motivacionais e pelos momentos de descontração. Sei que sem este apoio não chegaria a este ponto. Assim, conforme combinado, irei retribuir através de presentes em espécie líquida fermentada, tanto na forma de pão líquido ou mosto apurado em barricas.

Aos coordenadores de curso da Faculdade Pitágoras de Londrina, em especial 
ao Fábio Perfetto, Fábio Benfatti, Maria Angélica, Hertz, Eromi, José Ângelo e Maria de Lourdes pelo incentivo, dedicação e por dividirem as tarefas e experiências acadêmicas.

Aos professores Marcos Roberto Rossini, Alcides Beleze, Erica Takano, José de Lima, Liao Chi Tung, Airton José Sachetin, Lucídio de Jesus, Nilcéia Regina, Robson Naoto, Marcela Pedroza, Rosângela Tonon, Valdemir Antunes, Ana Mauricéia, Valter Crivilim e a todos os demais professores dos cursos de Engenharia da Faculdade Pitágoras de Londrina, pelo apoio e esmero com as aulas ministradas, pois são de extrema importância para o bom andamento das minhas atividades na coordenação.

Ao casal de amigos Tarcísio Villela e Kelly Cotosck que mesmo a distância, torcem pelo meu sucesso profissional e pessoal. Saibam que sou grato pelos conselhos e consideração que têm por mim e minha família. Desejo a vocês todas as vitórias.

Aos meus amigos e colegas de estudo, Bruno Angélico, André Kuramoto, Leonardo Dagui, Wagner Okano, Lisiane Heringer e Rafael Ribeiro entre outros, por compartilhar as conquistas, as descobertas e as dúvidas.

Aos amigos e antigos colegas de trabalho, Everaldo Ribeiro Brinhole, Leonimer Flávio de Melo, Jancer Destro, Hans Jurgen Muller, Fábio Durand, Luciano Bento Dantas, Rodrigo Fanucchi e outros, pelo incentivo, colaboração e exemplo de dedicação ao trabalho.

Aos profissionais de Engenharia, Taufik Abrão, José Fernando Mangili e Fábio Renan Durand que me ajudaram no início de carreira me proporcionando uma oportunidade de trabalho, pois a gratidão é algo que não se pode apenas interiorizar.

Aos muitos amigos que encontrei ao longo da vida, em especial ao Décio, Rausch, Fanucchi, Diogo, Igor, Brás, Carlinhos, Johnny, Gois, entre outros.

E àqueles que, de alguma forma, contribuíram para o avanço deste trabalho. 


\section{Resumo}

Esse trabalho de investigação visa a realização de uma análise sistemática, integrada e iterativa da utilização de algoritmos heurísticos aplicados aos problemas de estimativa de parâmetros e detecção multiusuário, sob o ponto de vista do compromisso desempenho $\times$ complexidade. O sistema considera topologias do tipo CDMA com exploração de diversidade multidimensional, ou seja, que utilizam uma ou mais técnicas de diversidade, considerando a diversidade de código, tempo, frequência e espaço, entre outras, sujeitos a desvanecimentos multipercurso. A solução integrada para os problemas de estimativa de parâmetros e detecção multiusuário consiste no uso recorrente de técnicas heurísticas. Além disso, estabelece-se uma análise comparada e sistêmica de convergência e de complexidade computacional da técnica de detecção proposta com alguns outros métodos, heurísticos ou determinísticos, relatados na literatura, considerando como métrica de desempenho o número de operações computacionais que cada estratégia requer para a detecção simultânea da informação de todos os usuários ativos no sistema. Por fim, e mais importante, considera-se como a principal contribuição deste trabalho a sistematização da utilização dos algoritmos heurísticos no processo de otimização dos problemas já citados, caracterização de limiares de desempenho e análise de complexidade destas técnicas, trazendo à comunidade científica parâmetros suficientes que devem ser respeitados na configuração dos algoritmos para garantia de resultados satisfatórios quando da utilização destes métodos em problemas de detecção multiusuário com diversidade multidimensional e estimativa de parâmetros. 


\section{Abstract}

This work will perform a systematic, integrated and iterative research of heuristic algorithms applied to parameter estimation and multiuser detection problems, considering the performance $\times$ complexity tradeoff. The CDMA systems with multidimensional diversity exploitation, i.e., with one or more diversity techniques, code diversity, frequency, time and space, among other, in multipath fading channel scenarios are considered. The integrated solution for parameter estimation and multiuser detection problem uses heuristic techniques in recurrent form. In addition, we intend to establish a systemic and comparative analysis of convergence and computational complexity of the proposal detection technique with some other methods, heuristic or deterministic, reported in the literature, considering the number of computational operations that each strategy requires for simultaneous detection from all active users as a performance metrics. Finally, and most importantly, this work systematizes the heuristic algorithms approach in the optimization problems process already mentioned, considering the thresholds for performance and complexity of these techniques, bringing the scientific community enough configuration parameters that must be respected in the setup algorithms step to guarantee satisfactory results when using these methods to multiuser detection with multidimensional diversity and parameter estimation problems. 


\section{Conteúdo}

$\begin{array}{ll}\text { Lista de Figuras ix } & \text { ix }\end{array}$

$\begin{array}{ll}\text { Lista de Tabelas } & \text { XV }\end{array}$

Lista de Siglas e Abreviaturas $\quad$ xviii

$\begin{array}{ll}\text { Notações } & \text { xxiii }\end{array}$

Lista de Símbolos $\quad$ xxv

1 Introdução ao Cenário $\quad 29$

1.1 Histórico Evolutivo dos Sistemas de Comunicação Sem Fio . . . . 29

1.2 Telefonia Celular . . . . . . . . . . . . . . . . . 34

1.2.1 A Tecnologia DS/CDMA . . . . . . . . . . 35

1.3 Redes Sem Fio . . . . . . . . . . . . . . . . . . 37

1.3.1 Escopos de Rede . . . . . . . . . . . . . . . . . . 40

1.4 Detecção Multiusuário . . . . . . . . . . . . . . . . . . 43

1.4.1 Heurísticas Aplicadas aos Sistemas de Comunicação . . . . 49

1.5 Estimativa de Parâmetros . . . . . . . . . . . . . . . 53

1.6 Outros Problemas . . . . . . . . . . . . . . . . . . . . 59

1.7 Motivação . . . . . . . . . . . . . . . . . . . . . . 60

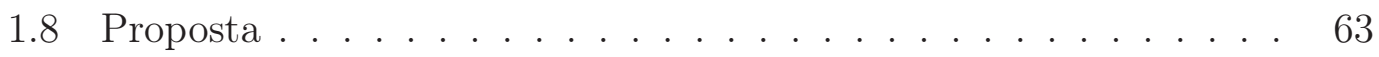

1.9 Descrição do Conteúdo . . . . . . . . . . . . . . . . 65

$\begin{array}{lll}2 & \text { Caracterização do Sistema } & 67\end{array}$

2.1 Transmissor . . . . . . . . . . . . . . . . . 68 
2.1 .1 Codificação de Canal . . . . . . . . . . . . . . . . . 70

2.1.2 Modulação de Múltipla Taxa . . . . . . . . . . . . . . . . . 81

2.1.3 Espalhamento Temporal por Sequência Direta . . . . . . . 86

2.1.4 Espalhamento na Frequência . . . . . . . . . . . . . . 88

2.1.5 Sistemas com Múltiplas Antenas de Transmissão . . . . . . 91

2.2 Canais MIMO Multipercurso . . . . . . . . . . . . . . . . . . . . 96

2.3 Receptor . . . . . . . . . . . . . . . . . . 104

2.3.1 Sistemas com Múltiplas Antenas de Recepção . . . . . . . 105

2.3.2 Detecção Convencional para Sistemas SIMO . . . . . . . . 105

2.3.3 Detector Multiusuário Ótimo . . . . . . . . . . . . . . 111

2.3.4 Decodificação . . . . . . . . . . . . . . . . 113

2.3.5 Decodificação Turbo . . . . . . . . . . . . . . . . . . 119

2.4 Estratégia de Decodificação Multidimensional . . . . . . . . . . 120

2.5 Estimativa de Parâmetros . . . . . . . . . . . . . . 126

2.5.1 Estimador de Canal via regra ML . . . . . . . . . . . . . 129

2.5.2 Estimador de Canal via Método do Gradiente . . . . . . . 131

2.5.3 Estimador de Canal via Algoritmo Heurístico . . . . . . . 132

3 Algoritmos Heurísticos

3.1 Codificação do Problema . . . . . . . . . . . . . . . . . . . . 134

3.1.1 Problema $\mathrm{MuD} \ldots \ldots \ldots \ldots$. . . . . . . . . . . 136

3.1.2 Problema MuChE . . . . . . . . . . . . . . . . 136

3.2 Definição do Espaço de Busca . . . . . . . . . . . . . . . . . . . . 141

3.3 Algoritmos Evolucionários . . . . . . . . . . . . . . . . 143

3.3.1 Tamanho da População . . . . . . . . . . . . . . . . . . . 144

3.3.2 Inicialização da População . . . . . . . . . . . . . . . . 147

3.3.3 Medida de Aptidão . . . . . . . . . . . . . . . . . . . . . 149

3.3.4 Reprodução . . . . . . . . . . . . . . . . . . . . . . . . 149 
3.3.5 Operadores Genéticos . . . . . . . . . . . . . . . 152

3.3.6 Estratégias de Reposição . . . . . . . . . . . . . . 156

3.3.7 Critério de Parada . . . . . . . . . . . . . . 157

3.3.8 Descrição sucinta dos Algoritmos Evolucionários . . . . . . 158

3.3.9 Pseudocódigos dos Algoritmos Evolucionários . . . . . . . 160

3.4 Algoritmos de Busca Local . . . . . . . . . . . . . . . . . . . 160

3.4.1 Estratégias de Escape e Deslocamento . . . . . . . . . 162

3.4 .2 Busca Local 1-Ótimo (1-OPT LS) . . . . . . . . . . . 163

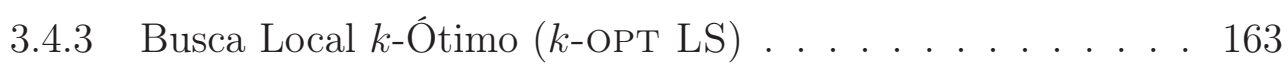

3.4.4 Recozimento Simulado SA . . . . . . . . . . . . . 164

3.4.5 Busca Tabu de Termo Curto (STTS) . . . . . . . . . . 166

3.4.6 Busca Tabu Reativa (RTS) . . . . . . . . . . . . . 169

3.5 Estratégias Hiperheurísticas . . . . . . . . . . . . . 170

3.5.1 Classificação das Hiperheurísticas . . . . . . . . . . . . . 172

3.5.2 Topologia Geral de uma Hiperheurística . . . . . . . . . . 173

3.6 Métricas para Avaliação de Algoritmos Heurísticos . . . . . . . . . 177

3.6.1 Controle Estatístico de Qualidade . . . . . . . . . . . . 179

4 Otimização de Parâmetros e Complexidade 183

4.1 Otimização de Funções . . . . . . . . . . . . . . . . . . . . . . . . 184

4.1 Função F1: De Jong . . . . . . . . . . . . . . . . 185

4.1 .2 Função F2: De Jong . . . . . . . . . . . . . . . 186

4.1 .3 Função F3: De Jong . . . . . . . . . . . . . . . . . . 187

4.1.4 Função F4: Michalewicz . . . . . . . . . . . . . . . . 188

4.1.5 Função F5: Schaffer . . . . . . . . . . . . . . . . 189

4.1.6 Função F6: Ackley . . . . . . . . . . . . . . . . . . . . . . 190

4.1 .7 Função F7: Rastrigin . . . . . . . . . . . . . . . . . . . 191

4.1.8 Função F8: Schwefel . . . . . . . . . . . . . . . . . . . . 192 
4.1.9 Função F9: 6-Hump CamelBack . . . . . . . . . . . . . . . 193

4.1 .10 Função F10: Shubert . . . . . . . . . . . . . . . . . 195

4.1.11 Resumo das características das funções . . . . . . . . . . 196

4.2 Resultados de Otimização dos Parâmetros . . . . . . . . . . . . . 199

4.2.1 Otimização dos parâmetros do Algoritmo Genético . . . . 200

4.2.2 Otimização dos parâmetros do algoritmo de EP . . . . . . 211

4.2.3 Parâmetros do algoritmo de busca local $k$-opt . . . . . . . 213

4.2.4 Otimização dos parâmetros do algoritmo de Recozimento Simulado. . . . . . . . . . . . . . 216

4.2.5 Otimização dos parâmetros dos algoritmos STTS e RTS 221

4.2.6 Otimização dos parâmetros do algoritmo Hiperheurístico 224

4.3 Resumo dos algoritmos considerando as otimizações realizadas . . 228

4.3.1 Análise de estabilidade dos algoritmos propostos . . . . . . 229

4.4 Complexidade computacional das topologias propostas . . . . . . 234

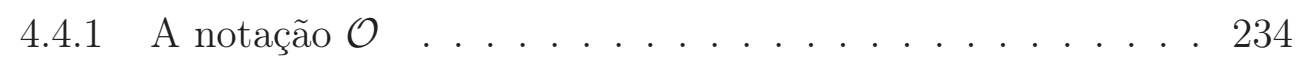

4.4.2 Operações de Ponto Flutuante . . . . . . . . . . . . . . 235

4.4 .3 Número de Operações . . . . . . . . . . . . . . . . 235

4.4.4 Determinação da complexidade . . . . . . . . . . . 236

4.4.5 Tempo Computacional . . . . . . . . . . . . . . 244

5 Resultados de Simulação para Sistemas de Telecomunicações 252

5.1 Detecção Multiusuário em Sistemas com Diversidade Multidimensional . . . . . . . . . . . . . . . . . . . . . 253

5.1.1 Detecção multiusuário em sistemas DS/CDMA . . . . . . 254

5.1.2 Detecção em sistemas codificados DS/CDMA . . . . . . 261

5.1.3 Detecção em sistemas multitaxa DS/CDMA . . . . . . . . 270

5.1.4 Detecção em sistemas multiportadora DS/CDMA . . . . . 272

5.1.5 Detecção em sistemas DS/CDMA com diversidade multidimensional ...................... 274 
5.1 .6 Sistema 3D iterativo . . . . . . . . . . . . 283

5.2 Estimativa de Parâmetros para Sistemas Multidimensionais . . . . 287

5.3 Discussão sobre Qualidade, Estabilidade e Complexidade em Sistemas de Telecomunicações . . . . . . . . . . . . . . . . 298

5.3.1 Complexidade Computacional . . . . . . . . . . . . 303

5.4 Escolha das Topologias e Discussão sobre Implementabilidade . . 310

5.4.1 Discussão sobre Implementabilidade dos Algoritmos Heurísticos . . . . . . . . . . . . . . . . . 310

6 Principais Conclusões e Trabalhos Futuros 314

6.1 Trabalhos Futuros . . . . . . . . . . . . . . 316

Apêndice A - Trabalhos Relevantes sobre Utilização de Algoritmos

$\begin{array}{ll}\text { Heurísticos em Sistemas CDMA } & 319\end{array}$

Apêndice B - Resumo das Principais Publicações 324

B.1 Trabalhos Anteriores .................. . . 324

B.2 Trabalhos Atuais . . . . . . . . . . . . . . . 327

Apêndice C - Canais de Rádio Móveis 332

C.1 Ruído Multiplicativo - Meio Físico de Propagação . . . . . . . . . 332

C.1.1 Modelo de Jakes Modificado . . . . . . . . . . . . . 333

C.2 Ruído de Fundo . . . . . . . . . . . . . . . . . . . . . 336

Apêndice D - Método de Simulação Monte Carlo 340

$\begin{array}{ll}\text { Referências } & 343\end{array}$ 


\section{Lista de Figuras}

1.1 Classificação geral para diversos detectores $\mathrm{SuD}$ e $\mathrm{MuD}$. . . . . . 44

1.2 Possível classificação para abordagens heurísticas . . . . . . . . 50

2.1 Sistema de transmissão e recepção visando disponibilização de diversidade . . . . . . . . . . . . . . . . . . . . 68

2.2 Exemplo de um codificador convolucional em sua representação

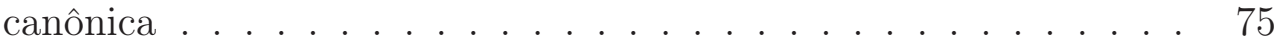

2.3 Exemplo de topologia para o codificador Turbo . . . . . . . . 78

2.4 Etapa de canalização do tipo códigos múltiplos para um sistema multitaxa ...................... 85

2.5 Etapa de embaralhamento do sinal em sistemas multitaxa . . . . . 87

2.6 Esquema TF-MC DS/CDMA . . . . . . . . . . . . . . . . 89

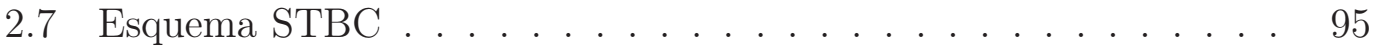

2.8 Exemplo de diagrama em treliça do codificador convolucional. . . 115

2.9 Topologia para o decodificador turbo. . . . . . . . . . . . . . 120

2.10 Sistema proposto para o transmissor e receptor com diversidade iterativa no domínio S-FT (3D) . . . . . . . . . . . . . . . 122

3.1 Equação (3.19) e equação (3.21) para os intervalos de confiança $\left(P_{b}\right)$ iniciando em 0,99 até 0,999 com incremento de 0,001 e tamanhos de população entre 1 e 250 indivíduos. . . . . . . . . . . . . 147

3.2 Operador crossover uniforme. . . . . . . . . . . . . . 153

3.3 Exemplo de operador crossover uniponto. . . . . . . . . . . . . . 154

3.4 Taxa de mudança dos bits em função do desvio padrão escolhido. 155

3.5 Mutação aleatória baseada no desvio padrão da figura 3.4. . . . . 155 
3.6 Classificação de uma HH de acordo com duas dimensões, a natureza do espaço de busca da heurística e a fonte de realimentação durante a aprendizagem. . . . . . . . . . . . . . . . . 172

3.7 Descrição de uma estratégia HH geral. . . . . . . . . . . . . . . 174

4.1 Representação da função F1 para duas variáveis. . . . . . . . . . . 186

4.2 Representação da função F2 para duas variáveis. . . . . . . . . . 187

4.3 Representação da função F3 para duas variáveis. . . . . . . . . . . 188

4.4 Representação da função F4 para duas variáveis e $m=10 . \quad$. . . 189

4.5 Representação da função F5 para duas variáveis. . . . . . . . . . . 190

4.6 Representação da função F6 para duas variáveis. . . . . . . . . . . . 191

4.7 Representação da função F7 para duas variáveis. . . . . . . . . . . 192

4.8 Representação da função F8 para duas variáveis. . . . . . . . . . . 193

4.9 Representação da função F9 para duas variáveis. . . . . . . . . . . . 194

4.10 Representação da função F10 para duas variáveis. . . . . . . . . . 195

4.11 Análise das estratégias de seleção dos genitores do GA para as funções F1, F5, F7 e F10. . . . . . . . . . . . . . . . . . 208

4.12 Análise das estratégias de crossover do GA para as funções F1, F5, F7 e F10. . . . . . . . . . . . . . . . . . . . 209

4.13 Análise da taxa de mutação do GA para as funções F1, F5, F7 e F10. . . . . . . . . . . . . . . . . 210

4.14 Análise das estratégias de reposição do GA para as funções F1, F5, F7 e F10. . . . . . . . . . . . . . . . . . . . 211

4.15 Análise da taxa de mutação do algoritmo EP-C para as funções $\mathrm{F} 1, \mathrm{~F} 5, \mathrm{~F} 7$ e F10 . . . . . . . . . . . . . . . . . . . 212

4.16 Análise do índice de clonagem do algoritmo EP-C para as funções F1, F5, F7 e F10. . . . . . . . . . . . . . . . . . . 214

4.17 Desempenho dos algoritmos de busca local 1-opt e 3-opt para as funções F1, F5 e F10. . . . . . . . . . . . . . . . . . . 215

4.18 Diminuição da temperatura de resfriamento do algoritmo SA para os parâmetros adotados. 
4.19 Convergência do algoritmo SA para as funções F1 a F10. . . . . . 220

4.20 Análise do período de proibição $P$ da lista Tabu para o algoritmo STTS e funções F1, F5, F7 e F10. . . . . . . . . . . . . . . . 223

4.21 Variação do período de proibição $P(i)$ da lista Tabu para o algoritmo RTS e função F7. . . . . . . . . . . . . . . . . . . . . 224

4.22 Variação média do período de proibição $P(i)$ da Lista Tabu para o algoritmo RTS e função F7. . . . . . . . . . . . . . . . 225

4.23 Análise das estratégias de seleção da HH para as funções F1, F5, F7 e F10. . . . . . . . . . . . . . . . . . . 227

4.24 Análise das estratégias de aceitação de soluções da HH para as funções F1, F5, F7 e F10.

4.25 Desempenho dos algoritmos metaheurísticos com parâmetros e estratégias otimizadas para as funções F1, F5, F7 e F10. . . . . . . 231

4.26 Tempo médio das etapas dos algoritmos por iteração e por aproximação polinomial. . . . . . . . . . . . . . . . . . . 248

4.27 Tempo médio para conversão de um número binário para decimal com o aumento do tamanho do candidato . . . . . . . . . . 248

5.1 Velocidade de convergência para os algoritmos heurísticos; sistema $\mathbf{S}_{1}$, perfil PD-1, $\bar{\gamma}=15 d B$ e $N F R=0 d B \ldots . . . . . .257$

5.2 BER média para o sistema $\mathbf{S}_{1}$, perfil PD-1 e $N F R=0 d B . \ldots 258$

5.3 BER média para o sistema $\mathbf{S}_{\mathbf{1}}, N F R=0 d B$ e perfil PD-2 com diversidade do receptor Rake, $D=L=2 \ldots \ldots$. . . . . 259

5.4 BER média para o sistema $\mathbf{S}_{1}, N F R=0 d B$ e perfil PD-3 com

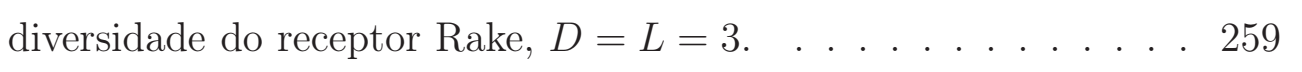

5.5 BER média para o sistema $\mathbf{S}_{\mathbf{2}}, N F R=0 d B$ perfil PD-2 e diversidade do receptor Rake, $D=L=2$. . . . . . . . . . . 260

5.6 BER média para metade dos usuários com $\bar{\gamma}=15 \mathrm{~dB}$ e demais usuários com NFR no intervalo $[-5,+15]$; sistema $\mathbf{S}_{1}$; perfil PD-2 com diversidade do receptor Rake, $D=L=2$. . . . . . . . . 261

5.7 BER média para metade dos usuários com $\bar{\gamma}=10 \mathrm{~dB}$ e demais usuários com NFR no intervalo $[-5,+25]$; sistema $\mathbf{S}_{\mathbf{2}}$; perfil PD-2 com diversidade do receptor Rake, $D=L=2$. . . . . . . . . 262 
5.8 Desempenho para a decodificação suave de Viterbi em canais Rayleigh plano; a) sem a utilização e b) com a utilização das estratégias heurísticas.

5.9 Comparação dos desempenho para a decodificação soft e hard de Viterbi para canais Rayleigh plano com e sem a utilização de heurísticas.

5.10 Desempenho para decodificação Turbo a) sem a utilização e b) com a utilização das estratégias heurísticas.

5.11 Desempenho para codificação LDPC a) sem a utilização e b) com a utilização das estratégias heurísticas.

5.12 Convergência dos algoritmos heurísticos para sistema 1 e $\bar{\gamma}=16 d B .271$

5.13 BER para o receptor Rake e estratégias heurísticas para sistema 1. 272

5.14 BER para o sistema multiportadora MC DS/CDMA com a) recepção convencional e b) estratégias heurísticas. . . . . . . . . . . . 274

5.15 Convergência para o detector convencional e algoritmos Heurísticos em cenários SIMO MC-CDMA para $E_{b} / N_{0}=9 \mathrm{~dB}, K=20 \ldots . .276$

5.16 Desempenho em termos da BER para os algoritmos heurísticos em cenário SIMO MC-CDMA para $K=20 \ldots \ldots$. . . . . 276

5.17 Desempenho em termos da BER para os algoritmos heurísticos em

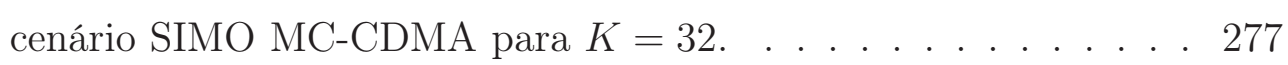

5.18 Desempenho em termos da BER para detector convencional e estratégias heurísticas em sistemas SIMO MC-CDMA em função do carregamento do sistema com $Q=2$ antenas de recepção. . . . . . 278

5.19 Comparação de desempenho entre os decodificadores baseados em heurísticas para sistemas QO-STBC MIMO com codificação LDPC (204,102) curto, $A_{T x}=4$ e $A_{R x}=1$ antenas e $K=1$ e $K=32$ usuários. . . 279

5.20 Comparação de desempenho entre os decodificadores baseados em heurísticas para sistemas QO-STBC MIMO com codificação LDPC $(204,102)$ curto, $A_{T x}=4$ e $A_{R x}=4$ antenas e $K=1$ e $K=32$ usuários. . . 280

5.21 Comparação da BER × relação sinal-ruído para um sistema sem codificação de canal.

5.22 Comparação da BER × relação sinal-ruído para um sistema com codificação de canal do tipo turbo. 
5.23 Comparação da BER $\times$ relação sinal-ruído para a) $K=40$ usuários e b) $K=100$ usuários; $A_{R x}=4, M=12$ e $N=9$. . . . . . . 285

5.24 Comparação da BER $\times$ relação sinal-ruído para a) $K=40$ usuários e b) $K=100$ usuários; $A_{R x}=8, M=12$ e $N=9 \ldots \ldots . .286$

5.25 Comportamento da BER em relação ao aumento do número de usuários do sistema para $\bar{\gamma}=10 \mathrm{~dB}, A_{R x}=8, M=12$ e $N=9 . \quad 287$

5.26 Evolução do MSE normalizado para $K=10$ usuários com 2 percursos em função do tamanho do frame $I$. . . . . . . . . . . . . . 289

5.27 Evolução típica do MSE normalizado, considerando $K=8$ usuários em função do número de gerações $G_{T}$; são apresentados o MSE normalizado para os coeficientes iniciais e para um coeficiente intermediário (197), de um grupo de 670 estimativas. . . . . . . . .

5.28 Acurácia das estimativas de canal (módulo e fase) sobre os 670 bits para quatro usuários distintos; sistema com $K=10$ usuários, $L=2$ percursos, espalhamento Doppler $f_{D}=17 \mathrm{~Hz}, N F R=0$ dB e tamanho do preâmbulo $I=10$ bits. (a) usuário 1, percurso 1 e (b) usuário 3 , percurso $1 \ldots \ldots \ldots \ldots$. . . . . . . . . .

5.29 Acurácia das estimativas de canal (módulo e fase) sobre os 670 bits para quatro usuários distintos; sistema com $K=10$ usuários, $L=2$ percursos, espalhamento Doppler $f_{D}=17 \mathrm{~Hz}, N F R=0$ dB e tamanho do preâmbulo $I=10$ bits. (a) usuário 7, percurso 2 e (b) usuário 10, percurso $2 \ldots \ldots \ldots \ldots$

5.30 PDF do erro percentual médio (MEP) para as três codificações tipo I, II e III, considerando sistema $\mathbf{S 1}$.

5.31 PDF do erro percentual médio (MEP) para os sistemas S1 e S3 e estimador GA, considerando a possibilidade de percursos não resolvíveis no receptor. . . . . . . . . . . . . . . . 296

5.32 Comparação entre as PDF's do erro percentual médio (MEP) para os estimadores GA e ML, considerando sistema $\mathbf{S 1}$

5.33 BER para as estratégias heurísticas GA e HH como estimador de canal e detector conjunto considerando sistema $\mathbf{S 1}$.

5.34 Tempo médio para o cálculo das funções custo e tempo por aproximação polinomial. . . . . . . . . . . . . . . . . . 308 
6.1 Sistema proposto para o transmissor e receptor com diversidade iterativa $5 \mathrm{D} \ldots \ldots \ldots \ldots$

C.1 Coeficientes de um canal Rayleigh Plano com 12500 amostras e com zoom em 800 amostras . . . . . . . . . . . . . . 335

C.2 Distribuição para amplitude e fase para coeficientes de um canal com desvanecimento Rayleigh implementado a partir modelo de Jakes modificado. . . . . . . . . . . . . . . . . . . . . 336

C.3 Função densidade de probabilidade para um conjunto de 60000 amostras representando um processo AWGN, em comparação com a $p d f$ teórica, dada pela equação (C.7) . . . . . . . . . . . . . . . . 339

D.1 (a) Inicialização dos parâmetros do sistema e Finalização da simulação com obtenção de gráficos de desempenho em termos da BER; (b) Geração, Transmissão e Recepção de Dados; (c) Estratégia Monte-Carlo de Parada e (d) Estimador da BER . . . . . . 341

D.2 Intervalos de Confiança sobre a BER quando o valor observado for igual a $P_{e}=10^{-v} \ldots \ldots \ldots$. . . . . . . . . . . . . . 342 


\section{Lista de Tabelas}

2.1 Principais aplicações multimídia e seus respectivos requisitos. . . . 67

2.2 Comparação de alguns parâmetros para esquemas multitaxa. . . . 83

3.1 Algoritmos heurísticos para o problema MuD e MuChE. . . . . . 160

3.2 Algoritmos heurísticos de Busca Local para o problema MuD e MuChE. . . . . . . . . . . . . . . . . . . . . . . 164

3.3 Algoritmo de Recozimento Simulado para o problema MuD e MuChE. . . . . . . . . . . . . . . . . 167

3.4 Algoritmo STTS para o problema MuD e MuChE. . . . . . . . . . 168

3.5 Algoritmo RTS para o problema MuD e MuChE. . . . . . . . . . 170

4.1 Resumo das principais características das funções objetivo utilizadas para testes. . . . . . . . . . . . . . . . . . 196

4.2 Principais valores associados a cada função de testes. . . . . . . 199

4.3 Parâmetros utilizados na simulação da otimização do tamanho do poço de cruzamento . . . . . . . . . . . . . . . . . . 201

4.4 Simulações para o tamanho do poço de cruzamento considerando as funções F1 a F10 . . . . . . . . . . . . . . . . . . . . . . 203

4.5 Tabela de pontuação utilizada . . . . . . . . . . . . . 206

4.6 Colocação atribuída aos parâmetros por prova e modalidade e total de pontos conquistados . . . . . . . . . . . . . . 207

4.7 Resumo dos parâmetros e estratégias otimizadas para cada algoritmo230

4.8 Valores ótimos e aceitáveis para cada função de testes. . . . . . . 232

4.9 Medida ACI para os algoritmos obtidas na prova de Decathlon. . . 233

4.10 Resumo do número aproximado de instruções média genérica dos algoritmos. . . . . . . . . . . . . . . . . . . . . 243 
4.11 Complexidade em termos do número médio de operações dos algoritmos para otimização das funções F1 a F10. . . . . . . . . . . . 244

4.12 Tempo de processamento para o cômputo das funções custo $\varpi$ para F1 a F10 considerando a média em $10^{6}$ realizações. . . . . . . . . 247

4.13 Complexidade em termos do tempo médio dos algoritmos em ms para otimização das funções F1 a F10. . . . . . . . . . . . . . . . 249

4.14 Resumo das Pontuações e Colocação dos algoritmos. . . . . . . . . 250

5.1 Principais parâmetros de sistema e canal adotados para o sistema unitaxa. . . . . . . . . . . . . . . . . . 255

5.2 Três perfis atraso-potência (PD) utilizados nas simulações. . . . . 255

5.3 Principais parâmetros do sistema DS/CDMA com codificação convolucional e decodificação multiusuário baseado em algoritmos heurísticos.

5.4 Polinômios da codificação Turbo e cenários do sistema. . . . . . . 266

5.5 Parâmetros da decodificação Turbo. . . . . . . . . . . . . . . . . . 267

5.6 Principais parâmetros para o sistema multitaxa. . . . . . . . . . . 270

5.7 Parâmetros do canal e do sistema multiportadora com múltiplas antenas. . . . . . . . . . . . . . . . . 275

5.8 Sistema MIMO e parâmetros do canal. . . . . . . . . . . . . . . . 279

5.9 Parâmetros do canal e do sistema multidimensional. . . . . . . . . 281

5.10 Parâmetros do sistema e do canal. . . . . . . . . . . . . . . . . . . 284

5.11 Principais parâmetros do sistema para o problema MuChE. . . . . 288

5.12 Valores de MEP obtidos para cada codificação e algoritmo. . . . . 295

5.13 Valores de MEP obtidos para cada sistema com codificação Tipo I. 297

5.14 Comparação do MEP para o estimador ML e GA em sistema S1. 297

5.15 Pontuação obtida para cada sistema e algoritmo heurístico em problemas MuChE. . . . . . . . . . . . . . . . . . . . . . 302

5.16 Número de operações para o cálculo de uma função custo. . . . . 304

5.17 Cenários utilizados nas simulações considerados para o cálculo do número de operações. . . . . . . . . . . . . . . . . . . . . . 306 
5.18 Número de operações necessárias para otimização dos cenários 1 a 42 apresentados de forma resumida na tabela 5.17 . . . . . . . . 307

5.19 Tempo médio em segundos para otimização dos cenários 1 a 42 apresentados de forma resumida na tabela 5.17 . . . . . . . . . 309

5.20 Resumo das pontuações e colocação dos algoritmos para os cenários de telecomunicações considerados. . . . . . . . . . . . . . . . . . 310

C.1 Momentos estatísticos, teóricos e numéricos, de $1^{a}$ e $2^{a}$ ordem para um processo AWGN . . . . . . . . . . . . . . . 338 


\section{Lista de Siglas e Abreviaturas}

$\begin{array}{ll}1 \mathrm{G} & \text { Sistemas de Comunicação de Primeira Geração } \\ 2 \mathrm{G} & \text { Sistemas de Comunicação de Segunda Geração } \\ 3 \mathrm{G} & \text { Sistemas de Comunicação de Terceira Geração } \\ 4 \mathrm{G} & \text { Sistemas de Comunicação de Quarta Geração } \\ \text { AA } & \text { Adaptative Acceptance - Aceitação Adaptativa } \\ \text { ACI } & \text { Algorithm Capability Index - Indice de Qualidade do Algoritmo } \\ \text { ACO } & \text { Ant Colony Optmisation - Otimização por Colônia de Formigas } \\ \text { AM } & \text { Amplitude Modulation - Modulação por Amplitude } \\ \text { AMPS } & \text { Advanced Mobile Telephone System - Sistema de Telefonia Móvel } \\ & \text { Avançada } \\ \text { ANATEL } & \text { Agência Nacional de Telecomunicações } \\ \text { APP } & \text { A Posteriori Probability - Probabilidade a posteriori } \\ \text { ASI } & \text { Algorithm Stability Index - Índice de Estabilidade do Algoritmo } \\ \text { AWGN } & \text { Additive White Gaussian Noise - Ruído Branco Aditivo Gaussiano } \\ \text { BER, Pe } & \text { Bit Error Rate - Taxa de Erro de Bit } \\ \text { BLAST } & \text { Bell Laboratories Layered Space-Time - Estratégia Espaço-Tempo } \\ & \text { desenvolvida pelos Laboratórios Bell }\end{array}$

BPSK Binary Phase Shift Keying - Modulação por Chaveamento de Fases

BW Band Width - Largura de banda

CD Conventional Detector - Detector Convencional

CDMA Code Division Multiple Access - Acesso Múltiplo por Divisão de Código

CDMA2000 Tecnologia CDMA de terceira geração

CP Cyclic Prefix - Prefixo Cíclico

CRC Cyclic Redundancy Check - Checagem de Redundância Cíclica

CSI Channel State Information - Informação de estado do canal

DD Decorrelator Detector - Detector de Descorrelação

DAMPS Sistema de Telefonia Móvel Avançada Digital

DOA Direction of Arrival - Direção de Ângulos de Chegada

DS Direct Sequence - Espalhamento por Seqüência Direta

DS/CDMA Direct Sequence CDMA - CDMA por Seqüência Direta

DSL Digital Subscriber Line - Linha de Assinante Digital

DSP Digital Signal Processing - Técnica de Processamento Digital de Sinais 
EGC Equal Gain Combining - Combinação de Ganho Igual

EP Evolutionary Programming - Algoritmo de Programação Evolucionária

EP-C Evolutionary Programming with Cloning - Algoritmo de Programação

Evolucionária com Clonagem

ERB Estação Rádio-base

ESPRIT Estimation of Signal Parameters via Rotational Invariant Techniques -

Estimativa de Parâmetros de Sinais via Técnicas de Invariância Rotacional

FCC Federal Communications Commission - Comissão Federal de Comunicações

FDD Frequency Division Duplex - Divisão de Frequência Duplex

FDMA Frequency Division Multiple Access - Acesso Múltiplo por Divisão de Frequência

FEC Forward Error Correction - Correção de Erro Direta

FFT Fast Fourier Transform - Transformada Rápida de Fourier

FHSS Frequency Hopping Spread Spectrum - Espalhamento Espectral por Salto em Frequência

FM Frequency Modulation - Frequência Modulada

GA Genetic Algorithm - Algoritmo Genético

GAMuChE GA utilizado para o problema MuChE

GAMUD GA utilizado para o problema $\mathrm{MuD}$

GD Gradient Descent - Algoritmo Gradiente Descendente ou estratégia

Grande Dilúvio dependendo do contexto

GSM Global System for Mobile Communications - Sistema Global para

Comunicações Móveis

HH Hiperheurística

IC Interference Cancellation - Cancelamento de Interferência

IEEE Institute of Electrical and Electronics Engineers - Instituto de

Engenheiros Eletricistas e Eletrônicos

IFFT Inverse Fast Fourier Transform - Transformada rápida de Fourier inversa

ILS Integer Least-Squares - Menor Inteiro Quadrático

IMT-2000 International Mobile Telecommunictaions 2000

IMTS Improved Mobile Telephone Service - Serviço de telefonia Móvel

Aperfeiçoado

IP Internet Protocol - Protocolo de Internet

ISI Intersymbol Interference - Interferência Intersimbólica

IS-54 Interim Standard 54 - Padrão Interino 54

IS-95 Interim Standard 95 - Padrão Interino 95

IS-136 Interim Standard 136 - Padrão Interino 136

ISM Industrial, Scientific and Medical - Bandas para fins industriais, 
científicos e médicos

ITU International Telecommunication Union - União Internacional de Telecomunicações

JTACS Japan TACS

LDPC Low Density Parity Check - Verificação de Paridade de Baixa Densidade LEO Low Earth Orbit - Órbita Baixa

LLF Log Likelihood Function - Função de Verossimilhança Logarítmica

LMS Least Mean Square - Algoritmo dos Mínimos Quadrados Médios

LSL Lower Specification Limit - Limite de Especificação Inferior

MAI Multiple Access Interference - Interferência de Múltiplo Acesso

MAP Maximum a Posteriori Probability - Máxima Probabilidade a posteriori

MC Multiple Codes - Sistema Multitaxa por Códigos Mmúltiplos ou Multicarriers - Sistema Multiportadora, dependendo do contexto

MCS Monte Carlo Simulation - Método de Simulação Monte Carlo

MEP Mean Error Percentage - Erro Percentual Médio

MFB Matched Filter Bank - Banco de Filtros Casados

MISO Multiple-Input Single-Output - Múltiplas Entradas e Saída Uúnica

MIMO Multiple-Input Multiple-Output - Múltiplas Entradas e Saídas

ML Maximum Likelihood - Máxima Verossimilhança

MM Multimodulation Scheme - Sistema Multitaxa por vários formatos de Modulação

MMSE Minimum Mean Square Error - Estimador baseado no Mínimo Erro Médio Quadrático

MPG $\quad$ Multiple Processing Gain - Sistema Multitaxa por Processamento Múltiplo inteiro

MRC Maximum Ratio Combiner - Regra de Combinação de Razão Máxima

MSE Mean Square Error - Medida do erro quadrático médio

Mu Multiuser - Multiusuário

MuCHE Problema da estimativa de parâmetros do canal para sistemas $\mathrm{Mu}$

MuD Multiuser Detection - Detecção Multiusuário

MUSIC Multiple Signal Classification Classificação de Sinais Múltiplos

NFR Near-Far Ratio - Efeito "perto-longe"

NMT Nordic Mobile Telephone System - Sistema Nórdico de Telefonia Móvel

NV Naive Acepptance - Aceitação Ingênua

OFDM Orthogonal Frequency Division Multiplexing - Mutiplexação por Divisão de Frequência Ortogonal

OFDMA Orthogonal Frequency Division Multiple Access - Acesso Múltiplo por Divisão de Frequência Ortogonal 
OMuD Optimum Multiuser Detector - Detector Multiusuário Ótimo

PCCC Parallel Concatenated Convolutional Codes

PDA Personal Digital Assistant - Assistente Digital Pessoal

PDC Personal Digital Cellular - Celular Pessoal Digital

PDF Probability Density Function - Função Densidade de Probabilidade

PIC Parallel Interference Cancelation-Cancelamento de Interferência

Paralelo

PLL Phase Locked Loop - Realimentação por Travamento de Fase

PN Pseudo-Noise - Trata-se de seqüências pseudo-aleatórias

PSO Particle Swarm Optimisation - Otimização por Nuvem de Partículas

QAM Quadrature Amplitude Modulation - Modulação por Amplitude em Quadratura

QoS Quality of Service - Qualidade do Serviço

QPSK Quadrature Phase Shift Keying - Modulação por Chaveamento de Fases em Quadratura

RAKE Receptor com diversos MFB para canais multipercurso

RLS Recursive Least Square - Algoritmo dos Mínimos Quadrados Recursivo

RSC Recursive Systematic Convolutional

RTS Reactive Tabu Search - Busca Tabu Reativa

SA Simulated Annealing - Recozimento Simulado

SC Sliding Correlator - Correlacionador de Escorregamento

SCCC Serial Concatenated Convolutional Code - Códigos Convolucionais Concatenados em Série

SDM Spatial Division Multiplexing - Multiplexação por Divisão Espacial

SI

$\mathrm{SIC}$

SIM

SIMO

SISO

$\mathrm{SM}$

SMS

SNR

$\mathrm{SPC}$

SS

STBC

STC

STTC
Self-interference - Auto-interferência

Sucessive Interference Cancellation - Cancelamento de Interferência Sucessivo

Subscriber Identification Module - Módulo de Identificação do Assinante

Single-Input Multiple-Output - Entrada Única e Múltiplas Saídas

Single-Input Single-Output - Entrada e Saída Única

Spatial Multiplexing - Multiplexação Espacial

Short Message Service - Serviço de Mensagens Curtas

Signal Noise Ratio - Relação Sinal Ruído

Statistical Process Control - Controle Estatístico de Processo

Spread Spectrum - Espalhamento Espectral

Space-Time Block Code - Codificação Espaço-Tempo por Blocos

Space-Time Coding - Codificação Espaço-Tempo

Space-Time Trellis Code - Codificação Espaço-Tempo por Treliça 
STTS

SuB

SuD

TACS

TC

TCM

TDD

TDMA

TGN

USL

UWB

UMTS

VCR

$\mathrm{VPG}$

VSL

WCDMA

W-H

WECA

WLAN

WMAN

WPAN

WWISE

ZF-DF
Short Term Tabu Search - Busca Tabu de Termo Curto

Single-User Bound - Limite de BER para usuário isolado

Single-User Detection - Detecção Uniusuário

Total Access Communications System - Sistema de Comunicações de Acesso Total

$$
\text { Turbo Codes - Códigos Turbo }
$$

Trellis Coded Modulation - Modulação por Código em Treliça

Time Division Duplex

Time Division Multiple Access - Múltiplo Acesso por Divisão de Tempo Task Group $n$ - Grupo de Trabalho n

Upper Specification Limit - Limite de Especificação Superior

Ultra Wideband - Banda Ultra-Larga

Universal Mobile Telecommunications System - Sistema de

Telecomunicações Móvel Universal

Variable Chip Rate - Taxa de chip variável

Variable Processing Gain - Ganho por Processamento Variável

Variable Spreading Length - Comprimento de Espalhamento variáveis

Wideband CDMA - Tecnologia CDMA de terceira geração

Walsh Hadamard - Família de seqüências de espalhamento

Wireless Ethernet Compability Alliance - Aliança para Compatibilidade

da Ethernet sem fio

Wireless Local Area Network - Rede Local sem fio

Wireless Metropolitan Area Network - Rede Metropolitana sem fio

Wireless Personal Area Network - Rede Pessoal sem fio

World Wide Spectrum Efficiency - Eficiência Espectral Mundial

Zero-Forcing Decision Feedback - Detector de Decisão Realimentada 


\section{Notações}

$$
a, \mu, A
$$$$
\text { a }
$$

A

$\hat{a}$

$\bar{a}$

$\underline{a}$

$A D C[\cdot]$

$\operatorname{arctg}\{\cdot\}$

$\arg \{\cdot\}$

$D A C[\cdot]$

$\operatorname{diag}\left(a_{1}, \ldots, a_{k}\right)$

$\{\cdot\}^{T}$

$\{\cdot\}^{H}$

$\{\cdot\}^{*}$

$\{\cdot\}^{-1}$

$\lfloor x\rfloor$

$\lceil x\rceil$

|.

$\measuredangle x$

$\|\cdot\|$

$\Im\{\cdot\}$

$\Re\{\cdot\}$

$\mathbb{E}[$.$] ou \langle\cdot\rangle$

$P_{r}($.

round $(x)$

$\operatorname{sgn}[$.

$\min [$.

$\max [$.

$\mathcal{U}(x, y)$

$\mathcal{N}(x, y)$
Letra em itálico: trata-se de um escalar

Letra minúscula e negrito: trata-se de um vetor

Letra maiúscula e negrito: trata-se de uma matriz

Valor estimado de uma dada variável $a$

Valor médio de uma dada variável $a$

Versão discretizada (binária) de $a$

Operador que converte um valor analógico em digital

Operador arco tangente

Operador que retorna o argumento

Operador que converte um valor digital em analógico

Matriz diagonal com elementos $a_{1}, \ldots, a_{k}$

Operador matriz transposta

Operador hermitiano transposto

Conjugado complexo

Operador matriz inversa

Operador que retorna o maior inteiro inferior a $x$

Operador que retorna o menor inteiro superior a $x$

Operador valor absoluto (módulo)

Operador fase do número complexo $x$

Operador norma

Operador parte imaginária

Operador parte real

Operador esperança estatística

Operador probabilidade

Operador inteiro mais próximo de $x$

Operador sinal do argumento

Valor mínimo assumido pelo argumento

Valor máximo assumido pelo argumento

Processo aleatório com distribuição uniforme entre as variáveis $x$ e $y$

Processo aleatório com distribuição normal de média $x$ e variância $y$ 


$\begin{array}{ll}x(t) & \text { Variável } x \text { de tempo contínuo } \\ \delta(t) & \text { Delta de Dirac. Função impulso unitário } \\ \otimes & \text { Produto de Kronecker } \\ \forall & \text { Para todo } \\ \epsilon & \text { Pertence ao conjunto } \\ \triangleq & \text { Por definição } \\ @ & \text { Dado que } \\ \# & \text { Número de }\end{array}$

Palavras em itálico são empregadas para identificar termos de língua inglesa não traduzidos. 


\section{Lista de Símbolos}

$A_{\max }$

$A_{R x}$

$A_{T x}$

a

A

$\mathcal{A}$

$b$

b

B

$\mathcal{B}$

c

c

C

$\mathcal{C}$

$c_{l u z}$

D

$E_{b}$

$E_{b} / N_{o}$

f

f

$f_{D}$

$f_{c}$

F

$\Omega(x)$

$g$

G

$G_{t}$
Relacionado com a amplitude do sinal

Máximo valor de amplitude do sinal recebido

Relacionado ao número de antenas receptoras

Relacionado ao número de antenas transmissoras

Vetor após etapa de codificação espaço-tempo

Matriz de amplitudes do sinal

Matriz de amplitudes do sinal para um frame transmitido

Relacionado ao bit transmitido

Vetor de bits transmitidos

Matriz de bits transmitidos

Vetor de bits para o cálculo da LLF

Relacionado ao coeficiente complexo do canal

Relacionado ao vetor de sinal após espalhamento na frequência

Matriz de coeficientes complexos do canal ou matriz de sinal após espalhamento na frequência, dependendo do contexto

Matriz de coeficientes complexos do canal para um frame transmitido

Velocidade da luz no vácuo

Diversidade Rake ou operador de atraso unitário, dependendo do contexto Energia de bit

Relação energia de bit recebido e densidade espectral de potência de ruído

Relacionado a frequência ou ao valor individual da função custo, dependendo do contexto

Vetor de frequências de esquemas multiportadora

Frequência Doppler

Frequência da portadora

Matriz de portadoras

fitness value - função custo da variável $x$ (medida de aptidão)

Geração atual nos Algoritmos Evolucionários ou g-ésimo grupo multitaxa, dependendo do contexto

Número total de grupos multitaxa

Número máximo de gerações adotado na simulação 


\begin{tabular}{|c|c|}
\hline $\mathrm{G}$ & Relacionado a matriz de codificação \\
\hline$h(t)$ & Resposta impulsiva do canal \\
\hline $\mathbf{H}$ & $\begin{array}{l}\text { Relacionado a matriz de canal ou matriz de checagem de paridade, } \\
\text { dependendo do contexto }\end{array}$ \\
\hline$I$ & Número de símbolos transmitidos (frame) \\
\hline $\mathbf{I}_{N}$ & Matriz identidade de ordem $N$ \\
\hline$K$ & Número de usuários ativos \\
\hline $\mathcal{K}_{v}$ & Número de usuários virtuais \\
\hline$l$ & Cardinalidade do alfabeto \\
\hline$L$ & Número de percursos \\
\hline$L_{c}$ & Confiabilidade do canal \\
\hline$m$ & $\begin{array}{l}\text { Variável escalar, relacionado com o número de grupos multitaxa ou } \\
\text { m-ésima subportadora, dependendo do contexto }\end{array}$ \\
\hline$M$ & $\begin{array}{l}\text { Tamanho do o poço de cruzamento ou número de subportadoras, } \\
\text { dependendo do contexto }\end{array}$ \\
\hline$n_{\text {erros }}$ & Número de erros por ponto nas simulações MCS \\
\hline $\mathbf{n}$ & Vetor de ruído AWGN \\
\hline$N$ & Ganho de processamento \\
\hline $\mathcal{N}$ & Tamanho do bloco de codificação \\
\hline$N_{C}$ & Ganho de processamento da canalização \\
\hline$N_{d}$ & Número de osciladores para modelo de Jakes \\
\hline$N_{o}$ & Densidade espectral de potência do ruído \\
\hline$N_{o s c}$ & Número de osciladores para modelo de Jakes modificado \\
\hline$N_{s}$ & Número de amostras por chip \\
\hline$p$ & Tamanho da população \\
\hline$p_{c}$ & Probabilidade de crossover \\
\hline$p_{m}$ & Probabilidade de mutação \\
\hline$p_{T_{c h}}$ & Formatação de pulso de canalização \\
\hline$p_{T c}$ & Formatação de pulso de embaralhamento \\
\hline$P$ & Relacionado a potência recebida \\
\hline $\mathbf{P}$ & Relacionado ao Interleaver \\
\hline $\mathcal{P}$ & Relacionado ao período da lista Tabu \\
\hline$q$ & Relacionado ao número de subportadoras \\
\hline$Q$ & Relacionado ao número de bits de precisão na conversão ADC ou DAC \\
\hline$Q_{\text {indiv }}$ & Tamanho do vetor candidato \\
\hline$R$ & Relacionado a Taxa de transmissão \\
\hline $\mathbf{r}$ & Vetor de sinal recebido \\
\hline $\mathbf{R}$ & Matriz de correlação entre todas as sequências ou matriz de sinal \\
\hline
\end{tabular}


recebido, dependendo do contexto

Função de correlação parcial

Sinal em tempo contínuo recebido

Relacionado a sequência de espalhamento

Vetor assinatura ou sequência de espalhamento

Relacionado a matriz de sequência de espalhamento

Sinal total recebido

Tempo contínuo

Relacionado a período de tempo (bit, símbolo)

Temperatura na iteração $i$

Período de chip

Carregamento do sistema

Matriz de espalhamento formada pela composição de duas sequências

Máxima velocidade de deslocamento do móvel

Vetor sinal em banda base após a canalização

Relacionado a matriz de sinal espalhado

Frequência angular Doppler

Relacionado a frequência angular

Saída amostrada de um correlacionador

Vetor de saída amostrada dos correlacionadores

Matriz de vetores à saída do MFB

Relacionado ao vetor de sinal no domínio do tempo ou frequência, dependendo do contexto

Banda de Transmissão

Variável escalar

Vetor de sinal após a codificação

Relacionado a matriz de sinal codificado

Vetor de resposta do canal ou vetor de sinal após embaralhamento, dependendo do contexto

Vetor de resposta do canal candidato para o problema $\mathrm{MuChE}$

Matriz de resposta do canal ou matriz de sinal após embaralhamento, dependendo do contexto

Relacionado a probabilidade

Módulo do coeficiente de canal ou probabilidade utilizada no TC

Vetor candidato para o problema $\mathrm{MuD}$

Relacionado a fase

Parâmetro de erro

Parcela devida ao ruído térmico de tempo contínuo 
$\sigma_{x}$

$\sigma_{x}^{2}$

Parcela devida ao ruído térmico de tempo discreto amostrado Relacionado a matriz de ruído térmico Relacionado ao atraso total Relacionado à diferença entre dois valores ou ao atraso de propagação, dependendo do contexto Relacionado com a parte inteira de um número Relacionado com a parte fracionária de um número Relação sinal-ruído a entrada do receptor Relacionado a função custo Define a unidade de processamento parcela do candidato Define a matriz de sinal à entrada da etapa de codificação espaço-tempo Relacionado a constelação de símbolos STBC Medida do erro quadrático médio (MSE) Medida do erro percentual médio (MEP) Indica universo de busca Amplitude do desvanecimento Tamanho do passo do método do gradiente Desvio padrão do processo $x$ Variância do processo $x$

Vários símbolos ou letras são utilizados para simbolizar diversas características distintas em etapas diferentes do texto. Portanto, deve-se considerar o significado específico da seção em análise. 


\section{Introdução ao Cenário}

\subsection{Histórico Evolutivo dos Sistemas de Comuni- cação Sem Fio}

Através dos tempos, os seres humanos desenvolveram vários métodos para transmitir seus pensamentos. No início, quando as pessoas viviam em pequenos grupos, ocupando áreas geográficas relativamente limitadas, a comunicação dentro do grupo ocorria por meio da voz, de gestos ou símbolos gráficos.

Com o aumento desses grupos e o nascimento de civilizações numerosas, espalhadas por áreas cada vez maiores, tornou-se necessário o desenvolvimento de técnicas que permitissem a comunicação à longa distância.

Os primeiros métodos de comunicação à distância incluíam sinais de fumaça, feixes de luz, pombos-correios e cartas transportadas por mensageiros. No entanto, o início da Revolução Industrial exigiu procedimentos mais rápidos e eficientes para a comunicação à longa distância.

A primeira solução moderna para a comunicação a longa distância, de forma breve e precisa, foi a transmissão de sinais elétricos por meios de fios. A telegrafia com fio foi inventada por Samuel Morse, nos EUA, em 1844 (HARLOW, 1936), e adotada no Brasil em 1852 (SILVA; MOREIRA, 2007).

No entanto, o desejo da humanidade em comunicar-se livre de fios remete aos primórdios da civilização. Nos séculos anteriores ao surgimento da comunicação via rádio ou celular, muitos dos princípios científicos sobre os quais estes meios de comunicação se baseiam já haviam sido descobertos. Foi Isaac Newton que em 1680 estudou, observou e foi o primeiro a sugerir o conceito de um espectro para a luz visível. Em 1831, Michael Faraday fez um avanço baseado na teoria de Newton e demonstrou que a luz, eletricidade e o magnetismo eram todos relacionados.

Dois desenvolvimentos críticos na história do rádio logo surgiram. Em 1864, James Clerk Maxwell descreveu matematicamente a existência de ondas eletro- 
magnéticas. Em 1876, Alexander Graham Bell patenteou o telefone fixo ${ }^{1}$. Então, em 1877, Heirich Hertz demonstrou que as velocidades das ondas de rádio eram igual a da luz e desenvolveu um aparato para gerá-las (HARLOW, 1936; TEBO, 1976; WHALEN, 2005).

Estas descobertas foram revolucionárias, contudo, não se acreditava que informações pudessem ser transmitidas através de ondas eletromagnéticas, até que em 1895, Guglielmo Marconi inventou um dispositivo que podia enviar código Morse a longas distâncias. Este dispositivo foi patenteado como o primeiro rádio transatlântico ${ }^{2}$. Marconi continuou a aperfeiçoar e promover benefícios de sua invenção até seu falecimento em 1937.

Muitos dos experimentos de Marconi com rádio no início do século passado se concentraram no estabelecimento de comunicação com embarcações em alto-mar. Durante a primeira guerra mundial (1914-1918), o rádio foi usado extensivamente a bordo de embarcações militares.

Em 1920, a KDKA em Pittsburgh se tornou a primeira estação comercial de radiodifusão dos Estados Unidos. O constante aperfeiçoamento técnico e a grande demanda de consumo logo fizeram do receptor de rádio (fenômeno que ocorreu particularmente nos EUA) um item doméstico padrão (BAUDINO; KITTROSS, 1977; FERRARI, 2005).

O primeiro sistema operacional de comunicação móvel iniciou-se em 7 de abril de 1928, e era usado pelo departamento de polícia de Detroit em seus carros de patrulha. Este sistema de rádio unidirecional utilizava modulação por amplitude $\left(\mathrm{AM}^{3}\right.$ - Amplitude Modulation), a qual se mostrou impraticável, pois prédios altos e terrenos irregulares afetavam significativamente o desempenho.

Em 1935, uma solução tecnológica foi proposta por Edwin H. Armstrong, chamada de modulação por frequência (FM - Frequency Modulation). Esta técnica de modulação disponibilizava um aumento na qualidade de voz e requeria muito menos potência que a modulação por amplitude, pois apresenta-se mais resistente aos problemas de propagação (ARMSTRONG, 1984).

O envolvimento americano na segunda Guerra Mundial criou uma necessidade urgente de aperfeiçoamento tecnológico. Companhias americanas como a

\footnotetext{
${ }^{1}$ A invenção do telefone foi creditada a Antonio Santi Giuseppe Meucci, quando o Congresso dos Estados Unidos aprovou a resolução n. 269 em 2002, estabelecendo que o inventor do telefone fora, na realidade, Antonio Meucci e não Alexander Graham Bell (BASILIO, 2002)

${ }^{2}$ A patente do rádio foi posteriormente creditada a Nikola Tesla (CHILDRESS; TESLA, 2004; SENGUPTA et al., 2006; BRENNER, 2009)

${ }^{3}$ Para as principais siglas e abreviaturas utilizadas neste trabalho, veja Lista de Siglas e Abreviaturas.
} 
AT\&T, Motorola e General Electric começaram a concentrar suas pesquisas na implementação de melhorias na área de comunicação móvel e de portabilidade do sistema. Este esforço originou produtos que estão disponíveis atualmente ao uso civil como os Walkie-talkies e Handie-Talkies.

Em 1946, a AT\&T criou o "Improved Mobile Telephone Service" (IMTS), o primeiro sistema de rádio móvel a se conectar com a rede telefônica pública. O IMTS consistia de um transmissor de alta potência na frequência de $150 \mathrm{MHz}$ que cobria uma área com aproximadamente $90 \mathrm{~km}$ de raio. Ele foi inicialmente operado em St. Louis, Missouri, e se espalhou rapidamente por 25 cidades (CONRAD, 1959; SCHWARTZ, 2008; RAPPAPORT, 2009).

No entanto, os sistemas móveis foram concebidos no final dos anos 40 como sistemas de rádio para despacho de viaturas (bombeiros, policiais, ambulâncias), nos quais um centro de operação de rádio comunicação cobre a região pretendida, em um raio de alguns quilômetros e com um ou mais canais modulados em diferentes frequências, sintonizados pelos rádios portáteis instalados nas viaturas. Em um segundo momento, esses sistemas de rádio comunicação foram interligados a comutadores de canais de rádio e interligados ao sistema fixo telefônico, dando origem ao serviço conhecido como telefonia celular (ALENCAR, 2001; JESZENSKY, 2004; FERRARI, 2005).

O ano de 1947 pode ser considerado como o marco do nascimento teórico da telefonia celular, quando engenheiros da AT\&T decidiram procurar um meio de utilizar mais eficientemente o espaço a partir do uso de vários transmissores de baixa potência por toda uma área urbana. As chamadas seriam repassadas de um transmissor a outro à medida que o usuário fosse se locomovendo.

Inicialmente, as unidades móveis eram instaladas em veículos, o que permitia apenas uma comunicação veicular e não pessoal. A era da telefonia celular pessoal teve seu início efetivo a partir de 1979, quando o usuário podia portar o aparelho, embora suas dimensões iniciais fossem grandes (ALENCAR, 2001; JESZENSKY, 2004; FERRARI, 2005; SCHWARTZ, 2008; RAPPAPORT, 2009).

No entanto, para que um sistema sem fio consiga atender diversos usuários simultaneamente, o espectro de frequências, que constitui o meio de transmissão das redes móveis sem fio, precisa ser compartilhado. É sob este espectro que as técnicas de acesso múltiplo ao meio operam, buscando um acesso compartilhado e com equidade para todos os terminais móveis. As principais técnicas responsáveis pela divisão dos recursos de frequência em vários canais possibilitando o 
acesso múltiplo dos usuários são a FDMA ${ }^{4}$ (Frequency Division Multiple Access), TDMA $^{5}$ (Time Division Multiple Access) e CDMA ${ }^{6}$ (Code Division Multiple Access).

Inicialmente, vários padrões para a telefonia celular foram adotados em diferentes países e ficaram conhecidos como sistemas de $1^{a}$ Geração $(1 \mathrm{G})$, entre eles: o AMPS (Advanced Mobile Telephone System) nos Estados Unidos, o TACS (Total Access Communications Systems) no Reino Unido, o JTACS (Japan Total Access Communications Systems) no Japão e o NMT (Nordic Mobile Telephones System) nos países do norte europeu (Dinamarca, Finlândia, Suécia e Noruega).

Os sistemas de $1 \mathrm{G}$ utilizavam a transmissão de dados no modo analógico e a técnica de acesso ao meio utilizada era a FDMA. Os principais problemas com esses sistemas eram a baixa qualidade do sinal (modulação analógica), facilidade na quebra de sigilo, capacidade dos canais de comunicação (pouca eficiência na divisão das frequências) e a incompatibilidade entre os diversos sistemas existentes (padrões proprietários).

Com o aumento expressivo da demanda, a primeira geração de sistemas móveis foi gradualmente substituída pelos sistemas conhecidos como de $2^{a}$ Geração $(2 \mathrm{G})$, que buscavam ampliar a capacidade e qualidade dos sistemas anteriormente existentes. O sistema AMPS evoluiu para o DAMPS (Digital Advanced Mobile Phone System), que utilizava TDMA e sinais digitalizados, também conhecido por IS-54 (Interim Standard - 54). Como uma alternativa ao IS-54 surgiu nos Estados Unidos o IS-95 (Interim Standard - 95), ainda na primeira metade da década de 90 e utilizava o CDMA, aumentando a capacidade em relação aos sistemas existentes. O IS-54 foi posteriormente sucedido pelo IS-136 (Interim Standard - 136). Portanto, em meados da década de 90 dois sistemas móveis digitais competiam nas Américas na faixa de $800 \mathrm{MHz}$.

Na Europa surgiu o GSM (Global System for Mobile Communications), no início da década de 90, alcançando um maior número de assinantes, pois estava disponível para uma maior área dentre os padrões de segunda geração. Uma grande inovação do sistema GSM consistia no módulo de identificação do usuário, o SIM (Subscriber Identification Module) que contém a identificação completa do usuário, chaves de código de privacidade e outras informações específicas sobre o usuário. O SIM apresenta-se sob a forma de um cartão/plug-in ${ }^{7}$ que é conectado

\footnotetext{
${ }^{4}$ Técnica de múltiplo acesso ao meio de transmissão por divisão da frequência.

${ }^{5}$ Técnica de múltiplo acesso ao meio de transmissão por divisão do tempo.

${ }^{6}$ Técnica de múltiplo acesso ao meio de transmissão por divisão de código.

${ }^{7}$ Hardware independente, que pode ser adicionado a um sistema a fim de se obter alguma funcionalidade extra.
} 
ao terminal GSM. Estes cartões podiam ser removidos de um telefone GSM e utilizados em outro terminal, permitindo ao usuário utilizar qualquer telefone GSM. Sem o SIM, o terminal tornava-se inoperante. Esse sistema padronizou as comunicações celulares na Europa, permitindo ao usuário utilizar seu telefone em qualquer país europeu. Ainda pode-se destacar como sistema $2 \mathrm{G}$ o PDC (Personal Digital Cellular) desenvolvido no Japão.

Com a $2^{a}$ geração de celulares foram introduzidos novos serviços de comunicação de voz, com maior qualidade e capacidade de transmissão, possibilitando atender um maior número de usuários e, também, foram criados serviços de transmissão de dados como o Serviço de Mensagens Curtas (SMS - Short Messages Service) para transmissão de pequenos pacotes de informação. O SMS permite que o usuário envie e receba mensagens de texto de até 160 bytes. Ainda no início da década de 90 surgiu a idéia da $3^{a}$ Geração (3G) dos sistemas celulares, como uma proposta para a padronização global das comunicações móveis, disponibilizando altas taxas de transmissão de dados e possibilitando o suporte a aplicações multimídia e acesso à Internet. A ITU $^{8}$ (International Telecommunication Union) formulou um padrão mundial conhecido como IMT-2000 (International Mobile Telecommunications 2000), consistindo em um sistema de rádio móvel digital, multifuncional e globalmente compatível, integrando sistemas de paging, celular e redes sem fio, além de satélites de baixa órbita terrestre (LEO - Low Earth Orbit) em um único sistema móvel universal. Os tipos de modulação, codificação de voz e esquemas de acesso múltiplo foram finalizados pela Assembleia Geral de Rádio do ITU em meados de 2000.

Atualmente, o número de celulares no mundo ultrapassa os 5,3 bilhões, sendo que 850 milhões destes já utilizam sistemas 3G. O Brasil encontra-se na quinta posição ${ }^{9}$ mundial de números de celulares, com mais de 224 milhões de assinantes. Destes, 30,5 milhões utilizam sistemas 3G, mostrando o atual cenário de consolidação dos sistemas celulares e, em particular, dos sistemas 3G (ALENCAR, 2001; JESZENSKY, 2004; FERRARI, 2005; SCHWARTZ, 2008; RAPPAPORT, 2009; TUDE et al., 2011).

Vale ressaltar que nas últimas duas décadas as tecnologias de comunicações móveis e Internet cresceram de forma quase exponencial, alcançando números muito expressivos de assinantes. O serviço móvel celular obteve um crescimento muito grande de usuários juntamente com o aumento por serviços de dados mó-

\footnotetext{
${ }^{8}$ Órgão internacional das Nações Unidas, com sede em Genebra, responsável pela padronização das Telecomunicações.

${ }^{9}$ Ranking liderado pela China, com mais de 900 milhões de celulares, seguida pela Índia com 812 milhões, pelos EUA com 306 milhões e pela Rússia com 230 milhões.
} 
veis. Por outro lado, a internet proporciona uma grande possibilidade de acesso às informações para os usuários fixos ou através de redes sem fio. Desta forma, a possibilidade de acesso à informação e serviços a qualquer hora e em qualquer lugar está moldando uma nova sociedade de informação com os usuários acessando a informação através de diversos dispositivos móveis, tais como telefones celulares, smartphones, PDAs (Assistentes Pessoais Digitais) e Laptops.

\subsection{Telefonia Celular}

A popularidade do serviço de telefonia celular se deve à liberdade, à mobilidade e ao aumento dos serviços que o sistema vem oferecendo. A telefonia móvel foi desenvolvida para libertar o telefone do par de fios que o prende à rede cabeada, substituindo a linha física por um enlace de rádio. Desta forma, a comunicação pessoal ocorre com maior mobilidade e individualidade.

As tentativas iniciais de criação da telefonia móvel, na década de 40 do século passado, conforme já mencionado, objetivaram viabilizar a comunicação veicular. As primeiras soluções resultaram em equipamentos complicados, volumosos e com grande consumo de energia. Além disso, necessitavam de adaptações nos veículos para acomodar baterias adicionais, acarretando inicialmente limitações em seu uso.

Com a evolução da tecnologia, dos equipamentos e dos componentes eletrônicos, o conceito de telefonia móvel foi aproximando-se daquilo que verdadeiramente possibilita uma comunicação móvel e individual. Esta evolução ocorreu com a utilização da comunicação digital, que é à base de toda uma nova concepção de comunicação eletrônica multimídia, capaz de proporcionar integração de voz, dados e vídeo em um único canal de comunicação.

Atualmente, a consolidação dos sistemas de comunicação móvel de terceira geração e posteriores tem pela frente o grande desafio de oferecer aos usuários finais terminais de baixo custo e simultaneamente disponibilizar um variado leque de serviços multimídia. Desta forma, pesquisas em todo o mundo têm sido focadas em sistemas de comunicação de alta capacidade, factíveis de serem implementados utilizando técnicas de processamento digital de sinais (DSP - Digital Signal Processing).

Dentro deste cenário, destaca-se a técnica de comunicação por espalhamento espectral (SS - Spread Spectrum) (PETERSON; ZIEMER; BORTH, 1995) que até meados da década de 80 esteve restrita às aplicações militares e atualmente encontra- 
se em uma fase final de consolidação tecnológica através dos sistemas de comunicação móveis celulares de terceira geração utilizados em todo o mundo, padrões WCDMA $^{10}$ e CDMA2000. A partir de 1989, após publicação dos trabalhos pioneiros de Dixon e Torrieri (DIXON, 1976; TORRIERI, 1985), os militares americanos liberaram a tecnologia SS para aplicações comerciais. Lucent, Motorola, Nec, Samsung e muitas outras empresas multinacionais têm investido enormes recursos humanos e financeiros nesta tecnologia. Hoje, o conceito e a técnica de comunicação SS estão sendo usados comercialmente, nos mais diversificados campos de aplicação, praticamente em todos os países do globo.

\subsubsection{A Tecnologia DS/CDMA}

Acesso múltiplo por divisão de código de sequência direta (DS/CDMA - Direct Sequence Code Division Multiple Access) é o nome da tecnologia largamente usada para comunicação sem fio baseada no conceito de espalhamento espectral, onde o sinal transmitido ocupa uma banda muito superior à mínima necessária. Este espalhamento no espectro é obtido por meio de um código/sequência de espalhamento que é independente da informação e ocupa uma banda espectral superior a da informação. Na recepção, este mesmo código é utilizado para desespalhar o sinal SS, recuperando a banda original da informação, proporcionando assim a detecção com certa imunidade à interferência.

Algumas vantagens desta tecnologia são:

- baixo consumo de energia;

- alto grau de segurança/privacidade na transmissão;

- facilidade de obtenção de soft handover ${ }^{11}$;

- rejeição à interferência de banda estreita;

- possibilidade de exploração da diversidade multipercurso.

Nesse sistema, quando o sinal é recebido e detectado por um banco de filtros casados (MFB - Matched Filter Bank), denomina-se receptor Convencional. Este tipo de receptor é incapaz de recuperar o sinal de forma ótima, ou seja, com a menor taxa de erro de bit possível, independente se está sujeito a um ruído branco aditivo Gaussiano (AWGN - Additive White Gaussian Noise) ou a

\footnotetext{
${ }^{10}$ CDMA de banda larga (Wideband).

${ }^{11}$ Comutação entre estações rádio base com a manutenção da transmissão de informação.
} 
canais com desvanecimentos (plano ou seletivo em frequência), uma vez que o sinal DS/CDMA é afetado pela interferência de múltiplo acesso (MAI - Multiple Access Interference) e pelo efeito near-far (NFR), resultando em um sistema cuja capacidade está bem abaixo da capacidade do canal de Shannon (SHANNON, 1948).

Assim, o sucesso da detecção convencional em sistemas de múltiplo acesso do tipo CDMA depende das propriedades de correlação cruzada e auto-correlação dos códigos de espalhamento envolvidos e de um rigoroso controle de potência. Sistemas CDMA comerciais geralmente usam técnicas de controle baseados em malha fechada para o controle de potência visando minimizar as variações de energia recebida e, consequentemente, minimizar o desvanecimento entre os usuários. Reconhece-se, no entanto, que a sensibilidade à potência de interferência não é inerente ao CDMA, mas sim uma característica do detector convencional baseado em filtros casados.

Uma das formas de reduzir substancialmente estes efeitos e aumentar a capacidade do sistema DS/CDMA consiste em modificar a estratégia de detecção, utilizando-se das informações dos sinais dos demais usuários interferentes no processo de deteç̧ão da informação do usuário de interesse. A esta estratégia denomina-se detecção multiusuário (MuD - Multiuser Detection) (VERDÚ, 1986a; DUEL-HALLEN; HOLTZMAN; ZVONAR, 1995; MOSHAVI, 1996; VERDÚ, 1998).

Na estratégia MuD, informações dos usuários ativos no sistema são utilizadas conjuntamente a fim de melhor detectar a informação de cada usuário individualmente, aumentando o desempenho e/ou capacidade do sistema móvel celular (ABRÃO, 2001). Em sistemas DS/CDMA, a limitação de desempenho e capacidade do sistema é causado principalmente pela MAI.

A MAI torna-se substancial quando o número de usuários cresce e/ou quando as disparidades de potência aumentam. Assim, enquanto a detecção convencional considera todos os usuários interferentes como ruído, a detecção multiusuário constitui uma melhor estratégia justamente por utilizar as informações destes usuários no processo de detecção, combatendo efetivamente a interferência de múltiplo acesso. Como resultado, tem-se uma melhoria significativa de desempenho em relação ao detector convencional (VERDÚ, 1986b).

Portanto, um dos maiores desafios no desenvolvimento de sistemas de comunicação multiusuário é a mitigação da interferência. Este desafio torna-se evidente para as modernas e atuais redes sem fio, como as redes celulares, redes locais sem fio (WLAN - Wireless Local Area Network) e redes metropolitanas sem fio 
(WMAN - Wireless Metropolitan Area Network), devido à necessidade de alta eficiência espectral, requerendo técnicas avançadas para reuso de frequência e mitigação da interferência. Mesmo em sistemas cabeados, a interferência limita o desempenho, como as da linha de assinante digital (DSL - Digital Subscriber Line). Ainda que cada DSL seja tipicamente associada com um usuário único, o acoplamento capacitivo entre pares de DSLs próximos fisicamente causa interferência (diafonia) degradando, assim, o desempenho (STARR; CIOFFI; SILVERMAN, 1999).

A interferência pode ser causada pela autointerferência ${ }^{12}$, pela interferência de múltiplo acesso ${ }^{13}$ ou por ambas. Claramente, técnicas de redução ou mitigação da interferência conduzem ao aumento de desempenho, seja em termos da redução da taxa de erro, do aumento da taxa de dados ou aumento do número de usuários possíveis (VERDÚ, 1986b).

\subsection{Redes Sem Fio}

A primeira rede sem fio foi desenvolvida por Normam Abramson na Universidade do Havaí, em 1971, para conectar computadores nas quatro ilhas sem utilizar cabos telefônicos, sendo chamada de ALOHA, a qual utilizava o primeiro algoritmo que permitia a comunicação entre computadores utilizando um canal único.

As redes sem fio entraram no reino da computação pessoal nos anos 80, quando a ideia de compartilhar dados entre computadores começava a tornar-se popular. Algumas das primeiras redes sem fio não utilizavam ondas de rádio; em vez disso, contavam com transceptores na faixa do infravermelho. Infelizmente, o infravermelho, devido a sua alta frequência, é muito suscetível a interferências causadas por obstáculos. Portanto, é necessário todo o tempo uma linha de visada direta, característica difícil de ser garantida em ambientes móveis.

No entanto, o uso comercial das redes sem fio deu-se apenas em meados da década de 80, quando a FCC (Federal Communications Commission), instituição reguladora das telecomunicações nos EUA, autorizou o uso de três faixas de radiofrequência para finalidades industriais, científicas e médicas, as chamadas bandas ISM (Industrial, Scientific and Medical) sem a necessidade de concessão.

A diminuição da burocracia para quem almejava usar as bandas ISM fez com

\footnotetext{
${ }^{12}$ Devido basicamente às reflexões de um mesmo sinal, uma derivação em um DSL e quando há restrições de banda.

${ }^{13}$ Associada com os sinais dos demais usuários compartilhando a mesma banda de frequências.
} 
que o interesse pela comunicação sem fio aumentasse. As bandas de frequência de $900 \mathrm{MHz}, 2,4 \mathrm{GHz}$, e grande parte das de $5 \mathrm{GHz}$ são reservadas nos EUA e em muitos outros países para a utilização não licenciada. As bandas ISM não apresentam custos de licenciamento e podem ser utilizadas pelas empresas de telecomunicações na construção de dispositivos sem fio. Entretanto, os equipamentos que trabalham nessas faixas ainda precisam ser certificados pela FCC nos EUA ou pelas agências reguladoras nos outros países, como a ANATEL (Agência Nacional de Telecomunicações) no Brasil.

Como uma licença não é necessária, a agência reguladora do país requer que dispositivos não licenciados utilizem bem pouca potência, restringindo o alcance máximo. Isso também significa que esses dispositivos devem ser altamente resistentes a interferências, pois não há garantias de que um usuário terá acesso exclusivo a quaisquer frequências não licenciadas. Infelizmente, é possível que a interferência ainda ocorra se um telefone sem fio, câmera sem fio, impressora sem fio, forno de micro-ondas ou qualquer outro dispositivo sem fio sejam utilizados próximos a uma rede operando na mesma faixa de frequência.

Redes sem fio baseadas em ondas de rádio ganharam notoriedade no início dos anos 90 quando os processadores tornaram-se rápidos o suficiente para gerenciar dados transmitidos e recebidos.

O IEEE (Institute of Electrical and Electronics Engineers), por exemplo, começou a trabalhar com redes locais sem fio (WLAN) em 1987, com a criação do grupo IEEE 802.4 que almejava projetar as especificações para as camadas inferiores de uma WLAN usando as bandas não licenciadas recém liberadas pelo governo. Entretanto, essas implementações iniciais eram caras e patenteadas, não garantindo a interoperabilidade dos dispositivos (ROSS, 2003; ENGST; FLEISHMAN, 2005).

Com o fracasso deste primeiro grupo, o IEEE criou outro grupo, o IEEE 802.11, especificamente voltado para WLAN. As primeiras gerações do 802.11, ratificadas em 1997 (IEEE Std. 802.11, 1997), eram relativamente lentas, operando a 1 e depois a $2 \mathrm{Mbps}$. No entanto, ficou evidente que a tecnologia poderia evoluir e, em 1999, o IEEE finalizou o padrão 802.11b (IEEE Std. 802.11b, 1999) de $2,4 \mathrm{GHz}$, aumentando a velocidade das redes sem fio para 11Mbps. Embora muitas empresas tenham participado na criação da especificação deste padrão, a Lucent Technologies e a Apple Computer foram as pioneiras na produção de dispositivos de rede sem fio para o mercado consumidor a um preço aceitável.

Embora o IEEE tenha realmente ratificado primeiro o padrão 802.11a (IEEE 
Std. 802.11a, 1999), realidades técnicas e políticas adiaram seu desenvolvimento de maneira que o primeiro equipamento 802.11a foi distribuído apenas em meados de 2002. O 802.11a supera significativamente o 802.11b em termos de velocidade, com uma vazão (throughput) bruta de $54 \mathrm{Mbps}$, se comparado aos $11 \mathrm{Mbps}$ do 802.11b. Entretanto, um equipamento 802.11a não é compatível com um hardware 802.11 b, pois o padrão 802.11 a trabalha na faixa de $5 \mathrm{GHz}$, trazendo uma diminuição da aceitação pelos consumidores.

No início de 2003, outro padrão foi proposto reduzindo ainda mais as probabilidades de o 802.11a assumir a posição do mais lento 802.11b. Esse novo padrão, o 802.11g (IEEE Std. 802.11g, 2003), utilizava a mesma banda de 2,4GHz do 802.11 b, fornecendo total interoperabilidade com todos os tipos de hardware 802.11b, igualando a velocidade de 54Mbps do 802.11a.

Com o crescimento das redes sem fio na década de 1990, empresas como 3Com, Apple, Compaq, Dell e IBM, se juntaram para formar a WECA (Wireless Ethernet Compatibility Alliance), que buscava promover a interoperabilidade com as redes Ethernet. As décadas de 80 e 90 também foram marcadas pelo surgimento de outros padrões de redes sem fio, como o Bluetooth, HomeRF, HiperLAN e UWB (Ultra Wideband), cada qual com suas peculiaridades, características e aplicações. Os primeiros produtos para essas redes sem fio somente saíram no mercado também na década de 1990.

No entanto, ainda eram necessárias melhorias, visto o aumento da demanda por sistemas com maior throughput e devido às taxas de transmissão de sistemas cabeados que ainda eram superiores. Por isso, no final de 2003, o IEEE iniciou o desenvolvimento de um novo padrão 802.11, com o objetivo de oferecer velocidades reais de transmissão superiores às das redes cabeadas de $100 \mathrm{Mbps}$, além de melhorias com relação à latência, ao alcance e à confiabilidade de transmissão. Considerando que uma rede $802.11 \mathrm{~g}$ transmite pouco mais de $25 \mathrm{Mbps}$ de taxa líquida (descontando todo o overhead do sistema de transmissão), a meta de chegar aos 100Mbps parecia bastante ambiciosa.

Diversas companhias de hardware e redes propuseram alternativas para este novo padrão, resultando em aproximadamente 60 propostas distintas submetidas ao IEEE. Em fevereiro de 2005, no entanto, estas propostas foram reduzidas para duas, ambas com forte apoio de várias empresas. A primeira proposta, submetida pelo grupo formado pelas empresas Airgo Networks, Broadcom, Motorola e Texas Instruments (WWiSE - World Wide Spectrum Efficiency) sugeriu a utilização de canais com largura de banda similar às redes $802.11 \mathrm{~b} / \mathrm{g}$ existentes $(20 \mathrm{MHz})$, bem 
como o uso de múltiplas antenas de transmissão e recepção (MIMO - MultipleInput Multiple-Output), alcançando taxas de transferência de aproximadamente $135 \mathrm{Mbps}$. A outra proposta, submetida pelo grupo formado pelas empresas Atheros Communications, Intel, Philips, Sony, entre outras (TGn - Task Group n) sugeria a duplicação da largura de banda $(40 \mathrm{MHz})$ e o uso de diversas técnicas distintas de embaralhamento (interleaver), codificação espaço-tempo, estimativa de canal, resultando em taxas de até 315Mbps.

Devido ao significativo apoio de cada proposta, nenhuma conseguiu a maioria dos votos exigidos para adoção como padrão. Finalmente, em julho de 2005, um conselho formado por membros de ambos os grupos concordaram em formular uma proposta conjunta, apresentando-a em janeiro de 2006. Esta proposta, denominada de proposta conjunta TGn ( TGn Joint Proposal), combinou os benefícios de cada proposta anterior, formando, assim, a base do atual padrão 802.11n.

A solução proposta indicava o uso de múltiplas antenas de transmissão e recepção (MIMO) e multiplexação por divisão espacial (SDM - Spatial-Division Multiplexing), uso de até 2 canais de $20 \mathrm{MHz}$ de largura de banda e o uso de codificação avançada, como os códigos LDPC (Low-density parity check). Com estas melhorias, aumentou-se a velocidade de transmissão e o alcance máximo de enlace. A velocidade nominal subiu de 54Mbps para aproximadamente 200-300Mbps em sistemas com configuração 2x3 e 3x3 (número de antenas de transmissão e recepção, respectivamente) e possibilidade de taxas próximas a 600Mbps em configurações $4 \times 4$. O alcance máximo, pelo uso de diversidade, tornou-se quase duas vezes maior do que os sistemas $802.11 \mathrm{~b} / \mathrm{g}$. Após 3 revisões da proposta inicial, chamadas de draft 1.0, draft 2.0 e draft 3.0, o padrão final foi aprovado e publicado em outubro de 2009 (XIAO, 2005; IEEE Std. 802.11g-2003, 2006; IEEE Std. 802.11n, 2009).

Atualmente, encontram-se inúmeros equipamentos comerciais que disponibilizam conexão sem fio através do padrão 802.11 , com preços acessíveis ${ }^{14}$, substituindo, gradativamente, os antigos aparelhos que disponibilizam acesso através dos padrões $802.11 \mathrm{~b} / \mathrm{g}$.

\subsubsection{Escopos de Rede}

Com o aumento das aplicações das redes sem fio surgiram diversos escopos, sendo baseados praticamente nas distâncias máximas que as redes precisam atingir para seu funcionamento.

\footnotetext{
${ }^{14}$ Encontra-se aparelhos a partir de $\mathrm{R} \$ 100,00$.
} 
As redes pessoais sem fio (WPAN - Wireless Personal Area Network) consistem em um escopo de rede que gira em torno do indivíduo. Possui um alcance pequeno, efetuando a comunicação entre dispositivos pessoais. Como exemplo de aplicação deste tipo de rede pode-se citar o celular que se conecta com um fone de ouvido sem fio, ou com um smartphone, ou até mesmo com o aparelho de som do carro. Apesar dos dispositivos estarem em diferentes locais como bolsos, pastas, entre outros, a distância entre eles é pequena e geralmente, para essas aplicações, não há necessidade de alto desempenho e velocidade. No entanto, cresce a cada dia a demanda por aplicações de transmissão de vídeo e dados para este tipo de rede, trazendo para algumas aplicações a necessidade de altas taxas de transmissão.

Atualmente, as redes WPAN comerciais estão definidas pelo padrão IEEE 802.15 e suas variações, garantindo comunicação entre diversos dispositivos portáteis ou móveis tais como computadores, celulares, periféricos, fones de ouvido e eletrodomésticos. Neste padrão, os dispositivos utilizam as técnicas FHSS (Frequency Hopping Spread Spectrum) em aplicações de baixas taxas, sendo conhecido comercialmente como Bluetooth (IEEE 802.15 Working Group for WPAN, 2002; Bluetooth Special Interest Group, 2002; IEEE Std. 802.15.1, 2005; IEEE Std. 802.15.2, 2003; ENGST; FLEISHMAN, 2005), ou UWB em aplicações de altas taxas de transmissão, para compartilhar o acesso ao meio (ORNDORFF, 2004; OPPERMANN; HäMäLäINEN; IINATTI, 2004; FCC Part15, 2003; YANG; GIANNAKIS, 2004; IEEE 802.15.4b, 2006; IEEE 802.15.4a, 2007; IEEE 802.15.5, 2008).

Atualmente, a técnica UWB está sendo considerada para diversos sistemas de comunicação, aplicações militares e radares devido às vantagens desta técnica, dentre as quais: possibilidade de altas taxas de transmissão decorrente do grande número de pulsos que podem ser criados dentro de um curtíssimo intervalo de tempo; sinal com baixa densidade espectral de potência, diminuindo a probabilidade de interceptação da informação; habilidade em discernir retardos de multipercurso na escala de nano segundos, possibilitando alta resolução; entre outros fatores. Observando esta potencialidade, a FCC definiu o UWB como sendo qualquer sistema de comunicação sem fio que ocupa uma banda dada pela relação $W / f_{c} \geq 20 \%$, onde $W$ é a banda de transmissão e $f_{c}$ a frequência central da portadora. A faixa espectral adotada vai de $3,1 \mathrm{GHz}$ a $10,6 \mathrm{GHz}$, resultando em uma enorme largura de banda de, aproximadamente, 7,5GHz (ANGéLICO, 2010).

Já as redes locais sem fio (WLAN) referem-se a uma rede local, proporcionando uma comunicação entre equipamentos que se encontram em um mesmo ambiente, como por exemplo, uma residência ou uma empresa. Como apresen- 
tado anteriormente, o padrão para as redes locais sem fio são baseadas no padrão IEEE 802.11, conhecido comercialmente como WiFi, sendo que o padrão 802.11b utiliza a tecnologia DS/CDMA. Já os padrões 802.11a e 802.11g utilizam a técnica OFDM (Orthogonal Frequency Division Multiplexing), sendo diferentes na faixa de frequência de operação. Além desses padrões anteriormente desenvolvidos, encontram-se disponíveis comercialmente sistemas baseados no padrão 802.11n, que aumentaram a taxa de transmissão para até 600Mbps através da utilização de técnicas MIMO, codificação espaço-tempo, entre outras técnicas (IEEE Std. 802.11, 1997; IEEE Std. 802.11a, 1999; IEEE Std. 802.11g, 2003; ROSS, 2003; ENGST; FLEISHMAN, 2005; IEEE Std. 802.11n, 2009).

E por fim, as redes metropolitanas sem fio (WMAN), cujo escopo se refere a redes metropolitanas de uso geralmente corporativo que atravessam cidades e estados, ou seja, grande raio de alcance. Esse tipo de conexão pode ser utilizado entre os provedores de acesso e seus pontos de distribuição e também para prover acesso de dados móvel. Atualmente, o padrão IEEE 802.16 (IEEE Std. 802.16, 2001, 2004; IEEE Std. 802.16.2, 2004; IEEE Std. 802.16a, 2003; IEEE Std. 802.16c, 2002; IEEE Std. 802.16f, 2005; IEEE Std. 802.16g, 2007; IEEE Std. 802.16, 2009) especifica as características para este tipo de rede, sendo conhecido comercialmente como WiMax, sendo similar às técnicas utilizadas nos padrões WiFi (uso de técnica OFDM, MIMO, SDM, entre outras). No entanto, para as aplicações WMAN geralmente necessita-se de maior taxa de transmissão do que para aplicações WLAN para enlaces fixos e maior robustez a interferência para enlaces móveis, fazendo com que o número de subportadoras do Wimax seja maior do que do WiFi ou a codificação mais robusta. Além disso, trata-se de um padrão de grande interesse comercial, por parte das operadoras e provedores de acesso, para utilização mesmo nas faixas licenciadas do espectro para prover acesso móvel e fixo.

Portanto, nota-se que os padrões atuais da indústria para as redes sem fio mais relevantes utilizam alguma das seguintes técnicas para melhoria da eficiência de uso do espectro de frequências: técnicas de multiportadoras (OFDM), espalhamento espectral por sequência direta (DSSS) e salto em frequência (FHSS), sistemas de banda ultra larga (UWB), sistemas com múltiplas antenas de transmissão e recepção (MIMO), multiplexação espacial (SDM) e sistemas com códigos corretores de erro. Com isso, torna-se essencial a realização de estudos buscando alternativas para a melhoria da capacidade desses sistemas, considerando métodos de deteç̧ão multiusuário sub-ótima e ótima, estimadores de parâmetros eficientes, entre outras (EASTWOOD et al., 2008; IEEE Std. 802.11n, 2009; IEEE Std. $802.16,2009)$. 


\subsection{Detecção Multiusuário}

Detecção multiusuário refere-se ao cenário na qual um único receptor é capaz de detectar conjuntamente transmissões simultâneas. Exemplos deste tipo de cenário incluem o canal reverso (uplink) em um sistema celular, um grupo de cabos de pares trançados para linha de assinante digital que terminam em uma mesma central telefônica, ou mesmo para sistemas com múltiplas antenas de transmissão, pois, nestes cenários, usuários múltiplos refere-se aos múltiplos pacotes de informação, mesmo que o sinal transmitido seja originado de um único usuário.

Intimamente relacionada com a deteç̧ão multiusuário está a supressão de interferência. A principal diferença é que um detector multiusuário tenta recuperar múltiplos sinais transmitidos ${ }^{15}$ ou pelo menos utiliza a informação dos usuários interferentes para melhoria do sinal de interesse, enquanto que a supressão de interferências implica que o receptor está interessado em apenas um sinal de superposição entre os múltiplos sinais transmitidos sem utilização da informação dos demais visando melhoria de desempenho.

No canal direto (downlink) de um sistema celular, geralmente deseja-se demodular um fluxo único de informações transmitidas na presença de sinais de interferência da estação rádio base associada e de estações rádio base nas proximidades. Note que, em geral, um receptor pode desejar demodular um subconjunto de dois ou mais sinais de uma grande mistura de sinais. Nesse caso, o receptor detecta o conjunto de sinais desejado enquanto suprime os sinais de interferência.

Nas últimas duas décadas, uma grande variedade de detectores multiusuário foram propostos na literatura com o intuito de melhorar o desempenho obtido com o detector convencional em sistemas de múltiplo acesso. Dada à elevadíssima complexidade do receptor ótimo (OMuD - Optimun Multiuser Detector) desenvolvido por Verdú (VERDÚ, 1986a, 1998), a atenção nesta área tem sido voltada ao desenvolvimento de receptores multiusuário sub-ótimos de menor complexidade.

O detector multiusuário ótimo possui uma complexidade computacional que cresce exponencialmente com o número de usuários, tornando proibitivo sua implementação. Faz-se necessário, portanto, investigações visando obter detectores multiusuário sub-ótimos que atendam os critérios de alto desempenho e baixa complexidade.

Alternativas ao $\mathrm{OMuD}$ incluem os detectores multiusuário clássicos linea-

\footnotetext{
${ }^{15}$ Utiliza, de forma inerente ao processo, informação de todos os usuários visando melhoria de desempenho.
} 
res, tais como o Descorrelacionador (VERDÚ, 1986a) e o MMSE (Minimum Mean Square Error) (POOR; VERDÚ, 1997), e os clássicos não-lineares, tais como os canceladores de interferência (IC - Interference Cancellation) (VARANASI; AAZHANG, 1990; PATEL; HOLTZMAN, 1994; ABRÃO, 2001) e o zero forcing decision feedback (ZF-DFE) (DUEL-HALLEN, 1993, 1995), além de detectores multiusuário baseados em heurísticas (CIRIACO, 2006) e outros métodos sub-ótimos (GOLDBARG; LUNA, 2000; SCHLEGEL; GRANT, 2006; HONIG, 2009).

Uma possível hierarquização para os principais tipos de detectores multiusuário pode ser vista na figura 1.1 (CIRIACO, 2006).

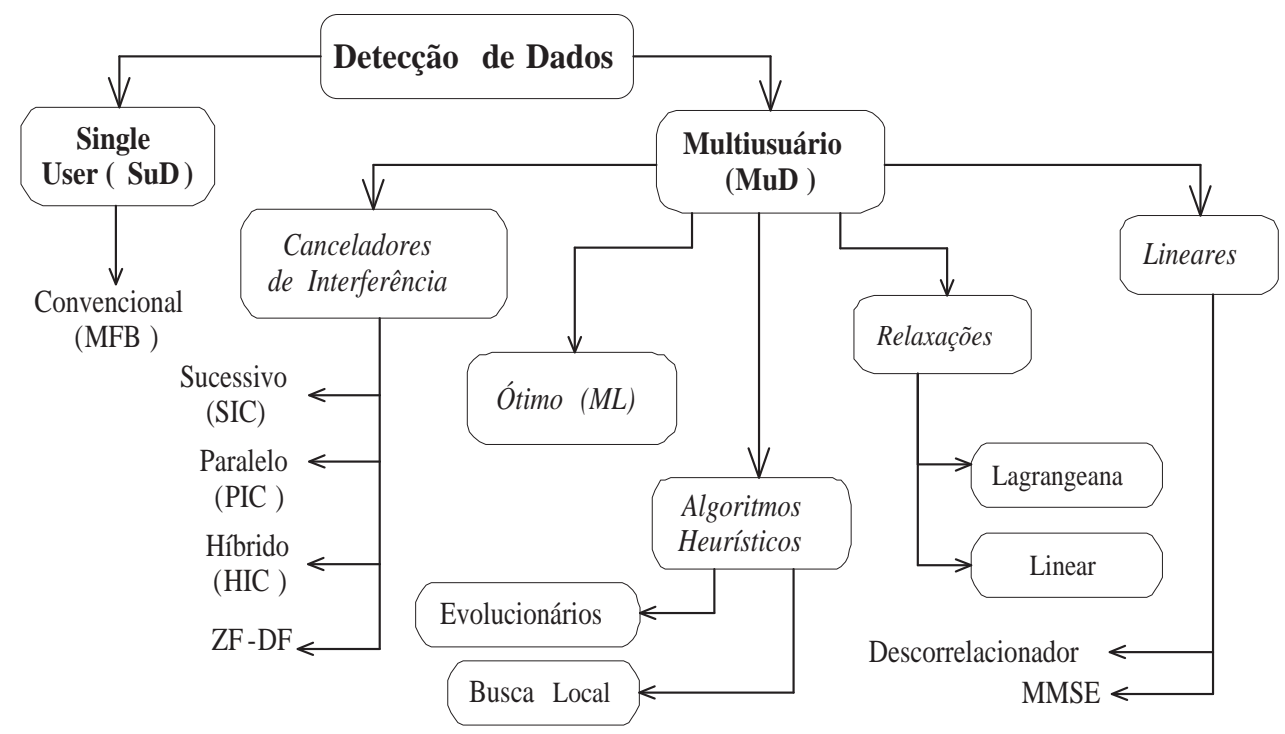

Figura 1.1: Classificação geral para diversos detectores SuD e MuD

Entre os detectores multiusuário lineares estudados na literatura encontramse o Descorrelacionador e o baseado no Mínimo Erro Quadrático Médio (MMSE). Ambos resultam em substancial aumento de desempenho e capacidade em relação ao detector convencional. A ideia básica em detecção multiusuário sub-ótima linear consiste na aplicação de uma transformação linear à saída do banco de filtros casados a fim de reduzir a MAI, vista a partir de cada usuário.

O receptor linear de descorrelação desacopla os usuários interferentes empregando uma transformação linear correspondente à matriz inversa de correlação das sequências de espalhamento. Isto significa que seu desempenho não é sensível às disparidades de potência dos usuários, possibilitando detectar o sinal de interesse sem o conhecimento das amplitudes de todos os sinais recebidos. Mas esta transformação linear acarreta um aumento do nível de ruído à saída do Descorrelacionador.

Uma alternativa ao Descorrelacionador consiste em selecionar uma transfor- 
mação que reduza o erro quadrático médio à saída do receptor Convencional, aliviando o problema do aumento de ruído presente à saída do Descorrelacionador. Por levar em consideração o nível de ruído na transformação linear, o detector MMSE possui melhor desempenho que o Descorrelacionador, principalmente na região de baixa relação sinal-ruído (SNR), porém requer estimativas das potências e do nível de ruído recebido.

No entanto, além de possuírem desempenho inferior ao obtido com o OMuD, o Descorrelacionador e o MMSE necessitam realizar uma operação de inversão da matriz de correlação, o que implica em uma alta complexidade em sistemas com um número elevado de usuários ativos ou em sistemas com entrada e saída de usuários de forma aleatória e com rapidez, tendo em vista a detecção em tempo real.

O princípio de operação para os detectores multiusuário do tipo canceladores de interferência (IC) e ZF-DF consiste na geração de estimativas para a interferência de múltiplo acesso seguido pelo cancelamento (subtração) da MAI do sinal do usuário de interesse. As operações de reconstrução e cancelamento da MAI podem ser repetidas em uma estrutura de múltiplos estágios, resultando em sinais mais confiáveis a cada novo estágio cancelador quando estimativas puderem ser obtidas com relativa acurácia. A complexidade destes detectores cresce com o número de estágios necessários para a demodulação e a partir de certo número de estágios não há mais ganho significativo de desempenho, devido à propagação do erro nas estimativas da interferência (ABRÃO, 2001). Isto limita o desempenho destes algoritmos. Embora seja baixa a complexidade por estágio, o desempenho atingido pelos detectores IC é inferior ao do OMuD.

Na última década, a literatura especializada vem colecionando propostas de soluções sub-ótimas baseadas em algoritmos iterativos e em heurísticas, particularmente as evolucionárias e de busca local, para problemas inerentes aos sistemas de comunicação de múltiplo acesso do tipo DS/CDMA, entre as quais podem ser citadas soluções para os problemas: de detecção ótima (JUNTTI; SCHLOSSER; LILLEBERG, 1997; YEN; HANZO, 2000; ERGUN; HACIOGLU, 2000; TAN, 2001; YEN; HANZO, 2001; SHAYESTEH; MENHAJ; NOBARY, 2001; ABEDI; TAFAZOLLI, 2001; WU et al., 2003; LIM; VENKATESH, 2003, 2004; CIRIACO; ABRÃO; JESZENSKY, 2004; ABRÃO; CIRIACO; JESZENSKY, 2004; AL-SAWAFI; JERVASE, 2004; YEN; HANZO, 2004; DONG et al., 2004; CIRIACO; ABRÃO; JESZENSKY, 2006a, 2006c), de seleção de sequências de espalhamento (GAMAL et al., 1987; JESZENSKY; STOLFI, 1998; CHAN et al., 2001; KURAMOTO; JESZENSKY; ABRÃO, 2004), de estimativa de parâmetros do sistema, particularmente o da estimativa dos coeficientes de canal, 
atraso e potência dos usuários (CHEN; WU, 1998; YEN; HANZO, 2001; CIRIACO; ABRÃO; JESZENSKY, 2006b), do controle de potência (ZHOU et al., 2002; MOUSTAFA; HABIB; NAGHSHINEH, 2004) e para o problema de alocação e otimização de recursos (MOUSTAFA; HABIB; NAGHSHINEH, 2004; ZHAO; LU, 2004), visando aumentar a capacidade e o desempenho dos sistemas de comunicação DS/CDMA.

No entanto, nos últimos anos, a principal motivação para a detecção multiusuário mudou do sistema DS/CDMA convencional para outras aplicações, considerando sistemas com múltiplas antenas de transmissão e recepção, sistemas com múltiplas taxas de transmissão, com multiportadoras e codificados. Existem diversas razões para isso. Primeiro, como demonstram os estudos iniciais sobre os enlaces sem fio com múltiplas antenas (FOSCHINI; GANS, 1998; TELATAR, 1999), podem ser obtidos ganhos substanciais de eficiência espectral e confiabilidade, estimulando uma enorme quantidade de pesquisa em codificação e técnicas de recepção para sistemas MIMO, de modo que quase todos os sistemas modernos sem fio incluem disposições para o uso de múltiplas antenas. Nesses cenários, as técnicas de detecção multiusuário são úteis para mitigar a interferência entre as diferentes antenas de transmissão (BIGLIERI et al., 2007).

A segunda razão para a diminuição do foco na pesquisa sobre detectores multiusuário para sistemas convencionais DS/CDMA é que os projetos atuais para a próxima geração de celulares e de redes sem fio de longa distância são baseados principalmente na técnica de Multiplexação por Divisão de Frequência Ortogonal (OFDM) e na técnica de Acesso Múltiplo por Divisão de Frequência Ortogonal (OFDMA - Orthogonal Frequency Division Multiple Access), devido à alteração de prioridade para a oferta de serviços de dados em relação aos serviços de voz.

Com isso, os sistemas celulares CDMA convencionais consideram a redução da "interferência média" através do controle de potência para atingir robustez com relação a variações no número de usuários ativos e canais utilizados. Isso requer um número relativamente grande de usuários de taxa baixa (de voz, por exemplo) em relação aos de taxas mais elevadas (dados). Em contrapartida, os dados para tráfego de Internet são do tipo em rajadas e dependem das taxas previstas para o assinante. Maiores taxas permitem o acesso à informação com rajadas mais curtas e com intervalos de tempo menores, tipicamente gerando mais interferência devido a maior energia irradiada. Portanto, sem uma maior coordenação entre os usuários, a interferência observada em uma estação base ou móvel, pode variar substancialmente quando usuários de alta taxa entram e saem do sistema, degradando o desempenho. 
Para minimizar as interferências causadas por usuários esporádicos e com altas taxas de dados, as transmissões podem ser agendadas (técnica de scheduling) em diversos intervalos de tempo (time slots) diferentes. Como a transmissão de dados é tolerante a atrasos, o sistema pode selecionar os usuários com as condições de canal favoráveis em certo momento, explorando, assim, o máximo de diversidade disponível (BENDER et al., 2000; ANDREWS et al., 2001; LIU; CHONG; SHROFF, 2001).

Desta forma, os sistemas de dados celulares de 3G normalmente utilizam a estratégia de agendamento, em oposição à técnica de espalhamento convencional do sistema DS/CDMA para reduzir a interferência. Sistemas emergentes baseados em OFDMA proporcionam uma grande flexibilidade na alocação de tempo e frequência visando à mitigação de interferências e exploração da diversidade multiusuário. No entanto, técnicas de mitigação são potencialmente úteis para OFDMA, embora a interferência proveniente de outras células (ou setores) e suas respectivas condições de canal sejam difíceis de estimar.

Sistemas celulares possuem vários desafios que impedem a aplicação direta da maioria das técnicas de detecção multiusuário. Isto é especialmente verdadeiro para o canal reverso (uplink) de sistemas DS/CDMA assíncronos com carregamento máximo ou reuso de frequência excessivo. A principal dificuldade para obter e controlar o nível de interferência média do sistema consiste na utilização de sequências de espalhamento longas de modo que a interferência de um determinado usuário é calculada como a média ao longo de vários períodos de símbolo (escolhidos aleatoriamente). Dessa forma, o desempenho não é limitado pela possibilidade da escolha de um determinado conjunto de assinaturas com propriedades de correlação indesejáveis.

Estas sequências de assinatura longas, no entanto, causam uma complicação na implementação de um detector multiusuário que explora as propriedades do conjunto particular de assinaturas atribuídas a cada símbolo. Ou seja, a estrutura do detector multiusuário deve mudar a cada período de símbolo, exigindo cálculo excessivo. As sequências do tipo longa dificultam também a aplicação de métodos de filtragem adaptativa, que requerem modulação linear com assinaturas de curta duração, ou seja, a assinatura de um usuário em particular é repetida de um símbolo a outro.

Outro desafio para os detectores multiusuário em sistemas celulares móveis é o desvanecimento. O detector multiusuário deve minimizar os efeitos causados pelas variações no tempo e frequência do canal devido à mobilidade. Isso inclui 
variações de canal associadas aos interferentes, bem como ao usuário de interesse. Isso torna-se viável quando as variações do canal são lentas (desvanecimento lento - slow fading), sendo, por exemplo, de algumas centenas de símbolos, ou quando o número de interferentes é relativamente pequeno, resultando em poucos parâmetros de canal a serem estimados.

No entanto, em um sistema celular CDMA convencional podem coexistir um grande número de usuários, muitos dos quais experimentando desvanecimentos rápidos (fast fading). A incapacidade de controlar todas as variações desses canais pode comprometer significativamente o desempenho. Além disso, a complexidade do detector multiusuário geralmente aumenta com o tamanho do sistema (número de usuários e ganho de processamento). Por esta razão, as aplicações de detecção multiusuário para canal reverso em sistemas CDMA têm sido quase sempre limitada a técnicas de cancelamento de interferência relativamente simples.

Uma maneira de enfrentar os desafios anteriores consiste em projetar sistemas CDMA considerando a deteç̧ão multiusuário como inerente ao processo e contemplando tal técnica. Para isso, deve-se preferir a utilização de sequências de espalhamento $\operatorname{curtas}^{16}$, facilitando o processamento conjunto dos sinais na estação rádio base e também melhorando a relação de desvanecimento do canal (taxa de variação do canal pela taxa de símbolo). Outro aspecto consiste na redução do número de usuários através da subdivisão dos recursos do canal no tempo e/ou frequência.

Como exemplo, o sistema UMTS ${ }^{17}$ utiliza a técnica de divisão por tempo TDD (Time-Division Duplex) e FDD (Frequency-Division Duplex) em uma combinação de Acesso Múltiplo por Divisão de Tempo (TDMA) e CDMA (HAARDT et al., 2000). O canal reverso é dividido em quadros de $10 \mathrm{~ms}$ com 15 slots de tempo, e vários usuários podem ser atribuídos a um slot específico através do uso da técnica de espalhamento por sequência direta. Por exemplo, se o sistema original CDMA suporta 75 usuários em uma célula, com a introdução de 15 slots de tempo, resulta na divisão dos usuários em 15 grupos, cada um contendo 5 usuários. Desta forma, a redução do ganho de espalhamento pode ser realizada em um fator de 15, aliviando a carga sobre um detector multiusuário. Além disso, a introdução de intervalos de tempo aumenta a taxa de símbolo e, consequente-

\footnotetext{
${ }^{16}$ Implica na redução do número de usuários ativos ou diminuição da taxa de informação transmitida.

${ }^{17}$ Universal Mobile Telecommunications System é um padrão de interface aérea para 3G de sistemas celulares. Este padrão foi aprovado em 1998 e consiste da utilização de FDD (Frequency-Division Duplex) e TDD (Time-Division Duplex) (OJANPERA; PRASAD, 1998; HAARDT et al., 2000).
} 
mente, diminui a taxa de variação do canal pela taxa de símbolo (fade rate), simplificando, inclusive, a estimação dos coeficientes de canal.

Como discutido anteriormente, o desejo de integrar serviços de voz com diferentes serviços de dados com garantia de qualidade de serviço motivou o uso de estratégias como a OFDM e CDMA. Nestas técnicas, o canal é dividido em slots de tempo e frequência, e cada slot é designado para um único usuário. Assim, em geral, os sinais transmitidos estão espalhados. Isso, a princípio, possibilita a utilização de detecção multiusuário no canal reverso, embora a interferência de outras células ainda limite o desempenho. Nestes casos, as técnicas de supressão de interferência são utilizadas. No entanto, a detecção multiusuário e a supressão de interferência para sistemas OFDM e CDMA são principalmente focadas na mitigação da interferência entre as múltiplas antenas e auto-interferência.

\subsubsection{Heurísticas Aplicadas aos Sistemas de Comunicação}

O termo heurística é derivado do grego heuriskein, que significa descobrir ou achar. Mas o significado da palavra, no contexto dos problemas inerentes aos sistemas de comunicação baseados em espalhamento espectral do tipo DS/CDMA, vai um pouco além de sua etimologia. É possível dizer que uma heurística, no sentido dado ao termo, refere-se a um método de busca por soluções em que não existe qualquer garantia de sucesso. Em um problema de otimização, o sucesso pode ser representado pela obtenção da solução ótima ou próxima o suficiente dela. Segundo (GOLDBARG; LUNA, 2000), o método heurístico pode ser definido como:

"Uma heurística é uma técnica que busca alcançar uma boa solução utilizando um esforço computacional considerado razoável, sendo capaz de garantir a viabilidade ou a otimalidade da solução encontrada ou, ainda, em muitos casos, ambas, especialmente nas ocasiões em que essa busca partir de uma solução viável próxima ao ótimo"

As primeiras heurísticas relatadas na literatura buscavam soluções para problemas específicos e não eram, via de regra, passíveis de serem utilizadas em outros problemas. As primeiras heurísticas de roteamento são um bom exemplo disso (GOLDBARG; LUNA, 2000).

As heurísticas modernas têm despertado crescente interesse da comunidade científica, tanto pela reduzida complexidade resultante de sua utilização, como pela qualidade das soluções encontradas, tornando-se uma alternativa cada vez 
mais atraente para a solução de grande parte das aplicações reais em problemas de otimização combinatória árduos (AARTS; LENSTRA, 1996; OSMAN; KELLY, 1996; OSMAN; LAPPORT, 1996; RAYWARD-SMITH et al., 1996).

Uma possível classificação ${ }^{18}$ para as heurísticas pode ser vista na figura 1.2 , resumindo as principais abordagens conhecidas na literatura (GOLDBARG; LUNA, 2000). Tipicamente, é bastante comum que as heurísticas explorem, de forma casual, a estrutura do problema, sem que, normalmente, se possa definir claramente uma estratégia universal de solução. No entanto, no caso das chamadas metaheurísticas, existe invariavelmente uma estratégia geral de solução, cabendo apenas adaptá-la ao problema específico.

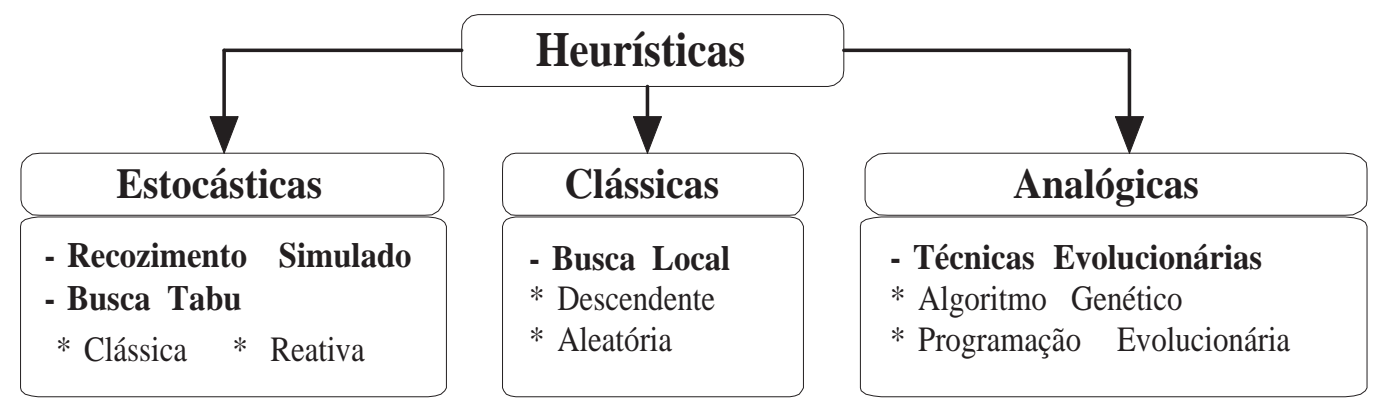

Figura 1.2: Possível classificação para abordagens heurísticas

Teoricamente, qualquer estratégia metaheurística pode ser adaptada para um problema específico em sistemas de comunicações do tipo CDMA. Dentre as heurísticas empregadas em distintos problemas de otimização, pode-se citar o algoritmo genético e outras técnicas evolutivas (ex. Programação Evolucionária), os de busca local ou baseados em vizinhança (ex. 1-opt, $k$-opt, Decodificador Esférico), os baseados em poda de árvores ou restrição de soluções visitadas (ex. Busca Tabu, GRASP) e os baseados em comportamento social de espécies (ex. Nuvem de Partículas, Colônia de Formigas), pois apresentam vantagens como robustez da solução encontrada (qualidade na solução), independentemente da dificuldade do problema, i.e., comportamento da função custo em termos da quantidade de máximos locais ${ }^{19}$.

No entanto, na literatura, poucos algoritmos heurísticos têm sido utilizados para problemas específicos em sistemas de comunicações. Segundo a classificação apresentada na figura 1.2, pode-se citar as Analógicas, as Estocásticas e as Clássicas. Fazem parte das heurísticas Analógicas os Algoritmos Genéticos (GA), os de Programação Evolucionária (EP) e suas variantes (HOLLAND,

\footnotetext{
${ }^{18}$ Outras formas de classificação podem ser encontradas na literatura.

${ }^{19} \mathrm{Ou}$ mínimos locais, dependendo se o problema a ser otimizado consiste em encontrar o máximo ou mínimo global.
} 
1970, 1973, 1975; GREFENSTETTE et al., 1985; GOLDBERG, 1989; FOGEL, 1994; MITCHELL, 1998). Compõem as heurísticas Estocásticas as técnicas de Recozimento Simulado (SA) (METROPOLIS et al., 1953; KIRKPATRICK; GELLAT; VECCHI, 1983; CERNY, 1985b; LAARHOVEN; AARTS, 1985; AARTS; KROST, 1989; OSMAN; POTTS, 1989; MAVRIDOU; PARDALOS, 1997), os algoritmos de Busca Tabu Clássica (GLOVER, 1977, 1986, 1987; GLOVER; LAGUNA, 1997), os de Busca Tabu Reativa (BATTITI; TECCHIOLI, 1994), entre outros. Já as heurísticas Clássicas são compostas pelos algoritmos de Busca Local 1-opt e os de Busca Local $k$-opt (REEVES, 1993; HANSEN; MLEDANOVIC, 1998), etc. Assim, para cada problema de otimização é possível elaborar estratégias aproximativas que levem em conta as particularidades do modelo descritivo.

Em comparação com as técnicas exatas, os métodos heurísticos não garantem encontrar uma solução ótima após atingirem um critério de parada; mas estes têm demonstrado alta eficiência em problemas de larga combinação para casos práticos, além de poderem ser modificados facilmente, adaptando-se ao problema analisado (GOLDBARG; LUNA, 2000; TAN, 2001).

Na literatura especializada, apesar de existirem vários trabalhos empregando procedimentos heurísticos para a detecção multiusuário sub-ótima, a maioria das investigações analisadas até 2004 estava restrita a canais não muito realistas para a maioria dos sistemas de comunicação, isto é, canais AWGN síncronos (JUNTTI; SCHLOSSER; LILLEBERG, 1997; YEN; HANZO, 2000; ERGUN; HACIOGLU, 2000; SHAYESTEH; MENHAJ; NOBARY, 2001; WU et al., 2003; LIM; VENKATESH, 2003; ALSAWAFI; JERVASE, 2004; DONG et al., 2004; ABRÃO; CIRIACO; JESZENSKY, 2004). No entanto, estas investigações demonstraram a possibilidade de alcance de um desempenho ótimo ou muito próximo ao ótimo com uma redução expressiva da complexidade computacional envolvida. Desta forma, motivou-se o desenvolvimento de diversos outros trabalhos pioneiros utilizando algoritmos heurísticos restritos a apenas um problema de otimização como detecção multiusuário (YEN; HANZO, 2001; ABEDI; TAFAZOLLI, 2001; CIRIACO; ABRÃO; JESZENSKY, 2004; YEN; HANZO, 2004; CIRIACO; ABRÃO; JESZENSKY, 2005a, 2005b, 2006a, 2006c), formatação de feixe (WOLFGANG et al., 2004), codificação espaço-tempo (YEN; HANZO, 2003; DU; CHAN, 2003), sistemas com OFDM (ALIAS; CHEN; HANZO, 2004) em canais planos ou seletivos em frequência. Mas a partir de 2007, com o trabalho de M. Jiang e L. Hanzo (JIANG; HANZO, 2007), evidenciou-se a possibilidade de utilização de algoritmos heurísticos na obtenção de desempenho próximo ao ótimo de forma conjunta ${ }^{20}$ para os diversos problemas inerentes aos sistemas de

\footnotetext{
${ }^{20} \mathrm{Com}$ a exploração de diversos tipos de diversidade no receptor.
} 
comunicação, trazendo uma nova perspectiva de utilização destas estratégias de otimização para os próximos sistemas sem fio de alto desempenho. Neste artigo, foi considerado a utilização do algoritmo genético para a otimização conjunta do sinal com diversidade em frequência e espaço (OFDM e SDMA), apresentando resultados de desempenho promissores.

Visando tornar o texto mais versátil e simultaneamente completo, optouse por descrever o histórico evolutivo bem como apresentar a contribuição dos trabalhos já citados e outros relevantes no apêndice A.

Mas mesmo com a apresentação de resultados promissores, nenhum padrão da indústria para os sistemas de comunicação sem fio de alto desempenho considera a utilização de técnicas heurísticas. Isso corrobora a ideia de descrédito da comunidade científica, da indústria e dos órgãos padronizadores das telecomunicações para a adoção destes métodos. Logicamente, esta não aceitação está intimamente ligada à falta de trabalhos que demonstrem de forma contundente, critérios e escolha de parâmetros dos algoritmos que proporcionem garantia de convergência, estabilidade das soluções ${ }^{21}$ ou mesmo capacidade do algoritmo de se comportar dentro de limites pré-estabelecidos, mantendo, ainda, uma complexidade computacional factível de implementação e inferior a outros métodos.

Desta forma, diferentemente dos trabalhos citados e da maioria dos resultados encontrados na literatura, este trabalho considera uma abordagem conjunta e iterativa multidimensional de deteç̧ão que visa recuperar de forma ótima ou muito próxima à ótima todos os bits de todos os usuários em um mesmo quadro de processamento, considerando canais multipercurso com vários perfis atraso-potência, taxas de transmissão, codificação temporal ou espaço-temporal, múltiplas antenas de transmissão/recepção e com multiportadoras, modelando, assim, sistemas que podem disponibilizar diferentes serviços como voz, dados e vídeo em alta taxa.

Além disso, visando estabelecer critérios de qualidade que atendam os requisitos de aceitação da comunidade científica, da indústria e dos órgãos padronizadores das telecomunicações, esta investigação realiza uma análise sobre os limiares de convergência e de desempenho dos algoritmos heurísticos utilizados, considerando métricas de qualidade em termos de estabilidade, capacidade, controle e facilidade de implementação, bem como da complexidade das topologias propostas em relação às convencionais utilizadas nos padrões comerciais.

\footnotetext{
${ }^{21}$ Com pouca variação de qualidade das soluções.
} 


\subsection{Estimativa de Parâmetros}

Muitas das soluções propostas para os receptores sub-ótimos descritos anteriormente assumem o perfeito conhecimento dos parâmetros do canal, como atraso de propagação, amplitudes e fases dos sinais recebidos, parâmetros que, na prática, devem ser estimados e atualizados continuamente.

No âmbito das comunicações DS/CDMA o principal objetivo dos estimadores de parâmetros consiste em determinar atrasos e atenuações variantes no tempo, através do processamento do sinal recebido de forma a auxiliar a detecção da informação transmitida pelos usuários.

Na segunda metade da década de 80 do século passado, com o crescente interesse pela teoria dos receptores multiusuário, após a publicação do trabalho de Verdú (VERDÚ, 1986b), começou a crescer também o interesse pela estimativa de parâmetros, já que um grande número dos trabalhos de detecção multiusuário que se seguiram necessitavam de estimativas relativamente precisas de amplitudes, fases e atrasos, conhecido como problema MuChE (Multiuser Channel Estimation).

Atualmente, existem mais de 2900 publicações na base do IEEE referente ao problema de estimativa de parâmetros de canal para sistemas do tipo CDMA. Desta forma, realiza-se aqui apenas um pequeno compêndio das principais contribuições na área de estimativa de parâmetros de canal considerando as obras pioneiras e os principais trabalhos que utilizam algoritmos heurísticos.

Em 1988, Vicent Poor (POOR, 1988) propôs um esquema de detecção e estimativa conjunta de parâmetros para todos os usuários. Este método considera como métrica uma função de máxima verossimilhança (ML - Maximum Likelihood) dependente dos parâmetros de canal e da sequência de bits transmitidos. A detecção é realizada através de uma busca exaustiva sobre uma árvore de decisão que cresce exponencialmente com o número de usuários e com o número de bits transmitidos. Apesar do ótimo desempenho não constitui uma solução prática para o problema, devido à elevadíssima complexidade computacional resultante.

É importante notar que a complexidade do algoritmo proposto em (POOR, 1988) pode ser reduzida através da transmissão periódica de uma sequência de treinamento, o que seria equivalente a fixar o caminho na árvore de busca. Porém, esta alternativa deve considerar o canal invariante entre os intervalos de envio das sequências de treinamento e, adicionalmente, considerar conhecido o atraso de cada usuário, uma vez que a sequência de bits analisada na árvore de decisão é uma sequência composta, ou seja, a soma das sequências dos usuários. Outros 
trabalhos de semelhante complexidade podem ser relatados, por exemplo (ILTIS, 1991).

Dois trabalhos publicados em 1993 apresentaram algoritmos sub-ótimos para o problema da detecção e estimativa conjunta de parâmetros (XIE et al., 1993) e (RADOVIC; AAZHANG, 1993). Em (XIE et al., 1993) os autores propuseram uma forma de redução da árvore de busca citada anteriormente. Basicamente, sugeriram que ao atingir um tamanho pré-fixado, a árvore deve ser truncada e então, ao invés de deixar a árvore crescer exponencialmente, utiliza-se uma métrica baseada em função de verossimilhança para identificar dentre os nós, quais são os nós com maior probabilidade de conter a sequência. Embora apresente uma menor complexidade do que a técnica exaustiva, o desempenho encontrado é substancialmente degradado com a diminuição do tamanho da árvore de busca.

Outras técnicas muito exploradas para a estimativa de parâmetros consistem na utilização dos algoritmos Mínimos quadrados médios (LMS - Least Mean Squares) e o Mínimos quadrados recursivo (RLS - Recursive Least Squares), mas estes não apresentam bom desempenho em canais variantes no tempo (LINDBOM, 1995). Também podem ser encontrados trabalhos que incluem o uso do filtro de Kalman, o qual utiliza as informações estatísticas do desvanecimento do canal para melhorar a acurácia do estimador. Logicamente, essas técnicas de filtragem requerem períodos de treinamento, o que pode se tornar impraticável em canais variantes no tempo, particularmente os canais com desvanecimento rápido.

Dentre os primeiros trabalhos que fugiram da tendência de deteç̧ão e estimativa conjunta de todos os usuários pode-se citar Bensley e Aazhang (BENSLEY; AAZHANG, 1996), e Ström et. al. (STRÖM et al., 1996). Estes artigos propõem uma adaptação de algoritmos inicialmente utilizados na estimativa de ângulos nas aplicações de estimação de direção (DOA - Direction of Arrival). Esse método utiliza a partição do espaço de observação em um subespaço de sinal e outro de ruído, sem o conhecimento a priori dos vetores de sinal, utilizando-se da decomposição da matriz de correlação em autovalores e autovetores (HAYKIN, 1996).

A partir desta época, a técnica ficou conhecida como "Estimativa de Canal Baseada em Subespaços". Algoritmos como o MUSIC (Multiple Signal Classification) (SCHMIDT, 1986) e ESPRIT (Estimation of Signal Parameters via Rotational Invariant Techniques) (ROY; KAILATH, 1989) são utilizados dentro desta técnica. Posteriormente, o conceito foi estendido para canais com multipercurso e atrasos variantes no tempo (STRÖM et al., 1996).

Em 1998, Bensley e Aazhang (BENSLEY; AAZHANG, 1998) sugeriram outra 
forma de obter estimativas baseadas em máxima verossimilhança. Neste trabalho, o problema de otimização multidimensional, apresentado anteriormente com a técnica de detecção e estimativa conjunta, foi reduzido a uma dimensão.

A motivação é que em várias aplicações se está interessado em apenas um usuário, ou pelo menos, se forem vários usuários, pode-se reduzir a complexidade do problema tratando-se cada um sequencialmente. $\mathrm{O}$ artigo modela a MAI como ruído colorido (não Gaussiano). Apresenta excelente desempenho, mas a desvantagem do método está na necessidade do uso de grandes sequências de treinamento.

Em 2001 o trabalho foi estendido para a inclusão de múltiplos sensores na estação rádio base (SENGUPTA; CAVALLARO; AAZHANG, 2001) e lança a ideia de se usar a resposta ao impulso do canal diretamente no processo de detecção da informação.

Já a abordagem para o problema de detecção e estimativa conjunta tratados em (POOR, 1988; MILLER; SCHWARTZ, 1989) e outros consiste apenas na estimação de amplitudes e detecção da informação, assumindo-se conhecidos os demais parâmetros. Claramente, esta não é uma forma realista de se tratar o problema, pois tanto os atrasos dos multipercursos quanto os coeficientes de canal não são conhecidos a priori e devem ser estimados.

De forma geral, o processo de detecção e estimação conjunta envolve a obtenção de inferências a partir de observações que nada mais são do que sinais distorcidos ou corrompidos pelo canal. Para o processo de detecção, a decisão a ser tomada está limitada a um número finito de possibilidades; no entanto, na estimação, a decisão se encontra em um intervalo contínuo de valores, ou seja, com infinitas possibilidades.

A estratégia adotada para se obter estimativas de parâmetros deve inicialmente se concentrar na determinação dos atrasos dos percursos dos usuários, pois nos sistemas DS/CDMA, a deteç̧ão da informação consiste na obtenção da medida de correlação do sinal recebido com uma cópia do código de espalhamento.

Para que o desempenho seja satisfatório, é necessário que a cópia da sequência que identifica o usuário de interesse utilizada no receptor esteja sincronizada com a sequência recebida. No entanto, a transmissão no canal reverso em sistemas de comunicação móveis DS/CDMA é intrinsecamente assíncrona, sendo necessária a obtenção de estimativas precisas para os atrasos. Assim, quando houver erros nas estimativas de atraso, o desempenho dos detectores multiusuário poderá ser 
comprometido (degradado) consideravelmente.

A forma mais simples e antiga, porém, ainda usual para se obter as estimativas de atrasos consiste na utilização do correlacionador deslizável (SC - Sliding Correlator) (PICKHOLTZ; SCHILling; MILSTEIN, 1982). Trata-se de um método de baixa complexidade com bons resultados em canais single-user. Para sistemas de múltiplo acesso CDMA, o desempenho do SC será razoável apenas se as potências recebidas forem similares, não sendo resistente ao efeito near-far e/ou à MAI. Este trabalho de doutoramento considera o SC para a estimativa inicial do atraso $^{22}$, considerando estimativas perfeitas. O refinamento dessa estimativa ${ }^{23}$ é obtido através da estratégia de estimativa via algoritmo heurístico proposto, pois esta técnica estima simultaneamente os coeficientes de canal, atraso e amplitude (potência) de todos os usuários.

Embora existam vários trabalhos referentes à estimativa de canal, encontramse poucos trabalhos ${ }^{24}$ na base do IEEE que analisam a estimativa através do uso de técnicas heurísticas. Considerando o problema da estimativa de canal para sistemas DS/CDMA, soluções heurísticas têm sido utilizadas como alternativa às técnicas tradicionais de estimação. Desta forma, conforme citado anteriormente, realiza-se aqui uma descrição dos principais trabalhos visando ajudar o leitor no entendimento da evolução e do estado da arte na área de estimativa de parâmetros de canal em sistemas sem fio do tipo CDMA.

Em (CHEN; WU, 1998), uma técnica para a estimativa de canal baseada no algoritmo denominado micro GA foi proposta, empregando o algoritmo de Viterbi na etapa subsequente de decisão em um receptor single-user sujeito a AWGN.

Em (YEN; HANZO, 2001) são obtidas estimativas conjuntas dos coeficientes de canal com desvanecimento plano síncrono e a detecção dos símbolos de informação codificadas diferencialmente, de tal sorte a aproveitar a mesma estrutura do algoritmo heurístico. Baseada na regra ML, os autores desenvolveram um GA capaz de estimar conjuntamente os coeficientes de canal de todos os usuários e também a sequência de bits transmitida quando são utilizadas as estatísticas provenientes do receptor convencional (banco de filtros casados).

A maioria dos trabalhos de estimativa do canal utiliza a técnica ML, onde se faz necessária a inversão da matriz do sinal multiusuário. No entanto, o custo computacional para esse processo é proibitivo quando o número de usuários e/ou percursos cresce. Na prática, aproximações são utilizadas.

\footnotetext{
${ }^{22}$ Conhecida como etapa de aquisição.

${ }^{23}$ Conhecida como etapa de tracking.

${ }^{24}$ Encontram-se aproximadamente 100 trabalhos que utilizam técnicas heurísticas nesta base.
} 
Ainda baseados na técnica ML, os autores em (BHASHYAM; AAZHANG, 2002) propuseram um estimador de canal para um sistema CDMA com códigos de espalhamento longos e canais multipercurso utilizando sequências de treinamento. No entanto, estimativas razoáveis para os coeficientes são obtidas somente após o processamento de um período de treinamento excessivo; considerando canais estáticos (sem espalhamento Doppler) obtiveram uma medida para o erro quadrático médio (MSE - Mean Square Error) normalizado de $\approx 0,6 \%$ empregando uma sequência de treinamento de 100 bits.

Entre os anos de 2003 e 2005 pouquíssimos trabalhos visando à extensão dos estudos anteriormente desenvolvidos são encontrados na base do IEEE, pois o foco da comunidade científica estava na consolidação das técnicas de detecção multiusuário e melhoria de desempenho através da exploração de diversidade, considerando sistemas MIMO, OFDM, STBC, Decodificação Turbo e LDPC, entre outros.

No entanto, em (CIRIACO; ABRÃO; JESZENSKY, 2006b) foi analisado o desempenho e complexidade do algoritmo genético para o problema de estimativa de canal para sistemas DS/CDMA e canais multipercurso. Os resultados de simulação mostraram-se promissores, pois o erro quadrático médio normalizado das estimativas apresentou-se inferior ao método do gradiente e no mesmo nível do estimador baseado em máxima verossimilhança. No entanto, a complexidade da topologia proposta mostrou-se expressivamente inferior, além da vantagem da possibilidade de diminuição do cabeçalho necessário à estimação.

Já em (CUI; TELlAMBURA, 2006), propõe-se um estimador baseado no perfil atraso-potência e na variância do ruído considerando a técnica conhecida como cyclic-prefix $\left(\mathrm{CP}^{25}\right)$ para sistemas OFDM. Uma classe de algoritmos heurísticos é utilizada baseada na técnica de máxima verossimilhança e os resultados apresentados mostraram-se promissores.

Outro trabalho interessante na área de estimativa de parâmetros de canal e detecção pode ser encontrado em (VIKALO; HASSIBI; STOICA, 2006), pois é proposto uma topologia de estimativa de parâmetros e detecção conjunta considerando uma modificação na função de otimização baseada em máxima verossimilhança por uma alternativa de menor complexidade baseada na técnica de menor inteiro quadrático (ILS - integer least-squares), sendo otimizado pelo algoritmo de decodificação esférica. O desempenho mostrou-se razoável com relativa proximidade do ótimo ${ }^{26}$, mas com uma redução significativa da complexidade conjunta.

\footnotetext{
${ }^{25} \mathrm{O}$ uso de tal técnica dispensa o requerimento de símbolos piloto adicionais.

${ }^{26}$ Modificações para melhoria de desempenho devem ser realizadas visando uma aproximação
} 
Em (JIANG; AKHTMAN; HANZO, 2007), de forma pioneira, uma solução consolidada para a estimativa e detecção conjunta é realizada considerando um sistema MIMO SDMA-OFDM. Utiliza-se o algoritmo genético para a otimização da função custo e demonstra-se a possibilidade de se obter saídas do tipo suaves (soft) à saída do detector conjunto, possibilitando a inclusão de códigos e esquemas de correção de erro.

Baseado nas propriedades da IFFT, em (XIN; JIAN-HUA; JONG, 2008) são propostos dois métodos de estimativa de coeficientes de canal considerando sistemas MIMO-OFDM. Esta técnica de estimação linear apresenta desempenho questionável, visto a não proximidade do ótimo. No entanto, a formulação do problema é interessante considerando a utilização de sinais pilotos distribuídos uniformemente entre as portadoras e observa-se a possibilidade de adaptação de técnicas heurísticas, indicando possibilidade de avanço em trabalhos futuros.

Em (TAN et al., 2010), utiliza-se um modelo semelhante ao apresentado em (JIANG; AKHTMAN; HANZO, 2007) e considera-se uma estratégia híbrida de otimização baseada nos algoritmos de recozimento simulado e genético. Desta forma, obtêm-se interessantes resultados de desempenho considerando as duas principais figuras de mérito (erro quadrático médio e taxa de erro de bit).

Por fim, em (FERTL; MATZ, 2010) apresenta-se uma estratégia peculiar para a definição dos sinais pilotos em sistemas MIMO OFDM. Diferentemente da maioria, este trabalho considera arranjos irregulares para a utilização de sinais piloto. Desta forma, são utilizadas técnicas não-uniformes e o estimador é baseado na medida de gradiente. Um critério de parada baseada em heurística é utilizado visando garantir a minimização do erro quadrático médio. O desempenho apresentado evidencia desempenho similar ao obtido com técnicas heurísticas e modelo de sistema tradicionais atrelado a uma diminuição considerável da complexidade computacional quando comparado às técnicas ótimas.

Considerando os avanços na área e a proposição/objetivo deste trabalho, serão propostas duas estratégias para o desenvolvimento de um estimador de parâmetros que visa reduzir o grande custo computacional inerente ao método de estimação ML, mantendo o erro quadrático médio normalizado em níveis aceitáveis. Diferentemente de (CHEN; WU, 1998; YEN; HANZO, 2001; BHASHYAM; AAZHANG, 2002), este trabalho considera sistemas mais realistas e com exploração de diversidade através de técnicas MIMO, OFDM, codificação temporal ou espaço-tempo e canais multipercursos. Adicionalmente, em (YEN; HANZO, 2001)

maior de desempenho ao ótimo. 
o processo de otimização do algoritmo genético é realizado no plano complexo.

Desta forma, a topologia realizará um mapeamento do problema para a forma binária, proporcionando uma facilidade adicional na etapa de implementação, além de ser possível controlar a complexidade do algoritmo em função da precisão da solução desejada. Assim, será desenvolvido um estimador de canal utilizando algoritmos heurísticos capazes de estimar os coeficientes complexos de canal para todos os usuários, a partir do sinal recebido em banda base. Esta topologia será utilizada de forma conjunta com a detecção/decodificação dos sinais dos usuários, considerando estruturas iterativas.

Outro parâmetro importante a ser estimado no receptor refere-se à fase da portadora. O problema de estimação da fase da portadora não faz parte do escopo deste trabalho. Existem diversas referências que tratam deste assunto, vide (PROAKIS, 1995) por exemplo, seja através da inserção de um sinal piloto e uso do laço de travamento por comparação de fases (PLL - Phase Locked Loop), seja através da estimação direta do sinal modulado.

\subsection{Outros Problemas}

Outros problemas inerentes aos sistemas de comunicação DS/CDMA podem ser resolvidos utilizando-se algoritmos heurísticos. Em comum, as diferentes abordagens visam garantir um aumento na capacidade e no desempenho do sistema como um todo, melhorando, assim, a eficiência. Um desses problemas consiste na garantia da qualidade de serviço (QoS - Quality of Service), sendo essencialmente um problema de gerenciamento de recursos, em que o gerenciamento da rede aloca apenas uma quantidade suficiente de recursos, proporcionando o QoS requerido para cada tipo de serviço e usuário. Em um sistema DS/CDMA, muitos dos parâmetros de QoS ${ }^{27}$, inclusive a BER (Bit Error Rate - Taxa de Erro e bit), dependem da relação sinal-ruído recebida, que por sua vez depende da potência, taxa de transmissão e tipo de serviço.

Neste contexto, o controle de potência é uma maneira eficiente para aumentar a capacidade e qualidade de transmissão. A potência de transmissão é controlada para garantir aos usuários uma conexão com um limite de interferência aceitável, sendo uma das abordagens mais convencionais para compensar a perda por propagação e por desvanecimento. Em (MOUSTAFA; HABIB; NAGHSHINEH, 2004) foi proposto um esquema para o gerenciamento de recursos baseado na técnica

\footnotetext{
${ }^{27}$ Como taxa de transmissão, taxa de erro de bit, cobertura da célula, disponibilidade de serviço, número de usuários máximo, eficiência espectral e de potência.
} 
evolucionária, especificamente o GA, proporcionando uma adequação da potência e taxa de transmissão de forma quase ótima para todos os usuários. Para cada usuário é alocada apenas uma quantidade suficiente de recursos para que seja atendido seu respectivo QoS.

Outra abordagem que visa aumentar a capacidade e o desempenho do sistema consiste na procura de conjuntos de sequências de espalhamento ótimos (boas propriedades de correlação, elevado número de sequências disponíveis, etc.). Busca-se através dessa abordagem incrementar o número de usuários suportados pelo sistema (aumento da capacidade) e, simultaneamente, atender todos os serviços de todos os usuários assegurando os respectivos QoS. Para isso, devem ser levados em conta as características do canal móvel celular, os requisitos de transmissão de cada usuário, isto é, as diversas taxas de transmissão de dados em um sistema multitaxa e o máximo atraso tolerável por serviço, resultando em um problema de otimização multivariável. Métodos heurísticos baseados nos algoritmos de Recozimento Simulado e busca Local (GAMAL et al., 1987; JESZENSKY; STOLFI, 1998; SUNG; KWAN, 2002; KURAMOTO; JESZENSKY; ABRÃO, 2004), Evolucionários (CHAN et al., 2001; NATARAJAN; DAS; STEVENS, 2005) e outros estudos comparando os métodos (KURAMOTO et al., 2010) têm se mostrado eficientes na solução deste tipo de problema.

Embora fuja do escopo desse trabalho, a análise desses problemas utilizando algoritmos heurísticos tem mostrado ser possível aproveitar a mesma estrutura do algoritmo heurístico utilizado para obter as estimativas dos parâmetros do sistema e dos bits transmitidos (etapa de detecção). Com isso, combate-se vários problemas inerentes ao sistema DS/CDMA com o desenvolvimento de apenas uma única metodologia de análise, trazendo uma diminuição significativa na complexidade de implementação das soluções.

\subsection{Motivação}

Conforme comentado anteriormente, os sistemas de comunicação sem fio 3G atuais e, futuramente, $4 \mathrm{G}$ consideram a utilização de detectores multiusuário para aumento do desempenho, capacidade e taxas de transmissão. Estas técnicas avançadas de detecção para sistemas CDMA necessitam de informações precisas dos parâmetros do sistema, como atraso dos percursos dos usuários, dos coeficientes do canal (módulo e fase) e das amplitudes (ou potências) dos usuários para tornar possível a detecção correta da informação transmitida. 
Assim, a estimativa de coeficientes de canal para sistemas CDMA constitui ainda um vasto campo com possibilidades de desenvolvimento e aplicações imediatas, constituindo um dos motivos deste trabalho. Diferentemente da maioria dos trabalhos encontrados na literatura, procurou-se utilizar, nas análises, modelos de sistemas e canais bem realistas.

Além disso, nos últimos anos os serviços de comunicação móvel vêm sofrendo grandes mudanças para poder atender a explosão na demanda simultânea de serviços de áudio, dados e vídeo. Para que esses serviços sejam oferecidos com qualidade, grupos de pesquisas em todo o mundo vêm fazendo grandes esforços na busca de sistemas de comunicação sem fio de alta eficiência espectral com capacidade e desempenhos melhorados, quer seja em termos do número máximo de usuários por unidade de área suportado em uma mesma banda, quer seja na obtenção de sistemas móveis capazes de atender a essa diversidade de serviços.

A terceira e quarta gerações de sistemas móveis celulares e de redes sem fio visam dar suporte a tais serviços, através do uso de esquemas de transmissão com taxas variadas, distintas exigências de QoS e utilização de diversidade multidimensional (OFDM, MIMO, STBC, codificação, entre outras). Com isso, os sistemas modernos devem acomodar usuários transmitindo simultaneamente a distintas taxas em canais com tráfego assimétrico (i.e., enlaces direto e reverso podem ser requisitados a trabalharem em taxas distintas), e ainda garantir as especificações mínimas de QoS para cada um dos serviços oferecidos.

No entanto, existem pouquíssimos trabalhos que consideram canais e sistemas realistas, ou seja, sistemas com diversidade multidimensional sujeitos a canais multipercurso, motivando, assim, a análise nesses cenários. Com isso, este trabalho de investigação pode ser considerado parte do esforço na busca de sistemas de comunicação sem fio de alta eficiência espectral com capacidade e desempenhos melhorados, pois realiza-se aqui uma análise da aplicabilidade de técnicas heurísticas para a estimativa dos coeficientes de canal e do sinal de informação de todos os usuários de forma conjunta e iterativa, obtendo um desempenho quase ótimo na etapa de detecção da informação transmitida atrelado a uma reduzida complexidade computacional.

Porém, visando à análise de otimização multidimensional para sistemas de alto desempenho, utilizar-se-á diversas técnicas baseadas em algoritmos heurísticos. Conforme apresentado na seção 1.4.1, algoritmos heurísticos têm sido aplicados em diversos problemas de otimização, apresentando excelentes resultados em problemas de larga combinação para casos práticos. Mesmo assim, existe 
uma dificuldade inerente na escolha e definição dos parâmetros de entrada destes algoritmos, visto que escolhas acertadas resultam em desempenho adequado e a utilização de parâmetros ou escolha de estratégias internas mal calibradas pode resultar em desempenho desastroso.

Portanto, a manipulação das diversas variáveis inerentes a cada algoritmo heurístico requer conhecimento do problema a ser otimizado ${ }^{28}$, experiência e percepção (feeling) aguçada do comportamento do algoritmo quando da escolha dos parâmetros. Muitas vezes, os parâmetros utilizados são adequados somente para cenários muito restritivos, além de não existir consenso nos valores ótimos ou subótimos ou mesmo das estratégias internas mais propícias para os parâmetros de entrada dos algoritmos heurísticos. Por isso, parâmetros são escolhidos através da experiência do pesquisador ou mesmo de testes não exaustivos realizados em ambientes simulados. Isso resultou no nível atual de descrédito de tais alternativas para a otimização de sistemas de comunicações sem fio de alto desempenho.

Pela experiência do candidato adquirida ao longo de sua formação técnica na área de otimização de sistemas sem fio utilizando heurísticas, considera-se os algoritmos heurísticos como uma das alternativas mais promissoras para implementação visando à otimização multidimensional em sistemas sem fio de alto desempenho, pois nestes cenários, o tamanho do problema e a quantidade de soluções candidatas ${ }^{29}$ tornam os métodos tradicionais de otimização proibitivos.

Desta forma, a motivação na busca de algoritmos heurísticos que garantam desempenho otimizado ${ }^{30}$ torna-se o cerne deste trabalho. Para isso, serão analisados de forma sistemática os principais algoritmos metaheurísticos utilizados em sistemas sem fio, podendo-se citar o algoritmo genético, o de programação evolucionária, o de busca local ( $k$-ótimo), o de recozimento simulado e os baseados em lista Tabu. Outros algoritmos podem ser utilizados e comparados com este estudo, como o de nuvem de partículas e o de colônia de formigas, mas não são analisados neste trabalho.

Buscar-se-á a otimização das estratégias e dos parâmetros inerentes a cada algoritmo de forma a garantir a obtenção de desempenho, no sentido mais amplo da palavra, e facilidade na utilização destes. Para isso, serão realizadas análises que resultem em equações apropriadas para os parâmetros baseadas apenas nos

\footnotetext{
${ }^{28}$ Em outras palavras, do comportamento da função custo.

${ }^{29}$ Que devem ser testadas e escolhidas em tempo real.

${ }^{30}$ No sentido mais amplo de garantia de qualidade das soluções, estabilidade, capacidade de produzir resultados dentro de limites pré-definidos, otimização automática de parâmetros visando facilitar a etapa de setup dos algoritmos e mantendo a complexidade computacional controlada e inferior aos métodos tradicionais.
} 
parâmetros do sistema de comunicação sem fio, como o número de usuários, taxas de transmissão, número de antenas, entre outros. Ao final, nenhum parâmetro inerente aos algoritmos deverá ser escolhido pelo usuário.

Mas a ideia de otimização no projeto das heurísticas não é nova, remetendo-se aos anos de 1961 (FISHER; THOMPSON, 1961) e 1973 (RECHENBERG, 1973). Logicamente, trata-se de trabalhos pioneiros mas não sistemáticos, resultando no atual cenário de rejeição para aplicações em sistemas de telecomunicações comerciais. Um avanço na área de otimização de projeto de heurísticas aconteceu somente em 1997 quando (DENZINGER; FUCHS; FUCHS, 1997), de forma pioneira, utilizou o termo hiperheurística, consistindo de um protocolo que combinava diversos métodos de inteligência artificial no contexto da teoria de automação. Somente em 2000 (COWLING; KENDALL; SOUBEIGA, 2000) este termo foi utilizado de forma independente para descrever heurísticas escolhendo metaheurísticas no contexto de otimização combinatória. O primeiro artigo em periódico contendo este termo apareceu somente em 2003 (BURKER; KENDALL; SOUBEIGA, 2003), sendo aplicado a problemas de escalas e calendário.

Uma hiperheurística pode ser vista como uma metodologia de alto nível que apresentado a um problema específico ou a uma classe de problemas, produz automaticamente uma combinação adequada dos componentes fornecidos para resolver efetivamente o problema através de uma série de heurísticas de baixo nível. Esta estratégia facilita a automação de técnicas de otimização em diversos aspectos, trazendo um impacto significativo para os desafios na área de otimização. Mesmo assim, a otimização deve ser realizada nas heurísticas de baixo nível, evidenciando o foco do trabalho.

Atualmente, existem apenas 26 trabalhos $^{31}$ utilizando hiperheurísticas publicados na base do IEEE e não encontram-se, até a presente data, trabalhos publicados na área de comunicações sem fio que utilizam hiperheurísticas. Isto motivou a utilização das metaheurísticas e também de estratégias hiperheurísticas para o problema de otimização multidimensional em sistemas de comunicação sem fio relatado anteriormente.

\subsection{Proposta}

Esse trabalho de investigação propõe a realização de uma análise sistemática, integrada e iterativa da utilização de algoritmos heurísticos aplicados aos proble-

\footnotetext{
${ }^{31} \mathrm{~A}$ maioria foi publicado nos últimos 2 anos.
} 
mas de estimativa de parâmetros e detecção multiusuário, sob o ponto de vista do compromisso desempenho $\times$ complexidade, em sistemas CDMA com exploração de diversidade multidimensional, ou seja, que utilizam uma ou mais técnicas relacionadas a seguir: OFDM, MIMO, STBC, SDMA, codificação Turbo, LDPC, entre outros, sujeitos a desvanecimentos multipercurso. A solução integrada para as duas classes de problemas consiste no uso recorrente de técnicas heurísticas.

Vale ressaltar que o vislumbre da proposta deste trabalho foi motivado pelos trabalhos pregressos do autor na área de telecomunicações considerando a utilização de algoritmos heurísticos. A descrição das etapas e principais trabalhos que contribuíram para a proposição do trabalho de doutoramento são apresentadas no apêndice B.

Para o problema da decodificação das informações dos usuários utiliza-se a regra de máxima verossimilhança e o método de otimização combinatória baseado no princípio da evolução genética ou de busca local, cujo objetivo consiste em atingir o desempenho ótimo ou quase-ótimo com reduzida complexidade computacional ${ }^{32}$, quando comparado ao ótimo, resultando, assim, em um expressivo aumento de capacidade do sistema em relação à decodificação Convencional (receptor Rake ${ }^{33}$ ), com garantia de QoS para os diferentes serviços oferecidos.

Como a estratégia utilizada na etapa de deteç̧ão é baseada na regra ML, torna-se necessário conhecer alguns parâmetros inerentes ao sistema DS/CDMA, como o atraso dos percursos, os coeficientes de canal e as potências dos usuários. No entanto, estes parâmetros não são conhecidos no receptor e devem ser estimados.

Portanto, a proposta desse trabalho visa diminuir a complexidade do sistema como um todo sem sacrificar substancialmente o desempenho. Assim, o decodificador multiusuário iterativo baseado nas técnicas heurísticas deve ser capaz de, em um mesmo bloco lógico,

- estimar os parâmetros de canal (coeficientes) necessários à etapa de detecção,

- realizar o processo de detecção para a obtenção da menor BER possível (próxima ou igual ao obtido pelo detector ótimo),

- explorar de forma eficiente a diversidade disponível visando melhoria de desempenho,

\footnotetext{
${ }^{32}$ Factível de implementação.

${ }^{33}$ Para canais multipercurso utiliza-se um MFB para cada percurso, acarretando numa estrutura com diversos filtros casados. A essa estrutura denomina-se receptor Rake.
} 
- otimizar o desempenho considerando uma topologia conjunta e iterativa,

- ser utilizado como alternativa aos padrões da indústria para sistemas sem fio de alto desempenho,

- ser implementável do ponto de vista computacional.

Este trabalho pretende ainda estabelecer uma análise comparada e sistêmica de convergência e de complexidade computacional da técnica de detecção proposta com alguns outros métodos, heurísticos ou determinísticos, relatados na literatura, considerando como métrica de desempenho o número de operações computacionais que cada estratégia requer para a detecção simultânea da informação de todos os usuários ativos no sistema.

Por fim, e mais importante, considera-se como a principal contribuição deste trabalho a sistematização da utilização dos algoritmos heurísticos no processo de otimização dos problemas já citados, considerando a definição de características de limiares para o desempenho e para a complexidade destas técnicas, trazendo à comunidade científica parâmetros suficientes que podem ser utilizados na configuração dos algoritmos para garantia de resultados satisfatórios quando da utilização destes métodos.

\subsection{Descrição do Conteúdo}

Este texto de doutorado contém, além do presente capítulo, de caráter introdutório, mais 4 capítulos que podem ser assim resumidos:

- Capítulo 2 - Neste capítulo, é descrito o modelo matemático para a transmissão e recepção em um sistema CDMA multidimensional em canal multipercurso. É demonstrada a limitação de desempenho da estratégia de detecção convencional, justificando o emprego e a análise de detectores multiusuário. Também são apresentados as formulações matemáticas baseadas na regra de máxima verossimilhança para o decodificador ótimo, com suas características de desempenho e complexidade. Adicionalmente, apresentase o modelo matemático para o problema da estimativa de parâmetros do sistema, como coeficiente de canal. Por fim, descreve-se o princípio da estratégia conjunta e iterativa aplicado ao problema de deteç̧ão e estimação de parâmetros.

- Capítulo 3 - Neste capítulo são apresentadas as características dos algoritmos heurísticos utilizados e descreve-se as etapas e adaptações inerentes 
a cada método. Também são descritos e comentados os respectivos pseudocódigos e estratégias para otimização dos parâmetros de entrada.

- Capítulo 4 - Neste capítulo é realizada uma análise sistemática das técnicas e parâmetros utilizados para os algoritmos heurísticos, considerando as métricas de qualidade para uma maratona do tipo Decathlon. São utilizadas 10 funções para a definição de limiares de desempenho e definição de parâmetros que proporcionam boas soluções. Além disso, são apontadas as melhores técnicas no sentido geral e para cada tipo de problema específico analisado, trazendo uma perspectiva de quais técnicas podem ser utilizadas com garantia de qualidade de desempenho quando aplicadas aos problemas de detecção multiusuário e de estimativa de parâmetros. Também é realizada uma análise de complexidade computacional visando apresentar as melhores técnicas que possuem compromisso desempenho $\times$ complexidade, considerando diversas figuras de mérito.

- Capítulo 5 - Neste capítulo são apresentados resultados que corroboram com a busca de algoritmos heurísticos eficientes para aplicação em problemas de detecção multiusuário e estimativa de parâmetros considerando sistemas mais realistas e passíveis de serem utilizados nas próximas gerações das comunicações sem fio. Os resultados foram apresentados utilizando-se das principais figuras de mérito para os problemas de telecomunicações citados, isto é, a taxa de erro de bit média (BER) e os erros quadrático médio normalizado (MSE) e médio percentual (MEP), além da análise da velocidade de convergência visando obtenção da complexidade computacional. Os resultados de simulação foram obtidos considerando as topologias de sistema em malha aberta e fechada multidimensional, para diversos arranjos de diversidade, evidenciando a possível aplicabilidade das técnicas heurísticas em sistemas de telecomunicações de terceira e quarta gerações. Por fim, realiza-se uma análise de complexidade computacional e de estabilidade/qualidade das soluções visando apresentar as melhores técnicas que possuem compromisso desempenho $\times$ complexidade para a utilização em sistemas de telecomunicações vindouros.

- Capítulo 6 - Por fim, neste capítulo são apresentadas as principais conclusões deste trabalho e apontamentos para a continuidade dos estudos em trabalhos futuros. 


\section{Caracterização do Sistema}

Como comentado anteriormente, os sistemas de comunicação atuais possibilitam atender serviços variados, tais como comunicação de dados, serviços de voz e transmissão de vídeos. Os sistemas de comunicação móveis $3 \mathrm{G}$ e futuramente $4 \mathrm{G}$ visam disponibilizar esses serviços com distintas taxas de dados e requisitos de qualidade (QoS), tais como máxima taxa de erro de bit por tipo de serviço e tolerância a atrasos. Os serviços de $3 \mathrm{G}$ atuais encontram-se em fase de consolidação, garantindo taxas de transmissão muitas vezes inferior às redes sem fio baseadas em IP (Internet Protocol). No entanto, as futuras redes de celulares 4G estão sendo projetadas para serem totalmente baseadas em IP e disponibilizarão um aumento das taxas de transmissão de forma significativa.

A tabela 2.1 sintetiza os requisitos típicos para a transmissão das principais aplicações multimídia com qualidade mínima aceitável para sistemas 3G (RAPELI, 1995; ABRÃO et al., 2005).

Tabela 2.1: Principais aplicações multimídia e seus respectivos requisitos.

\begin{tabular}{cccc}
\hline \multirow{2}{*}{ Aplicação } & Taxa de Bit Típica & \multicolumn{2}{c}{ Requisitos } \\
\cline { 3 - 4 } & {$[\mathrm{kbps}]$} & $\begin{array}{c}\text { BER } \\
\text { máxima }\end{array}$ & $\begin{array}{c}\text { Intolerância } \\
\text { a Atrasos }\end{array}$ \\
\hline \hline voz & 8 & $10^{-4}$ & $\boldsymbol{V}$ \\
\hline mensagens curtas & 2,4 & $10^{-6}$ & \\
\hline e-mail & 64 & $10^{-6}$ & \\
\hline acesso à base de dados & 768 & $10^{-6}$ & \\
\hline dados & 1920 & $10^{-6}$ & \\
\hline videoconferência & 384 & $10^{-7}$ & $\mathbf{V}$ \\
\hline
\end{tabular}

Para sistemas 4G, sendo totalmente baseados em transmissão de dados, observamse topologias que prometem taxas superiores a 100Mbps para o enlace direto e superiores a 50Mbps para o enlace reverso (JAMIL et al., 2008; KRENIK, 2008; AKAN; EDEMEN, 2010). Além disso, os trabalhos mais recentes apontam possibilidade futura de taxas superiores a $1 \mathrm{Gbps}$ em ambientes de baixa mobilidade e superiores a 500Mbps em ambientes de alta mobilidade (PARKVALL; FURUSKäR; 
DAHLMAN, 2011; BAI et al., 2012).

Portanto, note que a melhoria do sistema em termos do aumento da taxa de transmissão deverá ser superior a um fator de 50 vezes, quando considerado a comunicação de dados. Desta forma, observa-se a necessidade de utilização de técnicas de exploração de diversidade no receptor, pois somente com a utilização destas será possível a garantia destes requisitos. Logicamente, a presença de diversidade não é inerente ao receptor, devendo-se disponibilizá-la no transmissor. A seção 2.1 e seção 2.3 apresentam, respectivamente, o modelo de transmissor e receptor analisado neste trabalho visando à obtenção do desempenho desejado. Além disso, as sub-etapas do transmissor e receptor são apresentadas de forma mais detalhada na sequência de cada seção.

\subsection{Transmissor}

Considerando a necessidade de atendimento de diversos serviços e com alta qualidade, optou-se por um sistema de transmissão/recepção que agrega diversas dimensões para exploração de diversidade. A figura 2.1 apresenta o esquema de transmissor/receptor proposto neste trabalho, considerando diversas técnicas para cada sub-etapa do esquema.

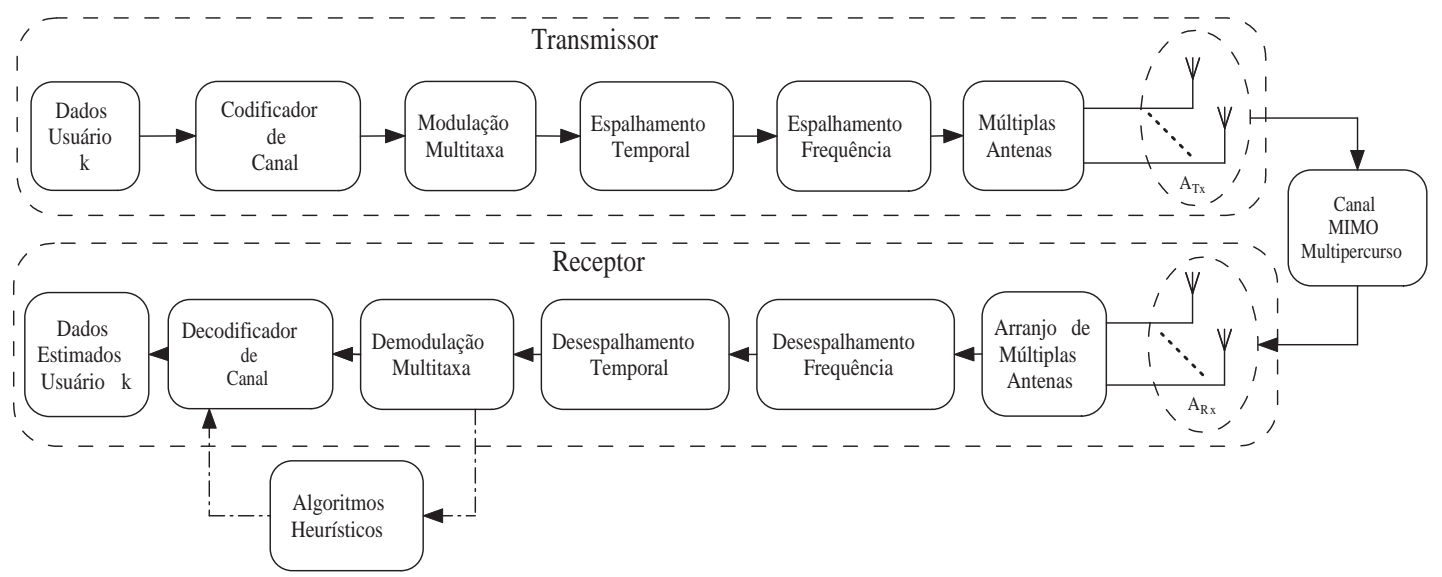

Figura 2.1: Sistema de transmissão e recepção visando disponibilização de diversidade

Considerando o transmissor do $k$-ésimo usuário, note que a etapa de codificação de canal visa à correção do sinal recebido quando na presença de erros através do uso de redundância, trazendo uma diversidade do tipo código. A etapa de modulação multitaxa visa garantir a oferta de diversos tipos de serviços aos usuários em taxas distintas, garantindo a possibilidade de estratégias de gerenciamento ótimo de recursos. A etapa de espalhamento temporal garante um 
nível de rejeição à interferência de múltiplo acesso, além da identificação de cada usuário DS/CDMA, sendo um tipo de diversidade temporal. A etapa de espalhamento na frequência, como o próprio nome diz, proporciona que informações possam ser transmitidas em sub-portadoras distintas, trazendo uma diversidade de frequência. Por fim, a etapa de múltiplas antenas (MIMO) utiliza técnicas que proporcionam diversidade espacial, seja através de arranjos simples com várias antenas ou mesmo através de técnicas espaço-tempo por código de blocos ou por códigos em treliça.

Os sinais do transmissor do $k$-ésimo usuário propagam-se através de um canal cujo modelo contempla atenuações de pequena e grande escala, ou seja, efeitos de sombreamento e multipercursos, sendo descrito na seção 2.2.

Os sinais do $k$-ésimo usuário à entrada do receptor são demodulados através de um arranjo de antenas com a finalidade de exploração de diversidade espacial. Podem-se utilizar estruturas com várias antenas de recepção fisicamente separadas de uma distância suficiente para evitar sobreposição de sinais e técnicas de processamento por blocos ou treliça. Posteriormente, os sinais são desespalhados na frequência e no tempo garantindo rejeição aos efeitos do canal e à interferência de múltiplo acesso, respectivamente. Além disso, fica evidente a exploração de diversidade em frequência e tempo. Assim, os sinais demodulados são reagrupados considerando as taxas de transmissão do $k$-ésimo usuário. Este receptor é conhecido como receptor Rake, sendo descrito na seção 2.3.2. Por fim, os sinais são decodificados através de técnicas como os algoritmos BCJR, algoritmo de Viterbi ou decodificação Turbo visando à correção de possíveis erros no processo de transmissão, resultando em um tipo de diversidade de código.

Note que a utilização de algoritmos heurísticos na etapa de recepção é opcional, devendo, se adotado, ser considerado na etapa posterior à demodulação multitaxa e anterior à etapa de decodificação de canal.

Desta forma, o modelo de transmissor e receptor proposto neste trabalho ${ }^{1}$ disponibiliza a exploração de pelo menos quatro tipos de diversidade. Dependendo do esquema adotado no receptor e das características do canal, podem-se explorar ainda outras dimensões, por exemplo, diversidade causada pelos múltiplos percursos de um mesmo sinal.

Mas vale ressaltar que fisicamente existem apenas 3 dimensões distintas para a diversidade, sendo no tempo, frequência e espaço. Assim, a diversidade de código e exploração de multipercursos são tipos de diversidade temporal. No

\footnotetext{
${ }^{1}$ Apresentado nas seções 2.1.1 a 2.3.5.
} 
entanto, para o restante do texto, será considerado que cada tipo de diversidade explora uma dimensão diferente ${ }^{2}$ visando facilitar a compreensão do número de estratégias utilizadas na etapa de recepção.

\subsubsection{Codificação de Canal}

A codificação do sinal original é uma estratégia comumente utilizada para tornar a transmissão mais confiável, ou de forma equivalente, para garantir que a taxa de erro seja baixa mesmo quando o nível de sinal no receptor esteja inferior ao desejado. Este ganho de eficiência no uso da potência é conhecido como ganho de codificação. Para sistemas atuais, o uso deste tipo de estratégia mostra-se muito atraente, visando à obtenção de ganho como se fosse uma técnica de diversidade.

Pode-se classificar o princípio da codificação do sinal original em três tipos principais: codificação de fonte, canal ou correção de erro direta (FEC) e criptografia. O desafio da codificação de fonte consiste na compressão de sinais amostrados buscando a utilização do mínimo número de bits necessário para representar o sinal analógico original na forma digital. Diferentemente da codificação de fonte, a criptografia utiliza códigos na tentativa de cifrar o sinal para que este seja interpretado/recuperado somente pelo usuário de interesse e fique obscuro para os demais. Neste trabalho, sem perda de generalidade, adotou-se a utilização da estratégia de codificação de canal, pois o objetivo consiste na "proteção" da informação contra erros de transmissão possibilitando o uso de decodificadores no receptor capazes de decodificar corretamente o sinal original mesmo na presença de erros à entrada de tal decodificador, introduzido pelas interferências inerentes ao sistema de comunicação sem fio de múltiplo acesso.

Para realizar esta tarefa, a codificação de canal adiciona redundância e memória à informação transmitida ${ }^{3}$, aumentando a taxa de dados a ser transmitida (para manter a quantidade de informação transmitida) aumentando a banda necessária ou reduzindo a taxa efetiva de transmissão (retirando a redundância).

A aplicação de códigos corretores de erro no receptor (FEC - Forward Error Correction) é utilizada para combater a MAI e o desvanecimento de forma conjunta.

Em 1948, Claude E. Shannon (SHANNON, 1948) em sua teoria matemática da comunicação, estabeleceu um parâmetro calculável denominado capacidade de

\footnotetext{
${ }^{2}$ Possuindo objetivos diferentes e sendo disponibilizados no receptor através de diferentes estratégias no transmissor ou pelo efeito do canal.

${ }^{3}$ Por isso muitos autores relacionam esta técnica como tendo diversidade de código.
} 
canal, prevendo que um determinado sistema de comunicação pode operar livre de erros, desde que a taxa de transmissão não seja maior que a capacidade do canal. A codificação do canal é o processo em que uma redundância controlada é adicionada à informação objetivando a detecção e a correção de erros introduzidos pelas características do canal. Essa adição controlada de redundância leva à redução da quantidade de erros na recepção, apesar da inevitável redução na taxa líquida de informação trafegada ou aumento de banda necessária.

As técnicas de codificação do canal podem ser classificadas de acordo com dois critérios: a) quanto à utilização e b) quanto ao tipo de código. O primeiro é dividido na técnica de correção dos erros no receptor (FEC), em que o código é utilizado na tentativa de se obter uma taxa de erro menor após a decodificação no receptor e na técnica da detecção dos erros, em que somente a existência dos erros no sinal recebido é detectada. O primeiro critério pode ser subdividido em: códigos de bloco, códigos convolucionais e codificação turbo.

Nos códigos de bloco, para cada bloco de bits da fonte é gerado um novo bloco de bits codificado, necessariamente maior que o bloco da fonte. A codificação neste caso é sem memória, i.e., cada bloco de bits codificado depende somente do bloco atual de bits da fonte considerada. A codificação por blocos apresenta diversas desvantagens, tais como a necessidade do recebimento completo da palavra de código antes de iniciar o processo de decodificação, necessidade de sincronismo de quadro e degradação considerável de desempenho na região de baixa relação sinal-ruído (SNR). Os códigos de blocos são utilizados na detecção dos erros, especialmente para verificação de redundância cíclica (CRC - cyclic redundacy check), cuja decodificação, relativamente simples, é obtida por divisão polinomial. Por isso, não são considerados neste trabalho.

Por sua vez, os códigos convolucionais são usados sempre como corretores de erros, sendo introduzidos inicialmente por Elias em 1955 (ELIAS, 1955). Nos códigos convolucionais, uma sequência contínua de bits de informação, com tamanho variável, é mapeada em uma sequência também contínua de bits codificados, sendo que um bit codificado depende de um ou mais bits de informação anteriores, combinados de forma linear. Tal configuração constitui um codificador com memória, resultando em uma estrutura de codificação mais complexa que não pode ser dividida em palavras de código. Desde o advento da codificação com memória, vários algoritmos de decodificação foram propostos, entre eles destacam-se o de Wozencraft e Reiffen (WOZENCRAF, 1957; WOZENCRAFT; REIFFEN, 1961), o de Fano (FANO, 1963) e o de Massey (MASSEY, 1963). 
Uma invenção marcante para o processo de decodificação baseada na estimação da sequência de máxima probabilidade foi estabelecida em 1967 com o advento do algoritmo de Viterbi (VITERBI, 1967). Uma interpretação clássica do algoritmo de Viterbi pode ser encontrada em Forney (FORNEY, 1973) e uma das primeiras aplicações foi proposta por Heller e por Jacobs (HELLER; JACOBS, 1971) durante o início dos anos 70. Entretanto, o algoritmo de Viterbi não garante que seja alcançada a menor taxa de erro de bit (BER) possível; tal algoritmo foi proposto em 1974 por Bahl e outros (BAHL et al., 1974), sendo denominado algoritmo de máxima probabilidade a posteriori (MAP - Maximum A Posteriori Probability) (BAHL et al., 1974; HAGENAUER; OFFER; PAPKE, 1996). Devido à sua alta complexidade de implementação para a época, foi pouco utilizado na prática.

O algoritmo de Viterbi utiliza a decodificação suave que minimiza a probabilidade de erros na decisão sobre os bits de informação transmitidos quando aplicado o critério de máxima verossimilhança na decodificação convolucional (LEE; MESSERSCHMITT, 1994; WICKER, 1995).

Na década de 70, os códigos FEC foram incorporados aos sistemas espaciais e de comunicação por satélites e tornaram-se comuns em sistemas de comunicação de rádio móvel celular nos anos 80. Porém, por muitos anos, a modulação e os códigos FEC foram tratados como assuntos distintos em sistemas de comunicação, até que em 1987, Ungerboeck (UNGERBOECK, 1987a, 1987b) propôs a modulação codificada por treliça (TCM - Trellis Coded Modulation), com a qual é possível obter ganhos de codificação sem exigir uma expansão da largura de banda ou diminuição da taxa de transmissão de bits de forma significativa.

Em 1993, os códigos turbo (TC - Turbo-Codes) foram apresentados por Berrou et.al. (BERROU; GLAVIEUX; THITIMAJSHIMA, 1993; BERROU; GLAVIEUX, 1996) e obtiveram uma grande repercussão por apresentarem um desempenho próximo ao limite de Shannon (SHANNON, 1948). O código turbo é obtido pela concatenação paralela (PCCC - Parallel Concatenated Convolutional Codes) de dois códigos convolucionais sistemáticos recursivos (RSC - Recursive Systematic Convolutional), separados por um entrelaçador (interleaver). Esta codificação com capacidade de correção de erros, apesar de possuir uma estrutura relativamente simples é capaz de transmitir a informação através do canal e prover uma taxa de erro de bit (BER) muito reduzida. O desempenho de um código turbo é fortemente influenciado pelo interleaver utilizado, o qual proporciona ao código turbo uma aparência aleatória, gerando poucos códigos com distância mínima de Hamming. Outra vantagem da codificação turbo é que existem diversas estruturas capazes de decodificar eficientemente a informação. 
Desde 1993, inúmeras pesquisas têm sido realizadas na área de codificação turbo, buscando reduzir a complexidade associada ao decodificador. Constituem decodificadores práticos de reduzida complexidade os algoritmos Max-Log-MAP, proposto por Koch e Baier (KOCH; BAIER, 1990) e também por Erfanian e outros (ERFANIAN; PASUPATHY; GULAK, 1994), o algoritmo Log-MAP sugerido por Robertson, Villebrun e Hoeher (ROBERTSON; VILLEBRUN; HOEHER, 1995) e o algoritmo SOVA proposto por Hagenauer e Hoeher (HAGENAUER; HOEHER, 1989; Hagenauer, 1995). Por sua vez, Le Goff et.al. (GOFF; GLAVIEuX; Berrou, 1994), Wachsmann e Huber (WACHSMANN; HUBER, 1995), além de Robertson e Worz (ROBERTSON; WORZ, 1997), sugeriram o uso destes códigos junto a esquemas eficientes de modulação.

Durante meados dos anos 90, Hagenauer et.al. (HAGENAUER; OFFER; PAPKE, 1996) além de Pyndiah (PYNDIAH, 1998) ampliaram o conceito dos códigos em blocos concatenados introduzindo o conceito de códigos em blocos concatenados paralelos. Nickl et.al. (NICKL; HAGENAUER; BURKETT, 1997) mostraram que o limite de Shannon pode ser aproximado, com uma separação de apenas 0, 27 dB, através do emprego de um simples código turbo. Por sua vez, Barbulescu e Pietrobon introduziram eficientes projetos de interleaver (BARBULESCU; PIETROBON, 1994). Uma visão compreensiva sobre codificação turbo pode ser encontrada em Benedetto e Montorsi (BenedetTo; MONTORsi, 1996a, 1996b) e Perez et.al. (PEREZ; SEGHERS; COSTELLO, 1996).

Com isso, os códigos turbo saíram muito rapidamente dos laboratórios de pesquisa para serem aplicados na prática em todo o mundo. Depois de seu anúncio em 1993, foram utilizados para diversos fins, principalmente nas comunicações móveis sem fio da terceira geração (3G) aos sistemas de exploração espaciais (BURR, 2001). A utilização de códigos turbo aliada a um esquema de decodificação iterativa resultam em diversas possibilidades de sistemas capazes de fornecer confiabilidade nas comunicações com uma relação sinal-ruído próxima ao limite de Shannon (SKLAR, 1997).

Os códigos convolucionais concatenados em série (SCCC - Serial Concatenated Convolutional Code) (BENEDETTO et al., 1997) surgiram como uma alternativa de melhoria nos ganhos de codificação quando se utilizam entrelaçadores de dimensão reduzida. Em contrapartida aos PCCC, os códigos SCCC possuem uma estrutura de concatenação em série, porém, similarmente aos PCCC podem ser decodificados por meio de estruturas iterativas. Os SCCC apresentam a característica de redução da BER mais eficaz com o aumento da dimensão dos entrelaçadores e de eliminar o patamar de BER irredutível existente nos PCCCs 
(BENEDETTO et al., 1997; SOLEYMANI; GAO; VILAIPORNSAWAI, 2002).

Diversos fatores devem ser considerados na escolha do esquema de codificação: complexidade, taxa de codificação, capacidade de correção de erro e a mínima relação sinal-ruído que permite uma recepção com a BER desejada, entre outros.

A utilização de códigos totalmente aleatórios proporciona a obtenção de taxas de erro tendendo a zero conforme o tamanho do bloco de codificação tende ao infinito. No entanto, não é possível codificar com um código totalmente aleatório. Além disto, a complexidade de decodificação aumenta exponencialmente com o aumento do bloco de codificação, tornando-o impraticável. Por isso, empregam-se códigos que oferecem um bom compromisso entre a taxa de erro e a complexidade de decodificação.

Assim, as técnicas de FEC procuram reduzir a quantidade de erros de recepção presentes em sistemas de comunicação digitais. Normalmente, a figura de mérito considerada consiste na taxa de erro de bits (BER), definida pela relação entre o número de bits recebidos de forma errônea e o total de bits recebidos.

A seguir são apresentados os três tipos de codificação de canal considerados como proeminentes e com indicativos de adoção para os próximos padrões de sistemas de comunicação sem fio de alto desempenho (PROAKIS, 1995; ZIEMER; PETERSON, 2001; LEE; MILLER, 1998; BENEDETTO; MONTORSI; DIVSALAR, 2003; CASELLA, 2004), sendo considerados neste trabalho.

\subsubsection{Codificação Convolucional}

Os códigos convolucionais possuem uma longa história de utilização e estudos desde sua introdução em 1955 com o trabalho pioneiro de P. Elias (ELIAS, 1955).

Assim como os códigos de bloco, os códigos convolucionais acrescentam redundância à informação além de dependência entre bits sucessivos através do emprego de registradores de deslocamento lineares. Assim, os dados codificados dependem não somente dos bits de informação atuais, mas dos bits anteriores, resultando em uma estrutura de codificação mais complexa que não pode ser dividida em palavras de código.

Os códigos convolucionais são empregados em vários sistemas de comunicação modernos e pertencem à classe dos códigos lineares. Diferente dos códigos de blocos de grande comprimento, apenas poucos códigos convolucionais são relevantes na prática. No entanto, estes possuem estrutura muito simples e podem ser graficamente descritos por diagramas de treliça e de estados finitos. Além 
da possibilidade de processar entradas do tipo suave (soft) ao invés de entradas abruptas (hard), a maior vantagem consiste na redução da complexidade de decodificação, principalmente após o surgimento do algoritmo de Viterbi (VITERBI, 1967).

Para esses códigos, a taxa de codificação $R_{c o d}$ é a relação entre o número de bits de entrada pelo número de bits de saída. A taxa de bits de entrada é dada por $R_{b}=1 / T_{b}$ e $T_{b}$ é o período de bit. Se a saída for modulada individualmente em um sinal BPSK (Binary Phase Shift Keying), pode-se afirmar que os códigos convolucionais não preservam a banda original do sinal, pois requerem $1 / R_{\text {cod }}$ vezes a banda do sinal original não codificado. Geralmente, este é o caso mais tradicional de estratégia de codificação utilizada para controle de erro em sistemas de potência limitada, canais em espaço profundo ${ }^{4}$, onde a potência necessária é minimizada a despeito de uma maior necessidade de banda.

Tradicionalmente, códigos convolucionais utilizam modulação do tipo BPSK ou QPSK (Quadrature Phase Shift Keying). Nestes casos, a distância euclidiana entre duas sequências de sinais, considerando sinais abruptos, depende da distância de Hamming ${ }^{5}$ entre as sequências binárias de saída.

A figura 2.2 apresenta um exemplo de codificador convolucional em sua representação canônica, considerando taxa $R_{c o d}=2 / 3$, neste caso, conhecido como tendo realimentação sistemática (systematic feedback).

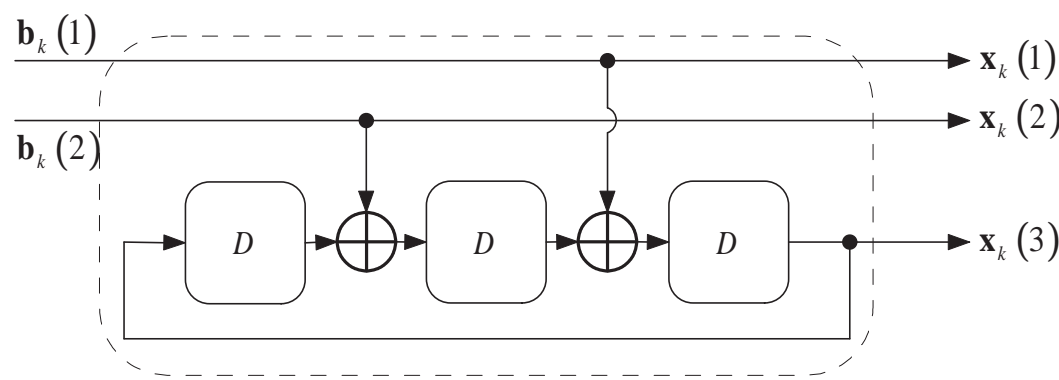

Figura 2.2: Exemplo de um codificador convolucional em sua representação canônica

O operador D (Delay) representa o operador de atraso unitário, correspondente a passar o símbolo através de um elemento de atraso unitário.

Outra forma existente utiliza o sinal de entrada apenas em um caminho direto até a saída, não considerando realimentação do sinal de saída. A este tipo de codificador denomina-se realimentação não sistemática (nonsystematic feed-

\footnotetext{
${ }^{4}$ Tradução do termo deep space comumente utilizado.

${ }^{5}$ Denotado como o número de posições binárias na qual os códigos são diferentes.
} 
forward). Na presença de realimentação, o codificador é comumente conhecido como tendo realimentação recursiva sistemática (RSC).

Desta forma, considerando uma entrada $\mathbf{b}_{k}$, de dimensão $1 \times m$ como sendo o vetor de bits de transmissão do $k$-ésimo usuário e $m$ representando, aqui, o bloco de bits de transmissão, em um codificador convolucional de taxa $R_{\text {cod }}$, obtém-se o sinal $\mathbf{x}_{k}$ dado por:

$$
\mathbf{x}_{k}=\mathbf{b}_{k}(D) \mathbf{G}(D)=\left[x_{k}(1), x_{k}(2), \ldots, x_{k}(n)\right]
$$

Onde $\mathbf{G}(D)$ denota a matriz geradora ${ }^{6}$ de códigos convolucionais, de dimensão $m \times n$, resultando na taxa $R_{c o d}=m / n, \mathbf{x}_{k}$ representa o vetor de símbolos codificados, com elementos $x_{k}(\cdot)$. Geralmente, representam-se os polinômios da matriz $\mathbf{G}$ através de números em octal. $\mathrm{O}$ vetor completo codificado considera a concatenação temporal dos diversos $x_{k}$ na ordem de saída.

Para maiores detalhes sobre os códigos convolucionais aconselha-se, além das referências previamente citadas, as referências (LIN; COSTELLO, 1983; CLARK; CAIN, 1983; DHOLAKIA, 1994; PROAKIS, 1995; JOHANNESSON; ZIGANGIROV, 1999).

\subsubsection{Codificação Turbo}

Conforme apresentado anteriormente, em 1993, foi apresentado por Berrou et. al., um novo esquema de codificação de canal que permitiu aumentar significativamente o desempenho dos métodos de FEC, denominado de codificação turbo (BERROU; GLAVIEUX; THITIMAJSHIMA, 1993). Estes resultados pioneiros indicaram que o emprego da codificação turbo possibilita atingir índices de capacidade muito próximos das predições indicadas por Shannon para canais AWGN, causando inicialmente, uma enorme contestação da comunidade científica, pois esta codificação supera a relação inversa entre a taxa de erro e o crescimento exponencial da complexidade de decodificação através da concatenação de códigos por meio de entrelaçadores, de forma que o código resultante seja suficientemente aleatório para obtenção de taxas de erro muito pequenas e possibilidade de uso de técnicas iterativas de decodificação baseadas em informação soft.

O significado do termo turbo associado ao método de codificação, conforme apresentado em (BERROU; GLAVIEUX; THITIMAJSHIMA, 1993), corresponde à si-

\footnotetext{
D.

${ }^{6}$ Os elementos da matriz $\mathbf{G}(D)$ são representados por polinômios dependentes do operador
} 
milaridade do conceito do método quando comparado ao princípio dos turbo compressores utilizados em motores a combustão, pois refere-se a um método iterativo baseado em realimentação. Este reprocessamento da informação na saída de cada um dos decodificadores empregados no processo de decodificação e na repetição do processo até se obter os índices de desempenho desejados caracteriza o decodificador turbo.

Por isso, conforme apresentado em (CASELLA, 2004), o princípio turbo é muito mais abrangente do que somente a estratégia de codificação turbo, podendo ser aplicado com sucesso a vários outros problemas, como o de equalização, de detecção multiusuário, de processamento espaço-temporal, de codificação espaçotemporal, de modulação codificada, entre outros.

Embora a estrutura dos códigos de bloco e convolucionais possibilite o desenvolvimento de codificadores e decodificadores com complexidade factível de ser implementada, o desempenho obtido é bastante inferior aos limites apresentados por Shannon para códigos aleatórios. Com o advento da codificação turbo, tornou-se possível a obtenção de resultados de desempenho muito próximos ao limite de Shannon, mantendo-se ainda uma complexidade de codificação e decodificação factível. A codificação turbo permite aumentar o bloco de codificação melhorando as propriedades aleatórias do processo de codificação com um aumento linear da complexidade de decodificação (HALEY; GRANT; BUETEFUER, 2002).

Vale ressaltar que a escolha adequada dos códigos concatenados e do entrelaçador é de grande importância para o ganho de codificação obtido pela codificação turbo (BARBULESCU; PIETROBON, 1999).

Quando um processo de decodificação iterativo é utilizado, além da informação dada pela sequência de dados recebida, há também a informação a priori, denominada de informação intrínseca, provida pelo processo de decodificação anterior. A informação suave trocada entre os decodificadores, também chamada de informação extrínseca, é a informação fornecida pelo processo de decodificação levando em consideração a sequência total de dados recebida e a informação $a$ priori de todos os outros sinais, excluindo a do sinal a ser decodificado. Assim, a informação extrínseca de um processo de decodificação é uma informação estatisticamente independente, podendo ser utilizada como informação a priori na próxima iteração.

Um codificador clássico para sistemas turbo consiste na concatenação de dois ou mais codificadores paralelos, usualmente idênticos e de taxa $R_{c o d}=1 / 2$, es- 
truturados de forma sistematicamente realimentada (RSC), utilizando um entrelaçador $(\mathbf{P})$ entre os codificadores, conforme figura 2.3.

Esta estrutura de codificação é chamada de concatenação paralela por operar os dois codificadores com o mesmo bloco de informações de entrada enquanto o sistema tradicional de concatenação serial utiliza a saída de um codificador como entrada do outro. Este trabalho considera a utilização apenas da topologia paralela, além de considerar os dois codificadores idênticos. No entanto, este método de codificação pode ser estendido para os casos de codificadores não idênticos ou utilização de mais de dois, além da topologia em série (DIVSALAR; POLLARA, 1995; SCHLEGEL; PéREZ, 2004).

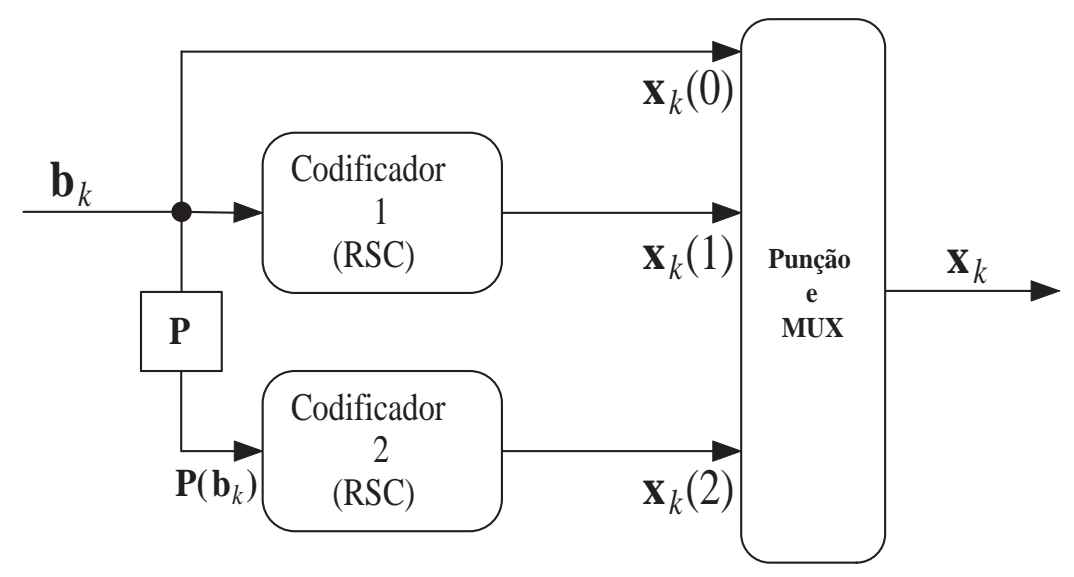

Figura 2.3: Exemplo de topologia para o codificador Turbo

O entrelaçador é utilizado para permutar a informação de entrada $\mathbf{b}_{k}$ entre os dois codificadores para que operem com o mesmo bloco mas com a informação em ordem diferente. A parcela $\mathbf{x}_{k}(0)$ refere-se a uma cópia do sinal de entrada. O primeiro codificador recebe diretamente a informação, denotada por $\mathbf{b}_{k}$, e produz a saída $\mathbf{x}_{k}(1)$. O segundo codificador recebe a informação entrelaçada pelo interleaver, denotado pelo operador $\mathbf{P}($.$) , resultando na saída \mathbf{x}_{k}(2)$.

Desta forma, o vetor codificado concatenado para cada usuário e considerando o codificador da figura 2.3 é descrito por:

$$
\mathbf{x}_{k}=\left[\mathbf{x}_{k}(0), \mathbf{x}_{k}(1), \mathbf{x}_{k}(2)\right]
$$

A sequência de entrada de informação $\mathbf{b}_{k}$ é agrupada em blocos de tamanho finito com comprimento $\mathcal{N}$, que corresponde ao comprimento do interleaver. Como os codificadores utilizados neste trabalho são idênticos, a taxa de codificação ao final neste caso é $R_{c o d}=1 / 3$. Em caso de necessidade de se alterar a taxa de codificação final para $R_{c o d}=1 / 2$, pode utilizar a estratégia conhecida como 
punção $^{7}$ (puncturing), que consiste em apagar alternativamente os elementos de $\mathbf{x}_{k}(1)$ e $\mathbf{x}_{k}(2)$

Desta forma, para uma taxa $R_{\text {cod }}=1 / n$, o vetor codificado concatenado para o k-ésimo usuário é denotado por:

$$
\mathbf{x}_{k}=\left[\mathbf{x}_{k}(0), \mathbf{x}_{k}(1), \ldots, \mathbf{x}_{k}(n)\right]
$$

Comumente utilizado na literatura, a notação $(h(1), h(2), \mathcal{N})$ corresponde ao código turbo utilizado, sendo $h(1)$ e $h(2)$ a representação em octal dos polinômios de conexão dos codificadores recursivos 1 e 2 , respectivamente, e $\mathcal{N}$ corresponde ao tamanho do bloco (block length).

Para maiores detalhes sobre codificação turbo, aconselham-se as referências (BERROU; GLAVIEUX; THITIMAJSHIMA, 1993; ROBERTSON; VILLEBRUN; HOEHER, 1995; BENEDETTO et al., 1996b, 1996a; HAGENAUER; OFFER; PAPKE, 1996; SKLAR, 1997; HALL; WILSON, 1998; WOODARD; HANZO, 2000; SHIN; KIM; LEE, 2000; BURR, 2001; SOLEYMANI; GAO; VILAIPORNSAWAI, 2002).

\subsubsection{Codificação LDPC}

Em 1962, Gallager (GALLAGER, 1962) apresentou os chamados códigos de cheque de paridade de baixa densidade (LDPC), mostrando a possibilidade de incremento significativo da capacidade de transmissão pela codificação do sinal utilizando-se códigos longos, mantendo um compromisso entre complexidade e desempenho. Na época, não existiam técnicas disponíveis para implementação dos códigos LDPC e estes caíram em esquecimento até 1997, quando Mackay (MACKAY; NEAL, 1997) os trouxe novamente à tona. Como as técnicas de processamento de sinais e os equipamentos haviam evoluído, a implementação em hardware de codificadores LDPC e decodificadores de alta velocidade em tempo real tornou-se possível, movimentando a comunidade científica no aprimoramento de tal técnica. Atualmente, estes códigos têm recebido um crescente interesse, principalmente após resultados de desempenho que apresentaram-se muito próximos do limite estabelecido por Shannon (RICHARDSON; URBANKE, 2003), além da complexidade que em diversos trabalhos mostrou-se como tendo um aumento linear em relação ao aumento do tamanho do código.

Desta forma, os códigos LDPC diferem dos códigos em treliça, convolucio-

\footnotetext{
${ }^{7}$ Normalmente, a punção é aplicada aos bits de paridade, já que a punção dos bits sistemáticos pode degradar significativamente o desempenho da codificação.
} 
nal e dos códigos de bloco primeiramente pela sua construção de maneira quase aleatória. Segundo, possuem um algoritmo de decodificação cuja complexidade torna-se linear com o tamanho do bloco de codificação.

Em uma forma simples, os códigos LDPC podem ser interpretados como um código de blocos linear com uma matriz de checagem de paridade (parity-check) que é esparsa ${ }^{8}$. Em (GALLAGER, 1962, 1963), os autores propuseram a construção de códigos LDPC alternando aleatoriamente as posições dos valores um (1) e zeros (0) em uma matriz de checagem de paridade $m \times n$ sujeita a condição de que cada linha da matriz possua o mesmo número de 1's ( $d_{c}$ valores iguais a 1$)$ e 0 's $\left(d_{v}\right.$ valores iguais a 0$)$.

Considerando $\mathbf{H}$ como a matriz de checagem de paridade e $\mathbf{G}$ como a matriz geradora, pode-se obter as seguintes condições:

$$
\mathbf{H x}=0
$$

onde $\mathbf{x}$ é a palavra codificada.

Quando a condição da equação (2.4) é respeitada, considera-se H como uma matriz de paridade válida.

Assim, pode-se encontrar a matriz geradora $\mathbf{G}$, de dimensão $m \times n$, como:

$$
\mathbf{G H}^{T}=0
$$

Esta matriz geradora $\mathbf{G}$ é então utilizada para codificar o sinal do $k$-ésimo usuário, resultando em:

$$
\mathbf{x}_{k}=\mathbf{b}_{k} \mathbf{G}
$$

A fração de 1's na matriz de checagem de paridade para um código regular LDPC é dado por:

$$
\frac{m d_{c}}{m n}=\frac{d_{c}}{n}
$$

Atualmente, encontram-se mais de 3900 trabalhos na base do IEEE a respeito do uso de códigos LDPC, evidenciando o grande interesse por este tipo de codificação. Para mais detalhes sobre a codificação LDPC aconselham-se as seguintes

\footnotetext{
${ }^{8}$ Uma matriz é dita esparsa quando possui uma pequena quantidade de elementos que assumem valores não nulos.
} 
referências: (RICHARDSON; URBANKE, 2001a; RICHARDSON; SHOKROLLAHI; URBANKE, 2001; RICHARDSON; URBANKE, 2001b; CHUNG et al., 2001; LUBY et al., 2001; Haley; GRAnt; Buetefuer, 2002; SCHLEGel; PéREZ, 2004; OHhashi; OHTSUKI, 2004; ZHONG; ZHANG, 2005; HONARY et al., 2008).

\subsubsection{Modulação de Múltipla Taxa}

Basicamente, existem quatro possíveis estratégias de sistemas com transmissão de dados de múltipla taxa que visam garantir os requisitos de taxa de transmissão dos serviços para cada usuário, além de variações e combinações destas, aplicáveis a sistemas de comunicação móveis, sendo:

1. MM, esquema de acesso de múltipla taxa baseado em vários formatos de modulação (Multimodulation Scheme) ${ }^{9}$.

2. MC, método de acesso de múltipla taxa com códigos de espalhamento múltiplos (Multicode Scheme) ${ }^{10}$.

3. VPG, ganho de processamento variável e taxa de chip fixa (Variable Processing Gain) ou ganho de processamento múltiplo inteiro (MPG, Multiple Processing Gain) ou ainda comprimento da sequências de espalhamento variáveis (VSL, Variable Spreading Length).

4. VCR, ganho de processamento fixo e taxa de chip variável (Variable Chip Rate).

A estratégia que emprega múltiplos formatos de modulação (MM) utiliza diferentes esquemas de modulação para atender os usuários com distintas taxas de dados. Normalmente, para acomodar as múltiplas taxas de bits emprega-se o esquema de modulação M-ário QAM (Quadrature Amplitude Modulation) com diferentes níveis de modulação. Tem-se todos os usuários com o mesmo ganho de processamento, uma vez que o período de símbolo é constante para todos os formatos de modulação. Porém, as amplitudes dos sinais variam conforme o nível de modulação. Para a mesma relação sinal-ruído por bit transmitido observam-se diferentes potências transmitidas para usuários com distintas taxas. Em um sistema DS/CDMA com detecção Uniusuário (SuD) combinado a sistemas multitaxa do tipo MM, usuários com altas taxas de dados transmitem com altas potências, causando severos problemas de interferência de múltiplo acesso para

\footnotetext{
${ }^{9}$ Também denominado Modulação Mista.

${ }^{10}$ Também denominado de Canais Paralelos.
} 
os usuários de baixas taxas relativas. A principal vantagem deste esquema está na simplicidade de implementação.

Como explanado anteriormente, na estratégia de acesso de múltipla taxa por código múltiplo, MC, todos os usuários multiplexam seus bits de informação utilizando várias sequências de espalhamento de baixa taxa, transmitindo os bits de informação em paralelo. Cada usuário transmite na mesma taxa básica e mesmo formato de modulação. Portanto, para variar a sua taxa de dados, permite-se ao usuário enviar, simultânea e sincronamente, utilizando uma quantidade de canais paralelos necessária para atender a sua taxa de dados específica. Todos os usuários terão o mesmo ganho de processamento, possibilitando a obtenção de um conjunto de sequências de espalhamento com ótimas propriedades de correlação cruzada, já que para este tipo de acesso pode resultar um grande número de sinais interferentes, caso a diferença da menor para a maior taxa do sistema seja elevada.

Já a estratégia de acesso de múltipla taxa VPG necessita de hardware simples para a construção da interface para sistema DS/CDMA de múltipla taxa. No entanto, deve-se associar detecção multiusuário a este esquema, uma vez que com detecção SuD resultará em degradação de desempenho para taxas de bits crescentes.

Finalmente, a estratégia VCR apresenta dificuldades de implementação, pois o receptor deve estar sincronizado a uma específica taxa de chip, além de o sistema necessitar de planejamento de frequência adicional devido à desigual largura de banda de espalhamento dos diferentes usuários.

Análises de sistemas DS/CDMA com detecção SuD que utilizam esquemas de múltipla taxa, em canais AWGN e com desvanecimento multipercurso podem ser encontradas em (OTTOSSON, 1995, 1997; RAMAKRISHNA; HOLTZMAN, 1998; ABRÃO, 2001; ROCHA, 2002; ABRÃO; JESZENSKY, 2002; FAN; HOFFMANN; SIU, 2003; ABRÃO et al., 2005).

Ressalta-se que é possível a obtenção de esquemas de múltipla taxa híbridos, que combinem duas ou mais estratégias de acesso de múltipla taxa, além das possibilidades de variação dos esquemas básicos, tais como o esquema denominado Combinação Paralela (PC/SS) e o VCR de frequência deslocada (VCRFS), encontrados em (OTTOSSON, 1997; LOPS; BUZZI; TULINO, 1998; ABRÃO et al., 2005). 
Uma síntese comparativa dos principais esquemas de múltipla taxa em sistemas SuD é apresentada na tabela 2.2. Não foram considerados o incremento no desempenho devido à deteç̧ão multiusuário, codificação de canal ou exploração de outro tipo de diversidade disponível. Um esquema em evidência é o que emprega códigos múltiplos para a transmissão de sinais de usuários com taxas variáveis justamente pela simplicidade no projeto dos sinais e implementação.

Tabela 2.2: Comparação de alguns parâmetros para esquemas multitaxa.

\begin{tabular}{l|c|c|c|c|c}
\hline Parâmetros & MC & PC/SS & MM & MPG & VCR \\
\hline \hline Desempenho & médio & alto & baixo & médio & médio \\
\hline $\begin{array}{l}\text { Complexidade do Projeto das } \\
\text { Sequências de Espalhamento }\end{array}$ & baixo & médio & baixo & alto & baixo \\
\hline Complexidade do Receptor & médio & alto & baixo & baixo & alto \\
\hline Número de Taxas Suportado & alto & baixo & médio & alto & médio \\
\hline
\end{tabular}

Em (OTTOSSON, 1995, 1997; RAMAKRISHNA; HOLTZMAN, 1998; ROCHA, 2002; ABRÃO; JESZENSKY, 2002; FAN; HOFFMANN; SIU, 2003; ABRÃO et al., 2005), foram analisados sistemas DS/CDMA com detecção SuD associados a esquemas de múltipla taxa do tipo MC e MM em canais AWGN e com desvanecimento multipercurso. Estas análises consideraram isoladamente esquemas de múltipla taxa na ausência de codificação de canal ou detecção MuD.

O desempenho para o esquema modulação mista (MM) mostra-se inviável para os usuários de altas taxas. Embora o esquema de múltipla taxa com ganhos de processamento variável (VPG, MPG ou VSL) possa suportar ampla faixa de taxas de bits, resulta em um projeto de códigos de espalhamento relativamente complexo.

Dentre os quatro esquemas básicos multitaxa analisados, as análises mostraram que o esquema $\mathrm{MC}$ resulta em melhor compromisso desempenho $\times$ número de taxas suportados, combinado à facilidade do projeto das sequências de espalhamento.

No entanto, é possível obter um esquema de múltipla taxa híbrido combinandose duas ou mais estratégias. Em (OTTOSSON; SVENSSON, 1994), é apresentado um sistema de múltipla taxa híbrido que combina MM e MC a fim de atender uma ampla faixa de taxa de dados, de alguns $\mathrm{kb} / \mathrm{s}$ a unidades de $\mathrm{Mb} / \mathrm{s}$, uma vez que esquemas de múltipla taxa básicos são incapazes de suportar simultaneamente baixa, média e alta taxa de bits, sem degradar o desempenho. O esquema MM é utilizado na transmissão dos sinais dos usuários com taxas baixas e médias, enquanto que sinais dos usuários de alta taxa são transmitidos empregando-se canais paralelos. 
Uma melhoria adicional no desempenho é obtida associando-se ao esquema de múltipla taxa uma forma de detecção multiusuário (JOHANSSON, 1998; SAQUIB, 1998) e codificação de canal (MADKOUR; GUPTA, 2000). Em (JOHANSSON, 1998) foi proposto uma estrutura MuD do tipo SIC (Sucessive Interference Cancellation) com esquema de múltipla taxa MC e MM. Um análise de desempenho considerando o receptor sub-ótimo Descorrelacionador e esquema MPG de dupla taxa em canais AWGN foi realizada em (SAQUIB, 1998). No entanto, encontram-se pouquíssimos trabalhos que utilizam algoritmos heurísticos aplicados ao problema $\mathrm{MuD}$ em sistemas multitaxa e canais realistas (CIRIACO; ABRÃO; JESZENSKY, 2005b, 2006c).

\subsubsection{Sistema Multitaxa por Códigos Múltiplos}

Este trabalho considera a estratégia de acesso de múltipla taxa por códigos múltiplos, também denominada canais paralelos, onde todos os usuários multiplexam seus bits de informação utilizando várias sequências de espalhamento, transmitindo seus bits de informação paralela e sincronamente. Cada usuário transmite na mesma taxa básica e mesmo formato de modulação, por exemplo, BPSK ou QPSK.

Portanto, para variar sua taxa de dados, permite-se ao usuário enviar, simultânea e sincronamente, uma quantidade necessária de canais paralelos para atender a sua taxa específica. Desta forma, o vetor $\mathbf{x}_{k}$ é dividido em pacotes de taxa $R$, sendo $R$ a taxa básica de transmissão.

A figura 2.4 esquematiza o transmissor para um sistema MC DS/CDMA em canal com desvanecimento multipercurso.

Em (JOHANSSON, 1996, 1998), investigou-se a abordagem de múltipla taxa cujos usuários transmitem através de um ou vários canais paralelos, de acordo com os seus requisitos de taxa de dados. Os bits transmitidos pelo $k$-ésimo usuário pertencente ao $g$-ésimo grupo multitaxa MC, de um total de $G$ grupos, utilizandose de $m^{(g)}=\frac{R^{(g)}}{R}$ códigos paralelos no intervalo de símbolo $T$, possuindo dimensão $m^{(g)} \times 1$, são:

$$
\mathbf{x}_{k^{(g)}}=\left[x_{k^{(g)}, 1}, x_{k^{(g)}, 2}, \ldots, x_{k^{(g)}, m^{(g)}}\right]
$$

onde $R^{(g)}$ é a taxa de dados do $g$-ésimo grupo multitaxa e $R=\frac{1}{T}$ é a taxa básica de transmissão, admitida submúltipla inteira de $R^{(g)}$.

Os símbolos de informação são espalhados em duas etapas, denominadas etapa de canalização e etapa de embaralhamento. 


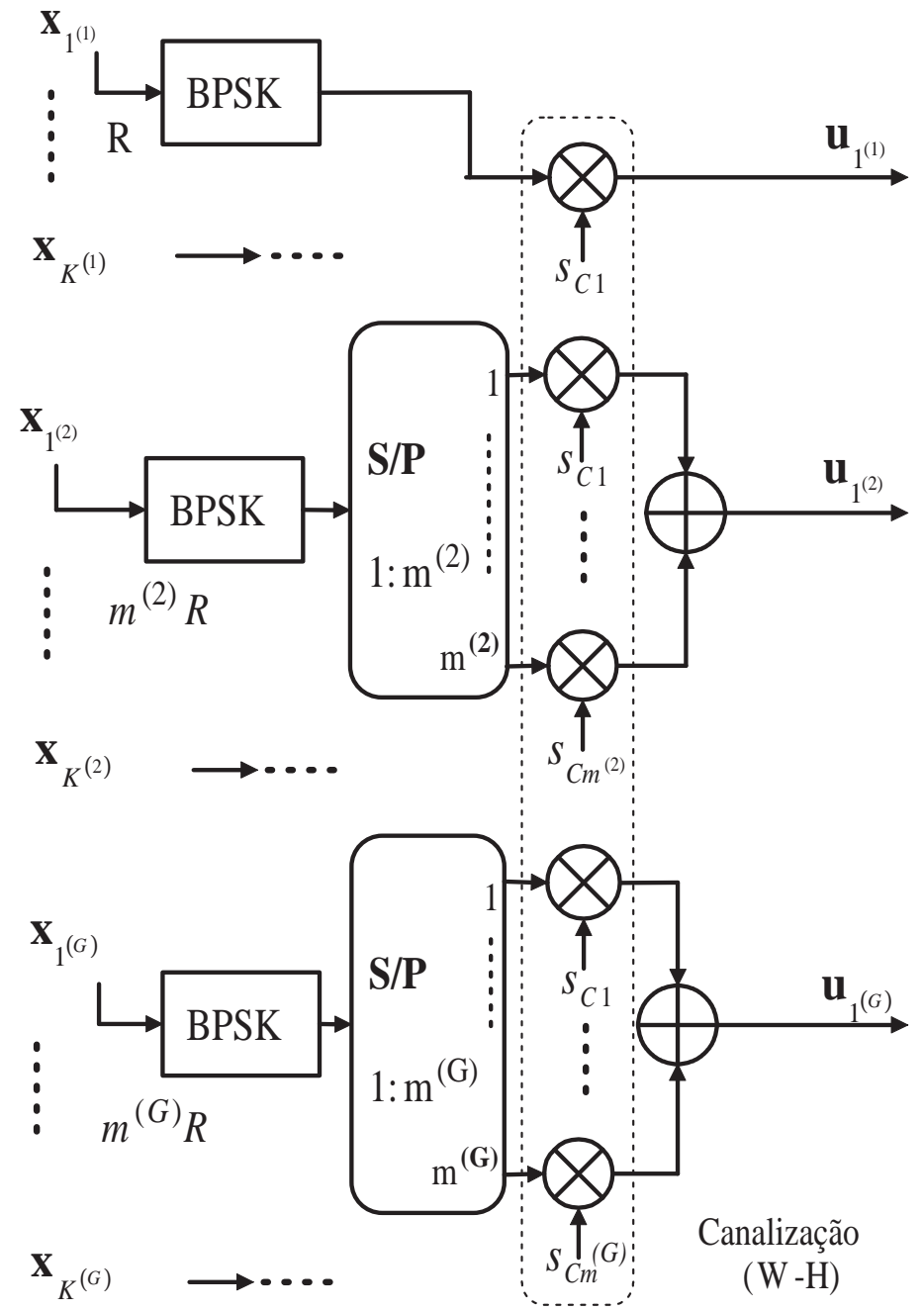

Figura 2.4: Etapa de canalização do tipo códigos múltiplos para um sistema multitaxa

A etapa de canalização permite que dados de canais paralelos de um mesmo usuário sejam ortogonais, pois estarão sujeitos às mesmas condições de canal, i.e., às mesmas condições de desvanecimento e de atrasos de propagação, possibilitando o uso de um conjunto de sequências de espalhamento com boas propriedades de correlação cruzada. Utiliza-se, para garantir a ortogonalidade, sequências de espalhamento Walsh-Hadamard (W-H).

Já a etapa de embaralhamento permite obter certa rejeição à interferência de múltiplo acesso, além da identificação de cada usuário DS/CDMA.

Assumindo-se que o $k$-ésimo usuário MC empregue modulação BPSK ${ }^{11}$ sobre as $m^{(g)}$ formas de ondas, o sinal em banda base após o espalhamento de canalização pode ser expresso por (RAMAKRISHNA; HOLTZMAN, 1998; ABRÃO, 2001;

\footnotetext{
${ }^{11}$ Cada símbolo codificado de $\mathbf{x}_{k^{(g)}} \in[0,1]$ é mapeado para os valores $[ \pm 1]$. Optou-se, neste trabalho, por manter a notação para o símbolo codificado.
} 
ROCHA, 2002; CIRIACO; ABRÃO; JESZENSKY, 2005b; ABRÃO et al., 2005):

$$
\mathbf{u}_{k^{(g)}}(t)=\sum_{j=1}^{m^{(g)}} \mathbf{x}_{k^{(g)}}[j] \mathbf{s}_{C k}^{(g)}(t-j T)
$$

onde o vetor forma de onda do código de canalização normalizado para o $k$-ésimo usuário é definido por:

$$
\mathbf{s}_{C k}^{(g)}(t)=\frac{1}{\sqrt{N_{C}}}\left[s_{C k, 1}^{(g)}(t) s_{C k, 2}^{(g)}(t) \ldots s_{C k, m^{(g)}}^{(g)}(t)\right]
$$

sendo o $m$-ésimo código de canalização do $k$-ésimo usuário, de comprimento $N_{C}$, dado por:

$$
s_{C k, m}^{(g)}(t)=\sum_{i=0}^{N_{C}-1} \underline{s}_{i, m}^{(g)} p_{T_{c h}}\left(t-i T_{c h}\right)
$$

onde $\underline{s}_{C}^{(g)}\left({ }_{i}\right) \in\{ \pm 1\}$ são os elementos do vetor de chips de canalização formatado, $T_{c h}$ é o intervalo de chip de canalização e $p_{T_{c h}}$ (.) é a formatação de pulso de canalização, assumindo-se formatação de pulso retangular e com amplitude unitária no intervalo $\left[0 ; T_{c h}\right)$ e zero fora.

Admite-se que para todos os usuários MC, o respectivo vetor de chips de canalização, equação (2.10), é designado a partir de um único conjunto de sequências de espalhamento Walsh-Hadamard, de comprimento $N_{C} \geq m^{(G)}$, atribuindo-se os primeiros $m^{(g)}$ códigos ao $k$-ésimo usuário de taxa $m^{(g)} R$.

A escolha de um conjunto de sequências W-H será particularmente vantajosa caso seja possível manter o sincronismo entre os sinais de todos os usuários, como por exemplo no enlace direto ou em um sistema CDMA síncrono ou quasesíncrono. Mantida a condição de fase preferencial para o conjunto de sequências ortogonais, a auto-interferência gerada será virtualmente zero. No entanto, fora de fase preferencial, as propriedades de correlação cruzada para estes conjuntos tornam-se piores que as das sequências determinísticas "tradicionais", como as de Gold e Kasami. Desta forma, deve-se considerar as características do enlace para a designação da família de sequências mais adequada a ser utilizada.

\subsubsection{Espalhamento Temporal por Sequência Direta}

Já a etapa de embaralhamento permite obter certa rejeição à interferência de múltiplo acesso, além da identificação de cada usuário DS/CDMA. Para isso, as sequências devem possuir boas propriedades de correlação cruzada e autocorrelação. No padrão WCDMA japonês e europeu designa-se para cada usuário uma única sequência do enorme conjunto de códigos de Kasami-VL256 (esten- 
dido), o qual resulta em mais de um milhão de códigos distintos. Opcionalmente para canais síncronos pode-se ter uma única sequência de embaralhamento PN (pseudoaleatórias) para todos os usuários, porém com distintos atrasos bem controlados. Esta sequência é gerada a partir do truncamento de uma sequência de Gold extra longa, $N=2^{18}-1$ para o canal direto e $N=2^{41}-1$ para o canal reverso no WCDMA norte-americano. A figura 2.5 apresenta a etapa de embaralhamento.

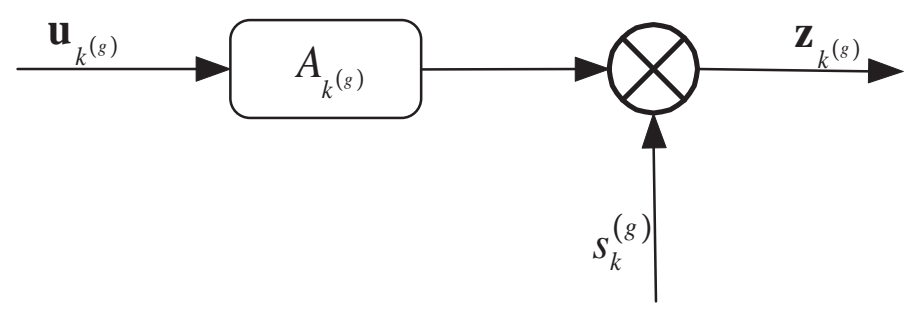

Figura 2.5: Etapa de embaralhamento do sinal em sistemas multitaxa

Neste trabalho, sem perda de generalidade, realiza-se a etapa de embaralhamento utilizando-se de sequências de espalhamento curtas pseudoaleatórias ${ }^{12}$. Para o $k$-ésimo usuário pertencente ao $g$-ésimo grupo multitaxa e $i$-ésimo período de símbolo, o sinal em banda base após o segundo espalhamento no domínio do tempo (T-domain) resulta em:

$$
\mathbf{z}_{k^{(g)}}(t)=\sqrt{2 P_{k, g}} \sum_{i=0}^{I-1} \mathbf{u}_{k^{(g)}}(t-i T) s_{k}^{(g)}(t-i T)
$$

onde $P_{k^{(g)}}=A_{k^{(g)}}^{2} / 2$ representa a potência de transmissão normalizada e $A_{k^{(g)}}$ representa a amplitude do sinal transmitido pelo $k$-ésimo usuário do $g$-ésimo grupo multitaxa, $I$ representa o número de símbolos e $s_{k}^{(g)}(t)$ corresponde à sequência de embaralhamento do $k$-ésimo usuário do $g$-ésimo grupo multitaxa.

Essa sequência de embaralhamento é definida no intervalo $\left[0, T_{c h}\right)$ e zero fora, sendo descrita por:

$$
s_{k}^{(g)}(t)=\frac{1}{\sqrt{N}} \sum_{n=0}^{N-1} \underline{s}_{k, n}^{(g)} p_{T_{c}}\left(t-n T_{c}\right)
$$

onde $\underline{s}_{k, n}^{(g)} \in\{ \pm 1\}$ é o $n$-ésimo chip da sequência PN de comprimento $N=\frac{T}{T_{c}}$ utilizada pelo $k$-ésimo usuário do $g$-ésimo grupo multitaxa e $T_{c}$ é o período de chip que define a largura de banda do sistema DS/CDMA .

Ambas as formatações de pulso, $p_{T_{c}}$ e $p_{T_{c h}}$, são assumidas retangulares com

\footnotetext{
${ }^{12}$ Devido à utilização de espalhamento no tempo-frequência, conforme apresentado na seção 2.1.4.
} 
amplitude unitária no intervalo $\left[0 ; T_{c}\right)$ e $\left[0 ; T_{c h}\right)$ e zero fora, respectivamente.

\subsubsection{Espalhamento na Frequência}

Em contraste com o espalhamento espectral por sequência direta, no qual o sinal original no domínio do tempo é espalhado por uma sequência específica para cada usuário, esquemas de espalhamento espectral multiportadora (MC-SS) constituem uma classe de esquemas que espalham o sinal original no domínio da frequência através do uso de $M$ subportadoras.

Portanto, topologias MC-SS podem ser interpretados como arranjos DS-SS para o domínio da frequência. Esquemas multiportadora podem ser classificados através dos modelos de espalhamento do sinal. Especificamente, estes podem ser divididos em duas grandes categorias.

A primeira classe consiste no uso dos dados de entrada na forma serial sendo mapeados por uma sequência e posteriormente cada chip é modulado em $M$ subportadoras paralelas. Desta forma, a taxa original é mantida e a velocidade de processamento necessária mantêm-se constante. No entanto, ao invés de uma portadora, o sinal é transmitido através de $M$ subportadoras paralelas ${ }^{13}$, sendo chamado de arranjo MC CDMA no domínio da frequência. Este tipo de sistema pode combinar a robustez da modulação ortogonal com a flexibilidade de esquemas CDMA (HARA; PRASAD, 1997; GUI; NG, 1999; YANG, 2009). Este esquema, por ser particular, é conhecido como espalhamento MC CDMA no domínio da frequência (F-domain). Os outros esquemas conhecidos encontram-se na segunda classificação (YANG, 2009).

A segunda classe de sistemas MC CDMA considera primeiramente a conversão serial/paralela $(\mathrm{S} / \mathrm{P})$ do sinal de entrada (pacote) em um número fixo de subpacotes. Após, cada subpacote de informação é espalhado utilizando uma sequência no domínio do tempo, e, finalmente, modulado por diferentes subportadoras para cada subpacote. Neste tipo de esquema MC CDMA cada sinal à saída de sua subportadora é similar ao caso do esquema DS/CDMA de portadora única (SOUROUR; NAKAGAWA, 1996; YANG; HANZO, 2002). Por esta razão, o segundo tipo de esquema MC CDMA é usualmente chamado de multiportadora DS/CDMA (MC DS/CDMA). Diferentemente do esquema MC CDMA, onde a taxa de símbolo é primeiramente incrementada por um fator de $M$ e depois mapeada em $M$ subportadoras, mantendo a mesma taxa original, no esquema MC DS/CDMA a taxa de símbolo é primeiramente reduzida pelo fator do número de

\footnotetext{
${ }^{13}$ Se utilizar frequências ortogonais denomina-se OFDM.
} 
subpacotes. A taxa de símbolo dos subpacotes é então incrementada através do espalhamento baseado em sequência direta para cada subportadora.

Além disso, a informação em esquemas MC DS/CDMA pode ser espalhada no domínio da frequência de forma adicional ao espalhamento no domínio do tempo. Este tipo de esquema multiportadora DS/CDMA é conhecido como esquema MC DS/CDMA com espalhamento no domínio do tempo-frequência (time-frequency domain spread MC DS/CDMA) (YANG; HANZO, 2003; YANG; HUA; HANZO, 2003).

Este trabalho considera, sem perda de generalidade, a utilização de espalhamento no domínio do tempo-frequência MC DS/CDMA para o modelo de sistema proposto. Mesmo assim, apresentam-se as diferentes topologias para sistemas multiportadora, evidenciando os motivos pela escolha do modelo utilizado.

\subsubsection{Esquema TF-MC DS/CDMA}

Sabe-se que no contexto de sistemas DS/CDMA pode-se utilizar uma sequência para espalhar o sinal original dos diversos usuários no domínio do tempo e transmiti-los através de uma portadora em uma frequência única. No entanto, observa-se o uso de sequências de espalhamento no domínio da frequência onde cada chip do resultado entre o sinal e sequência é transmitido através de uma subportadora. Nesta caso, o esquema é conhecido como MC CDMA.

Este trabalho considera um esquema que expande o arranjo de espalhamento com a ajuda de duas sequências de espalhamento, onde as sequências são utilizadas e correspondem, respectivamente, ao domínio do tempo (T-domain) e ao domínio da frequência (F-domain). Desta forma, o sistema é conhecido como sendo no domínio do tempo-frequência (TF-domain) MC DS/CDMA.

A figura 2.6 apresenta o esquema TF-MC DS/CDMA.

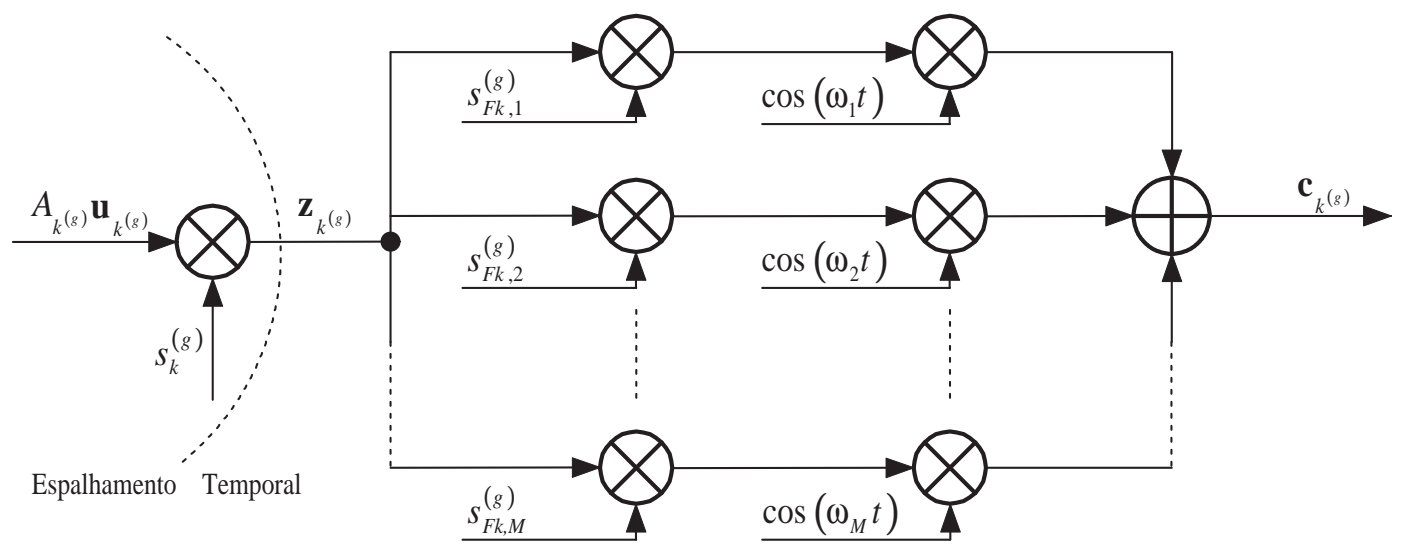

Figura 2.6: Esquema TF-MC DS/CDMA 
Note que este trabalho utiliza, de forma inerente, o esquema da figura 2.6, pois a etapa de espalhamento no tempo já é realizada devido à escolha do sistema multitaxa $^{14}$, seção 2.1.2.1 e seção 2.1.3.

O sistema adotado visa proporcionar um aumento de diversidade no receptor, além da flexibilidade na escolha das sequências, pois estas podem ser do tipo curtas, pois a banda total ocupada será proporcional ao produto dos ganhos de espalhamento das sequências individuais, facilitando, em muito, o projeto de sequências. Além disso, os sistemas de acesso múltiplo de banda larga devem fornecer uma gama variada de serviços e taxas, bem como assegurar um número elevado de usuários simultâneos. O uso de detectores multiusuário, conforme comentado anteriormente, visa garantir a supressão da interferência aumentando a capacidade do sistema. Quando utiliza-se apenas uma única frequência e grande espalhamento no tempo ou sem espalhamento no tempo e diversas frequências (subportadoras), o uso destes detectores se torna impraticável, devido à complexidade inerente. Em contrapartida, considerando esquemas TF-MC DS/CDMA, usuários simultâneos podem ser separados, tanto no domínio do tempo quanto no domínio da frequência através das sequências separadamente utilizadas. Desta forma, a detecção multiusuário pode ser realizada separadamente, reduzindo significativamente a complexidade quando comparado aos esquemas típicos MC CDMA ou DS/CDMA de portadora única.

Considerando que o espalhamento no domínio do tempo já foi realizado, conforme equação (2.12), o sinal à saída da etapa de espalhamento na frequência é dado por:

$$
\mathbf{c}_{k^{(g)}}(t)=\sum_{m=1}^{M} \mathbf{z}_{k^{(g)}}(t) s_{F k, m}^{(g)} \cos \left(2 \pi f_{m} t+\phi_{k, m}^{(g)}\right)
$$

Onde $\phi_{k, m}^{(g)}$ representa a fase inicial para o $k$-ésimo usuário do $g$-ésimo grupo multitaxa e $m$-ésima subportadora e $f_{m}$ representa as respectivas frequências das subportadoras.

A sequência de espalhamento na frequência é definida no intervalo $\left[0, T_{c}\right)$ e zero fora, sendo cada chip descrito para cada subportadora como:

$$
s_{F k, m}^{(g)}=\frac{1}{\sqrt{M}} \underline{s}_{F k, m}^{(g)}
$$

onde $\underline{s}_{F k, m}^{(g)} \in\{ \pm 1\}$ é o $m$-ésimo chip da sequência PN de comprimento $M$ utili-

\footnotetext{
${ }^{14}$ Sistema por Códigos Múltiplos requer etapa de canalização e embaralhamento.
} 
zada pelo $k$-ésimo usuário do $g$-ésimo grupo multitaxa.

Utilizando notação vetorial, pode-se reescrever a equação (2.14) como:

$$
\mathbf{c}_{k^{(g)}}=\left[\mathbf{c}_{k^{(g)}, 1}, \mathbf{c}_{k^{(g)}, 2}, \ldots, \mathbf{c}_{k^{(g)}, N}\right]
$$

Onde cada elemento $\mathbf{c}_{k^{(g)}, n}$ representa o símbolo $n$ após todas as etapas no transmissor.

\subsubsection{Sistemas com Múltiplas Antenas de Transmissão}

A diversidade de transmissão é um campo que têm despertado interesse nos últimos 20 anos da comunidade científica e da indústria, pois trata-se de técnicas eficientes de combate ao desvanecimento que aumentam a capacidade de sistemas de comunicação sem fio. No entanto, a ideia de utilização de diversidade espacial e formatação de feixe iniciou-se em 1970, com o trabalho de A. R. Kaye (KAYE; GEOrGE, 1970) e W. V. Etten (ETTEn, 1975). Na década de 80, J. Winters e J. Salz, da Bell Laboratories, publicaram alguns artigos referente à área de múltiplas antenas e formatação de feixe (WINTERS, 1984; SALZ, 1985).

Mas somente em 1993, com o trabalho pioneiro de A. Paulraj e T. Kailath (PAULRAJ; KAILATH, 1994), foi apresentado o conceito de multiplexação espacial (SM - Spatial Multiplexing) para sistemas MIMO e em 1994 estes receberam a patente americana no. 5345599, enfatizando-o em aplicações de transmissão sem fio.

Em (Foschini, 1996; RAleigh; CIOFFI, 1998), G. J. Foschini e G. Raleigh propuseram novas topologias para sistemas MIMO, considerando uma configuração onde múltiplas antenas de transmissão são co-localizadas em um transmissor para aumentar eficientemente a vazão (throughput) de informação.

A Bell Labs foi a primeira empresa a demonstrar um protótipo de multiplexação espacial em 1998, sendo utilizada posteriormente pela indústria como uma das principais técnicas para aumento de desempenho de sistemas de comunicação MIMO (GOLDEN et al., 1999).

Sabe-se, da teoria da informação, que utilizando-se de $A_{T x}$ antenas de transmissão e $A_{R x}$ antenas de recepção, existe a possibilidade de obtenção de ganho de capacidade de $A_{n}$ vezes (FOSCHINI; GANS, 1998; MARZETTA; HOCHWALD, 1999; GESBERT et al., 2000) em canais seletivos, onde $A_{n}=\min \left(A_{T x}, A_{R x}\right)$ é também denominado ganho de multiplexação. 
Na última década do século passado, diversas técnicas foram propostas no intuito de explorar as vantagens oferecidas pelos canais de múltiplas entradas e múltiplas saídas (MIMO). Pode-se citar duas principais técnicas para exploração destas vantagens. A primeira consiste na multiplexação espacial, também conhecida como BLAST (Bell Labs Layered Space-Time) (FOSCHINI, 1996), que utiliza os canais de MIMO para aumentar a eficiência espectral. A segunda abordagem possível é conhecida como STC (Space-Time Coding) (TAROKH; SESHADRI; CALDERBANK, 1998; TAROKH; JAFARKHANI; CALDERBANK, 1999), que usa os canais de MIMO para aumentar o ganho de diversidade.

Nos dois casos, as técnicas não requerem nenhuma informação prévia do estado do canal no transmissor. A eficiência espectral na técnica BLAST é incrementada mediante a transmissão de pacotes de dados de forma independente a partir de antenas distintas, requerendo um número de antenas receptoras pelo menos igual ao número de antenas de transmissão, ou seja, $A_{R x} \geq A_{T x}$, impactando diretamente na relação custo-benefício do sistema. Para a técnica STC, a qualidade do serviço (QoS) é aumentada pela obtenção de ganho de diversidade e de codificação, que são introduzidos pela correlação espaço-tempo entre os sinais transmitidos pelas diferentes antenas de transmissão. Diferentemente da técnica BLAST, a técnica STC pode ser implementada de forma mais singela no receptor, pois torna-se possível o emprego de um número arbitrário de antenas de recepção. Desta forma, este trabalho considera a utilização da técnica STC, especificamente a $\mathrm{STBC}^{15}$ devido às vantagens apresentadas.

\subsubsection{Codificação Espaço Temporal}

Conforme descrito anteriormente, as técnicas STC têm recebido atenção diferenciada devido a suas vantagens. Primeiro, pelo aumento de desempenho sem a obrigação de utilização de muitas antenas no receptor. Segundo, podem ser facilmente combinadas com codificadores de canal obtendo ganho de codificação e diversidade espacial. Terceiro, não requerem conhecimento prévio das características do canal, ou seja, trabalham em malha aberta. Finalmente, mostram-se robustos contra variações das condições ideais de operação como correlação entre as antenas, erros nas estimativas de canal e efeito Doppler (TAROKH; SESHADRI; CALDERBANK, 1998; NAGUIB et al., 1998; TAROKH et al., 1999).

Na estratégia STC, os dados codificados são divididos em $A_{T x}$ conjuntos que são, posteriormente transmitidos simultaneamente pelas $A_{T x}$ antenas. Do lado do

\footnotetext{
${ }^{15}$ Apresentada na seção 2.1.5.2.
} 
receptor, o sinal é visto como uma sobreposição linear dos símbolos transmitidos, corrompidos por ruído e interferência intersimbólica. Desta forma, os algoritmos de decodificação espaço-temporais e as técnicas de estimativa do canal são então utilizados visando à obtenção de diversidade e de ganho de codificação (DIGGAVI et al., 2004; CASELLA, 2004).

Com isso, torna-se possível transferir a complexidade para o transmissor (múltiplas antenas) permitindo que o receptor seja implementado de forma mais singela. Este cenário mostra-se atraente para o enlace direto em sistemas móveis devido à dificuldade de utilização de muitas antenas nos terminais móveis. Além disso, os efeitos do desvanecimento são minimizados sem a necessidade de utilização de recursos de banda adicional (eficiência espectral) melhorando significativamente a capacidade do sistema (TAROKH; SESHADRI; CALDERBANK, 1998; FOSCHINI; GANS, 1998; DIGGAVI et al., 2004).

Considerando a técnica STC, note-se que existem dois tipos de diversidade espacial conhecidas como diversidade de transmissão e diversidade de recepção. Na diversidade de recepção, múltiplas antenas são utilizadas para obter réplicas distintas do sinal que estão sujeitos a desvanecimentos individuais. Desta forma, pode-se combinar os sinais adequadamente através de técnicas simples, como a de combinação de ganho igual (EGC - Equal Gain Combining), o de combinação por razão máxima (MRC - Maximum Ratio Combining), entre outras. Considerando o enlace direto, a utilização de muitas antenas no receptor mostra-se inviável, pois existem limitações de potência e tamanho dos terminais móveis. Isto reforça a possibilidade de uso da diversidade de transmissão, pois a complexidade pode ser alocada na estação base (ZEXIAN; LATVA-AHO, 2002), quando considera-se enlace direto.

Mesmo assim, existe a dificuldade de separação dos sinais no receptor, pois estes estão misturados espacialmente e temporalmente e não se conhece a priori as características de propagação do canal. Desta forma, necessita-se de processamento adicional no receptor para a exploração da diversidade disponível. Com isso, esta estratégia mostra-se vantajosa pela não obrigatoriedade de muitas antenas no receptor.

Uma das estruturas mais simples de STC consiste na utilização de intervalos distintos para a transmissão de símbolos, criando artificialmente um efeito de propagação seletivo em frequência, podendo ser explorado no receptor. Esta estratégia foi proposta inicialmente por (WITTNEBEN, 1991, 1993), sendo conhecida como diversidade de atraso (delay diversity). No entanto, embora ofereça ganho 
de diversidade igual ao número de antenas de transmissão, o resultado pode ser melhorado através do uso de técnicas com codificação.

Assim, a busca por técnicas mais eficazes resultaram nos métodos STTC, proposto inicialmente por (TAROKH; SESHADRI; CALDERBANK, 1998) e STBC, proposto inicialmente por (ALAMOUTI, 1998; TAROKH; JAFARKHANI; CALDERBANK, 1999). Para este trabalho de doutoramento será considerada a técnica STBC, pois requer apenas um processamento linear para a decodificação espaçotemporal dos símbolos. Vale ressaltar que a técnica STTC pode ser utilizada, mas esta requer estimativa de máxima verossimilhança no receptor, cuja complexidade aumenta exponencialmente com a taxa de transmissão.

Atualmente existem mais de 1000 trabalhos sobre técnicas de diversidade espacial na base do IEEE, mas entre os anos de 1996 e 1999, surgiram os principais trabalhos voltados às propostas de métodos de exploração de diversidade de transmissão com superação das dificuldades de processamento no receptor. Entre eles, aconselham-se as referências (FOSCHINI, 1996; WINTERS, 1998; TAROKH; SESHADRI; CALDERBANK, 1998; ALAMOUTI, 1998; TAROKH; JAFARKHANI; CALDERBANK, 1999). Além destas referências históricas, deve-se considerar as referências mais atuais que realizam estudos comparativos entre as diversas técnicas, além de análises consolidadas a respeito dos trabalhos anteriormente realizados, podendo-se citar (ZEXIAN; LATVA-AHO, 2002; LARSSON; STOICA; GANESAN, 2003; DIGGAVI et al., 2004; BOLCSKEI et al., 2006; PAULRAJ; NABAR; GORE, 2008; MIETZNER et al., 2009).

\subsubsection{Codificação Espaço Temporal em Bloco}

Alamouti (ALAMOUTI, 1998) introduziu um método simples de malha aberta utilizando duas antenas de transmissão para a redução da complexidade exponencial do decodificador para o método STTC, apresentando um ganho de diversidade da ordem do obtido pelo método de combinação por razão máxima. Em (TAROKH; JAFARKHANI; CALDERBANK, 1999), este método foi generalizado para um número arbitrário de antenas transmissoras, resultando na topologia conhecida como codificação espaço-temporal em bloco (STBC).

Na técnica de STBC, os símbolos são codificados no domínio espaço-tempo, gerando blocos de símbolos ortogonais que são transmitidos por antenas distintas. Do lado do receptor, a decodificação dos símbolos é obtida pela combinação dos blocos recebidos pelas distintas antenas de recepção através de um processamento linear. Como os sinais transmitidos são ortogonais, a técnica STBC oferece um 
ganho significativo de diversidade, mas esta não disponibiliza ganho de codificação (CASELLA, 2004).

A figura 2.7 apresenta o bloco de transmissão da técnica STBC para taxa 1 e $A_{T x}=2$.

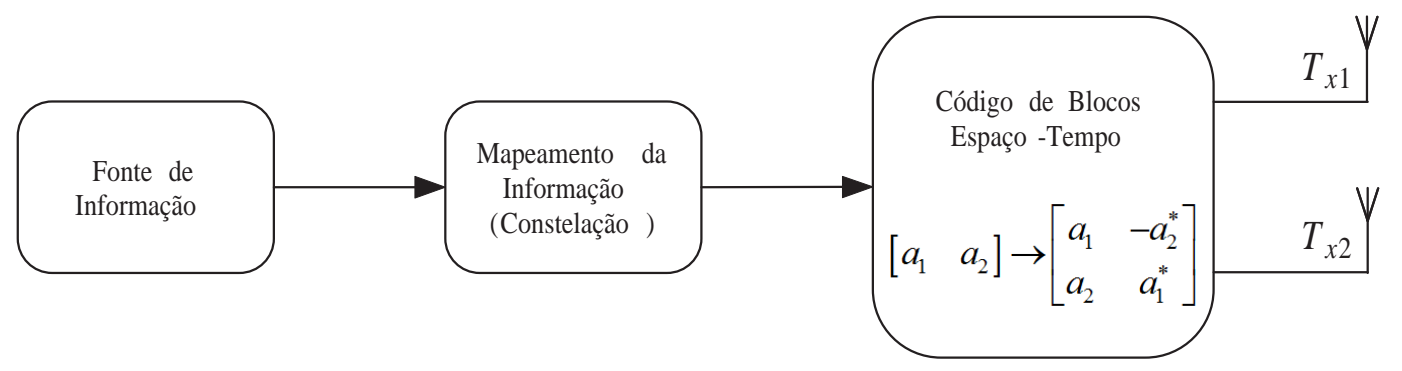

Figura 2.7: Esquema STBC

De acordo com o esquema apresentado na figura 2.7 os símbolos de entrada $\left[\mathbf{c}_{k, i}^{(g)}, \mathbf{c}_{k, i+1}^{(g)}, \ldots, \mathbf{c}_{k, i+\Psi}^{(g)}\right]$ são mapeados em uma constelação real ou complexa com $2^{\Psi}$ símbolos, resultando em $\mathbf{a}_{k, j}^{(g)}$.

Posteriormente, são agrupados em pares $\mathbf{a}_{k, j}^{(g)}$ e $\mathbf{a}_{k, j+1}^{(g)}$ e transmitidos pela primeira e segunda antenas, respectivamente. No próximo período de símbolo, transmite-se o símbolo $-\left(\mathbf{a}_{k, j+1}^{(g)}\right)^{*}$ na primeira antena e o símbolo $\left(\mathbf{a}_{k, j}^{(g)}\right)^{*}$ na segunda antena, onde o operador $(\cdot)^{*}$ corresponde à operação de complexo conjugado.

O símbolo $\mathbf{a}_{k, j}^{(g)}$, considerando mapeamento real BPSK, é denotado por:

$$
\mathbf{a}_{k, j}^{(g)}=\mathbf{c}_{k, i}^{(g)}
$$

Desta forma, pode-se reescrever equação (2.14) como:

$$
\mathbf{a}_{k^{(g)}}(t)=\sum_{m=1}^{M} \mathbf{z}_{k^{(g)}}(t) s_{F k, m}^{(g)} \cos \left(2 \pi f_{m} t+\phi_{k, m}^{(g)}\right)
$$

Esta representação corresponde a uma taxa de codificação plena e igual a 1, pois dois símbolos de informação são transmitidos em dois períodos de símbolo. Este sinal é transformado em banda passante através de uma portadora $f_{c, n_{T x}}$ para cada uma das $A_{T x}$ antenas transmissoras e transmitido. 


\subsection{Canais MIMO Multipercurso}

Considerando o enlace reverso e assumindo um conjunto de bits transmitidos (frame) consistindo de $I$ bits para cada usuário multitaxa, o sinal resultante na equação (2.18) propaga-se através de $L$ percursos independentes com desvanecimento Rayleigh. Assim, o sinal equivalente em banda base recebido (assumindo filtro passa-baixa ideal) em uma das antenas é:

$$
r_{n_{R x}}(t)=\sum_{i=0}^{I-1} \sum_{k=1}^{K^{(g)}} \sum_{g=1}^{G} \mathbf{a}_{k^{(g)}}\left(t-d_{k}^{(g)}-i T\right) * h_{k, g}^{(i)}(t)+\eta(t)
$$

Reescrevendo a equação (2.19) utilizando-se das equação (2.9), equação (2.12) e equação (2.14), resulta em:

$$
\begin{gathered}
r_{n_{R x}}(t)=\sum_{i=0}^{I-1} \sum_{k=1}^{K^{(g)}} \sum_{g=1}^{G}\left[\sum_{m=1}^{M} \sum_{j=1}^{m^{(g)}} A_{k, g}^{\prime} \mathbf{x}_{k(g)}^{(i)}[j] s_{C k}^{(g)}(t-j T) s_{k}^{(g)}\left(t-\tau_{k, \ell}^{(g)}-i T\right) .\right. \\
\left.. s_{F k, m}^{(g)} \cos \left(2 \pi f_{m} t+\phi_{k, m}^{(g)}\right)\right] * h_{k, g}^{(i)}(t)+\eta(t)
\end{gathered}
$$

Onde $K^{(g)}$ é o número de usuários físicos pertencentes ao $g$-ésimo grupo multitaxa, sendo $K=K^{(1)}+K^{(2)}+\ldots+K^{(g)}+\ldots+K^{(G)}$ o número total de usuários físicos ativos no sistema, subdivididos em $G$ grupos de usuários de mesma taxa; $t \in[0, T]$; a amplitude $A_{k, g}^{\prime}$ é a amplitude recebida do $k$-ésimo usuário do $g$-ésimo grupo multitaxa, incluindo os efeitos de perdas de percurso e sombreamento do canal, sendo assumida constante ao longo dos $I$ bits de taxa básica transmitidos; $\mathbf{x}_{k^{(g)}}^{(i)}[j] \in\{ \pm 1\}$ é o símbolo codificado de informação transmitido para o $i$-ésimo intervalo de símbolo; $\tau_{k, \ell}^{(g)}$ é o atraso aleatório correspondente e o termo $\eta(t)$ representa o AWGN com densidade de potência bilateral igual a $N_{0} / 2$.

O atraso do $k$-ésimo usuário do $g$-ésimo grupo multitaxa leva em consideração a natureza assíncrona da transmissão, $d_{k}^{(g)}$, como também o atraso de propagação, $\Delta_{k, \ell}^{(g)}$ para o $k$-ésimo usuário, $\ell$-ésimo percurso do $g$-ésimo grupo multitaxa, resultando em:

$$
\tau_{k, \ell}^{(g)}=\Delta_{k, \ell}^{(g)}+d_{k}^{(g)}
$$

A resposta impulsiva do canal para o $k$-ésimo usuário do $g$-ésimo grupo multitaxa no intervalo do $i$-ésimo bit pode ser escrita como:

$$
h_{k, g}^{(i)}(t)=\sum_{\ell=1}^{L} c_{k, \ell, g}^{(i)} \delta\left(t-\Delta_{k, \ell}^{(g)}-i T\right)
$$


onde $c_{k, \ell, g}^{(i)}=\beta_{k, \ell, g}^{(i)} e^{j \phi_{k, \ell, g}^{(i)}}$ indica o coeficiente complexo do canal para o $k$-ésimo usuário do $g$-ésimo grupo multitaxa, $\ell$-ésimo percurso e $\delta(t)$ representa a função impulso unitário. Assume-se que a fase de $c_{k, \ell, g}^{(i)}$ terá uma distribuição uniforme em $\phi_{k, \ell, g}^{(i)} \in[0,2 \pi)$ e o módulo do canal $\beta_{k, \ell, g}^{(i)}$ representa o desvanecimento de pequena escala com envoltória seguindo uma distribuição Rayleigh. Adicionalmente, considerou-se ganho de canal normalizado para todos os usuários, ou seja, $\mathbb{E}\left[\sum_{\ell=1}^{L}\left|c_{k, \ell, g}\right|^{2}\right]=1$ para $\forall k, g, i$.

Portanto, pode-se reescrever o sinal recebido em cada uma das $A_{R x}$ antenas substituindo a equação (2.22) na equação (2.20), resultando em:

$$
\begin{aligned}
r_{n_{R x}}(t)= & \sum_{i=0}^{I-1} \sum_{k=1}^{K^{(g)}} \sum_{g=1}^{G} \sum_{m=1}^{M} \sum_{j=1}^{m^{(g)}} \sum_{\ell=1}^{L} A_{k, g, \ell}^{\prime} \mathbf{x}_{k(g)}^{(i)}[j] s_{C k}^{(g)}(t-j T) s_{k}^{(g)}\left(t-\tau_{k, \ell}^{(g)}-i T\right) . \\
& . s_{F k, m}^{(g)} \cos \left(2 \pi f_{m} t+\phi_{k, m}^{(g)}\right) c_{k, \ell, g}^{(i)} \delta\left(t-\Delta_{k, \ell}^{(g)}-i T\right)+\eta_{n_{R x}}(t)
\end{aligned}
$$

Por simplicidade e sem perda de generalidade, consideram-se atrasos aleatórios ordenados, ou seja:

$$
0=\tau_{1,1}^{(1)} \leq \tau_{1,2}^{(1)} \leq \cdots \tau_{1, L}^{(1)} \leq \tau_{2,1}^{(1)} \leq \cdots \leq \tau_{K^{(1)}, L}^{(1)} \leq \cdots \tau_{K^{(G)}, L}^{(G)}<T
$$

Visando facilitar a compreensão do sinal recebido, optou-se pela apresentação em notação vetorial, conforme desenvolvimento a seguir.

Considerando o vetor de símbolos codificados à saída da etapa de codificação para o $k$-ésimo usuário multitaxa $\mathbf{x}_{k^{(g)}}$, de dimensão $1 \times m^{(g)}$, e considerando o $i$-ésimo intervalo de símbolo, pode-se utilizar um vetor de chips, de dimensão $1 \times N_{c}$ que corresponde ao símbolo codificado amostrado $N_{c}$ vezes $^{16}$, dado por:

$$
\mathbf{x}_{k^{(g)}}^{(i)}=\left[x_{k^{(g)}, i}, x_{k^{(g)}, i}, \ldots, x_{k^{(g)}, i}\right]
$$

O vetor de símbolos codificados amostrados para cada usuário, de dimensão $1 \times N_{c} m^{(g)}$, pode ser expresso por:

$$
\mathbf{x}_{k^{(g)}, m^{(g)}}^{(i)}=\left[\mathbf{x}_{k^{(g)}}^{(i)}[1], \mathbf{x}_{k^{(g)}}^{(i)}[2], \ldots, \mathbf{x}_{k^{(g)}}^{(i)}\left[m^{(g)}\right]\right]
$$

Desta forma, pode-se escrever a matriz de símbolos codificados para o $i$-ésimo intervalo de símbolo, de dimensão $K \times N_{c} \mathcal{K}_{v}$, como:

\footnotetext{
${ }^{16}$ Lembrando que $N_{c}$ corresponde ao ganho de processamento da etapa de canalização.
} 


$$
\mathbf{X}_{i}=\left[\begin{array}{cccc}
\mathbf{x}_{1^{(1)}, 1}^{(i)} & {[0]} & \cdots & {[0]} \\
{[0]} & \mathbf{x}_{k^{(g)}, m^{(g)}}^{(i)} & \cdots & {[0]} \\
\vdots & \vdots & \ddots & {[0]} \\
{[0]} & {[0]} & \cdots & \mathbf{x}_{K^{(G)}, m^{(G)}}^{(i)}
\end{array}\right]
$$

Onde $\mathcal{K}_{v}$ é o número de usuários virtuais do sistema multitaxa DS/CDMA, sendo descrito como:

$$
\mathcal{K}_{v}=\sum_{g=1}^{G} K^{(g)} m^{(g)}
$$

Com isso, finalmente pode-se expressar a matriz de símbolos codificados para todos os usuários considerando todos os $I$ intervalos de símbolo, de dimensão $K I \times N_{c} \mathcal{K}_{v} I$, como:

$$
\mathbf{X}=\left[\begin{array}{cccc}
\mathbf{X}_{1} & {[0]} & \cdots & {[0]} \\
{[0]} & \mathbf{X}_{2} & \cdots & {[0]} \\
\vdots & \vdots & \ddots & {[0]} \\
{[0]} & {[0]} & \cdots & \mathbf{X}_{I}
\end{array}\right]
$$

Por outro lado, o vetor das sequências de espalhamento da etapa de canalização para o $k$-ésimo usuário do $g$-ésimo grupo multitaxa, de dimensão $N_{c} m^{(g)} \times 1$, conforme equação (2.10), considerando chips amostrados, é expresso por:

$$
\mathbf{s}_{C k}^{(g)}=\frac{1}{\sqrt{N_{C}}}\left[\mathbf{s}_{C k, 1}^{(g)}, \mathbf{s}_{C k, 2}^{(g)}, \ldots, \mathbf{s}_{C k, m^{(g)}}^{(g)}\right]^{T}
$$

Desta forma, pode-se escrever a matriz de sequências de canalização para o $i$-ésimo intervalo de símbolo, de dimensão $N_{c} \mathcal{K}_{v} \times K$, como:

$$
\mathbf{S}_{C, i}=\left[\begin{array}{cccc}
\mathbf{s}_{C 1}^{(1)} & {[0]} & \cdots & {[0]} \\
{[0]} & \mathbf{s}_{C k}^{(g)} & \cdots & {[0]} \\
\vdots & \vdots & \ddots & {[0]} \\
{[0]} & {[0]} & \cdots & \mathbf{s}_{C K}^{(G)}
\end{array}\right]
$$

Por fim, a matriz sequências de canalização para todos os usuários considerando todos os $I$ intervalos de símbolo, de dimensão $N_{c} \mathcal{K}_{v} I \times K I$, como: 


$$
\mathbf{S}_{C}=\left[\begin{array}{cccc}
\mathbf{S}_{C, 1} & {[0]} & \cdots & {[0]} \\
{[0]} & \mathbf{S}_{C, 2} & \cdots & {[0]} \\
\vdots & \vdots & \ddots & {[0]} \\
{[0]} & {[0]} & \cdots & \mathbf{S}_{C, I}
\end{array}\right]
$$

Com isso, pode-se obter a saída da etapa de canalização, matriz diagonal $\mathbf{U}$, de dimensão $K I \times K I$, através da operação:

$$
\mathbf{U}=\mathbf{X S}_{C}
$$

Para a etapa de embaralhamento, considera-se a matriz de amplitude dos usuários, de dimensão $K \times K$, para o $i$-ésimo período de símbolo, como sendo:

$$
\mathbf{A}_{i}=\left[\begin{array}{cccc}
A_{1} & 0 & \cdots & 0 \\
0 & A_{k^{(g)}} & \cdots & 0 \\
\vdots & \vdots & \ddots & 0 \\
0 & 0 & \cdots & A_{K^{(g)}}
\end{array}\right]
$$

Assim, a matriz de amplitude dos usuários para os $I$ períodos de símbolo, de dimensão $K I \times K I$, é expressa como:

$$
\mathbf{A}=\left[\begin{array}{cccc}
\mathbf{A}_{1} & {[0]} & \cdots & {[0]} \\
{[0]} & \mathbf{A}_{2} & \cdots & {[0]} \\
\vdots & \vdots & \ddots & {[0]} \\
{[0]} & {[0]} & \cdots & \mathbf{A}_{I}
\end{array}\right]
$$

Ainda na etapa de espalhamento temporal, deve-se representar corretamente a matriz de sequência de embaralhamento. Desta forma, a matriz de sequência para os $K$ usuários e $i$-ésimo intervalo de símbolo, de dimensão $K \times N$, é dada por:

$$
\mathbf{S}_{i}=\left[\begin{array}{c}
\mathbf{s}_{1}^{(1)} \\
\mathbf{s}_{k}^{(g)} \\
\vdots \\
\mathbf{s}_{K}^{(G)}
\end{array}\right]
$$

Com isso, pode-se expressar a matriz de sequência de embaralhamento para todos os $I$ intervalos de símbolo, de dimensão $K I \times N$. 


$$
\mathbf{S}=\left[\begin{array}{c}
\mathbf{S}_{1} \\
\mathbf{S}_{2} \\
\vdots \\
\mathbf{S}_{I}
\end{array}\right]
$$

Assim, obtém-se o sinal espalhado à saída da etapa de embaralhamento para todos os usuários, de dimensão $K I \times N$, onde as primeiras $K$ linhas representam o período de símbolo atual, as linhas $K+1$ até a linha $2 K$ representam o próximo período de símbolo e assim sucessivamente, sendo expresso por:

$$
\mathrm{Z}=\mathbf{U A S}
$$

Considerando a topologia TF-MC DS/CDMA, pode-se expressar a matriz de espalhamento na frequência para o $k$-ésimo usuário, de dimensão $1 \times M$ como:

$$
\mathbf{s}_{F, k}=\left[s_{F k, 1}, s_{F k, 2}, \ldots, s_{F k, M}\right]
$$

E o vetor de frequências das subportadoras, de dimensão $M \times 1$ como:

$$
\mathbf{f}_{k}=\left[f_{k, 1}, f_{k, 2}, \ldots, f_{k, M}\right]^{T}
$$

Desta forma, obtém-se o operador de espalhamento no tempo e frequência para o $k$-ésimo usuário, denotado por $S_{T F, k}$, de dimensão $1 \times 1$, como:

$$
S_{T F, k}=\mathbf{s}_{F, k} \mathbf{f}_{k}
$$

Com isso, expressa-se a matriz de espalhamento para todos os usuários e $i$-ésimo período de símbolo, dimensão $K \times K$, como:

$$
\mathbf{S}_{T F, i}=\left[\begin{array}{cccc}
S_{T F, 1} & 0 & \cdots & 0 \\
0 & S_{T F, 2} & \cdots & 0 \\
\vdots & \vdots & \ddots & 0 \\
0 & 0 & \cdots & S_{T F, K}
\end{array}\right]
$$

Portanto, pode-se representar a matriz de espalhamento tempo-frequência para todos os usuários e períodos de símbolo, dimensão $K I \times K I$, resultando em: 


$$
\mathbf{S}_{T F}=\left[\begin{array}{cccc}
\mathbf{S}_{T F, 1} & {[0]} & \cdots & {[0]} \\
{[0]} & \mathbf{S}_{T F, 2} & \cdots & {[0]} \\
\vdots & \vdots & \ddots & \vdots \\
{[0]} & {[0]} & \cdots & \mathbf{S}_{T F, I}
\end{array}\right]
$$

Utilizando-se da equação (2.38) e equação (2.43), pode-se expressar o sinal à saída do espalhamento em frequência, denotado por $\mathbf{C}$, de dimensão $K I \times N$, como:

$$
\mathbf{C}=\mathbf{S}_{T F} \mathbf{Z}
$$

Neste ponto, deve-se considerar a topologia do sistema para a diversidade espacial.

Para o caso de apenas uma antena de transmissão, o sinal C modula ${ }^{17}$ uma portadora de frequência central $f_{c}$ e transmitido.

Para o caso apresentado na seção 2.1.5.2, sistema STBC, observa-se que dois ou mais símbolos são transmitidos simultaneamente através de várias antenas de transmissão.

Desta forma, para este caso, a matriz $\mathbf{C}$ deve ser fragmentada em blocos de $A_{T x}$ símbolos codificados espalhados para cada usuário. Desta forma, a matriz $\mathbf{C}$ pode ser expressa como uma composição de várias sub-matrizes para cada período de símbolo, na forma:

$$
\mathbf{C}=\left[\begin{array}{c}
\mathbf{C}_{1} \\
\mathbf{C}_{i} \\
\vdots \\
\mathbf{C}_{I}
\end{array}\right]
$$

onde $\mathbf{C}_{i}$ possui dimensão $K \times N$.

Além disso, utilizando a notação $\overline{\mathbf{C}}_{i}=\mathbf{C}_{i}^{T}$, é possível obter uma matriz fragmentada, de dimensão $N \times K$, a seguir:

\footnotetext{
${ }^{17}$ Transformado em banda passante.
} 


$$
\overline{\mathbf{C}}_{i}=\mathbf{C}_{i}^{T}=\left[\begin{array}{c}
\mathbf{C}_{A_{T x} \times K, i, 1} \\
\mathbf{C}_{A_{T x} \times K, i, 2} \\
\vdots \\
\mathbf{C}_{A_{T x} \times K, i, N / A_{T x}}
\end{array}\right]
$$

onde $\mathbf{C}_{A_{T x} \times K, i, n}$ denota uma matriz com $A_{T x}$ símbolos para cada usuário no $i$ ésimo período de símbolo e $n$-ésimo período de chip $\left(n \in\left[1, N / A_{T x}\right]\right)$, de dimensão $A_{T x} \times K$. Admite-se, sem perda de generalidade, que o ganho de processamento $N$ é um número múltiplo de $A_{T x}$.

Note que para o $k$-ésimo usuário, $i$-ésimo período de símbolo e $n$-ésimo período de chip, o vetor de transmissão $\mathbf{C}_{k, i, n}$, de dimensão $A_{T x} \times 1$, é dado por:

$$
\mathbf{C}_{k, i, n}=\mathbf{C}_{A_{T x} \times K, i, n}(k)
$$

onde $\mathbf{C}_{A_{T x} \times K, i, n}(k)$ consiste no vetor coluna $A_{T x} \times 1$ referente à posição $k$ da matriz $\mathbf{C}_{A_{T x} \times K, i, n}$.

Observe que para cada período de símbolo, o sistema STBC transmite $A_{T x}$ linhas simultaneamente. Posteriormente, no outro período, transmite-se os mesmos símbolos, sempre utilizando a matriz de codificação espaço-tempo para cada um dos $K$ usuários, $\mathbf{G}_{A_{T x}}$, que neste caso, utilizou-se a matriz $\mathbf{G}_{2}$, dada por:

$$
\mathbf{G}_{2}=\left[\begin{array}{cc}
a_{1} & -a_{2}^{*} \\
a_{2} & a_{1}^{*}
\end{array}\right]
$$

onde $a_{1}=\mathbf{C}_{k, i, n}(1)$ e $a_{2}=\mathbf{C}_{k, i, n}(2)$ representam o símbolo do vetor coluna do $k$-ésimo usuário $\mathbf{C}_{k, i, n}$ referente a primeira e segunda linha, primeira e segunda antenas, respectivamente, e (.)* denota a operação de complexo conjugado do sinal de entrada.

Define-se a matriz de portadoras de banda passante para o $k$-ésimo usuário, $\mathbf{F}_{k}$, diagonal e de dimensão $A_{T x} \times A_{T x}$, como:

$$
\mathbf{F}_{k}=\left[\begin{array}{cccc}
f_{c, k, 1} & 0 & \cdots & 0 \\
0 & f_{c, k, 2} & \cdots & 0 \\
\vdots & \vdots & \ddots & \vdots \\
0 & 0 & \cdots & f_{c, k, A_{T x}}
\end{array}\right]
$$

onde $f_{c, k, n_{T x}}$ refere-se à portadora em banda passante para o $k$-ésimo usuário e $n_{T x}$-ésima antena de transmissão. Como não é desejável aumentar a banda do 
sistema, pois já é utilizado outra etapa para diversidade de frequência e visando facilitar as simulações computacionais, optou-se por adotar, sem perda de generalidade, que $f_{c, 1,1}=f_{c, 1,2}=f_{c, k, n_{T x}}=f_{c, K, A_{T x}}$.

Desta forma, obtém-se a matriz de codificação espaço-tempo em banda passante para o $k$-ésimo usuário, dimensão $A_{T x} \times A_{T x}$ da forma:

$$
\mathbf{M}_{\mathbf{P G}, k}=\mathbf{F}_{k} \mathbf{G}_{A_{T x}}
$$

A matriz de coeficientes complexos de canal, $\mathbf{H}_{i, n, k}$, de dimensão $A_{T x} \times L$, para o $k$-ésimo usuário, pode ser expressa por:

$$
\mathbf{H}_{i, k, n, A_{T x}}=\left[\begin{array}{cccc}
c_{i, k, 1,1} & c_{i, k, 2,1} & \cdots & c_{i, k, L, 1} \\
c_{i, k, 1,2} & c_{i, k, 2,2} & \cdots & c_{i, k, L, 2} \\
\vdots & \vdots & \ddots & \vdots \\
c_{i, k, 1, A_{T x}} & c_{i, k, 2, A_{T x}} & \cdots & c_{i, k, L, A_{T x}}
\end{array}\right]
$$

onde $L$ representa o número de percursos (diversidade de percurso) disponíveis no receptor, $A_{T x}$ representa o número de antenas de transmissão ${ }^{18}$ e $c_{i, k, \ell, n_{T x}}$ representa o coeficiente complexo de canal (módulo e fase) para o $i$-ésimo intervalo de símbolo, $n$-ésimo período de chip, $k$-ésimo usuário, $\ell$-ésimo percurso e $n_{T x^{-}}$ ésima antena.

Como o canal afeta simultaneamente os símbolos transmitidos no mesmo intervalo de tempo, pode-se utilizar a notação:

$$
\mathbf{H}_{i, k, n}=\mathbf{H}_{i, k, n, A_{T x}} \mathbf{o}_{L}
$$

onde $\mathbf{o}_{L}$ representa um vetor unitário de dimensão $L \times 1$.

Desta forma, o sinal com efeito multipercurso e da codificação espaço-tempo em banda passante para o $k$-ésimo usuário, $i$-ésimo período de símbolo e $n$-ésimo período de chip, de dimensão $A_{T x} \times 1$, é dado por:

$$
\boldsymbol{\Lambda}_{i, k, n}=\left(\mathbf{M}_{\mathbf{P G}, k}\right)^{T} \mathbf{H}_{i, k, n}
$$

Com isso, pode-se representar a matriz codificada no espaço-tempo para todos os usuários no $i$-ésimo período de símbolo e $n$-ésimo período de chip, de dimensão $A_{T x} \times K$, como:

\footnotetext{
${ }^{18}$ Neste caso, utilizou-se, sem perda de generalidade, $A_{T x}=2$.
} 


$$
\boldsymbol{\Lambda}_{i, n}=\left[\begin{array}{llll}
\boldsymbol{\Lambda}_{i, 1, n} & \boldsymbol{\Lambda}_{i, 2, n} & \cdots & \boldsymbol{\Lambda}_{i, K, n}
\end{array}\right]
$$

Desta forma, a representação da matriz codificada no espaço-tempo para todos os usuários e $i$-ésimo período de símbolo, de dimensão $K \times N$, é dada por:

$$
\boldsymbol{\Lambda}_{i}=\left[\begin{array}{c}
\boldsymbol{\Lambda}_{i, 1} \\
\boldsymbol{\Lambda}_{i, 2} \\
\vdots \\
\boldsymbol{\Lambda}_{i, N / A_{T x}}
\end{array}\right]^{T}
$$

Finalmente, a matriz codificada para todos os usuários e todos os períodos de símbolo, de dimensão $K \times N I$, é dada por:

$$
\Lambda=\left[\begin{array}{llll}
\Lambda_{1} & \Lambda_{2} & \cdots & \Lambda_{I}
\end{array}\right]
$$

Note que a cada período de chip do $i$-ésimo símbolo transmite-se uma coluna da matriz $\Lambda$.

Portanto, de forma simples, pode-se representar em notação vetorial o sinal à entrada do sistema de codificação espaço-tempo como sendo:

$$
\mathbf{C}=\mathbf{S}_{T F}\left(\mathbf{X S}_{C}\right)(\mathbf{A S})
$$

Sendo posteriormente mapeada em sub-matrizes $\mathbf{C}_{A_{T x} \times K, i, n}$ e na sequência em $\boldsymbol{\Lambda}$ através da operação com a matriz de codificação espaço-tempo $\mathbf{G}_{2}$.

Vale ressaltar que este modelo de sistema pode ser estendido para um número arbitrário de antenas de transmissão $A_{T x}$, devendo alterar somente a matriz de codificação espaço-tempo $\mathbf{G}_{2}$ por outra de ordem superior.

\subsection{Receptor}

O efeito do ruído AWGN é então acrescentado ao sinal recebido, modelando, assim, o sinal completo que deve ser decodificado. Este ruído possui densidade de potência bilateral igual a $N_{0} / 2$ para cada antena de recepção $\left(A_{R x}\right)$, sendo, em notação vetorial, representado pela matriz $\Gamma_{n_{R x}}$, de dimensão $K \times N I$, por: 


$$
\Gamma_{n_{R x}}=\left[\begin{array}{ccccc}
\eta_{1,1,1} & \cdots & \eta_{1, N, 1} & \cdots & \eta_{1, N, I} \\
\eta_{2,1,1} & \cdots & \eta_{2, N, 1} & \cdots & \eta_{2, N, I} \\
\vdots & \vdots & \vdots & \ddots & \vdots \\
\eta_{K, 1,1} & \cdots & \eta_{K, N, 1} & \cdots & \eta_{K, N, I}
\end{array}\right]
$$

onde cada elemento da matriz $\Gamma_{n_{R x}}$ representa o ruído AWGN para o $k$-ésimo usuário, $n$-ésimo chip do $i$-ésimo período de símbolo para a $n_{R x}$-ésima antena de recepção.

O sinal à entrada do decodificador de cada antena de recepção corresponde ao sinal apresentado na equação (2.56) adicionando o efeito do ruído AWGN da equação (2.58). Desta forma, reescrevendo, obtém-se:

$$
\mathbf{R}_{n_{R x}}=\Lambda+\Gamma_{n_{R x}}
$$

\subsubsection{Sistemas com Múltiplas Antenas de Recepção}

O sinal recebido é então demodulado para banda base considerando as frequências utilizadas em cada antena de transmissão.

No caso de apenas uma antena de transmissão e múltiplas de recepção (SIMO), o sinal demodulado em todas as $M$-subportadoras é submetido a um filtro casado para cada usuário, gerando um vetor de saída de dimensão $1 \times m^{(g)}$ para cada usuário físico multitaxa.

Para sistemas de múltiplas antenas de transmissão e recepção (MIMO), utilizando a técnica STBC, obtém-se um ganho de diversidade na entrada e posteriormente o método de recepção convencional segue o apresentado em cenários SIMO.

Desta forma, optou-se por apresentar o receptor convencional para o sistema SIMO e posteriormente adiciona-se a etapa de ganho de diversidade da estratégia STBC.

\subsubsection{Detecção Convencional para Sistemas SIMO}

Considerando o sistema com apenas uma antena de transmissão, pode-se reescrever a equação (2.23) considerando a $n_{R x}$-ésima antena receptora e $m$-ésima subportadora como sendo: 


$$
\begin{array}{r}
r_{n_{R x}, m}(t)=\sum_{i=0}^{I-1} \sum_{k=1}^{K^{(g)}} \sum_{g=1}^{G} \sum_{j=1}^{m^{(g)}} \sum_{\ell=1}^{L} A_{k, g, \ell} \mathbf{x}_{k^{(g)}}^{(i)}[j] s_{C k}^{(g)}(t-j T) s_{k}^{(g)}\left(t-\tau_{k, \ell}^{(g)} i T\right) s_{F k, m}^{(g)} \\
\cdot \beta_{k, \ell, g, m}^{(i)} e^{\jmath\left(\omega_{m} t+\varphi_{k, \ell, g, m}^{(i)}\right)}+\eta_{n_{R x}}(t)
\end{array}
$$

onde $\eta_{q}(t)$ corresponde ao ruído Gaussiano branco aditivo (AWGN) para a $n_{R x^{-}}$ ésima antena receptora.

A estrutura do receptor consiste na demodulação das $M$ subportadoras e posteriormente por um filtro casado para o $k$-ésimo usuário do $g$-ésimo grupo multitaxa.

Esta saída, por fim, é encaminhada ao decodificador que retornará a melhor sequência de bits possíveis segundo suas regras particulares. Além disso, pode-se utilizar a saída do filtro casado para alimentar um estimador heurístico baseado em máxima verossimilhança visando melhorar ainda mais o sinal à entrada dos decodificadores.

As informações do estado do canal (CSI - Channel State Information) devem ser estimados no receptor. Para isso, pode-se utilizar sequências de treinamento ou mesmo técnicas do tipo cegas (Blind). Este trabalho utilizará técnicas de estimativa de parâmetros baseado em sequências de treinamento, pois a própria estrutura do transmissor permite a utilização de prefixos na metodologia de codificação de canal e na etapa de espalhamento em frequência.

Para canais com desvanecimento multipercurso e esquema multitaxa e multiportadora, o receptor consiste na demodulação para cada subportadora e na utilização do receptor Rake, que consiste de um banco de $K D$ filtros casados às sequências de embaralhamento dos usuários físicos multitaxa, com ordem de diversidade de percurso ${ }^{19} D \leq L$, seguido do segundo desespalhamento (canalização) objetivando recuperar os $m^{(g)}$ bits transmitidos simultaneamente nos canais paralelos. Para ser possível realizar um perfeito sincronismo (máxima auto-correlação) das sequências de embaralhamento no receptor, deve-se utilizar uma estimativa precisa para o atraso do $\ell$-ésimo percurso do $k$-ésimo usuário do $g$-ésimo grupo multitaxa, $\hat{\tau}_{k, \ell}^{(g)}$. Quando há erros nas estimativas desses atrasos o desempenho é degradado proporcionalmente.

Assim, as $m^{(g)}$ saídas do filtro casado para o $k$-ésimo usuário físico, pertencente ao $g$-ésimo grupo multitaxa e correspondente ao $\ell$-ésimo componente

\footnotetext{
${ }^{19}$ Caso $D<L$, em cada receptor Rake os filtros casados às sequências de embaralhamento são sincronizados aos $D$ percursos de maior energia.
} 
multipercurso, $m$-ésima subportadora e $n_{R x}$-ésima antena, amostrado ao final do período básico de informação $T$ do $i$-ésimo intervalo de símbolo pode ser expresso como:

$$
\begin{aligned}
y_{k, \ell, g, n_{R x}, m}^{(i)}[j] & =\frac{1}{\sqrt{N_{C}}} \int_{0}^{T} r_{n_{R x}, m}(t) s_{k}^{(g)}\left(t-\tau_{k, \ell}^{(g)}-i T\right) s_{C k}^{(g)}(t-j T) s_{F k, m}^{(g)} e^{\left(-\jmath \omega_{m} t\right)} d t \\
& =A_{k, g}^{\prime} T c_{k, \ell, g, m}^{(i)} \mathbf{x}_{k(g)}^{(i)}[j]+S I_{k, \ell, g, n_{R x}, m}^{(i)}+M A I_{k, \ell, g, n_{R x}, m}^{(i)}+n_{k, \ell, g, n_{R x}, m}^{(i)}
\end{aligned}
$$

onde $j=1: m^{(g)}$.

O primeiro termo corresponde ao sinal desejado, o segundo termo à autointerferência $(S I)$, o terceiro à interferência de múltiplo acesso $(M A I)$ sobre o $\ell$-ésimo componente multipercurso do $k$-ésimo usuário do $g$-ésimo grupo multitaxa, $m$-ésima subportadora e $n_{R x}$-ésima antena, e o último termo corresponde ao AWGN filtrado.

Utilizando notação vetorial, a saída do banco de filtros casados para o $k$-ésimo usuário, pertencente ao $g$-ésimo grupo multitaxa no $i$-ésimo intervalo de bit, $m$ ésima subportadora e $n_{R x}$-ésima antena, considerando $D$ ramos de diversidade de percurso, dimensão $1 \times m^{(g)} D$, é expresso por:

$$
\mathbf{y}_{k, g, n_{R x}, m}^{(i)}=\left[\mathbf{y}_{k, 1, g, n_{R x}, m}^{(i)}, \mathbf{y}_{k, 2, g, n_{R x}, m}^{(i)}, \ldots, \mathbf{y}_{k, D, g, n_{R x}, m}^{(i)}\right]
$$

onde:

$$
\mathbf{y}_{k, \ell, g, n_{R x}, m}^{(i)}=\left[y_{k, \ell, g, n_{R x}, m}^{(i)}[1], y_{k, \ell, g, n_{R x}, m}^{(i)}[2], \ldots, y_{k, \ell, g, n_{R x}, m}^{(i)}\left[m^{(g)}\right]\right]
$$

Portanto, o $i$-ésimo vetor de saída do banco de filtros casados, considerando todos os usuários, $m$-ésima subportadora e $n_{R x}$-ésima antena, de todos os grupos multitaxa, possui dimensão $1 \times D K_{v}$, sendo dado por:

$$
\mathbf{y}_{n_{R x}, m}^{(i)}=\left[\begin{array}{lllll}
\mathbf{y}_{1,1, n_{R x}, m}^{(i)} & \mathbf{y}_{2,1, n_{R x}, m}^{(i)} \ldots & \mathbf{y}_{K^{(1)}, 1, n_{R x}, m}^{(i)} \ldots & \mathbf{y}_{1, G, n_{R x}, m}^{(i)} \ldots & \mathbf{y}_{K^{(G)}, G, n_{R x}, m}^{(i)}
\end{array}\right]
$$

onde $K_{v}$ é o número de usuários virtuais do sistema multitaxa DS/CDMA expresso pela equação (2.28).

É bem caracterizado na literatura especializada que os termos $S I$ e $M A I$ da equação (2.61) dependem da função de correlação parcial, que no caso do duplo 
espalhamento do esquema multitaxa resulta (VERDÚ, 1998; ABRÃO, 2001):

$\mathcal{R}_{u, m, k, n}(\tau, i, m)=\int_{0}^{T} s_{F k}^{(g)} s_{C u, m}^{(g)}(t-i T) s_{u}^{(g)}(t-i T) s_{F u}^{(g)} s_{C k, n}^{(g)}(t-i T-\tau) s_{k}^{(g)}(t-i T-\tau) d t$

cujos índices $m$ e $n$ indicam os respectivos canais paralelos do $u$-ésimo e $k$-ésimo usuário físico multitaxa, para a $m$-ésima subportadora e $n_{R x}$-ésima antena.

Portanto, pode-se reescrever a equação (2.64) utilizando as matrizes de correlação parcial, amplitude recebida, coeficientes de canal e vetor de símbolos transmitidos para a $m$-ésima subportadora e $n_{R x}$-ésima antena ${ }^{20}$, resultando em:

$\mathbf{y}^{(i)}=\mathbf{R}^{T}[1] \mathbf{A}^{(i+1)} \mathbf{C}^{(i+1)} \mathbf{x}^{(i+1)}+\mathbf{R}[0] \mathbf{A}^{(i)} \mathbf{C}^{(i)} \mathbf{x}^{(i)}+\mathbf{R}[1] \mathbf{A}^{(i-1)} \mathbf{C}^{(i-1)} \mathbf{x}^{(i-1)}+\mathbf{n}^{(i)}$

onde:

As matrizes de correlação parcial $\mathbf{R}[0]$ e $\mathbf{R}[1]$, de dimensão $D \mathcal{K}_{v} \times D \mathcal{K}_{v}$, são definidas pelos elementos:

$$
\begin{aligned}
& \mathbf{R}_{i j}[0]=\left\{\begin{array}{cl}
1 & , \text { se } u=k \text { e } m=n \\
\mathcal{R}_{u, m, k, n}\left(\tau_{u k}, 0\right) & , \text { se } u<k \\
\mathcal{R}_{k, n, u, m}\left(\tau_{u k}, 0\right) & , \text { se } u>k \\
\mathcal{R}_{u, m, k, n}\left(\tau_{u k}, 0\right) & , \text { se } u=k \text { e } m<n \\
\mathcal{R}_{k, n, u, m}\left(\tau_{u k}, 0\right) & , \text { se } u=k \text { e } m>n
\end{array}\right. \\
& \mathbf{R}_{i j}[1]=\left\{\begin{array}{cc}
0 & , \text { se } u \geq k \\
\mathcal{R}_{k, n, u, m}\left(\tau_{u k}, 0\right) & , \text { se } u<k
\end{array}\right.
\end{aligned}
$$

para $i=u . m$ e $j=k . n$.

A matriz diagonal das amplitudes recebidas dos usuários, incluindo os efeitos de perdas de percurso e sombreamento do canal (desvanecimento de grande escala) possui dimensão $D \mathcal{K}_{v} \times D \mathcal{K}_{v}$, sendo dada por:

$\mathbf{A}^{(i)}=\operatorname{diag}[\overbrace{A_{1,1}^{\prime} A_{1,1}^{\prime} \ldots A_{1,1}^{\prime}}^{D} \overbrace{A_{2,1}^{\prime} A_{2,1}^{\prime} \ldots A_{2,1}^{\prime} \ldots}^{D} \ldots \overbrace{A_{K^{(G)}, G}^{\prime} A_{K^{(G)}, G}^{\prime} \ldots A_{K^{(G)}, G}^{\prime}}^{D}]$

A matriz diagonal de coeficientes de canal (desvanecimento de pequena escala) também possui dimensão $D \mathcal{K}_{v} \times D \mathcal{K}_{v}$, sendo representada por:

$$
\mathbf{C}^{(i)}=\operatorname{diag}\left[\begin{array}{llllllll}
c_{1,1,1}^{(i)} & c_{1,2,1}^{(i)} \ldots & c_{1, D, 1}^{(i)} & c_{2,1,1}^{(i)} & c_{2,2,1}^{(i)} \ldots & c_{2, D, 1}^{(i)} \ldots & c_{K^{(G)}, 1, G}^{(i)} \ldots & c_{K^{(G)}, D, G}^{(i)}
\end{array}\right]
$$

\footnotetext{
${ }^{20}$ Por simplicidade, omitiu-se os índices $m$ e $n_{R x}$ deste ponto até a equação (2.73).
} 
E, finalmente, o vetor de símbolos transmitidos possui dimensão $D K_{v} \times 1$, sendo dado por:

$$
\mathbf{x}^{(i)}=\left[\begin{array}{lllll}
\mathbf{x}_{1,1}^{(i)} & \mathbf{x}_{2,1}^{(i)} \ldots \mathbf{x}_{K^{(1)}, 1}^{(i)} \ldots & \mathbf{x}_{1, G}^{(i)} & \mathbf{x}_{2, G}^{(i)} \ldots & \mathbf{x}_{K}^{(i)}, G
\end{array}\right]^{T}
$$

O vetor $\mathbf{x}^{(i)}$ é definido recursivamente pela equação (2.72):

$$
\mathbf{x}_{k, g}^{(i)}=\left[x_{k, 1, g}^{(i)} x_{k, 2, g}^{(i)} \ldots x_{k, D, g}^{(i)}\right]
$$

onde:

$$
x_{k, \ell, g}^{(i)}=\left[\mathbf{x}_{k}^{(g)}[i]\right]
$$

Neste caso, o receptor Rake consiste em combinar as saídas disponíveis do banco de filtros casados para cada usuário (fingers) de forma coerente ${ }^{21}$ e ponderada pelos respectivos ganhos de canal (PROAKIS, 1995). O combinador de razão máxima (MRC - Maximal Ratio Combiner) combina os sinais dos D correlacionadores de forma coerente:

$$
\hat{\mathbf{y}}_{k, g}^{(i)}=\sum_{\ell=1}^{D} \sum_{n_{R x}=1}^{A_{R x}} \sum_{m=1}^{M} \Re\left\{\mathbf{y}_{k, \ell, g, n_{R x}, m}^{(i)} \hat{\beta}_{k, \ell, g, n_{R x}, m}^{(i)} e^{-j \hat{\phi}_{k, \ell, g, n_{R x}, m}^{(i)}}\right\}
$$

onde $\Re\{$.$\} é o operador parte real; \hat{\beta}_{k, \ell, g, n_{R x}, m}^{(i)}$ e $\hat{\phi}_{k, \ell, g, n_{R x}, m}^{(i)}$ são as estimativas ${ }^{22}$ para o módulo e fase dos coeficientes de canal, respectivamente, referente ao $i$-ésimo intervalo de processamento para o $k$-ésimo usuário, $\ell$-ésimo percurso, pertencente ao $g$-ésimo grupo multitaxa, $n_{R x}$-ésima antena e $m$-ésima subportadora. Também nesse caso, quando há erros nas estimativas dos coeficientes de canal o desempenho é degradado proporcionalmente.

Finalmente, as estimativas para os $m^{(g)}$ símbolos de informação do $k$-ésimo usuário pertencente ao $g$-ésimo grupo multitaxa são obtidas através de uma regra de decisão abrupta:

$$
\hat{\mathbf{x}}_{k, g}^{(i)}=\operatorname{sgn}\left(\hat{\mathbf{y}}_{k, g}^{(i)}\right)
$$

Portanto, o quadro de símbolos estimados para todos os usuários no intervalo do $i$-ésimo bit, com dimensão $D K_{v} \times 1$ é dado por:

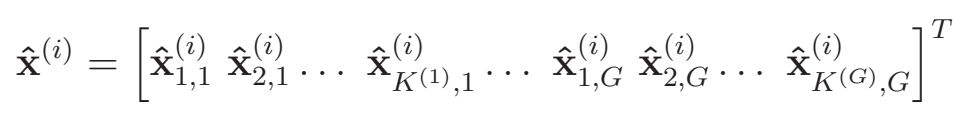

O desempenho obtido com o receptor Rake MRC será consideravelmente de-

\footnotetext{
${ }^{21}$ Somando-se os efeitos de múltiplos percursos, múltiplas subportadoras e múltiplas antenas de recepção.

${ }^{22}$ Estes coeficientes devem ser estimados continuamente.
} 
teriorado quando o número de usuários compartilhando o mesmo canal crescer $^{23}$ e/ou quando a potência dos usuários interferentes aumentar. Portanto, visando garantir os requisitos de QoS para os diferentes serviços e usuários, deve-se utilizar algum mecanismo para amenizar os efeitos da MAI e do efeito near-far; por exemplo, o emprego de detecção multiusuário.

\subsubsection{Decodificador STBC}

No processo de decodificação espaço-temporal, o receptor pode empregar a detecção de máxima verossimilhança através de simples processamento linear. Assim, para a STBC empregando a matriz $\mathbf{G}_{2}$, o processo de decodificação consiste na minimização da seguinte métrica:

$$
\hat{\mathbf{x}}=\underset{\mathbf{x} \in\{ \pm 1\}}{\arg \min } \sum_{n_{R x}=1}^{A_{T x}} \sum_{\ell=1}^{L}\left|\mathbf{r}_{\ell, n_{R x}}-\sum_{k=1}^{K^{(g)}} \mathbf{H}_{k, \ell, n_{R x}} \mathbf{c}_{k, \ell, n_{R x}}\right|^{2}
$$

$\mathrm{O}$ vetor de sinais recebidos para o $\ell$-ésimo percurso e $n_{R x}$-ésima antena receptora, $\mathbf{r}_{\ell, n_{R x}}$, de dimensão $2 \times 1$ é dado por $^{24}$ :

$$
\mathbf{r}_{\ell, n_{R x}}=\left[\mathbf{r}_{\ell, n_{R x}}(1), \mathbf{r}_{\ell, n_{R x}}^{*}(2)\right]^{T}
$$

onde os termos (1) e (2) em $\mathbf{r}$ referem-se ao sinal no primeiro e segundo período de símbolo.

A matriz de canal $\mathbf{H}_{k, \ell, n_{R x}}$, de dimensão $2 \times 2$ é dada por:

$$
\mathbf{H}_{k, \ell, n_{R x}}=\left[\begin{array}{cc}
c_{k, \ell, n_{R x}}(1) & c_{k, \ell, n_{R x}}(2) \\
c_{k, \ell, n_{R x}}^{*}(2) & -c_{k, \ell, n_{R x}}^{*}(1)
\end{array}\right]
$$

Novamente, os termos (1) e (2) em $c_{k, \ell, n_{R x}}$ referem-se ao sinal no primeiro e segundo período de símbolo e $c_{k, \ell, n_{R x}}$ corresponde ao coeficiente complexo de canal para o $k$-ésimo usuário, $\ell$-ésimo percurso e $n_{R x}$-ésima antena.

Por fim, o vetor coluna c, de dimensão $2 \times 1$ é dado por:

$$
\mathbf{c}_{k, \ell, n_{R x}}=\left[\mathbf{c}_{k, \ell, n_{R x}}(1), \mathbf{c}_{k, \ell, n_{R x}}(2)\right]
$$

\footnotetext{
${ }^{23}$ Aumento da MAI, terceiro termo da equação (2.61).

${ }^{24}$ Caso específico para $\mathbf{G}_{2}$, podendo-se estender a análise para valores superiores.
} 
Considerando:

$$
\mathbf{c}_{k, \ell, n_{R x}}(q)=\sum_{g=1}^{G} \sum_{j=1}^{m^{(g)}} \sum_{m=1}^{M} A_{k, g, \ell} \mathbf{x}_{k^{(g)}}^{(i)}(q) s_{C k, j}^{(g)}(t-i T) s_{k}^{(g)}\left(t-\tau_{k, \ell}^{(g)} i T\right) s_{F k, m}^{(g)} e^{\jmath \omega_{m} t}
$$

onde $q=1,2$.

Deve-se, portanto, realizar a análise de minimização para todos os valores possíveis de $\mathbf{x}$, resultando em $2 \mathcal{K}_{v}^{2}$ possibilidades.

Desta forma, o vetor de sinal recebido maximizado será dado por:

$$
\hat{\mathbf{r}}_{\ell, n_{R x}}=\mathbf{H}_{\ell, n_{R x}} \hat{\mathbf{c}}_{\ell, n_{R x}}
$$

onde $\hat{\mathbf{c}}_{\ell, n_{R x}}$ é obtido substituindo-se $\hat{\mathbf{x}}$ na equação $(2.81)$.

Com isso, após otimização do vetor recebido, este deve ser desacoplado normalmente utilizando-se das técnicas apresentadas na seção 2.3.2, utilizando o vetor $\hat{\mathbf{r}}_{\ell, n_{R x}}$ como sendo o vetor recebido na equação (2.61). Por ser um vetor obtido via técnica de máxima verossimilhança, o desempenho tende a melhorar significativamente à custa de um aumento de complexidade marginal.

Após as etapas de desespalhamento no tempo e frequência ${ }^{25}$, deve-se realizar a etapa de decodificação do sinal.

\subsubsection{Detector Multiusuário Ótimo}

O melhor desempenho, dentre os detectores multiusuário, é alcançado com o detector OMuD (Optimum Multiusuer Detector), onde o objetivo consiste em maximizar a função de máxima verossimilhança (VERDÚ, 1998). Dado a probabilidade condicional:

$$
P_{r}\left(\mathbf{y}^{(i)} \mid \hat{\mathbf{x}}^{(i)}, i \in[0, I-1]\right)=e^{\left\{-\frac{1}{2 \sigma^{2}} \int_{i=0}^{I-1}\left[\mathbf{y}^{(i)}-\mathbf{S}_{t}\left(\hat{\mathbf{x}}^{(i)}\right)\right]^{2} d t\right\}}
$$

onde o sinal total recebido, reconstruído a partir de parâmetros estimados e conhecidos no receptor é:

$\mathbf{S}_{t}\left(\hat{\mathbf{b}}^{(i)}\right)=\sum_{k=1}^{K^{(g)}} \sum_{g=1}^{G} \sum_{m=1}^{M} \sum_{j=1}^{m^{(g)}} \sum_{n_{R x}=1}^{A_{R x}} \sum_{\ell=1}^{L} A_{k, g, \ell, n_{R x}}^{\prime} \hat{\mathbf{x}}_{k, g}^{(i)} \mathbf{s}_{C k}^{(g)}(t-j T) s_{k}^{(g)}\left(t-\tau_{k, \ell, n_{R x}}^{(g)}-i T\right)$.
$\cdot s_{F k, m}^{(g)} \hat{\beta}_{k, \ell, g, n_{R x}}^{(i)} e^{j\left(\omega_{m} t+\hat{\phi}_{k, \ell, g, n_{R x}}^{(i)}\right)}$

Neste contexto, o vetor de máxima verossimilhança que deve ser encontrado

\footnotetext{
${ }^{25}$ Pode-se utilizar técnicas de detecção multiusuário.
} 
pelo $\mathrm{OMuD}$ possui dimensão $D K_{v} I \times 1$, sendo escrito por:

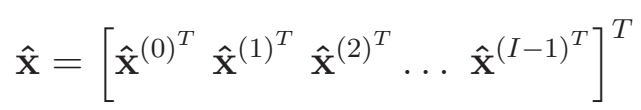

Observa-se que a minimização da diferença quadrática existente na equação (2.83) garante a maximização da função de máxima verossimilhança. Expandindo a diferença quadrática, observa-se, baseado na saída do filtro casado, vetor $\mathbf{y}^{(i)}$ na equação (2.64), que encontrar o vetor de máxima verossimilhança $\hat{\mathbf{x}}$ é equivalente a selecionar o vetor de bits $\mathcal{B}$, de mesma dimensão, que maximiza a chamada função de verossimilhança logarítmica (LLF - Log Likelihood Function) (VERDÚ, 1998):

$$
\Omega(\mathcal{B})=2 \sum_{n_{R x}=1}^{A_{R x}} \Re\left\{\mathcal{B}^{T} \mathcal{C}^{H} \mathcal{A} \mathcal{Y}\right\}-\mathcal{B}^{T} \mathcal{C} \mathcal{A} \mathbf{R} \mathcal{A} \mathcal{C}^{H} \mathcal{B}
$$

onde cada matriz descrita deve ser determinada para cada antena de recepção e $(\cdot)^{H}$ refere-se ao operador Hermitiano transposto.

As matrizes diagonais coeficientes de canal e amplitudes ${ }^{26}$ para a $n_{R x}$-ésima antena de recepção, de dimensão $D K_{v} I$, são definidas, respectivamente, por:

$$
\begin{aligned}
& \mathcal{C}=\operatorname{diag}\left[\mathbf{C}^{(0)} \mathbf{C}^{(1)} \mathbf{C}^{(2)} \ldots \mathbf{C}^{(I-1)}\right] \\
& \mathcal{A}=\operatorname{diag}\left[\mathbf{A}^{(0)} \mathbf{A}^{(1)} \mathbf{A}^{(2)} \ldots \mathbf{A}^{(I-1)}\right]
\end{aligned}
$$

O vetor a saída do banco de filtros casados, composto por $I$ vetores $\mathbf{y}^{(i)}$, ou seja, de dimensão $D K_{v} I \times 1$, é dado por:

$$
\mathcal{Y}=\left[\mathbf{y}^{(0)} \mathbf{y}^{(1)} \mathbf{y}^{(2)} \ldots \mathbf{y}^{(I-1)}\right]^{T}
$$

$\mathrm{O}$ vetor $\mathcal{Y}$ deve garantir a maximização da função custo, considerando-o o mesmo para todas as antenas de recepção.

E a matriz de correlação tridiagonal por blocos e Toeplitz por blocos $\mathbf{R}$, de

\footnotetext{
${ }^{26}$ Optou-se por omitir o índice $n_{R x}$ de cada matriz para auxiliar a compreensão.
} 
dimensão $D \mathcal{K}_{v} I \times D \mathcal{K}_{v} I$, é definida como (VERDÚ, 1998):

$$
\mathbf{R}=\left[\begin{array}{cccccc}
\mathbf{R}[0] & \mathbf{R}^{T}[1] & \mathbf{0} & \cdots & \mathbf{0} & \mathbf{0} \\
\mathbf{R}[1] & \mathbf{R}[0] & \mathbf{R}^{T}[1] & \cdots & \mathbf{0} & \mathbf{0} \\
\mathbf{0} & \mathbf{R}[1] & \mathbf{R}[0] & \ddots & \mathbf{0} & \mathbf{0} \\
\vdots & \vdots & \ddots & \ddots & \ddots & \vdots \\
\vdots & \vdots & \vdots & \ddots & \mathbf{R}[0] & \mathbf{R}^{T}[1] \\
\mathbf{0} & \mathbf{0} & \mathbf{0} & \cdots & \mathbf{R}[1] & \mathbf{R}[0]
\end{array}\right]
$$

Portanto, o quadro completo para os $I$ símbolos estimados de todos os $K_{v}$ usuários pode ser obtido otimizando a equação (2.86), resultando em:

$$
\widehat{\mathbf{x}}=\arg \left\{\max _{\mathcal{B} \in\{ \pm 1\}^{\mathcal{K}_{v} I}}[\Omega(\mathcal{B})]\right\}
$$

O OMuD consiste na busca do melhor vetor de símbolos de dados em um conjunto com todas as possibilidades, ou seja, é um problema de combinação NP-completa (VERDÚ, 1989), no qual os algoritmos tradicionais são ineficientes (GOLDBARG; LUNA, 2000). A maioria destes apresenta crescimento exponencial da complexidade quando do aumento de um ou mais fatores a seguir: número de usuários, tamanho do frame de bits, número de antenas de recepção, número de percursos, número de subportadoras, entre outros.

Portanto, a utilização de métodos heurísticos para esse tipo de problema mostra-se atraente, pois é possível obter soluções ótimas (ou próximas) utilizando espaços de busca reduzidos. Desta forma, a estratégia proposta neste trabalho procurará maximizar a LLF testando distintos vetores de símbolos candidatos a cada nova iteração/geração. Tais tentativas buscam maximizar o desempenho médio do sistema, aproximando ou mesmo igualando ao obtido pelo detector $\mathrm{OMuD}$, porém com reduzida complexidade computacional.

Vale ressaltar que estes sinais estão codificados, devendo ser submetidos a um estágio de decodificação, melhorando ainda mais a taxa de erro de bit.

\subsubsection{Decodificação}

Em 1974, Bahl et.al. (BAHL et al., 1974) publicaram um algoritmo de decodificação de códigos baseado em probabilidades a posteriori denominado algoritmo BCJR, algoritmo MAP ou ainda "forward-backward algorithm". O procedimento pode ser aplicado tanto a códigos de blocos como a códigos convolucionais mas, como possui uma maior complexidade que o algoritmo de Viterbi, durante cerca de 
vinte anos não o utilizaram na prática, situação que foi substancialmente alterada com o advento dos códigos turbo em 1993 (BERROU; GLAVIEUX; THITIMAJSHIMA, 1993).

Considerando modulação BPSK, o bit de informação à entrada do codificador, $b_{k}^{(i)}= \pm 1$, possui uma probabilidade de ocorrência a priori $P\left(b_{k}^{(i)}\right)$. Associada a esta probabilidade define-se a relação de verossimilhança logarítmica, denominada LLR (log-likelihood ratio), como:

$$
L\left(b_{k}^{(i)}\right)=\ln \frac{P\left(b_{k}^{(i)}=+1\right)}{P\left(b_{k}^{(i)}=-1\right)}
$$

Se os bits $b_{k}^{(i)}= \pm 1$ forem equiprováveis a LLR a priori é nula.

Quando os bits $b_{k}^{(i)}$ forem utilizados na entrada de um codificador em blocos ou convolucional de taxa $1 / n$, observa-se em sua saída um código $x_{k}^{(i)}$, ou símbolos, de $n$ bits cada. Considerando $I$ bits de entrada, resulta em um vetor de saída da forma:

$$
\mathbf{x}_{k}=\left[\begin{array}{llll}
x_{k}^{(1)} & x_{k}^{(2)} \ldots x_{k}^{(I)}
\end{array}\right]
$$

onde $x_{k}^{(i)}$ representa o símbolo produzido pelo codificador para o $k$-ésimo usuário no instante $i$.

A sequência codificada $\mathbf{y}_{k}$ que chega ao decodificador, considerando um canal com desvanecimento multipercurso, é expressa pela composição das diversas saídas do combinador MRC, equação (2.74).

A partir da chegada desta sequência, o algoritmo BCJR, ou qualquer outro, procurará estimar a sequência de bits originais $b_{k}^{(i)}$. Utiliza-se, neste contexto, a LLR a posteriori, definida pela razão:

$$
L\left(b_{k} \mid \mathbf{y}_{k}\right)=\ln \frac{P\left(b_{k}=+1 \mid \mathbf{y}_{k}\right)}{P\left(b_{k}=-1 \mid \mathbf{y}_{k}\right)}
$$

O sinal da LLR indica a estimativa do bit enviado, e o seu valor absoluto representa uma maior ou menor confiabilidade na estimativa obtida, ou seja, quanto mais afastado o valor de $L\left(b_{k} \mid \mathbf{y}_{k}\right)$ estiver do limiar de decisão, maior é o grau de confiança na estimativa do bit.

A informação contida em $L\left(b_{k} \mid \mathbf{y}_{k}\right)$ pode ser passada a outro elemento de decodificação, se houver, ou convertida em decisões abruptas. Note-se que o numerador e o denominador da equação (2.94) são probabilidades condicionais a posteriori, ou seja, probabilidades calculadas após a chegada completa da sequência 
$\mathbf{y}_{k}$. Em outras palavras, têm-se as probabilidades de no instante $i$ o bit à entrada do codificador ter sido $b_{k}^{(i)}=+1$ ou $b_{k}^{(i)}=-1$, conhecendo toda a sequência $\mathbf{y}_{k}$. São estas as probabilidades condicionais que o algoritmo BCJR original (BAHL et al., 1974) de fato calcula e compara.

No contexto de codificação, é comum utilizar a ideia de que a sequência codificada percorre um caminho em uma árvore de possibilidades de tamanho fixo, chamada de treliça. Visando esclarecer o conceito de codificação, considere um exemplo de codificador convolucional de taxa $1 / 2$, resultando em quatro estados possíveis $\mathbf{S}=\{0,1,2,3\}$ considerando um instante de tempo $i$ arbitrário. Adotouse que um bit -1 na entrada do codificador produz um ramo de traço contínuo e um bit +1 produz um ramo tracejado e que cada ramo está rotulado com a correspondente saída de dois bits $x_{k}^{(i)}$, em que 0 e 1 correspondem a -1 e +1 , respectivamente. A figura 2.8 representa uma treliça do codificador utilizado.

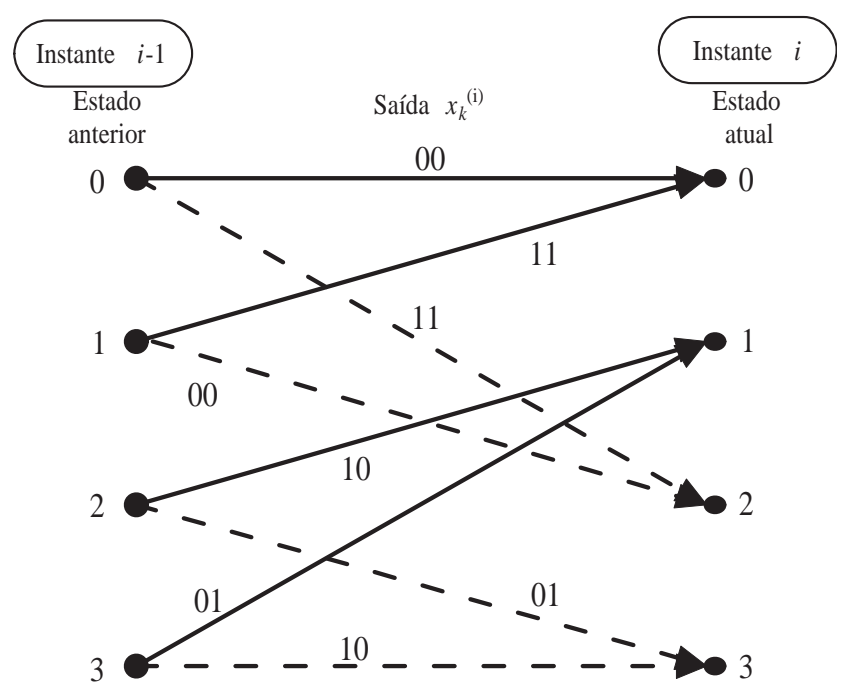

Figura 2.8: Exemplo de diagrama em treliça do codificador convolucional.

No instante $i$, adota-se que o estado correspondente é $S_{i}=s$, o estado anterior é $S_{i-1}=s^{\prime}$ e o símbolo recebido no decodificador é $y_{k}^{(i)}$. Note-se que até este instante já foram recebidos $i-1$ símbolos e que ainda serão recebidos $I$ - $i$ símbolos. Com isso, a sequência completa $\mathbf{y}_{k}$ pode ser dividida em três subsequências, uma representando o passado, outra o presente e outra o futuro:

$$
\mathbf{y}_{k}=[\underbrace{y_{k}^{(1)} y_{k}^{(2)} \ldots y_{k}^{(i-1)}}_{y_{k}^{(<i)}} \underbrace{y_{k}^{(i)}}_{y_{k}^{(=i)}} \underbrace{y_{k}^{(i+1)} y_{k}^{(i+2)} \ldots y_{k}^{(I)}}_{y_{k}^{(>i)}}]=\left[\mathbf{y}_{k}^{(<i)} \mathbf{y}_{k}^{(=i)} \mathbf{y}_{k}^{(>i)}\right]
$$


Com isso, a LLR a posteriori é dada por (BAHL et al., 1974):

$$
L\left(b_{k}^{(i)} \mid \mathbf{y}_{k}\right)=\ln \frac{\sum_{R_{1}} P\left(s^{\prime}, s, \mathbf{y}_{k}\right)}{\sum_{R_{0}} P\left(s^{\prime}, s, \mathbf{y}_{k}\right)}=\ln \frac{\sum_{R_{1}} \alpha_{i-1}\left(s^{\prime}\right) \gamma_{i}\left(s^{\prime}, s\right) \beta_{i}(s)}{\sum_{R_{0}} \alpha_{i-1}\left(s^{\prime}\right) \gamma_{i}\left(s^{\prime}, s\right) \beta_{i}(s)}
$$

onde $P\left(s^{\prime}, s, \mathbf{y}_{k}\right)$ representa a probabilidade conjunta de estar no estado $s^{\prime}$ no instante $i-1$, estar no estado $s$ no instante corrente $i$, e de a sequência de $I$ bits recebida ser $\mathbf{y}_{k}$. No numerador, $R_{1}$ significa que o somatório se estende às transições entre estados $s^{\prime}$ e $s$ provocadas por um bit $b_{k}^{(i)}=+1$ (ramos tracejados na figura 2.8). Da mesma maneira, no denominador, $R_{0}$ designa os outros ramos, originados por um bit $b_{k}^{(i)}=-1$. As variáveis $\alpha, \gamma$ e $\beta$ são probabilidades definidas a seguir.

\subsubsection{Cálculo da Probabilidade Conjunta}

A probabilidade conjunta $P\left(s^{\prime}, s, \mathbf{y}_{k}\right)$ pode ser obtida pelo produto de outras três probabilidades, da forma:

$$
P\left(s^{\prime}, s, \mathbf{y}_{k}\right)=\alpha_{i-1}\left(s^{\prime}\right) \gamma_{i}\left(s^{\prime}, s\right) \beta_{i}(s)
$$

onde as probabilidades $\alpha, \gamma$ e $\beta$ são definidas como:

$$
\begin{gathered}
\alpha_{i-1}\left(s^{\prime}\right)=P\left(s^{\prime}, \mathbf{y}_{k}^{(<i)}\right) \\
\gamma_{i}\left(s^{\prime}, s\right)=P\left(\mathbf{y}_{k}^{(i)}, s \mid s^{\prime}\right) \\
\beta_{i}(s)=P\left(\mathbf{y}_{k}^{(>i)} \mid s\right)
\end{gathered}
$$

No instante $i$ as probabilidades $\alpha, \gamma$ e $\beta$ estão associadas ao passado, ao presente e ao futuro da sequência $\mathbf{y}_{k}$, respectivamente.

\subsubsection{Cálculo de $\gamma$}

A probabilidade $\gamma_{i}\left(s^{\prime}, s\right)$ é a probabilidade condicional de receber o símbolo $\mathbf{y}_{k}^{(i)}$ no instante $i$ e o estado atual ser $S_{i}=s$, dado que o estado anterior foi $S_{i-1}=s^{\prime}$. Essa probabilidade é composta pelo produto de probabilidades:

$$
\begin{aligned}
y_{k}^{(i)}\left(s^{\prime}, s\right) & =P\left(y_{k}^{(i)} \mid x_{k}^{(i)}\right) P\left(b_{k}^{(i)}\right) \\
& =C_{i} \exp \left(b_{k}^{(i)} L\left(b_{k}^{(i)}\right) / 2\right) \exp \left(\frac{L_{c}}{2} \sum_{l=1}^{n} x_{k, l}^{(i)} y_{k, l}^{(i)}\right)
\end{aligned}
$$


onde $C_{i}$ é irrelevante no cálculo da confiabilidade da estimativa, pois surgindo no numerador e no denominador da equação (2.96), vai desaparecer ao se calcular LLR condicional $L\left(b_{k}(i) \mid \mathbf{y}_{k}\right)$. Os termos $x_{k, l}^{(i)}$ e $y_{k, l}^{(i)}$ representam o bit $l$ no instante $i$ da sequência à saída do codificador e à entrada do decodificador, respectivamente. O termo $L_{c}$ é denominado valor ou medida de confiabilidade do canal, sendo descrita na literatura como (WOODARD; HANZO, 2000; SOLEYMANI; GAO; VILAIPORNSAWAI, 2002):

$$
L_{c}=4 x \frac{E_{c}}{N_{0}}=4 x R_{c o d} \frac{E_{b}}{N_{0}}
$$

onde $E_{c}$ e $E_{b}$ são as energias transmitidas por bit codificado e bit de informação, respectivamente, $R_{c o d}$ é a taxa do código e $x$ é a amplitude de desvanecimento. No caso de canal puramente AWGN, $x=1$.

No entanto, resultados de desempenho mostraram que a equação (2.103) acarreta bons desempenhos para a estratégia turbo apenas nas regiões de baixo e médio $\frac{E_{b}}{N_{0}}$. Para valores de $\frac{E_{b}}{N_{0}}>14 \mathrm{~dB}$, o desempenho é degradado consideravelmente, tornando sua utilização inviável. Com isso, utilizou-se uma equação (OKANO; CIRIACO; ABRãO, 2010), obtida de forma não exaustiva, baseada em uma curva sigmoide, capaz de apresentar bons desempenhos, tanto nas faixas de baixo e médio $\frac{E_{b}}{N_{0}}$ quanto na região de alto $\frac{E_{b}}{N_{0}}$ em canais com desvanecimento, dada por:

$$
L_{c}=\frac{-16,6785}{1+\exp \left(\frac{\frac{E_{b}}{N_{0}}(d B)-8,8324}{2,7642}\right)}+17,622
$$

\subsubsection{Cálculo recursivo de $\alpha$ e $\beta$}

As probabilidades $\alpha$ e $\beta$ são calculadas recursivamente por:

$$
\begin{aligned}
& \alpha_{i}(s)=\sum_{s^{\prime}} \gamma_{i}\left(s^{\prime}, s\right) \alpha_{i-1}\left(s^{\prime}\right) \\
& \beta_{i-1}\left(s^{\prime}\right)=\sum_{s} \gamma_{i}\left(s^{\prime}, s\right) \beta_{i}(s)
\end{aligned}
$$

Onde as condições iniciais são:

$$
\begin{aligned}
& \alpha_{0}(s)= \begin{cases}1 & s=0 \\
0 & s \neq 0\end{cases} \\
& \beta_{I}(s)= \begin{cases}1 & s=0 \\
0 & s \neq 0\end{cases}
\end{aligned}
$$


Note-se que para o cômputo das probabilidades $\alpha$ e $\beta$ necessita-se conhecer a probabilidade $\gamma_{i}\left(s^{\prime}, s\right)$. Com isso, inicia-se o cálculo da LLR a posteriori pelo cômputo de $\gamma_{i}\left(s^{\prime}, s\right)$.

No caso de $\alpha_{i}(s)$ os somatórios são efetuados para todos os estados anteriores $S_{i}=s^{\prime}$ dos quais saem ramos que convergem no estado $s$, enquanto que no caso de $\beta_{i-1}\left(s^{\prime}\right)$ os somatórios são efetuados para todos os estados seguintes $S_{i}=$ $s$ que se atingem do estado $s$. Considerando códigos binários, os somatórios possuem apenas duas parcelas. A probabilidade $\alpha$ é calculada à medida que se for recebendo a sequência $\mathbf{y}_{k}$, ou seja, no cálculo de $\alpha$ o sentido é do início para o fim da treliça (forward) e a probabilidade $\beta$ só pode ser calculada depois de ter sido recebido toda a sequência $\mathbf{y}_{k}$, ou seja, no cálculo de $\beta$ o sentido é do fim para o começo da treliça (backward). Os valores iniciais $\alpha_{0}(s)$ e $\beta_{I}(s)$ pressupõem que o percurso na treliça começa e termina em um estado nulo ${ }^{27}$. Para isso é necessário acrescentar ao fim da mensagem ou ao início da próxima transmissão alguns bits nulos (tail bits) capazes de levar o codificador a produzir uma saída também nula.

\subsubsection{Instabilidade Numérica}

Os problemas de instabilidade numérica associados ao algoritmo BCJR são bem conhecidos. De fato, a natureza iterativa de alguns cálculos pode conduzir a indesejáveis situações de "underflow" ou "overflow" que devem ser evitadas. Nesse sentido, as equações recursivas (equação (2.105) e equação (2.106)) devem ser previamente normalizadas pela soma de todos os $\alpha$ e $\beta$ em cada instante, respectivamente. Com isso, define-se as probabilidades normalizadas como:

$$
\begin{aligned}
\alpha_{i}(s) & =\frac{\alpha_{i}^{\prime}(s)}{\sum_{s} \alpha_{i}^{\prime}(s)} \\
\beta_{i-1}\left(s^{\prime}\right) & =\frac{\beta_{i-1}^{\prime}\left(s^{\prime}\right)}{\sum_{s^{\prime}} \beta_{i-1}^{\prime}\left(s^{\prime}\right)}
\end{aligned}
$$

onde $\alpha_{i}^{\prime}(s)$ e $\beta_{i-1}^{\prime}\left(s^{\prime}\right)$ são as versões não normalizadas calculadas como em (equação (2.105)) e (equação (2.106)).

Do mesmo modo, depois de todos os $2 I$ produtos $\alpha_{i-1}\left(s^{\prime}\right) \gamma_{i}\left(s^{\prime}, s\right) \beta_{i}(s)$ em

\footnotetext{
${ }^{27}$ Diz-se que se trata de uma treliça terminada.
} 
todos os ramos da treliça terem sido calculados no instante $i$ a sua soma,

$$
\begin{aligned}
\sum_{P i} & =\sum_{R_{0}, R_{1}} \alpha_{i-1}\left(s^{\prime}\right) \gamma_{i}\left(s^{\prime}, s\right) \beta_{i}(s) \\
& =\sum_{R_{0}} \alpha_{i-1}\left(s^{\prime}\right) \gamma_{i}\left(s^{\prime}, s\right) \beta_{i}(s)+\sum_{R_{1}} \alpha_{i-1}\left(s^{\prime}\right) \gamma_{i}\left(s^{\prime}, s\right) \beta_{i}(s)
\end{aligned}
$$

irá normalizar $P\left(i^{\prime}, s, \mathbf{y}_{k}\right)$ :

$$
P_{n o r m}\left(s^{\prime}, s, \mathbf{y}_{k}\right)=\frac{P\left(s^{\prime}, s, \mathbf{y}_{k}\right)}{\sum_{P i}}
$$

Garante-se, assim, que as somas de todos os $\alpha$ e $\beta$ e $P_{n o r m}\left(s^{\prime}, s, \mathbf{y}_{k}\right)$ são sempre iguais a 1 em cada instante $i$. Note-se que nenhuma destas somas de normalização afeta o valor da LLR a posteriori.

$$
L\left(b_{k}^{(i)} \mid \mathbf{y}_{k}\right)=\ln \frac{\sum_{R_{1}} P\left(s^{\prime}, s, \mathbf{y}_{k}\right)}{\sum_{R_{0}} P\left(s^{\prime}, s, \mathbf{y}_{k}\right)}=\ln \frac{\sum_{R_{1}} P_{\text {norm }}\left(s^{\prime}, s, \mathbf{y}_{k}\right)}{\sum_{R_{0}} P_{\text {norm }}\left(s^{\prime}, s, \mathbf{y}_{k}\right)}
$$

\subsubsection{Decodificação Turbo}

A aplicação do algoritmo BCJR à decodificação iterativa resulta na estratégia conhecida como decodificação Turbo. Considerando uma sequência codificada com taxa $1 / n$ no qual o primeiro bit codificado, $x_{k, 1}^{(i)}$, é igual ao bit de informação $b_{k}^{(i)}$, a razão LLR a posteriori pode ser decomposta em uma soma de três parcelas (BERROU; GLAVIEUX; THITIMAJSHIMA, 1993):

$$
L\left(b_{k}^{(i)} \mid \mathbf{y}_{k}\right)=L\left(b_{k}^{(i)}\right)+L_{c} y_{k, 1}^{(i)}+L_{e}\left(b_{k}^{(i)}\right)
$$

As primeiras duas parcelas estão relacionadas com o bit de informação $x_{k}^{(i)}$. No entanto, a terceira, $L_{e}\left(b_{k}^{(i)}\right)$, depende somente dos bits de paridade da palavra de código, denominada de informação extrínseca. Pode-se dizer que $L_{e}\left(b_{k}^{(i)}\right)$ é uma estimativa da LLR a priori $L\left(b_{k}^{(i)}\right)$, pois caso sejam fornecidos os valores de $L\left(b_{k}^{(i)}\right)$ e $L_{c} y_{k, 1}^{(i)}$ a um decodificador MAP (ou outro), obtém-se $L\left(b_{k}^{(i)} \mid \mathbf{y}_{k}\right)$ na sua saída. Por subtração, a estimativa de $L\left(b_{k}^{(i)}\right)$ pode ser obtida por:

$$
L_{e}\left(b_{k}^{(i)}\right)=L\left(b_{k}^{(i)} \mid \mathbf{y}_{k}\right)-L\left(b_{k}^{(i)}\right)-L_{c} y_{k, 1}^{(i)}
$$

Esta estimativa de $L\left(b_{k}^{(i)}\right)$ é, presumivelmente, um valor mais preciso da LLR a priori, devendo substituir o valor anterior de $L\left(b_{k}^{(i)}\right)$. Caso esse procedimento seja repetido em um modo iterativo fornecendo a outro decodificador os valores de $L_{c} y_{k, 1}^{(i)}$ e a nova $L\left(b_{k}^{(i)}\right)=L_{e}\left(b_{k}^{(i)}\right)$, espera-se obter uma $L\left(b_{k}^{(i)} \mid \mathbf{y}_{k}\right)$ mais confiá- 
vel a cada iteração. A utilização dessa estratégia diversas vezes (utilizando a equação (2.110)) caracteriza a chamada codificação Turbo.

Os inventores dos códigos turbo (BERROU; GLAVIEUX; THITIMAJSHIMA, 1993) usaram dois códigos convolucionais recursivos e sistemáticos (RSC), de taxa 1/2, concatenados em paralelo e entrelaçados, e realizaram a decodificação iterativamente com dois decodificadores MAP, conforme figura 2.3 e figura 2.9, onde P e $\mathrm{P}^{-1}$ representam o entrelaçador e o desentrelaçador, respectivamente.

Considerando bits transmitidos equiprováveis, na primeira iteração a LLR a priori $L\left(b_{k}^{(i)}\right)$ é nula. A informação extrínseca $L_{e}\left(b_{k}^{(i)}\right)$ que cada decodificador fornece será usada para atualizar a $L\left(b_{k}^{(i)}\right)$ de iteração em iteração e desse decodificador para o outro. Desta maneira o decodificador turbo ganha progressivamente mais confiança nas decisões que terá de tomar no fim do processo iterativo.

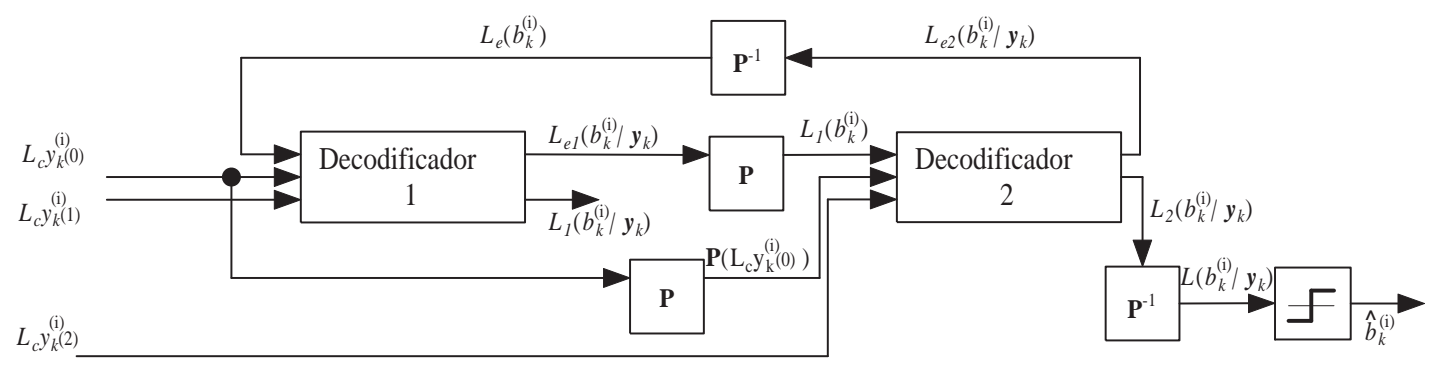

Figura 2.9: Topologia para o decodificador turbo.

\subsection{Estratégia de Decodificação Multidimensional}

Observa-se da estratégia de decodificação tradicional apresentada nas seções anteriores, que esta é realizada apenas em malha aberta e no sentido direto, ou seja, não existe realimentação do sinal decodificado em estruturas de múltiplos estágios, visando à realização de iterações na busca de melhoria de desempenho.

Assim, cada sub-etapa do receptor procura realizar a deteç̧ão de forma isolada até o processo de decodificação. Desta forma, busca-se melhorar individualmente o sinal detectado. No entanto, cada sub-etapa pode ser implementada em estruturas iterativas, i.e., como o decodificador Turbo ou mesmo estratégias de detecção multiusuário do tipo PIC ou ZF-DF.

Com isso, existe a possibilidade de utilização de estratégias iterativas que consideram mais de uma diversidade simultaneamente, resultando em topologias que são realizadas de forma conjunta e iterativa, onde dois ou mais estágios do receptor trocam informações buscando melhorar o desempenho individual e, 
consequentemente, em um nível mais geral, a cada nova iteração.

Na literatura, encontram-se poucos trabalhos que consideram a utilização de otimização multidimensional de forma iterativa, podendo-se citar (YANG; HUA; HANZO, 2006; SERBETLI; YENER, 2006; LU; FANG, 2009; LU, 2011). Nestes trabalhos, a otimização e exploração da diversidade é realizada de forma conjunta e iterativa considerando uma dimensão ou duas dimensões (tempo e frequência). Utiliza-se, para a detecção, os algoritmos de MMSE e Descorrelacionador. Vale ressaltar que os trabalhos desenvolvidos até 2009 consideram apenas exploração conjunta e iterativa de duas dimensões de diversidade $(2 \mathrm{D})^{28}$ e somente com o trabalho recente de (LU, 2011) foi apresentado a possibilidade de expansão para exploração conjunta e iterativa com mais dimensões $(3 \mathrm{D})^{29}$.

Os resultados apresentados indicam similaridade de desempenho em relação às técnicas tradicionais de detecção individuais e a complexidade da topologia mostra-se algumas unidades de vezes inferior à estratégia de otimização multiobjetivo.

A figura 2.10 apresenta o modelo de sistema considerando uma estratégia iterativa multidimensional, sendo, neste caso, de três dimensões.

Note que para três dimensões, a análise pode ser realizada primeiramente no domínio S e posteriormente na busca do símbolo ótimo considerando a diversidade temporal e em frequência de forma conjunta (estratégia $S-F T$ ) ou mesmo alterando para iniciar com o tempo e posteriormente com o domínio espacial e em frequência (estratégia $T-S F$ ) ou, por fim, considerando inicialmente a diversidade em frequência e posteriormente considerando a diversidade temporal e espacial de forma conjunta (estratégia $F-S T$ ).

Nestes casos, não é utilizado um filtro casado à sequência de espalhamento na frequência e casado ao embaralhamento, mas sim uma métrica baseada na minimização do erro quadrático médio ${ }^{30}$ para otimizar os símbolos espalhados com diversidade tempo-frequência-espaço à entrada do receptor. O sinal resultante é, então, devolvido à entrada do receptor multidimensional para re-otimização. Este processo iterativo deverá ser realizado por algumas iterações até que o sinal resultando não apresente ganho significativo de desempenho. Após, este sinal é repassado aos demais estágios de decodificação.

Visando obter o modelo para detecção iterativa no domínio SFT (Space-

\footnotetext{
${ }^{28}$ Exploração conjunta e iterativa da diversidade tempo-frequência.

${ }^{29}$ Exploração conjunta e iterativa da diversidade tempo-frequência-espaço em uma estrutura $1 \mathrm{D}$ seguida de uma estrutura 2D, resultando em três possibilidades de arranjos.

${ }^{30}$ Neste caso, esta estratégia resulta em máxima verossimilhança.
} 


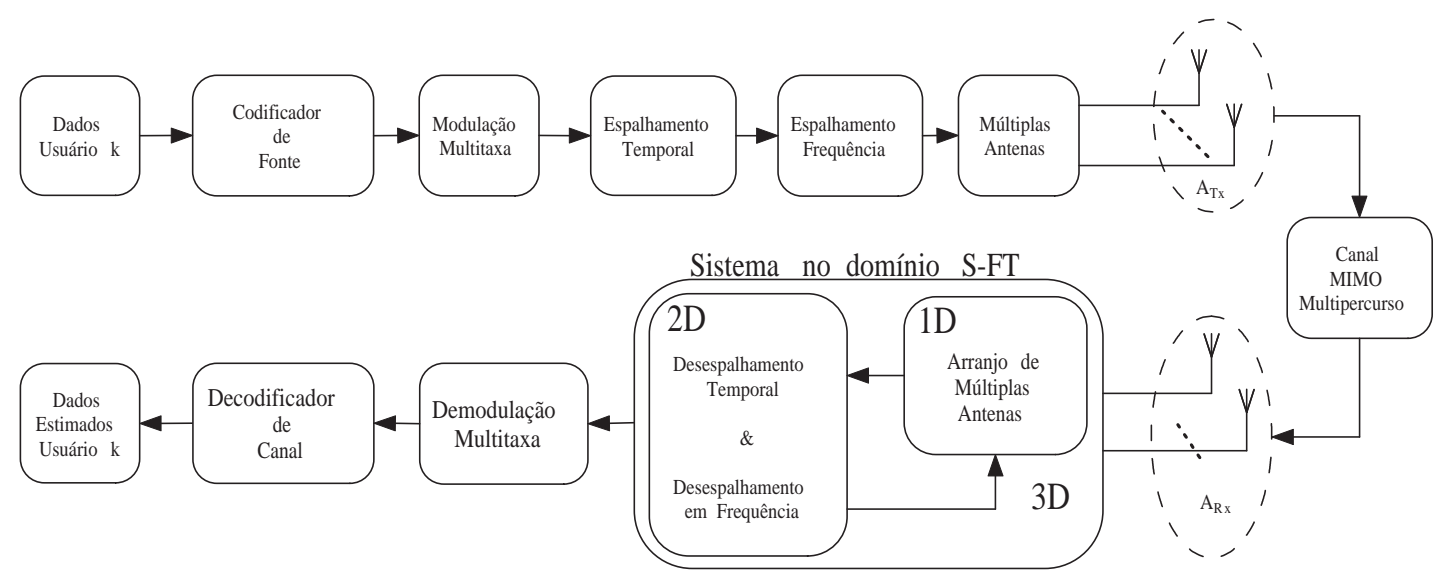

Figura 2.10: Sistema proposto para o transmissor e receptor com diversidade iterativa no domínio S-FT (3D)

Frequency-Time), torna-se necessário a definição do sinal recebido considerando a contribuição de cada uma das dimensões de diversidade envolvidas.

Com isso, define-se a sequência de espalhamento temporal para cada usuário como:

$$
\mathbf{s}_{k}^{(g)}=\left[s_{k, 1}^{(g)}, s_{k, 2}^{(g)}, \ldots, s_{k, N}^{(g)}\right]^{T}
$$

onde $s_{k, n}{ }^{(g)}$ corresponde ao $n$-ésimo chip da sequência de embaralhamento de comprimento $N$ do $k$-ésimo usuário do $g$-ésimo grupo multitaxa e $(.)^{T}$ denota operador de transposição.

Da mesma forma, define-se a sequência de espalhamento na frequência para cada usuário como:

$$
\mathbf{s}_{F k}^{(g)}=\left[s_{F k, 1}^{(g)}, s_{F k, 2}^{(g)}, \ldots, s_{F k, M}^{(g)}\right]^{T}
$$

onde $s_{F k, m}{ }^{(g)}$ corresponde ao $m$-ésimo chip da sequência de espalhamento na frequência de comprimento $M$ do $k$-ésimo usuário do $g$-ésimo grupo multitaxa e $(.)^{T}$ denota operador de transposição.

Assim, o sinal recebido no $n$-ésimo tempo de chip para a $m$-ésima subportadora e $n_{R x}$-ésima antena, denotado por $r_{n_{R x}, m, n}$, é dado por:

$$
r_{n_{R x}, m, n}=\sum_{k=1}^{K^{(g)}} a_{k, n_{R x}} h_{k, n_{R x}, m} s_{F k, m} s_{k, n} A_{k}^{\prime} u_{k}^{(g)}+\eta_{n_{R x}, m, n}
$$

onde $1 \leq n_{R x} \leq A_{R x}, 1 \leq m \leq M, 1 \leq n \leq N, a_{k, n_{R x}}$ denota a resposta da $n_{R x}$-ésima antena do $k$-ésimo usuário, $h_{k, n_{R x}, m}$ corresponde ao coeficiente de canal do $k$-ésimo usuário no domínio F para a $m$-ésima subportadora e $n_{R x}$-ésima antena, $A_{k}^{\prime}$ corresponde a amplitude recebida do $k$-ésimo usuário incluindo os efeitos de perdas de percurso e sombreamento, $u_{k}^{(g)}$ corresponde ao sinal codificado 
e canalizado do $k$-ésimo usuário do $g$-ésimo grupo multitaxa e $\eta_{n_{R x}, m, n}$ denota o AWGN com densidade de potência bilateral igual a $N_{0} / 2$.

Conforme apresentado em (LU, 2011), a estratégia no domínio $S-F T$ apresentou superioridade de desempenho em relação as estratégias nos domínios $F-S T$ e $T-S F$. Portanto, a estratégia $S-F T$ foi considerada, sem perda de generalidade, para o modelo do sistema multidimensional utilizado neste trabalho.

Desta forma, deve-se combinar os $A_{R x}$ sinais recebidos, equação (2.114), formando um vetor de sinal recebido no domínio $\mathrm{S}$, de dimensão $A_{R x} \times 1$, dado por:

$$
\begin{aligned}
\mathbf{r}_{m, n}^{S} & =\left[r_{1, m, n}, r_{2, m, n}, \ldots, r_{A_{R x}, m, n}\right]^{T} \\
& =\sum_{k=1}^{K^{(g)}}\left[\begin{array}{c}
a_{k, 1} h_{k, 1, m} s_{F k, m} s_{k, n} \\
a_{k, 2} h_{k, 2, m} s_{F k, m} s_{k, n} \\
\vdots \\
a_{k, A_{R x}} h_{k, A_{R x}, m} s_{F k, m} s_{k, n}
\end{array}\right] A_{k}^{\prime} u_{k}^{(g)}+\left[\begin{array}{c}
\eta_{1, m, n} \\
\eta_{2, m, n} \\
\vdots \\
\eta_{A_{R x}, m, n}
\end{array}\right]
\end{aligned}
$$

Simplificando a notação, denota-se o vetor de sequência e coeficientes no domínio S como sendo:

$$
\mathbf{a h}_{k, m}=\mathbf{a}_{k} \circ \mathbf{h}_{k, m}
$$

onde o operador (o) representa o operador de produto de Hadamard ${ }^{31}$ e os vetores $\mathbf{a}_{k}$ e $\mathbf{h}_{k, m}$ são definidos respectivamente por:

$$
\begin{gathered}
\mathbf{a}_{k}=\left[a_{k, 1}, a_{k, 2}, \ldots, a_{k, A_{R x}}\right]^{T} \\
\mathbf{h}_{k, m}=\left[h_{k, 1, m}, h_{k, 2, m}, \ldots, h_{k, A_{R x}, m}\right]^{T}
\end{gathered}
$$

Portanto, define-se novamente o sinal recebido no domínio S com sendo:

$$
\mathbf{r}_{m, n}^{S}=\sum_{k=1}^{K^{(g)}} \mathbf{a h}_{k, m} s_{F k, m} s_{k, n} A_{k}^{\prime} u_{k}^{(g)}+\eta_{m, n}^{S}
$$

onde $1 \leq m \leq M, 1 \leq n \leq N$.

Por fim, deve-se considerar o efeito do espalhamento temporal e em frequência combinando todos os $N M$ vetores para obtenção da matriz de sinal recebido,

\footnotetext{
${ }^{31}$ Para matrizes de mesma dimensão, também é conhecido como produto interno e produto de Schur (GOLUB; VAN LOAN, 1996).
} 
denotado por $R^{S-F T}$, sendo dada por:

$$
\begin{aligned}
\mathbf{R}^{S-F T} & =\left[\mathbf{r}_{1,1}^{S} ; \mathbf{r}_{1,2}^{S} ; \ldots ; \mathbf{r}_{M, N}^{S}\right] \\
& =\sum_{k=1}^{K^{(g)}} \mathbf{A} \mathbf{H}_{k} \mathbf{C}_{k}^{F T} A_{k}^{\prime} u_{k}^{(g)}+\mathbf{N}^{S-F T}
\end{aligned}
$$

onde as matrizes $\mathbf{A H}_{k}, \mathbf{C}_{k}^{F T}$ e $\mathbf{N}^{S-F T}$ são definidas respectivamente por:

$$
\begin{gathered}
\mathbf{A H}_{k}=\left[\begin{array}{cccc}
\mathbf{a h}_{k, 1} & \mathbf{a h}_{k, 2} & \ldots & \mathbf{a h}_{k, M}
\end{array}\right] \\
\mathbf{C}_{k}^{F T}=\left[\begin{array}{cccc}
s_{F k, 1}\left(\mathbf{s}_{k}\right)^{T} & \mathbf{0}_{1 \times M} & \ldots & \mathbf{0}_{1 \times M} \\
\mathbf{0}_{1 \times M} & s_{F k, 2}\left(\mathbf{s}_{k}\right)^{T} & \ldots & \mathbf{0}_{1 \times M} \\
\vdots & \vdots & \ddots & \vdots \\
\mathbf{0}_{1 \times M} & \mathbf{0}_{1 \times M} & \ldots & s_{F k, M}\left(\mathbf{s}_{k}\right)^{T}
\end{array}\right] \\
\mathbf{N}^{S-F T}=\left[\begin{array}{cccc}
\eta_{1,1}^{S} & \eta_{1,2}^{S} & \ldots & \eta_{M, N}^{S}
\end{array}\right]
\end{gathered}
$$

considerando $0_{1 \times M}$ como sendo um vetor com $1 \times M$ zeros.

Baseado na estrutura da matriz de sinal recebido $\mathbf{R}^{S-F T}$, pode-se obter uma métrica de decisão que opera de forma iterativa baseada na minimização do erro quadrático médio entre o símbolo codificado e espalhado através da sequência de canalização $\mathbf{u}_{k^{(g)}}$ e a saída do detector no domínio $S-F T$, sendo dada por:

$$
\left[\mathbf{w}_{k}^{S}, \mathbf{w}_{k}^{F T}\right]=\underset{\mathbf{w}_{k}^{S}, \mathbf{w}_{k}^{F T}}{\arg \min } E\left[\left|u_{k}^{(g)}-\left(\mathbf{w}_{k}^{S}\right)^{H} \mathbf{R}^{S-F T}\left(\mathbf{w}_{k}^{F T}\right)^{*}\right|^{2}\right]
$$

onde $1 \leq k \leq K$ e $\mathbf{w}_{k}^{S}$ e $\mathbf{w}_{k}^{F T}$ são, respectivamente, os sinais no domínio $\mathrm{S}$ e no domínio do Tempo-Frequência $(F T)$ para o usuário $k$.

Segundo (YANG; HUA; HANZO, 2006; SERBETLI; YENER, 2006; LU; FANG, 2009) não existe um forma fechada para solução da equação (2.124). Desta forma, podese obter de forma iterativa, considerando para a $i$-ésima iteração um vetor fixo de $\mathbf{w}_{k}^{S}$, para $k=1, \ldots, K$, igual ao valor obtido na iteração anterior, ou seja, $\mathbf{w}_{k}^{F T}(i-1)$. Desta forma, substituindo $\mathbf{w}_{k}^{F T}(i-1)$ na equação $(2.124)$ obtém-se:

$$
\begin{aligned}
\mathbf{w}_{k}^{S}(i)=\left(E \left[\left(\mathbf{R}^{S-F T}\left(\mathbf{w}_{k}^{F T}(i-1)\right)^{*}\right)\right.\right. & \left.\left.\left(\mathbf{R}^{S-F T}\left(\left(\mathbf{w}_{k}^{F T}(i-1)\right)^{*}\right)^{H}\right)\right]^{-1}\right) \\
& \left(E\left[\mathbf{R}^{S-F T}\left(\mathbf{w}_{k}^{F T}(i-1)\right)^{*} u_{k}^{(g)}\right]\right)
\end{aligned}
$$


e

$$
\begin{array}{r}
\mathbf{w}_{k}^{F T *}(i)=\left(E\left[\left(\mathbf{R}^{S-F T} \mathbf{w}_{k}^{S}(i)\right)\left(\left(\mathbf{w}_{k}^{S}(i)\right)^{H}\left(\mathbf{R}^{S-F T}\right)^{H}\right)^{H}\right]^{-1}\right) \\
\left(E\left[\left(\mathbf{R}^{S-F T}\right)^{H} \mathbf{w}_{k}^{S}(i) u_{k}^{(g)}\right]\right)
\end{array}
$$

onde $1 \leq k \leq K$.

Como o processo é iterativo, encontra-se $\mathbf{w}_{k}^{S}(i)$ pelo uso de $\mathbf{w}_{k}^{F T}(i-1)$ e consequentemente, $\mathbf{w}_{k}^{F T}(i)$ pelo uso de $\mathbf{w}_{k}^{S}(i)$. Após, encontra-se $\mathbf{w}_{k}^{S}(i+1)$ pelo uso de $\mathbf{w}_{k}^{F T}(i)$ e assim sucessivamente em uma topologia de múltiplas iterações.

Segundo o autor (LU, 2011), o desempenho encontrado assemelha-se ao limite da estimativa de erro quadrático médio para uma estratégia multiobjetivo mas com uma redução da complexidade computacional inerente à estratégia SFT. Note que a estratégia utilizada considera o detector multiusuário MMSE, apresentando desempenho sub-ótimo.

Diferentemente de (LU, 2011) este trabalho considera o uso de detectores multiusuário baseados em heurísticas, onde o desempenho é superior ao encontrado com o detector MMSE iterativo multidimensional, tendendo ao limite de usuário simples quando são utilizados parâmetros adequados para os algoritmos heurísticos. Os resultados das estratégias heurísticas aplicadas aos sistemas com detecção multidimensional são apresentados no capítulo 5 .

Mas vale ressaltar que a maior dificuldade está na definição das matrizes $\mathbf{R}^{S-F T}$ (efeito da correlação entre as sequências de espalhamento temporal e em frequência) e os vetores $\mathbf{w}_{k}^{S}$ (sinal espalhado no domínio do tempo) e $\mathbf{w}_{k}^{F T}$ (sinal espalhado no domínio da frequência) para o caso deste trabalho devido às inúmeras estratégias de diversidade disponíveis no transmissor, além das três utilizadas pela estratégia multidimensional. Note que o sinal $u_{k}^{(g)}$ representa o símbolo codificado e considerando a etapa de canalização, conforme seção 2.1.2.1. Desta forma, o sinal à saída da estratégia de detecção multidimensional baseada em heurística deve ainda ser desacoplado considerando as diferentes taxas utilizadas e posteriormente decodificados através de algoritmos específicos dependendo da estratégia de codificação existentes no transmissor.

Por fim, evidencia-se a possibilidade de expansão desta técnica para um número superior de diversidade. No entanto, esta expansão não faz parte do escopo deste trabalho sendo descrita sucintamente na seção 6.1 uma topologia resultante que deverá ser considerada em trabalhos futuros. 


\subsection{Estimativa de Parâmetros}

Para o problema de estimativa de parâmetros em sistemas MIMO e multiportadora, deve-se considerar a necessidade de estimação dos parâmetros de canal e atraso para cada antena de recepção, bem como para cada subportadora. Desta forma, será apresentado uma topologia para estimativa de parâmetros que visa garantir compromisso razoável de complexidade $\times$ desempenho.

Com isso, toda a notação utilizada não considerou os índices $n_{R x}$ referentes à $n_{R x}$-ésima antena e $m$ referente a $m$-ésima subportadora, visando facilitar a compreensão. No entanto, reforça-se a necessidade de estimativa individual para cada subportadora e antena de recepção, resultando em $2 M A_{T x} A_{R x} L K$ parâmetros a serem estimados (canal e atraso) para cada período de símbolo codificado.

Para o problema da estimativa de parâmetros, o sinal recebido $r(t)$ é discretizado no receptor utilizando uma taxa de amostragem igual à taxa de chip ou maior (BENSLEY; AAZHANG, 1996). Assim, os vetores amostrados são formados por pelo menos $N$ saídas sucessivas de $r(t)$, pois $N=\frac{T}{T_{c}}$ define o ganho de processamento do sistema e $\frac{1}{T_{c}}$ define a largura de banda ocupada pelo sinal DS/CDMA. Com isso, define-se $N$ como sendo a razão de espalhamento total multitaxa e $K$ como sendo o número total de usuários físicos, ou seja, $K=K^{(1)}+K^{(2)}+\ldots K^{(g)}+\ldots K^{(G)}$.

Os vetores resultantes da amostragem do sinal recebido correspondem a um intervalo de tempo igual a um período de símbolo codificado e iniciam-se em um tempo de referência arbitrário no receptor. Assumindo atrasos ordenados conforme a equação (2.24) e que todos os percursos de todos os usuários de todos os grupos multitaxa chegam ao receptor dentro de um período de bit, ter-se-á, no máximo, apenas dois símbolos de cada usuário por janela de observação. Assim, utilizando notação vetorial e considerando a discretização do sinal recebido em intervalos de chip, a equação (2.23) pode ser reescrita conforme (BHASHYAM; AAZHANG, 2002) como:

$$
\mathbf{r}_{i}=\mathcal{U} \mathbf{Z} \mathbf{x}_{i}+\mathbf{n}_{i}
$$

onde $\mathbf{r}_{i}$ é o vetor discretizado do sinal recebido para o $i$-ésimo intervalo de bit com dimensão $N \times 1 ; \mathcal{U}$ é a matriz de espalhamento de dimensão $N \times 2 K N$, formada pela composição das sequências de embaralhamento e canalização; $\mathbf{Z}$ é a matriz de resposta do canal de dimensão $2 K N \times 2 K$; $\mathbf{x}_{i}$ é o vetor de símbolos codificados transmitidos de dimensão $2 K \times 1$ e $\mathbf{n}_{i}$ é o vetor aleatório Gaussiano complexo de média zero e dimensão $N \times 1$. 
Vale ressaltar que a equação (2.127) refere-se a cada subportadora e antena de recepção.

A matriz de espalhamento, formada pela composição das sequências de embaralhamento e canalização, é construída utilizando-se de versões atrasadas dos códigos correspondentes ao $i$-ésimo e $(i+1)$-ésimo intervalo de símbolo para cada usuário. Assumindo-se códigos $\operatorname{curtos}^{32}$, resulta:

$$
\mathcal{U}=\left[\mathcal{U}_{1}^{R} \mathcal{U}_{1}^{L} \mathcal{U}_{2}^{R} \mathcal{U}_{2}^{L} \ldots \mathcal{U}_{k}^{R} \mathcal{U}_{k}^{L} \ldots \mathcal{U}_{K}^{R} \mathcal{U}_{K}^{L}\right]
$$

onde as matrizes $\mathcal{U}_{k}^{R}$ e $\mathcal{U}_{k}^{L}$ são definidas respectivamente por:

$$
\mathcal{U}_{k}^{R}=\left[\begin{array}{ccccc}
s_{k, 1} & s_{k, 2} & s_{k, 3} & \cdots & s_{k, N} \\
s_{k, 2} & s_{k, 3} & s_{k, 4} & \cdots & 0 \\
s_{k, 3} & s_{k, 4} & s_{k, 5} & \cdots & 0 \\
\vdots & \vdots & \vdots & \ddots & \vdots \\
s_{k, N-1} & s_{k, N} & 0 & \cdots & 0 \\
s_{k, N} & 0 & 0 & \cdots & 0
\end{array}\right]
$$

$\mathrm{e}$

$$
\mathcal{U}_{k}^{L}=\left[\begin{array}{ccccc}
0 & 0 & 0 & \cdots & 0 \\
0 & 0 & 0 & \cdots & s_{k, 1} \\
0 & 0 & 0 & \cdots & s_{k, 2} \\
\vdots & \vdots & \vdots & \ddots & \vdots \\
0 & 0 & s_{k, 1} & \cdots & s_{k, N-2} \\
0 & s_{k, 1} & s_{k, 2} & \cdots & s_{k, N-1}
\end{array}\right]
$$

Os elementos $s_{k, n}$ das matrizes $\mathcal{U}_{k}^{R}$ e $\mathcal{U}_{k}^{L}$ são obtidos pela composição das sequências de embaralhamento e canalização. Como realizou-se a discretização (amostragem) do sinal recebido no período de $\operatorname{chip}\left(T_{c}\right)$, a composição das sequências de espalhamento para o $k$-ésimo usuário físico resulta em:

$$
s_{k, n}=\frac{1}{\sqrt{N}} \sum_{m=1}^{m^{(g)}} \underline{s}_{m, n} \underline{s}_{k, n}
$$

para $n=1: N$ e $k=1: K$; ambos os elementos $\underline{s}_{C, n}$ e $\underline{s}_{k, n} \in[ \pm 1]$ e representam as versões discretizadas a cada intervalo de chip das sequências de canalização e embaralhamento, respectivamente.

A matriz de resposta do canal é formada pela composição dos efeitos de pequena e grande escala (desvanecimento seletivo, perda de percurso e sombreamento), das amplitudes recebidas dos usuários e dos atrasos dos multipercursos,

\footnotetext{
${ }^{32}$ Comprimento da sequência de espalhamento igual ao ganho de processamento $N$.
} 
resultando em:

$$
\mathbf{Z}=\operatorname{diag}\left(\mathbf{z}_{1}, \mathbf{z}_{1}, \mathbf{z}_{2}, \mathbf{z}_{2}, \ldots \mathbf{z}_{K}, \mathbf{z}_{K}\right)
$$

onde $\mathbf{z}_{k}$ é o vetor resposta do canal, de dimensão $N \times 1$, para o $k$-ésimo usuário. Assume-se que toda a energia do $\ell$-ésimo percurso possa ser capturado em $\tau_{k, \ell}=$ $q_{k, \ell} T_{c}$, i.e., na $q_{k, \ell}$ posição em $\mathbf{z}_{k}$. Por exemplo, quando o sinal recebido referente a um usuário resultar em dois percursos com atrasos $\tau_{k, 1}=3 T_{c}$ e $\tau_{k, 2}=5 T_{c}$, o vetor $\mathbf{z}_{k}$ terá o formato:

$$
\mathbf{z}_{k}=\left[\begin{array}{lllllllll}
0 & 0 & 0 & z_{k, 1} & 0 & z_{k, 2} & 0 & \ldots & 0
\end{array}\right]^{T}
$$

sendo os elementos de $\mathbf{z}_{k}$ formados pela composição dos efeitos de pequena e grande escala e das amplitudes recebidas, dados por:

$$
z_{k, \ell}=A_{k}^{\prime} c_{k, \ell}
$$

Deste modo, as localizações (posições) do vetor onde existirem valores diferentes de zero determinam os atrasos dos percursos.

Finalmente, o vetor de símbolos $\mathbf{x}_{i}$ que considera o $i$-ésimo e o $(i+1)$-ésimo intervalo de símbolo é dado por:

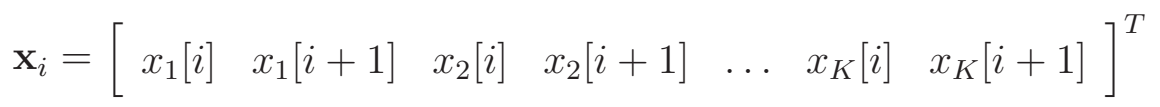

Visando obter estimativas para os parâmetros atraso e resposta do canal, a equação (2.127) pode ser reescrita como:

$$
\mathbf{r}_{i}=\mathcal{U} \mathbf{B}_{i} \mathbf{z}+\mathbf{n}_{i}
$$

onde o vetor de resposta do canal possui dimensão $N K \times 1$, sendo dado por:

$$
\mathbf{z}=\left[\begin{array}{llll}
\mathbf{z}_{1}^{T} & \mathbf{z}_{2}^{T} & \cdots & \mathbf{z}_{K}^{T}
\end{array}\right]^{T}
$$

e a matriz de informação multiusuário possui dimensão $2 K N \times K N$, sendo definida por: 


$$
\mathbf{B}_{i}=\left[\begin{array}{ccccc}
x_{1}^{(i)} & 0 & 0 & \cdots & 0 \\
x_{1}^{(i+1)} & 0 & 0 & \cdots & 0 \\
0 & x_{2}^{(i)} & 0 & \cdots & 0 \\
0 & x_{2}^{(i+1)} & 0 & \cdots & 0 \\
\vdots & \vdots & \vdots & \ddots & \vdots \\
\vdots & \vdots & \vdots & \ddots & \vdots \\
0 & 0 & 0 & \cdots & x_{K}^{(i)} \\
0 & 0 & 0 & \cdots & x_{K}^{(i+1)}
\end{array}\right] \otimes \mathbf{I}_{N}
$$

onde $\otimes$ denota o produto de Kronecker e $\mathbf{I}_{N}$ é a matriz identidade de ordem $N$.

Assim, pode-se estimar até $N$ parâmetros de canal para cada usuário.

Como foi assumido que os atrasos dos percursos para cada usuário estão contidos em um intervalo de bit, ou seja, $\tau_{k, \ell} \leq T$, o número de coeficientes diferentes de zero contidos no vetor de resposta do canal do $k$-ésimo usuário $\mathbf{z}_{k}$ determina o número de percursos resolvíveis e suas posições indicam os respectivos atrasos contidos no intervalo $N T_{c}=T$ segundos.

\subsubsection{Estimador de Canal via regra ML}

O estimador de canal baseado na regra de máxima verossimilhança consiste em encontrar o vetor $\mathbf{z}$ na equação (2.136) que maximiza a função de verossimilhança da resposta do canal para todos os usuários simultaneamente utilizando suas respectivas sequências de espalhamento e bits transmitidos. Estes bits podem ser enviados na forma de um preâmbulo antes dos dados, sendo conhecidos no receptor, ou obtidos via canal piloto ${ }^{33}$. Na fase de estimação dos coeficientes de canal, as sequências de treinamento ou canal piloto são utilizados; na fase de sintonia (tracking), ou estimativa de atrasos, alimenta-se o estimador com as decisões de dados obtidas pelo detector utilizado; finalmente, na etapa de detecção da informação, estimativas prévias de atrasos, coeficientes de canal e amplitudes são utilizadas. Desta forma, esta estratégia iterativa é adequada para canais multipercurso (ou plano) lentamente variáveis no tempo.

Neste contexto, a função de máxima verossimilhança, que é a probabilidade condicional conjunta do recebimento de $I$ vetores de dados, dado que as sequências

\footnotetext{
${ }^{33}$ Símbolos conhecidos enviados em uma faixa de frequências diferente da frequência utilizada para transmitir a informação.
} 
de espalhamento, do canal e dos bits de informação são conhecidos, é dada por:

$$
\begin{aligned}
& P_{r}\left(\mathbf{r}_{1}, \mathbf{r}_{2}, \ldots, \mathbf{r}_{I} \mid \mathcal{U}, \mathbf{z}, \mathbf{B}_{1}, \mathbf{B}_{2}, \ldots, \mathbf{B}_{I}\right)= \\
& =-\frac{1}{\left(\pi \sigma^{2}\right)^{N I}} \exp \left\{-\frac{1}{\sigma^{2}} \sum_{i=1}^{I}\left(\mathbf{r}_{i}-\mathcal{U} \mathbf{B}_{i} \mathbf{z}\right)^{H}\left(\mathbf{r}_{i}-\mathcal{U} \mathbf{B}_{i} \mathbf{z}\right)\right\}
\end{aligned}
$$

A estimativa que maximiza a função de verossimilhança deve satisfazer a equação (BHASHYAM; AAZHANG, 2002):

$$
\left\{\sum_{i=1}^{I}\left(\mathcal{U} \mathbf{B}_{i}\right)^{H}\left(\mathcal{U} \mathbf{B}_{i}\right)\right\} \hat{\mathbf{z}}_{M L}(I)=\sum_{i=1}^{I}\left(\mathcal{U} \mathbf{B}_{i}\right)^{H} \mathbf{r}_{i}
$$

Para realizar essa estimativa, define-se a matriz de correlação média do sinal multiusuário de dimensão $N K \times N K$ como sendo:

$$
\mathbf{R}_{I}=\frac{1}{I} \sum_{i=1}^{I}\left(\mathcal{U} \mathbf{B}_{i}\right)^{H}\left(\mathcal{U} \mathbf{B}_{i}\right)
$$

e o vetor de informação, com dimensão $N K \times 1$ :

$$
\mathbf{y}_{I}=\frac{1}{I} \sum_{i=1}^{I}\left(\mathcal{U} \mathbf{B}_{i}\right)^{H} \mathbf{r}_{i}
$$

A sequência de informação deve ter no mínimo $I=K+\lceil K / N\rceil$ bits para que $\mathbf{R}_{I}$ seja de ordem completa ${ }^{34}$ (full rank). Consequentemente, assumindo que $\mathbf{R}_{I}$ seja de ordem completa, conclui-se que a obtenção da estimativa para a resposta do canal pelo método ML é dada por:

$$
\hat{\mathbf{z}}_{M L}(I)=\mathbf{R}_{I}^{-1} \mathbf{y}_{I}
$$

onde o vetor resposta do canal $\hat{\mathbf{z}}_{M L}(I)$ é conjuntamente Gaussiano possuindo média z e matriz de covariância $\frac{\sigma^{2}}{I} \mathbf{R}_{I}^{-1}$ (BHASHYAM; AAZHANG, 2002).

Note-se que o estimador de máxima verossimilhança necessita construir a matriz de correlação do sinal e, além disso, realizar uma operação de inversão de matriz para cada janela de processamento (frame), acarretando em uma complexidade computacional (tempo de processamento) muito elevada em sistemas de alta taxa de dados ou quando pequenas janelas de processamento forem utilizadas. Além disso, em sistemas onde o número de usuários é elevado e/ou em sistemas onde usuários "entram" no e "saem" do sistema frequentemente, torna-se impraticável a utilização desse método.

\footnotetext{
${ }^{34}$ Essa afirmação é válida quando forem utilizadas sequências de espalhamento aleatórias que sejam linearmente independentes.
} 


\subsubsection{Estimador de Canal via Método do Gradiente}

É possível obter estimativas de canal próximas às obtidas via método ML utilizando-se algoritmos iterativos desenvolvidos pelo processo de adaptação baseado no gradiente.

Algoritmos iterativos baseados no chamado gradiente verdadeiro ${ }^{35}$ ou em estimativas estocásticas para o gradiente vem sendo utilizados para diversos problemas de filtragem adaptativa e detecção de sinais (HONIG; MADHOW; VERDÚ, 1995; HAYKIN, 1996). No âmbito da estimativa do canal, esses algoritmos visam diminuir a complexidade do cômputo da matriz de correlação $\mathbf{R}_{I}$ e do cômputo $\mathbf{R}_{I}^{-1} \mathbf{y}_{I}$ ao final do preâmbulo.

Como comentado anteriormente, o cálculo da inversa da matriz de correlação ao final do preâmbulo é computacionalmente dispendioso ${ }^{36}$, podendo acarretar atrasos na obtenção das estimativas ou mesmo limitar a taxa de transmissão a patamares indesejáveis.

Visando diminuir essa complexidade, os algoritmos iterativos baseados no método do gradiente utilizam aproximações da solução ML, trocando o cômputo da expressão $\mathbf{R}_{I}^{-1} \mathbf{y}_{I}$ pela equação linear aproximada $\mathbf{R}_{i} \hat{\mathbf{z}}=\mathbf{y}_{i}$ em uma estrutura de múltiplas iterações, como é o caso do algoritmo baseado no método do gradiente descendente (BHASHYAM; AAZHANG, 2002).

\subsubsection{Algoritmo Gradiente Descendente}

O algoritmo baseado no método do gradiente descendente realiza as seguintes operações para a obtenção da estimativa do canal no $i$-ésimo intervalo de bit (BHASHYAM; AAZHANG, 2002):

1. cálculo da matriz de correlação para o bit atual:

$$
\mathbf{R}_{i}=\left(\frac{i-1}{i}\right) \mathbf{R}_{i-1}+\left(\frac{1}{i}\right)\left(\mathcal{U} \mathbf{B}_{i}\right)^{H}\left(\mathcal{U} \mathbf{B}_{i}\right)
$$

2. cálculo do vetor:

$$
\mathbf{y}_{i}=\left(\frac{i-1}{i}\right) \mathbf{y}_{i-1}+\left(\frac{1}{i}\right)\left(\mathcal{U} \mathbf{B}_{i}\right)^{H} \mathbf{r}_{i}
$$

\footnotetext{
${ }^{35}$ Gradiente de valor determinístico.

${ }^{36}$ Número de operações elevado, consumindo muitos recursos computacionais (tempo e memória).
} 
3. atualização do vetor de canal estimado $\hat{\mathbf{z}}$ através da equação:

$$
\hat{\mathbf{z}}^{(i)}=\hat{\mathbf{z}}^{(i-1)}-\mu\left(\mathbf{R}_{i} \hat{\mathbf{z}}^{(i-1)}-\mathbf{y}_{i}\right)
$$

onde $\left(\mathbf{R}_{i} \hat{\mathbf{z}}^{(i-1)}-\mathbf{y}_{i}\right)$ é o gradiente da superfície de erro quadrático ${ }^{37}$ e $\mu$ é chamado de tamanho do passo, sendo uma constante que garante e controla a velocidade de convergência para o ponto de mínimo ou máximo mais próximo.

A cada iteração, o algoritmo atualiza a estimativa do canal proporcionalmente ao tamanho do passo em direção à região da superfície de mínimo erro quadrático. No entanto, a etapa 3 do algoritmo (atualização) pode ser repetida inúmeras vezes, limitada pela quantidade de recursos computacionais disponíveis.

Neste trabalho, assume-se que a etapa de atualização é realizada apenas uma vez a cada período de bit. Portanto, o número de iterações do algoritmo é igual ao tamanho do preâmbulo. Segundo a literatura especializada (HAYKIN, 1996; BHASHYAM; AAZHANG, 2002), a média das estimativas $|\hat{\mathbf{z}}|$ obtidas por este algoritmo convergem ao valor atual de z. Neste caso, diz-se que este estimador é assintoticamente despolarizado $^{38}$ (unbiased).

\subsubsection{Estimador de Canal via Algoritmo Heurístico}

O estimador proposto neste trabalho também visa minimizar a complexidade intrínseca da estratégia de máxima verossimilhança com a manutenção da qualidade das estimativas obtidas. Desta forma, o objetivo da estratégia heurística consiste em maximizar a função de verossimilhança dada pela equação (2.139). Essa maximização pode ser obtida minimizando-se o erro quadrático médio (argumento do somatório), resultando, para o método heurístico, na seguinte função de verossimilhança logarítmica:

$$
\Omega(\breve{\mathbf{z}})=\sum_{i=m-I}^{m}\left(\mathbf{r}_{i}-\mathcal{U} \mathbf{B}_{i} \breve{\mathbf{z}}\right)^{H}\left(\mathbf{r}_{i}-\mathcal{U} \mathbf{B}_{i} \breve{\mathbf{z}}\right)
$$

Com isso, o vetor estimado deve minimizar a equação (2.147), resultando em:

$$
\begin{aligned}
\hat{\mathbf{z}}_{\text {Heur }}^{(m)} & =\min _{\breve{\mathbf{z}} \in \mathbb{C}^{N K \times 1}} \Omega(\breve{\mathbf{z}}) \\
& =\min _{\breve{\mathbf{z}} \in \mathbb{C}^{N K \times 1}} \sum_{i=m-I}^{m}\left(\mathbf{r}_{i}-\mathcal{U} \mathbf{B}_{i} \breve{\mathbf{z}}\right)^{H}\left(\mathbf{r}_{i}-\mathcal{U} \mathbf{B}_{i} \breve{\mathbf{z}}\right)
\end{aligned}
$$

onde, neste contexto, I é a janela de processamento. Esta função custo é o

\footnotetext{
${ }^{37}$ Corresponde ao termo da função de máxima verossimilhança a ser minimizado.

${ }^{38}$ Característica desejável para qualquer estimador.
} 
negativo da função de verossimilhança logarítmica definida na equação (2.139), ignorando as constantes. Portanto, admitindo-se um conjunto de bits iniciais conhecidos (matriz dos bits de informação, B), pode-se estimar simultaneamente tanto a resposta do canal para todos os usuários quanto os respectivos atrasos indicados pelas posições em $\hat{\mathbf{z}}_{\text {Heur }}^{(m)}$ (veja exemplo da equação (2.133) para o $m^{-}$ ésimo intervalo de bit).

Com isso, os algoritmos heurísticos propostos visam estimar um vetor $\breve{\mathbf{z}}$ próximo ou igual ao encontrado pelo estimador ML testando diversos vetores candidatos que pertencem a um subespaço menor que o espaço de busca total, reduzindo substancialmente o número de operações computacionais necessárias à estimação. Os resultados são apresentados no capítulo 5. 


\section{Algoritmos Heurísticos}

Neste capítulo é realizado uma revisão dos algoritmos heurísticos, especificamente os de busca local e evolucionários, procurando descrever suas diversas variantes, focados na busca de soluções de problemas encontrados nos sistemas de comunicação sem fio apresentados no capítulo 2, especificamente o problema $\mathrm{MuD}$ e MuChE. Tais variantes incluem a codificação (mapeamento) do problema, a etapa de inicialização dos algoritmos (escolha dos parâmetros), o cálculo da função custo, a etapa de variação de varredura do espaço de busca, a etapa de reposição de candidatos e os tipos de critérios de parada dos algoritmos. Para a análise, são considerados os algoritmos de busca local 1-opt e $k$-opt, o de recozimento simulado, os algoritmos de busca Tabu de termo curto e reativo, o algoritmo genético e o algoritmo de programação evolucionária.

Os resultados de simulação são apresentados no capítulo 4 considerando análise dos parâmetros na etapa de inicialização ${ }^{1}$ dos algoritmos visando a garantia de obtenção de resultados satisfatórios.

\subsection{Codificação do Problema}

Para qualquer método de busca heurística, o modo no qual as soluções candidatas são codificadas é de suma importância, se não o mais importante fator no sucesso de um algoritmo heurístico. A maioria das aplicações utilizam vetores de comprimento fixo e ordem fixa de bits para codificar as soluções candidatas. Porém, recentemente, muitas experiências com outros tipos de codificações têm sido realizadas, incluindo codificações para problemas onde deve-se otimizar diversas características (multivariável) e codificações para problemas com valores no domínio dos números reais. Desta forma, a codificação do problema consiste em uma forma de representação numérica da informação a ser analisada, transformando-a em uma maneira apropriada para ser manipulada em um computador.

\footnotetext{
${ }^{1}$ Definição e escolha dos melhores parâmetros e técnicas para cada algoritmo.
} 
A codificação adequada de um problema para utilização de algoritmos heurísticos deve ser considerada um dos principais assuntos que podem proporcionar a construção de algoritmos eficientes. Novamente, quanto mais esta tradução for adequada ao problema, maior será a qualidade dos resultados obtidos pelos algoritmos. Cada parcela indivisível desta tradução receberá o nome de parcela individual de um candidato, podendo assumir nomes específicos dentro dos algoritmos, como "gene" no algoritmo genético ou posição nos algoritmos de busca local.

Vale ressaltar que a representação do candidato é completamente arbitrária, ficando sua definição de acordo com o programador e com um nível de adequação própria. No entanto, deve-se considerar algumas diretrizes para serem seguidas nesta codificação:

- A representação deve ser a mais simples possível

- Se existirem soluções candidatas proibidas, estas não devem possuir representação

- Se o problema impuser condições de algum tipo, estas devem estar implícitas dentro da representação

Basicamente, os problemas associados a este trabalho lidam com variáveis no domínio binário (problema de deteç̧ão) e com variáveis no domínio contínuo (estimativa de parâmetros).

A maioria dos pesquisadores opta pela representação binária para todos os problemas, por questões históricas e pela facilidade de construção dos algoritmos. No entanto, em muitos casos, principalmente para problemas onde os candidatos são apresentados no domínio dos números reais, esta representação pode não ser a mais adequada, pois a representação binária tem dificuldades ao lidar com múltiplas dimensões de variáveis contínuas, especialmente quando um nível de precisão muito grande é requerido. Deve-se considerar também que a codificação binária facilita a implementação em linguagem computacional e consequentemente em hardware, explorando de maneira eficiente a capacidade dos processadores digitais, pois esses realizam operações na forma binária. Além disso, a complexidade e resolução podem ser controladas pelo número de bits utilizados para codificar o problema.

Mas isto pode acarretar, na codificação binária, em candidatos de tamanho muito grande (muitos bits) para atingir a precisão necessária, dificultando a operação dos algoritmos. Além disso, existirá uma discretização inerente nos valores 
reais quando utiliza-se codificação binária. Outro problema consiste nos abismos de Hamming ${ }^{2}$. Existem estratégias que minimizam os efeitos dos abismos de Hamming, como o uso de codificação Gray (DORAN, 2007).

Por isso, deve-se considerar a estrutura de cada problema para a escolha do tipo de codificação, mas recomenda-se a utilização do princípio KIS (Keep it simple, ou de forma equivalente, faça da forma mais simples) para a tomada de decisão. Em muitos casos de problemas no domínio dos reais, a representação binária mostra-se eficiente. Desta forma, uma análise mais criteriosa sobre as codificações possíveis para o problema de estimativa de parâmetros é apresentada no presente capítulo e posteriormente comparada no capítulo 5.

\subsubsection{Problema MuD}

A codificação para o problema $\mathrm{MuD}$ é intrinsecamente binária, pois o vetor de dados a ser otimizado é na sua forma natural binário (sistema digital). Por isso, seguindo o princípio KIS não é necessário realizar uma codificação (mapeamento) das soluções candidatas de forma diferente à forma binária. Portanto, esses vetores candidatos serão representados diretamente pelos bits de informação a serem testados pela função custo, considerando apenas codificação binária bipolarizada, ou seja, candidatos podem assumir apenas valores \pm 1 .

\subsubsection{Problema MuChE}

Já o problema MuChE é intrinsecamente não binário, pois os vetores de resposta do canal a serem otimizados pertencem ao domínio dos números complexos.

Devido às grandes vantagens associadas à codificação binária e à busca por uma arquitetura simplificada no receptor, buscou-se uma codificação binária eficiente para o problema MuChE. Adicionalmente, a arquitetura do receptor torna-se mais simples quando tanto o estimador quanto o detector utilizam a mesma estrutura do algoritmo heurístico para realizar suas otimizações. Isso só é possível se ambos os problemas apresentem a mesma codificação, que neste caso, é binária.

Portanto, este trabalho considera a análise de três possíveis codificações binárias para o problema da estimativa de parâmetros. Essas codificações serão comparadas através da figura de mérito MSE (acurácia) × complexidade (nú-

\footnotetext{
${ }^{2}$ Por exemplo, para mudar do número 7 (0111) para o número 8 (1000) deve-se alterar todos os bits. Na mudança do número 8 (1000) para o 9 (1001), deve-se alterar apenas um bit. Ou seja, mudanças de mesmo efeito final (alteração de uma unidade) no candidato requerem alterações completamente díspares nos candidatos representados de forma binária.
} 
mero de operações), indicando a codificação mais adequada para esse problema. Logicamente, o número de possíveis codificações para esse problema não pode ser definido, deixando margem para a implementação e comparação futura de outras possíveis codificações.

A seguir, são apresentadas as codificações modeladas em ordem cronológica de idealização e implementação.

\subsubsection{Codificação tipo I}

A primeira codificação binária para o problema $\mathrm{MuChE}$ adotada consiste inicialmente em separar a resposta do canal $z_{k, \ell}$ em parte real e parte imaginária, resultando em dois valores reais:

$$
z_{k, \ell}^{\Re}=\left|\Re\left\{z_{k, \ell}\right\}\right| \text { e } z_{k, \ell}^{\Im}=\left|\Im\left\{z_{k, \ell}\right\}\right|
$$

onde $|\Re\{\}$.$| e |\Im\{\}$.$| representam os operadores módulo da parte real e módulo da$ parte imaginária do número complexo $\{$.$\} , respectivamente. Após realizar esse$ procedimento, separa-se $z_{k, \ell}^{\Re}$ e $z_{k, \ell}^{\Im}$ em partes inteiras e fracionárias:

$$
\begin{aligned}
& \chi_{k, \ell}^{\Re}=\left\lfloor z_{k, \ell}^{\Re}\right\rfloor \text { e } \psi_{k, \ell}^{\Re}=z_{k, \ell}^{\Re}-\chi_{k, \ell}^{\Re} \\
& \chi_{k, \ell}^{\Im}=\left\lfloor z_{k, \ell}^{\Im}\right\rfloor \text { e } \psi_{k, \ell}^{\Im}=z_{k, \ell}^{\Im}-\chi_{k, \ell}^{\Im}
\end{aligned}
$$

onde o operador $\lfloor x\rfloor$ retorna o maior inteiro inferior a $x$. Os valores $\chi_{k, \ell}^{\Re}$ e $\psi_{k, \ell}^{\Re}$ são então digitalizados através de um conversor Analógico/Digital (ADC - Analog to Digital Converter) da forma:

$$
\begin{gathered}
\underline{\chi}_{k, \ell}^{\Re}=\operatorname{ADC}\left[\chi_{k, \ell}^{\Re}\right]_{Q_{\text {int }}} \\
\underline{\psi}_{k, \ell}^{\Re}=\operatorname{ADC}\left[\operatorname{round}\left(\frac{1}{\psi_{k, \ell}^{\Re}}\right)\right]_{Q_{\mathrm{frac}}}
\end{gathered}
$$

onde o operador $\mathrm{ADC}[\cdot]_{n}$ converte o valor do argumento em vetor binário com $n$ bits e a notação $\underline{\vartheta}$ representa versão binária de $\vartheta$.

Os valores para a parte imaginária são digitalizados de forma análoga aos da parte real. As quantidades de bits $Q_{\text {int }}$ e $Q_{\text {frac }}$ são parâmetros de entrada do algoritmo e contribuem para a determinação da precisão da solução e complexidade do algoritmo heurístico.

Com isso, define-se a unidade de processamento "parcela do candidato" como sendo o vetor formado pelas partes inteira e fracionária da parte real e imaginária 
de $z_{k, \ell}$, na sua versão binária, resultando em:

$$
\Lambda_{k, \ell}=\left[\underline{\chi}_{k, \ell}^{\Re} \underline{\psi}_{k, \ell}^{\Re} \underline{\chi}_{k, \ell}^{\Im} \underline{\psi}_{k, \ell}^{\Im}\right]
$$

Com isso, o $i$-ésimo candidato é constituído de $K L$ parcelas, resultando num vetor coluna binário $\underline{\breve{z}}_{i}$ dado por:

$$
\underline{\breve{z}}_{i}=\left[\Lambda_{1,1} \ldots \Lambda_{1, L} \Lambda_{2,1} \ldots \Lambda_{2, L} \ldots \Lambda_{k, 1} \ldots \Lambda_{k, L} \ldots \Lambda_{K, 1} \ldots \Lambda_{K, L}\right]^{T}
$$

Portanto, o tamanho de cada candidato será proporcional ao número total de usuários, percursos, número de bits de resolução da parte inteira e fracionária, resultando em um candidato de tamanho $Q_{\text {indiv }}=2 K L\left(Q_{\text {int }}+Q_{\text {frac }}\right)$ bits.

Logicamente, isso se refere à primeira característica do candidato, ou seja, ao valor absoluto da parte real e imaginária ${ }^{3}$.

A obtenção do sinal de cada parte do número complexo deve ser compreendido como uma segunda característica do candidato, onde cada sinal, de cada parte do número complexo, pode ser representado por apenas um bit. Com isso, a segunda característica do candidato a ser otimizada é proporcional apenas ao número total de usuários e à quantidade de percursos, resultando em $Q_{\text {sign }}=2 K L$ bits.

\subsubsection{Codificação tipo II}

A segunda codificação binária para o problema $\mathrm{MuChE} \mathrm{adotada} \mathrm{consiste} \mathrm{em}$ separar a resposta do canal $z_{k, \ell}$ da mesma maneira que a codificação tipo I, ou seja, em parte real e parte imaginária segundo a equação (3.1).

Após realizar esse procedimento, digitaliza-se a parte real e imaginária juntamente com suas partes fracionárias (não são separadas as partes fracionárias das partes inteiras). Esse procedimento visa garantir a não saturação do estimador ${ }^{4}$ a partir do emprego da medida de energia (amplitude ou módulo) do sinal recebido no $i$-ésimo intervalo de bit. Assim, a estimativa dos coeficientes (universo de busca) não contemplará valores proibidos ou que resultam em energia superior à recebida. Portanto, utiliza-se a energia do sinal recebido a cada $i$-ésimo intervalo de bit como valor superior para o módulo da parte real e imaginária dos coeficientes. Com isso, a medida da amplitude (módulo) do sinal recebido no $i$-ésimo

\footnotetext{
${ }^{3}$ Sem considerar o sinal de cada termo.

${ }^{4}$ Maior valor possível para a representação do módulo do coeficiente garantidamente superior ao valor verdadeiro do módulo do coeficiente.
} 
intervalo de bit utilizada pode ser facilmente obtida através da relação:

$$
A_{\max }=\left\|\mathbf{r}_{i}\right\|
$$

Claramente, observa-se que o valor $A_{\max }$ é o maior valor possível para a estimativa de amplitude e coeficiente de canal conjuntamente, pois esse valor representa a energia total recebida no $i$-ésimo intervalo de bit, garantindo uma não saturação da estimativa obtida.

Finalmente, os valores $z_{k, \ell}^{\Re}$ e $z_{k, \ell}^{\Im}$ são então digitalizados através de um conversor Analógico/Digital da forma:

$$
\begin{aligned}
& \underline{z}_{k, \ell}^{\Re}=\operatorname{ADC}\left[\frac{A_{\max }}{z_{k, \ell}^{\Re}}\right]_{Q_{\mathrm{int}}} \\
& \underline{z}_{k, \ell}^{\Im}=\operatorname{ADC}\left[\frac{A_{\max }}{z_{k, \ell}^{\Im}}\right]_{Q_{\mathrm{int}}}
\end{aligned}
$$

Como no caso da codificação tipo I, a quantidade de bits $Q_{\text {int }}$ é um parâmetro de entrada do algoritmo e contribui para a determinação da precisão e complexidade do algoritmo heurístico utilizado. Com isso, define-se a unidade de processamento parcela do candidato como sendo o vetor formado pelas partes real e imaginária do número complexo $z_{k, \ell}$, na forma binária, resultando em:

$$
\Lambda_{k, \ell}=\left[\underline{z}_{k, \ell}^{\Re} \underline{z}_{k, \ell}^{\Im}\right]
$$

Novamente, o $i$-ésimo candidato é constituído de $K L$ parcelas, resultando em um vetor coluna binário $\underline{\breve{z}}_{i}$ dado pela equação (3.3).

Portanto, para a codificação tipo II, o tamanho de cada candidato será proporcional ao número total de usuários, percursos e número de bits de resolução $\left(Q_{\text {int }}\right)$, resultando em um candidato de tamanho $Q_{\text {indiv }}=2 K L\left(2 Q_{\text {int }}\right)=4 K L Q_{\text {int }}$ bits.

Da mesma forma que a codificação tipo I, esta análise refere-se à primeira característica do candidato, ou seja, ao valor absoluto da parte real e imaginária ${ }^{5}$.

Novamente, a obtenção do sinal de cada parte do número complexo deve ser encarado como uma segunda característica do candidato, onde cada sinal, de cada parte do número complexo, pode ser representado por apenas um bit. Com isso, a segunda característica do candidato a ser otimizada é proporcional ao número

\footnotetext{
${ }^{5}$ Sem considerar o sinal de cada termo.
} 
total de usuários e a quantidade de percursos apenas, resultando em $Q_{\text {sign }}=2 \mathrm{KL}$ bits.

\subsubsection{Codificação tipo III}

A terceira e última codificação implementada e testada neste trabalho visa manipular o coeficiente de $\mathrm{canal}^{6}$ a ser estimado na sua forma polar, ou seja, módulo e fase.

Logicamente, essa forma de codificação exclui a necessidade da utilização de uma segunda característica ao candidato (sinal de cada parte do número complexo), buscando facilitar a implementação e minimizar a complexidade computacional.

Com isso, definem-se as variáveis a serem otimizadas (módulo e fase) da forma:

$$
\begin{gathered}
\left|z_{k, \ell}\right|=\sqrt{\left(\Re\left\{z_{k, \ell}\right\}\right)^{2}+\left(\Im\left\{z_{k, \ell}\right\}\right)^{2}} \\
\measuredangle z_{k, \ell}=\operatorname{arctg}\left(\frac{\Im\left\{z_{k, \ell}\right\}}{\Re\left\{z_{k, \ell}\right\}}\right)
\end{gathered}
$$

Após realizar esse procedimento, digitaliza-se o módulo e a fase juntamente com suas partes fracionárias (não são separadas as partes fracionárias das partes inteiras). Novamente, esse procedimento visa garantir a não saturação do estimador pela medida da energia (amplitude ou módulo) do sinal recebido no $i$-ésimo intervalo de bit.

Com isso, utiliza-se o valor $A_{\max }$, definido na equação (3.4), para a obtenção do módulo não saturado. No entanto, a fase pode ser encontrada considerando-se apenas o valor de seu ângulo, que está contido entre 0 e $2 \pi$.

Portanto, o módulo e a fase de $z_{k, \ell}$ são digitalizados através de um conversor ADC da forma:

$$
\begin{aligned}
& \underline{\left|z_{k, \ell}\right|}=\operatorname{ADC}\left[\frac{A_{\max }}{\left|z_{k, \ell}\right|}\right]_{Q_{\mathrm{abs}}} \\
& \underline{\measuredangle z_{k, \ell}}=\operatorname{ADC}\left[\frac{2 \pi}{\measuredangle z_{k, \ell}}\right]_{Q_{\mathrm{phs}}}
\end{aligned}
$$

Novamente, como no caso das codificações anteriores, a quantidade de bits $Q_{\text {abs }}$ e $Q_{\text {phs }}$ são parâmetros de entrada do algoritmo e contribuem para a determinação da precisão e complexidade do algoritmo heurístico.

Note-se que o coeficiente de canal pode ser facilmente reescrito na sua forma

\footnotetext{
${ }^{6}$ Trata-se de um número complexo definido na equação (2.134).
} 
retangular através da relação:

$$
z_{k, \ell}=\left|z_{k, \ell}\right| e^{j \measuredangle z_{k, \ell}}
$$

onde $j=\sqrt{-1}$.

Com isso, define-se a unidade de processamento parcela do candidato como sendo o vetor formado pelo módulo e fase do coeficiente, na forma binária, resultando em:

$$
\Lambda_{k, \ell}=\left[\underline{\left|z_{k, \ell}\right|} \underline{\measuredangle z_{k, \ell}}\right]
$$

Da mesma forma que a codificação do tipo I e II, o $i$-ésimo candidato para a codificação tipo III é constituído de $K L$ parcelas, resultando em um vetor coluna binário $\underline{\underline{\mathbf{z}}}_{i}$ dado pela equação (3.3).

Portanto, nesse caso, o tamanho de cada candidato será proporcional ao número total de usuários, percursos, número de bits de resolução para o módulo e número de bits de resolução para a fase, resultando em um candidato de tamanho $Q_{\text {indiv }}=2 K L\left(Q_{\mathrm{abs}}+Q_{\mathrm{phs}}\right)$ bits.

Logicamente, na codificação tipo III não há a necessidade de uma segunda característica do candidato (sinal), pois o número complexo é descrito na sua forma polar. Com isso, facilita-se uma possível implementação e garante-se uma diminuição da complexidade computacional por geração.

Entretanto, resultados de simulação apresentados no capítulo 5 indicaram que o desempenho obtido pela codificação tipo III é inferior às codificações tipo I e II.

Note-se que, independentemente do tipo de codificação adotado, o objetivo do algoritmo heurístico aplicado ao problema MuChE é otimizar o vetor candidato, para que após o processo de conversão Digital/Analógico (DAC - Digital to Analog Converter), o respectivo vetor $\breve{\mathbf{z}}_{i}$ apresente um menor valor para a função custo, equação (2.147).

\subsection{Definição do Espaço de Busca}

Após a etapa de codificação, deve-se definir o espaço de busca do problema, que no caso do problema $\mathrm{MuD}$ é caracterizado por todas as possíveis combinações de bits que os usuários podem transmitir. Neste caso, para $K_{v}$ usuários virtuais transmitindo $I$ bits através de um canal multipercurso com $L$ percursos e $D$ ramos de processamento do sinal no receptor, o universo de busca total, considerando a 
otimização à saída do filtro casado e combinação dos sinais dos usuários multitaxa, será um conjunto binário de dimensão:

$$
\Theta\left(K_{v}, I, D\right)=2^{D K_{v} I}
$$

$\operatorname{com} 1 \leq D \leq L$

É evidente que o universo de busca a ser percorrido será $\Theta\left(K_{v}, I, D\right)<2^{D K_{v} I}$, pois cada bit transmitido deve ser detectado de forma a resultar em um mesmo valor de bit estimado para todos os $D$ ramos de processamento, ou seja:

$$
\hat{b}_{k, 1, g}^{(i)}=\hat{b}_{k, 2, g}^{(i)}=\ldots=\hat{b}_{k, D, g}^{(i)} \in\{+1,-1\}
$$

Isto implica que o universo de busca a ser percorrido pelo algoritmo heurístico para o problema da detecção multiusuário independe da quantidade de percursos, resultando em:

$$
\Theta\left(K_{v}, I\right)=2^{K_{v} I}
$$

O universo de soluções possíveis é então formado por todos os vetores candidatos que satisfizerem a equação (3.11).

As demais possibilidades fazem parte do chamado universo proibido, não sendo testadas pelo algoritmo heurístico. Com isso, garante-se a qualidade da solução final, pois permite-se que uma possível estimativa correta para todos os percursos de um mesmo bit transmitido possa ser feita.

Já o universo de busca para o problema da estimativa de parâmetros não deve levar em consideração o número de bits transmitido, pois o universo é percorrido a cada período de bit, subportadora e antena de recepção, sendo definido originalmente pelo conjunto dos números complexos:

$$
\Theta(K, L)=\mathbb{C}
$$

No entanto, após a codificação do problema para a forma binária ou real, o universo de busca para o problema $\mathrm{MuChE}$, restringe-se aos seguintes conjuntos binários (Codificação Tipo I, II e III):

- Codificação tipo I:

$$
\Theta(K, L)=2^{2 K L\left(Q_{\mathrm{int}}+Q_{\mathrm{frac}}\right)}
$$

- Codificação tipo II:

$$
\Theta(K, L)=2^{4 K L Q_{\text {int }}}
$$


- Codificação tipo III:

$$
\Theta(K, L)=2^{2 K L\left(Q_{\mathrm{abs}}+Q_{\mathrm{phs}}\right)}
$$

A partir da definição do espaço de busca a ser percorrido, inicia-se a determinação dos parâmetros e a escolha de boas estratégias para as diversas etapas dos algoritmos heurísticos.

\subsection{Algoritmos Evolucionários}

Os algoritmos heurísticos evolucionários constituem métodos não determinísticos de busca baseados em mecanismos de seleção e evolução natural seguindo a teoria da evolução das espécies de Darwin (DARWIN, 1859) ${ }^{7}$. Esta teoria descreve o comportamento complexo que ocorre na interação entre os diversos níveis biológicos: a célula, o organismo, o indivíduo e a população.

A mais extensa coleção de teorias evolucionárias aceita é chamada de paradigma neodarwiniano, que explica a história da vida pela ação de processos físicos e operadores genéticos em populações ou espécies. Estes processos são conhecidos por reprodução, perturbação, competição e seleção.

O processo de reprodução consiste na transferência de características genéticas de um indivíduo para a sua progênie. O processo de perturbação descreve os erros que ocorrem na transferência do material genético na reprodução. Estes erros são modelados por operadores genéticos que modificam as características de um indivíduo na etapa de reprodução, sendo conhecidos principalmente como mutação e crossover. O operador mutação consiste na alteração de um gene por outro que possua uma característica diferente. Já o operador crossover modela o cruzamento entre indivíduos com o objetivo de formar uma nova população que possui uma mistura de características de seus genitores (HOLLAND, 1975; GOLDBERG, 1989; MITCHELL, 1998).

Na literatura existem diversas estratégias para modelar os operadores mutação e crossover, podendo-se citar o operador mutação modelado com uma probabilidade fixa, governada por uma função densidade de probabilidade específica ou de forma dirigida (GOLDBERG, 1989; YEN; HANZO, 2000; LIM; VENKATESH, 2003; CIRIACO; ABRÃO; JESZENSKY, 2004). No processo de perturbação do tipo crossover, o operador pode atuar em um único ponto, em pontos múltiplos, baseados

\footnotetext{
${ }^{7}$ Por se tratar de uma referência antiga e de difícil aquisição, deve-se considerar as edições mais novas de seu trabalho, por exemplo (DARWIN, 2000).
} 
em maioria ou ainda podem ocorrer sobre cada unidade de informação de forma uniforme para cada par de indivíduos genitores (GOLDBERG, 1989; MITCHELL, 1998).

Outros operadores serão analisados, como o operador para intensificação proposto em (ABRÃO; CIRIACO; JESZENSKY, 2004), especificamente para tratar o problema $\mathrm{MuD}$, que consiste em clonar (replicar) os indivíduos que possuem melhores características, no intuito de produzir uma população altamente evoluída na geração posterior. Outra estratégia de intensificação aplicada ao problema $\mathrm{MuD}$ consiste na tentativa de quantificar, de forma adaptativa, o número necessário de mutações que um indivíduo deve sofrer para que este resulte em um melhor conjunto de genes (ABRÃO; CIRIACO; JESZENSKY, 2004). Maiores detalhes sobre os operadores genéticos e processos são apresentados na seção 3.3.5.1 e seção 3.3.5.2.

Já os processos de competição e seleção são a consequência natural da expansão do tamanho da população em um espaço de recursos limitados. Segundo a teoria neodarwiniana, apenas os indivíduos mais adaptados a esse espaço conseguem sobreviver, sendo suas características genéticas repassadas à sua respectiva descendência.

\subsubsection{Tamanho da População}

A escolha do tamanho da população é um fator importante na determinação do custo computacional e da qualidade das soluções obtidas pelos algoritmos evolucionários. Com uma população pequena, o desempenho pode ser comprometido, pois deste modo a população fornece uma pequena cobertura do espaço de busca do problema. Uma grande população geralmente fornece uma cobertura representativa do domínio do problema, além de prevenir convergências prematuras para soluções locais ao invés de globais. No entanto, para se trabalhar com grandes populações, são necessários maiores recursos computacionais, ou que o algoritmo trabalhe por um período de tempo muito maior e possivelmente desnecessário.

O tamanho da população mais adequado para cada tipo de problema de otimização, visando a minimização do custo computacional é um interessante tópico de pesquisa que vem sendo estudado desde o trabalho de Holland (HOLLAND, 1975). Em 1975, De Jong (JONG, 1975), baseado em (HOLLAND, 1975), reconheceu a importância do ruído no processo de decisão propondo uma estimativa para o tamanho da população baseada nas características do sinal e do ruído presentes no problema. Infelizmente, ele não a utilizou no restante do seu trabalho e o resul- 
tado acabou não sendo verificado, caindo em esquecimento. Só em 1991, Goldberg e Rudnick (GOLDBERG; RUDNICK, 1991) desenvolveram a primeira equação para o tamanho da população baseada na variância da função custo. No ano seguinte, Goldberg, Deb e Clark (GOLDBERG; DEB; CLARK, 1992) encontraram um limite conservador para o tamanho da população, garantindo certo nível de qualidade de convergência dos algoritmos.

Em 1999, Harik et al. (HARIK et al., 1999), baseados em (GOLDBERG; DEB; CLARK, 1992), desenvolveram uma equação para o tamanho da população inspirados no clássico problema do caminho aleatório (random walk): particularmente, analisou-se o problema da ruína do jogador (gambler's ruin). Usando problemas simples e complicados como teste, Harik et al. demonstraram a acurácia do modelo proposto. No entanto, o resultado do trabalho de Harik et al. é limitado apenas a problemas onde o tamanho do indivíduo é constante, além de requerer informações estocásticas sobre a variância (ruído) e diferença média esperada (sinal) da função custo entre o segundo e primeiro bloco de construção. Em muitos problemas práticos, estas informações são impossíveis ou muito difíceis de serem obtidas com acurácia. A expressão encontrada por Harik et al. é dada por:

$$
p=-2^{k-1} \ln (\alpha) \frac{\sigma_{f}}{d} \sqrt{\pi m^{\prime}}
$$

onde $p$ é o tamanho da população, ou de forma equivalente, a quantidade de indivíduos que o algoritmo processa por geração, $k$ é a ordem do bloco de construção; $\alpha=1-P_{b}$ é a probabilidade do algoritmo evolucionário falhar na etapa de decisão, ou seja, $P_{b}$ é a probabilidade de acerto; $\sigma_{f}$ é a variância (ruído) da função custo; $d$ é a diferença média esperada (sinal) da função custo entre o segundo e o primeiro bloco de construção; e $m^{\prime}=m-1$, sendo $m=\frac{Q_{\text {indiv }}}{k}$ e $Q_{\text {indiv }}$ o tamanho do candidato.

Posteriormente, Ahn e Ramakrishna (AHN; RAMAKRISHNA, 2002) estenderam o estudo realizado em (HARIK et al., 1999) encontrando uma expressão geral razoável, fácil de ser obtida, para o tamanho da população sem a necessidade de se conhecer as características estocásticas do sinal e do ruído, além de possibilitar sua utilização em problemas de tamanho variável. Esta expressão necessita apenas das informações básicas do problema, como cardinalidade do alfabeto $(l)$, ordem do bloco de construção $(k)$, tamanho do indivíduo $\left(Q_{\text {indiv }}\right)$ e probabilidade de falha do algoritmo genético na etapa de decisão $(\alpha)$, sendo dada por:

$$
p=-\frac{l^{k}}{2} \ln (\alpha)\left(\frac{l^{k}-1}{2} \sqrt{\pi m^{\prime}}+1\right)
$$


Este trabalho utiliza a equação (3.18) para encontrar o tamanho adequado da população para o problema da detecção multiusuário e da estimativa de parâmetros de sistema. A utilização da equação (3.18) é conveniente, pois permite que o tamanho da população seja determinada apenas na etapa de inicialização do algoritmo evolucionário, sendo mantido constante em todas as gerações.

Para o problema onde os sinais são digitais binários, o alfabeto (binário) implica em $l=2$ e a ordem do bloco de construção unitário implica em $k=1$. Assim, reescrevendo a equação (3.18) para o problema de sinais binários, resulta em:

$$
p=-\ln (\alpha)\left(0,5 \sqrt{\pi\left(Q_{\text {indiv }}-1\right)}+1\right)
$$

Neste trabalho, considerou-se $P_{b}=99,9 \%$ como sendo a máxima percentagem de acerto. Além disso, visando evitar tamanhos de população fracionários ou com aumento unitário, derivou-se uma população de tamanho inteiro com crescimento considerando multiplicidade de 10 indivíduos ${ }^{8}$. Reescrevendo a equação (3.19), resulta em:

$$
p=10 \cdot\left\lfloor\frac{-\ln (1-0,999)\left(0,5 \sqrt{\pi\left(Q_{\text {indiv }}-1\right)}+1\right)}{10}\right\rfloor
$$

Manipulando os valores, resulta em uma expressão geral dada por:

$$
p=10 \cdot\left\lfloor 0,3454\left(\sqrt{\pi\left(Q_{\text {indiv }}-1\right)}+2\right)\right\rfloor
$$

onde o operador $\lfloor x\rfloor$ retorna o maior inteiro inferior a $x$.

A figura 3.1 sintetiza o comportamento da equação (3.19) para diversos valores de $P_{b}$ e $Q_{\text {indiv }}$, bem como o tamanho da população obtido via equação (3.21). Observa-se que a adoção da equação (3.21) garante uma confiabilidade acima dos $99 \%$ para qualquer valor de $Q_{i n d i v}$ e entre $99,7 \%$ à $99,9 \%$ para $Q_{i n d i v}>60$.

Logicamente, o tamanho do indivíduo $\left(Q_{\text {indiv }}\right)$ para o problema $\mathrm{MuD}$ é diferente do tamanho do indivíduo para o problema da estimativa de parâmetro com codificação binária. Para o problema MuD, o tamanho do indivíduo candidato é dado pelo número de usuários virtuais multiplicado pelo número de bits transmitidos, ou seja:

$$
Q_{\text {indiv }}=m \cdot k=K_{v} I
$$

\footnotetext{
${ }^{8} \mathrm{O}$ uso da multiplicidade visa facilitar a implementação das etapas de reprodução que atuarão somente com tamanho de populações inteiras e facilmente fracionadas pelos operadores genéticos.
} 


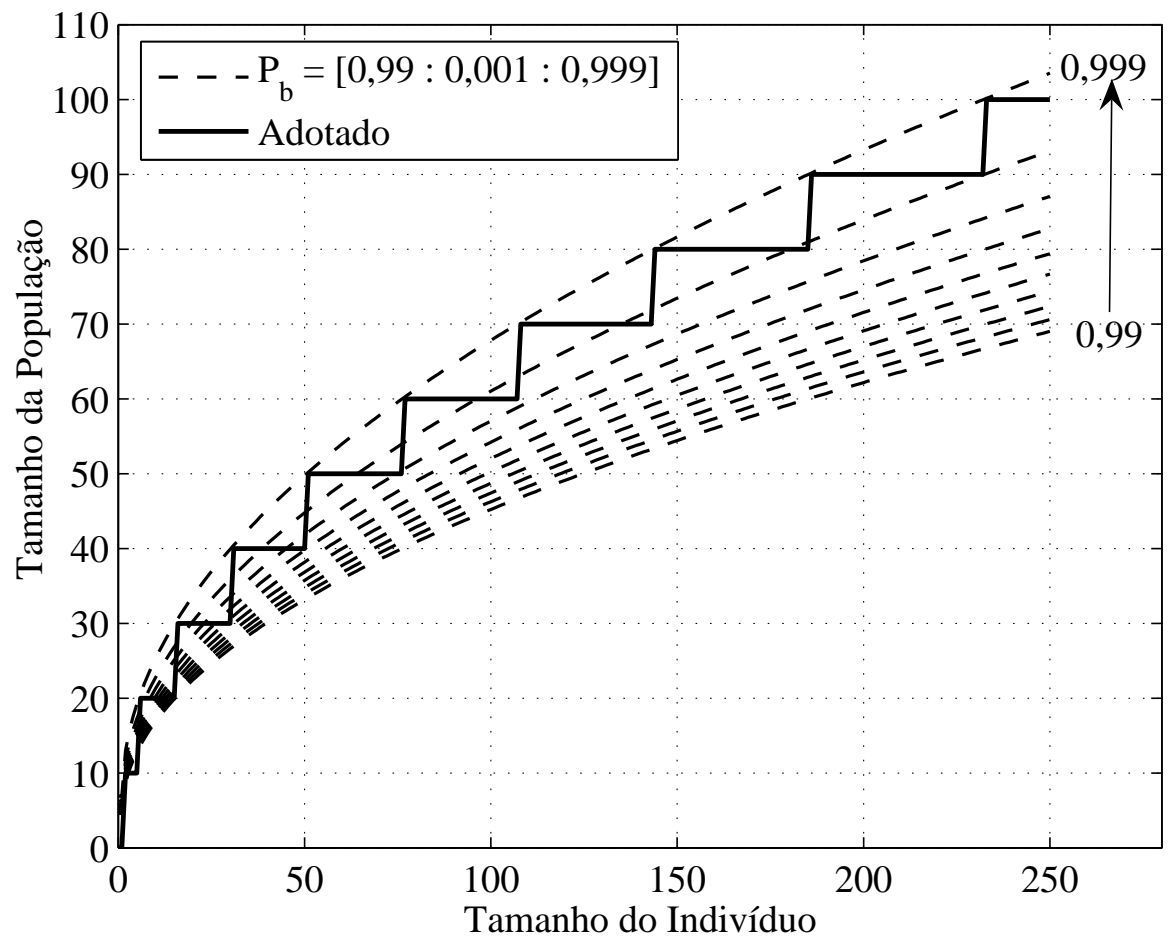

Figura 3.1: Equação (3.19) e equação (3.21) para os intervalos de confiança $\left(P_{b}\right)$ iniciando em 0,99 até 0,999 com incremento de 0,001 e tamanhos de população entre 1 e 250 indivíduos.

Já para o problema da estimativa de parâmetros, o tamanho do indivíduo depende do tipo de codificação adotado, resultando em:

- Codificação tipo I:

$$
Q_{\text {indiv }}=2 K L\left(Q_{\text {int }}+Q_{\text {frac }}\right)
$$

- Codificação tipo II:

$$
Q_{\text {indiv }}=4 K L Q_{\text {int }}
$$

- Codificação tipo III:

$$
Q_{\text {indiv }}=2 K L\left(Q_{\mathrm{abs}}+Q_{\mathrm{phs}}\right)
$$

\subsubsection{Inicialização da População}

Em muitas aplicações dos algoritmos evolucionários é comum a inicialização da população ser feita escolhendo-se aleatoriamente indivíduos no espaço de soluções. Este procedimento é geralmente adotado em problemas onde não se tem nenhum conhecimento sobre uma região atrativa do universo de busca ou não esteja disponível previamente nenhuma solução que já esteja próxima da solução global. 
Para o problema da detecção multiusuário, adotam-se as estimativas obtidas à saída do detector convencional (Rake) como solução prévia para o caso de otimização apresentado na seção 2.3.2, equação (2.75). Esta é utilizada como o indivíduo inicial da população, sendo que os outros membros da primeira população podem ser gerados aleatoriamente ou obtidos a partir do indivíduo inicial com perturbações convenientes (ver seção 3.3.5.2) (YEN; HANZO, 2000, 2001; WU et al., 2003; CIRIACO; ABRÃO; JESZENSKY, 2004; ABRÃO; CIRIACO; JESZENSKY, 2004; YEN; HANZO, 2004). É comum também encontrar na literatura trabalhos que utilizam outros detectores, diferentes do convencional, como estimativa inicial para o algoritmo evolucionário. Esta estratégia diminui o número de gerações do algoritmo evolucionário para se alcançar a solução global, mas em contrapartida, estes detectores normalmente tem uma complexidade alta, não trazendo ganho na redução global da complexidade do sistema (WU et al., 2003; DONG et al., 2004).

Neste trabalho utilizou-se a saída do detector convencional como estimativa inicial para o algoritmo evolucionário:

$$
\mathcal{B}^{(1)}=\left[\hat{\mathbf{b}}^{(0)^{T}}, \hat{\mathbf{b}}^{(1)^{T}}, \ldots, \hat{\mathbf{b}}^{(I-1)^{T}}\right]^{T}
$$

onde a partir da equação $(2.75)$ tem-se $\hat{\mathbf{b}}_{k, g}^{(i)}=\operatorname{sgn}\left(\hat{\mathbf{y}}_{k, g}^{(i)}\right)$, sendo este a saída do receptor Rake MRC.

Os outros membros são obtidos através do indivíduo inicial $\left(\mathcal{B}_{1}\right)$ com perturbações do tipo:

$$
\mathcal{B}^{(j)}=\mathcal{B}^{(1)}+\mathcal{N}\left(0, \sigma^{2}\right)
$$

onde $j=2,3, \ldots, p$ e $\mathcal{N}\left(0, \sigma^{2}\right)$ representa um processo aleatório Gaussiano com média 0 e variância $\sigma^{2}$. Este processo é denominado mutação, sendo descrito na seção 3.3.5.2.

Portanto, a matriz de indivíduos que forma a primeira população no algoritmo heurístico evolucionário é dada por:

$$
\mathcal{B}=\left[\mathcal{B}^{(1)} \mathcal{B}^{(2)} \ldots \mathcal{B}^{(p)}\right]
$$

Já a primeira população para o problema das estimativas da resposta do canal no primeiro intervalo de bit, dimensão $Q_{\text {indiv }} \times p$, é obtida aleatoriamente:

$$
\underline{\breve{\mathbf{Z}}}=\left[\underline{\breve{\mathbf{z}}}_{1} \underline{\breve{\mathbf{z}}}_{2} \underline{\breve{\mathbf{z}}}_{3} \ldots \underline{\breve{\mathbf{z}}}_{p}\right]
$$

No entanto, a partir do segundo intervalo de bit, o primeiro indivíduo da população $\underline{\breve{z}}^{(m)}$ consiste do melhor indivíduo encontrado na otimização do bit 
anterior, ou seja:

$$
\underline{\breve{\mathbf{z}}}_{1}^{(m)}=\underline{\hat{\mathbf{z}}}_{G A}^{(m-1)}
$$

Os outros $p-1$ indivíduos da primeira população são então gerados aleatoriamente.

\subsubsection{Medida de Aptidão}

Deve-se encontrar um valor associado ao desempenho para cada indivíduo candidato através de uma função custo (medida de aptidão). A avaliação deste valor associado ao desempenho é o resultado mais importante no procedimento dos algoritmos evolucionários.

A aptidão é uma característica intrínseca ao indivíduo. Esta indicará, em nível biológico, qual é a habilidade que um determinado indivíduo possui para sobreviver a predadores, pestes e a outros obstáculos para a subsequente reprodução. Transportando para o procedimento matemático no algoritmo, representa a habilidade do indivíduo em produzir a melhor solução.

Utilizou-se para o contexto da detecção $\mathrm{MuD}$, a medida de aptidão obtida através da função LLF, equação (2.86), sendo diretamente responsável pela morte ou vida dos indivíduos (VERDÚ, 1998). Já para a estimativa de parâmetros, a medida de aptidão é obtida através da equação (2.147), sendo também responsável pela morte ou vida dos indivíduos (YEN; HANZO, 2001).

\subsubsection{Reprodução}

A reprodução em um algoritmo evolucionário é o processo no qual os indivíduos, ou vetores candidatos, transferem suas características (material genético) para a próxima geração de acordo com os valores dados pela função custo. Os indivíduos com elevados valores de aptidão possuem maior probabilidade de formar a próxima geração. Este operador é um modelo artificial da seleção natural.

\subsubsection{Tamanho do Poço de Cruzamento (Mating Pool Size)}

Geralmente, os algoritmos evolucionários consideram todos os indivíduos como possíveis genitores da próxima geração. Desta forma, mesmo considerando um modelo de seleção natural baseado na probabilidade de um indivíduo se tornar genitor considerando os valores de aptidão, existe uma probabilidade de escolha de genitores com valores pequenos de aptidão, acarretando no repasse de caracte- 
rísticas não desejáveis para sua progênie. Mesmo assim, a maioria dos trabalhos que utilizam algoritmos evolucionários consideram a população de genitores como sendo todos os indivíduos existentes no momento.

Uma abordagem alternativa consiste em separar apenas os indivíduos que apresentam maiores valores de aptidão e somente estes irão produzir descendentes $^{9}$. Os escolhidos pelas características genéticas, ou seja, com maiores valores de aptidão, são então colocados em uma piscina de acasalamento, mais conhecida como poço de cruzamento, e somente estes indivíduos formam a próxima geração.

O tamanho do poço de cruzamento $(M)$ controla a pressão no processo de competição entre os indivíduos. Ao se escolher um $M$ pequeno, certamente os melhores genitores (parents) serão selecionados; no entanto, haverá uma diminuição na diversificação do universo de busca, podendo-se encontrar uma solução local. Utilizando um $M$ grande, genitores com uma aptidão pequena serão selecionados e suas características ruins serão mantidas nas próximas gerações, trazendo lentidão na convergência (MITCHELL, 1998; YEN; HANZO, 2004).

Deve-se utilizar um valor de $M$ que garanta velocidade na convergência e qualidade na solução encontrada. O tamanho do poço de cruzamento deve estar na faixa $2 \leq M \leq p$. Em trabalhos anteriores, considerando o problema da deteç̧ão $\mathrm{MuD}$, adotou-se $M=0,1 p$ e para o problema da estimativa de parâmetros, adotou-se $M=0,2 Q_{\text {indiv }}$. Isso é perfeitamente aceitável, pois o tamanho da população é proporcional ao tamanho do indivíduo.

Uma análise criteriosa a respeito das características da escolha ótima do poço de cruzamento, exploração e pressão, considerando o universo de busca, é apresentada no capítulo 4.

\subsubsection{Método de Seleção}

Após ter sido determinado o tamanho do poço de cruzamento, deve-se escolher a estratégia de seleção. O processo de seleção determina como os genitores são escolhidos para formar a próxima geração e quantos descendentes cada genitor irá produzir.

A proposta da seleção é privilegiar os melhores genitores na esperança de que seus descendentes possuam melhores valores de aptidão. Deve-se escolher uma estratégia de seleção que seja bem ajustada aos operadores de mutação, de crossover ou outro para um algoritmo evolucionário, visando obter um balanço

\footnotetext{
${ }^{9}$ Esta prática é muito utilizada na criação de gado e outros animais, onde o novo rebanho é descendente de poucos genitores com melhores características.
} 
adequado entre exploração e aproveitamento.

Uma das formas mais tradicionais de seleção utilizada para os evolucionários, proposto originalmente em (HOLLAND, 1975) para o algoritmo genético, seleciona os genitores proporcionalmente ao valor da aptidão medido pela função custo.

O método mais conhecido para implementar a seleção proporcional é denominado de roleta circular (roulette wheel), onde cada indivíduo é representando por uma parte (segmento ou área parcial) da roleta circular e o tamanho desse segmento é proporcional à sua medida de aptidão. A roleta é girada $M T$ vezes. A cada rodada, o indivíduo que cair sobre a marca da roleta é selecionado para ser um genitor da próxima geração. Este método pode ser implementado em três passos, descritos a seguir:

1. Soma-se os valores de aptidão para todos os membros da população:

$$
\kappa_{M}=\sum_{i=1}^{p} \Omega(i)
$$

2. Gera-se um número aleatório $x$ uniformemente distribuído em $\left[0, \kappa_{M}\right]$.

3. Seleciona-se o $k$-ésimo membro que satisfaz:

$$
\sum_{i=1}^{k} \kappa(i) \geq x
$$

Este método prioriza indivíduos que possuem maiores valores associados à função custo, pois suas probabilidades de seleção são proporcionais às suas respectivas aptidões, correspondendo a uma maior área na roleta.

Outra estratégia é baseada no método de seleção utilizado no algoritmo de programação evolucionária (EP - Evolutionary Programming), sendo mais simples que a estratégia da roleta circular, pois escolhem-se apenas os $M$ melhores indivíduos da população $p$ para serem os genitores da próxima geração (FOGEL, 1994). Os $M$ indivíduos com maiores valores de aptidão são selecionados para serem os genitores da próxima geração. Já os $p-M$ indivíduos com menores valores de aptidão são removidos. Esta estratégia de seleção será denominada, daqui para frente, de seleção $p$-sort.

Pode-se citar vários outros métodos conhecidos na literatura para seleção dos indivíduos, como o método do torneio, onde $p / k$ grupos com $k$ indivíduos cada são sorteados aleatoriamente e posteriormente apenas o melhor indivíduo de cada uma dos $p / k$ grupos é escolhido como genitor da próxima geração. Outros métodos podem ser considerados, como o método de seleção por ranking. 
No entanto, resultados prévios considerando uma comparação justa entre as duas estratégias de seleção, aplicadas ao problema da deteç̧ão $\mathrm{MuD}$ foi realizada anteriormente. Estes resultados de convergência indicaram superioridade da estratégia de seleção $p$-sort sobre a estratégia de roleta circular. Desta forma, o capítulo 4 apresenta uma análise para estes métodos para verificação da melhor estratégia a ser utilizada.

\subsubsection{Operadores Genéticos}

Uma importante decisão para a implementação de um algoritmo evolucionário é a escolha de quais operadores genéticos utilizar, sendo altamente afetada pelo tipo de problema a ser solucionado.

Os operadores genéticos são necessários para que a população se diversifique e mantenha características de adaptação adquiridas nas gerações anteriores. Estes transformam a população através de sucessivas gerações, estendendo a busca até chegar a um resultado satisfatório.

O algoritmo genético utiliza o operador crossover como seu principal operador genético no intuito de trazer variabilidade de busca sem perder as características de adaptação adquiridas. A mutação acarreta em um percentual pequeno de variação, pois em uma população real a taxa de mutação é muito baixa, fazendo com que a mutação seja um mecanismo secundário no processo de adaptação dos algoritmos genéticos.

Para o algoritmo EP, o único operador genético (além da seleção) é a mutação, não existindo crossover. Esta é uma das maiores diferenças, senão a maior, entre os algoritmos GA e EP. Outros algoritmos, como o EP-C (programação evolucionária com clonagem) e o Clonalg (Clonagem Seletiva) consideram o operador de clonagem como o operador principal, possuindo ainda, o operador de mutação.

\subsubsection{Operador Crossover}

Como dito anteriormente, o operador crossover é um operador que combina subpartes de dois genitores com a finalidade de produzir descendentes que apresentem material genético de ambos. Para muitos estudiosos da área, o fator determinante que distingue o algoritmo GA dos demais algoritmos de otimização é a utilização exclusiva do operador crossover no algoritmo GA.

Na literatura, encontram-se inúmeras variações para a implementação do ope- 
rador crossover, sendo o crossover ponto-simples (single-point crossover), o crossover multi-ponto (multi-point crossover), o crossover uniforme (uniform crossover) e o crossover baseado em maioria os mais conhecidos e utilizados. Neste trabalho, devido a estudos preliminares, optou-se pelo uso do operador crossover uniforme. No entanto, é apresentada no capítulo 4 uma análise dos tipos de operadores de crossover e o respectivo desempenho.

Para o crossover uniforme, cada gene (locus) é considerado como um ponto em potencial para que seja possível ocorrer a troca genética, que é controlado pela chamada máscara de crossover (crossover mask) (MITCHELL, 1998). A máscara de crossover é uma sequência que consiste de um vetor de bits aleatórios ("1" e "0") com o mesmo tamanho dos indivíduos, onde a cada posição, correspondente a cada bit dos indivíduos, é realizada a troca quando a máscara de crossover possuir valor "1" para aquela posição. Se a máscara possuir valor "0" na posição, não há troca de bits. Uma ilustração do processo de crossover uniforme é apresentada na figura 3.2 .

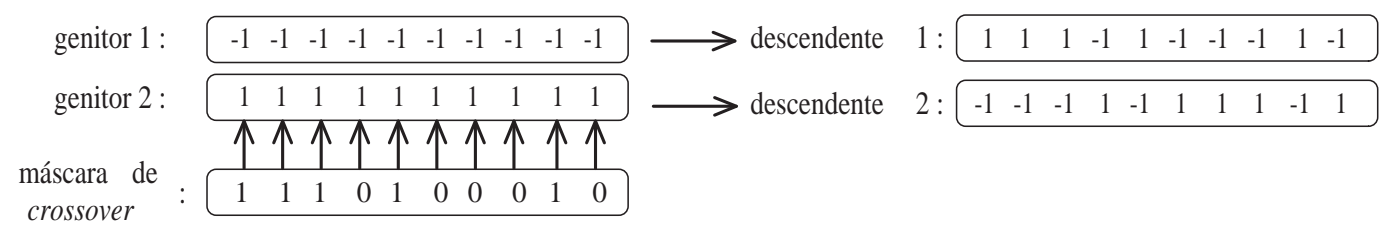

Figura 3.2: Operador crossover uniforme.

Durante a permuta de material genético entre os indivíduos, haverá uma tendência da transmissão das características dominantes para as gerações futuras. Após algumas gerações, pode-se observar que uma elevada percentagem de indivíduos apresenta variáveis (características) "dominantes". O percentual deste sorteio pode ser variado, pois apenas quando o valor "1" é sorteado ocorrerá a troca. Desta forma, pode-se variar o percentual do sorteio entre $0 \%$ e 100\%. A maioria dos trabalhos na literatura utilizam um percentual de $50 \%$, sendo utilizado neste trabalho.

Para a estratégia de crossover de um ponto ou multipontos utiliza-se dois indivíduos genitores, com o objetivo de formar novos indivíduos a partir da troca de genes entre os indivíduos genitores. O ponto de crossover tipicamente é escolhido de forma aleatória e de uma quantidade arbitrária definida no processo de inicialização do algoritmo. A figura 3.3 apresenta a troca genética causada por um operador de apenas um ponto. Vale ressaltar que a estratégia multiponto considera um número mais elevado de pontos de ocorrência de crossover. 


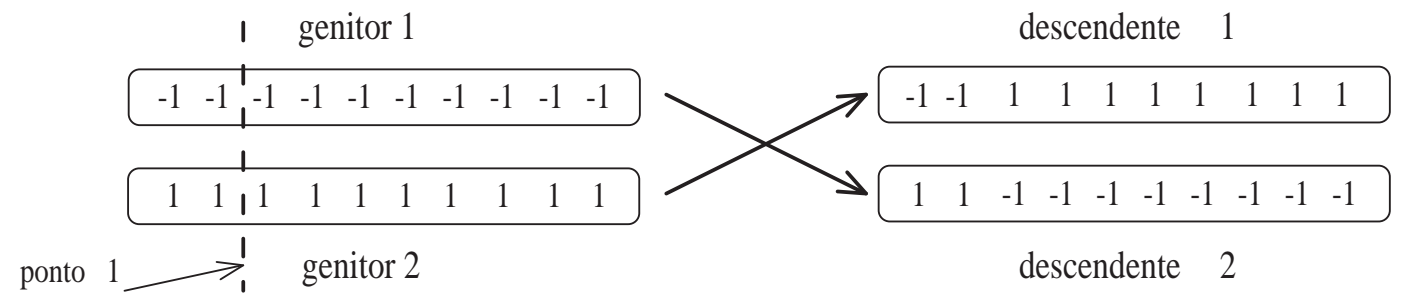

Figura 3.3: Exemplo de operador crossover uniponto.

Observa-se, no capítulo 4, resultados de desempenho considerando as diferentes técnicas de crossover, indicando a de maior desempenho em termos de convergência e complexidade de realização. Vale ressaltar que este parâmetro afeta significativamente o desempenho do GA, pois trata-se do principal operador genético para este algoritmo.

\subsubsection{Operador Mutação}

O operador mutação consiste em alterar características dos indivíduos. Este procedimento é necessário para a introdução e manutenção da diversidade genética na população, alterando arbitrariamente um ou mais componentes de uma estrutura escolhida, fornecendo assim meios para a introdução de novos elementos na população. Desta forma, a mutação assegura que a probabilidade de se chegar a qualquer ponto do espaço de busca nunca será zero.

Uma maneira de se implementar a mutação é a geração de uma perturbação (ruído), que será adicionada a cada gene. No caso de alfabeto binário bipolarizado, -1 e +1, quando a perturbação for pequena, não haverá mudança (mutação) do gene (LIM; VENKATESH, 2003; CIRIACO; ABRÃO; JESZENSKY, 2004; ABRÃO; CIRIACO; JESZENSKY, 2004). No entanto, quando a perturbação for grande o suficiente para trocar o sinal do gene, ocorrerá mutação. Este ruído pode ser escolhido seguindo uma distribuição estatística específica. Neste trabalho, adotou-se uma distribuição Gaussiana:

$$
\text { novo }_{\text {individuo }}=\operatorname{sgn}\left(\text { individuo }+\mathcal{N}\left(0, \sigma^{2}\right)\right)
$$

onde $\mathcal{N}\left(0, \sigma^{2}\right)$ é definida como na equação (3.27). A variância deste processo $\left(\sigma^{2}\right)$ está intimamente ligada à taxa média de mutação. No caso binário bipolarizado, essa variância representará uma taxa média de mutação seguindo a figura 3.4. A figura 3.4 apresenta a taxa média e máxima de mutação em relação à variância. Para cada problema escolheu-se uma variância que correspondesse a uma taxa de mutação média adequada. 


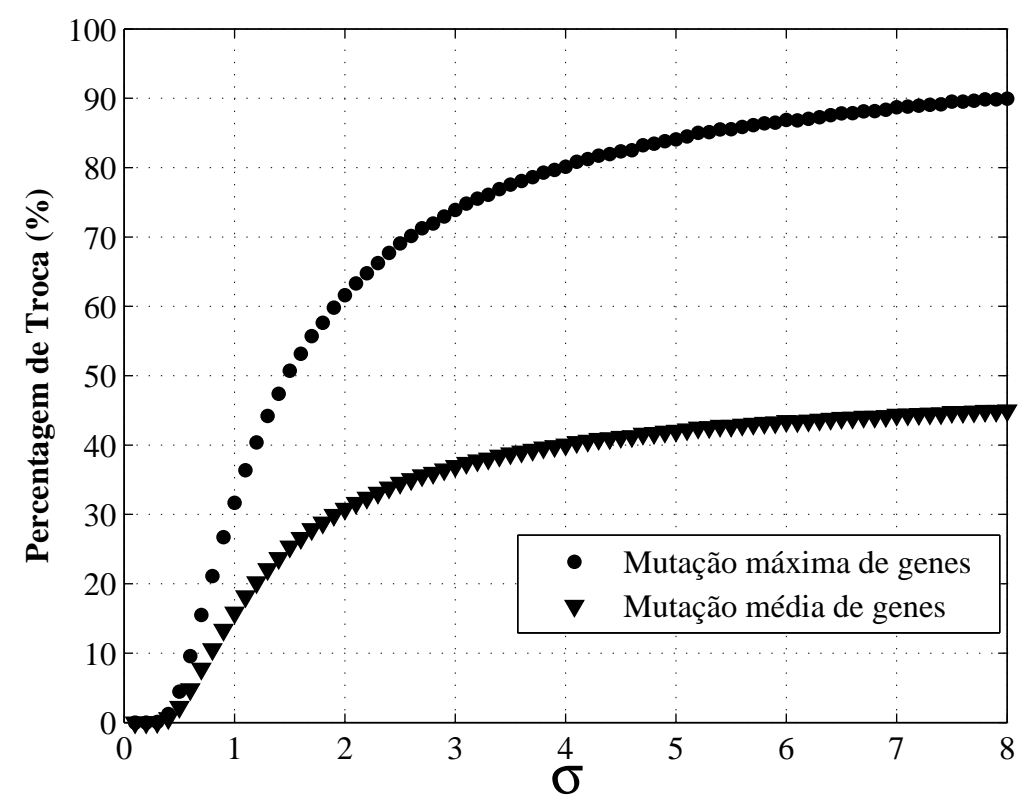

Figura 3.4: Taxa de mudança dos bits em função do desvio padrão escolhido.

A figura 3.5 apresenta o operador mutação para um alfabeto binário bipolarizado. Fica evidente que a mutação pode ocorrer em um ou mais pontos, ou ainda não ocorrer em nenhum, devido à natureza estocástica do processo.

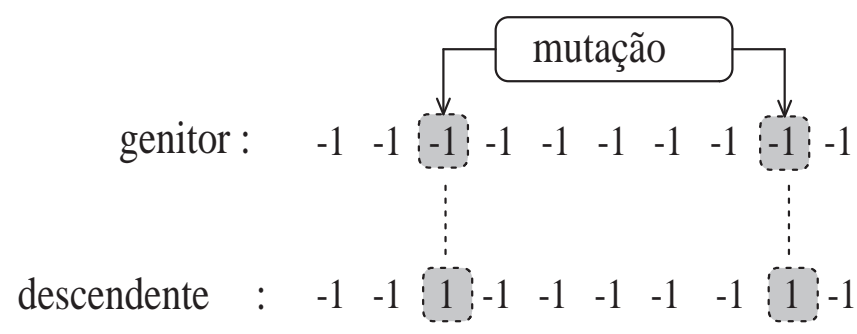

Figura 3.5: Mutação aleatória baseada no desvio padrão da figura 3.4.

No entanto, existem outras formas de implementação do operador mutação, como a mutação dirigida, onde adota-se um percentual determinístico de mutação a ser realizado e este é aplicado a cada geração. Desta forma, considerando um indivíduo de tamanho $Q_{\text {indiv }}$, pode-se realizar a mutação em uma parcela de seus genes, como por exemplo 5\%. Ou mesmo estratégias baseadas no tamanho do indivíduo, onde a mutação deve ocorrer em por exemplo $1 / Q_{\text {indiv }} \%$, ou seja, em um gene. Para cada problema deve-se considerar ajustes na forma e nos valores dos parâmetros, pois os valores e estratégias ótimas não são conhecidas. Este trabalho visa a determinação da escolha destes parâmetros através de uma análise sistemática realizada no capítulo 4.

Outros operadores podem ser encontrados na literatura, como o operador de 
intensificação clonagem (CIRIACO; ABRÃO; JESZENSKY, 2004; ABRÃO; CIRIACO; JESZENSKY, 2004) e aqueles que possuem estratégias adaptativas para a mutação e crossover (VASCONCELOS et al., 2001; CIRIACO; ABRÃO; JESZENSKY, 2004), específicas para cada tipo de otimização.

O operador de clonagem consiste no repasse das características genéticas do genitor de forma idêntica para sua progênie. A primeira vista isso não parece muito apropriado, pois a função aptidão já foi calculada sobre este genitor, não trazendo variabilidade genética. No entanto, os algoritmos que utilizam esta estratégia geralmente utilizam grandes percentuais de mutação, pois assim, as características podem ser alteradas. Assim, a maioria das boas características serão mantidas, garantindo certo compromisso entre exploração e pressão na busca. Novamente, estratégias adicionais e escolha dos valores percentuais ótimos são analisadas e apresentadas no capítulo 4 uma comparação entre as técnicas.

\subsubsection{Estratégias de Reposição}

Estratégias de reposição procuram estabelecer uma regra biológica de composição de indivíduos visando a próxima geração, determinando o número máximo de indivíduos suportado no espaço físico em populações reais. Em termos da descrição matemática, estratégias de reposição correspondem à determinação do número de vetores candidatos a serem mantidos na próxima geração.

Muitos autores consideram a etapa de reposição como parte da etapa de seleção; no entanto, podem ser identificadas as seguintes estratégias: a estratégia elitista (elitism), a estratégia de estado permanente (steady-state) e a estratégia $(\mu+\lambda)$. A primeira força o algoritmo evolucionário a reter alguns dos melhores indivíduos a cada geração. Esses indivíduos serão perdidos caso não sejam selecionados para a etapa de reprodução ou se forem destruídos pela mutação e crossover. Nessa estratégia, sucessivas gerações são sobrepostas, i.e., alguma parte da geração precedente é retida para a nova população. Na estratégia de estado permanente, apenas poucos indivíduos são trocados a cada geração; usualmente um número pequeno dos piores indivíduos são trocados pelos descendentes resultantes do processo de crossover e mutação dos melhores genitores (JONG, 1975; MITCHELL, 1998).

Resultados preliminares utilizaram a estratégia de reposição denominada de $(\mu+\lambda)$, ou de forma equivalente, de elitismo global, onde são mantidos para a próxima geração apenas os melhores $\mu$ indivíduos oriundos da população conjunta 
dos genitores e descendentes ${ }^{10}$.

Novamente análises adicionais foram realizadas, pois a escolha de estratégias eficientes de reposição garantem qualidade nos resultados obtidos e estabilidade ao algoritmo no sentido de sempre produzir soluções interessantes, sendo apresentadas no capítulo 4.

\subsubsection{Critério de Parada}

Existem basicamente três formas de se finalizar a etapa de busca em algoritmos evolucionários. Pode-se finalizar a busca do algoritmo após:

1. executar um número fixo de gerações,

2. atingir um limiar,

3. após um tempo pré-determinado.

Dependendo da natureza do problema, um dos critérios de parada acima pode se mostrar mais adequado que os demais. Para as duas classes de problemas tratados neste trabalho, $\mathrm{MuD}$ e $\mathrm{MuChE}$, o critério inicial de parada adotado foi o mesmo utilizado comumente na literatura, que consiste em finalizar a busca após a execução de um número fixo de gerações $\left(G_{t}\right)$. No entanto, para o problema $\mathrm{MuChE}$ o vetor obtido está na forma binária e, deve ser convertido, após $G_{t}$ gerações, para a forma analógica (número complexo). Isso é realizado pela utilização de um conversor Digital/Analógico, sendo descrito como o processo inverso do operador $\mathrm{ADC}[\cdot]$; neste caso, para cada tipo de codificação, tem-se:

- Codificação tipo I:

$$
\hat{\mathbf{z}}_{G A}^{(m)}=\mathrm{DAC}\left[\underline{\underline{\mathbf{z}}}_{\text {best }}^{(m)}\right]_{Q_{\text {int }}, Q_{\text {frac }}}
$$

- Codificação tipo II:

$$
\hat{\mathbf{z}}_{G A}^{(m)}=\mathrm{DAC}\left[\underline{\breve{\mathbf{z}}}_{\mathrm{best}}^{(m)}\right]_{Q_{\mathrm{int}}, Q_{\mathrm{int}}}
$$

- Codificação tipo III:

$$
\hat{\mathbf{z}}_{G A}^{(m)}=\mathrm{DAC}\left[\underline{\underline{\underline{z}}}_{\text {best }}^{(m)}\right]_{Q_{\mathrm{abs}}, Q_{\mathrm{phs}}}
$$

Vale ressaltar que o número de gerações suficientes para garantir bons resultados não é conhecida previamente e deve ser ajustado conforme o problema.

\footnotetext{
${ }^{10}$ Os resultados preliminares utilizaram o parâmetro $\mu=p$ como métrica inicial, ou seja, metade da população conjunta $2 p$, com os melhores pais e filhos, sobrevive.
} 


\subsubsection{Descrição sucinta dos Algoritmos Evolucionários}

Todos os algoritmos evolucionários devem considerar as etapas e critérios descritos anteriormente. No entanto, estes diferem um pouco na nomenclatura e estratégias de varredura de busca no espaço de soluções. Desta forma, optou-se por descrever sucintamente cada um deles e quais as teorias que os originaram. Posteriormente, serão apresentados os seus pseudocódigos, evidenciando as etapas distintas.

\subsubsection{Algoritmo Genético (GA)}

A teoria do algoritmo GA é baseada na evolução natural. Este algoritmo procura descrever as interações biológicas existentes entre as células de um organismo, alterando o genótipo na etapa de transferência do material genético. Neste caso, por se tratar de reprodução de células, os operadores genéticos mutação e crossover são utilizados como estratégias de diversificação e intensificação, respectivamente (ERGUN; HACIOGLU, 2000; YEN; HANZO, 2000).

O operador crossover visa criar novos indivíduos que contém características mescladas em relação à geração que o precedeu, sendo que este processo ocorre com uma alta probabilidade, $p_{c}$. No algoritmo GA a percentagem de mutação, $p_{m}$, é geralmente inferior que a do EP.

\subsubsection{Programação Evolucionária (EP)}

O algoritmo heurístico EP descreve as interações biológicas que ocorrem entre os indivíduos de uma população, utilizando apenas o operador genético mutação na diversificação do universo de busca. Este operador, neste caso, atua no sentido de alterar uma característica fenotípica do genitor na etapa de transferência do material genético, reprodução, que será transmitida a um novo indivíduo.

Por utilizar apenas o operador de mutação como critério de diversificação e nenhum critério de intensificação, este algoritmo possui a menor complexidade computacional por geração (FOGEL, 1994; LIM et al., 2003). Mas sua convergência é mais lenta, sendo necessárias gerações extras para se atingir o desempenho desejado. 


\subsubsection{Programação Evolucionária com Clonagem (EP-C)}

Este algoritmo é baseado na mesma teoria do algoritmo EP, porém aqui são aplicadas as estratégias de intensificação e diversificação, a clonagem (descrita anteriormente) e a mutação, conforme figura 3.4 (ABRÃO; CIRIACO; JESZENSKY, 2004).

Na obtenção da taxa de mutação otimizada, analisou-se a percentagem de troca dos genes na etapa de reprodução na g-ésima geração do algoritmo EP em função do desvio padrão total, $\sigma_{E P}$, a qual indicou um comportamento acentuadamente crescente na faixa de $\sigma_{E P} \approx[0,5 ; 2]$, figura 3.4. Otimizações feitas a seguir levaram em consideração este intervalo. Considerou-se esta faixa para $\sigma_{E P}$, uma vez que, valores muito abaixo ou muito acima desta faixa representam ou uma chance remota de troca de genes ou uma chance elevada de troca, respectivamente. No último caso, é computacionalmente menos complexo gerar um novo indivíduo candidato. No primeiro caso, não há evolução (geração sem evolução).

Assim, adotando-se $\sigma_{E P}=[0,5 ; 2]$, verifica-se que a faixa de troca de pico estará confinada ao intervalo $\approx[5 \% ; 60 \%]$, respectivamente. Efetivamente estáse restringindo a probabilidade média de troca do gene na $g$-ésima geração à faixa de $[2,5 \% ; 30 \%]$, garantindo um compromisso entre variabilidade (entropia) e evolução. O capítulo 4 apresenta uma análise da taxa de mutação que resulta no melhor resultado médio, sendo adotado para as demais simulações.

\subsubsection{Algoritmo de Clonagem Seletiva (Clonalg)}

Este algoritmo foi proposto inicialmente por (CASTRO; VON ZUBEN, 2002), sendo baseado na resposta imunológica de um sistema na presença de um antígeno. Quando um antígeno entra em contato com um organismo são produzidos diversos tipos de anticorpos no intuito de combater o antígeno introduzido. Apenas os anticorpos que tiverem maior afinidade com o antígeno são mantidos para as próximas gerações.

Quando este antígeno é novamente colocado em contato com o organismo, a reação a ele se torna mais rápida, pois o antígeno é reconhecido e apenas os melhores anticorpos são utilizados. Quanto mais vezes o organismo for colocado em contato com o antígeno, mais rápido se torna a resposta a ele.

Este algoritmo utiliza o operador mutação como critério de diversificação e o operador clonagem como critério de intensificação. Desta forma, a diferença entre este algoritmo e o algoritmo EP-C está na teoria que os originou e na construção 
das estratégias individuais de mutação e percentuais de clonagem que podem ser implementados de maneiras distintas.

\subsubsection{Pseudocódigos dos Algoritmos Evolucionários}

As arquiteturas (pseudocódigos) para os algoritmos evolucionários aplicados aos problemas $\mathrm{MuD}$ e $\mathrm{MuChE}$ são apresentadas na tabela 3.1. Note-se que a diferença entre as arquiteturas é bem pequena, limitando-se à conversão digital analógica (inexistente no algoritmo para o problema $\mathrm{MuD}$ ) e a equação que rege a medida de aptidão (equação (2.86) e equação (2.147))). Portanto, fica evidente que caso sejam aplicadas as duas técnicas em conjunto, a implementação em DSP das duas estratégias é simplificada.

Além disso, vale ressaltar que a definição de cada estratégia e escolha de parâmetros para as etapas seleção, reprodução e reposição devem ser consideradas pré-estabelecidas. Desta forma, não foram representadas como parâmetros de entrada do algoritmo, pois estas são estabelecidas na construção do algoritmo, sendo analisadas no capítulo 4.

Tabela 3.1: Algoritmos heurísticos para o problema MuD e MuChE.

\begin{tabular}{|l|}
\hline \multicolumn{1}{|c|}{$\mathrm{MuD}$} \\
\hline Entrada: $p, \mathcal{B}_{1}, M, G_{t}$ \\
Saída: $\mathcal{B}_{1}$ \\
Início \\
1. Inicializa a primeira população $\mathcal{B} ;$ \\
2. Cálculo da Aptidão $\Omega(\mathcal{B}) ; g=0 ;$ \\
3. Enquanto $g<G_{t}$ faça; \\
4. $\quad \mathcal{B}_{\text {selected }}=\operatorname{Seleção~}(\mathcal{B}, M) ;$ \\
\hline Se GA \\
5. $\quad \mathcal{B}_{c}=$ Crossover $\left(\mathcal{B}_{\text {selected }}\right) ;$ \\
\hline Se EP-C ou Clonalg \\
5. $\quad \mathcal{B}_{c}=$ Clonagem $\left(\mathcal{B}_{\text {selected }}\right) ;$ \\
\hline $6 . \quad \mathcal{B}_{\text {new }}=\operatorname{Mutação}\left(\mathcal{B}_{c}\right) ;$ \\
7. $\quad$ Cálculo da Aptidão $\Omega(\mathcal{B}) ;$ \\
8. $\quad \mathcal{B}=$ Reposição $\left(\mathcal{B} \cup \mathcal{B}_{\text {new }}\right) ;$ \\
9. fim \\
fim \\
\end{tabular}

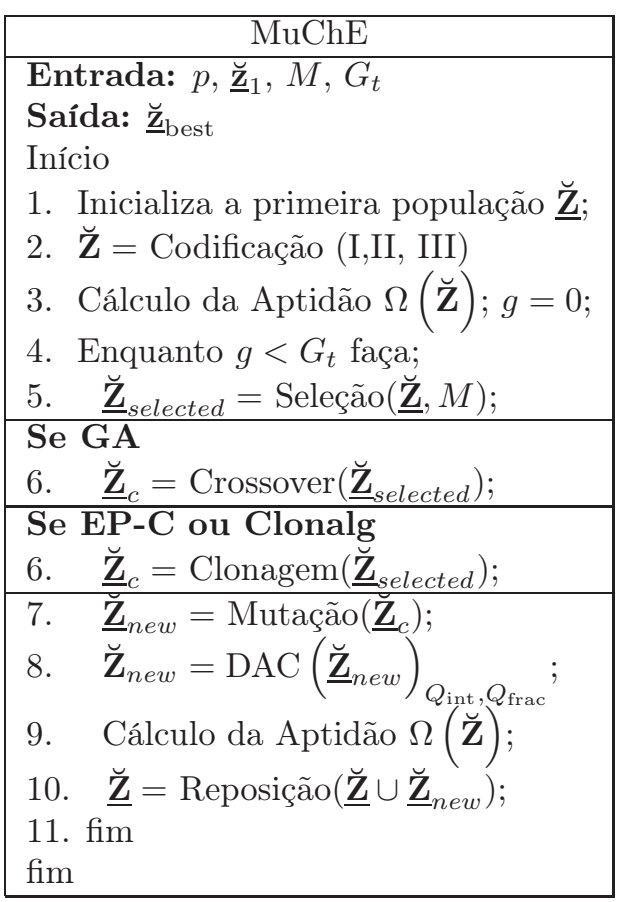

\subsection{Algoritmos de Busca Local}

A estratégia de Busca Local é baseada no princípio mais bem estabelecido existente para métodos de otimização combinatória: tentativa e erro. Esta é uma 
ideia simples e natural, mas que de fato, surpreende pelo grau de sucesso que este método possui nos mais variados tipos de problemas combinatórios.

Para aplicar este método em um problema específico, é necessário realizar algumas escolhas. Primeiro, decidir de que maneira obter e qual será a solução inicial do problema (ou ponto de partida).

A seguir, deve-se escolher uma "boa" vizinhança" para começar a busca no espaço de soluções. Esta escolha é usualmente guiada pela intuição, porque pouquíssimos problemas possuem um guia ou direção. Uma maneira clara de visualização de compromisso é a escolha de pequenas ou grandes vizinhanças ${ }^{12}$.

Pequenas vizinhanças acarretam em uma baixa complexidade do algoritmo, pois o espaço consiste de poucas alternativas. Em contrapartida, podem não proporcionar boas soluções devido a mínimos ou máximos locais nesta região limitada. Grandes vizinhanças, por outro lado, proporcionam boas soluções, mas trazem uma complexidade muito maior, pois podem possuir espaço de busca tão grandes quanto a de métodos de força bruta (PAPADIMITRIOU; STEIGLITZ, 1998; REEVES, 1993; TAN, 2001).

Três ideias podem ser utilizadas para resumir como é se trabalhar com Busca Local:

Quanto tempo, ou espaço de busca, quer-se despender ou varrer?

O que deve ser encontrado, poucas soluções locais "fortes", ou muitas "fracas"?

Onde se encontra a solução ótima, esta é a solução ótima?

Questões como estas e outras são usualmente levantadas, o que torna o estudo de algoritmos de Busca Local uma arte.

Métodos de busca local são muito diferentes dos algoritmos evolucionários, porque aqui, o espaço de busca é vasculhado de forma determinística, trazendo uma restrição no universo de soluções possíveis ao se escolher uma vizinhança. A estratégia heurística está na escolha deste subespaço de busca.

Isto faz com que o algoritmo não consuma uma quantidade excessiva de tempo, caso a vizinhança escolhida não seja muito grande. Mas em compensação, a qualidade das soluções pode não ser satisfatória (soluções locais).

Algoritmos de busca local otimizados devem conciliar as características de

\footnotetext{
${ }^{11}$ No sentido de atratividade.

${ }^{12}$ Relativo à distância de Hamming da solução inicialmente adotada.
} 
garantia de escape de regiões com soluções locais e espaço de busca analisado menor possível.

A garantia de escape de regiões com soluções locais só é possível através de um conhecimento do que se está buscando, ou seja, um conhecimento sobre o comportamento da função custo. A partir deste prévio conhecimento, pode-se criar estratégias eficientes de escape com a manutenção do tamanho do espaço de busca analisado.

\subsubsection{Estratégias de Escape e Deslocamento}

Os algoritmos de Busca Local simples, como é o caso dos algoritmos 1-opt LS e $k$-opt LS, não possuem estratégias de escape universais, ficando a cargo do usuário a criação ou não de possíveis estratégias específicas para o problema analisado.

Já os algoritmos de Busca Local mais complexos, como é o caso dos algoritmos SA, STTS e RTS, possuem estratégias universais de escape que podem ser facilmente adaptadas a qualquer tipo de problema analisado, ao custo de um aumento na complexidade em relação ao algoritmo 1-opt.

Portanto, faz-se necessário um estudo da aplicação destes algoritmos a cada tipo de problema para que se possa determinar o que é melhor; estratégias mais complexas ou menos complexas e qual o algoritmo possui o melhor compromisso complexidade $\times$ qualidade das soluções.

Esta análise é realizada neste trabalho, aplicando algoritmos de busca local ao problema da deteç̧ão multiusuário e estimativa de parâmetros, observando-se a complexidade computacional e a eficiência dos algoritmos na maximização ou minimização da função custo associada, apresentada no capítulo 4 e no capítulo 5 .

Uma característica dos algoritmos de busca local é a existência de duas estratégias para a realização do deslocamento no espaço de busca, sendo conhecidas como estratégia de deslocamento pelo maior ganho e estratégia de deslocamento pelo primeiro ganho.

A estratégia de deslocamento pelo maior ganho utiliza a melhor solução de uma vizinhança como entrada da próxima iteração. Já a estratégia de deslocamento pelo primeiro ganho utiliza a primeira solução que apresentar um maior valor que a solução atual como entrada da próxima iteração.

Neste trabalho, optou-se, de resultados prévios, pela utilização da estratégia 
de deslocamento pelo maior ganho. Além disso, torna-se possível determinar a complexidade computacional teórica das estratégias de otimização.

\subsubsection{Busca Local 1-Ótimo (1-OPT LS)}

O algoritmo 1-opt LS (1-optimum Local Search) é um algoritmo de busca local que procura por uma solução ao redor de uma vizinhança composta por todas as possíveis soluções cuja distância de Hamming é igual a 1 no caso binário ou com alteração de todos os candidatos em apenas uma posição (números reais) e de um valor arbitrário seguindo uma estratégia específica.

Para o caso binário, visando a redução de retornos aos máximos locais, propôsse aqui um procedimento adicional à estratégia de deslocamento do algoritmo 1-opt LS clássica.

No contexto da detecção multiusuário e estimativa de parâmetros binário, o procedimento adicional adotado consiste em não retornar à última solução visitada e tida como a melhor solução, tentando fazer com que o algoritmo não retorne ao último máximo local. Apesar desta estratégia melhorar a taxa de escape de máximos locais, este procedimento adicional não garante que o algoritmo consiga sair de uma região com vários mínimos ou máximos locais, ou que atinja o máximo global.

\subsubsection{Busca Local $k$-Ótimo ( $k$-OPT LS)}

O algoritmo de busca local k-opt LS (k-optimum Local Search), também é um algoritmo de busca local baseado na mesma estratégia que o algoritmo 1-opt LS.

Porém, este algoritmo procura soluções em uma vizinhança maior, cuja distância de Hamming é igual ou menor a $k$. Desta forma, o subespaço de soluções candidatas é obtida segundo a relação $C_{k}^{Q_{\text {indiv }}}$, onde $Q_{\text {indiv }}$ é o tamanho do can$\operatorname{didato}^{13}$.

No caso de implementação de busca local considerando apenas as etapas básicas, este é conhecido como método da subida, ou hill climbing (EDELKAMP; SCHRöDL, 2012).

Na literatura observam-se diversas formas de implementação dos algoritmos de busca local visando minimizar as limitações destes métodos com relação ao

${ }^{13}$ Válido somente para a codificação binária. 
problema de soluções locais e regiões chamadas de platô ${ }^{14}$.

Entre as possíveis implementações, costumam-se fazer alterações aleatórias no espaço de busca, alterando o vetor candidato e consequentemente a vizinhança para verificar se não há estados melhores. Esta estratégia é chamada de reinício aleatório (random restart). Outra estratégia de escape consiste na utilização de uma probabilidade de aceite de soluções inferiores baseada em uma regra estocástica de aumento ou diminuição desta probabilidade (AARTS; LENSTRA, 1996; GOLDBARG; LUNA, 2000).

Este trabalho considera a utilização apenas da estratégia de busca local convencional adicionando o procedimento de não retornar à última solução visitada e tida como a melhor solução. O pseudocódigo para os algoritmos de busca local 1-opt LS e $k$-opt LS aplicados aos problemas MuD e MuChE são apresentados na tabela 3.2 .

Tabela 3.2: Algoritmos heurísticos de Busca Local para o problema MuD e $\mathrm{MuChE}$.

\begin{tabular}{l}
\hline \multicolumn{1}{|c|}{ MuD } \\
\hline Entrada: $\mathcal{B}_{1}, k$ \\
Saída: $\mathcal{B}_{1}$ \\
Início \\
1. Inicializa a busca local com $t=1$ \\
1.a $\quad \mathcal{B}^{\text {best }}=\mathcal{B}_{1} ;$ \\
2. Para $t=1,2, \ldots ;$ \\
2.a $\breve{\mathcal{B}}=$ Vizinhança $\left(\mathcal{B}^{\text {best }}, k\right) ;$ \\
2.b Cálculo da Função Custo $\Omega(\breve{\mathcal{B}}) ;$ \\
2.c Se $\exists \breve{\mathcal{B}}_{i}$ onde $\Omega\left(\breve{\mathcal{B}}_{i}\right)>\Omega\left(\mathcal{B}^{\text {best }}\right) ;$ \\
$\quad \mathcal{B}^{\text {best }}=\breve{\mathcal{B}}_{i}$ \\
Caso contrário, \\
$\quad$ Ir para passo $4 ;$ \\
3. fim; \\
4. $\mathcal{B}_{1}=\mathcal{B}^{\text {best }} ;$ \\
fim
\end{tabular}

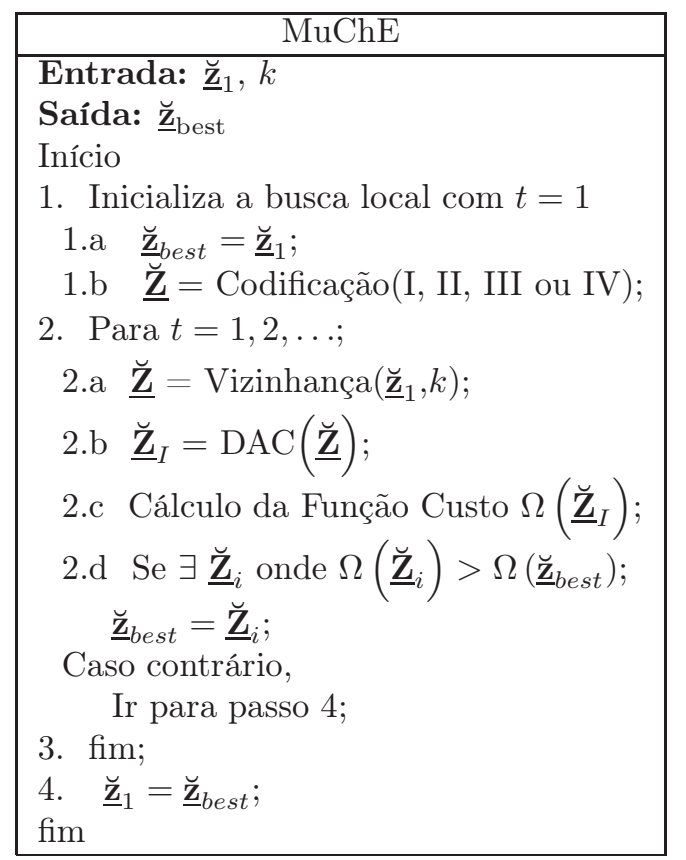

\subsubsection{Recozimento Simulado SA}

O algoritmo de recozimento simulado proposto por Kirkpatrick (KIRKPATRICK; GELLAT; VECCHI, 1983) foi inspirado no processo de recozimento (annealing) de sistemas físicos. Este foi baseado no algoritmo originalmente proposto por Metropolis (METROPOLIS et al., 1953) como uma estratégia de determinação de estados (configurações) de equilíbrio de uma coleção de átomos a uma dada

\footnotetext{
${ }^{14}$ Diversos candidatos que apresentam a mesma medida de maximização ou minimização.
} 
temperatura. A ideia básica têm suas origens na termodinâmica estatística, ramo da física responsável por apresentar predições teóricas sobre o comportamento de sistemas macroscópicos baseados nas leis que governam seus átomos. Utilizando analogia, propuseram o algoritmo através da semelhança entre o procedimento de recozimento estudado com o algoritmo de Metropolis e processos de otimização combinatória.

Com isso, o algoritmo de recozimento simulado foi desenvolvido baseado em um procedimento utilizado para levar um material a seu estado de equilíbrio máximo, ou seja, a um estado de energia mínima. De forma lúdica, um determinado material é inicialmente aquecido a uma alta temperatura, de forma que ele derreta e seus átomos possam se mover com relativa liberdade. Após, a temperatura desta substância derretida é lentamente reduzida de forma que, a cada temperatura, os átomos possam se mover o suficiente para adotarem uma orientação mais estável.

Se a substância derretida for resfriada apropriadamente, seus átomos serão capazes de atingir um estado de equilíbrio máximo (energia mínima), produzindo um cristal. Caso contrário, um vidro ou outra substância (quebradiça) semelhante será produzida.

Assim, o conceito do algoritmo SA (Simulated Annealing) está associado ao princípio da termodinâmica, onde um sólido aquecido a uma temperatura muito alta e depois resfriado gradualmente, tenderá a se solidificar de modo a formar uma estrutura de menor energia possível (KIRKPATRICK; GELLAT; VECCHI, 1983; CERNY, 1985a; TAN, 2001).

Para escapar de soluções locais, o SA utiliza uma função de probabilidade de aceitação, proporcional à temperatura, podendo então aceitar uma solução particular que possui um menor valor de energia. Isto possibilita que o algoritmo saia de uma região de solução local e procure pela solução global em outras regiões. Ao longo das iterações, a temperatura sofre decréscimo baseado geralmente na função de distribuição de Boltzman.

O SA utilizado neste trabalho é baseado na busca local, procurando uma melhor solução na vizinhança cuja distância de Hamming é obtida de forma aleatória e com distribuição uniforme, sendo inferior a metade do comprimento do vetor candidato, sendo chamado de SA-LS (KATAYAMA; NARIHISA, 2001).

O critério da probabilidade de aceitação, $x(i)$, é inspirado na termodinâmica, 
onde a distribuição de Boltzman é usualmente utilizada:

$$
x(i)=\exp \left[\frac{|\Delta e|}{T(i)}\right]-1
$$

onde $T(i)$ é a temperatura na iteração $i, \Delta e$ é a variação de energia associado a diferença entre a solução anterior e a solução atual.

Geralmente, a temperatura inicial possui um valor alto, $T(0)>0$, sendo gradativamente reduzida através do processo de resfriamento. Existem vários métodos para o processo de resfriamento.

Um dos mais eficientes para vários problemas de otimização consiste em:

1. Inicializar a temperatura $T(0)$.

2. Manter a temperatura constante por $L_{S A}$ iterações consecutivas.

3. A cada série de $L_{S A}$ iterações, ocorre um decréscimo da temperatura através de um fator $\epsilon$. A cada $i L_{S A}$ iterações, a temperatura decai:

$$
T\left(i L_{S A}\right)=\epsilon^{i} T(0)
$$

Portanto, o algoritmo SA deve ser iniciado com os três parâmetros: temperatura inicial, $T(0)$, passo de resfriamento, $\epsilon$, e tamanho da série (platô), $L_{S A}$.

O pseudocódigo para o algoritmo SA aplicado aos problemas MuD e MuChE é apresentado na tabela 3.3.

\subsubsection{Busca Tabu de Termo Curto (STTS)}

O algoritmo de Busca Tabu foi originalmente proposto em 1977 com o trabalho pioneiro de Glover (GLOVER, 1977) e posteriormente descrito na forma atual em 1986 (GLOVER, 1986), sendo utilizado em diversas áreas e campos do conhecimento.

A origem etimológica do nome tabu remonta a uma palavra do idioma praticado em uma ilha da Polinésia, sendo utilizada pelos nativos para indicar objetos que não podiam ser tocados por serem sagrados.

Considerando a descrição da palavra em dicionários da língua portuguesa, pode-se afirmar que tabu refere-se a uma restrição imposta por costumes sociais como uma medida de proteção ou algo banido por constituir risco. Assim, podese utilizar esta definição de risco a ser evitado em analogia ao algoritmo de seguir 
Tabela 3.3: Algoritmo de Recozimento Simulado para o problema MuD e $\mathrm{MuChE}$.

\begin{tabular}{|c|}
\hline$\frac{\mathrm{MuD}}{\text { Entrada: } \mathcal{B}_{1}, T_{0}, \epsilon, L_{S A}}$ \\
\hline $\begin{array}{l}\text { Entrada: } \mathcal{B}_{1}, T_{0}, \epsilon, L_{S A} \\
\text { Saída: } \mathcal{B}_{1} \\
\text { Início } \\
\text { 1. } \mathcal{B}^{\text {best }}=\mathcal{B}_{1} \text { e } \mathcal{B}=\mathcal{B}_{1} ; \\
\text { 2. Calcula } E=\Omega\left(\mathcal{B}^{\text {best }}\right) \text { e } E^{\text {best }}=E ; \\
\text { 3. Para } i=1,2, \ldots, I_{t} ; \\
\text { 3.a } \breve{\mathcal{B}}=\text { Vizinhança }(\mathcal{B}, 1) ; \\
\text { 3.b Cálculo da Função Custo } \\
\quad \mathbf{E}=\Omega(\breve{\mathcal{B}}) ; \\
\quad \text { 3.c } \text { Se } \Delta E=\max [\mathbf{E}]-E^{\text {best }}<0 ; \\
\quad E^{\text {best }}=\max [\mathbf{E}] \text { e } E=\max [\mathbf{E}] \\
\quad \mathcal{B}^{\text {best }}=\breve{\mathcal{B}} \text { max } ; \\
\text { 3.d fim; } \\
\text { 3.e Se } t=k . L S A \\
\quad k=k+1 ; \\
\text { 3.f fim; } \\
\text { 3.g Calcule } P(\Delta E) ; \\
\text { 3.g.1. Se } \Delta E=\max [\mathbf{E}]-E \leq 0 ; \\
\quad E=\max [\mathbf{E}] \text { e } \mathcal{B}=\mathcal{B}_{\max } ; \\
\text { 3.g.2. Caso contrário, se: } \\
\mathcal{U}(0,1)<P(\Delta E) ; \\
\quad E=\max [\mathbf{E}] \text { e } \mathcal{B}=\mathcal{B}_{\max } ; \\
\text { 3.g.3. fim; } \\
\text { 3.h } i=i+1 ; \\
\text { fim; } \mathcal{B}_{1}=\mathcal{B}^{\text {best }} ; \\
\text { fim } \quad\end{array}$ \\
\hline
\end{tabular}

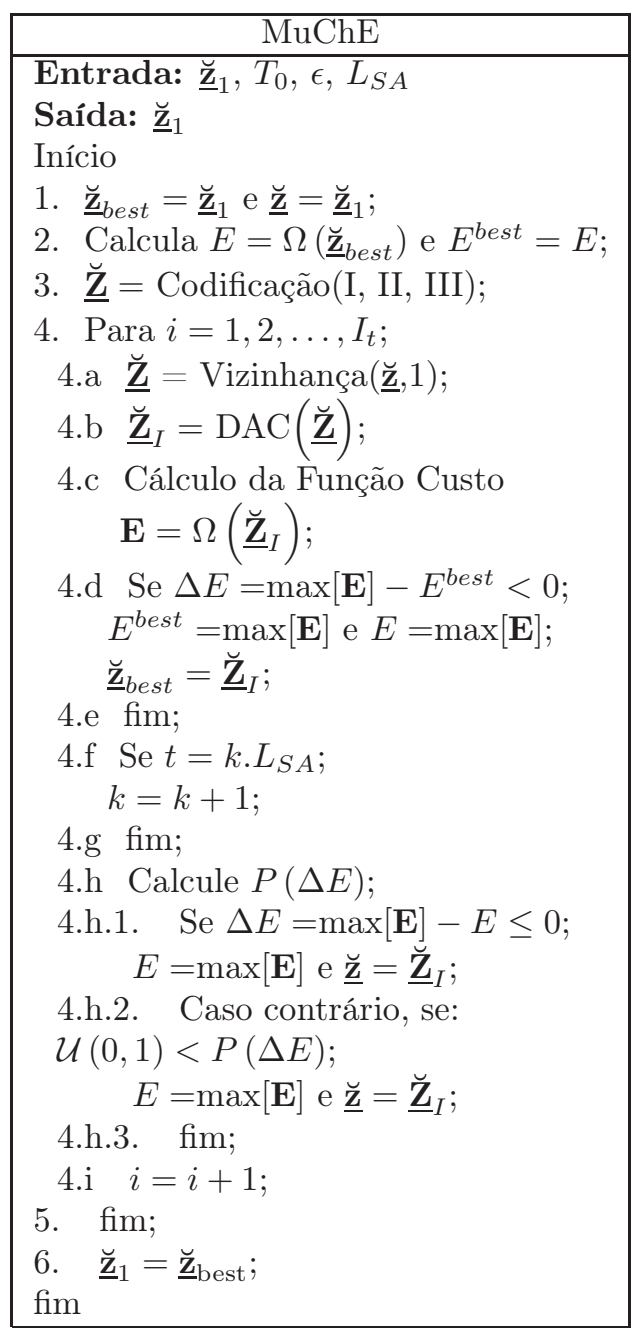

um caminho não eficiente, incluindo direcionamento a regiões de mínimos ou máximos locais.

Além disso, o uso convencional da palavra tabu vem do fato que tabus são normalmente transmitidos através da memória social, sendo sujeita a mudanças ao longo do tempo. Isto cria a conexão fundamental para o princípio de funcionamento do algoritmo, onde os elementos proibidos recebem esta definição pela dependência em uma memória evolutiva, permitindo alteração de acordo com o momento e circunstância. Assim, consistem em listas com soluções não permitidas.

Por isso, esta metaheurística conhecida como Busca Tabu é um procedimento adaptativo auxiliar que guia um algoritmo de busca local na exploração contínua dentro de um espaço de busca. Partindo de uma solução inicial, a busca move-se, a cada iteração, para a melhor solução na vizinhança, não aceitando movimentos que levem a regiões já visitadas e tidas como não atrativas que permanecem armazenadas na lista. 
Portanto, o algoritmo STTS (Short Term Tabu Search) é baseado no modo determinístico do funcionamento de uma memória. A memória é implementada através da gravação de características de deslocamento de soluções previamente visitadas. Esta é descrita pela lista Tabu, a qual é formada pelo passado recente de busca, sendo chamada de efeito de memória de termo curto (Short Term).

Estas características de deslocamento são proibidas pela lista Tabu por certo número de iterações. Isto ajuda a evitar retornos a soluções locais, promovendo uma diversificação na busca de soluções. Além disso, o critério de aspiração aceita uma nova solução, independente da lista Tabu, quando esta possuir um valor de energia maior que todas as soluções já visitadas anteriormente (GLOVER, 1977, 1986; GLOVER; LAGUNA, 1997; TAN, 2001).

O pseudocódigo para o algoritmo STTS aplicado aos problemas MuD e MuChE é apresentado na tabela 3.4.

Tabela 3.4: Algoritmo STTS para o problema MuD e MuChE.
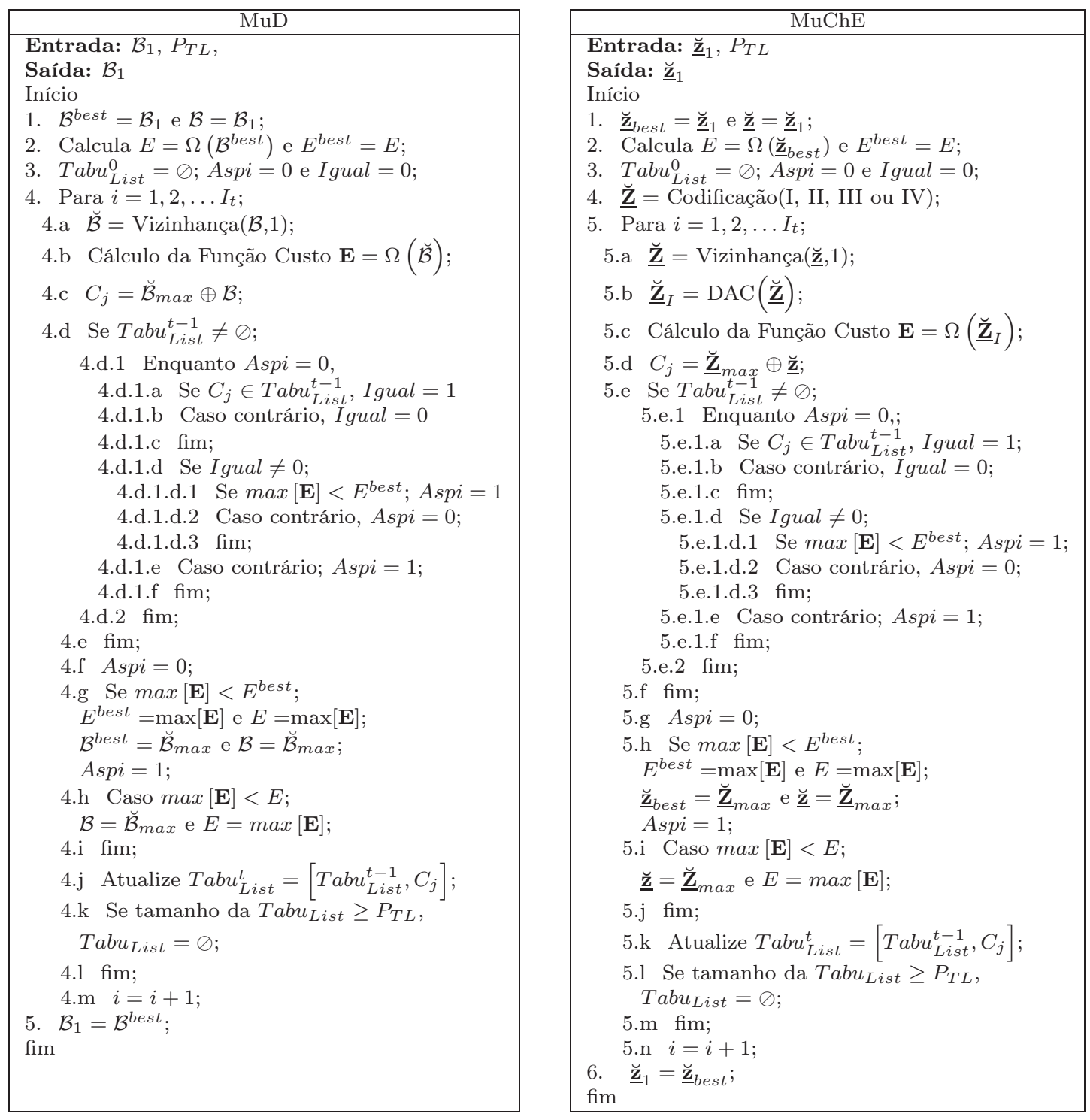


\subsubsection{Busca Tabu Reativa (RTS)}

O algoritmo RTS (Reactive Tabu Search) combina o efeito de termo curto com outro efeito de memória para evitar retornos aos máximos locais e garantir uma busca eficiente. Este efeito é conhecido como memória de termo longo (Long Term), o qual alterna entre as fases de intensificação e diversificação da busca (BATTITI; TECCHIOLI, 1994; TAN, 2001).

A lista Tabu do algoritmo STTS é implementada utilizando os efeitos de termo curto (short term). Mas isto não garante escapar de retornos aos máximos locais. Adicionalmente, a escolha de um período de proibição $(\mathcal{P})$ fixo, adequado para cada problema, torna-se uma tarefa difícil, pois um período pequeno é insuficiente para evitar retornos a máximos locais e um período grande demais reduz a quantidade de deslocamentos possíveis, acarretando em uma busca ineficiente.

A memória de termo longo do RTS é constituída pelo efeito de memória de termo curto do algoritmo STTS adaptando o período de proibição durante a busca, admitindo-se que este período assuma diferentes valores a cada iteração $(\mathcal{P}(i))$.

O período de proibição é inicializado com um pequeno valor, $\mathcal{P}(0)$, sendo adaptado na ocorrência de repetições.

Quando uma repetição é encontrada, encoraja-se a diversificação pelo acréscimo do período $\mathcal{P}(i)$ em uma taxa de $1+x$. Para que essa diversificação não assuma valores muito altos após algumas iterações, reduz-se o período $\mathcal{P}(i)$ em um taxa de $1-x$ quando $\left|f_{i}-f_{\text {best }}\right|<x f_{\text {best }}$, onde $0<x<1, f_{i}$ corresponde à solução na iteração $i$ e $f_{\text {best }}$ é a melhor solução até o momento.

Em (TAN, 2001) foi obtido experimentalmente um valor para a constante que controla a redução do período $\mathcal{P}(i)$, sendo encontrado o valor $x=0,3$ para a aplicação da detecção multiusuário em canal AWGN síncrono. No entanto, tratase de um valor obtido de forma não sistemática, devendo-se realizar uma análise para definição deste parâmetro que agrega bom desempenho para uso geral. Esta análise é realizada no capítulo 4.

O pseudocódigo para o algoritmo RTS aplicado aos problemas MuD e MuChE é apresentado na tabela 3.5. Vale ressaltar que apenas a etapa 5.l é implementada de forma distinta visando agregar as características de memória de termo curto e longo. 
Tabela 3.5: Algoritmo RTS para o problema MuD e MuChE.

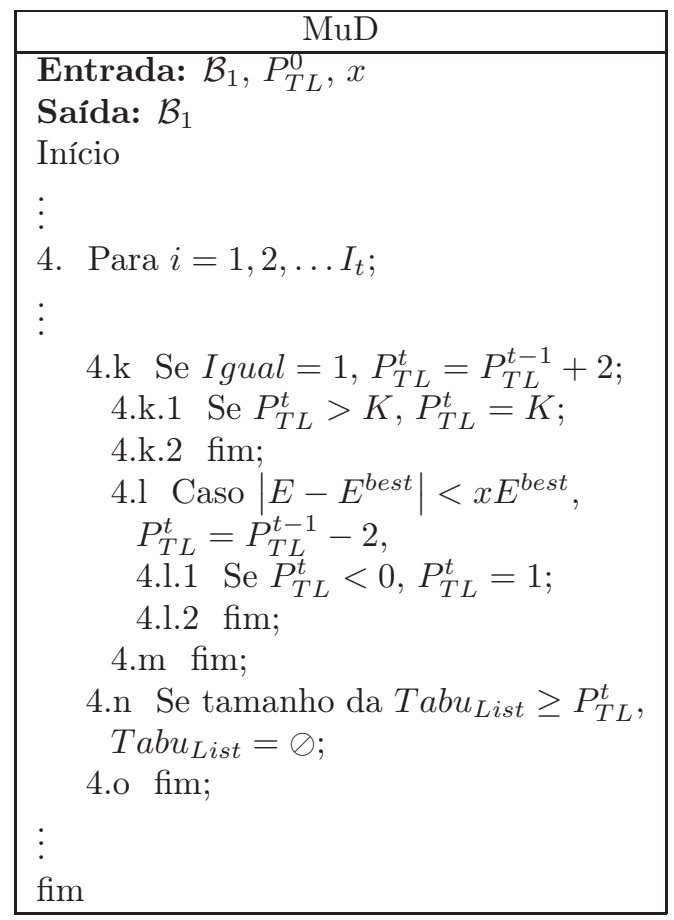

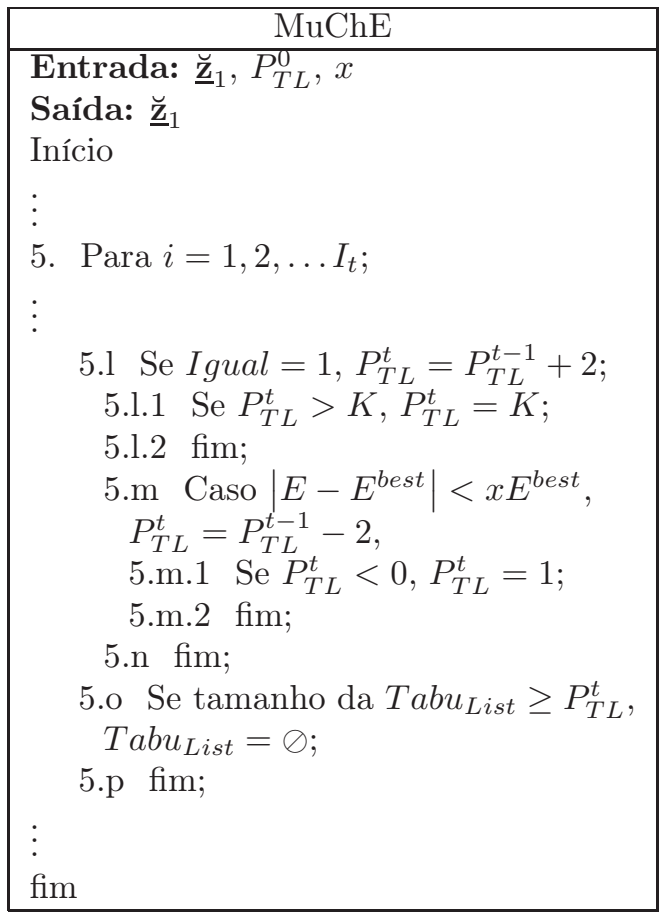

\subsection{Estratégias Hiperheurísticas}

Nos últimos 50 anos os algoritmos conhecidos como metaheurísticos vem sendo utilizados como estratégias de solução para uma larga gama de problemas de otimização. A habilidade dos algoritmos metaheurísticos de evitar soluções locais proporciona a possibilidade de adaptação em diversos problemas com robustez nas soluções e facilidade de implementação, contribuindo para diversos campos de pesquisa principalmente em problemas onde as soluções determinísticas ou métodos tradicionais não são eficientes.

No entanto, não é fácil, ou mesmo possível, predizer qual dos muitos algoritmos existentes é o mais adequado ao problema a ser otimizado e reproduzir o mesmo resultado considerando os mesmos parâmetros de entrada. A dificuldade de escolha atrelada à não previsibilidade no desempenho é um dos principais fatores que limitam seu uso por parte da comunidade científica e da indústria.

Além disso, para uma variedade grande de problemas os valores dos parâmetros devem ser controlados conforme a busca avança. Neste contexto, a ideia de se trabalhar com um nível mais elevado de automatização no projeto de uma heurística acarretou no desenvolvimento da estratégia conhecida como Hiperheurística (HH) (BURKE et al., 2010; GROBLER et al., 2010).

As HH's dispõem de métodos mais gerais que podem ser aplicados em otimização tendo como foco um desempenho estável e razoável para uma grande 
quantidade de problemas diferentes, ao contrário da maioria das estratégias heurísticas que são adaptadas a um problema específico.

Os algoritmos HH's consistem de uma metodologia de alto nível (High Level) para controlar a seleção ou geração de estratégias de busca genéricas utilizando uma quantidade específica de heurísticas de baixo nível (Low Level) diferentes.

Esta estratégia facilita o desenvolvimento de estratégias automáticas em muitos aspectos, trazendo um impacto grande e muito recente ${ }^{15}$ na comunidade científica.

Por isso, pode-se considerar que uma metaheurística é um conjunto de conceitos que pode ser utilizado para definir métodos heurísticos aplicáveis a um extenso conjunto de diferentes problemas. Em outras palavras, trata-se de uma estrutura algorítmica geral que pode ser aplicada a diferentes problemas de otimização com poucas modificações que possam adaptá-la a um problema específico.

Já o termo HH refere-se aos processos algorítmicos que se utilizam de heurísticas em um nível maior de generalidade, uma vez que o domínio de uma $\mathrm{HH}$ é composto não por instâncias do problema mas por um conjunto de heurísticas que podem ser utilizadas na busca por soluções de um problema que, por definição, não é conhecido pela $\mathrm{HH}$.

Por isso, a maior diferença entre as estratégias meta e hiperheurísticas consiste na definição do domínio do problema, sendo:

- Metaheurística: busca ocorre diretamente no espaço de soluções candidatas

- Hiperheurística: busca ocorre em um nível mais geral, sendo um mecanismo de aprendizagem para seleção ou geração de heurísticas

Vale ressaltar que as metaheurísticas são técnicas de qualidade para a resolução de problemas complexos, mas implementações realmente eficientes desses métodos normalmente requerem muitos conhecimentos específicos sobre o problema que se pretende tratar. Assim, as HH foram propostas com o objetivo de viabilizarem a construção de algoritmos robustos, possibilitando a utilização de métodos metaheurísticos com pequenas adaptações.

Portanto, de forma resumida, uma estratégia $\mathrm{HH}$ pode ser descrita, conforme já mencionado anteriormente, como heurísticas que escolhem heurísticas.

Em (BURKER; KENDALL; SOUBEIGA, 2003), o termo HH é definido como:

\footnotetext{
${ }^{15}$ Conforme apresentado na seção 1.7.
} 
Um método de busca ou mecanismo de aprendizagem para seleção ou geração de heurísticas que resolvem problemas de busca em um computador.

O foco não consiste em se encontrar soluções apropriadas para um problema específico, mas manter o foco na facilidade de sua utilização mantendo respostas estáveis e com qualidade para uma larga escala de problemas. Para isso, um espaço de busca de heurísticas de baixo nível é definida, enquanto a estratégia de alto nível controla esta busca.

Isto acarreta na mudança tradicional das técnicas heurísticas onde a busca ocorre diretamente no espaço de soluções candidatas para um espaço onde a correlação com o problema não é direta (alto nível).

\subsubsection{Classificação das Hiperheurísticas}

Uma classificação unificada descrita em (BURKER et al., 2010; GROBLER et al., 2010) é apresentada na figura 3.6.

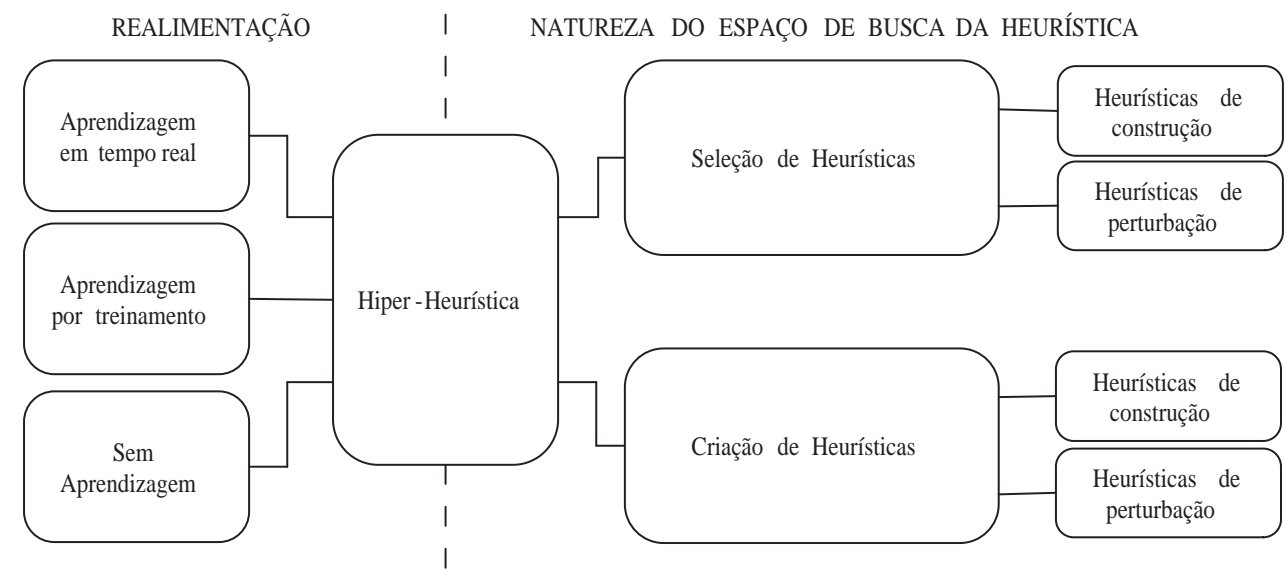

Figura 3.6: Classificação de uma HH de acordo com duas dimensões, a natureza do espaço de busca da heurística e a fonte de realimentação durante a aprendizagem.

De acordo com esta classificação, uma HH deve considerar dois aspectos importantes:

- a natureza do espaço de busca da heurística

- a fonte de realimentação durante a aprendizagem

Com relação a natureza do espaço de busca da heurística, duas abordagens 
convencionais, conhecidas como seleção de heurísticas e criação de heurísticas são identificadas.

A seleção de heurísticas consiste em combinar heurísticas pré-elaboradas em uma estratégia de busca de alto nível, enquanto a criação de heurísticas concentrase em gerar novas heurísticas a partir de componentes básicos ${ }^{16}$ de heurísticas existentes.

Note que para ambas as estratégias, existem duas subdivisões, conhecidas como heurísticas de construção e heurísticas de perturbação. Na estratégia de heurística de construção, o objetivo consiste em encontrar apenas uma solução que apresenta-se superior à iteração anterior. Desta forma, realiza-se o teste de viabilidade da solução para apenas um candidato por vez e caso este seja superior, o processo é reiniciado considerando este como a nova solução (melhor solução) até o momento. Com isso, o resultado final vai sendo construído conforme novas soluções individuais são encontradas. Para a estratégia de heurística de perturbação, considera-se o uso de uma heurística de baixo nível para construir uma solução completa (várias iterações internas e com vários candidatos por iteração) por iteração da HH. A cada nova geração da HH, realiza-se outra busca completa com uma heurística de baixo nível.

\subsubsection{Topologia Geral de uma Hiperheurística}

A figura 3.7 apresenta uma topologia geral para a construção de hiperheurísticas, evidenciando a separação entre os domínios da HH e do problema (BURKER et al., 2010; GROBLER et al., 2010).

Note que dois componentes do algoritmo HH devem ser especificados visando a concreta implementação de uma HH. Estes componentes são conhecidos como a estratégia de seleção de heurística e o critério de aceitação a ser utilizado em cada iteração.

\subsubsection{Métodos de Seleção de Heurísticas e Aceitação de Soluções}

Para o caso da estratégia classificada como seleção de heurísticas, conforme figura 3.6, deve-se considerar que cada heurística de baixo nível presente no repositório esteja completamente construída, com todos os seus respectivos blocos. Desta forma, após escolhida, esta heurística buscará, por si só, otimizar a função

\footnotetext{
${ }^{16}$ Blocos de construção para a seleção dos candidatos, variação do espaço de busca, critério de reposição, entre outros.
} 


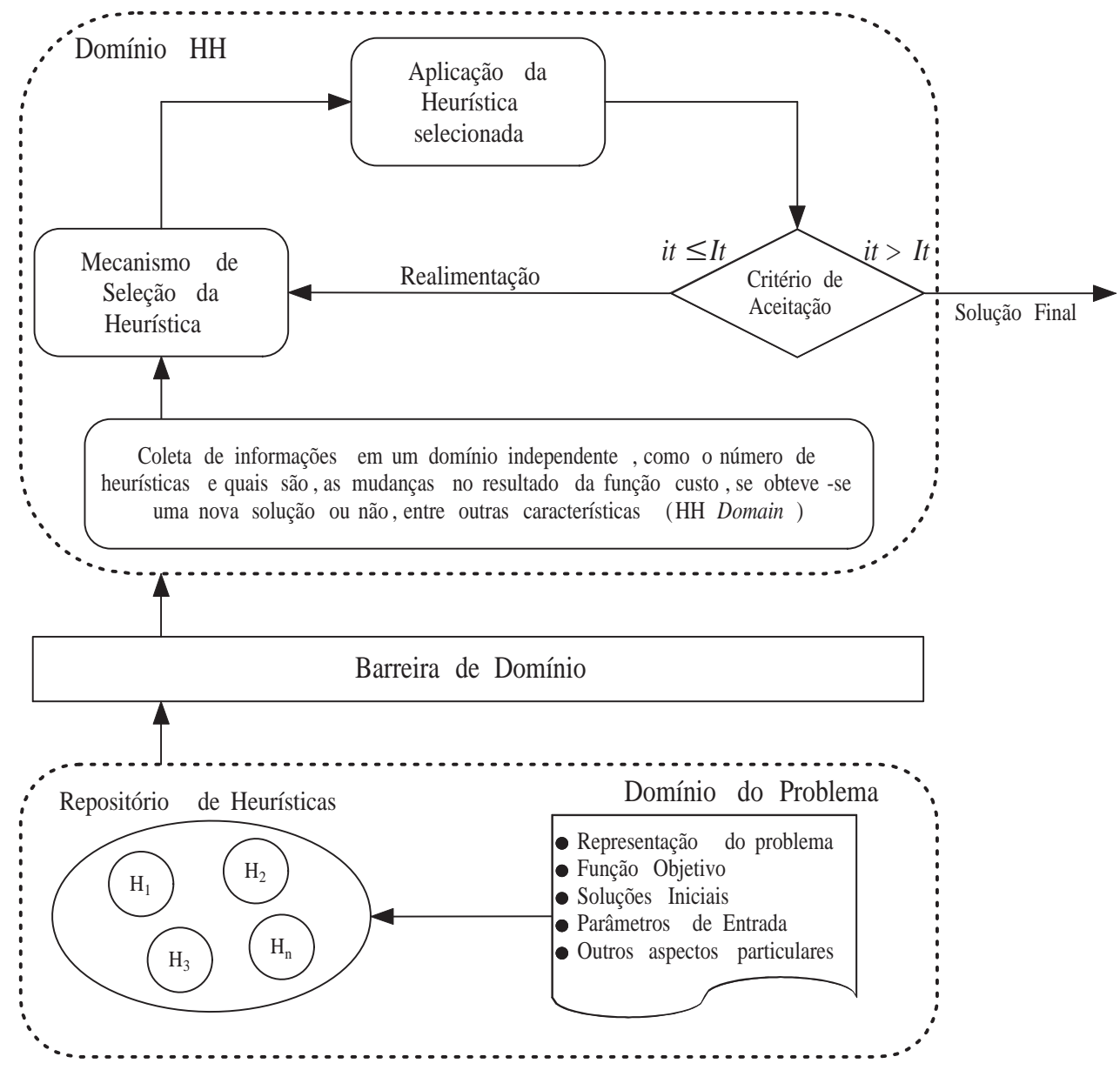

Figura 3.7: Descrição de uma estratégia HH geral.

custo.

No caso da estratégia classificada como de criação de heurísticas, deve-se considerar que apenas blocos de construção das heurísticas fazem parte do repositório e, desta forma, a seleção é realizada no intuito de selecionar todos os blocos necessários à construção de uma heurística completa de baixo nível. Este trabalho considera apenas a estratégia de seleção de heurísticas completas, pois torna possível a identificação da complexidade além de utilizar os algoritmos otimizados descritos no capítulo 4.

Com isso, serão apresentados dois critérios para a realização desta seleção, seja com heurísticas de baixo nível completas ou blocos de construção.

- Simplesmente Aleatório: Seleciona aleatoriamente uma heurística do repositório com uma densidade de probabilidade uniforme. Para o caso dos blocos de construção, seleciona de forma aleatória um número de blocos necessário à construção de uma heurística.

- Reforço de Aprendizagem com Busca Tabu: As heurísticas de baixo 
nível são selecionadas de acordo com os respectivos desempenhos. Este mecanismo incorpora a dinâmica da lista Tabu (lista proibida) que exclui temporariamente heurísticas ou blocos de construção, se for o caso, do repositório. Desta forma, esta estratégia seleciona uma heurística ou um bloco de construção que não estiver na lista Tabu. Se a estratégia selecionada produzir uma melhoria na solução, será considerada para a etapa de seleção posterior. Caso a estratégia produza resultados inferiores, ela vai para a lista Tabu por um período pré-definido. A lista Tabu é esvaziada conforme a estratégia do algoritmo STTS ou quando todas as possibilidades de seleção estiverem na lista.

O critério de aceitação é a segunda estratégia que deve ser escolhida para uma possível implementação de uma HH, podendo-se identificar pelo menos cinco formas distintas. Logicamente, outras estratégias podem ser criadas e utilizadas, principalmente com o avanço das pesquisas nesta área tão recente.

As cinco estratégias que serão analisadas como critério de aceitação são:

- Aceitação Cruel: Neste caso, somente as soluções que apresentam melhorias são aceitas. Note que desta forma não existe uma estratégia geral para o HH escapar de soluções locais, ficando dependente apenas das estratégias das heurísticas de baixo nível para este escape.

- Aceitação Ingênua (NV - Naive Acceptance): Neste caso, são aceitas todas as soluções que apresentam melhoria. Além disso, em 50\% das vezes que a solução encontrada for inferior à solução prévia, esta é aceita.

- Aceitação Adaptativa (AA - Adaptative Acceptance): são aceitas todas as soluções que apresentam melhoria. No caso de soluções inferiores, estas são aceitas segundo uma taxa de aceitação, que depende de como a busca está progredindo ou se esta parecer ter encontrado uma solução local. A taxa de aceitação inicia-se em $0 \%$, tornando a estratégia AA como uma estratégia que só aceita soluções com melhoria. No entanto, se a solução não for incrementada de uma iteração à outra ou durante certo número de iterações, então a taxa de aceitação é incrementada de 5\%. Se continuar não apresentando melhoria na próxima ou durante algumas iterações, a taxa é novamente incrementada de mais 5\% (tornando-se 10\%). Desta forma, basta escolher se o critério levará em conta apenas uma iteração ou um número maior de iterações para realizar o ajuste na taxa de aceitação. Mas se uma melhoria for encontrada, reduz-se a taxa de forma absoluta 
de $5 \%$ (retornando a taxa para 5\%, conforme valor do exemplo acima). Estas modificações ajudam no escape de soluções locais em busca da solução ótima.

- Grande Dilúvio (GD - Great Deluge): O algoritmo do grande dilúvio pode ser interpretado como uma variante determinística do algoritmo de recozimento simulado. Desta forma, a cada iteração, qualquer solução com melhoria é aceita e também se não for muito pior que o valor esperado como referência. Com isso, a solução com redução no desempenho é aceita se:

$$
f\left(s_{\text {new }}\right)<f\left(s_{\text {old }}\right)-\frac{i \Delta e}{I_{t}}
$$

onde $s_{\text {old }}$ é a solução anterior, $i$ é a iteração atual, $\Delta e$ é a diferença entre a solução anterior e a solução atual e $I_{t}$ é o número total de iterações.

- Baseada no Recozimento Simulado: Esta estratégia utiliza o conceito estocástico do recozimento simulado, onde uma solução sem incremento é aceita de acordo com uma probabilidade decrescente com o progresso da otimização. Assim, todas as soluções com melhoria são aceitas e as demais são aceitas com a probabilidade:

$$
p=e^{\left(f\left(s_{\text {new }}\right)-f\left(s_{\text {old }}\right)\right) / T}
$$

onde $T$ representa o parâmetro de temperatura do algoritmo de recozimento simulado, conforme seção 3.4.4.

Os algoritmos heurísticos de baixo nível bem como as técnicas HH são utilizados neste trabalho, sendo os resultados de desempenho bem como uma análise de convergência, escolha de parâmetros e de complexidade apresentados no capítulo 4. Vale ressaltar que foi considerado para este trabalho somente a estratégia de seleção de heurísticas de baixo nível, ou seja, uso de heurísticas pré-elaboradas em uma estratégia de busca de alto nível.

\subsubsection{Medidas de Qualidade para Comparação}

Geralmente os algoritmos metaheurísticos e os hiperheurísticos são analisados, em termos de comparações, seguindo um princípio de competição onde o vencedor é aquele que produz a melhor solução. Esta estratégia foi originalmente considerada utilizando uma metáfora com as características esportivas, onde um 
desafio do tipo Decathlon ${ }^{17}$ é realizada. Desta forma, diferentes domínios e problemas são considerados como as provas a serem executadas pelos algoritmos.

Após, os resultados podem ser agrupados para cada competidor (algoritmo), realizando-se uma média aritmética de suas notas ou através de pesos onde a consistência dos resultados é valorizada.

Para ambos os casos, o resultado pode ser questionado, pois em um evento esportivo, o desempenho de um atleta em uma prova pode não ser igual à média de desempenho que este mesmo atleta possui nesta prova. Desta forma, as conclusões a respeito das melhores práticas são questionáveis, acarretando em descrédito. Uma forma de eliminar este efeito consiste em realizar inúmeras provas e analisar o desempenho pela média e desvio padrão dos resultados. Esta estratégia de comparação é aceita como métrica de avaliação justa pela indústria, além de indicar o nível de estabilidade da solução proposta (MONTGOMERY, 1996).

Desta forma, dedicou-se uma seção especificamente para expor as métricas que serão adotadas para a confeç̧ão e comparação dos algoritmos heurísticos utilizados.

Vale ressaltar que o capítulo 4 apresenta figuras de mérito para cada topologia proposta, facilitando a determinação de qual ou quais técnicas são mais atraentes para cada tipo de cenário de comunicações sem fio.

\subsection{Métricas para Avaliação de Algoritmos Heu- rísticos}

Observando o início deste capítulo é possível verificar que estão sendo considerados sete algoritmos metaheurísticos distintos. No entanto, na literatura, é possível observar pelo menos 20 tipos. Com isso, a maioria dos trabalhos científicos se preocupam em apresentar suas medidas de qualidade da solução obtida em comparação com outras e muitas vezes a diminuição da complexidade.

No entanto, existe um grande vazio nesta área que merece ser preenchido. Isto é justificado pelo fato de não existir um padrão universalmente aceito de testes e comparação entre os métodos. Desta forma, existe uma distância grande entre o que se é pesquisado e aquilo que, de fato, é implementado pela indústria, pois a linguagem utilizada não é a mesma quando o assunto é desempenho de algoritmos.

\footnotetext{
${ }^{17}$ Trata-se de uma modalidade esportiva composta por dez provas distintas, exigindo um extremo esforço físico.
} 
Este problema está na descrição dos resultados dos algoritmos, pois os pesquisadores apresentam figuras de mérito que, em muitos casos, causam dúvidas sobre quão boa são as soluções encontradas.

Em segundo lugar, a maioria dos resultados está associada a uma restrição de experimentos, não cobrindo as opções mais utilizadas comercialmente ou mesmo apresentam desempenho satisfatório somente para uma parcela das características do problema a ser otimizado.

Como resultado, a maioria dos algoritmos metaheurísticos não são bem aceitos para atuação em problemas práticos de telecomunicações. Desta forma, este trabalho pode ser visto como um esforço na tentativa de se quantificar a qualidade das técnicas propostas seguindo padrões aceitos e que são utilizados na indústria (VOB, 2001).

Ao final, demonstra-se a possibilidade de construção de topologias que utilizam algoritmos heurísticos de fácil aplicação e que apresentam previamente o desempenho alcançado segundo os critérios do sistema. Logicamente, este desempenho é comprovado através de simulações, evidenciando os resultados obtidos. Assim, espera-se minimizar a desconfiança existente e proporcionar critérios e metodologias de análise para outras instâncias de aplicação dos algoritmos heurísticos.

Por isso, deve-se incorporar as melhores práticas de gerenciamento de qualidade de algoritmos, i.e., adotando-se um critério conhecido como Controle de Processo Estatístico (SPC - Statistical Process Control). O SPC vêm sendo utilizado nos últimos 80 anos pela indústria em geral e também pelas de software. Portanto, será considerado esta prática de gerenciamento de qualidade neste trabalho (GRANT; LEAVENWORTH, 1999; FLORAC; CARLETON, 2001).

Considera-se neste trabalho a ideia de círculo de teste empírico (empirical test cycle), possibilitando a análise estatística dos resultados, alinhando, assim, a nomenclatura entre indústria e pesquisadores.

Em vários trabalhos, os autores afirmam que o algoritmo utilizado apresenta melhor desempenho em termos de qualidade, em termos de um número de iterações para convergência e diminuição de tempo de processamento, entre outros. Mas se o algoritmo não for estável ${ }^{18}$, comete-se um erro quando o algoritmo é considerado passível de utilização na prática, pois a principal diretriz não é atendida. A análise inicial realizada considera o uso de gráficos de controle e posteriormente

\footnotetext{
${ }^{18} \mathrm{~A}$ descrição de estabilidade será realizada a seguir.
} 
através de métricas de estabilidade e capacidade.

\subsubsection{Controle Estatístico de Qualidade}

A regra mais aceita pela indústria consiste no controle de estabilidade do algoritmo. Para isso, pode-se utilizar a estratégia proposta por Shewart (SHEWART, 1931) chamada de Gráficos de Controle. Esta estratégia influenciou significativamente as medidas de qualidade utilizadas na indústria, tornando-se a base do conceito de controle de qualidade moderno. Os gráficos de controle ajudam a visualizar se a estabilidade está sob controle ou não.

Assim, o gráfico de controle consiste em um gráfico com uma linha central, representando o valor médio de desempenho alcançado e duas linhas, uma superior e outra inferior, caracterizando os limites de estabilidade.

Se todos os valores impressos neste gráfico estiverem dentro dos intervalos dos limiares, este é considerado sob controle e estável. Se em algum momento o resultado apresenta-se fora destes limites, então o processo é considerado fora de controle (Out of Control), ou instável, não sendo utilizado para aplicações práticas até que medidas sejam tomadas para estabilizar o desempenho (SHEWART, 1931; GRANT; LEAVENWORTH, 1999; ZHANG, 2003).

Para a construção do gráfico de controle, são comumente utilizados os seguintes limites:

$$
\begin{aligned}
& L S=\bar{X}+3 \sigma_{X} \\
& L I=\bar{X}-3 \sigma_{X}
\end{aligned}
$$

onde $L S$ representa o limite superior, $L I$ o limite inferior, $\bar{X}$ representa o valor médio da solução encontrada e $\sigma_{X}$ o desvio padrão.

Desta forma, o processo de geração de um gráfico de controle consiste nos passos:

- Selecionar o algoritmo a ser analisado.

- Determinar um plano para aquisição dos resultados.

- Coletar os dados do algoritmo e inseri-los no gráfico de controle.

- Calcular os limites e valor médio e inserir no gráfico de controle.

Esta é uma primeira abordagem para verificação da estabilidade do algoritmo. 
Adicionalmente, deve-se considerar uma análise de tendência central e dispersão, pois trata-se de uma análise importante que visa agregar informações a respeito da estabilidade.

No gráfico de controle a tendência central corresponde ao valor médio do algoritmo e a dispersão relacionada com os limiares superior e inferior.

Se o algoritmo for estável, deve-se criar um gráfico de distribuição (histograma) para verificar o formato e tendência de dispersão da solução.

Normalmente utiliza-se a análise através da distribuição Normal, considerando a média de desempenho e o desvio padrão. Mas outras funções densidade de probabilidade podem ocorrer, como a distribuição desviada (Skewed), a de cauda longa (Long-tailed) ou a Bimodal. Para cada uma delas, utiliza-se uma métrica para análise de dispersão e tendência central.

Considerando a tendência de distribuição normal, é evidente que algoritmos com menor desvio padrão médio resultam em algoritmos com maior estabilidade e, provavelmente, atingem o objetivo de forma mais rápida. Quanto mais estreita e alta for a distribuição, maior é a capacidade do algoritmo de produzir boas soluções. Esta análise de dispersão foi utilizada para comparação entre os tipos de codificação para o problema MuChE, sendo apresentada no capítulo 5.

Mas apenas analisando gráficos de dispersão torna-se difícil avaliar diversos algoritmos com desempenhos próximos ou com características conflitantes. Desta forma, pode-se utilizar as métricas numéricas para a estabilidade e capacidade de produção de boas soluções.

Para quantificar o desempenho dos algoritmos é necessário o conhecimento dos limites especificados para cálculo das tolerâncias, sendo chamados de Limite de Especificação Superior (USL - Upper Specification Limit) e o Limite de Especificação Inferior (LSL - Lower Specification Limit) (SHEWART, 1931; GRANT; LEAVENWORTH, 1999; ZHANG, 2003).

O USL representa um valor cujo desempenho abaixo é aceitável. O LSL considera um valor no qual qualquer valor acima para o desempenho do algoritmo o torna aceitável. Desta forma, como no caso do gráfico de controle, deseja-se que o algoritmo se comporte dentro destes dois limites. Estes parâmetros são muitas vezes estipulados pela necessidade de qualidade, podendo assumir valores mais brandos ou mais restritivos. Uma forma usual mais branda consiste em adotar $U S L>L S$ e $L S L<L I$. Mas esta análise de qualidade deve considerar os limites de aceitação da solução, ou seja, quais são os limiares máximos de desvio 
em relação ao valor desejado que ainda podem ser aceitos como solução para o problema.

Uma das métricas utilizadas, consiste no índice de estabilidade do algoritmo (ASI - Algorithm Stability Index), que corresponde a uma medida de habilidade do algoritmo de produzir resultados consistentes, sendo descrita pela relação de espalhamento permitido pelo espalhamento atual da solução. A outra métrica, denominada de índice de capacidade do algoritmo (ACI - Algorithm Capability Index), indica uma medida de quão longe o algoritmo está, em termos de qualidade das soluções obtidas, dos limites especificados.

A ASI e a ACI são calculadas como:

$$
\begin{gathered}
A S I=\frac{(U S L-L S L)}{6 \sigma_{\bar{X}}} \\
A C I=\frac{(U S L-\bar{X})}{3 \sigma_{\bar{X}}} \text { ou } A C I=\frac{(\bar{X}-L S L)}{3 \sigma_{\bar{X}}}
\end{gathered}
$$

Na literatura, esta metodologia é também conhecida como metodologia "Six Sigma" (BREYFOGLE, 1999). Note que para $U S L=L S$ e $L S L=L I$, os valores de ASI e ACI resultam em $A S I=A C I=1$, sendo utilizados apenas os gráficos de controle.

Para os problemas considerados no capítulo 4 visando a otimização dos parâmetros e estratégias dos algoritmos percebe-se que o objetivo consiste na minimização da função custo. Desta forma, existe invariavelmente um limite inferior (valor ótimo), reduzindo a definição de estabilidade do algoritmo para uma análise unilateral (SHEWART, 1931; GRANT; LEAVENWORTH, 1999; ZHANG, 2003). Assim, busca-se apenas garantir a métrica ACI para o limite de especificação superior (USL).

Vale ressaltar que para questões práticas na indústria, considera-se um bom critério para algoritmos práticos que garantam os seguintes valores (SHEWART, 1931; GRANT; LEAVENWORTH, 1999; ZHANG, 2003):

$$
A S I>2 \quad \text { e } \quad A C I>1,33
$$

A métrica ACI mede quão próximo o algoritmo está do seu objetivo e a consistência em torno de seu desempenho médio. Um algoritmo pode apresentar uma variação mínima, mas se estiver afastado do valor objetivo para um dos limites de especificação, resultará em um ACI inferior, enquanto a métrica ASI poderá 
ser alta. Por outro lado, um algoritmo pode resultar, em média, em soluções exatamente iguais à objetivo, mas possuir uma grande variação no desempenho. Nesse caso, ACI ainda será pequeno e ASI ainda poderá ser grande. Assim, a métrica ACI só será grande apenas quando atingir proximidade de desempenho com o valor objetivo de forma consistente e com variação mínima.

Portanto, este trabalho considera a análise do gráfico de controle ${ }^{19}$ e das análises de índice de estabilidade e índice de capacidade do algoritmo quando passíveis de cálculo.

Com isso, busca-se estabelecer critérios que garantam primeiramente a estabilidade dos algoritmos propostos e posteriormente seja possível quantificar os limiares de desempenho.

Além disso, observa-se a possibilidade de expansão da análise em outros trabalhos considerando outras técnicas heurísticas para os problemas de telecomunicações apresentados ou em problemas de combinação existentes em outras áreas do conhecimento, pois estas podem ser comparadas e classificadas teoricamente em termos de qualidade, estabilidade, facilidade de utilização e complexidade.

Ao final, são indicadas as topologias utilizando algoritmos heurísticos capazes de otimizar os problemas de detecção multiusuário e estimativa de parâmetros.

\footnotetext{
${ }^{19}$ Baseado nas métricas LS e LI $\left( \pm 3 \sigma_{X}\right)$.
} 


\section{Otimização de Parâmetros e Complexidade}

Neste capítulo são apresentados os resultados desenvolvidos ao longo do programa de doutorado considerando a utilização de técnicas heurísticas na otimização de diversos problemas de otimização. Inicialmente, uma análise sistemática das técnicas e parâmetros utilizados para os algoritmos apresentados no capítulo 3 é realizada, considerando as métricas de qualidade discutidas previamente para uma maratona do tipo Decathlon (BURKE et al., 2009, 2010). São utilizadas 10 funções ${ }^{1}$ para a definição de limiares de desempenho e definição de parâmetros que proporcionam boas soluções.

Além disso, são apontadas as melhores técnicas no sentido geral e para cada tipo de problema específico analisado, trazendo uma perspectiva de quais técnicas podem ser utilizadas com garantia de qualidade de desempenho quando aplicadas aos problemas de detecção multiusuário e de estimativa de parâmetros apresentados no capítulo 2.

Também é realizada uma análise de complexidade computacional visando apresentar as melhores técnicas que possuem compromisso desempenho $\times$ complexidade, considerando diversas figuras de mérito.

Uma forma comum para a comparação da complexidade de algoritmos pode ser feita através da notação $\mathcal{O}$, a qual representa a ordem de grandeza da complexidade de um determinado algoritmo. Mas comparar algoritmos apenas através da notação $\mathcal{O}$ pode ser insuficiente, principalmente quando os algoritmos forem muito parecidos ou possuírem a mesma ordem de grandeza. Por isso, a análise realizada apresenta a complexidade dos algoritmos utilizando até três figuras de mérito: a notação $\mathcal{O}$, o número de instruções computadas e o tempo computacional médio necessário para uma determinada otimização.

Ao fim do capítulo é apresentado um resumo considerando o desempenho das técnicas analisadas bem como suas respectivas complexidades computacio-

\footnotetext{
${ }^{1}$ Que correspondem as 10 provas da maratona.
} 
nais visando à indicação das melhores técnicas para a utilização em sistemas de telecomunicações futuros, além da consolidação dos limiares de desempenho e determinação dos parâmetros que podem ser utilizados para a garantia de boas soluções.

\subsection{Otimização de Funções}

Visando a utilização de funções de testes (benchmarks), optou-se pela escolha de funções comumente utilizadas na literatura (JONG, 1975; GOLDBERG, 1989; WHITLEY et al., 1995; MICHALEWICZ, 1993; GROBLER et al., 2010), mas que apresentam características distintas. Desta forma, podem-se classificar as funções de teste considerando suas características principais, sendo descritas por:

- Contínuas e Descontínuas,

- Convexa e não convexa,

- Unimodal e Multimodal,

- Quadrática e não quadrática,

- Pequena dimensão e grande dimensão,

Note que as funções de testes podem possuir diversas características apresentadas de forma conjunta, resultando em inúmeras possibilidades de escolha. Este trabalho considera 10 funções tipicamente utilizadas como medidas de benchmark e para facilitar a compreensão e visualização do problema, optou-se pela apresentação utilizando versões com poucas variáveis que devem ser otimizadas simultaneamente, resultando, na maioria, em figuras de três dimensões.

Além disso, todos os testes consideraram a formulação do problema de minimização, sem perda de generalidade, pois poderia ser facilmente adaptado para problemas de maximização invertendo-se os sinais das funções.

O trabalho pioneiro de De Jong (JONG, 1975) é considerado uma literatura de referência para investigações considerando algoritmos heurísticos, pois foi utilizado um ambiente de experimentação totalmente controlado e relativamente simples, acarretando em métricas de escolha de parâmetros e estratégias de construção do algoritmo genético que são utilizados atualmente. O trabalho de De Jong utilizou um ambiente de teste constituído por cinco funções com o objetivo 
de minimização e cuja abrangência estava relacionada às características de cada função teste.

Este trabalho considera as três primeiras funções do trabalho de De Jong e, para complementar as características, foram escolhidas um conjunto de testes suplementares constituído pelas seguintes funções:

- Função de Michalewicz (MICHALEWICZ, 1993)

- Função de Schaffer (SCHAFFER et al., 1989)

- Função de Ackley (ACKLEY, 1987)

- Função de Rastrigin (RASTRIGIN, 1963)

- Função de Schwefel (SCHWEFEL, 1977)

- Função de 6-Hump Camelback (DIXON; SZEGO, 1978)

- Função de Shubert (MICHALEWICZ, 1996)

Após a definição de cada função teste é apresentado uma tabela resumo com as principais caraterísticas individuais, ressaltando as diferenças dos testes que cada algoritmo heurístico foi submetido.

\subsubsection{Função F1: De Jong}

A função F1 de De Jong é definida por:

$$
F 1(\mathbf{x})=\sum_{i=1}^{n} i \cdot x_{i}^{2}
$$

onde $n$ define a dimensão da função e $\mathbf{x}=\left[x_{1}, x_{2}, \ldots, x_{n}\right]$.

A figura 4.1 apresenta a versão de duas variáveis para esta função.

Note que a função F1 é uma parábola simples de dimensão $n$. Além disso, é contínua, convexa, unimodal, podendo ser implementada com baixa ou grande dimensão e quadrática.

Para este trabalho considerou-se o uso de $n=3$ (baixa dimensão). Como o problema é de minimização, o valor de mínimo da função coincide com os valores $x_{i}=0$ para $i=1: n$, resultando em $F 1(\mathbf{x})=0$. 


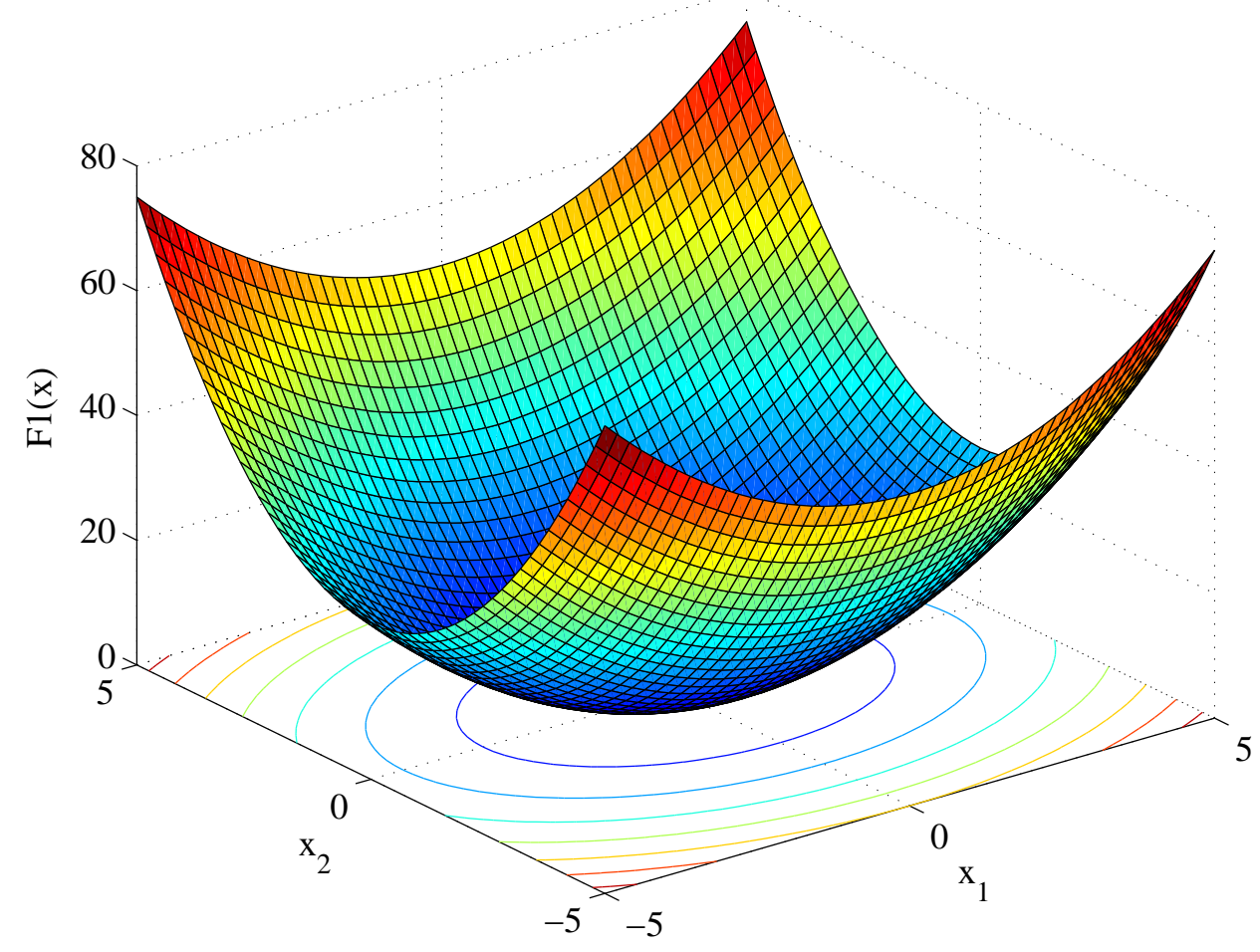

Figura 4.1: Representação da função F1 para duas variáveis.

Para a realização dos testes foram considerados restrição do espaço de busca definido por $-5,12 \leq x_{i} \leq 5,12$, onde $n=3$ e considerando uma precisão de duas casas decimais.

\subsubsection{Função F2: De Jong}

A função F2 de De Jong é definida por:

$$
F 2(\mathbf{x})=\sum_{i=1}^{n-1} 100\left(x_{i-1}-x_{i}^{2}\right)^{2}+\left(1-x_{i}\right)^{2}
$$

onde $n$ define a dimensão da função.

A função F2 é uma função padrão utilizada na literatura de otimização. É uma função contínua, não convexa, unimodal, quadrática e pode ser implementada com pequena ou grande dimensão. Neste trabalho considerou-se $n=2$, resultando em uma função teste de baixa dimensão.

A figura 4.2 apresenta a versão para $n=2$ utilizada neste trabalho.

Esta função também é conhecida como vale de Rosenbrock (ROSENBROCK, 1960), ou função da banana. Note que a solução global está inserida em um 


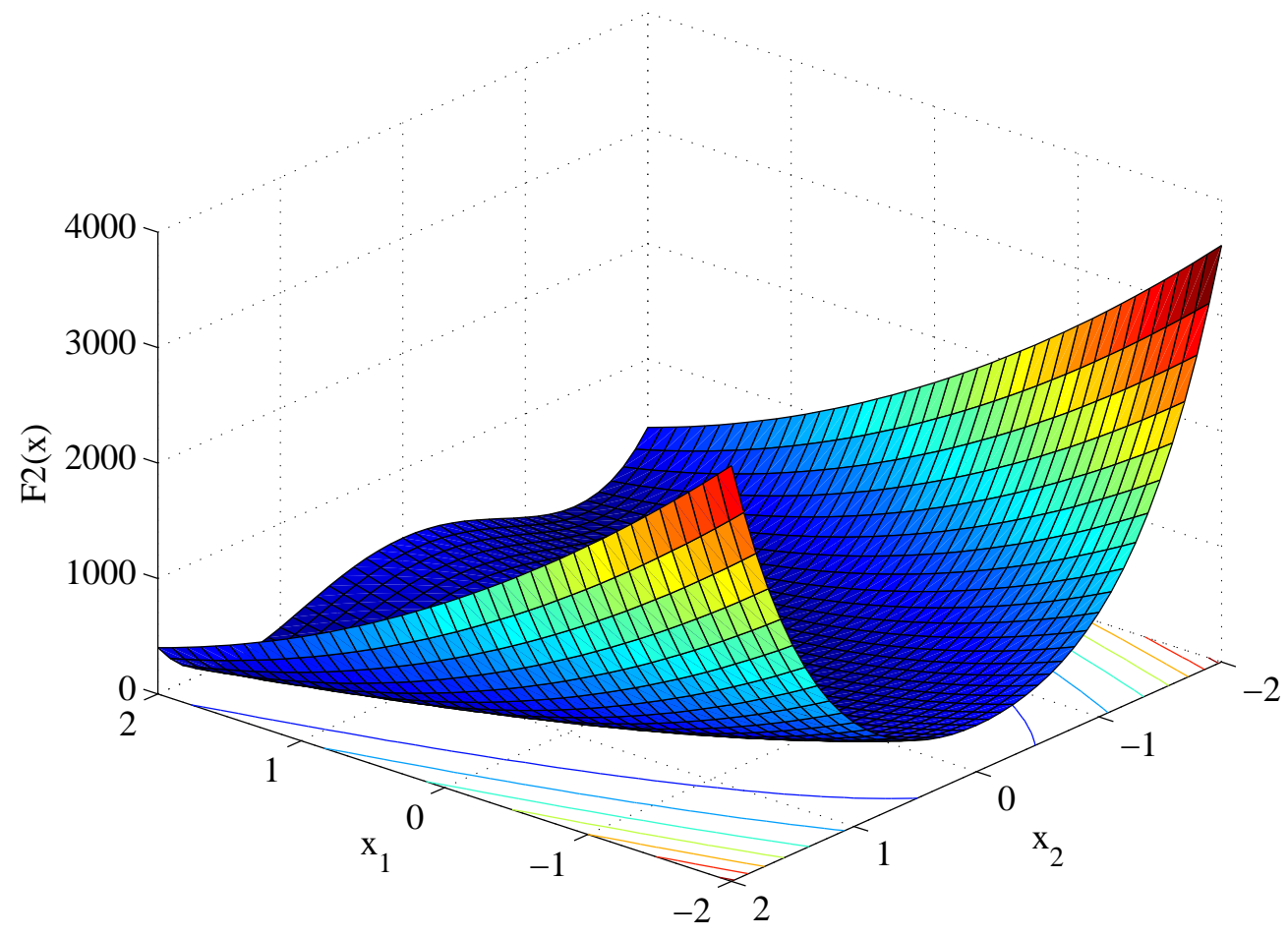

Figura 4.2: Representação da função F2 para duas variáveis.

vale longo, estreito, com formato parabólico. Para encontrar o vale os algoritmos não precisam de muitas iterações (solução local). No entanto, a convergência para a solução ótima é difícil justificando a utilização desta função de testes na determinação de desempenho dos algoritmos.

O valor de mínimo da função coincide com os valores $x_{i}=1$ para $i=1: n$, resultando em $F 2(\mathbf{x})=0$.

Para a realização dos testes foram considerados restrição do espaço de busca definido por $-2,048 \leq x_{i} \leq 2,048$, onde $n=2$ e considerando uma precisão de três casas decimais.

\subsubsection{Função F3: De Jong}

A função F3 de De Jong é definida por:

$$
F 3(\mathbf{x})=\sum_{i=1}^{n}\left\lfloor x_{i}\right\rfloor
$$

onde $n$ define a dimensão da função e o operador $\lfloor x\rfloor$ retorna o maior inteiro menor que $x$. 
Esta função é uma função em degrau de $n$ variáveis sendo descontínua, não convexa, unimodal e não quadrática. Este trabalho, da mesma forma que em (JONG, 1975), considera $n=5$, podendo-se classificar como de média/alta dimensão.

A figura 4.3 apresenta a versão da função F3 para $n=2$.

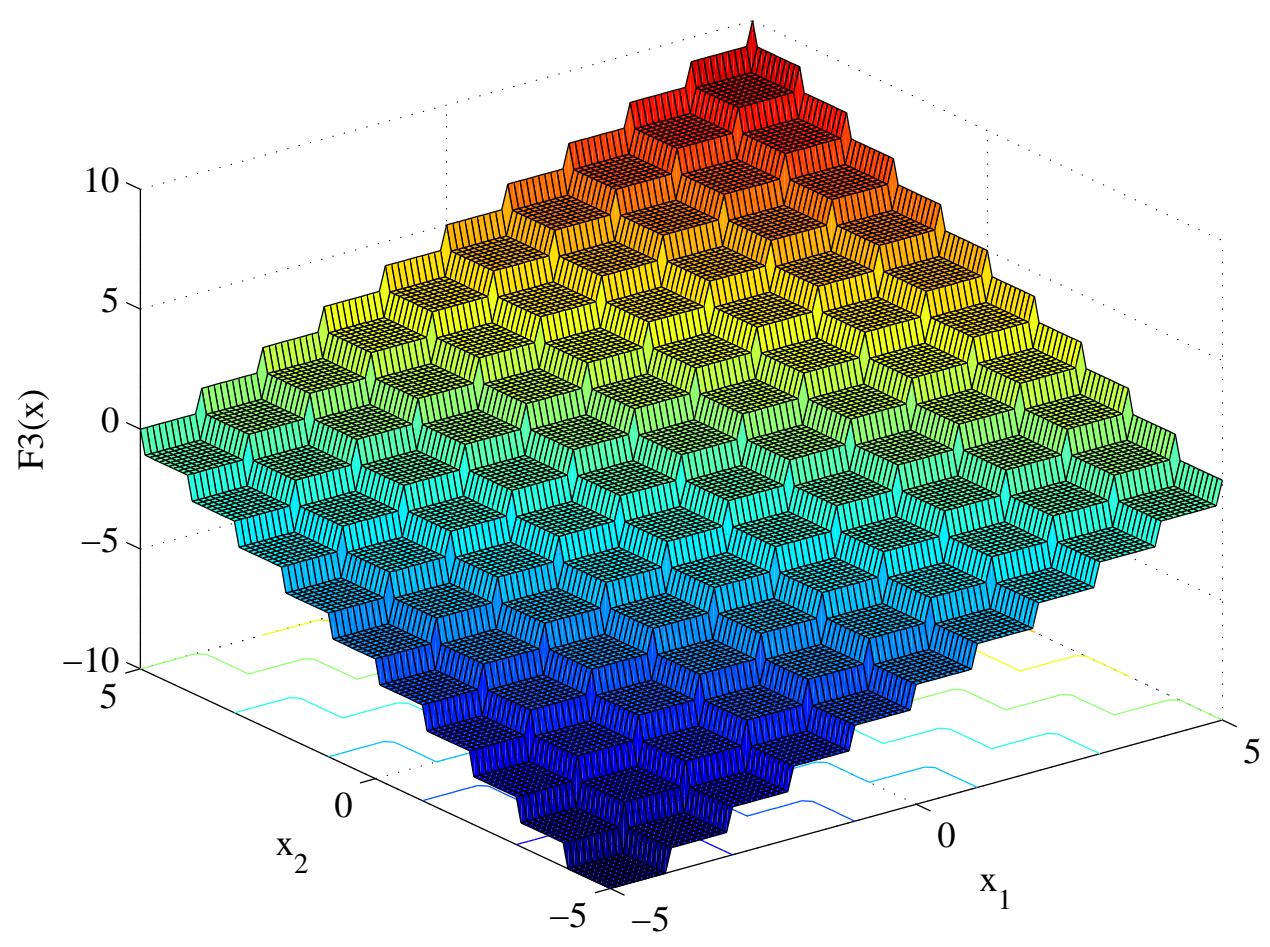

Figura 4.3: Representação da função F3 para duas variáveis.

Nos testes realizados restringiu-se o espaço de busca da F3 para $-5,12 \leq$ $x_{i} \leq 5,12$ considerando $n=5$ com uma precisão de duas casas decimais.

Note que para $n=5$ o valor de mínimo coincide para $x_{i}=-5$, resultando em $F 3(\mathbf{x})=-25$.

\subsubsection{Função F4: Michalewicz}

A função F4 de Michalewicz (MICHALEWICZ, 1993) é definida por:

$$
F 4(\mathbf{x})=-\sum_{i=1}^{n} \sin \left(x_{i}\right)\left(\sin \left(\frac{i x_{i}^{2}}{\pi}\right)\right)^{2 m}
$$

onde $n$ define a dimensão da função e o parâmetro $m$ define a inclinação dos vales e arestas.

A figura 4.4 apresenta a versão da função $\mathrm{F} 4$ para $n=2$. 


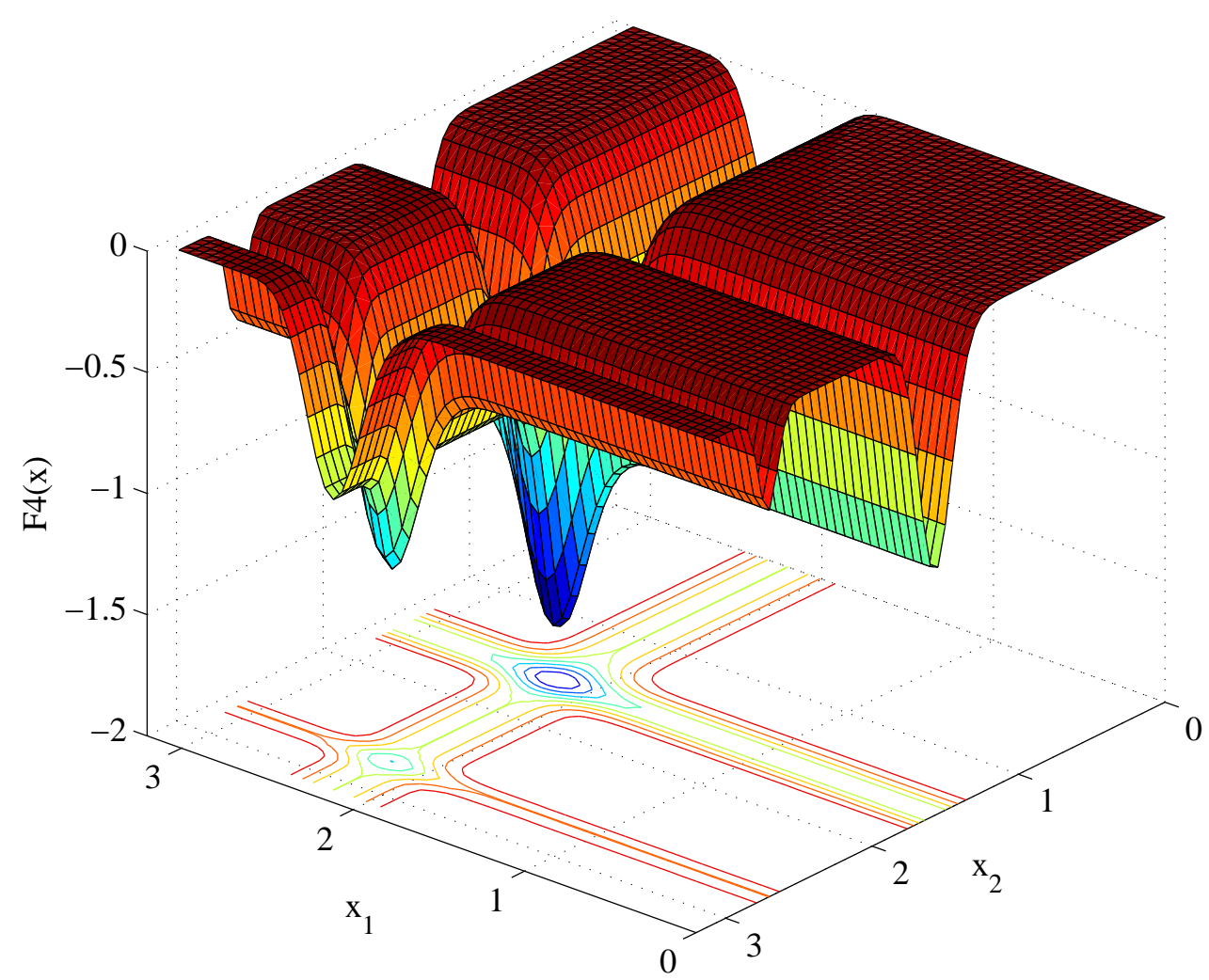

Figura 4.4: Representação da função F4 para duas variáveis e $m=10$.

A função de Michalewicz é contínua, não convexa, multimodal, não quadrática e apresenta $n$ ! soluções locais. Vale ressaltar que para grandes valores de $m$ a função F4 apresenta dificuldade na busca da solução global, pois os valores da função para pontos no espaço fora dos picos estreitos resultam em pouca informação ${ }^{2}$ sobre a localização do ótimo global, dificultando significativamente o avanço dos algoritmos.

Este trabalho considera restrição na busca considerando $0 \leq x_{i} \leq \pi$ e utilização de $n=2$ e $m=10$. Além disso, consideraram-se duas casas decimais de precisão, resultando nos valores de solução ótima para $x_{1}=2,19, x_{2}=1,92 \mathrm{e}$ $F 4(\mathbf{x})=-1,735$.

\subsubsection{Função F5: Schaffer}

A função F5 de Schaffer (SCHAFFER et al., 1989) é definida por:

$$
F 5(\mathbf{x})=\left(x_{1}^{2}+x_{2}^{2}\right)^{0,25}\left(\sin ^{2}\left(50\left(x_{1}^{2}+x_{2}^{2}\right)^{0,1}\right)+1\right)
$$

\footnotetext{
${ }^{2}$ Regiões denominadas de platô.
} 
Note que esta função considera duas variáveis. A figura 4.5 apresenta a função F5 utilizada neste trabalho.

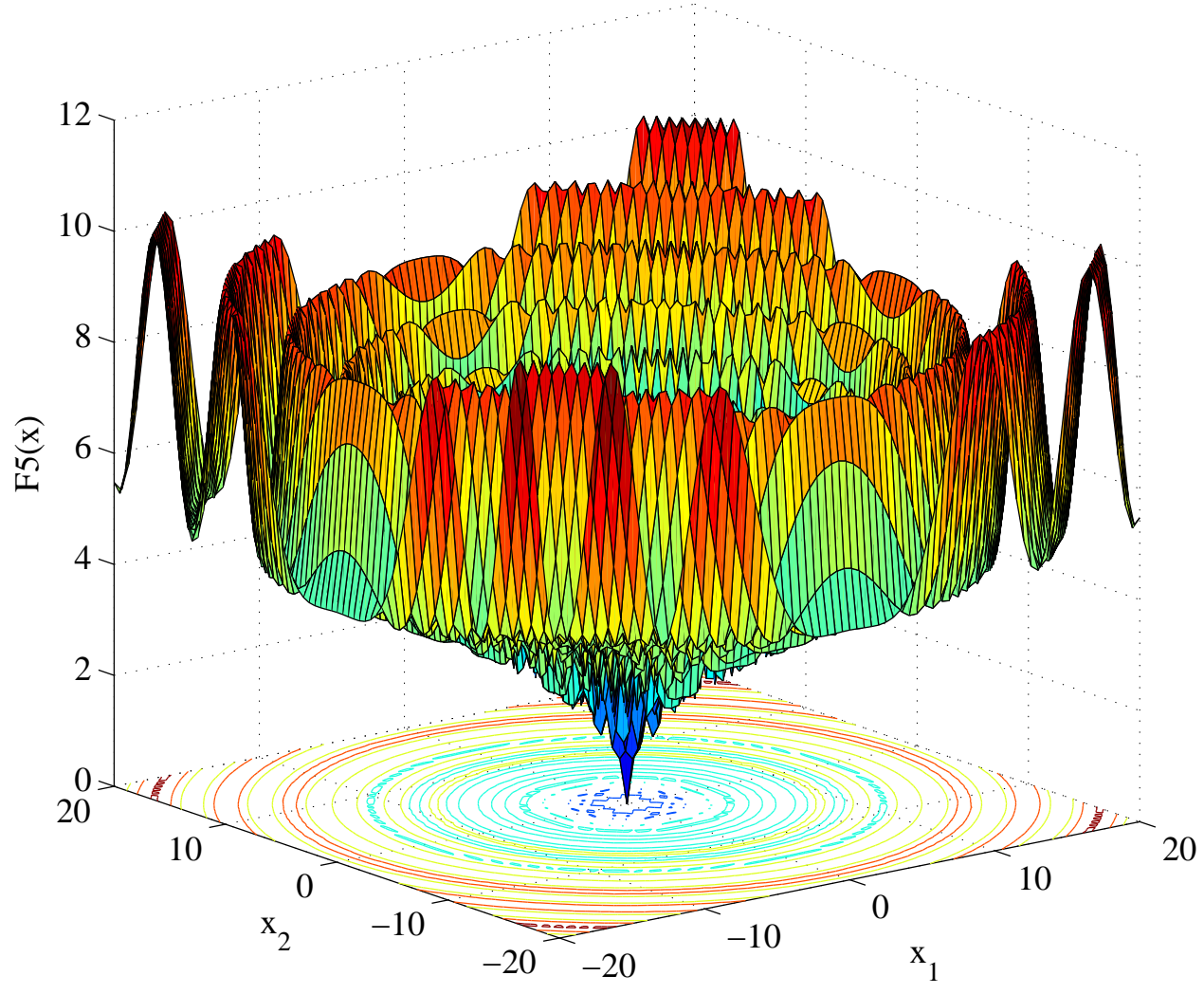

Figura 4.5: Representação da função F5 para duas variáveis.

A função de Schaffer é contínua, não convexa, multimodal, quadrática e podese observar que existem diversos vales de soluções locais dificultando a busca dos algoritmos pela solução global.

Este trabalho considera restrição na busca considerando $-20 \leq x_{i} \leq 20$. Além disso, foram utilizadas duas casas decimais de precisão, resultando nos valores de solução ótima para $x_{i}=0$ e $F 5(\mathbf{x})=0$.

\subsubsection{Função F6: Ackley}

A função de Ackley (ACKLEY, 1987) é definida por:

$$
F 6(\mathbf{x})=x_{1}^{2}+2 x_{2}^{2}-0,3 \cos \left(3 \pi x_{1}\right)-0,4 \cos \left(4 \pi x_{2}\right)+0,7
$$

A função F6 utilizada considera duas variáveis, sendo apresentada na figura 4.6. 


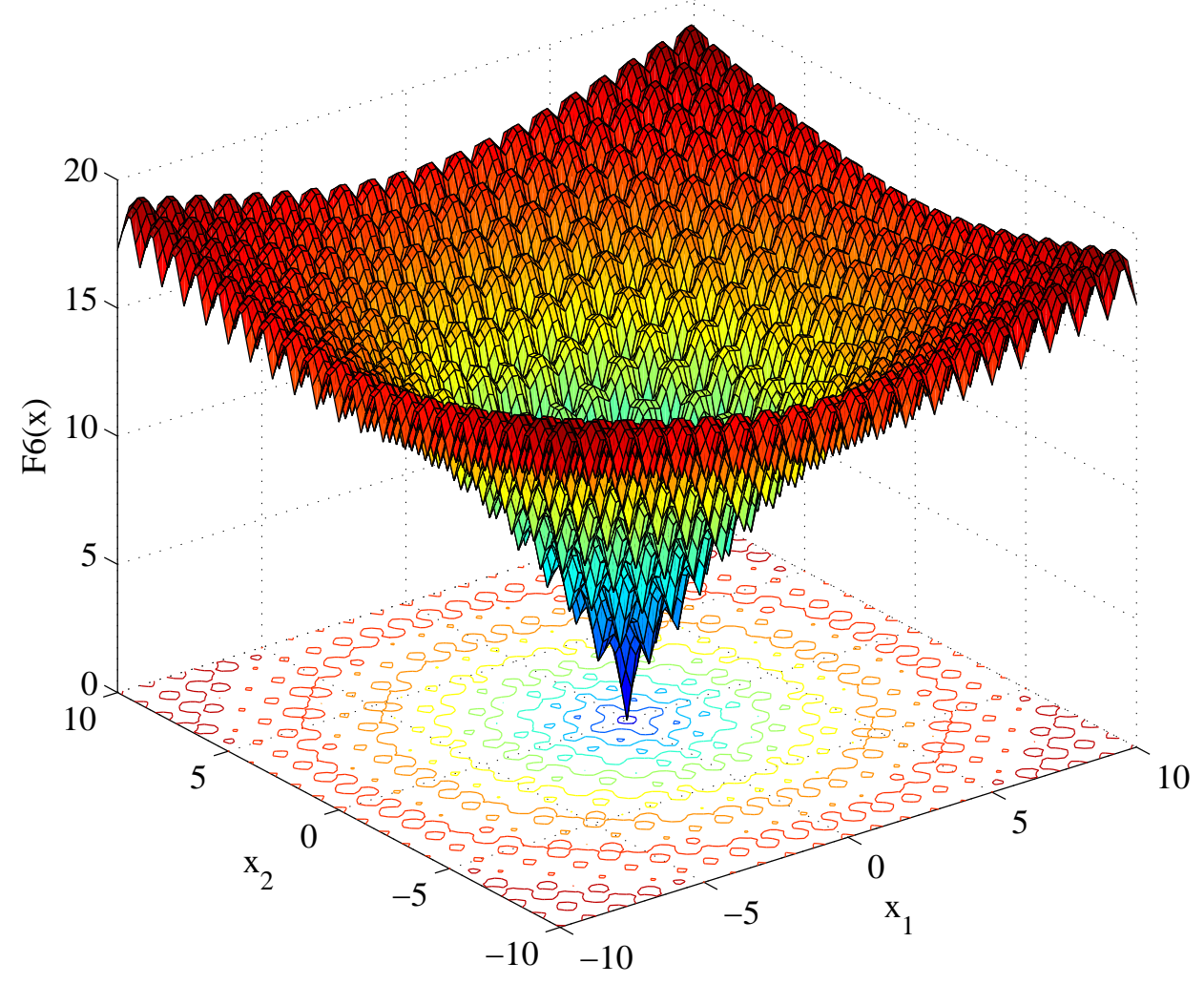

Figura 4.6: Representação da função F6 para duas variáveis.

A função F6 é contínua, não convexa, multimodal, quadrática e de baixa dimensão, resultando nos valores de solução ótima para $x_{i}=0$ e $F 6(\mathbf{x})=0$. Vale ressaltar que existem inúmeras soluções locais presentes nesta função teste dificultando sobremaneira a busca pelo ótimo global.

Para as simulações realizadas, restringiu-se a função F6 ao espaço definido por $-50 \leq x_{i} \leq 50$ para $n=2$ e uma precisão de três casas decimais.

\subsubsection{Função F7: Rastrigin}

A função de Rastrigin (RASTRIGIN, 1963) é definida por:

$$
F 7(\mathbf{x})=A n+\sum_{i=1}^{n}\left[x_{i}^{2}-A \cos \left(2 \pi x_{i}\right)\right]
$$

onde $A$ é uma constante e $n$ define a dimensão da função.

A figura 4.7 apresenta a versão da função F7 para $n=2$ e $A=10$ utilizada neste trabalho.

A função F7 é contínua, de dimensão variável, multimodal, não convexa e 


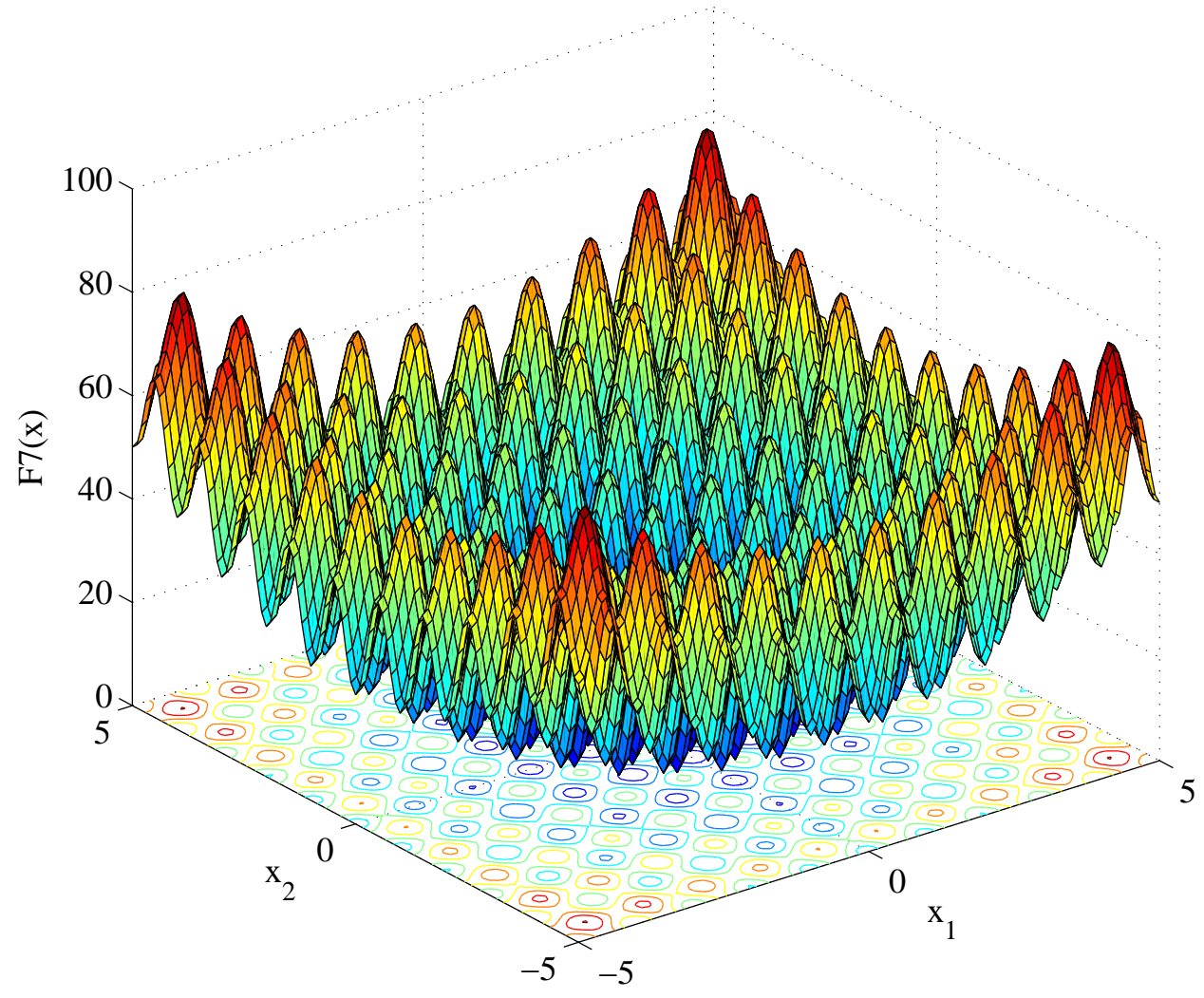

Figura 4.7: Representação da função F7 para duas variáveis.

quadrática, sendo uma típica função não linear de testes. Esta foi inicialmente proposta por (RASTRIGIN, 1963) como uma função de dimensão 2 e posteriormente foi generalizada por Mühlenbein et. al. (MüHLENBEIN; SCHOMISCH; BORN, 1991). Esta função é considerada de difícil otimização devido ao seu grande espaço de busca e seu grande número de soluções locais. No caso considerado, $n=2$ e $A=10$, os valores de solução ótima resultam em $x_{i}=0$ e $F 7(\mathbf{x})=0$.

Para os testes realizados considerou-se uma restrição no espaço de busca sendo definido por $-5,12 \leq x_{i} \leq 5,12 \operatorname{com} n=2$ e uma precisão de três casas decimais.

\subsubsection{Função F8: Schwefel}

A função F8 de Schwefel (SCHWEFEL, 1977) é definida por:

$$
F 8(\mathbf{x})=A n+\sum_{i=1}^{n}\left[-x_{i} \sin \left(\sqrt{\left|x_{i}\right|}\right)\right]
$$

onde $A$ é uma constante e $n$ define a dimensão da função.

A figura 4.8 apresenta a versão da função F8 para $n=2$ utilizada neste 
trabalho.

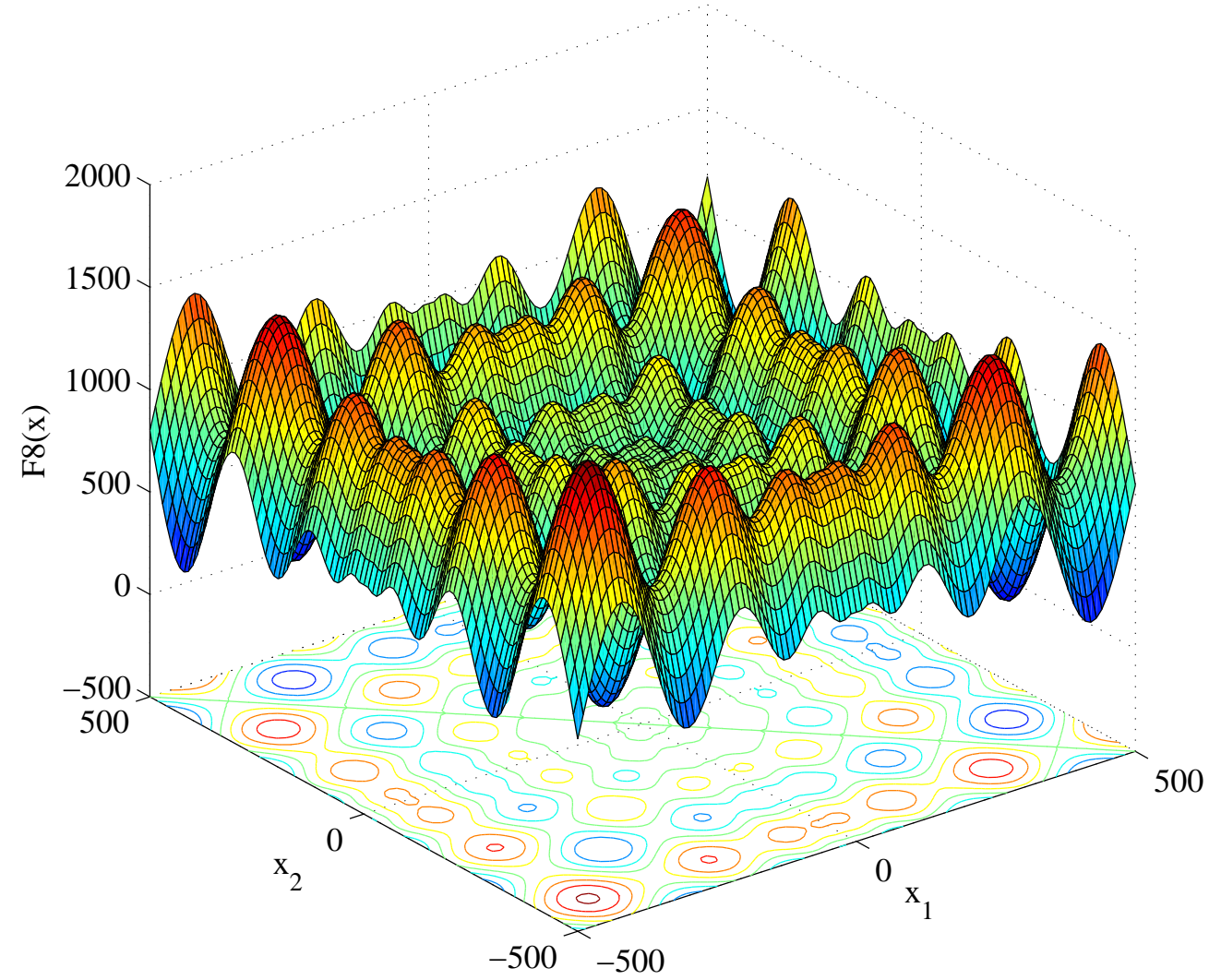

Figura 4.8: Representação da função F8 para duas variáveis.

Este trabalho considerou $A=418,9829$, resultando em $x_{i}=420,9687 \mathrm{e}$ $F 8(\mathbf{x})=0$.

Além disso, a função F8 é contínua, unimodal, de dimensão variável, não convexa e não quadrática. Os testes realizados consideraram restrição no espaço de busca da função $\mathrm{F} 8$ considerando $-500 \leq x_{i} \leq 500, n=2$ e uma precisão de duas casas decimais.

Vale ressaltar que a função F8 é de difícil resolução, pois a solução global encontra-se geometricamente distante das soluções locais. Desta forma, os algoritmos de busca são potencialmente propensos pela busca na direção incorreta.

\subsubsection{Função F9: 6-Hump CamelBack}

A função F9 denominada 6-Hump Camelback (DIXON; SZEGO, 1978) é definida por: 


$$
F 9(\mathbf{x})=\left(4-2,1 x_{1}^{2}+\frac{x_{1}^{4}}{3}\right) x_{1}^{2}+x_{1} x_{2}+\left(-4+4 x_{2}^{2}\right) x_{2}^{2}
$$

A figura 4.9 apresenta a versão da função F9 utilizada neste trabalho.

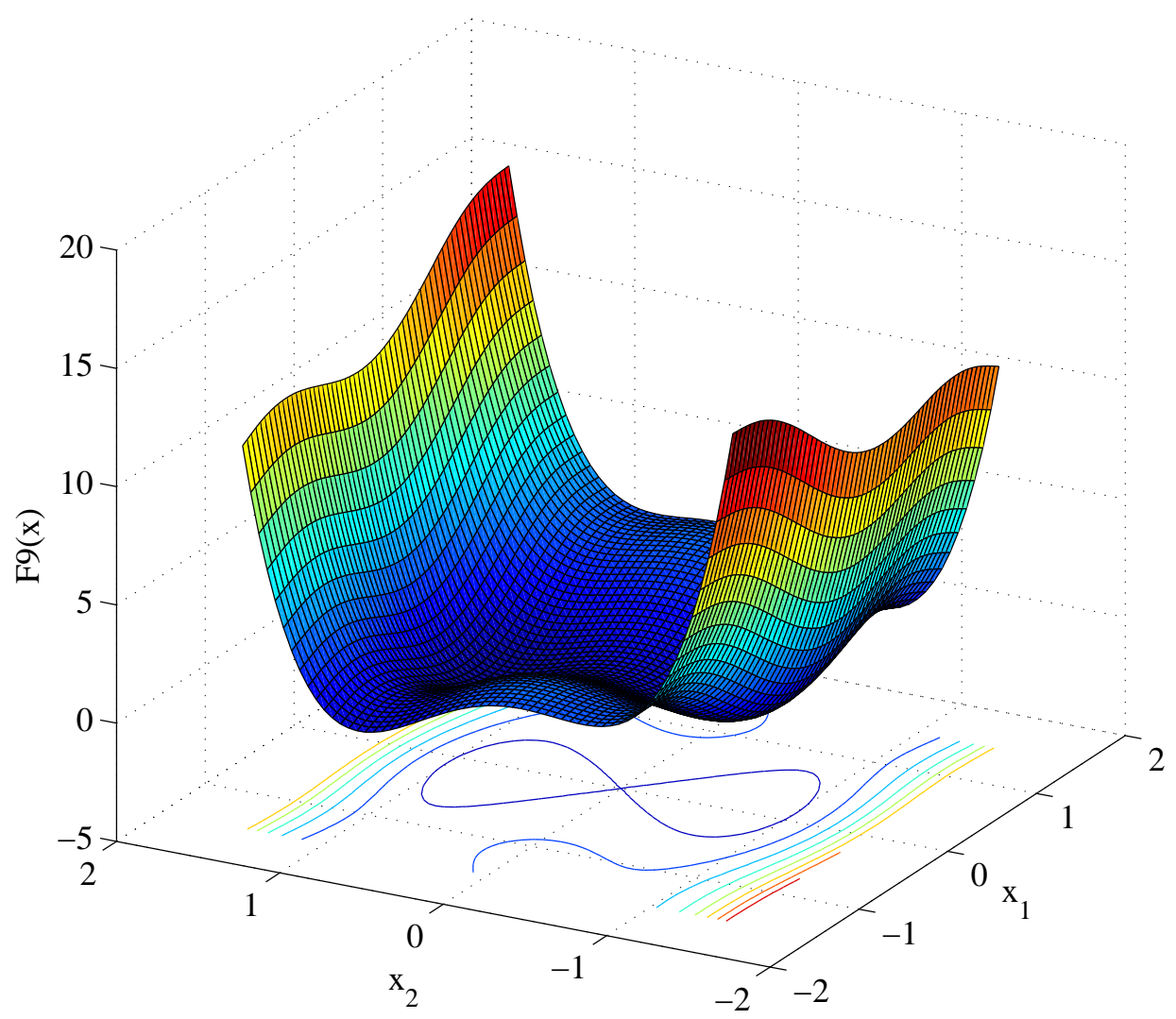

Figura 4.9: Representação da função F9 para duas variáveis.

A função F9 é contínua, não convexa, multimodal (4 soluções locais e 2 soluções globais), quadrática e de baixa dimensão.

O mínimo da função $F 8(\mathbf{x})=-1,03162$ para o par correspondente $x_{1}=$ $(0,08984,-0,71265)$ e $x_{2}=(0,08984,-0,71265)$. Desta forma, os algoritmos podem encontrar o mesmo desempenho mas com soluções distintas. Isso pode acarretar problemas na convergência dos algoritmos devido à indecisão de qual caminho resulta na solução global. Assim, em um instante o algoritmo está procurando por soluções na região positiva de $x_{i}$ e em outro momento sair desta região para a região negativa de $x_{i}$.

Os testes realizados consideraram restrição do espaço de busca para $-3,0 \leq$ $x_{i} \leq 3,0$ e uma precisão de três casas decimais. 


\subsubsection{Função F10: Shubert}

A função de Shubert (MICHALEWICZ, 1996) é definida por:

$$
F 10(\mathbf{x})=\prod_{i=1}^{n}\left(\sum_{j=1}^{m} j \cos \left[(j+1) x_{i}+j\right]\right)
$$

A figura 4.10 apresenta a versão da função F10, considerando $n=2$ e $m=5$ utilizados neste trabalho.

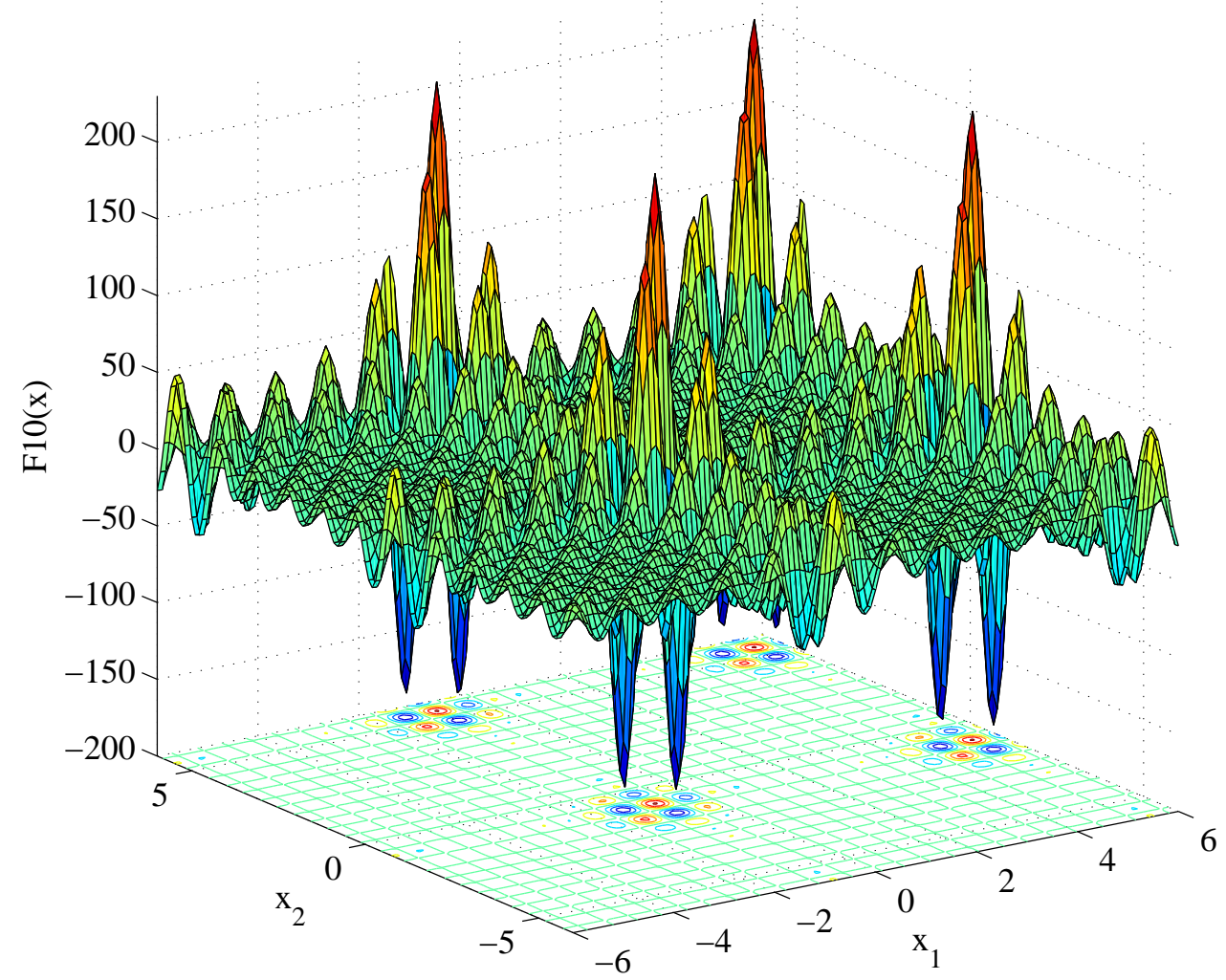

Figura 4.10: Representação da função F10 para duas variáveis.

A função F10 é contínua, não convexa, multimodal, não quadrática e de baixa dimensão $(n=2)$. Além disso, a função de duas dimensões F10 apresenta 742 soluções locais, sendo 18 soluções globais desigualmente espaçadas geometricamente.

O mínimo da função $F 10(\mathbf{x})=-186,73067$.

Nos testes realizados considerou-se a restrição do espaço de busca para $-5 \leq$ $x_{i} \leq 5$ e uma precisão de quatro casas decimais. 


\subsubsection{Resumo das características das funções}

Visando facilitar a compreensão e observação dos resultados, optou-se por apresentar um resumo das principais características de cada função custo considerada na análise dos algoritmos heurísticos, conforme tabela 4.1.

Tabela 4.1: Resumo das principais características das funções objetivo utilizadas para testes.

\begin{tabular}{|c|c|c|c|c|c|c|c|c|c|c|}
\hline & F1 & $\mathrm{F} 2$ & F3 & $\mathrm{F} 4$ & $\overline{\mathrm{F} 5}$ & $\mathrm{~F} 6$ & F7 & F8 & F9 & F10 \\
\hline $\begin{array}{l}\text { Contínua } \\
\text { Descontínua }\end{array}$ & $\bar{\nu}$ & $\bar{V}$ & $\boldsymbol{V}$ & $\bar{V}$ & $\bar{V}$ & $\bar{\nu}$ & $\bar{\nu}$ & $\bar{\nu}$ & $\bar{V}$ & $\bar{V}$ \\
\hline $\begin{array}{l}\text { Convexa } \\
\text { Não Convexa }\end{array}$ & $V$ & $\checkmark$ & $\checkmark$ & $\checkmark$ & $\checkmark$ & $\checkmark$ & $\checkmark$ & $\checkmark$ & $\checkmark$ & $\checkmark$ \\
\hline $\begin{array}{l}\text { Unimodal } \\
\text { Multimodal }\end{array}$ & $V$ & $\checkmark$ & $\checkmark$ & $\checkmark$ & $\checkmark$ & $\checkmark$ & $\checkmark$ & $\checkmark$ & $\checkmark$ & $\checkmark$ \\
\hline $\begin{array}{l}\text { Quadrática } \\
\text { Não Quadrática }\end{array}$ & $\checkmark$ & $\boldsymbol{V}$ & $\checkmark$ & $\boldsymbol{V}$ & $\checkmark$ & $\checkmark$ & $\checkmark$ & $\checkmark$ & $\checkmark$ & $\boldsymbol{\nu}$ \\
\hline $\begin{array}{l}\text { Pequena Dimensão } \\
\text { Grande Dimensão }\end{array}$ & $\checkmark$ & $\checkmark$ & $\checkmark$ & $\checkmark$ & $\checkmark$ & $V$ & $V$ & $V$ & $\checkmark$ & $\checkmark$ \\
\hline
\end{tabular}

Vale ressaltar que as funções adotadas para testes representam uma parcela dos possíveis problemas de otimização onde os algoritmos heurísticos podem ser utilizados como métodos de solução, pois a literatura coleciona inúmeras outras com possibilidade de análise. Mas vale ressaltar que as funções adotadas neste trabalho são comumente utilizadas como medidas de benchmark, facilitando a compreensão dos resultados e possibilitando comparações futuras.

\subsubsection{Definição das Escalas de Precisão e Tamanho do Vetor Can- didato}

Antes da realização dos testes de desempenho de cada técnica e da definição de parâmetros e características de construção dos algoritmos, deve-se considerar a codificação do problema considerando as escalas de precisão. Assim, para cada função escolheu-se, sem perda de generalidade, uma quantidade de casas de precisão, considerando codificação binária, resultando em um tamanho de vetor candidato (denominado de $Q_{\text {indiv }}$ ) da forma:

$$
Q_{\text {indiv }}=n\left\lceil\log _{2}\left(\Delta x \cdot 10^{Q_{i n t}}\right)\right\rceil
$$

onde $Q_{\text {indiv }}$ representa o tamanho do vetor candidato em bits, $n$ representa a dimensão, ou seja, a quantidade de variáveis que devem ser encontradas, $Q_{\text {int }}$ representa o número de casas decimais de precisão escolhida, $\lceil$.$\rceil representa o$ 
operador menor inteiro maior que o argumento e $\Delta x$ é definido como:

$$
\Delta x=x_{\max }-x_{\min }
$$

onde $x_{\max }$ e $x_{\min }$ representam o limite superior e o limite inferior do valor que cada $x_{i}$ pode assumir, respectivamente.

Função F1: $\quad$ Para a função F1 de De Jong foi considerado $n=3$, uma precisão de duas casas decimais e um intervalo de busca de $-5,12 \leq x_{i} \leq 5,12$. Portanto, para o exemplo utilizado neste trabalho, resulta em um vetor candidato de tamanho:

$$
Q_{\text {indiv }}=3\left\lceil\log _{2}\left(10,24.10^{2}\right)\right\rceil=30 \text { bits }
$$

Função F2: Para a função F2 de De Jong foi considerado $n=2$, uma precisão de três casas decimais e um intervalo de busca de $-2,048 \leq x_{i} \leq 2,048$. Desta forma, considerando codificação binária, resulta em um tamanho de vetor candidato dado por:

$$
Q_{\text {indiv }}=2\left\lceil\log _{2}\left(4,096.10^{3}\right)\right\rceil=24 \text { bits }
$$

Função F3: Para a função F3 de De Jong foi considerado $n=5$, uma precisão de duas casas decimais e um intervalo de busca de $-5,12 \leq x_{i} \leq 5,12$. Desta forma, considerando codificação binária, resulta em um tamanho de vetor candidato dado por:

$$
Q_{\text {indiv }}=5\left\lceil\log _{2}\left(10,24.10^{2}\right)\right\rceil=50 \text { bits }
$$

Função F4: Para a função F4 de Michalewicz foi considerado $n=2$, uma precisão de duas casas decimais e um intervalo de busca de $0 \leq x_{i} \leq \pi$. Desta forma, considerando codificação binária, resulta em um tamanho de vetor candidato dado por:

$$
Q_{\text {indiv }}=2\left\lceil\log _{2}\left(\pi \cdot 10^{2}\right)\right\rceil=18 \text { bits }
$$


Função F5: Para a função F5 de Schaffer foi considerado $n=2$, uma precisão de duas casas decimais e um intervalo de busca de $-20 \leq x_{i} \leq 20$. Desta forma, considerando codificação binária, resulta em um tamanho de vetor candidato dado por:

$$
Q_{\text {indiv }}=2\left\lceil\log _{2}\left(40.10^{2}\right)\right\rceil=24 \text { bits }
$$

Função F6: Para a função F6 de Ackley foi considerado $n=2$, uma precisão de três casas decimais e um intervalo de busca de $-50 \leq x_{i} \leq 50$. Desta forma, considerando codificação binária, resulta em um tamanho de vetor candidato dado por:

$$
Q_{\text {indiv }}=2\left\lceil\log _{2}\left(100.10^{3}\right)\right\rceil=34 \text { bits }
$$

Função F7: $\quad$ Para a função F7 de Rastrigin foi considerado $n=2$, uma precisão de três casas decimais e um intervalo de busca de $-5,12 \leq x_{i} \leq 5,12$. Desta forma, considerando codificação binária, resulta em um tamanho de vetor candidato dado por:

$$
Q_{\text {indiv }}=2\left\lceil\log _{2}\left(10,24.10^{3}\right)\right\rceil=28 \text { bits }
$$

Função F8: Para a função F8 de Schwefel foi considerado $n=2$, uma precisão de duas casas decimais e um intervalo de busca de $-500 \leq x_{i} \leq 500$. Desta forma, considerando codificação binária, resulta em um tamanho de vetor candidato dado por:

$$
Q_{\text {indiv }}=2\left\lceil\log _{2}\left(1000.10^{2}\right)\right\rceil=34 \text { bits }
$$

Função F9: Para a função F9 denominada 6-Hump Camelback foi considerado $n=2$, uma precisão de três casas decimais e um intervalo de busca de $-3 \leq x_{i} \leq 3$. Desta forma, considerando codificação binária, resulta em um tamanho de vetor candidato dado por:

$$
Q_{\text {indiv }}=2\left\lceil\log _{2}\left(6.10^{3}\right)\right\rceil=32 \text { bits }
$$


Função F10: Para a função F10 de Shubert foi considerado $n=2$, uma precisão de quatro casas decimais e um intervalo de busca de $-5 \leq x_{i} \leq 5$. Desta forma, considerando codificação binária, resulta em um tamanho de vetor candidato dado por:

$$
Q_{\text {indiv }}=2\left\lceil\log _{2}\left(10.10^{4}\right)\right\rceil=34 \text { bits }
$$

Por fim, a tabela 4.2 apresenta um resumo dos principais valores para cada função de testes visando à comparação com os resultados obtidos.

Tabela 4.2: Principais valores associados a cada função de testes.

\begin{tabular}{|c|c|c|c|c|c|c|}
\hline & Dimensão & $\begin{array}{c}\text { Intervalo } \\
\text { de } \\
\text { busca }\end{array}$ & $\begin{array}{c}\text { Precisão } \\
\text { (casas } \\
\text { decimais) }\end{array}$ & $\begin{array}{c}\text { Tamanho } \\
\text { indivíduo } \\
\text { (bits) }\end{array}$ & $\begin{array}{c}x_{i} \\
\text { ótimo }\end{array}$ & $\begin{array}{l}F(\mathbf{x}) \\
\text { ótimo }\end{array}$ \\
\hline 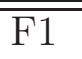 & 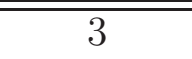 & $-5,12$ a 5,12 & $\overline{2}$ & $\overline{30}$ & $\overline{0}$ & $\overline{0}$ \\
\hline $\mathrm{F} 2$ & 2 & $-2,048$ a 2,048 & 3 & 24 & 1 & 0 \\
\hline F3 & 5 & $-5,12$ a 5,12 & 2 & 50 & -5 & -25 \\
\hline F4 & 2 & 0 a $\pi$ & 2 & 18 & 2,19 e 1,92 & $-1,735$ \\
\hline F5 & 2 & -20 a 20 & 2 & 24 & 0 & 0 \\
\hline F6 & 2 & -50 a 50 & 3 & 34 & 0 & 0 \\
\hline F7 & 2 & $-5,12$ a 5,12 & 3 & 28 & 0 & 0 \\
\hline F8 & 2 & -500 a 500 & 2 & 34 & 420,97 & 0 \\
\hline F9 & 2 & -3 a 3 & 3 & 32 & $\begin{array}{c}0,08984 \mathrm{ou} \\
-0,71265\end{array}$ & $-1,032$ \\
\hline F10 & 2 & -5 a 5 & 4 & 34 & 18 possíveis & $-186,7$ \\
\hline
\end{tabular}

\subsection{Resultados de Otimização dos Parâmetros}

Visando a determinação de estratégias heurísticas que possibilitam encontrar boas soluções, torna-se necessário uma etapa de otimização para a definição dos parâmetros e estratégias inerentes a cada algoritmo. Vale ressaltar que valores comumente utilizados na literatura podem não garantir boas soluções, pois a maioria dos trabalhos consideram aplicações em problemas específicos, sendo testados poucos valores. Desta forma, esta seção tem por finalidade a análise sistemática dos parâmetros e estratégias específicas de cada algoritmo considerando uma competição do tipo Decathlon (BURKE et al., 2009, 2010) para as 10 funções descritas na seção 4.1 .

Outra informação relevante diz respeito ao número de simulações realizadas, pois para a obtenção das tabelas e figuras foram consideradas médias de pelo menos 1000 simulações de cada algoritmo para cada função, parâmetro ou estra- 
tégia visando à determinação dos valores médios, respectivos desvios padrões e das medidas de qualidade descritas na seção 3.6. Assim, os resultados apresentam intervalos de confiança que proporcionam análises consistentes.

Como exemplo da análise realizada para cada parâmetro e estratégia optou-se por apresentar a análise de otimização do tamanho do poço de cruzamento considerando a descrição das tabelas de resultados para todas as simulações realizadas. Após, é possível atribuir a pontuação a cada resultado (competição Decathlon), resultando na escolha daquele que atingir a maior pontuação.

Entretanto, estas tabelas são extensas, dificultando uma análise rápida dos melhores valores. Assim, para o caso do poço de cruzamento foi apresentada a análise completa, considerando as tabelas de resultados, de pontuação e as respectivas figuras de convergência.

Para os outros parâmetros e estratégias optou-se pela apresentação somente das figuras de convergência para 4 funções (provas) das 10 realizadas e uma descrição da pontuação dos parâmetros e estratégias vencedoras evitando tornar o texto longo e cansativo.

\subsubsection{Otimização dos parâmetros do Algoritmo Genético}

Inicialmente, optou-se pela análise e otimização do parâmetro de tamanho de poço de cruzamento $(M)$ do algoritmo genético após definição do tamanho da população ${ }^{3}$. Assim, a determinação do tamanho do poço de cruzamento pode ser realizada considerando certa proporção do tamanho da população $p$ que será destinada para a etapa de reprodução.

Posteriormente, realiza-se uma análise sobre a estratégia de seleção dos genitores mais adequada para cada problema, considerando as opções de roleta circular (roulette wheel) e estratégia denominada $p$ - sort.

Após definição da quantidade de genitores e da forma de selecioná-los, devemse ajustar as taxas de crossover e mutação, respectivamente. Por fim, é necessário estabelecer a estratégia de reposição da população considerando a população conjunta (genitora e progênie).

\footnotetext{
${ }^{3}$ Equação apresentada na seção 3.3.1.
} 


\subsubsection{Tamanho do poço de cruzamento}

Conforme descrito na seção 3.3.4.1, o tamanho do poço de cruzamento $(M)$ controla a pressão no processo de competição entre os indivíduos. Ao se escolher um $M$ pequeno, certamente os melhores genitores (parents) serão selecionados; no entanto, haverá uma diminuição na diversificação do universo de busca, podendose encontrar uma solução local. Utilizando um $M$ grande, genitores com uma aptidão pequena serão selecionados e suas características ruins serão mantidas nas próximas gerações, trazendo lentidão na convergência (MITCHELL, 1998; YEN; HANZO, 2004).

Desta forma, visando à definição do valor mais adequado, ou seja, que garante boas soluções independente da prova realizada (função) e facilidade de adaptação em outros problemas, realizou-se simulações considerando o tamanho do poço de cruzamento como uma parcela do tamanho da população, sendo dividida em 10 possibilidades de valores, resultando em $M=[0,1 p, 0,2 p, \ldots, 0,9 p, 1 p]$. Além disso, as figuras de mérito consideradas foram:

- $F(\overline{\mathbf{x}})$ que corresponde ao valor médio da função custo após otimização.

- $\sigma_{F(\overline{\mathbf{x}})}$ que corresponde ao desvio padrão médio da função custo após otimização .

- $\overline{\mathbf{x}_{i}}$ que corresponde ao valor médio das variáveis após otimização ${ }^{4}$.

- $\sigma_{\overline{\mathbf{x}_{i}}}$ que corresponde ao desvio padrão médio das variáveis após otimização ${ }^{4}$.

Para as simulações do algoritmo genético na otimização do poço de cruzamento foram consideradas os parâmetros apresentados na tabela 4.3.

Tabela 4.3: Parâmetros utilizados na simulação da otimização do tamanho do poço de cruzamento

\begin{tabular}{l|c}
\hline Parâmetro & Tipo / Valor \\
\hline$G_{t}$ & gerações / 40 \\
mutação & gaussiana / $10 \%$ \\
crossover & uniforme / $50 \%$ \\
seleção & $p$-sort \\
reposição & elitismo global $/ 2 p$ \\
\hline
\end{tabular}

A tabela 4.4 apresenta os valores obtidos ${ }^{5}$ para cada valor de $M$ e para cada função (F1 a F10).

\footnotetext{
${ }^{4}$ Esta figura de mérito só foi considerada para os casos onde $\mathbf{x}_{1}=\mathbf{x}_{2}=\ldots=\mathbf{x}_{n}$.

${ }^{5}$ Conforme já mencionado, os valores apresentados consideram a média de pelo menos 1000 simulações realizadas para cada valor analisado.
} 
Nota-se que os melhores valores da tabela 4.4 estão destacados utilizando formatação sublinhado e itálico para ajudar na análise do melhor valor para o tamanho do poço de cruzamento. Além disso, os valores obtidos para todas as provas (funções) apresentam proximidade com os valores teóricos. 
Tabela 4.4: Simulações para o tamanho do poço de cruzamento considerando as funções F1 a F10

\begin{tabular}{|c|c|c|c|c|c|c|c|c|c|c|c|}
\hline & & $0,1 \mathrm{p}$ & $0,2 p$ & $0,3 \mathrm{p}$ & $0,4 \mathrm{p}$ & $0,5 \mathrm{p}$ & $0,6 \mathrm{p}$ & $0,7 \mathrm{p}$ & $0,8 \mathrm{p}$ & $0,9 \mathrm{p}$ & $\mathrm{p}$ \\
\hline \multirow{4}{*}{ F1 } & $F(\overline{\mathbf{x}})$ & $\underline{4,13 E-04}$ & $8,60 \mathrm{E}-04$ & $9,84 \mathrm{E}-04$ & 2,38E-03 & $6,46 \mathrm{E}-03$ & 1,08E-02 & $2,10 \mathrm{E}-02$ & $3,20 \mathrm{E}-02$ & $3,86 \mathrm{E}-02$ & 7,39E-02 \\
\hline & $\sigma_{F(\overline{\mathbf{x}})}$ & 5,42E-04 & $2,28 \mathrm{E}-03$ & $1,61 \mathrm{E}-03$ & $3,66 \mathrm{E}-03$ & $1,20 \mathrm{E}-02$ & $2,15 \mathrm{E}-02$ & $3,53 \mathrm{E}-02$ & $5,62 \mathrm{E}-02$ & $4,98 \mathrm{E}-02$ & $1,09 \mathrm{E}-01$ \\
\hline & $\overline{\mathbf{x}_{i}}$ & $-5,11 \mathrm{E}-03$ & $-5,26 \mathrm{E}-03$ & $-4,86 \mathrm{E}-03$ & $-4,06 \mathrm{E}-03$ & $-4,55 \mathrm{E}-03$ & $-7,16 \mathrm{E}-04$ & $-6,21 \mathrm{E}-03$ & $7,75 \mathrm{E}-03$ & $1,16 E-04$ & $-2,43 \mathrm{E}-03$ \\
\hline & $\sigma_{\overline{\mathbf{x}_{i}}}$ & 5,00E-05 & $5,50 \mathrm{E}-04$ & $3,40 \mathrm{E}-04$ & $1,56 \mathrm{E}-03$ & $1,80 \mathrm{E}-03$ & $5,77 \mathrm{E}-03$ & $3,69 \mathrm{E}-03$ & $4,82 \mathrm{E}-03$ & $1,35 \mathrm{E}-02$ & 4,10E-03 \\
\hline \multirow{4}{*}{$\mathrm{F} 2$} & $F(\overline{\mathbf{x}})$ & $2,40 \mathrm{E}-01$ & $1,45 \mathrm{E}-01$ & $1,25 \mathrm{E}-01$ & $8,24 \mathrm{E}-02$ & $7,46 \mathrm{E}-02$ & $6,49 \mathrm{E}-02$ & $5,42 \mathrm{E}-02$ & $4,24 \mathrm{E}-02$ & $3,98 \mathrm{E}-02$ & $3,43 E-02$ \\
\hline & $\sigma_{F(\overline{\mathbf{x}})}$ & $4,17 \mathrm{E}-01$ & $2,76 \mathrm{E}-01$ & $2,59 \mathrm{E}-01$ & $1,96 \mathrm{E}-01$ & $1,91 \mathrm{E}-01$ & $1,73 \mathrm{E}-01$ & $1,52 \mathrm{E}-01$ & $1,21 \mathrm{E}-01$ & $1,25 \mathrm{E}-01$ & $\underline{1,08 E-01}$ \\
\hline & $\overline{\mathbf{x}_{i}}$ & $7,74 \mathrm{E}-01$ & $8,34 \mathrm{E}-01$ & $8,78 \mathrm{E}-01$ & $9,17 \mathrm{E}-01$ & $9,44 \mathrm{E}-01$ & $9,43 \mathrm{E}-01$ & $9,59 \mathrm{E}-01$ & $9,75 \mathrm{E}-01$ & $\underline{9,80 E-01}$ & $9,74 \mathrm{E}-01$ \\
\hline & $\sigma_{\overline{\mathbf{x}_{i}}}$ & $5,01 \mathrm{E}-01$ & $4,19 \mathrm{E}-01$ & $4,04 \mathrm{E}-01$ & $3,51 \mathrm{E}-01$ & $3,37 \mathrm{E}-01$ & $3,14 \mathrm{E}-01$ & $2,90 \mathrm{E}-01$ & $2,65 \mathrm{E}-01$ & $2,47 \mathrm{E}-01$ & $\underline{2,30 E-01}$ \\
\hline \multirow{4}{*}{ F3 } & $F(\overline{\mathbf{x}})$ & $-24,59$ & $-24,85$ & $-24,93$ & $-24,96$ & $-24,98$ & $-24,98$ & $-24,99$ & $-24,98$ & $-24,98$ & $-24,97$ \\
\hline & $\sigma_{F(\overline{\mathbf{x}})}$ & $5,92 \mathrm{E}-01$ & $3,79 \mathrm{E}-01$ & $2,63 \mathrm{E}-01$ & $1,78 \mathrm{E}-01$ & $1,36 \mathrm{E}-01$ & $1,36 \mathrm{E}-01$ & 8,34E-02 & $1,04 \mathrm{E}-01$ & $1,21 \mathrm{E}-01$ & $1,53 \mathrm{E}-01$ \\
\hline & $\overline{\mathbf{x}_{i}}$ & $\underline{-5}$ & $-5,04$ & $-5,05$ & $-5,06$ & $-5,06$ & $-5,06$ & $-5,06$ & $-5,06$ & $-5,06$ & $-5,06$ \\
\hline & $\sigma_{\overline{\mathbf{x}_{i}}}$ & $2,09 \mathrm{E}-01$ & $1,32 \mathrm{E}-01$ & $9,59 \mathrm{E}-02$ & $6,64 \mathrm{E}-02$ & $5,61 \mathrm{E}-02$ & $5,46 \mathrm{E}-02$ & $\underline{3,97 E-02}$ & $4,72 \mathrm{E}-02$ & 4,69E-02 & $5,16 \mathrm{E}-02$ \\
\hline \multirow{5}{*}{$\mathrm{F} 4$} & $F(\overline{\mathbf{x}})$ & $-1,76$ & $-1,793$ & $-1,791$ & $-1,793$ & $-1,798$ & $-1,797$ & $-1,799$ & $-1,799$ & $-1,798$ & $-1,799$ \\
\hline & $\sigma_{F(\overline{\mathbf{x}})}$ & $1,11 \mathrm{E}-01$ & $3,35 \mathrm{E}-02$ & $4,81 \mathrm{E}-02$ & $3,98 \mathrm{E}-02$ & $8,68 \mathrm{E}-03$ & $2,35 \mathrm{E}-02$ & $6,62 \mathrm{E}-03$ & $6,62 \mathrm{E}-03$ & $2,27 \mathrm{E}-02$ & 3,23E-03 \\
\hline & $\overline{\mathbf{x}_{i}}$ & $2,207 \mathrm{e}$ & $2,202 \mathrm{e}$ & $\underline{2,200 e}$ & $2,204 \mathrm{e}$ & $2,201 \mathrm{e}$ & $2,203 \mathrm{e}$ & $2,203 \mathrm{e}$ & $2,202 \mathrm{e}$ & $2,204 \mathrm{e}$ & $2,204 \mathrm{e}$ \\
\hline & & 1,573 & 1,567 & 1,573 & 1,567 & 1,567 & 1,567 & 1,567 & 1,567 & 1,567 & 1,567 \\
\hline & $\sigma_{\overline{\mathbf{x}_{i}}}$ & $7,33 \mathrm{E}-02$ & $1,25 \mathrm{E}-02$ & $5,05 \mathrm{E}-02$ & $1,29 \mathrm{E}-02$ & $7,53 \mathrm{E}-03$ & $9,01 \mathrm{E}-03$ & $6,31 \mathrm{E}-03$ & $5,71 \mathrm{E}-03$ & 7,35E-03 & $\underline{4,34 E-03}$ \\
\hline
\end{tabular}


Tabela 4.4: Simulações para o tamanho do poço de cruzamento considerando as funções F1 a F10 - continuação

\begin{tabular}{|c|c|c|c|c|c|c|c|c|c|c|c|}
\hline & & $0,1 \mathrm{p}$ & $0,2 p$ & $0,3 p$ & $0,4 \mathrm{p}$ & $0,5 p$ & $0,6 \mathrm{p}$ & $0,7 \mathrm{p}$ & $0,8 \mathrm{p}$ & $0,9 p$ & p \\
\hline \multirow{4}{*}{ F5 } & $(\overline{\mathbf{x}})$ & $1,40 \mathrm{E}-01$ & $1,30 \mathrm{E}-01$ & $1,38 \mathrm{E}-01$ & 1,32E-01 & $1,27 \mathrm{E}-01$ & 1,33E-01 & $\underline{1,23 E-01}$ & $1,32 \mathrm{E}-01$ & $1,28 \mathrm{E}-01$ & $1,36 \mathrm{E}-01$ \\
\hline & $\sigma_{F(\overline{\mathbf{x}})}$ & $9,32 \mathrm{E}-02$ & 8,39E-02 & 7,97E-02 & 8,32E-02 & 8,09E-02 & 7,63E-02 & 8,10E-02 & 7,67E-02 & 7,88E-02 & 7,62E-02 \\
\hline & $\overline{\mathbf{x}_{i}}$ & $-6,67 \mathrm{E}-03$ & $-5,46 \mathrm{E}-03$ & $-5,51 \mathrm{E}-03$ & $-4,26 E-03$ & $-5,21 \mathrm{E}-03$ & $-4,86 \mathrm{E}-03$ & $-4,52 \mathrm{E}-03$ & $-4,93 \mathrm{E}-03$ & $-4,97 \mathrm{E}-03$ & $-5,07 \mathrm{E}-03$ \\
\hline & $\sigma_{\overline{\mathbf{x}_{i}}}$ & $2,87 \mathrm{E}-02$ & $2,55 \mathrm{E}-02$ & $1,86 \mathrm{E}-02$ & 2,08E-02 & $1,58 \mathrm{E}-02$ & $1,23 \mathrm{E}-02$ & 1,19E-02 & $1,31 \mathrm{E}-02$ & 1,07E-02 & $1,28 \mathrm{E}-02$ \\
\hline \multirow{4}{*}{ F6 } & $F(\overline{\mathbf{x}})$ & $1,91 \mathrm{E}-03$ & 1,91E-03 & $1,87 E-03$ & 1,89E-03 & $2,24 \mathrm{E}-03$ & $3,10 \mathrm{E}-03$ & $4,15 \mathrm{E}-03$ & 7,96E-03 & 1,08E-02 & $1,98 \mathrm{E}-02$ \\
\hline & $\sigma_{F(\overline{\mathbf{x}})}$ & $1,11 \mathrm{E}-03$ & $1,09 E-03$ & 1,13E-03 & 1,39E-03 & $2,44 \mathrm{E}-03$ & $4,11 \mathrm{E}-03$ & $5,04 \mathrm{E}-03$ & 1,33E-02 & 1,49E-02 & $5,08 \mathrm{E}-02$ \\
\hline & $\overline{\mathbf{x}_{i}}$ & $-3,95 \mathrm{E}-04$ & $-3,91$ & $-3,83 \mathrm{E}-04$ & -04 & $-3,81 \mathrm{E}-04$ & $-3,52 \mathrm{E}-04$ & $-3,02 \mathrm{E}-04$ & $-3,92 \mathrm{E}-04$ & $-2,96 E-04$ & $-5,31 \mathrm{E}-04$ \\
\hline & $\sigma_{\overline{\mathbf{x}_{i}}}$ & $3,81 \mathrm{E}-04$ & $3,81 E-04$ & $3,84 \mathrm{E}-04$ & $4,51 \mathrm{E}-04$ & $6,89 \mathrm{E}-04$ & 1,13E-03 & $1,48 \mathrm{E}-03$ & $3,21 \mathrm{E}-03$ & $3,92 \mathrm{E}-03$ & 7,95E-03 \\
\hline \multirow{4}{*}{ F7 } & $F(\overline{\mathbf{x}})$ & $9,10 \mathrm{E}-01$ & -01 & 5,8 & -01 & -01 & -01 & 01 & -01 & -01 & E-01 \\
\hline & $\sigma_{F(\overline{\mathbf{x}})}$ & 1,18 & $9,30 \mathrm{E}-01$ & $7,96 \mathrm{E}-01$ & $6,77 \mathrm{E}-01$ & $6,48 \mathrm{E}-01$ & $5,68 \mathrm{E}-01$ & $5,58 \mathrm{E}-01$ & 5,24E-01 & $5,51 \mathrm{E}-01$ & $5,32 \mathrm{E}-01$ \\
\hline & $\overline{\mathbf{x}_{i}}$ & $-3,98 \mathrm{E}-02$ & $-2,48 \mathrm{E}-02$ & $\underline{1,50 E-03}$ & 8,86E-03 & $-7,48 \mathrm{E}-03$ & $-4,15 \mathrm{E}-03$ & $5,51 \mathrm{E}-03$ & $-1,09 \mathrm{E}-02$ & $-6,20 \mathrm{E}-03$ & $\mathrm{E}-02$ \\
\hline & $\sigma_{\overline{\mathbf{x}_{i}}}$ & $6,02 \mathrm{E}-01$ & $5,34 \mathrm{E}-01$ & $4,88 \mathrm{E}-01$ & $4,30 \mathrm{E}-01$ & $4,12 \mathrm{E}-01$ & $3,85 \mathrm{E}-01$ & $3,56 \mathrm{E}-01$ & $3,64 \mathrm{E}-01$ & $3,68 \mathrm{E}-01$ & $3,55 E-01$ \\
\hline \multirow{4}{*}{ F8 } & $F(\overline{\mathbf{x}})$ & 4,08 & 2,48 & 1,91 & 1,74 & 1,49 & 0,97 & 0,95 & 0,82 & 0,84 & 0,93 \\
\hline & $\sigma_{F(\overline{\mathbf{x}})}$ & 16,81 & 13,58 & 10,16 & 10,96 & 9,92 & 7,62 & 5,87 & 6,77 & 6,72 & 8,12 \\
\hline & $\overline{\mathbf{x}_{i}}$ & 416,31 & 419,52 & 420,05 & 419,25 & 419,55 & 420,15 & 421,34 & 420,54 & 420,95 & 420,14 \\
\hline & $\sigma_{\overline{\overline{\mathbf{x}}_{i}}}$ & 62,64 & 39,65 & 32,44 & 39,65 & 36,3 & 28,06 & 1,91 & 22,92 & 16,27 & 28,05 \\
\hline & $F(\overline{\mathbf{x}})$ & $-1,023$ & $-1,025$ & $-1,025$ & $-1,026$ & $-1,027$ & $-1,027$ & 1,027 & $-1,028$ & $-1,027$ & $-1,026$ \\
\hline F9 & $\sigma_{F(\overline{\mathbf{x}})}$ & 1,19E-02 & $1,04 \mathrm{E}-02$ & 1,03E-02 & $9,67 \mathrm{E}-03$ & 7,33E-03 & $7,84 \mathrm{E}-03$ & 7,32E-03 & $6,55 E-03$ & 8,00E-03 & $7,82 \mathrm{E}-03$ \\
\hline
\end{tabular}


Tabela 4.4: Simulações para o tamanho do poço de cruzamento considerando as funções F1 a F10 - continuação

\begin{tabular}{|c|c|c|c|c|c|c|c|c|c|c|c|}
\hline & & $0,1 \mathrm{p}$ & $0,2 \mathrm{p}$ & $0,3 p$ & $0,4 \mathrm{p}$ & $0,5 \mathrm{p}$ & $0,6 \mathrm{p}$ & $0,7 \mathrm{p}$ & $0,8 \mathrm{p}$ & $0,9 \mathrm{p}$ & $\mathrm{p}$ \\
\hline & $\overline{\mathbf{x}_{i}}$ & $2,19 \mathrm{E}-02$ & 4,99E-03 & $6,17 \mathrm{E}-03$ & $2,15 \mathrm{E}-02$ & $3,18 \mathrm{E}-03$ & $-1,08 \mathrm{E}-02$ & 6,39E-03 & $-7,09 \mathrm{E}-03$ & $6,08 \mathrm{E}-03$ & 8,07E-03 \\
\hline & $\sigma_{\overline{\mathbf{x}_{i}}}$ & $5,13 \mathrm{E}-01$ & $5,14 \mathrm{E}-01$ & $5,13 \mathrm{E}-01$ & $5,12 \mathrm{E}-01$ & $5,13 \mathrm{E}-01$ & $5,13 \mathrm{E}-01$ & $5,12 \mathrm{E}-01$ & 5,12E-01 & $5,13 \mathrm{E}-01$ & $5,12 \mathrm{E}-01$ \\
\hline \multirow{4}{*}{ F10 } & $F(\overline{\mathbf{x}})$ & $-184,78$ & $-185,48$ & $-185,7$ & $-186,38$ & $-186,36$ & $-186,41$ & $-186,56$ & $-186,54$ & $-186,52$ & $-186,62$ \\
\hline & $\sigma_{F(\overline{\mathbf{x}})}$ & 12,52 & 10,16 & 9,05 & 3,98 & 3,42 & 3,27 & 1,31 & 1,16 & 1,96 & 0,25 \\
\hline & $\overline{\mathbf{x}_{i}}$ & $6,65 \mathrm{E}-01$ & $6,17 \mathrm{E}-01$ & $5,76 \mathrm{E}-01$ & $5,70 \mathrm{E}-01$ & $5,66 \mathrm{E}-01$ & $6,13 \mathrm{E}-01$ & $5,21 \mathrm{E}-01$ & $4,40 \mathrm{E}-01$ & $5,03 \mathrm{E}-01$ & $5,40 \mathrm{E}-01$ \\
\hline & $\sigma_{\overline{\mathbf{x}_{i}}}$ & 2,63 & 2,63 & 2,6 & 2,6 & 2,6 & 2,62 & 2,58 & 2,54 & 2,57 & 2,59 \\
\hline
\end{tabular}


A partir da tabela 4.4 é possível atribuir uma pontuação para cada prova realizada (função) e cada modalidade (figuras de mérito) considerando a distribuição de pontos ${ }^{6}$ apresentada na tabela 4.5. Neste trabalho considerou-se que cada figura de mérito possui mesmo peso, ou seja, os valores obtidos para as médias e desvio padrões possuem a mesma escala de pontuação. Todavia, outras escalas de pontuação não convencionais podem ser utilizadas, mas estas devem ser escolhidas com cautela, pois podem enviesar a análise.

Tabela 4.5: Tabela de pontuação utilizada

\begin{tabular}{c|c}
\hline Colocação & Pontuação \\
\hline $1^{o}$ colocado & 10 \\
$2^{o}$ colocado & 9 \\
$3^{o}$ colocado & 8 \\
$4^{o}$ colocado & 7 \\
$5^{o}$ colocado & 6 \\
$6^{o}$ colocado & 5 \\
$7^{o}$ colocado & 4 \\
$8^{o}$ colocado & 3 \\
$9^{o}$ colocado & 2 \\
$10^{o}$ colocado & 1 \\
\hline
\end{tabular}

A tabela 4.6 apresenta a pontuação para cada prova considerando as figuras de mérito envolvidas. Nota-se ao final da tabela a somatória da pontuação obtida. Assim, o valor para o tamanho do poço de cruzamento escolhido deve ser o que possuir a maior pontuação geral, pois este resultará, em média, em melhores resultados.

Para os testes realizados, o melhor valor do poço de cruzamento resultou em $M=0,7 p$. Este resultado é interessante, pois apresenta-se como um balanço entre poucos genitores (pouca variabilidade genética) e muitos genitores (características genéticas ruins). Desta forma, o tamanho do poço de cruzamento para as demais simulações consideram $M=0,7 p$, ou seja, $70 \%$ da população com melhor aptidão é destinada à etapa de reprodução.

\subsubsection{Escolha da estratégia de seleção dos genitores}

A estratégia procura privilegiar os melhores genitores na esperança de que seus descendentes possuam melhores valores de aptidão. Desta forma, implementouse as duas estratégias de seleção comentadas na seção 3.3.4.2, sendo denominadas $p$-sort e roulette wheel (roleta circular).

\footnotetext{
${ }^{6}$ Considerou-se atribuição de pontuação convencional utilizada em provas esportivas.
} 
Tabela 4.6: Colocação atribuída aos parâmetros por prova e modalidade e total de pontos conquistados

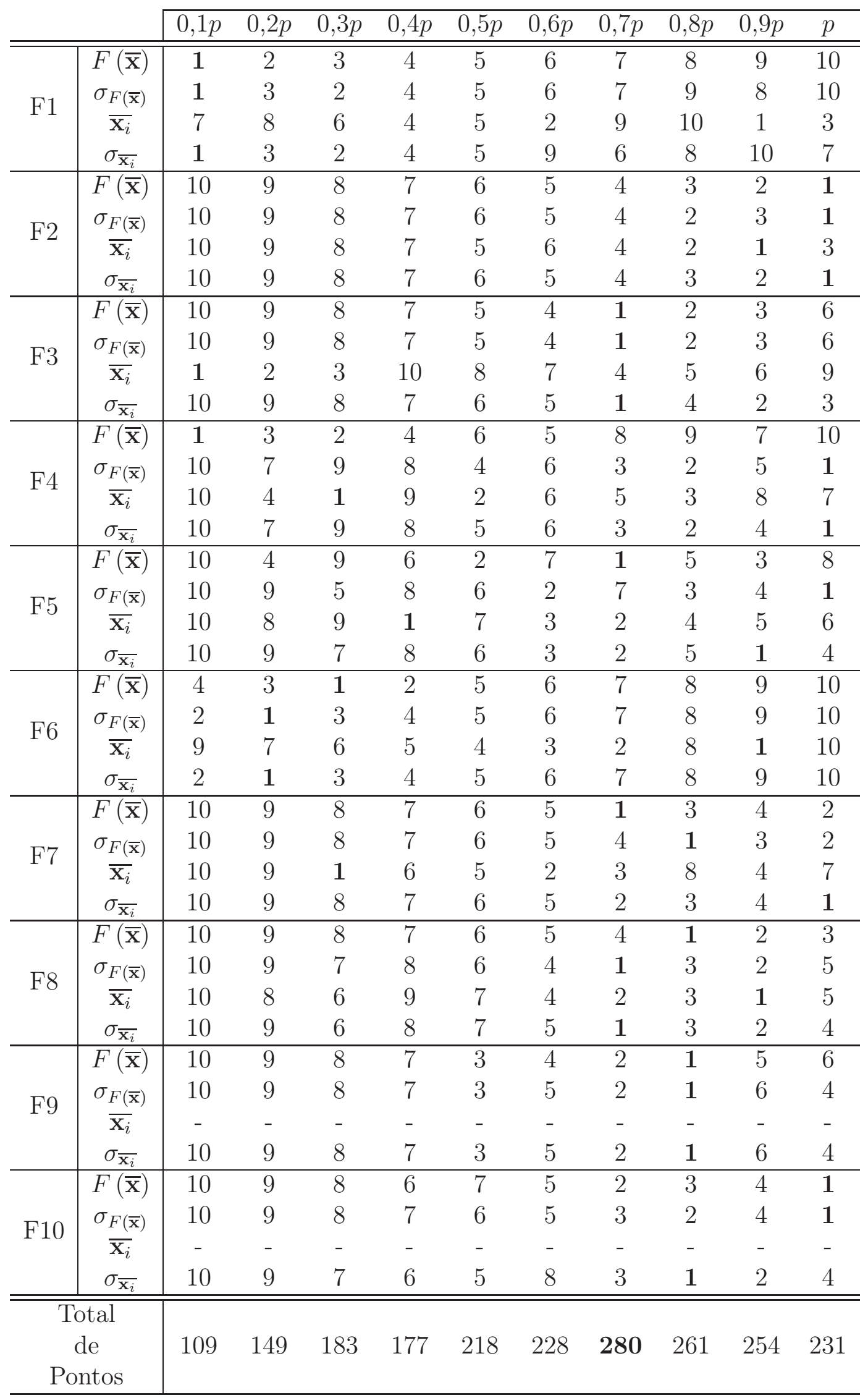


A figura 4.11 apresenta o resultado de desempenho e convergência para as duas estratégias considerando as funções F1, F5, F7 e F10. Vale ressaltar que o mesmo comportamento foi observado para as demais funções. Por isso, optou-se por não inserir as demais figuras no corpo do trabalho. Nota-se que a estratégia $p$ sort apresenta uma convergência mais abrupta/rápida além de apresentar limiares de desempenho coerentes e próximos aos valores teóricos ótimos. Desta forma, todas as simulações posteriores consideraram a estratégia de seleção $p$-sort.
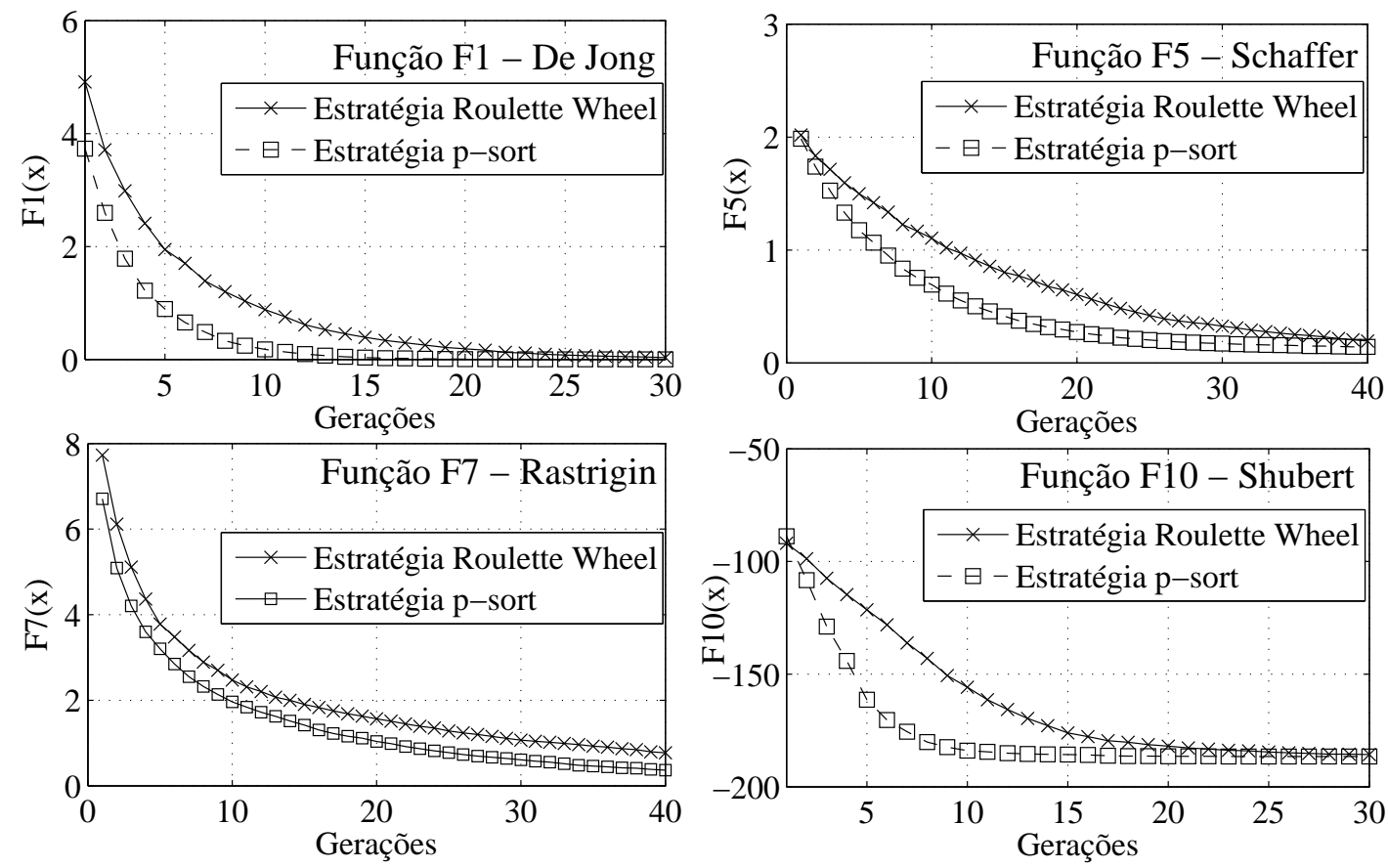

Figura 4.11: Análise das estratégias de seleção dos genitores do GA para as funções F1, F5, F7 e F10.

\subsubsection{Escolha da estratégia de crossover}

Os operadores genéticos (crossover e mutação) são necessários para que a população se diversifique e mantenha características de adaptação adquiridas nas gerações anteriores. Assim, devem garantir que qualquer posição do espaço de busca possa ser testado mas ao mesmo tempo devem identificar regiões mais atrativas em busca de refinamento da solução.

A figura 4.12 apresenta a convergência e a tendência de resultado para três estratégias de crossover utilizadas na análise para as funções F1, F5, F7 e F10. Novamente, para todas as simulações realizadas, a estratégia conhecida como crossover uniforme apresentou o melhor desempenho, tornando-se o vencedor da maratona. Portanto, a estratégia de crossover uniforme foi adotada para as demais simulações. Mas nota-se que as demais estratégias, principalmente a de crossover multiponto (com quatro pontos), apresentaram desempenho satisfató- 
rio sendo marginalmente inferiores à estratégia uniforme. Portanto, podem ser utilizadas sem comprometer significativamente o desempenho do algoritmo genético. Mas a estratégia de crossover uniforme, além de apresentar desempenho ligeiramente superior, apresenta facilidade de implementação e baixa complexidade inerente ${ }^{7}$.
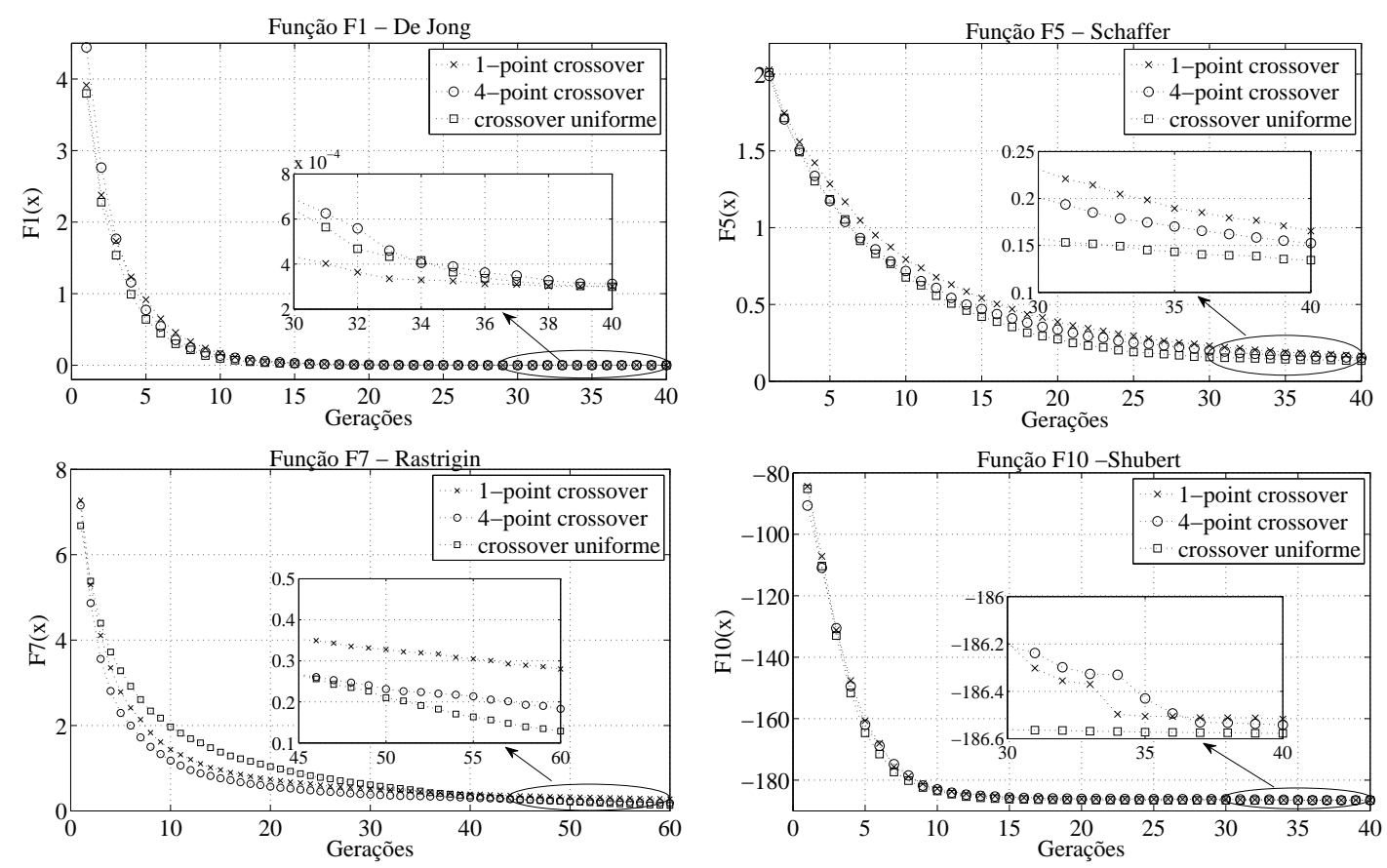

Figura 4.12: Análise das estratégias de crossover do GA para as funções F1, F5, F7 e F10.

\subsubsection{Taxa de mutação}

Para a análise de otimização da taxa de mutação do algoritmo genético, optouse pelo teste de dez possíveis valores considerando a taxa média de mutação conforme apresentado no capítulo 2, resultando em:

$$
p_{m}=[0,01 \%, 0,5 \%, 1 \%, 3 \%, 5 \%, 7 \%, 10 \%, 15 \%, 20 \%, 30 \%]
$$

Além disso, considera-se a utilização da mutação aleatória baseada na função normal, sendo denominada de mutação gaussiana.

Os resultados foram tabelados da mesma forma que a análise do tamanho do poço de cruzamento e posteriormente foi atribuída a pontuação. Ao final, a taxa de mutação $p_{m}=10 \%$ apresentou a maior pontuação final, sendo adotada para as demais simulações.

\footnotetext{
${ }^{7} \mathrm{~A}$ complexidade das etapas dos algoritmos e a complexidade total são discutidas na seção 4.4 .
} 
Visando demonstrar a análise realizada, optou-se por apresentar os resultados na forma gráfica. A figura 4.13 apresenta os resultados de convergência para alguns valores de taxa de mutação para as funções F1, F5, F7 e F10. Os demais valores foram retirados visando facilitar a visualização do desempenho e o comportamento de convergência quando da alteração da taxa de mutação. Nota-se que valores muito pequenos $\left(p_{m}<1 \%\right)$ e valores altos $\left(p_{m}>10 \%\right)$ resultam em desempenho inferior, ou seja, lentidão na convergência e/ou patamares de desempenho não satisfatórios para o número de gerações considerado.
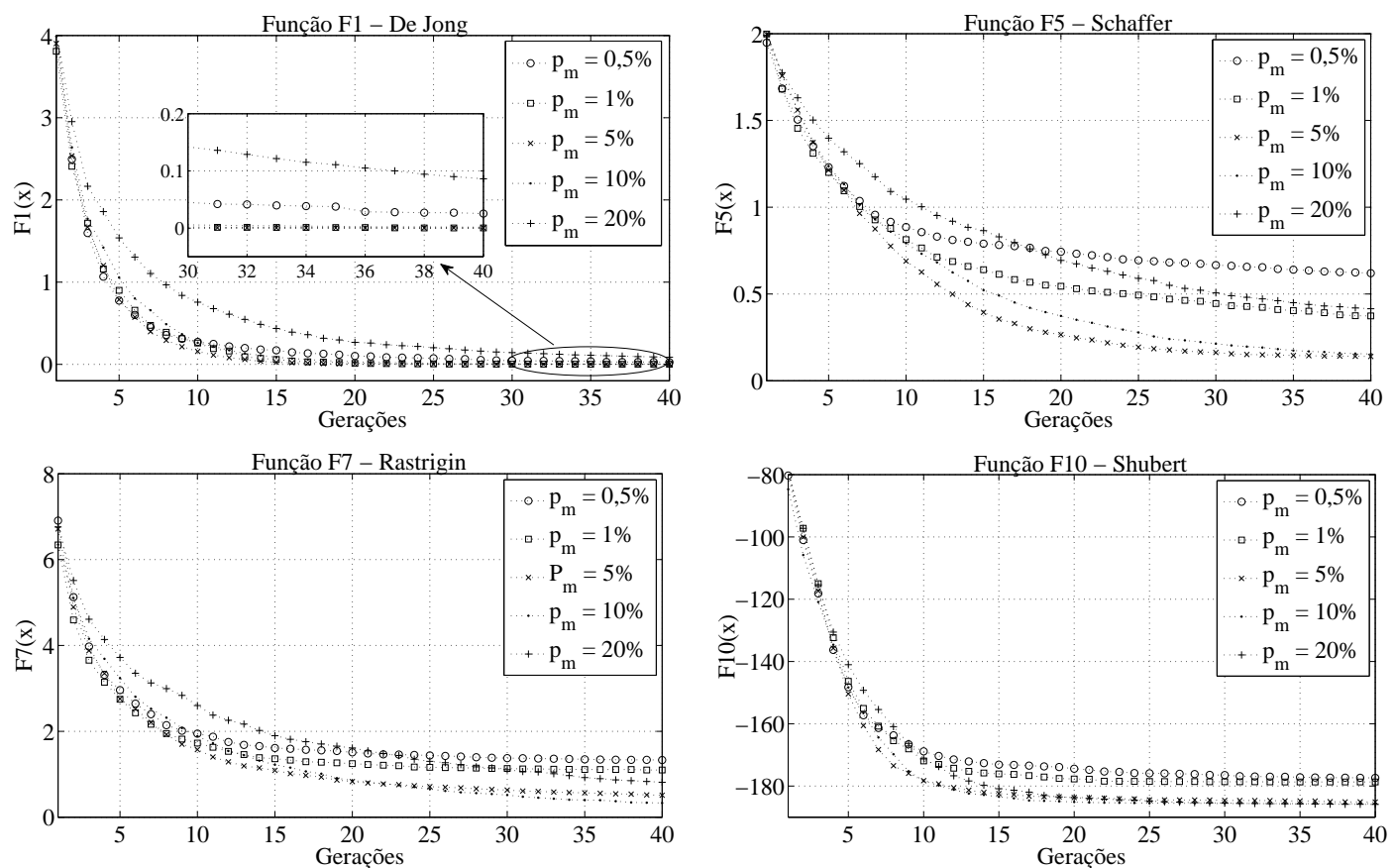

Figura 4.13: Análise da taxa de mutação do GA para as funções F1, F5, F7 e F10.

\subsubsection{Escolha da estratégia de reposição da população}

As estratégias de reposição estabelecem uma regra biológica de composição da próxima geração, correspondendo ao número de vetores candidatos a ser mantido na próxima geração. A análise considerou três estratégias, sendo conhecidas como estratégia elitista (elitism), a estratégia de estado permanente (steady-state) e a estratégia de elitismo global $(\mu+\lambda)$.

Novamente, para apresentação dos resultados, optou-se pelas funções F1, F5, F7 e F10. Vale ressaltar que a convergência para todas as simulações e funções apresentaram mesmo comportamento, ou seja, a estratégia $\mu+\lambda$ apresentou melhor desempenho. Após todas as simulações, evidenciou-se a superioridade desta estratégia, sendo adotada para as demais simulações. Entretanto, todas as estratégias atingem patamares de desempenho satisfatórios, podendo ser utiliza- 
das. Mas as demais estratégias necessitam de um número maior de gerações para convergirem.
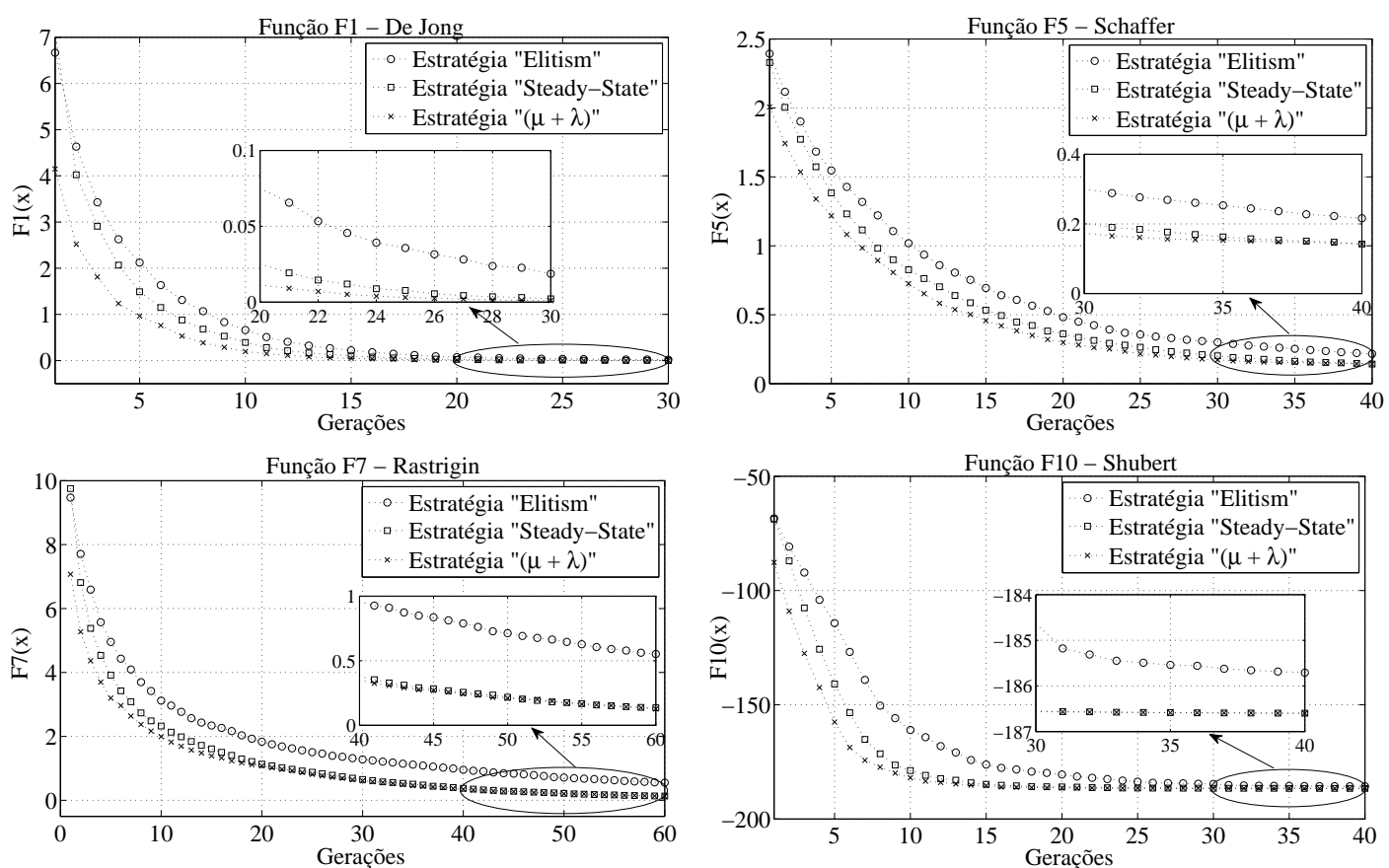

Figura 4.14: Análise das estratégias de reposição do GA para as funções F1, F5, F7 e F10.

Assim, são mantidos para a próxima geração apenas os melhores $\mu=p$ indivíduos oriundos da população conjunta dos genitores e descendentes $(2 p)$. Os demais $p$ piores indivíduos não sobrevivem para a próxima geração.

\subsubsection{Otimização dos parâmetros do algoritmo de EP}

O algoritmo de programação evolucionária apresenta diversas similaridades com o algoritmo genético em termos de nomenclatura utilizada e também de etapas e parâmetros necessários. Desta forma, a análise realizada para o algoritmo genético considerando a estratégia de seleção $^{8}$ e a estratégia de reposição da população ${ }^{9}$ pode ser estendida para o algoritmo de programação evolucionária, pois este apresenta estas mesmas etapas.

No entanto, o algoritmo de programação evolucionária não utiliza o operador genético de crossover para promover variabilidade genética, utilizando somente o operador de mutação para tal finalidade. Portanto, uma análise específica para a taxa de mutação do algoritmo de programação evolucionária foi realizada. Além disso, pode-se utilizar outro operador genético conhecido como clonagem (ABRÃO; CIRIACO; JESZENSKY, 2004) visando à melhoria na convergência do algoritmo.

\footnotetext{
${ }^{8}$ Resultou na escolha da estratégia $p$-sort.

${ }^{9}$ Resultou na escolha da estratégia $\mu+\lambda$.
} 
Assim, realizou-se também uma análise a respeito dos melhores valores para o índice de clonagem.

\subsubsection{Taxa de mutação}

Para a análise de otimização da taxa de mutação do algoritmo de programação evolucionária, optou-se pelo teste de dez possíveis valores, conforme testes realizados para o GA, resultando em $p_{m}=[0,01 \%, 0,5 \%, 1 \%, 3 \%, 5 \%, 7 \%, 10 \%, 15 \%$, ,20\%,30\%] utilizando mutação gaussiana.

Novamente, os resultados foram tabelados conforme análise do tamanho do poço de cruzamento e atribuída a pontuação. Ao final, a taxa de mutação $p_{m}=$ $15 \%$ apresentou a maior pontuação final, sendo adotada para as demais simulações do algoritmo de programação evolucionária.

A figura 4.15 apresenta os resultados de convergência para alguns valores de taxa de mutação para as funções F1, F5, F7 e F10. Nota-se que valores pequenos $\left(p_{m}<5 \%\right)$ e valores altos $\left(p_{m}>20 \%\right)$ resultam em desempenho inferior, ou seja, lentidão na convergência e/ou patamares de desempenho não satisfatórios para o número de gerações considerado.
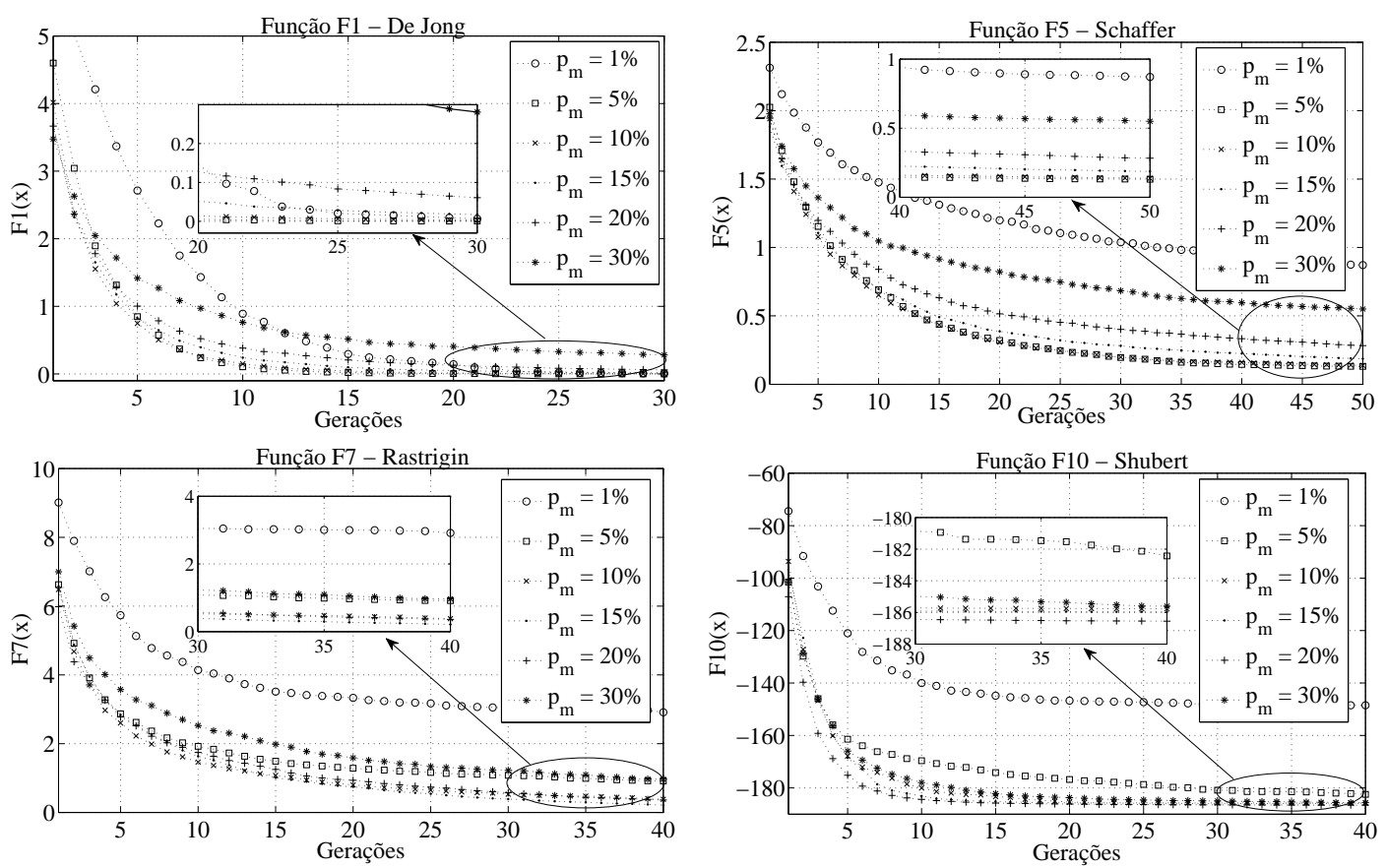

Figura 4.15: Análise da taxa de mutação do algoritmo EP-C para as funções F1, F5, F7 e F10.

Assim, percebe-se que o algoritmo de programação evolucionária necessita de uma valor superior para a taxa de mutação do que o algoritmo genético, pois é a única estratégia que provoca modificações nas soluções candidatas. Mas deve-se 
ter cautela na definição de tal parâmetro, pois o desempenho é significativamente afetado quando não são utilizados valores adequados, reforçando a necessidade da análise realizada.

\subsubsection{2 Índice de clonagem}

Conforme descrito no final da seção 3.3.5.2, o operador de clonagem consiste no repasse das características genéticas do genitor de forma idêntica para sua progênie. Após a clonagem, o operador de mutação visa garantir variabilidade genética sem alterar significativamente as melhores caraterísticas genéticas, trazendo certo compromisso entre pressão na busca e exploração.

Para os testes do índice de clonagem foram considerados dez possíveis valores definidos por $I_{c}=[0,05 p, 0,1 p, \ldots, 0,45 p, 0,5 p]$. Como exemplo, para um índice de clonagem $I_{c}=0,2 p$, ou seja, $20 \%$ da população mais evoluída ${ }^{10}$ é utilizada para formar a próxima geração, sendo realizadas 5 cópias de cada indivíduo para formar a nova população com $p$ membros. Após, utiliza-se o operador de mutação para obtenção de variabilidade genética.

A figura 4.16 apresenta os resultados de convergência para alguns valores de índice de clonagem para as funções F1, F5, F7 e F10.

Nota-se que valores acima de $I_{c}>0,2 p$ resultam em desempenho inferior, ou seja, lentidão na convergência e/ou patamares de desempenho não satisfatórios para o número de gerações considerado.

Após finalização das simulações e análise da pontuação dos valores testados, observou-se que o índice $I_{c}=0,1 p$ apresentou a maior pontuação e consequentemente o melhor desempenho geral, sendo utilizado para as demais simulações.

\subsubsection{Parâmetros do algoritmo de busca local $k$-opt}

O algoritmo de busca local $k$-opt não possui parâmetros de entrada a serem otimizados, pois utiliza apenas a informação do valor de $k$ para definir o espaço de busca, tornando-o um algoritmo de fácil implementação e utilização. Assim, o espaço de busca é definido como todos os vetores candidato que possuírem distância de Hamming igual ou inferior a $k$ da solução atual. Valores muito altos de $k$ resultam em um universo de busca muito grande e pequenos valores de $k$ não garantem o escape de soluções locais.

\footnotetext{
${ }^{10}$ Que possui melhores valores para a medida de aptidão.
} 

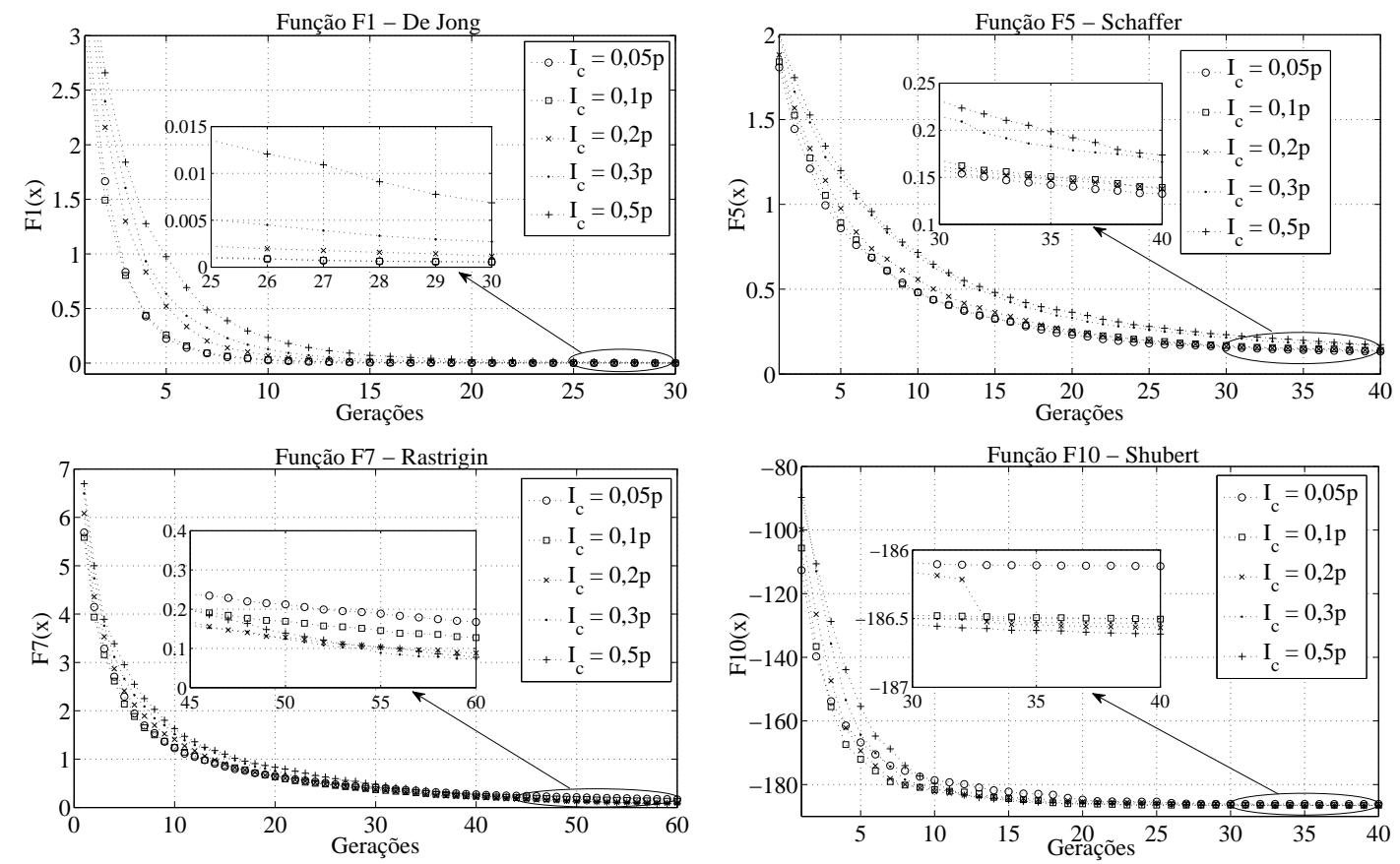

Figura 4.16: Análise do índice de clonagem do algoritmo EP-C para as funções F1, F5, F7 e F10.

O algoritmo 1-opt é uma caso particular do algoritmo $k$-opt, pois realiza a busca apenas na vizinhança mais próxima da solução inicial. Desta forma, apresenta dificuldade de escape em problemas com diversas soluções locais. Visando aumentar as chances de escape, implementou-se uma estratégia para a escolha da solução inicial do algoritmo $k$-opt a cada iteração quando o valor obtido para o melhor candidato da iteração atual é superior à melhor solução já visitada até o momento ${ }^{11}$. Nesta condição, escolhe-se aleatoriamente um candidato da solução atual para ser a solução inicial da próxima iteração (random start). Esta estratégia aumenta significativamente as chances de escape de soluções locais mas não a garante. Além disso, o algoritmo de busca local $k$-opt necessita de um número de iterações superior aos demais algoritmos pois não possui estratégias de controle de pressão da busca ${ }^{12}$.

Visando apresentar o desempenho do algoritmo $k$-opt, optou-se pela apresentação da figura 4.17, onde são apresentadas a convergência dos algoritmos 1-opt e 3-opt para as funções F1, F5 e F10. Nota-se que a versão 3-opt resulta em uma convergência mais abrupta, mas isso é explicado pelo tamanho do universo de busca testado, sendo calculado como:

\footnotetext{
${ }^{11}$ Lembrando que os problemas são de minimização, ou seja, se a solução atual apresentar valor superior à melhor solução já visitada, significa que a solução atual é pior.

${ }^{12}$ Refinamento da busca evitando a análise de regiões do espaço de busca pouco atraentes.
} 


$$
N_{\text {candidatos }}\left(Q_{\text {indiv }}, k\right)=\sum_{i=1}^{k} \frac{Q_{\text {indiv }} !}{i !\left(Q_{\text {indiv }}-i\right) !}
$$

onde $N_{\text {candidatos }}$ é o número de soluções candidatas testadas a cada iteração, $Q_{\text {indiv }}$ é o tamanho da solução candidata e $k$ é a ordem da vizinhança.

Desta forma, o algoritmo 1-opt analisa $Q_{\text {indiv }}$ possíveis soluções por iteração enquanto o algoritmo 3-opt analisa $\frac{Q_{\text {indiv }}^{3}+5 Q_{\text {indiv }}}{6}$ possíveis soluções a cada iteração.
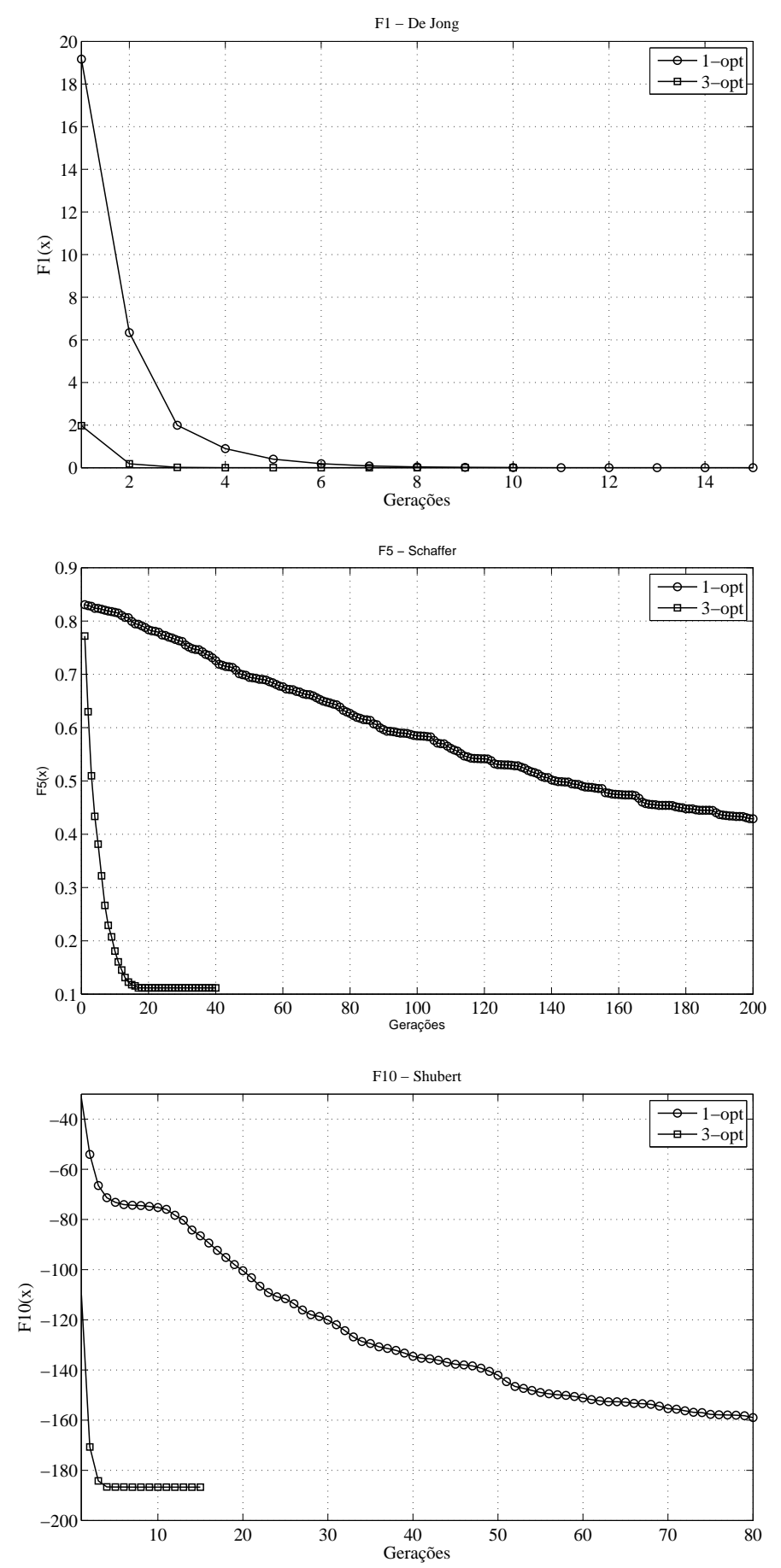

Figura 4.17: Desempenho dos algoritmos de busca local 1-opt e 3-opt para as funções F1, F5 e F10. 
Nota-se que para funções com diversas soluções locais (funções F5 e F10), o algoritmo 1-opt necessita de um número muito grande de iterações para atingir a convergência, sendo superior a 500 iterações $^{13}$. Já a versão 3-opt apresenta convergência para os valores mínimos com um número de iterações pequeno, mas apresenta uma complexidade por iteração muitas vezes superior devido ao número de soluções candidatas testadas por iteração.

\subsubsection{Otimização dos parâmetros do algoritmo de Recozi- mento Simulado}

O algoritmo SA deve ser inicializado com os parâmetros de temperatura inicial, $T$ (0), passo de resfriamento, $\epsilon$, e tamanho da série (platô), $L_{S A}$. Com isso, deve-se considerar uma análise de otimização visando a garantia de obtenção de boas soluções independente do problema.

Entretanto, estes parâmetros estão todos relacionados ao cálculo da temperatura em uma determinada iteração do algoritmo e, consequentemente, à probabilidade de aceite de soluções temporárias inferiores. Desta forma, pode-se considerar que existem dois parâmetros que devem ser otimizados, sendo a temperatura inicial $(T(0))$ e a taxa de resfriamento $\left(\epsilon^{L_{S A}}\right)$. O primeiro determina a temperatura inicial que o metal se encontra. O segundo indica a taxa de resfriamento, ou seja, o quão rápida é a diminuição de temperatura até a solidificação do metal.

$\mathrm{Na}$ literatura encontram-se alguns trabalhos e formulações a respeito de limites teóricos para a determinação da taxa de resfriamento, mas não existe um critério universalmente utilizado (KIRKPATRICK; GELLAT; VECCHI, 1983; AARTS; KROST, 1989; DUECK; SCHEUER, 1990). Em problemas do tipo caixeiro viajante, por exemplo, encontram-se valores $T(0)=0,5^{\circ} \mathrm{C}$ sendo decrementado de $10 \%$ a cada tamanho da série (CHO; OH; CHOI, 1998) e outros que iniciam em $T(0)=1000^{\circ} \mathrm{C}$, reduzindo de $1 \%$ a cada iteração (YIP; PAO, 1995). No entanto, a maioria dos trabalhos utilizam a temperatura inicial na faixa de $0,001 \leq T(0) \leq 100($ SOHN, 1995)

O conceito de formulação do algoritmo SA é relativamente simples, mas determinar os parâmetros ótimos como a temperatura inicial e a taxa de resfriamento não resulta em uma tarefa trivial. Primeiramente, nota-se que os valores otimizados dependem do tipo do problema, sendo calibrados através de tentativa e erro. Além disso, diversos trabalhos demonstram que o algoritmo SA é sensível

\footnotetext{
${ }^{13}$ Não apresentado na figura 4.17 devido a necessidade de visualização do algoritmo 3-opt.
} 
aos valores utilizados para os parâmetros, e seu desempenho é altamente dependente do ajuste fino realizado (WONG; CONSTANTINIDES, 1996). Desta forma, a robustez do SA pode ser imprópria para problemas onde os parâmetros não foram ajustados ou onde não são utilizadas regras bem estabelecidas.

No entanto, existe comprovação na literatura para a convergência do SA em relação à solução global utilizando uma taxa de resfriamento muito lenta e uma temperatura inicial muito alta, sendo decrementada no máximo segundo a relação $\frac{T(0)}{\ln (i)}$, onde $i$ corresponde a iteração atual (INGBER; ROSEN, 1992). Mas desta forma o número de iterações necessária à convergência mostra-se impraticável, pois resulta em uma quantidade superior quando comparada a de outros métodos heurísticos aplicados a problemas de otimização.

\subsubsection{Temperatura Inicial}

Nota-se que existe uma relação de compromisso entre a escolha de valores altos para a temperatura inicial e pequena taxa de resfriamento com a velocidade de convergência e a qualidade dos resultados. Desta forma, pode-se considerar as seguintes premissas:

- Temperatura inicial alta resulta em lentidão na convergência (grande número de iterações)

- Taxa de resfriamento pequena resulta em lentidão na convergência (grande número de iterações)

- Temperatura inicial pequena resulta em energia final alta (solução local)

- Taxa de resfriamento alta resulta em energia final alta (solução local)

Considerando o conceito do algoritmo SA, percebe-se que temperaturas muito altas resultam em materiais no estado líquido/gasoso e taxa de resfriamento pequena resulta em um tempo para solidificação excessivo. No entanto, temperaturas muito pequenas correspondem a materiais que já estão se solidificando e taxas de resfriamento altas resultam em processos rápidos de solidificação formando estruturas não cristalinas.

Assim, deve-se determinar uma região onde o material apresenta características de maleabilidade e ao mesmo tempo a taxa de resfriamento permita a formação de redes cristalinas. Este estado de maleabilidade é conhecido como estado mole (mushy state) e a taxa de resfriamento neste estado deve resultar em 
uma probabilidade de aproximadamente $10 \%$ de aceitação de soluções inferiores (SHAKOURI; SHOJAEE; BEHNAM, 2009). Desta forma, agrega-se os benefícios de rapidez na convergência e qualidade das soluções obtidas. Vale ressaltar que a probabilidade de aceitação é descrita como na equação (3.35), sendo dada por:

$$
x(i)=\exp \left[\frac{|\Delta e|}{T(i)}\right]-1
$$

Em (INGBER; ROSEN, 1992) demonstrou-se que uma máquina de Boltzmann pode encontrar um ótimo global se a temperatura $T_{i}$ é reduzida não mais rápida do que $\frac{T(0)}{\ln (i)}$. Desta forma, optou-se pela utilização da seguinte relação de resfriamento máxima:

$$
T_{i+1}=\frac{T_{i}}{\ln (\sqrt{i})}
$$

onde $i$ corresponde a iteração atual.

Assim, visando simplificar o processo de escolha dos parâmetros do SA optouse por estabelecer uma regra dependente do número de iterações total para adoção da temperatura inicial definida por:

$$
T(0)=\ln \left(I_{t}\right)
$$

onde $I_{t}$ corresponde ao número total de iterações do algoritmo SA.

Assim, deve-se ajustar a taxa de resfriamento $\left(\epsilon^{L_{S A}}\right)$ para garantia de exploração do universo de busca e pressão visando obtenção de boas soluções.

\subsubsection{Tamanho do Platô}

O tamanho do platô corresponde ao número de iterações onde a temperatura permanece constante. Assim, valores muito altos de $L_{S A}$ permitem redução significativa da temperatura quando $\epsilon<1$ mas ao mesmo tempo demoram a ocorrer, resultando em patamares constantes de temperatura. Valores pequenos reduzem a temperatura de forma menos acentuada mas ocorrem mais vezes, resultando em um modelo matemático mais próximo do conceito do algoritmo de recozimento simulado.

Desta forma, optou-se, sem perda de generalidade, pela redução da temperatura a cada duas iterações, resultando em:

$$
L_{S A}=2
$$

Com isso, a taxa de redução da temperatura apresenta característica quadrá- 
tica, sendo um modelo mais adequado para a redução da temperatura ${ }^{14}$ (INGBER; ROSEN, 1992).

\subsubsection{Passo de Resfriamento}

Por fim, visando simplificar a utilização/inicialização do algoritmo SA deve-se definir o passo de resfriamento adequado para garantir variabilidade de exploração e ao mesmo tempo pressionar a busca em regiões atrativas. Como os demais parâmetros já foram definidos, pode-se reescrever a equação (4.25) como:

$$
T(i+1)=\frac{T(0)}{\ln (\sqrt{i})}=\varepsilon^{L_{S A}} T(0)
$$

Portanto, observando os termos da equação (4.28), define-se o passo de resfriamento como sendo:

$$
\varepsilon=\sqrt[L_{S A}]{\frac{1}{\ln (\sqrt{i})}}=\sqrt[L_{S A}]{\frac{2}{\ln (i)}}
$$

Utilizando o valor adotado $L_{S A}=2$, resulta em um passo de resfriamento dado por:

$$
\varepsilon=\sqrt{\frac{2}{\ln (i)}}
$$

Assim, o algoritmo SA precisa apenas do número de iterações total para ajustar a temperatura inicial e a taxa de resfriamento visando o compromisso entre pressão e exploração na busca, além de garantir facilidade na inicialização do algoritmo.

Vale ressaltar que o valor do passo de resfriamento é calculado para cada iteração $i=1,2, \ldots, I_{t}$. A figura 4.18 apresenta um exemplo da diminuição da temperatura ao longo das iterações para $I_{t}=50$. Nota-se o comportamento de redução quadrática da temperatura a medida que o número de iterações aumenta diminuindo a probabilidade de aceite de soluções locais.

A estratégia descrita para a obtenção dos parâmetros foi utilizada na otimização das funções F1 a F10, sendo os resultados apresentados na figura 4.19.

Nota-se que para todas as funções o resultado aproxima-se do mínimo teórico validando as expressões obtidas para o cálculo dos parâmetros de entrada do SA. Assim, alia-se a facilidade de inicialização com obtenção de boas soluções.

\footnotetext{
${ }^{14}$ Para $L_{S A}=1$ resulta em uma redução de forma linear.
} 


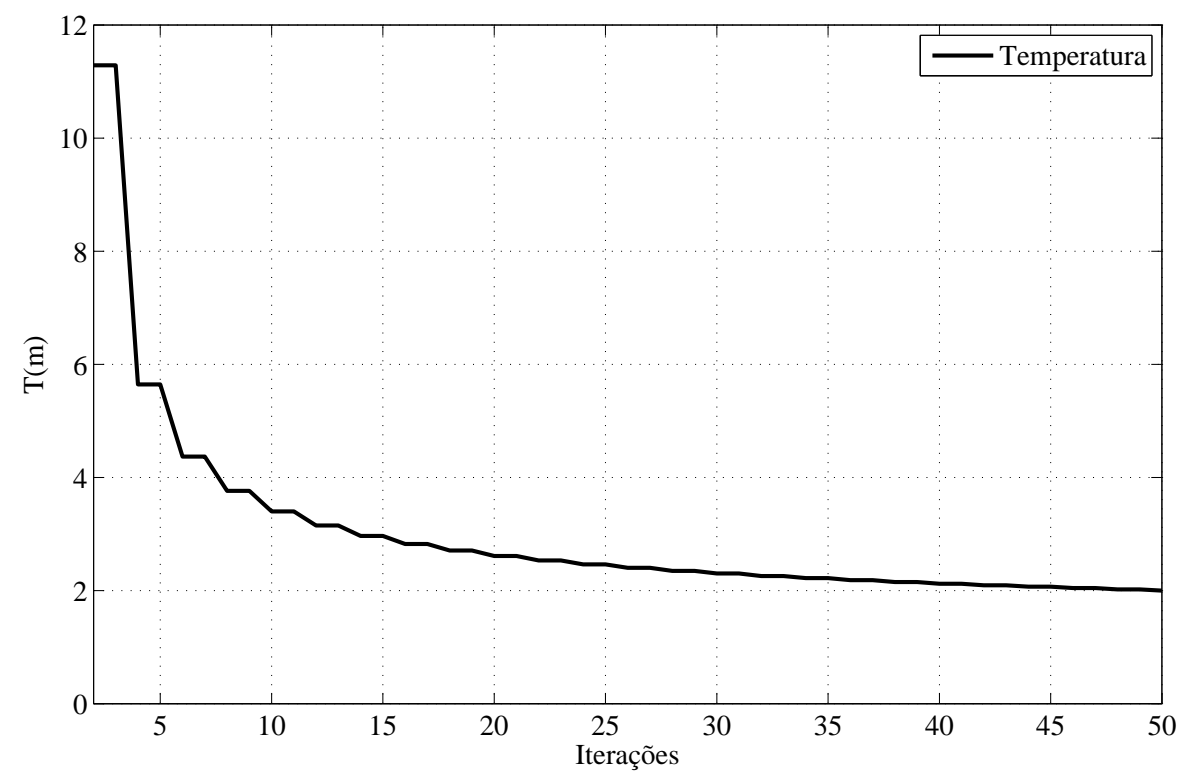

Figura 4.18: Diminuição da temperatura de resfriamento do algoritmo SA para os parâmetros adotados.
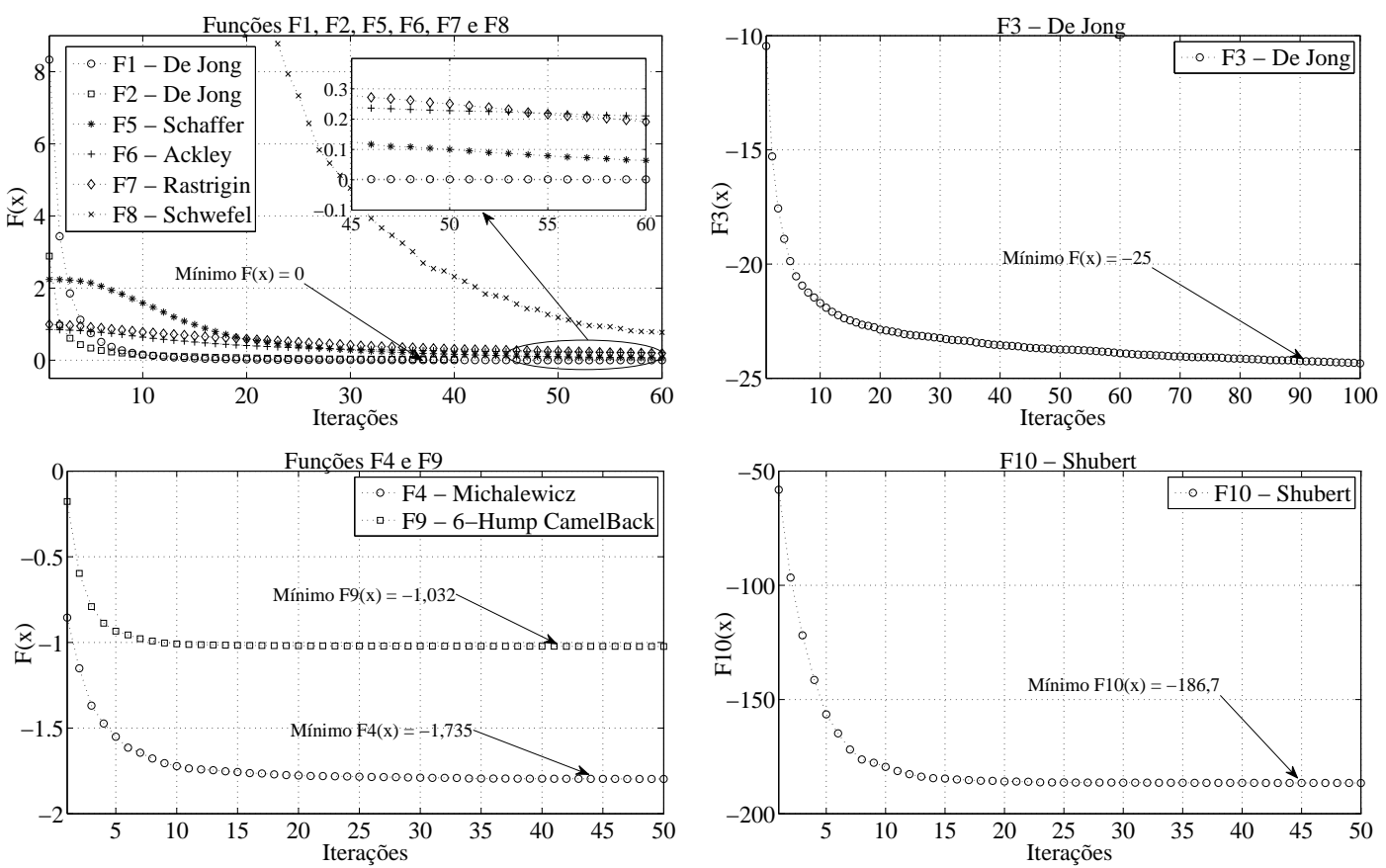

Figura 4.19: Convergência do algoritmo SA para as funções F1 a F10. 
No entanto, para as funções F5, F6, F7 e F8 são necessárias mais iterações para que o algoritmo alcance bons resultados. Nos três casos, são necessárias 200 iterações para atingir a convergência com qualidade nos valores obtidos.

\subsubsection{Otimização dos parâmetros dos algoritmos STTS e RTS}

A lista Tabu do algoritmo STTS considera a definição de um período fixo durante toda a otimização, o que pode não garantir escape de retornos aos máximos locais, pois um período pequeno é insuficiente para evitar retornos a máximos locais e um período grande demais reduz a quantidade de deslocamentos possíveis, acarretando em uma busca ineficiente.

Desta forma, deve-se considerar uma análise para definição de uma regra para o período de proibição $P$ que resulte em boas soluções e mantenha o número de iterações para convergência em patamares adequados. De preferência, visando facilitar a utilização deste algoritmo, deve-se definir um número para o período de proibição $(P)$ proporcional ao número de iterações $\left(I_{t}\right)$ ou ao tamanho do candidato $\left(Q_{\text {indiv }}\right)$. Assim, o algoritmo STTS pode ser inicializado somente com o número de iterações e tamanho do indivíduo, facilitando seu uso independente do problema a ser otimizado.

Para o algoritmo RTS deve-se definir o período de proibição inicial $P(0)$ e a taxa de redução/incremento do período de proibição, sendo definida no intervalo $0 \leq x \leq 1$. Assim, o período de proibição é adaptado durante a busca, admitindose que este período assuma diferentes valores a cada iteração $\mathcal{P}(i)$ definido por:

$$
\begin{array}{cc}
\text { Se: } & \text { repeticao }=1, \\
& \mathcal{P}(i)=\lfloor(1+x) \mathcal{P}(i-1)\rfloor \\
\text { Caso Contrário Se: } & \left|f_{i}-f_{\text {best }}\right|<x f_{\text {best }}, \\
& \mathcal{P}(i)=\lfloor(1-x) \mathcal{P}(i-1)\rfloor
\end{array}
$$

Fim

onde $i$ é a iteração atual, $x$ é a taxa de redução/incremento do período de proibição e $\lfloor$.$\rfloor corresponde ao operador maior inteiro menor que o argumento.$

Quando ocorre uma repetição, ou seja, quando encontram-se as características de deslocamento da solução na iteração $i$ na Lista Tabu, aumenta-se o período de proibição forçando o algoritmo em outra direção do universo de busca. No entanto, quando a diferença entre a melhor solução visitada até a iteração $i$ e a 
solução na iteração $i$ apresentar diferença inferior a $x f_{\text {best }}$ encoraja-se a pressão na busca por uma melhor solução global através da diminuição do período da lista Tabu, proporcionando a análise de características de deslocamento semelhantes em candidatos diferentes.

\subsubsection{Período de proibição do STTS}

A figura 4.20 apresenta os resultados da análise do período de proibição da lista Tabu considerando os valores de testes $P=\left[I_{t}, \frac{I_{t}}{2}, \frac{I_{t}}{5}, \frac{I_{t}}{10}, \frac{I_{t}}{20}, Q_{\text {indiv }}, \frac{Q_{\text {indiv }}}{2}\right]$ para as funções F1, F5, F7 e F10.

Percebe-se que aparentemente o período da lista Tabu para todas as funções pode assumir qualquer valor, pois a modificação do período acarreta em melhoria marginal de desempenho (qualidade da solução ou velocidade de convergência). No entanto, o desempenho é alterado de forma sutil conforme ocorre a variação do período de proibição. Nota-se que ao apresentar o desempenho com zoom ${ }^{15}$ observa-se que existe variação de desempenho. Além disso, observou-se uma variação da estabilidade no desempenho ${ }^{16}$ quando são realizados os gráficos de controle. Esta análise é realizada e apresentada na seção 4.3.1.

Após finalização das simulações para as provas F1 a F10 e análise da pontuação dos valores testados, observou-se que o índice $P=Q_{\text {indiv }} / 2$ apresentou a maior pontuação e consequentemente o melhor desempenho geral, inclusive resultando em maior estabilidade, sendo utilizado para as demais simulações.

\subsubsection{Controle de redução/aumento do período de proibição do al- goritmo RTS}

Visando a análise da taxa de redução/aumento da lista Tabu do algoritmo RTS, foram realizados simulações considerando os valores:

$$
x=[5 \%, 10 \%, 20 \%, 30 \%, 50 \%, 80 \%]
$$

A figura 4.21 apresenta os resultados desta análise para as funções F1, F5, F7 e F10. Mas vale ressaltar que foram realizadas simulações para todas as 10 funções testes apresentadas anteriormente. Para todas as simulações considerouse o período de proibição inicial da lista Tabu como sendo o período de proibição do algoritmo STTS, $P(0)=Q_{\text {indiv }} / 2$, pois trata-se de um valor médio adequado para os problemas de otimização conforme apresentado na seção 4.2.5.1.

\footnotetext{
${ }^{15}$ Quadros inseridos em miniatura na figura.

${ }^{16}$ Resultando em valores diferentes para as medidas de qualidade.
} 

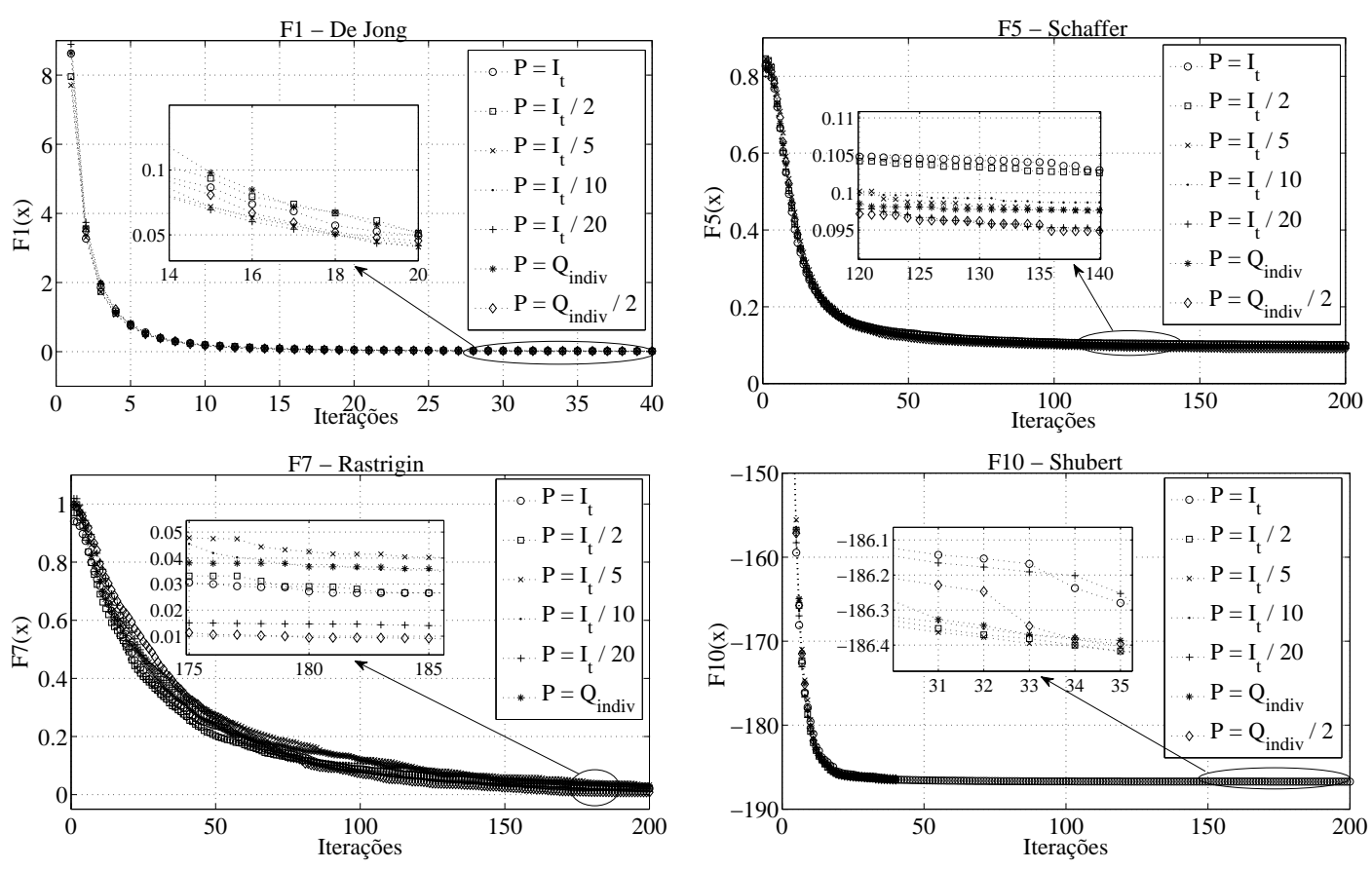

Figura 4.20: Análise do período de proibição $P$ da lista Tabu para o algoritmo STTS e funções F1, F5, F7 e F10.

Novamente, nota-se que o período da lista Tabu aparentemente pode assumir qualquer valor, ou seja, a taxa de variação do período de proibição, pois não percebe-se mudança significativa de desempenho (qualidade da solução ou velocidade de convergência). Mas, conforme descrito para o algoritmo STTS, existe uma variação pequena de desempenho e também da estabilidade do algoritmo. O desempenho com zoom possibilita observar que existe variação de desempenho e a estabilidade resultou em diferentes medidas de qualidade.

Neste caso, após finalização das simulações para as provas F1 a F10 e análise da pontuação dos valores testados, observou-se que a taxa de redução/incremento do algoritmo RTS, $x=50 \%$, apresentou a maior pontuação e consequentemente o melhor desempenho geral, sendo utilizado para as demais simulações.

A figura 4.22 apresenta um exemplo de variação do período de proibição médio $^{17}$ da lista Tabu para o algoritmo RTS e função F7. Nota-se que o período de proibição diminui de forma acentuada no início da busca devido a diminuição da diferença entre as soluções atual e melhor até o momento, forçando o algoritmo a realizar uma pressão em busca da solução global em torno desta vizinhança. No entanto, quando as opções de testes são reduzidas e começa a ocorrer repetições de características de deslocamento, ou seja, tentativas de deslocamento que pertencem a lista Tabu, o período de proibição é incrementado visando garantir exploração em outras regiões do universo de busca. Desta forma, percebe-se

\footnotetext{
${ }^{17}$ Média realizada considerando 1000 iterações.
} 

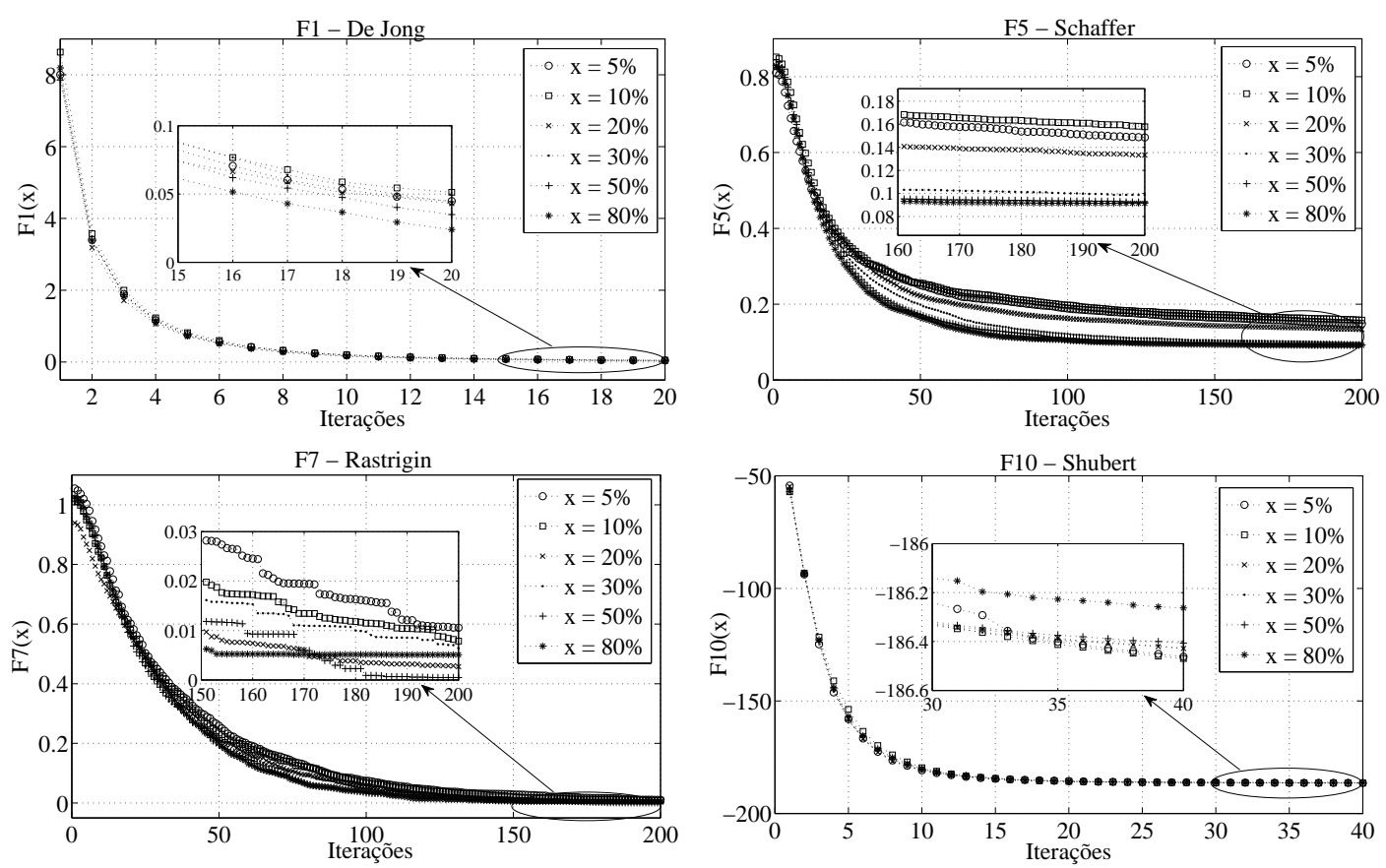

Figura 4.21: Variação do período de proibição $P(i)$ da lista Tabu para o algoritmo RTS e função F7.

a adaptabilidade do período de proibição da lista Tabu a medida que o algoritmo avança na busca, garantindo um compromisso entre pressão e exploração. Vale ressaltar que este comportamento foi observado para as demais funções e, portanto, não foram incluídas.

\subsubsection{Otimização dos parâmetros do algoritmo Hiperheu- rístico}

Conforme apresentado no capítulo 3, os algoritmos HH's consistem de uma metodologia de alto nível que controla a seleção ou geração de estratégias de busca genéricas utilizando uma quantidade específica de heurísticas de baixo nível.

Neste caso, o foco consiste na facilidade de sua utilização com obtenção de respostas estáveis e com qualidade para uma larga escala de problemas. Portanto, deve-se analisar as estratégias de alto nível que controlam as heurísticas de baixo nível.

Este trabalho considerou a estratégia de heurística de perturbação, onde utiliza-se de uma heurística de baixo nível para construir uma solução completa $^{18}$ por iteração da HH. A cada nova iteração da HH, realiza-se outra busca completa com uma heurística de baixo nível. Desta forma, procura-se utilizar cada heurística de baixo nível para um percentual do número de iterações total.

\footnotetext{
${ }^{18}$ As heurísticas de baixo nível realizam várias iterações internas e com vários candidatos por iteração.
} 


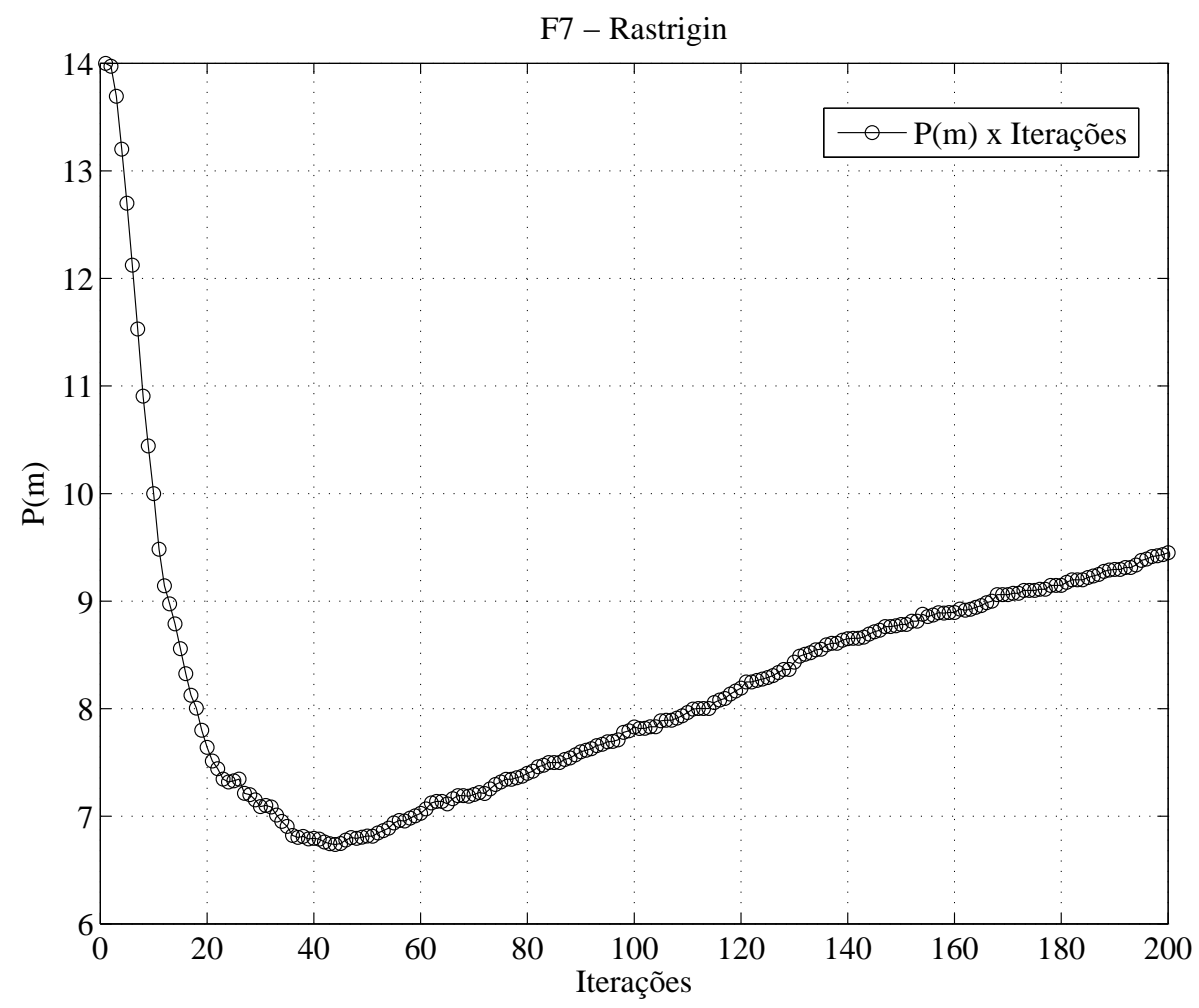

Figura 4.22: Variação média do período de proibição $P(i)$ da Lista Tabu para o algoritmo RTS e função F7.

Como exemplo, pode-se definir o número de iterações total $I_{t}=100$ e assumir que cada heurística de baixo nível executa internamente $I_{t}$ (baixo nível) $=10$ iterações. Assim, a seleção de uma heurística, ou seja, o número de iterações da HH, $I_{t}$ (hiper) = 10 iterações, resultando em um número total de iterações $I_{t}=I_{t}$ (baixo nível). $I_{t}$ (hiper $)=100$ iterações. Com isso, torna-se possível comparar o desempenho de uma $\mathrm{HH}$ com diversas estratégias metaheurísticas, pois o número total de candidatos testados será o mesmo se o número de iterações total for idêntico.

Este trabalho considerou que cada heurística de baixo nível selecionada deve executar $10 \%$ do número total de iterações, ou seja $I_{t}$ (baixo nível) $=0,1 I_{t}$, resultando em $I_{t}$ (hiper) $=10$ para todos os testes. Como serão utilizados 5 heurísticas de baixo nível ${ }^{19}$, existe uma probabilidade média de que cada heurística seja selecionada 2 vezes, colaborando com a resposta final em 20\%. Nota-se que se o número de iterações de cada heurística de baixo nível for pequeno, a contribuição por iteração na $\mathrm{HH}^{20}$ será muito pequena. No entanto, valores muito altos para o número de iterações de cada heurística de baixo nível acarretam em poucas se-

\footnotetext{
${ }^{19}$ Algoritmos EP-C, GA, SA, STTS e RTS, devido ao compromisso de estabilidade $\times$ complexidade.

${ }^{20}$ Melhoria de desempenho, ou seja, convergência.
} 
leções, não aproveitando a diversidade de busca que cada heurística possui. Por fim, conforme já descrito anteriormente, escolheu-se um número médio de seleção de cada heurística de 2 vezes, trazendo um compromisso entre variação de heurísticas de baixo nível com melhoria significativa na convergência a cada iteração da HH. Vale ressaltar que outras relações para $I_{t}$ (baixo nível) foram analisados, mas resultaram em desempenho inferiores ${ }^{21}$, não sendo apresentados.

Após definição do número de iterações da estratégia $H H, I_{t}$ (hiper) $=10$, devese analisar a estratégia de seleção da heurística e posteriormente o critério de aceitação a ser utilizado em cada iteração buscando garantir ao final do processo de otimização boas soluções com estabilidade.

\subsubsection{Escolha da estratégia de seleção das heurísticas}

Para a análise da escolha da estratégia de seleção de heurísticas de baixo nível foram consideradas as duas estratégias apresentadas no capítulo 3, sendo descritas de forma resumida como:

- Simplesmente Aleatório: Seleciona aleatoriamente uma heurística do repositório com uma densidade de probabilidade uniforme.

- Reforço de Aprendizagem com lista Tabu: As heurísticas de baixo nível disponíveis são selecionadas de acordo com a lista Tabu (lista proibida) que exclui temporariamente heurísticas de baixo nível do repositório caso a estratégia produza resultados inferiores, sendo incluída na lista Tabu por um período pré-definido.

A figura 4.23 apresenta o resultado de desempenho e convergência para as duas estratégias de seleção de heurísticas de baixo nível considerando as funções F1, F5, F7 e F10. Vale ressaltar que o mesmo comportamento foi observado para as demais funções, mas optou-se por não inseri-las. Após todas as simulações e contagem da pontuação, a estratégia de seleção "Simplesmente Aleatório" apresenta uma convergência média sutilmente superior quando comparada à estratégia de reforço de aprendizagem com lista Tabu, além de apresentar limiares de desempenho coerentes e próximos aos valores teóricos ótimos.

Este resultado é interessante, pois a princípio espera-se que uma estratégia mais complexa como a de reforço de aprendizagem apresente um desempenho superior quando comparada à uma estratégia mais singela. Todavia, como os

\footnotetext{
${ }^{21} I_{t}($ baixo nível $)=\left[0,05 I_{t}, 0,1 I_{t}, 0,2 I_{t}, 0,25 I_{t}, 0,5 I_{t}\right]$.
} 

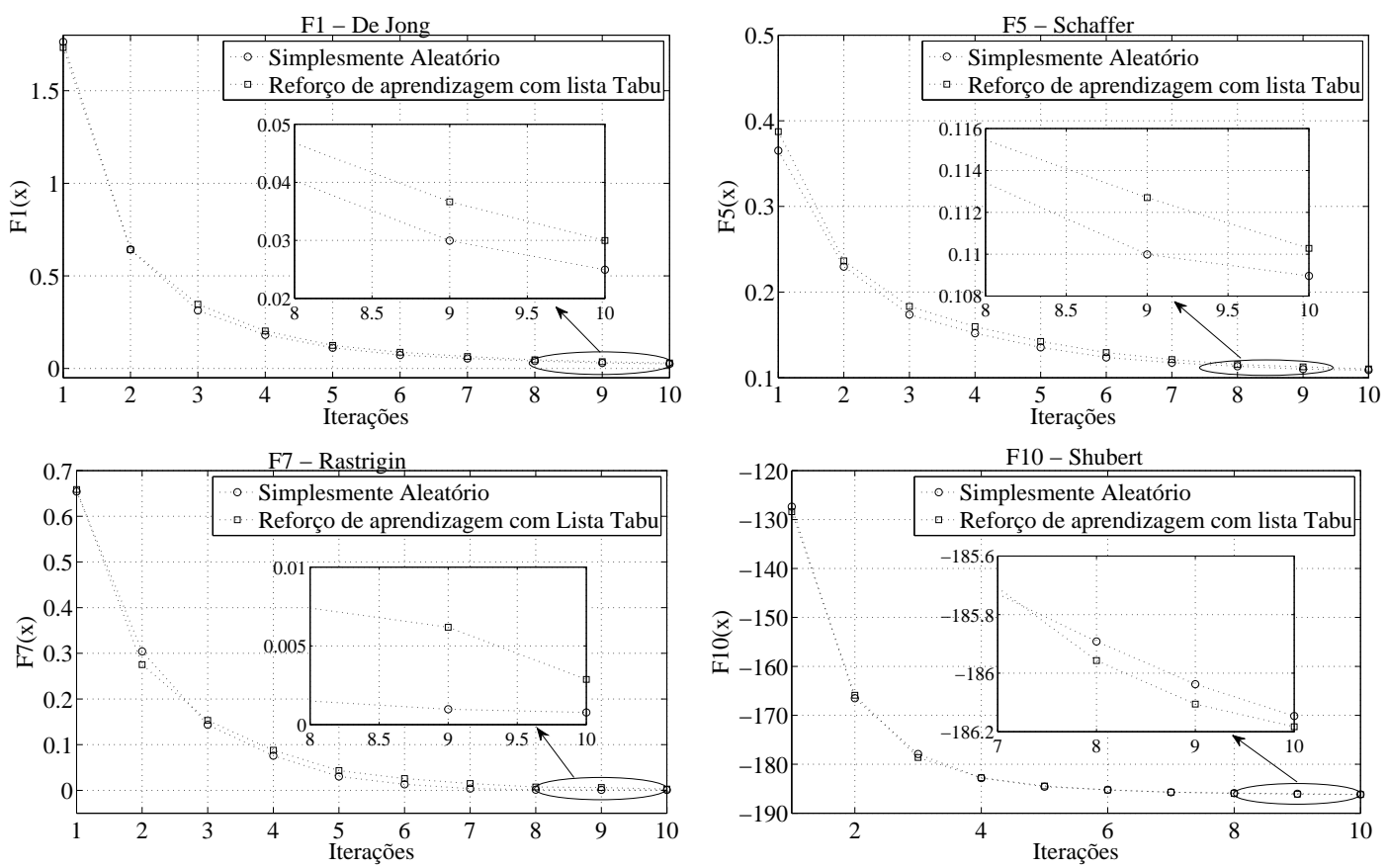

Figura 4.23: Análise das estratégias de seleção da HH para as funções F1, F5, F7 e F10.

algoritmos de baixo nível foram inicializados conforme parâmetros e estratégias otimizadas, estes resultam na maioria das vezes, a cada iteração da HH, em melhores soluções que a precedeu. Desta forma, a quantidade de heurísticas que são enviadas para a lista Tabu é pequena, mas o suficiente para limitar a variabilidade de características de escape de soluções locais que todas as heurísticas de baixo nível possuem quando atuam em conjunto. Assim, percebe-se que é mais vantajoso manter todas as heurísticas com possibilidade de escolha para as próximas iterações, pois podem resultar em melhores soluções mesmo que não tenham alcançado tal resultado em iterações anteriores.

Desta forma, a estratégia de seleção Simplesmente Aleatório foi considerado para as demais simulações.

\subsubsection{Escolha da estratégia de aceitação de soluções}

Conforme apresentado no capítulo 3, existem na literatura a descrição de pelo menos 5 estratégias para aceitação de soluções que serão utilizadas como solução inicial na próxima iteração do algoritmo HH. Desta forma, foram consideradas para análise de desempenho e convergência visando a definição da estratégia que resulta em melhor desempenho médio para os problemas de otimização considerados. Segue uma descrição resumida das estratégias de aceitação ${ }^{22}$ :

\footnotetext{
${ }^{22}$ Apresentadas em maiores detalhes na seção 3.5.2.1.
} 
- Aceitação Cruel: somente as soluções que apresentam melhorias são aceitas.

- Aceitação Ingênua (NV - Naive Acceptance): são aceitas todas as soluções que apresentam melhoria e 50\% das vezes que a solução encontrada for inferior a solução prévia.

- Aceitação Adaptativa (AA - Adaptative Acceptance): são aceitas todas as soluções que apresentam melhoria e baseada em uma probabilidade adaptativa onde a taxa de aceitação é incrementada de 5\% caso não ocorra melhoria em uma iteração e reduzida de uma taxa de 5\% caso ocorra melhoria.

- Grande Dilúvio (GD - Great Deluge): são aceitas todas as soluções que apresentam melhoria e também se $f\left(s_{\text {new }}\right)<f\left(s_{\text {old }}\right)-\frac{i \Delta e}{I_{t}}$ onde $s_{\text {old }}$ é a solução anterior, $i$ é a iteração atual, $\Delta e$ é a diferença entre a solução anterior e a solução atual e $I_{t}$ é o número total de iterações.

- Baseada no Recozimento Simulado: todas as soluções com melhoria são aceitas e as demais são aceitas com a probabilidade $p=e^{\left(f\left(s_{\text {new }}\right)-f\left(s_{\text {old }}\right)\right) / T}$ onde $T$ representa o parâmetro de temperatura do algoritmo de recozimento simulado, conforme seção 3.4.4.

A figura 4.24 apresenta o resultado de desempenho e convergência para as cinco estratégias de aceitação de soluções obtidas pelas heurísticas de baixo nível considerando as funções F1, F5, F7 e F10. Vale ressaltar que o mesmo comportamento foi observado para as demais funções, mas optou-se por não inserir as demais figuras.

Após simulações e cômputo da pontuação de cada estratégia, observou-se que a estratégia denominada de "Aceitação Ingênua" apresentou o melhor desempenho, sendo adotada para as demais simulações realizadas.

\subsection{Resumo dos algoritmos considerando as oti- mizações realizadas}

A tabela 4.7 tem por finalidade apresentar um resumo dos resultados das análises de otimização dos parâmetros e estratégias dos algoritmos metaheurísticos e hiperheurística visando praticidade na consulta e posterior utilização na etapa de inicialização dos algoritmos. 

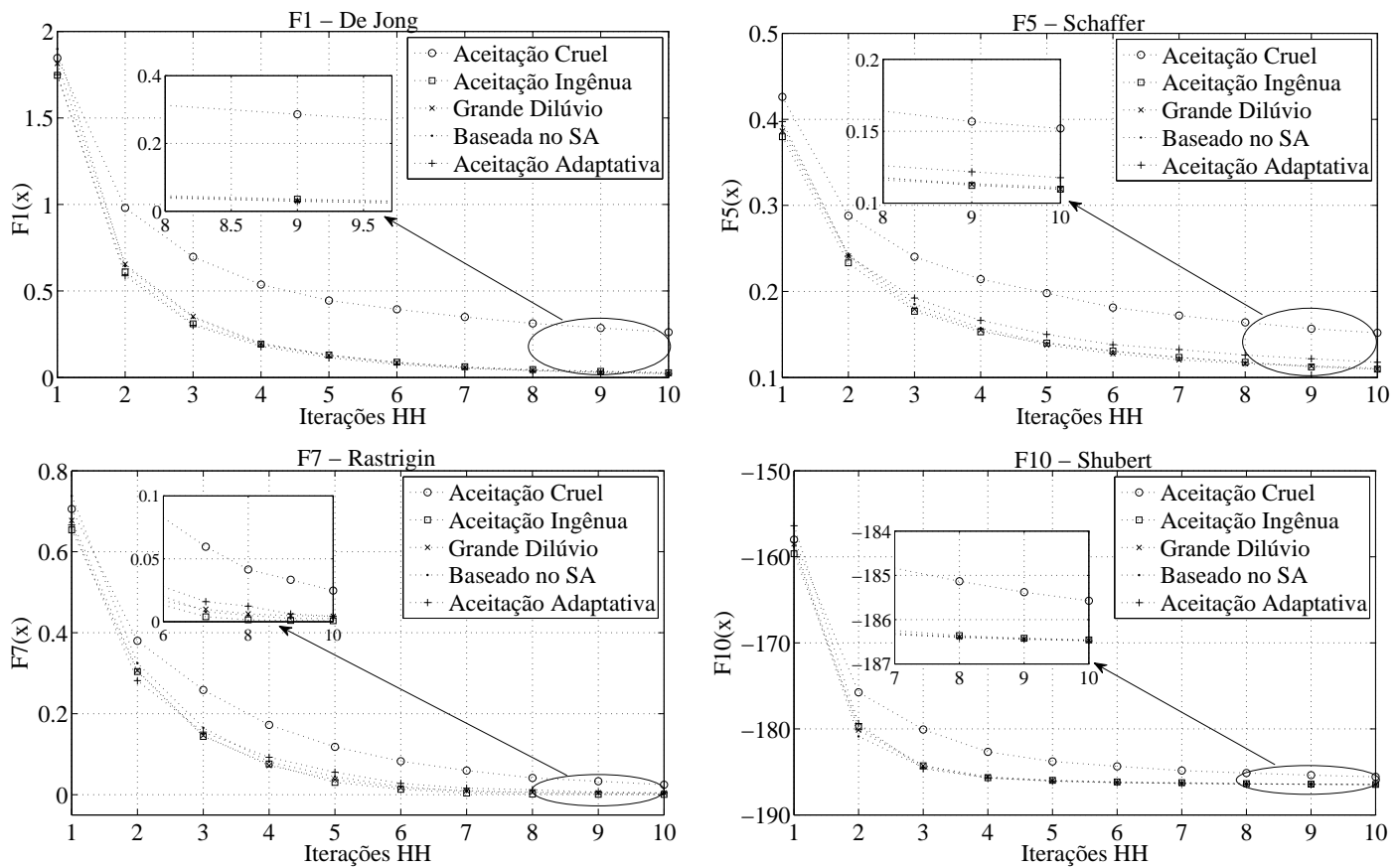

Figura 4.24: Análise das estratégias de aceitação de soluções da HH para as funções F1, F5, F7 e F10.

Além dos valores e estratégias otimizadas, deve-se considerar que os algoritmos SA, STTS e RTS realizam, a cada iteração, uma modificação na solução atual de forma aleatória e uniforme, considerando um espaço de busca com até $Q_{\text {indiv }} / 2$ modificações, gerando $Q_{\text {indiv }}$ para teste por iteração. Esta quantidade de testes por iteração é o mesmo que o utilizado pelo algoritmo 1-opt. Desta forma torna-se possível comparar as topologias em relação a velocidade de convergência e uma mesma base de complexidade ${ }^{23}$.

\subsubsection{Análise de estabilidade dos algoritmos propostos}

Para a determinação dos algoritmos que serão utilizados na otimização de desempenho e estimativa de parâmetros em sistemas de telecomunicações de $3 \mathrm{G}$ e 4G, deve-se considerar uma análise visando estabelecer critérios que garantam primeiramente a estabilidade dos algoritmos e posteriormente seja possível quantificar os limiares de desempenho.

Desta forma, foram realizados testes de estabilidade considerando os critérios anteriormente apresentados, além da apresentação da convergência média para os algoritmos indicando o número de iterações/gerações necessárias para cada problema.

Além disso, observa-se a possibilidade de expansão da análise considerando

\footnotetext{
${ }^{23}$ Análise posteriormente apresentada na seção 4.4 .
} 
Tabela 4.7: Resumo dos parâmetros e estratégias otimizadas para cada algoritmo

\begin{tabular}{|c|c|}
\hline GA & $\begin{array}{c}\text { Tamanho da população: } p=10 \cdot\lfloor 0,3454(\sqrt{\pi(l-1)}+2) \\
\text { Tamanho poço cruzamento: } T=0,7 p \\
\text { Estratégia de seleção: } p \text {-sort } \\
\text { Tipo/taxa de crossover: uniforme } / p_{c}=50 \% \\
\text { Tipo/taxa de mutação: gaussiana } / p_{m}=10 \% \\
\text { Estratégia de reposição: } \mu+\lambda(\operatorname{com} \mu=p)\end{array}$ \\
\hline $\mathrm{EP}-\mathrm{C}$ & $\begin{array}{c}\text { Tamanho da população: } p=10 \cdot\lfloor 0,3454(\sqrt{\pi(l-1)}+2) \\
\text { Taxa de clonagem: } I_{c}=20 \% \\
\text { Estratégia de seleção: } p \text {-sort } \\
\text { Tipo/taxa de mutação: gaussiana } / p_{m}=15 \% \\
\text { Estratégia de reposição: } \mu+\lambda(\operatorname{com} \mu=p)\end{array}$ \\
\hline$k$-opt & não existe parâmetro a ser otimizado \\
\hline \multirow{3}{*}{ SA } & $\begin{array}{c}\text { Temperatura inicial: } T(0)=\ln \left(I_{t}\right) \\
\text { Tamanho platô: } L_{s a}=2\end{array}$ \\
\hline & Passo de resfriamento: $\varepsilon=\sqrt{\frac{2}{\ln (i)}}$ \\
\hline & Probabilidade de aceitação: $x(i)=\exp \left[\frac{|\Delta e|}{T(i)}\right]-1$ \\
\hline STTS & Período de proibição: $P=Q_{\text {indiv }} / 2$ \\
\hline RTS & $\begin{array}{l}\text { Período de proibição inicial: } P(0)=Q_{\text {indiv }} / 2 \\
\text { Taxa de redução/incremento do período: } x=50 \%\end{array}$ \\
\hline $\mathrm{HH}$ & $\begin{array}{l}\text { Número de iterações da HH: } I_{t}(H H)=10 \\
\text { Estratégia de seleção: Simplesmente Aleatório } \\
\text { Estratégia de aceitação: Aceitação Ingênua }\end{array}$ \\
\hline
\end{tabular}

outras técnicas heurísticas, pois estas podem ser comparadas e classificadas em termos de qualidade, estabilidade, facilidade de utilização e complexidade.

Ao final da presente seção são indicadas as topologias utilizando algoritmos heurísticos capazes de otimizar os problemas apresentados (F1 a F10) e que serão utilizadas para os problema $\mathrm{MuD}$ e $\mathrm{MuChE}$.

Vale ressaltar que são utilizados as estratégias e parâmetros otimizados para 
cada topologia, conforme análise realizada na seção 4.2 e apresentada de forma resumida na tabela 4.7 .

Assim, optou-se por apresentar inicialmente o desempenho dos algoritmos para a otimização das funções F1, F5, F7 e F10, conforme figura 4.25. Nota-se que, com exceção do algoritmo 1-opt, todos os demais apresentam desempenho satisfatório para os problemas considerados.

Observando o desempenho com zoom percebe-se que existe variação sutil de desempenho e consequentemente resulta em diferentes níveis de estabilidade para os algoritmos, sendo apresentado posteriormente na tabela 4.9.
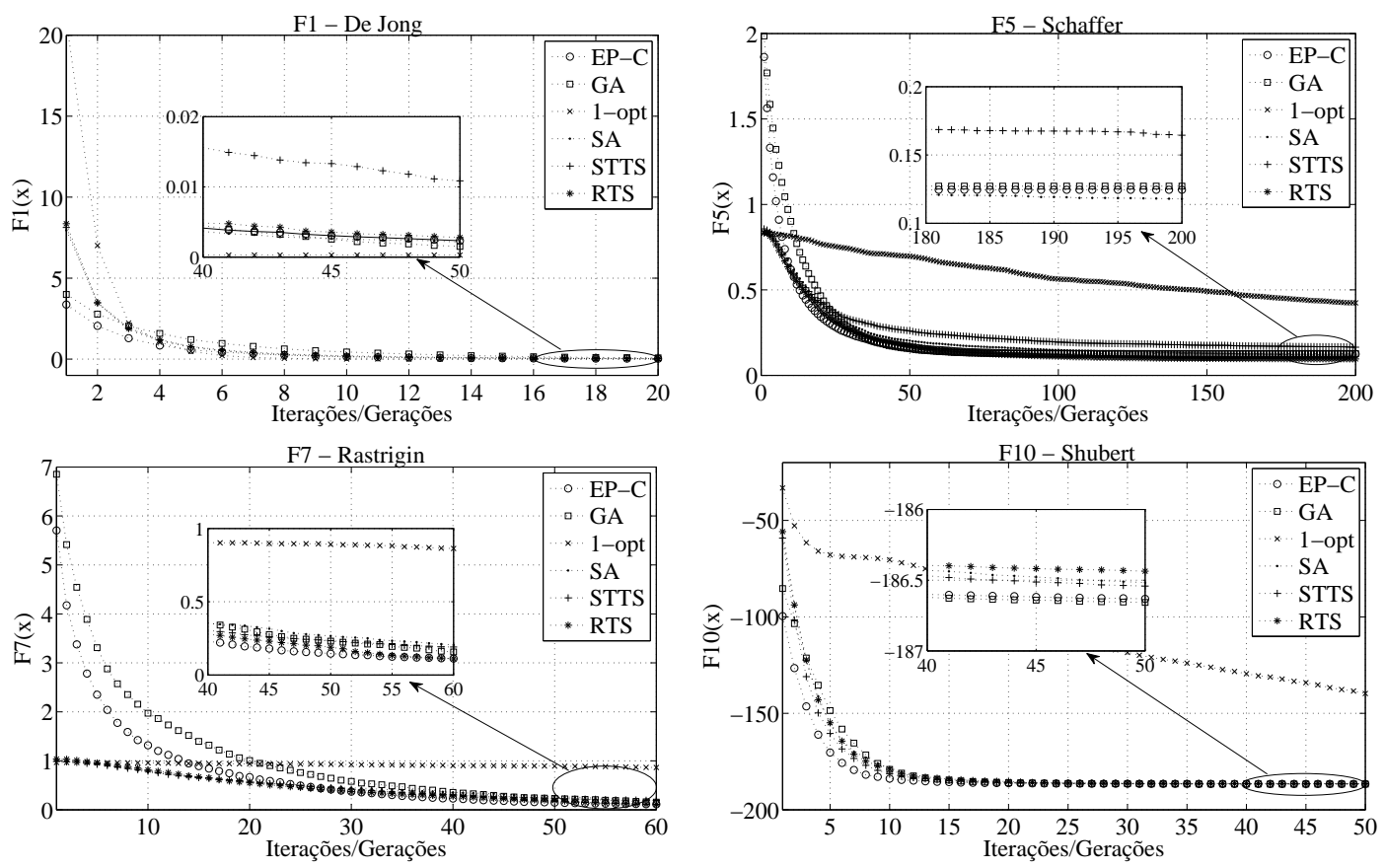

Figura 4.25: Desempenho dos algoritmos metaheurísticos com parâmetros e estratégias otimizadas para as funções F1, F5, F7 e F10.

Após a visualização do desempenho dos algoritmos deve-se quantificar de maneira mais criteriosa a medida de estabilidade. Com isso, deve-se definir os valores para o limite de especificação superior e inferior. No entanto, conforme descrito na seção 3.6.1, é utilizada somente a medida ACI para os algoritmos, pois as funções consideradas na prova de Decathlon são do tipo unilaterais, ou seja, possuem uma limitação inferior nos valores testados ${ }^{24}$. Por isso, definese os valores aceitáveis da USL para cada função analisada conforme valores típicos adotados nos trabalhos que utilizam estas funções de testes (RASTRIGIN, 1963; SCHWEFEL, 1977; DIXON; SZEGO, 1978; ACKLEY, 1987; MICHALEWICZ, 1996, 1993; SCHAFFER et al., 1989).

A tabela 4.8 apresenta as características de cada função bem como os limites

\footnotetext{
${ }^{24}$ Este limite corresponde à solução global do sistema.
} 
de especificação superiores. Vale ressaltar que pode-se utilizar condições mais restritivas, mas isso resultará em aumento das casas de precisão e do número de iterações/gerações para a convergência.

Tabela 4.8: Valores ótimos e aceitáveis para cada função de testes.

\begin{tabular}{l|c|c|c|c}
\hline & Dimensão & $\begin{array}{c}\text { Intervalo } \\
\text { de } \\
\text { busca }\end{array}$ & $\begin{array}{c}F(\mathbf{x}) \\
\text { ótimo }\end{array}$ & $\begin{array}{c}F(\mathbf{x}) \\
\text { aceitável } \\
\text { (USL) }\end{array}$ \\
\hline \hline F1 & 3 & $-5,12$ a 5,12 & 0 & $<0,015$ \\
F2 & 2 & $-2,048$ a 2,048 & 0 & $<0,38$ \\
F3 & 5 & $-5,12$ a 5,12 & -25 & $<-21,3$ \\
F4 & 2 & 0 a $\pi$ & $-1,735$ & $<-1,725$ \\
F5 & 2 & -20 a 20 & 0 & $<0,72$ \\
F6 & 2 & -50 a 50 & 0 & $<0,16$ \\
F7 & 2 & $-5,12$ a 5,12 & 0 & $<1,4$ \\
F8 & 2 & -500 a 500 & 0 & $<0,45$ \\
F9 & 2 & -3 a 3 & $-1,032$ ou & $<-1,02$ \\
F10 & 2 & -5 a 5 & $-186,7$ & $<-185,5$ \\
\hline
\end{tabular}

Após a definição das condições para cada função foram realizadas simulações visando a obtenção da medida ACI para cada algoritmo. Ao todo, foram considerados 8 possíveis algoritmos para a utilização da prova Decathlon (otimização de 10 funções), totalizando 80 simulações. Estes resultados consideraram uma média de desempenho com número mínimo de 1000 simulações para cada algoritmo.

A tabela 4.9 apresenta os resultados numéricos para a medida ACI considerando os limites de especificação superiores adotados. Nota-se que os algoritmos, com exceção do 1-opt e $k$-opt, atingem patamares inferiores ao mínimo desejado. Para esta análise, considerou-se que a medida mínima para $A C I \geq 2$. Outra observação importante consiste nos valores de ACI para os algoritmos 1-opt e $k$-opt que não resultaram em níveis de estabilidade satisfatório, fato devidamente possível, pois não possuem estratégias robustas de escape de soluções locais.

Desta forma, os algoritmos 1-opt e $k$-opt não são utilizados como metaheurísticas de baixo nível para a construção da $\mathrm{HH}$ e tampouco para a otimização dos problemas de $\mathrm{MuD}$ e MuChE.

Os demais algoritmos resultaram em desempenho satisfatório, com destaque para os algoritmos HH e SA que apresentam-se como os dois melhores, na sequência, em relação a qualidade e estabilidade das soluções obtidas. Ao final da tabela apresenta-se um resumo da pontuação dos algoritmos e a classificação em relação a estabilidade e qualidade das soluções. Vale ressaltar que o algoritmo HH resulta em melhor desempenho médio, pois aproveita as diversas estratégias de exploração e pressão que as metaheurísticas de baixo nível possuem, resultando 
em uma estratégia altamente eficiente para problemas de combinação árduos com espaço de busca com inúmeras soluções locais.

Também é possível observar o número de iterações/gerações que cada algoritmo utilizou para atingir o desempenho apresentado. Caso seja necessário um maior nível de qualidade (limites de especificação superior mais restritivo), aumenta-se o número de casas de precisão (aumentando o tamanho do candidato) e ao mesmo tempo deve-se considerar um incremento no número de iterações ou gerações utilizadas.

Tabela 4.9: Medida ACI para os algoritmos obtidas na prova de Decathlon.

\begin{tabular}{|c|c|c|c|c|c|c|c|c|}
\hline Medida ACI & 1-opt & 3 -opt & $\overline{\text { GA }}$ & $\overline{\mathrm{EP}-\mathrm{C}}$ & $\mathrm{SA}$ & STTS & RTS & $\mathrm{HH}$ \\
\hline$\overline{\text { F1 }}$ & $\overline{201,94}$ & $\overline{21,30}$ & 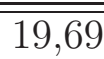 & $\overline{10,73}$ & $\overline{\overline{77,80}}$ & 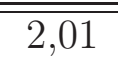 & $\overline{\overline{5,42}}$ & 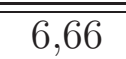 \\
\hline $\mathrm{F} 2$ & 9,53 & 10,27 & 2,64 & 2,09 & 108,93 & 90,82 & $\overline{57,56}$ & 227,49 \\
\hline F3 & 1,98 & 10,15 & 2,39 & 2,36 & 2,21 & 2,02 & 2,07 & 2,30 \\
\hline F4 & 0,20 & 2,31 & 2,44 & 2,28 & 2,47 & 2,04 & 2,37 & 2,58 \\
\hline F5 & 1,24 & 1,43 & 3,24 & 3,09 & 2,43 & 2,06 & 2,71 & 3,00 \\
\hline F6 & 0,02 & 0,02 & 14,60 & 6,09 & 4,68 & 2,03 & 9,75 & 6,56 \\
\hline F7 & 0,69 & 1,11 & 2,08 & 5,93 & 22,08 & 6,67 & 6,51 & 5,82 \\
\hline F8 & 0,03 & 2,06 & 2,41 & 2,21 & 4,57 & 4,26 & 2,04 & 3,13 \\
\hline F9 & 1,72 & 2,21 & 2,25 & 2,07 & 3,01 & 11,00 & 2,85 & 10,46 \\
\hline F10 & 0,08 & 3,17 & 3,69 & 2,69 & 9,43 & 7,43 & 2,02 & 10,73 \\
\hline & & & & & & & & \\
\hline Média & 3,74 & 5,39 & 6,53 & 3,95 & 16,01 & 13,03 & 9,33 & 27,87 \\
\hline $\begin{array}{l}\text { Iterações } \\
\text { ou } \\
\text { Gerações }\end{array}$ & 500 & 20 & 100 & 100 & 200 & 200 & 200 & 200 \\
\hline Pontuação & $\mathrm{x}$ & $\mathrm{x}$ & 74 & 62 & 79 & 65 & 62 & 81 \\
\hline Colocação & $\mathrm{X}$ & $\mathrm{x}$ & $3^{\circ}$ & $6^{\circ}$ & $2^{o}$ & $4^{o}$ & $5^{\circ}$ & $1^{o}$ \\
\hline
\end{tabular}

Por fim, a obtenção da medida de qualidade, embora seja extremamente importante, não deve ser a única característica analisada visando a escolha de um algoritmo para uso em aplicações práticas. A outra medida essencial está relacionada com a complexidade, pois o algoritmo pode apresentar desempenho satisfatório mas ao mesmo tempo resultar em uma complexidade computacional proibitiva. Assim, a seção 4.4 considera esta análise de complexidade para determinação da melhor relação custo computacional $\times$ desempenho (qualidade e estabilidade das soluções) para os algoritmos analisados neste trabalho. 


\subsection{Complexidade computacional das topologias propostas}

Uma forma convencional de comparação da complexidade entre algoritmos pode ser feita através da notação $\mathcal{O}$, que representa a ordem de grandeza da complexidade. Mas comparar algoritmos apenas através da notação $\mathcal{O}$ pode ser insuficiente, principalmente quando os algoritmos forem muito parecidos ou possuírem a mesma ordem de grandeza. Assim, apresenta-se a complexidade dos algoritmos utilizando de até três figuras de mérito: a notação $\mathcal{O}$, o número de instruções computadas e o tempo computacional médio necessário para uma determinada otimização.

\subsubsection{A notação $\mathcal{O}$}

A notação $\mathcal{O}$, ou notação assintótica, considera uma representação matemática para analisar o comportamento assintótico de funções quando o argumento tende para um valor particular ou infinito, sendo principalmente utilizada na área de análise de algoritmos computacionais. Assim, a notação $\mathcal{O}$ é usada para classificar algoritmos considerando a maneira como eles respondem ${ }^{25}$ a mudanças no tamanho da entrada. Esta notação é creditada ao matemático Paul Bachmann em seu trabalho de 1984, sendo posteriormente difundida por Edmund Landau a partir de 1909, sendo, por isso, também conhecida como "Símbolo de Landau". Mas somente a partir do trabalho de D. Knuth (KNUTH, 1976), esta notação foi popularizada na área de computação para análise de algoritmos.

Por definição, considerando duas funções reais $f(x)$ e $g(x)$, a notação $\mathcal{O}$ é definida como (KNUTH, 1997):

$$
f(x)=\mathcal{O}(g(x)) \quad \text { se } \quad f(x) \leq n . g(x)
$$

para alguma constante positiva $n$ e para todo $x$ maior que um número $x_{0}$.

Assim, diz-se que uma função $f(x)$ pode ser representada como $O(g(x))$ se ambas as funções, para um $x$ suficientemente grande, apresentam crescimento da mesma ordem, ou seja, são proporcionais ${ }^{26}$.

\footnotetext{
${ }^{25}$ Em termos do seu tempo de processamento ou no número de operações.

${ }^{26}$ Como exemplo, se em um dado intervalo $f(x)$ triplica, então $g(x)$ também triplicou, apresentando apenas uma pequena diferença.
} 


\subsubsection{Operações de Ponto Flutuante}

Na obtenção do número de instruções que cada algoritmo realiza em um processo de otimização, pode-se utilizar o conceito de medição de operações de ponto flutuante por segundo (flops - float point operations per second) (HIGHAM, 1996). Esta medida considera como uma instrução todas aquelas operações realizadas por um processador que apresentarem um tempo computacional relevante, sendo denominadas operações principais. Neste trabalho, as operações de multiplicação, adição, subtração e divisão foram consideradas como operações principais, sendo consideradas como tendo o mesmo custo computacional.

Além disso, os algoritmos realizam outras operações que resultam em tempo computacional relevante, denominados de processo de ordenação, de transposição, de comparação, de troca, de geração de números aleatórios, de seleção, entre outras. Estas operações possuem uma complexidade proporcional ao tamanho do problema, tamanho do vetor ou número de elementos de uma matriz. Portanto, também são considerados no cômputo da complexidade das topologias.

\subsubsection{Número de Operações}

Considerando que cada instrução relevante x possuirá um tempo associado t(x), um programa qualquer Prog, com certa entrada fixa, processará $r_{1}$ instruções do tipo $\mathrm{x}_{1}, \mathrm{r}_{2}$ instruções do tipo $\mathrm{x}_{2}$, até $\mathrm{r}_{m}$ instruções do tipo $\mathrm{x}_{m}$. Nesse caso, o tempo para executar o programa Prog será dado por:

$$
\text { Tempo }(\operatorname{Prog})=\sum_{j=1}^{m} \mathrm{r}_{j} \mathrm{t}\left(\mathrm{x}_{j}\right)
$$

Em última análise, o estudo da complexidade de um algoritmo poderia ser resolvido através da avaliação do somatório, equação (4.33). Para simplificar o problema da avaliação do tempo computacional das instruções $\mathbf{x}_{j}, j=1, \ldots, m$, considera-se $\mathrm{t}(\mathrm{x})=1$ para qualquer instrução $\mathrm{x}$. Essa simplificação é coerente com o uso da notação $\mathcal{O}$ para a análise da ordem do tempo computacional, uma vez que as relações entre as durações das diversas instruções é de natureza constante, o que seria irrelevante no cálculo da ordem da complexidade. Outra vantagem em adotar $\mathrm{t}(\mathrm{x})=1$ é que assim o valor do tempo de execução de um programa iguala-se ao número total de instruções computadas, respeitando-se a 
ordem de cada instrução.

$$
\text { Instruções }(\text { Prog })=\sum_{j=1}^{m} r_{j}
$$

\subsubsection{Determinação da complexidade}

Visando obter expressões fechadas e genéricas para a complexidade computacional dos algoritmos é necessário identificar as operações relevantes que resultam em tempo computacional expressivo. Além disso, a complexidade total depende da função custo a ser utilizada resultando em uma medida de complexidade dependente de tal função. Portanto, esta seção apresenta a complexidade na forma genérica $^{27}$ dos algoritmos segundo as duas figuras de mérito (notação $\mathcal{O}$ e número de operações) ${ }^{28}$ considerando os respectivos algoritmos com parâmetros e estratégias otimizadas. Visando facilitar a comparação entre as complexidades dos algoritmos, optou-se pela padronização da nomenclatura do número de iterações $\left(I_{t}\right)$ e do número de gerações $\left(G_{t}\right)$, sendo utilizado a nomenclatura $G_{t}$ para representar ambos os números. Todavia, a nomenclatura para os algoritmos de busca local deve ser mantida, considerando $G_{t}$ como o número de iterações dos algoritmos.

\subsubsection{Complexidade genérica para o GA}

O algoritmo genético, considerando as estratégias de seleção p-sort, crossover uniforme, mutação gaussiana e reposição do tipo $\mu+\lambda \operatorname{com} \mu=p$ e ainda os parâmetros otimizados para o poço de cruzamento $T=0,7 p$, taxa de mutação $p_{m}=10 \%$ e tamanho da população calculado conforme equação (3.21), resulta em uma complexidade dada por:

- $3 G_{t}$ ordenações de vetores de ordem $1 \times p$, resultando em aproximadamente $3 p \log (p) G_{t}$ flops

- $(T+2) G_{t}$ seleções de valores em vetores ordenados de ordem 1, resultando em $(T+2) G_{t}$ flops

- $p G_{t}$ sorteios de números aleatórios de ordem $1 \times Q_{\text {indiv }}$, resultando em $p Q_{\text {indiv }} G_{t}$ flops

\footnotetext{
${ }^{27}$ Pode-se utilizar estas expressões para qualquer tipo de problema, necessitando apenas de informações sobre a função custo associada.

${ }^{28}$ A determinação do tempo computacional deve considerar análise da função custo e, por isso, será realizada na seção 5.3 .
} 
- $(3 p+T) G_{t}$ seleções de valores de ordem $1 \times Q_{\text {indiv }}$, resultando em $(3 p+T) Q_{i n d i v} G_{t}$ flops

- $G_{t}$ cálculos de mutação, resultando em $3 p Q_{\text {indiv }} G_{t}$ flops

- $G_{t}$ cálculos de crossover, resultando em $5 p Q_{\text {indiv }} G_{t}$ flops

- $p G_{t}$ cálculos da função custo, resultando em $p G_{t} \cdot \mathcal{O}_{F C}$ flops

onde $\mathcal{O}_{F C}$ representa o número de operações necessárias para a realização do cálculo da função custo uma vez.

Desta forma, o número de operações para o GA resulta em:

$$
\operatorname{Instruções~}(G A) \approx p G_{t}\left(\mathcal{O}_{F C}+11,7 Q_{\text {indiv }}+3 \log (p)\right)
$$

Considerando apenas a notação $\mathcal{O}$ e assumindo que o custo computacional do cálculo da função custo significativamente superior às etapas do GA, pode-se afirmar que o GA possui uma complexidade descrita por:

$$
\mathcal{O}(G A)=p G_{t} \mathcal{O}_{F C}
$$

\subsubsection{Complexidade genérica para o EP-C}

O algoritmo de programação evolucionária com clonagem, considerando as estratégias de seleção $p$-sort, mutação gaussiana e reposição do tipo $\mu+\lambda$ com $\mu=p$ e ainda os parâmetros otimizados para o índice de clonagem $I_{c}=0,1 p$, taxa de mutação $p_{m}=15 \%$ e tamanho da população calculado conforme equação (3.21), resulta em uma complexidade dada por:

- $3 G_{t}$ ordenações de vetores de ordem $1 \times p$, resultando em aproximadamente $3 p \log (p) G_{t}$ flops

- $\left(I_{c}+2\right) G_{t}$ seleções de valores em vetores ordenados de ordem 1, resultando em $\left(I_{c}+2\right) G_{t}$ flops

- $p G_{t}$ sorteios de números aleatórios de ordem $1 \times Q_{\text {indiv }}$, resultando em $p Q_{\text {indiv }} G_{t}$ flops

- $\left(3 p+I_{c}\right) G_{t}$ seleções de valores de ordem $1 \times Q_{\text {indiv }}$, resultando em $\left(3 p+I_{c}\right) Q_{\text {indiv }} G_{t}$ flops

- $G_{t}$ cálculos de mutação, resultando em $3 p Q_{\text {indiv }} G_{t}$ flops 
- $p G_{t}$ cálculos da função custo, resultando em $p G_{t} \cdot \mathcal{O}_{F C}$ flops

Desta forma, o número de operações para o EP-C resulta em:

$$
\operatorname{Instruções~}(E P-C) \approx p G_{t}\left(\mathcal{O}_{F C}+6,1 Q_{\text {indiv }}+3 \log (p)\right)
$$

Vale ressaltar que a complexidade do EP-C é similar à do GA retirando a complexidade do operador crossover e acrescentando a complexidade do operador de clonagem. Assim, a complexidade considerando a notação $\mathcal{O}$ para o algoritmo EP-C é igual a do GA, ou seja:

$$
\mathcal{O}(E P-C)=p G_{t} \mathcal{O}_{F C}
$$

\subsubsection{Complexidade genérica para o k-opt}

O algoritmo de busca local $k$-opt resulta em uma complexidade dada por:

- $\sum_{i=1}^{k}\left(\begin{array}{c}Q_{\text {indiv }} \\ i\end{array}\right) G_{t}$ repetições de vetores de ordem $1 \times Q_{\text {indiv }}$, resultando em aproximadamente $\sum_{i=1}^{k}\left(\begin{array}{c}Q_{\text {indiv }} \\ i\end{array}\right) G_{t} Q_{\text {indiv }}$ flops

- $\sum_{i=1}^{k}\left(\begin{array}{c}Q_{\text {indiv }} \\ i\end{array}\right) G_{t}$ operações binárias "ou exclusivo" de ordem $1 \times Q_{\text {indiv }}$, resultando em $\sum_{i=1}^{k}\left(\begin{array}{c}Q_{\text {indiv }} \\ i\end{array}\right) G_{t} Q_{\text {indiv }}$ flops

- $\sum_{i=1}^{k}\left(\begin{array}{c}Q_{\text {indiv }} \\ i\end{array}\right) G_{t}$ comparações de números de ordem 1, resultando em $\sum_{i=1}^{k}\left(\begin{array}{c}Q_{\text {indiv }} \\ i\end{array}\right) G_{t}$ flops

- $G_{t}$ sorteios de números aleatórios de ordem $1 \times Q_{\text {indiv }}$, resultando em $G_{t} Q_{\text {indiv }}$ flops

- $2 G_{t}$ seleções de valores de ordem $1 \times Q_{\text {indiv }}$, resultando em $2 Q_{\text {indiv }} G_{t}$ flops

- $\sum_{i=1}^{k}\left(\begin{array}{c}Q_{\text {indiv }} \\ i\end{array}\right) G_{t}$ cálculos da função custo, resultando em $\sum_{i=1}^{k}\left(\begin{array}{c}Q_{\text {indiv }} \\ i\end{array}\right) G_{t} \cdot \mathcal{O}_{F C}$ flops 
Desta forma, o número de operações para o $k$-opt resulta em:

$$
\operatorname{Instruções~}(k-o p t) \approx \sum_{i=1}^{k}\left(\begin{array}{c}
Q_{\text {indiv }} \\
i
\end{array}\right) G_{t}\left(\mathcal{O}_{F C}+2 Q_{\text {indiv }}+2\right)
$$

Nota-se que para $k$ grande resulta em uma complexidade extremamente alta, pois o número de cálculos da função custo aumenta exponencialmente com $k$. Assim, a complexidade considerando a notação $\mathcal{O}$ para o algoritmo $k$-opt é dada por:

$$
\mathcal{O}(k-\text { opt })=\sum_{i=1}^{k}\left(\begin{array}{c}
Q_{\text {indiv }} \\
i
\end{array}\right) G_{t} \mathcal{O}_{F C}
$$

Caso $k=1$, resultará em uma complexidade da ordem de $\mathcal{O}(1-$ opt $)=$ $Q_{\text {indiv }} G_{t} \mathcal{O}_{F C}$.

\subsubsection{Complexidade genérica para o SA}

O algoritmo de recozimento simulado, considerando os parâmetros otimizados para a temperatura inicial $T(0)=\ln \left(G_{t}\right)$, tamanho do platô $L_{s a}=2$, passo de resfriamento $\varepsilon=\sqrt{\frac{2}{\ln (i)}}$ e probabilidade de aceitação $x(i)=\exp \left[\frac{|\Delta e|}{T(i)}\right]-1$, apresenta uma complexidade dada por:

- $G_{t}$ cálculos da temperatura, resultando em aproximadamente $8 G_{t}$ flops

- $Q_{\text {indiv }} G_{t}$ repetições de vetores de ordem $1 \times Q_{\text {indiv }}$, resultando em $Q_{\text {indiv }}^{2} G_{t}$ flops

- $Q_{\text {indiv }} G_{t}$ sorteios de números aleatórios de ordem $1 \times Q_{\text {indiv }}$, resultando em $Q_{\text {indiv }}^{2} G_{t}$ flops

- $Q_{\text {indiv }} G_{t}$ sorteios de números aleatórios de ordem 1 , resultando em $Q_{\text {indiv }} G_{t}$ flops

- $Q_{\text {indiv }} G_{t}$ operações binárias "ou exclusivo" de ordem $1 \times Q_{\text {indiv }}$, resultando em $Q_{\text {indiv }}^{2} G_{t}$ flops

- $Q_{\text {indiv }} G_{t}$ comparações de ordem 1 , resultando em $Q_{\text {indiv }} G_{t}$ flops

- $G_{t}$ cálculos para o critério de aceitação, resultando em aproximadamente $\left(3 Q_{\text {indiv }}+12\right) G_{t}$ flops

- $Q_{\text {indiv }} G_{t}$ cálculos da função custo, resultando em $Q_{\text {indiv }} G_{t} \cdot \mathcal{O}_{F C}$ flops 
Desta forma, o número de operações para o SA resulta em:

$$
\operatorname{Instruções~}(S A) \approx Q_{\text {indiv }} G_{t}\left(\mathcal{O}_{F C}+3 Q_{\text {indiv }}+5\right)
$$

Nota-se que a complexidade do SA é similar a do algoritmo 1-opt, acrescida do cálculo da temperatura e do critério de aceitação. Assim, a complexidade considerando a notação $\mathcal{O}$ para o algoritmo SA é igual a do 1-opt, ou seja:

$$
\mathcal{O}(S A)=Q_{\text {indiv }} G_{t} \mathcal{O}_{F C}
$$

\subsubsection{Complexidade genérica para o STTS}

O algoritmo baseado em lista Tabu de termo curto, considerando o parâmetro otimizado para o período de proibição $P=Q_{\text {indiv }} / 2$, apresenta uma complexidade dada por:

- $Q_{\text {indiv }} G_{t}$ repetições de vetores de ordem $1 \times Q_{\text {indiv }}$, resultando em $Q_{\text {indiv }}^{2} G_{t}$ flops

- $Q_{\text {indiv }} G_{t}$ sorteios de números aleatórios de ordem $1 \times Q_{\text {indiv }}$, resultando em $Q_{\text {indiv }}^{2} G_{t}$ flops

- $Q_{\text {indiv }} G_{t}$ sorteios de números aleatórios de ordem 1 , resultando em $Q_{\text {indiv }} G_{t}$ flops

- $Q_{\text {indiv }} G_{t}$ operações binárias "ou exclusivo" de ordem $1 \times Q_{\text {indiv }}$, resultando em $Q_{\text {indiv }}^{2} G_{t}$ flops

- $Q_{\text {indiv }} G_{t}$ ordenações de vetores de ordem 1 , resultando em aproximadamente $Q_{\text {indiv }} G_{t} \log \left(Q_{\text {indiv }}\right)$ flops

- $G_{t}$ seleções de vetores de ordem $1 \times Q_{\text {indiv }}$, resultando em $Q_{\text {indiv }} G_{t}$ flops

- $G_{t}$ verificações e atualizações da Lista Tabu, resultando em aproximadamente $(P+4) Q_{\text {indiv }} G_{t}$ flops

- $Q_{\text {indiv }} G_{t}$ cálculos da função custo, resultando em $Q_{\text {indiv }} G_{t} \cdot \mathcal{O}_{F C}$ flops

Desta forma, o número de operações para o STTS resulta em:

$$
\operatorname{Instruções~}(S T T S) \approx Q_{\text {indiv }} G_{t}\left(\mathcal{O}_{F C}+3,5 Q_{\text {indiv }}+\log \left(Q_{\text {indiv }}\right)+6\right)
$$


Assim, a complexidade considerando a notação $\mathcal{O}$ para o algoritmo STTS é dada por:

$$
\mathcal{O}(S T T S)=Q_{\text {indiv }} G_{t} \mathcal{O}_{F C}
$$

\subsubsection{Complexidade genérica para o RTS}

O algoritmo baseado em lista Tabu de termo longo, considerando o parâmetro otimizado para o período de proibição inicial $P(0)=Q_{\text {indiv }} / 2$ e taxa de redução/incremento do período de proibição $x=50 \%$, apresenta uma complexidade média dada por:

- $Q_{\text {indiv }} G_{t}$ repetições de vetores de ordem $1 \times Q_{\text {indiv }}$, resultando em $Q_{\text {indiv }}^{2} G_{t}$ flops

- $Q_{\text {indiv }} G_{t}$ sorteios de números aleatórios de ordem $1 \times Q_{\text {indiv }}$, resultando em $Q_{\text {indiv }}^{2} G_{t}$ flops

- $Q_{\text {indiv }} G_{t}$ sorteios de números aleatórios de ordem 1 , resultando em $Q_{\text {indiv }} G_{t}$ flops

- $Q_{\text {indiv }} G_{t}$ operações binárias "ou exclusivo" de ordem $1 \times Q_{\text {indiv }}$, resultando em $Q_{\text {indiv }}^{2} G_{t}$ flops

- $Q_{\text {indiv }} G_{t}$ ordenações de vetores de ordem 1 , resultando em aproximadamente $Q_{\text {indiv }} G_{t} \log \left(Q_{\text {indiv }}\right)$ flops

- $G_{t}$ seleções de vetores de ordem $1 \times Q_{\text {indiv }}$, resultando em $Q_{i n d i v} G_{t}$ flops

- $G_{t}$ verificações e atualizações da Lista Tabu, resultando em aproximadamente $(\bar{P}+5) Q_{\text {indiv }} G_{t}$ flops

- $Q_{\text {indiv }} G_{t}$ cálculos da função custo, resultando em $Q_{\text {indiv }} G_{t} \cdot \mathcal{O}_{F C}$ flops

onde $\bar{P}$ representa a média do período de proibição para o algoritmo RTS.

Desta forma, o número de operações para o RTS resulta em:

$$
\operatorname{Instruções~}(R T S) \approx Q_{\text {indiv }} G_{t}\left(\mathcal{O}_{F C}+3,5 Q_{\text {indiv }}+\log \left(Q_{\text {indiv }}\right)+7\right)
$$

Percebe-se que a complexidade do algoritmo RTS é muito próxima do algoritmo STTS, pois a única diferença consiste na adição da etapa 5.1 apresentada na tabela 3.5. Assim, a complexidade considerando a notação $\mathcal{O}$ para o algoritmo RTS é dada por:

$$
\mathcal{O}(R T S)=Q_{\text {indiv }} G_{t} \mathcal{O}_{F C}
$$




\subsubsection{Complexidade genérica para o $\mathrm{HH}$}

Por fim, para obter a complexidade do algoritmo HH deve-se considerar primeiramente quais metaheurísticas serão utilizadas como heurísticas de baixo nível. Conforme apresentado na seção 4.3 .1 e seção 4.4, observa-se que o algoritmo 1-opt não apresenta boa estabilidade, ou seja, bons valores de ACI e o algoritmo $k$-opt apresenta uma complexidade muito superior a dos demais algoritmos, além de não apresentar bom desempenho para as funções F5, F6 e F7. Desta forma, para a construção da HH foram considerados apenas os algoritmos EP-C, GA, SA, STTS e RTS visando a manutenção de bons resultados.

Com isso, considerando as estratégias e parâmetros otimizados para o HH, como o número de iterações $I_{t}(H H)=10$, estratégia de seleção Simplesmente Aleatório e estratégia de Aceitação Ingênua, pode-se afirmar que a complexidade do HH consiste na média das complexidades dos algoritmos de baixo nível acrescida da complexidade para as estratégias de seleção e aceitação de alto nível.

Desta forma, o número de operações para o HH resulta em:

$$
\begin{aligned}
\operatorname{Instruções~}(H H) \approx & \left(0,6 Q_{\text {indiv }}+0,4 p\right) G_{t} \mathcal{O}_{F C}+ \\
& +0,2 Q_{\text {indiv }} G_{t}\left(10 Q_{\text {indiv }}+18 p+28\right)
\end{aligned}
$$

Nota-se que a complexidade do algoritmo HH é a média da complexidade dos algoritmos de baixo nível, pois a estratégia de seleção é do tipo aleatória com distribuição uniforme. Assim, pode-se expressar a complexidade considerando a notação $\mathcal{O}$ para o algoritmo $\mathrm{HH}$, sendo dada por:

$$
\mathcal{O}(H H)=\left(0,6 Q_{\text {indiv }}+0,4 p\right) G_{t} \mathcal{O}_{F C}
$$

\subsubsection{Resumo da complexidade genérica dos algoritmos}

A tabela 4.10 tem por finalidade apresentar um resumo das expressões de complexidade genéricas dos algoritmos metaheurísticos e hiperheurística visando praticidade na consulta e posterior utilização na etapa de determinação da complexidade para os sistemas de telecomunicações considerados, além da apresentação quantitativa da complexidade computacional dos algoritmos para a aplicação na prova de Decathlon considerada neste trabalho (funções F1 a F10).

A tabela 4.11 apresenta o número de operações que cada algoritmo necessita para a otimização de cada função (F1 a F10) considerada na prova de Decathlon. Esta tabela possibilita a visualização, em negrito, dos algoritmos que resultaram 
Tabela 4.10: Resumo do número aproximado de instruções média genérica dos algoritmos.

\begin{tabular}{|c|c|c|}
\hline & Flops & Notação $\mathcal{O}$ \\
\hline GA & $p G_{t}\left(\mathcal{O}_{F C}+11,7 Q_{\text {indiv }}+3 \log \left(Q_{\text {indiv }}\right)\right)$ & $p G_{t} \mathcal{O}_{F C}$ \\
\hline EP-C & $p G_{t}\left(\mathcal{O}_{F C}+6,1 Q_{\text {indiv }}+3 \log \left(Q_{\text {indiv }}\right)\right)$ & $p G_{t} \mathcal{O}_{F C}$ \\
\hline 1-opt & $Q_{\text {indiv }} G_{t}\left(\mathcal{O}_{F C}+2 Q_{\text {indiv }}+2\right)$ & $Q_{\text {indiv }} G_{t} \mathcal{O}_{F C}$ \\
\hline$k$-opt & $\sum_{i=1}^{k}\left(\begin{array}{c}Q_{\text {indiv }} \\
i\end{array}\right) G_{t}\left(\mathcal{O}_{F C}+2 Q_{\text {indiv }}+2\right)$ & $\sum_{i=1}^{k}\left(\begin{array}{c}Q_{\text {indiv }} \\
i\end{array}\right) G_{t} \mathcal{O}_{F C}$ \\
\hline $\mathrm{SA}$ & $Q_{\text {indiv }} G_{t}\left(\mathcal{O}_{F C}+3 Q_{\text {indiv }}+5\right)$ & $Q_{\text {indiv }} G_{t} \mathcal{O}_{F C}$ \\
\hline STTS & $Q_{\text {indiv }} G_{t}\left(\mathcal{O}_{F C}+3,5 Q_{\text {indiv }}+\log \left(Q_{\text {indiv }}\right)+6\right)$ & $Q_{i n d i v} G_{t} \mathcal{O}_{F C}$ \\
\hline RTS & $Q_{\text {indiv }} G_{t}\left(\mathcal{O}_{F C}+3,5 Q_{\text {indiv }}+\log \left(Q_{\text {indiv }}\right)+7\right)$ & $Q_{\text {indiv }} G_{t} \mathcal{O}_{F C}$ \\
\hline $\mathrm{HH}$ & $\begin{array}{c}\left(0,6 Q_{i n d i v}+0,4 p\right) G_{t} \mathcal{O}_{F C}+ \\
+0,2 Q_{\text {indiv }} G_{t}\left(10 Q_{\text {indiv }}+18 p+28\right)\end{array}$ & $\left(0,6 Q_{\text {indiv }}+0,4 p\right) G_{t} \mathcal{O}_{F C}$ \\
\hline
\end{tabular}


em menores valores de complexidade para cada prova (função), além de uma comparação rápida e consistente entre as diversas complexidades dos algoritmos.

Vale ressaltar que os algoritmos 1-opt e $k$-opt resultam em complexidades superiores para a maioria das funções além de não resultar em soluções boas e estáveis. Desta forma, como não atendem a primeira característica (qualidade e estabilidade) e também resultam em complexidade superiores, não serão utilizadas na otimização para os problemas MuD e MuChE.

Observa-se também que o algoritmo SA resultou na menor complexidade média, mas muito próxima a do algoritmo EP-C. A classificação dos algoritmos em relação à complexidade é apresentada ao final da tabela 4.11.

Tabela 4.11: Complexidade em termos do número médio de operações dos algoritmos para otimização das funções F1 a F10.

\begin{tabular}{|c|c|c|c|c|c|c|c|c|}
\hline$\left(10^{6}\right)$ flops & 1-opt & 3-opt & GA & EP-C & $\mathrm{SA}$ & STTS & RTS & $\mathrm{HH}$ \\
\hline$\overline{\mathrm{F} 1}$ & 4,53 & 27,33 & $\bar{~} 1,79$ & 1,28 & 2,01 & 2,11 & 2,12 & 2,48 \\
\hline $\mathrm{F} 2$ & 0,80 & 3,11 & 0,91 & $\overline{0,50}$ & 0,45 & 0,52 & 0,53 & 0,87 \\
\hline F3 & 3,15 & 52,61 & 2,46 & 1,34 & $\overline{1,79}$ & 2,07 & 2,08 & 2,72 \\
\hline $\mathrm{F} 4$ & 0,58 & 1,26 & 0,72 & $\overline{0,42}$ & 0,31 & 0,35 & 0,35 & 0,66 \\
\hline F5 & 0,92 & 3,58 & 0,94 & 0,53 & $\overline{0,50}$ & 0,57 & 0,57 & 0,92 \\
\hline F6 & 1,60 & 12,37 & 1,71 & 0,94 & $\overline{0,89}$ & 1,02 & 1,03 & 1,65 \\
\hline F7 & 1,34 & 7,07 & 1,11 & 0,64 & $\overline{0,71}$ & 0,80 & 0,81 & 1,17 \\
\hline F8 & 1,36 & 10,53 & 1,65 & $\overline{0,89}$ & 0,80 & 0,93 & 0,94 & 1,55 \\
\hline F9 & 0,78 & 3,54 & 0,94 & 0,51 & 0,46 & 0,54 & 0,55 & 0,89 \\
\hline F10 & 1,28 & 9,87 & 1,63 & 0,87 & $\overline{0,76}$ & 0,89 & 0,90 & 1,52 \\
\hline & & & & & & & & \\
\hline Pontuação & $\mathrm{x}$ & $\mathrm{x}$ & 49 & 91 & $\underline{96}$ & 80 & 70 & 51 \\
\hline Colocação & $\mathrm{x}$ & $\mathrm{x}$ & $6^{\circ}$ & $2^{o}$ & $1^{o}$ & $3^{\circ}$ & $4^{o}$ & $5^{o}$ \\
\hline
\end{tabular}

\subsubsection{Tempo Computacional}

A complexidade computacional dos algoritmos também pode ser medida através do tempo computacional que cada algoritmo necessita para realizar uma otimização. Um modelo que expressa o tempo computacional requerido pelos algoritmos para realizar uma otimização foi descrito em (FITZPATRICK; GREFENSTETTE, 1988), o qual indica que o tempo necessário depende dos parâmetros de entrada e das constantes de tempo envolvidas nas diversas etapas descritas no capítulo 3 para cada algoritmo, resultando em:

$$
\text { Tempo }(\operatorname{Prog})=\sum_{j=1}^{m} r_{j} \mathrm{t}\left(\mathrm{x}_{j}\right)=(\mu \cdot p+\varpi \cdot p) \cdot G_{t}
$$


onde $G_{t}$ representa o número de iterações / gerações para convergência, $p$ é o tamanho da população ou número de candidatos analisados por iteração ${ }^{29}$. A variável $\mu$ representa uma quantidade de tempo de processamento para as etapas dos algoritmos por candidato/indivíduo e por iteração/geração, representando a medida do custo computacional para todas as etapas descritas no capítulo 3 inerente a cada algoritmo, mas desconsiderando o custo computacional do cômputo da função custo. A variável $\varpi$ representa o custo de um simples cálculo da função custo. Neste modelo, desconsidera-se o custo para a inicialização do algoritmo, pois representa um parcela desprezível do tempo total de otimização.

Nota-se que ao se conhecer o tempo médio para a realização das etapas de cada algoritmo e do tempo médio para o cômputo de cada função custo, torna-se possível estimar com precisão o tempo médio de otimização para um determinado problema. Esta análise é de suma importância, pois ao realizar apenas a análise do número de operações, está-se utilizando uma aproximação onde todas as operações relevantes são consideradas como tendo o mesmo tempo computacional ${ }^{30}$.

Vale ressaltar que cada etapa de um algoritmo pode ser implementada de diversas maneiras com realização de distintas operações. Assim, assumir que todas as operações possuem um mesmo tempo computacional pode acarretar em conclusões não condizentes com a realidade do tempo necessário à otimização para cada algoritmo. Por isso, deve-se utilizar o número de operações para indicar a ordem de grandeza envolvida bem como uma estimativa inicial do tempo computacional, mas este pode resultar em um tempo de realização diferente para cada algoritmo, devido as diferentes operações computadas. Portanto, a análise da complexidade através do tempo computacional conforme equação (4.49) mostrase mais apropriada para ambientes reais visando comparação de complexidade entre algoritmos que possuem um número de operações muito próximo.

Outro aspecto consiste no hardware utilizado, pois existe uma variedade enorme de possíveis configurações e capacidade de processamento. Assim, a medida de tempo computacional para este trabalho considerou a seguinte configuração para um computador pessoal de alto desempenho ${ }^{31}$ :

\section{- Placa Mãe: ASUS P8H67-M EVO}

\footnotetext{
${ }^{29}$ Obtido pela equação (3.21) para os algoritmos evolucionários e igual ao tamanho do candidato $\left(Q_{\text {indiv }}\right)$ para os algoritmos de busca local.

${ }^{30}$ Operações distintas podem apresentar diferença substancial no tempo de execução, dependendo da linguagem implementada, do nível de conhecimento do programador e hardware utilizado (MCCABE, 1976; FITZPATRICK; GREFENSTETTE, 1988; GOLUB; VAN LOAN, 1996; PAPADIMITRIOU; STEIGLITZ, 1998).

${ }^{31}$ Apresenta-se a configuração completa, pois a mudança de qualquer um dos itens pode alterar o desempenho geral do hardware.
} 
- Processador: Intel I7-2600 com 3,4GHz de clock e 8Mb de cache

- Memória: 8Gb Corsair Dominator DDR3 1333MHz

- Placa de Vídeo: Radeon HD6950 2Gb DDR5

- Cooler: Cooler Master Hyper N620

- Gabinete: Cooler Master Storm Scout

- HD: 1Tb Seagate Barracuda 7200

- Sistema Operacional: Windows7 64bits

- Fonte: Dr. Hank 700W RMS

- Monitor: Samsung Syncmaster 2233RZ

- Teclado: Razer Cyclosa

- Mouse: Razer DeathAdder 3,5GHz Black Edition

- Mousepad: Razer Vespula

Além disso, a linguagem de programação utilizada e o nível de conhecimento do programador afetam significativamente o desempenho em termos do tempo computacional para um determinado algoritmo. Neste trabalho, o candidato é o autor de todas as rotinas implementadas e, com isso, o nível de otimização dos códigos fontes tende a ser o mesmo para as rotinas devido à manutenção do estilo de programação. O software utilizado para todas as simulações foi o Matlab ${ }^{\circledR}$.

Definido o hardware e o software, obteve-se os valores para as variáveis $\varpi$ e $\mu$ para as funções F1 a F10 e para as etapas dos algoritmos GA, EP-C, 1-opt, SA, STTS, RTS e HH, respectivamente, resultando nos tempos computacionais apresentados na tabela 4.12 e figura 4.26 .

A tabela 4.12 apresenta o tempo médio em $\mu$ s necessário ao cômputo das funções $^{32}$ custo F1 a F10 e características apresentadas na tabela 4.2. Notase que os tempos médios necessários para o cálculo das funções custo F1 a F9 são relativamente próximos. No entanto, o cômputo da função F10 exige maior tempo de processamento devido ao laço que deve ser utilizado a medida que $m$ aumenta $^{33}$.

\footnotetext{
${ }^{32}$ Custo de um simples cálculo da função custo.

${ }^{33}$ Conforme equação (4.10).
} 
Tabela 4.12: Tempo de processamento para o cômputo das funções custo $\varpi$ para F1 a F10 considerando a média em $10^{6}$ realizações.

\begin{tabular}{|c|c|c|}
\hline & $\begin{array}{c}\text { Média } \\
(\mu \mathrm{s})\end{array}$ & $\begin{array}{c}\text { Desvio } \\
\text { padrão }\end{array}$ \\
\hline \hline F1 & 9,40 & 0,28 \\
F2 & 7,20 & 0,23 \\
F3 & 8,40 & 0,25 \\
F4 & 8,50 & 0,25 \\
F5 & 8,30 & 0,24 \\
F6 & 9,90 & 0,27 \\
F7 & 8,60 & 0,25 \\
F8 & 9,10 & 0,26 \\
F9 & 7,80 & 0,27 \\
F10 & 22,00 & 0,31 \\
\hline
\end{tabular}

Além da informação do tempo de processamento para um cômputo da função custo deve-se considerar o tempo necessário para as demais etapas dos algoritmos. Observa-se que as funções custo F1 a F10 e a função custo para o problema MuChE são intrinsecamente descritas no domínio dos números reais e dos números complexos, respectivamente. Desta forma, deve-se realizar um procedimento de conversão binária para decimal nas funções F1 a F10 e binária para número complexo no problema MuChE, aumentando o tempo necessário para a otimização. Portanto, optou-se por apresentar na figura 4.26 o tempo necessário para as etapas dos algoritmos por iteração e por candidato a medida que o tamanho do candidato aumenta e considerando indivíduos codificados na forma binária ${ }^{34}$.

Observa-se na figura 4.26 que os algoritmos 1-opt e SA apresentam o menor tempo para o cômputo das etapas internas durante uma iteração. Já o GA apresenta a maior complexidade por iteração considerando a realização de suas etapas. Vale ressaltar que foram realizadas médias em 1000 simulações para cada algoritmo. Além disso, visando obter expressões para o tempo de processamento dos algoritmos, realizou-se uma etapa de ajuste de curvas $^{35}$ através do método de regressão polinomial disponível no software Matlab ${ }^{\circledR}$ (BOBER; TSAI; MASORY, 2009). Desta forma, obteve-se equações genéricas para a complexidade em termos do tempo para o cômputo das etapas dos algoritmos considerando o computador e o software descritos anteriormente.

Assim, estes valores de $\mu$ para cada algoritmo são utilizados para a análise de complexidade em termos do tempo computacional para os problemas $\mathrm{MuD}$ e MuChE, sendo apresentada na seção 5.3.

\footnotetext{
${ }^{34} \mathrm{O}$ tempo necessário para a realização da conversão binária para decimal visando o cálculo das funções F1 a F10 é apresentada posteriormente na figura 4.27.

${ }^{35}$ Do termo em inglês curve fitting.
} 

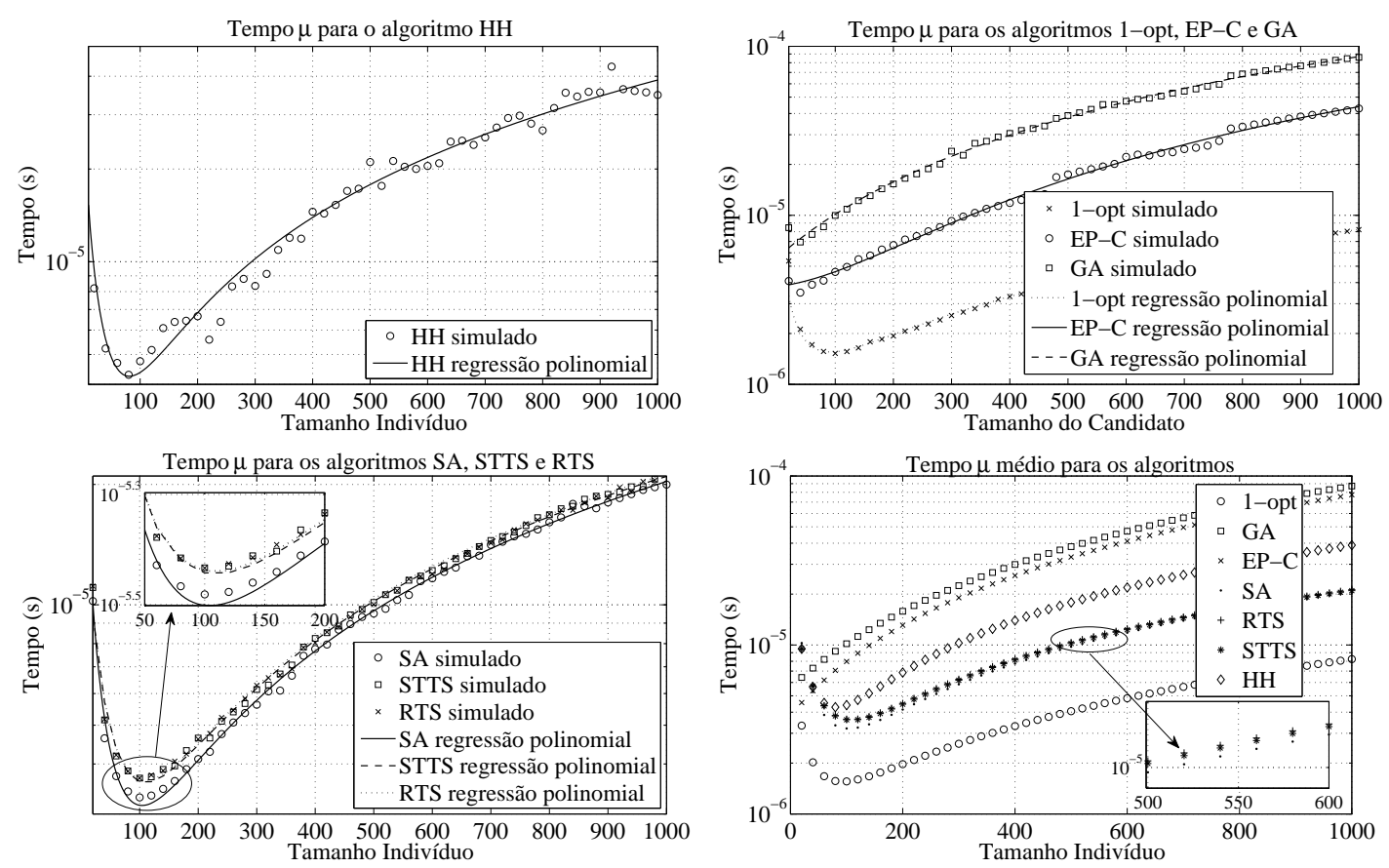

Figura 4.26: Tempo médio das etapas dos algoritmos por iteração e por aproximação polinomial.

Por fim, para obter a complexidade total em termos do tempo computacional para os algoritmos 1-opt, GA, EP-C, SA, STTS, RTS e HH aplicados à prova de Decathlon (funções F1 a F10) deve-se considerar o custo para a operação de conversão binária para decimal. A figura 4.27 apresenta o tempo necessário para a etapa de conversão com o aumento do tamanho do candidato, considerando o hardware e software utilizado.

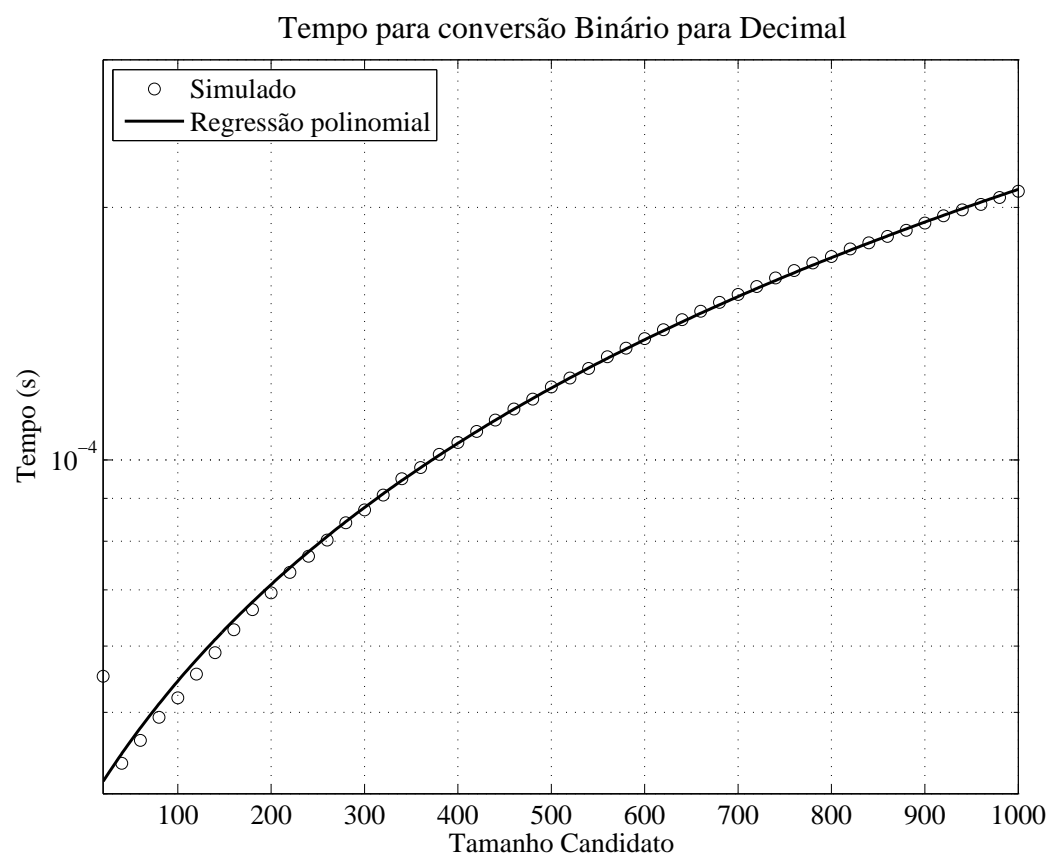

Figura 4.27: Tempo médio para conversão de um número binário para decimal com o aumento do tamanho do candidato. 
Vale ressaltar que a operação de conversão binária para decimal é realizada uma vez por iteração visando o cálculo da função custo. Com isso, torna-se possível encontrar o tempo médio total necessário para a otimização das funções F1 a F10 para todos os algoritmos.

A tabela 4.13 apresenta o tempo médio total em ms para a otimização das funções F1 a F10 considerando todos os algoritmos. Nota-se, conforme esperado para esta configuração de problemas, que o algoritmo SA apresenta a menor complexidade em termos do tempo computacional. No entanto, devido às diferentes etapas e implementação de cada algoritmo, ocorreu inversão nas colocações ${ }^{36}$ dos algoritmos EP-C com o STTS e do GA com o HH quando compara-se às complexidades em termos do número de operações e do tempo computacional necessário.

No entanto, os tempos computacionais entre os algoritmos EP-C e STTS apresentam-se próximos para a maioria das funções. Este comportamento também é observado entre os algoritmos GA e HH.

Tabela 4.13: Complexidade em termos do tempo médio dos algoritmos em ms para otimização das funções F1 a F10.

\begin{tabular}{|c|c|c|c|c|c|c|c|}
\hline$\left(10^{-3}\right) \mathrm{s}$ & 1-opt & GA & EP-C & SA & STTS & RTS & $\mathrm{HH}$ \\
\hline F1 & 822,53 & 311,07 & 301,10 & 355,38 & 356,80 & 356,84 & 356,00 \\
\hline $\mathrm{F} 2$ & 625,14 & 293,01 & $\overline{283,15}$ & 276,98 & 276,20 & 276,22 & 299,40 \\
\hline F3 & 1411,80 & 436,93 & 423,13 & 590,37 & $\overline{595,62}$ & 595,74 & 552,22 \\
\hline F4 & 478,54 & 293,35 & $\overline{283,60}$ & 219,01 & 214,96 & 214,97 & 262,88 \\
\hline F5 & 638,34 & 298,78 & 288,93 & 282,26 & 281,48 & 281,50 & 305,21 \\
\hline F6 & 948,42 & 424,06 & 410,68 & 405,44 & $\overline{407,96}$ & 408,02 & 432,82 \\
\hline F7 & 753,65 & 304,70 & 294,77 & 328,00 & 328,77 & 328,81 & 336,26 \\
\hline F8 & 934,82 & 418,46 & $\overline{405,08}$ & 400,00 & 402,52 & 402,58 & 426,99 \\
\hline F9 & 855,28 & 406,46 & 393,12 & 368,33 & 370,33 & 370,37 & 402,20 \\
\hline F10 & 1154,10 & 508,76 & 495,38 & 487,72 & 490,24 & 490,30 & 520,90 \\
\hline
\end{tabular}

\begin{tabular}{c|c|c|c|c|c|c|c}
\hline Pontuação & 40 & 67 & 78 & $\underline{\mathbf{8 7}}$ & 85 & 75 & 58 \\
Colocação & $7^{\circ}$ & $5^{\circ}$ & $3^{\circ}$ & $1^{\circ}$ & $2^{\circ}$ & $4^{o}$ & $6^{\circ}$ \\
\hline
\end{tabular}

Assim, para a figura de mérito relacionada à complexidade, optou-se pela média entre as pontuações de complexidade (número de operações e tempo computacional) evitando, assim, uma análise injusta entre as estratégias de otimização ou possíveis viés existentes.

Desta forma, pode-se adotar uma estratégia para definição de qual algoritmo resulta na melhor opção, acarretando em inúmeras possibilidades de classificação. Dentre elas, destacam-se três estratégias de escolha:

\footnotetext{
${ }^{36}$ Conforme tabela 4.11 .
} 
- Escolha pelo melhor desempenho (qualidade e estabilidade)

- Escolha pela menor complexidade (desde que atinja desempenho mínimo aceitável)

- Escolha por uma regra de pesos entre desempenho $\times$ complexidade

Por isso, a classificação dos algoritmos através de regime de pontuação mostrase como uma metodologia adequada, pois pode ser utilizada como medida para qualquer uma das estratégias de escolha dos algoritmos. A tabela 4.14 apresenta um resumo das pontuações e colocação final obtida pelos algoritmos utilizados considerando pesos iguais entre as características.

Tabela 4.14: Resumo das Pontuações e Colocação dos algoritmos.

\begin{tabular}{|c|c|c|c|c|c|c|c|}
\hline Pontuação & 1-opt & $\mathrm{GA}$ & $\mathrm{EP}-\mathrm{C}$ & $\overline{\mathrm{SA}}$ & STTS & $\overline{\mathrm{RTS}}$ & $\mathrm{HH}$ \\
\hline Número de operações & 40 & 49 & 91 & 96 & 80 & 70 & 51 \\
\hline Tempo computacional & 40 & 67 & 78 & 87 & 85 & 75 & 58 \\
\hline Média Complexidade & 40 & 58 & 85 & 92 & 83 & 73 & 55 \\
\hline Qualidade e Estabilidade & 58 & 74 & 62 & 79 & 65 & 62 & 81 \\
\hline Pontuação Final Média & 49 & 66 & 73 & 85 & 74 & 67 & 68 \\
\hline Colocação & $7^{\circ}$ & $6^{\circ}$ & $3^{\circ}$ & $1^{o}$ & $2^{o}$ & $5^{\circ}$ & $4^{o}$ \\
\hline
\end{tabular}

De forma ilustrativa, caso seja adotado um método de pesos iguais entre as características de qualidade/estabilidade e complexidade computacional, conforme tabela 4.14, resultará, para os problemas da prova de Decathlon, na seguinte escolha:

- Escolha pelo melhor desempenho: Algoritmo HH (com 81 pontos)

- Escolha pela menor complexidade: Algoritmo SA (com média de 92 pontos)

- Escolha pelo compromisso desempenho $\times$ complexidade: Algoritmo SA (com média geral de 85 pontos)

Por fim, através desta metodologia é possível separar os algoritmos analisados pelo desempenho obtido considerando 4 grupos abaixo nominados:

1. Melhor compromisso: SA

2. Desempenho de complexidade: EP-C e STTS 
3. Desempenho de qualidade: GA, RTS e HH

4. Desempenho não aceitável: k-opt

Desta forma, considera-se os algoritmos SA, EP-C, STTS, GA, RTS e HH como promissores para otimização de problemas combinatórios árduos considerando as estratégias de inicialização e parâmetros conforme tabela 4.7. Além disso, o uso desta metodologia de comparação de desempenho e complexidade mostra-se adequada para análise em cenários de telecomunicações, considerando os problemas $\mathrm{MuD}$ e MuChE, sendo apresentada na seção 5.3. 


\section{Resultados de Simulação para Sistemas de Telecomunicações}

Neste capítulo são apresentados alguns resultados que resultaram em publicações científicas citadas no apêndice B e que corroboram a proposta deste trabalho na busca de algoritmos heurísticos eficientes para aplicação em problemas de detecção multiusuário e estimativa de parâmetros considerando sistemas mais realistas e passíveis de serem utilizados nas próximas gerações das comunicações sem fio, bem como novos resultados que foram obtidos ao final do programa de doutoramento e que serão utilizados na confecção dos próximos trabalhos científicos a serem submetidos.

Para apresentação dos resultados foram consideradas as principais figuras de mérito para os problemas de telecomunicações citados, isto é, a taxa de erro de bit média (BER) para os problemas de detecção multiusuário e os erros quadrático médio normalizado (MSE) e médio percentual (MEP) para os problemas de estimativa de parâmetros de canal, respectivamente, além da análise da velocidade de convergência visando obtenção da complexidade computacional.

Os resultados de simulação foram obtidos considerando as topologias dos sistemas descritos no capítulo 2 considerando os modelos de sistemas em malha aberta e fechada multidimensional, para diversos arranjos de diversidade, evidenciando a possível aplicabilidade das técnicas heurísticas em sistemas de telecomunicações de terceira e quarta gerações.

Por fim, realiza-se uma análise de complexidade computacional e de estabilidade/qualidade das soluções visando apresentar as melhores técnicas que possuem compromisso desempenho $\times$ complexidade, considerando as figuras de mérito apresentadas no capítulo 4. Ao fim do capítulo é apresentado um resumo considerando o desempenho das técnicas analisadas bem como suas respectivas complexidades computacionais visando a indicação das melhores técnicas para a utilização em sistemas de telecomunicações vindouros.

Vale ressaltar que para todas as simulações foi considerado o método de si- 
mulação Monte Carlo, descrito de forma sucinta no apêndice D, com um número mínimo de 10 erros por ponto para a faixa de alta $\mathrm{SNR}^{1}$ e de 100 erros por ponto para a faixa de baixa e média SNR visando garantir precisão e exatidão ${ }^{2}$ na simulação aliado a um tempo de simulação factível.

\subsection{Detecção Multiusuário em Sistemas com Di- versidade Multidimensional}

A análise realizada nessa seção apresenta os resultados de desempenho em termos da taxa de erro de bit e, em alguns casos, da convergência dos algoritmos heurísticos que corroboram com a proposta deste trabalho na busca de algoritmos heurísticos eficientes para aplicação em problemas de detecção multiusuário em diversos tipos de sistemas. Conforme apresentado no capítulo 4, são utilizados os algoritmos GA, EP-C, SA, STTS, RTS e HH para a otimização de desempenho, considerando os parâmetros otimizados no referido capítulo.

Os cenários escolhidos visam apresentar o ganho de desempenho e demonstrar a aplicabilidade das técnicas heurísticas propostas para diversas configurações de sistemas de telecomunicações, considerando topologias com algum tipo de diversidade, por exemplo, código, frequência, tempo e espaço. Além disso, apresenta-se o desempenho em alguns cenários com diversidade multidimensional e ao final o desempenho para uma topologia de receptor que considera o domínio S-FT em um arranjo iterativo.

Desta forma, são considerados os seguintes cenários de telecomunicações:

1. Sistemas em Malha Aberta

- Detecção multiusuário em sistemas DS/CDMA

- Detecção em sistemas codificados DS/CDMA

- Detecção em sistemas multitaxa DS/CDMA

- Detecção em sistemas multiportadora DS/CDMA

- Detecção em sistemas DS/CDMA com diversos tipos de diversidade

2. Sistema 3D iterativo

- Detecção no domínio S-FT

\footnotetext{
${ }^{1}$ Considerou-se alta SNR todos os valores que resultam em BER inferior a $10^{-4}$ e baixa e média SNR os que resultam em BER superior a $10^{-4}$.

${ }^{2}$ Precisão é o grau de variação de resultados e exatidão refere-se à conformidade com o valor real.
} 
Inicialmente, foi considerado para todos estes cenários estimativas perfeitas para os parâmetros do canal. Assim, em nenhum destes sistemas é considerada uma topologia conjunta para detecção e obtenção das estimativas de parâmetros do canal em um único bloco de recepção, visando evidenciar os ganhos de desempenho em termos da taxa de erro de bit proporcionada pelas topologias. Posteriormente, resultados de desempenho de uma topologia conjunta de detecção e de obtenção de estimativa de parâmetros do canal foram obtidos, sendo apresentados na figura 5.33.

Neste trabalho considera-se como um sistema de telecomunicações em malha aberta todas as topologias que realizam as etapas de detecção de forma contínua e que não possuem realimentação entre as etapas. Assim, todos os sistemas que podem ser representados pela figura 2.1, apresentada no capítulo 2, são considerados como de malha aberta. Note que os processos internos de cada etapa de um sistema podem ser implementados considerando topologias com realimentação, mas o sistema continuará classificado como sendo de malha aberta.

\subsubsection{Detecção multiusuário em sistemas DS/CDMA}

Para um sistema DS/CDMA convencional todos os usuários transmitem à mesma taxa básica, desconsiderando, com isso, a etapa de canalização. Além disso, as etapas de espalhamento em frequência, codificação de canal e arranjo de múltiplas antenas, apresentadas na seção 2.1 não estão presentes. Embora apareça como uma estrutura singela de transmissão e recepção, esta topologia foi extensamente utilizada a partir do advento do padrão comercial para os sistemas celulares conhecido como IS-95.

Neste caso, procura-se utilizar uma estratégia de recepção que seja capaz de minimizar o efeito da MAI e que apresente robustez ao NFR, resultando em um sinal recebido mais confiável, ou seja, com uma menor BER. Desta forma, este trabalho considera a utilização das estratégias heurísticas apresentadas no capítulo 4 para a otimização do desempenho através da maximização da equação $(2.86)^{3}$.

Assim, a tabela 5.1 sintetiza os principais parâmetros de configuração para os sistemas DS/CDMA convencionais simulados.

As sequências escolhidas são do tipo aleatória, onde $K$ é o número de usuários ativos no sistema, $N$ é o ganho de processamento; foram considerados 10 e 20 usuários para o sistema DS/CDMA sujeitos a canal Rayleigh lentamente variável

\footnotetext{
${ }^{3}$ Considerando as respectivas simplificações na equação (2.86) devido à topologia do sistema.
} 
Tabela 5.1: Principais parâmetros de sistema e canal adotados para o sistema unitaxa.

\begin{tabular}{cccccccc}
\hline Sequência & $N$ & $K$ & Canal & $R$ & $v_{\max }$ & $f_{D}$ & $D$ \\
\hline Aleatória & 31 & $10 ; 20$ & Rayl. Lento & $384 k b p s$ & $120 \mathrm{Km} / \mathrm{h}$ & $222 \mathrm{~Hz}$ & $\leq 3$ \\
\hline
\end{tabular}

no tempo do tipo plano (1 percurso), dois e três percursos (seletivo em frequência). Para a mobilidade, considerou-se perfis de velocidades uniformemente distribuídas no intervalo $\left[0 ; v_{\max }\right]$, resultando em uma máxima frequência Doppler de $f_{D}=$ $\frac{v_{\max }}{\lambda_{c}}=222,2 \mathrm{~Hz}$, adotando-se uma frequência da portadora de $f_{c}=\frac{1}{\lambda_{c}}=2 \mathrm{GHz}$; a máxima diversidade para o receptor Rake é $D=3$ e, por se tratar de um sistema unitaxa, todos os usuários transmitem com a mesma taxa de bit $R$.

Os perfis atraso-potência adotados para a obtenção da análise de desempenho em canais multipercursos com desvanecimento Rayleigh são apresentados na tabela 5.2. Considerou-se três perfis exponenciais decrescentes de atraso-potência, sendo PD-3 um canal com três percursos, o perfil PD-2 representa um canal com dois percursos e o perfil PD-1 representa um canal do tipo Rayleigh plano. Estes perfis com um número reduzido de percursos foram adotados com intuito de diminuir a complexidade computacional de simulação e, consequentemente, o tempo de processamento. Visando acomodar os $L=3$ percursos de todos os $K=10$ usuários em um mesmo intervalo temporal $[0 ; N] T_{c}$, adotou-se o valor mínimo de número de amostras por chip igual a 2. Idem para a situação com $K=20$ usuários e $L=2$ percursos, viabilizando a execução das simulações computacionais Monte Carlo no computador pessoal de alto desempenho e capacidade de memória apresentado na seção 4.4.5.

Tabela 5.2: Três perfis atraso-potência (PD) utilizados nas simulações.

\begin{tabular}{ccc}
\hline$\ell$ & $\Delta_{\ell}$ & $\mathbb{E}\left[\beta_{\ell}^{2}\right]$ \\
\hline 1 & 0 & 0,8047 \\
2 & $T_{c}$ & 0,1625 \\
3 & $2 T_{c}$ & 0,0328 \\
\hline \multicolumn{3}{c}{$\mathrm{PD}-3$} \\
\hline
\end{tabular}

\begin{tabular}{ccc}
\hline$\ell$ & $\Delta_{\ell}$ & $\mathbb{E}\left[\beta_{\ell}^{2}\right]$ \\
\hline 1 & 0 & 0,8320 \\
2 & $T_{c}$ & 0,1680 \\
\hline \multicolumn{2}{c}{ PD-2 } \\
\hline
\end{tabular}

\begin{tabular}{ccc}
\hline$\ell$ & $\Delta_{\ell}$ & $\mathbb{E}\left[\beta_{\ell}^{2}\right]$ \\
\hline 1 & 0 & 1 \\
\hline \multicolumn{2}{c}{ PD-1 } \\
\hline
\end{tabular}

Para a análise de desempenho nessas condições, assumiu-se que as potências, fases, amplitudes, ganho de canal e atrasos de todos os usuários são perfeitamente conhecidos no receptor. Na geração dos coeficientes de canal ${ }^{4}$, adotou-se o modelo de Jakes modificado (JAKES, 1974; DENT; BOTTOMLEY; CROFT, 1993).

Adicionalmente, considerou-se um cenário com controle perfeito de potência $\left(A_{1}^{\prime}=A_{2}^{\prime}=\ldots=A_{K}^{\prime}\right)$, bem como cenários com desbalanços de potência recebida,

\footnotetext{
${ }^{4}$ Mais detalhes sobre a geração do canal podem ser encontrados no apêndice C.
} 
com metade dos usuários com $N F R \in[-5 ;+15]$ dB para $K=10$ usuários, e $N F R \in[-5 ;+25] \mathrm{dB}$ para $K=20$ usuários.

A SNR, ou seja, o valor de $E_{b} / N_{0}$ médio à entrada do receptor é dado por:

$$
\bar{\gamma}=\sum_{\ell=1}^{L} \bar{\gamma}_{\ell}
$$

onde

$$
\bar{\gamma}_{\ell}=\frac{E_{b}}{N_{0}} \mathbb{E}\left[\beta_{\ell}^{2}\right]
$$

Para efeito de comparação foram incluídos o desempenho do método Monte Carlo para o detector convencional (Rake) e o limite quando não há MAI no sistema (usuário único). Este limitante para a $B E R$, considerando modulação BPSK, canal Rayleigh lento, receptor Rake com MRC e diversidade $D=L$, e todos os percursos com valores médio quadráticos distintos $(\mathrm{SuB}$ - single user bound) é dado por (PROAKIS, 1995):

$$
B E R_{S u B}=\frac{1}{2} \sum_{\ell=1}^{D}\left\{\left[1-\sqrt{\frac{\bar{\gamma}_{\ell}}{\bar{\gamma}_{\ell}+1}}\right] \prod_{i, i \neq \ell}^{D} \frac{\bar{\gamma}_{\ell}}{\bar{\gamma}_{\ell}+\bar{\gamma}_{i}}\right\}
$$

Para as simulações, foram utilizados os algoritmos GA, EP-C, SA, STTS, RTS e HH considerando as estratégias e os valores otimizados para os parâmetros conforme obtido no capítulo 4 . Em todas as simulações, os receptores heurísticos processaram e otimizaram um frame de $D K I$ bits por vez, onde $K=10$ ou 20 usuários, sendo chamados de sistemas $\mathbf{S}_{\mathbf{1}}$ e $\mathbf{S}_{\mathbf{2}}$, respectivamente. Além disso, considerou-se $I=7$ bits/usuário, $D=1,2$, ou 3 ramos/usuário, sob idênticas condições de canal, de transmissão e de estimativas iniciais provenientes da saída do receptor Rake.

\subsubsection{Análise de Convergência}

A figura 5.1 indica que os algoritmos heurísticos convergem para próximo do limite $\mathrm{SuB}$ após poucas iterações, $G_{t} \approx 20$ para o EP-C e GA e após $G_{t} \approx 24$ para os demais algoritmos, resultando em um enorme ganho de desempenho em relação ao receptor convencional.

Para esta condição de operação do sistema DS/CDMA considerando o tipo de canal, baixo carregamento aproximado de $32 \%$ e controle perfeito de potência, o algoritmo GA apresentou uma melhor convergência inicial do que os demais algoritmos e o algoritmo EP-C apresentou a convergência mais lenta. No entanto, a geração de convergência final para os algoritmos GA e EP-C mostrou-se igual, 


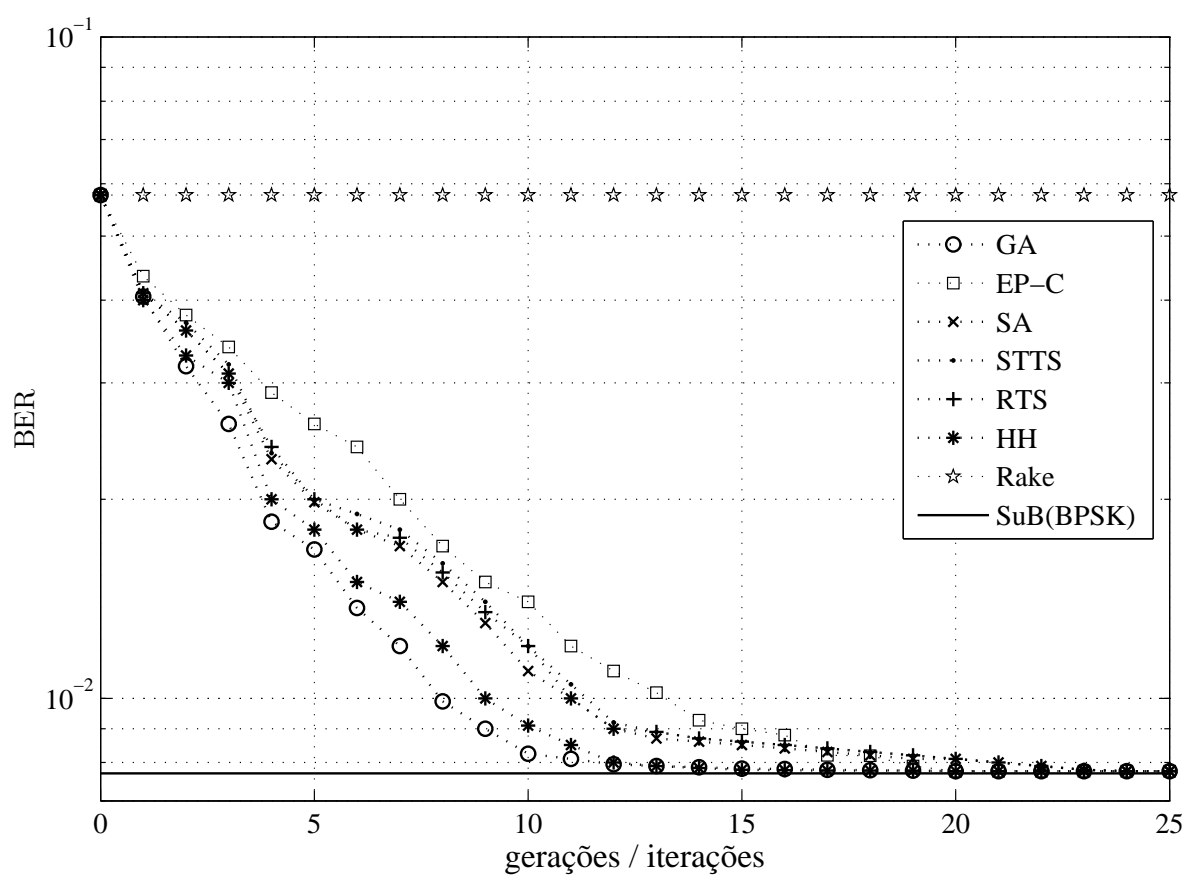

Figura 5.1: Velocidade de convergência para os algoritmos heurísticos; sistema $\mathbf{S}_{\mathbf{1}}$, perfil PD-1, $\bar{\gamma}=15 d B$ e $N F R=0 d B$.

sendo de $G_{t}=20$ enquanto que para os demais algoritmos a convergência ocorreu para $G_{t}=24$. Por isso, adotou-se $G_{t}=25$ para todos os heurísticos quando $K=10$.

As análises de convergência para as demais combinações de cenários $\left(\mathbf{S}_{\mathbf{2}}, \mathrm{PD}\right.$ 2 e PD-3) resultaram no mesmo comportamento, não sendo apresentadas. No entanto, o número de gerações necessárias deve ser incrementado em cenários $\mathbf{S}_{\mathbf{2}}$, passando de $G_{t}=25$ para $G_{t}=45$.

Vale ressaltar que todos os algoritmos proporcionam boas soluções nos cenários testados, não observando diferenças de desempenho em termos da BER quando da convergência. Assim, a escolha da melhor topologia deve levar em consideração a complexidade computacional para a otimização.

\subsubsection{Análise de Desempenho}

Nas figuras 5.2 a 5.7 são apresentados os desempenhos alcançados pelos detectores em função da relação sinal-ruído média $(\bar{\gamma})$ ou $N F R$ para os algoritmos heurísticos adotados neste trabalho.

Em geral, para todas as condições de sistema e de canal analisadas, os algoritmos convergiram para o mesmo ponto e muito próximo ao desempenho SuB. O 
comportamento de convergência dos algoritmos mantém-se o mesmo apresentado na figura 5.1. Observe que não necessariamente maior velocidade de convergência resulta em menor complexidade computacional. A análise apresentada na seção 5.3 quantifica a complexidade dos algoritmos nos diversos cenários.

A figura 5.2 sintetiza o ótimo desempenho alcançado pelos algoritmos heurísticos em condições não tão agressivas de canal e baixo carregamento. Nesta situação, os algoritmos necessitaram de um menor número de gerações/iterações para razões de $\bar{\gamma}$ médias e elevadas, evidenciando o efeito do ruído de fundo sobre a velocidade de convergência em baixas razões de $\bar{\gamma}$.

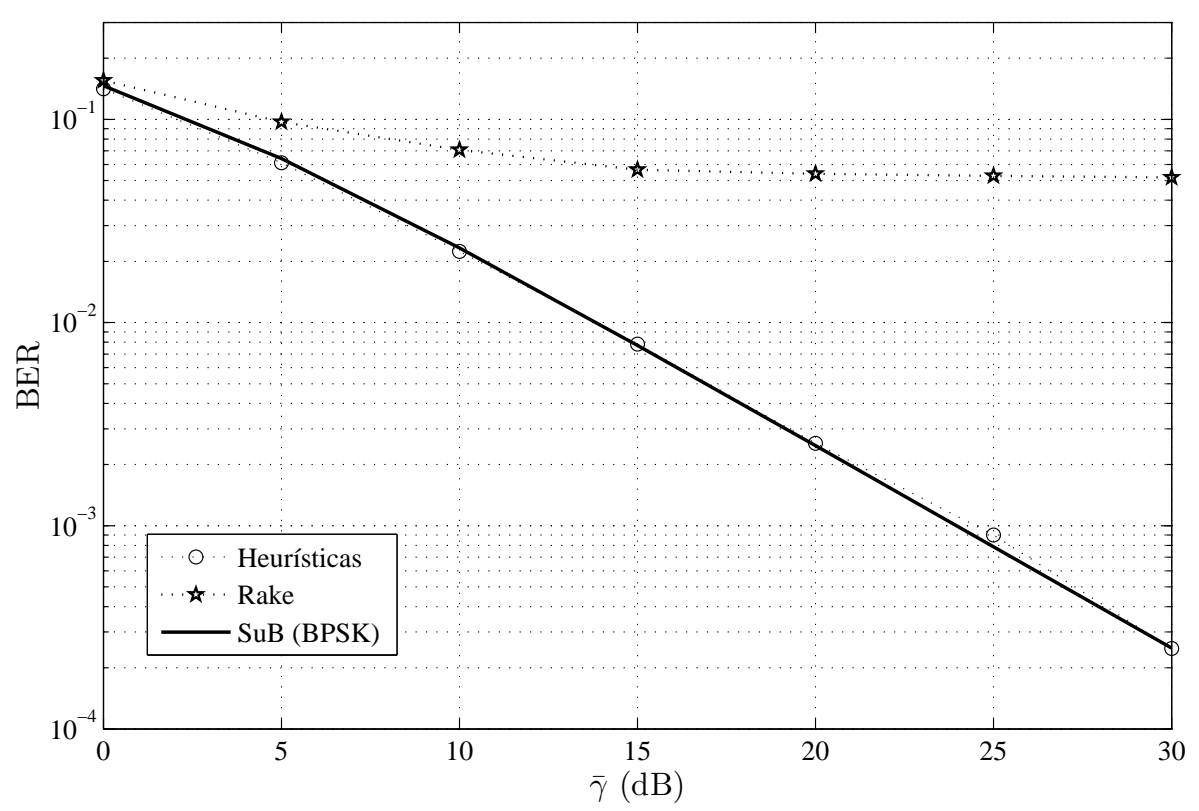

Figura 5.2: BER média para o sistema $\mathbf{S}_{\mathbf{1}}$, perfil PD-1 e $N F R=0 d B$.

O comportamento dos algoritmos para canal Rayleigh com 2 e 3 percursos, perfis PD-2 e PD-3 respectivamente, são apresentados nas figuras 5.3 e 5.4. A diversidade do receptor Rake contribui para a manutenção do desempenho ótimo dos algoritmos quando há o aproveitamento total desta diversidade, $D=L$, resultando em um número menor de gerações/iterações do que o caso unipercurso. Para todos os pontos simulados, o desempenho dos algoritmos apresentam-se muito próximos ao SuB evidenciando a melhoria de desempenho pela mitigação do efeito da MAI.

Mesmo para elevados carregamentos em canais multipercurso, os algoritmos de detecção baseados em heurísticas propostos mantém um elevado ganho de desempenho em relação ao receptor Rake. A figura 5.5 sintetiza o ganho de desempenho para canal com perfil PD-2 e sistema com carregamento elevado S2. 


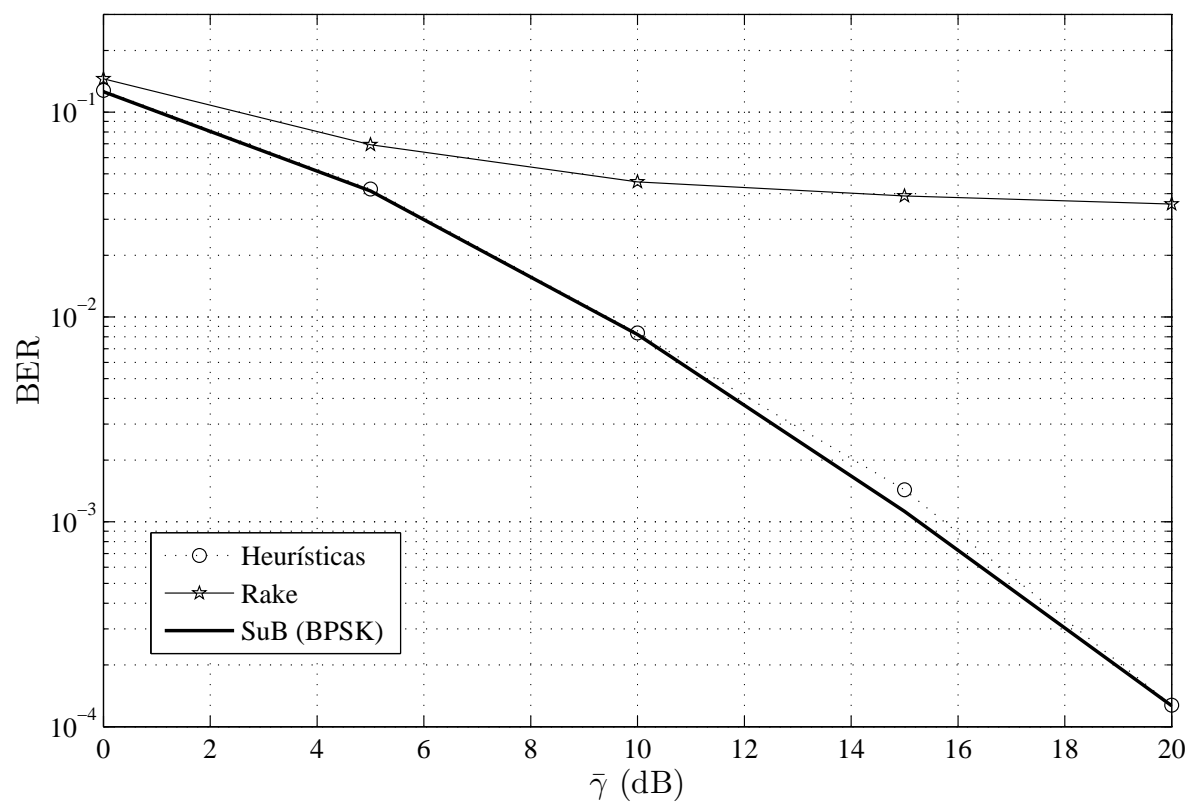

Figura 5.3: BER média para o sistema $\mathbf{S}_{\mathbf{1}}, N F R=0 d B$ e perfil PD-2 com diversidade do receptor Rake, $D=L=2$.

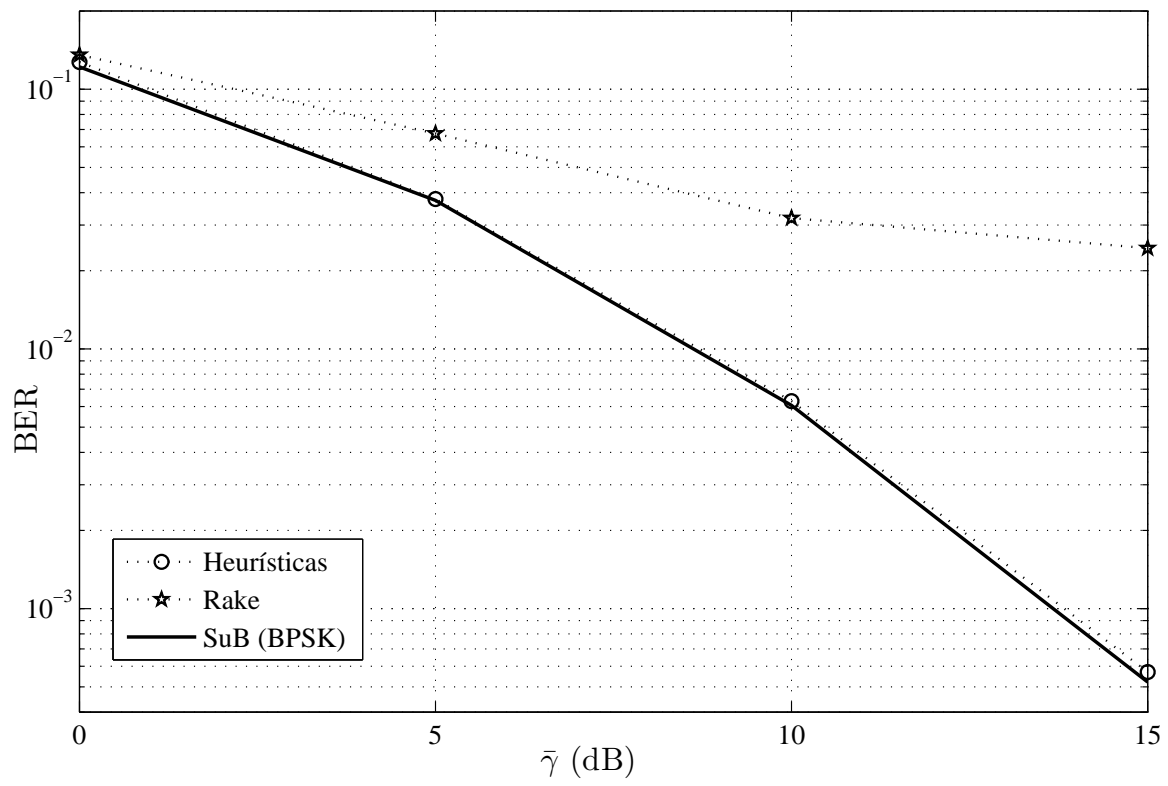

Figura 5.4: BER média para o sistema $\mathbf{S}_{\mathbf{1}}, N F R=0 d B$ e perfil PD-3 com diversidade do receptor Rake, $D=L=3$.

Vale ressaltar que em cenários $\mathbf{S}_{\mathbf{2}}$ considerou-se $G_{t}=45$. 


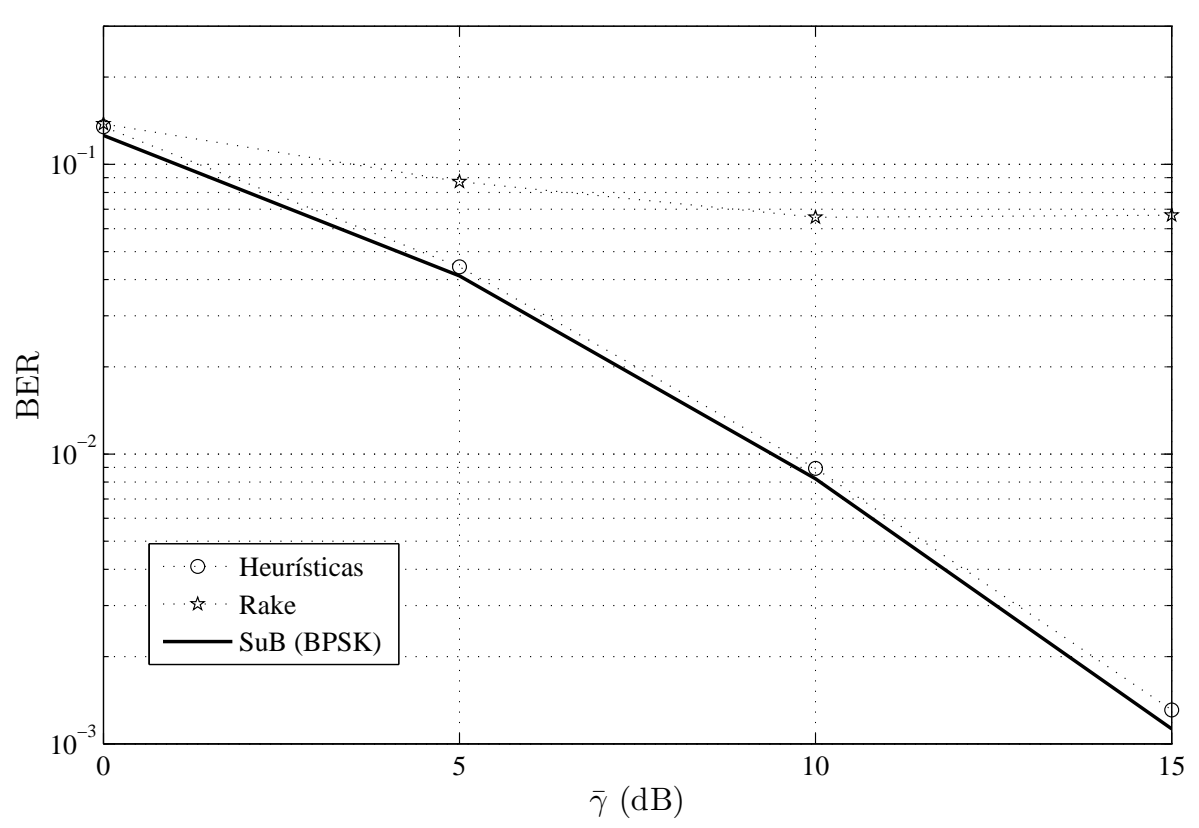

Figura 5.5: BER média para o sistema $\mathbf{S}_{\mathbf{2}}, N F R=0 d B$ perfil PD-2 e diversidade do receptor Rake, $D=L=2$.

\subsubsection{Robustez ao efeito near-far}

Em sistemas de acesso múltiplo CDMA, o parâmetro razão perto-longe ( $N F R$ - Near-Far Ratio) expressa os efeitos de desbalanceamento de potência entre os sinais dos usuários, dado por:

$$
N F R=\frac{P_{i}^{\prime}}{P_{d}^{\prime}}=10 \log _{10}\left(\frac{P_{i}^{\prime}}{P_{d}^{\prime}}\right)[d B]
$$

onde $P_{d}^{\prime}$ é a potência recebida do usuário de interesse e $P_{i}^{\prime}$ é a potência recebida para os usuários interferentes.

Os sistemas CDMA convencionais são limitados em interferência; dessa forma, engenhosos e complexos mecanismos de controle de potência são necessários para se atingir uma capacidade expressiva. Receptores capazes de recuperar a informação do usuário de interesse em condições adversas de desbalanceamento de potência podem contribuir para a redução ou mesmo eliminação dos mecanismos de controle de potência do sistema.

Nas figuras 5.6 e 5.7, a razão de potência do eixo $N F R$, em dB, é a razão entre a potência do sinal recebido dos usuários interferentes ( $K / 2$ usuários) pela potência do sinal recebido dos usuários de interesse (os outros $K / 2$ usuários). Estes resultados mostram que os algoritmos heurísticos propostos possuem elevada robustez ao efeito near-far. Por sua vez, o desempenho do receptor Rake 
é drasticamente reduzido com o aumento da potência dos usuários interferentes, mesmo na condição de baixo carregamento do sistema $\mathbf{S}_{\mathbf{1}}$.

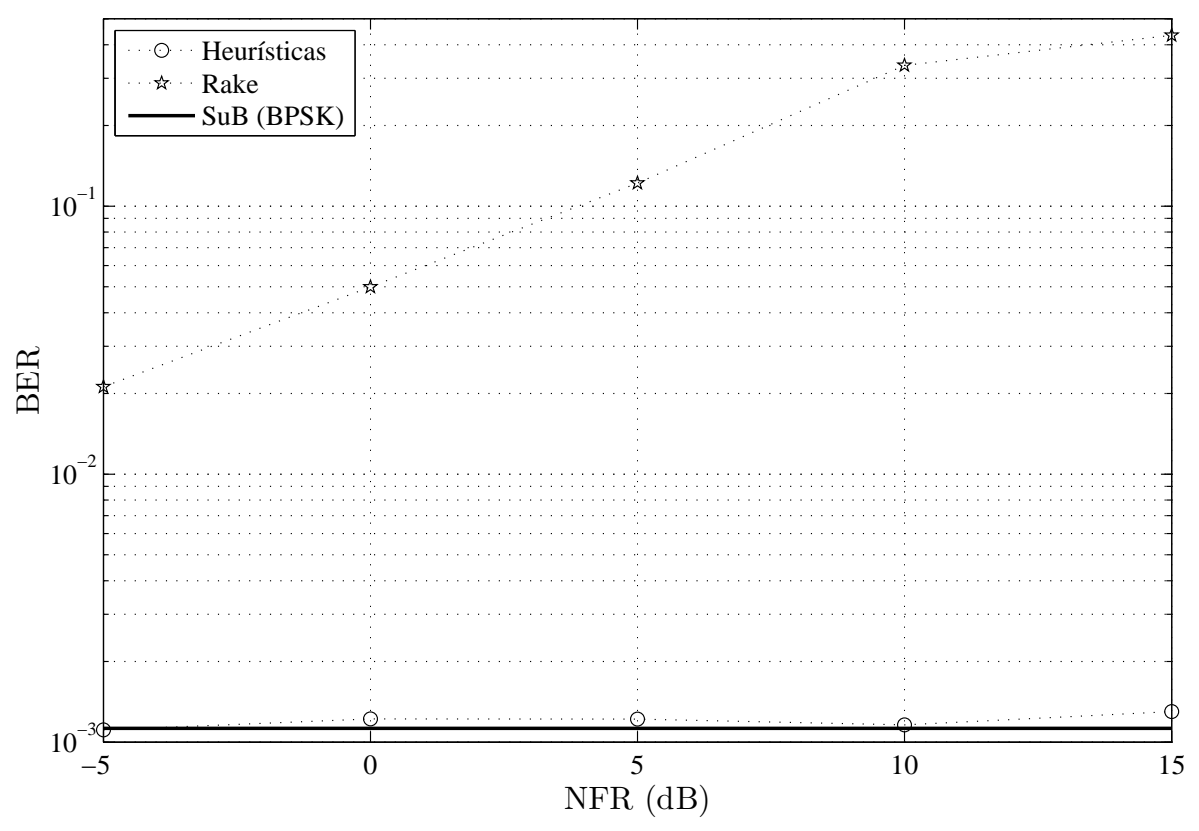

Figura 5.6: BER média para metade dos usuários com $\bar{\gamma}=15$ dB e demais usuários com NFR no intervalo $[-5,+15]$; sistema $\mathbf{S}_{1}$; perfil PD-2 com diversidade do receptor Rake, $D=L=2$.

Desta forma, evidencia-se a aplicabilidade de estratégias heurísticas no processo de detecção multiusuário mesmo desconsiderando a exploração de diversidade adicional, pois estes podem ser utilizados para mitigar substancialmente o efeito da MAI, entregando na saída melhores estimativas para as informações transmitidas. Os demais estágios de recepção, que exploram as outras características de diversidade, podem, assim, ser implementadas de forma convencional ou também através do uso de estratégias heurísticas, conforme apresentado nas próximas seções.

\subsubsection{Detecção em sistemas codificados DS/CDMA}

Conforme seção 2.1.1, a codificação do sinal é uma técnica extensamente utilizada para tornar a transmissão mais confiável, ou de forma equivalente, para garantir que a taxa de erro seja baixa mesmo quando o nível de sinal no receptor esteja inferior a um mínimo desejado.

Assim, topologias baseadas em algoritmos heurísticos que consideram a recepção em sistemas codificados mostram-se promissoras devido à redução da MAI à entrada do decodificador, possibilitando a este obter resultados de desempenho 


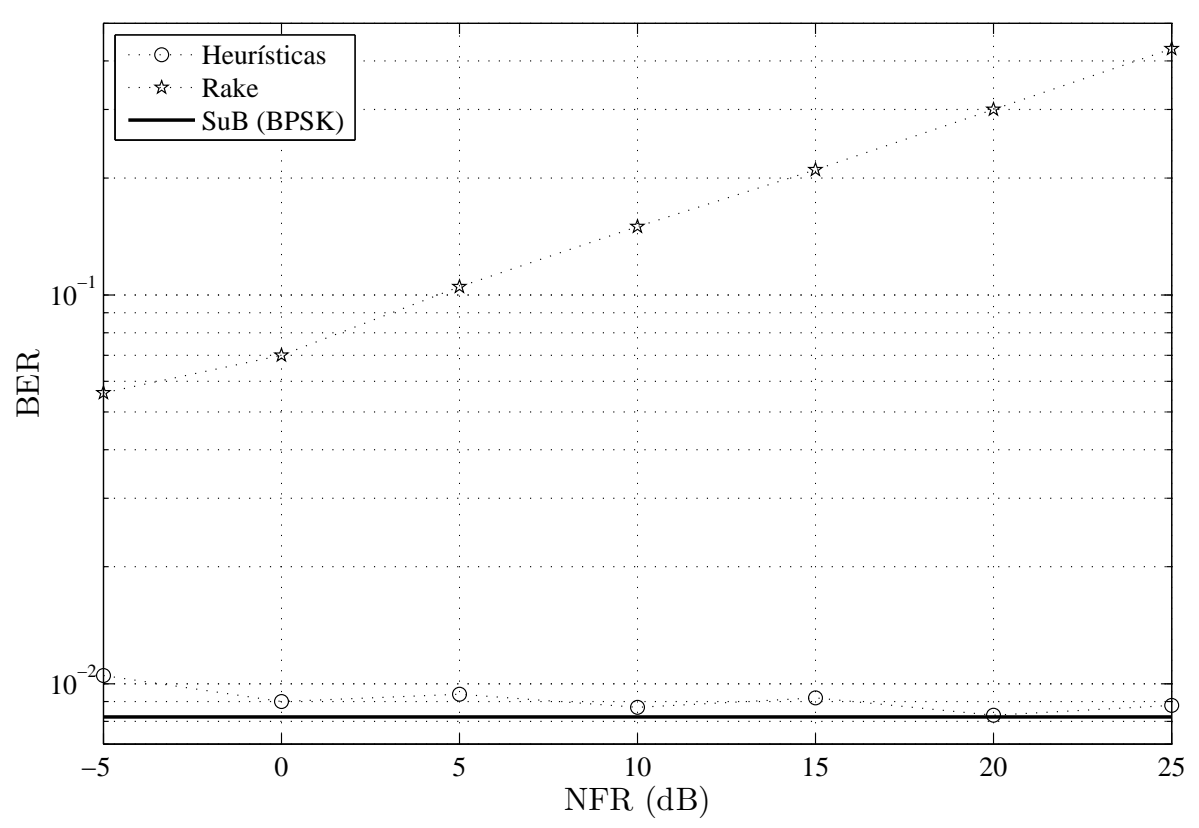

Figura 5.7: BER média para metade dos usuários com $\bar{\gamma}=10 \mathrm{~dB}$ e demais usuários com NFR no intervalo [-5, +25$]$; sistema $\mathbf{S}_{\mathbf{2}}$; perfil PD-2 com diversidade do receptor Rake, $D=L=2$.

próximos aos limites teóricos para sistemas uniusuário codificados.

Visando apresentar o desempenho em sistemas codificados, são considerados neste trabalho três cenários utilizando:

- codificação convolucional

- estratégia turbo

- códigos de cheque de paridade de baixa densidade (LDPC)

Para todas as simulações, adotou-se que os usuários transmitem à mesma taxa básica, desconsiderando, com isso, a etapa de canalização (sistema multitaxa) e demais etapas de recepção que não estão presentes no transmissor (diversidade de frequência e espaço).

\subsubsection{Detecção em sistemas com codificação Convolucional}

Nesta seção são apresentados os resultados de desempenho para o sistema DS/CDMA codificado, o qual utiliza os algoritmos heurísticos no processo de decodificação multiusuário. Os principais valores de parâmetros de sistema utilizados nas simulações são indicados na tabela 5.3, sendo adotadas sequências de 
espalhamento aleatórias com ganho de processamento $N=31$ e controle perfeito de potência entre os usuários.

Para a codificação convolucional, foram utilizados os valores relativos ao padrão CDMA2000 (TIA/EIA/IS-2000-2, 1999) propostos pela IS-2000 (IS - Interim Standard), cujo comprimento de restrição possui valor 9 , resultando em oito registradores, taxa de codificação $R_{c}=1 / 3$, polinômios geradores definidos por $g_{0}=557, g_{1}=663$ e $g_{2}=711$ em octal, bloco do entrelaçamento (interleaver) dos bits de informação codificados formados por uma matriz de 576 células, sendo 32 linhas e 18 colunas, com entrada por coluna e saída por linha, enquanto o desentrelaçador (deinterleaver) é formado por uma matriz com 18 linhas e 32 colunas de modo a desentrelaçar os bits codificados (símbolos). Além disso, utilizou-se um valor de melhor compromisso, obtido em (CIRIACO et al., 2009), para o comprimento do traceback, sendo de 3 vezes o comprimento de restrição. Este valor está associado ao número de percursos sobreviventes dos estados correntes da treliça.

Tabela 5.3: Principais parâmetros do sistema DS/CDMA com codificação convolucional e decodificação multiusuário baseado em algoritmos heurísticos.

\begin{tabular}{l|c}
\hline Modulação & BPSK \\
\hline Sequências de Espalhamento & Aleatória, $N=31$ \\
\hline Tipo de Codificação & Convolucional \\
\hline Taxa de Codificação & $1 / 3$ \\
\hline Comprimento de Restrição & 9 \\
\hline Polinômio Gerador & $(557,663,711)_{8}$ \\
\hline Comprimento do Traceback & 27 \\
\hline Número Bits de Quantização & 6 \\
\hline Tamanho do Frame & 192 \\
\hline Duração do Frame & $20 \mathrm{~ms}$ \\
\hline Frequência da Portadora & $2 \mathrm{GHz}$ \\
\hline Tamanho do Entrelaçador & 576 \\
\hline
\end{tabular}

Para os parâmetros do canal, adotou-se o modelo de Jakes modificado (DENT; BOTTOMLEY; CROFT, 1993), com frequência da portadora $f_{c}=2 \mathrm{GHz}$, número de osciladores $N_{d}=36$, velocidades de deslocamento dos móveis uniformemente distribuídas entre 0 e $120 \mathrm{~km} / \mathrm{h}$ e número de usuários ativos $K=[1,10,15,20,25,31]$, i.e., carregamento do sistema na faixa de $3,23 \% \leq K / N \leq 100 \%$.

A figura 5.8 apresenta o desempenho em termos da taxa de erro de bit média (BER) do decodificador soft na presença e ausência dos algoritmos heurísticos, em função da relação sinal-ruído média, $\bar{\gamma}$, sendo parametrizado pelo carregamento do sistema $(K / N)$. Note-se que à medida que o número de usuários é incrementado, o desempenho do sistema sofre apreciável degradação quando na ausência de 
alguma estratégia heurística (figura 5.8.a), sendo de duas ordens de grandeza em $\bar{\gamma}=10 \mathrm{~dB}$ quando o número de usuários aumenta de $K=1$ para $K=31$, indicando que o desempenho do decodificador suave de Viterbi é extremamente sensível ao aumento da MAI.

Vale ressaltar que todos os algoritmos heurísticos discutidos no capítulo 2 que apresentaram desempenho satisfatório foram utilizados e resultaram, da mesma forma que na figura 5.1, nos mesmos patamares de desempenho. No entanto, o número de gerações/iterações para a convergência mostrou pequenas diferenças. Considerou-se 50 gerações para os algoritmos GA e EP-C e 60 iterações para os algoritmos SA, STTS, RTS e HH para todos os cenários simulados.

Assim, nas figuras de desempenho optou-se por apresentar somente o desempenho obtido ao final das gerações/iterações, sendo denotado pelo nome de Heurísticas.
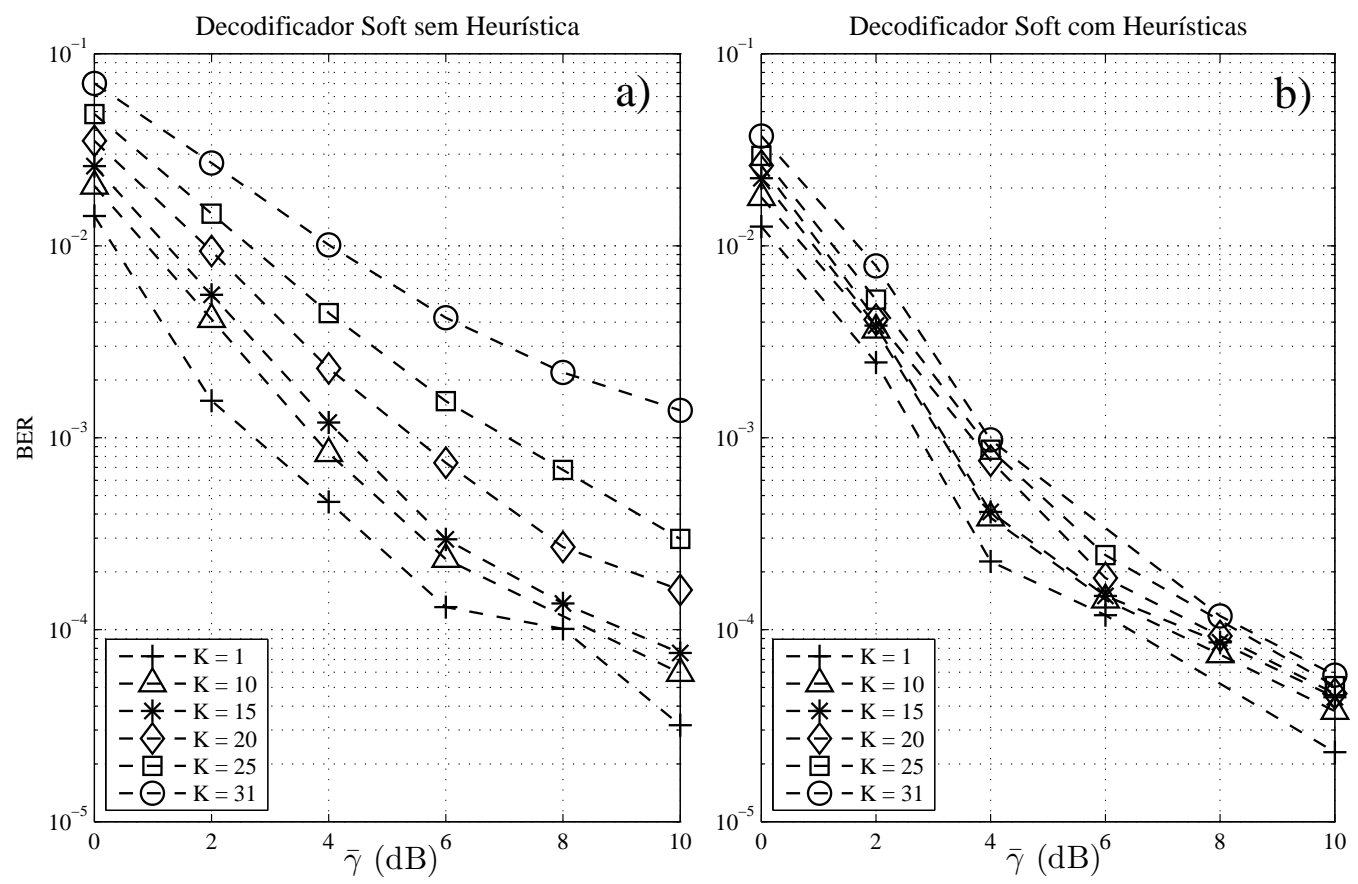

Figura 5.8: Desempenho para a decodificação suave de Viterbi em canais Rayleigh plano; a) sem a utilização e b) com a utilização das estratégias heurísticas.

No entanto, com a utilização dos algoritmos heurísticos, figura 5.8.b, há um apreciável ganho de desempenho em relação ao método convencional de decodificação soft, principalmente quando o carregamento do sistema aumenta. Observase que para a condição $\bar{\gamma}=10 \mathrm{~dB}$ e carregamento igual a $100 \%$ ( $K=31$ usuários) da figura 5.8.a, o sistema atinge $B E R=1,5 \times 10^{-3}$ com o uso da decodificação convencional. Porém, empregando-se as técnicas heurísticas, figura 5.8.b, nas mesmas condições, o sistema atinge $B E R=5,84 \times 10^{-5}$, um incremento de 
desempenho em termos da BER da ordem de $\approx 1,4$ décadas.

A figura 5.9 apresenta a melhoria de desempenho da estratégia proposta em relação à estratégia convencional de decodificação convolucional em função do aumento da relação sinal-ruído considerando detecção soft e hard. Considerou-se a situação de pior caso para a MAI, ou seja, carregamento de $100 \%$ ( $K=31)$. Nesta condição, nota-se que o desempenho da estratégia baseada em heurísticas é próximo da situação de melhor caso, ou seja, na ausência de MAI $(K=1)$ para ambos os tipos de decodificação (soft e hard). No entanto, observa-se que na ausência de estratégia heurística, o desempenho obtido pelo decodificador é extremamente degradado quando o número de usuários aumenta de $K=1$ para $K=31$, evidenciando o ganho obtido.

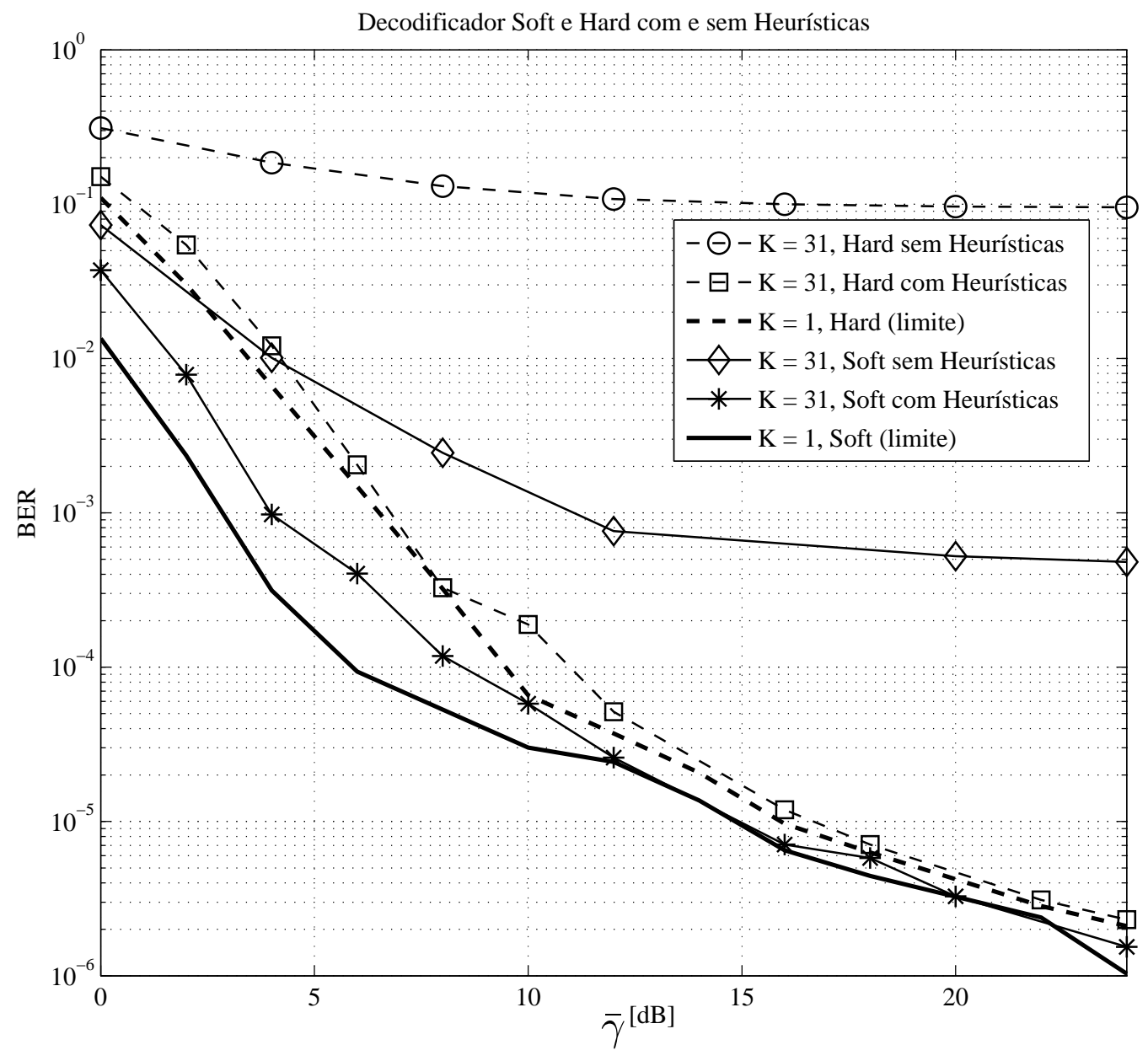

Figura 5.9: Comparação dos desempenho para a decodificação soft e hard de Viterbi para canais Rayleigh plano com e sem a utilização de heurísticas.

Outras análises, em diferentes cenários foram testados e corroboraram com as conclusões apresentadas nesta seção, mas não foram inseridas no trabalho. 


\subsubsection{Detecção em sistemas com codificação Turbo}

Em todas as simulações Monte-Carlo desta seção os seguintes parâmetros de sistema foram adotados: sequências de espalhamento aleatórias com ganho de processamento $N=31$; canal com dois percursos e desvanecimento lento seguindo a distribuição Rayleigh com atrasos aleatórios ordenados no intervalo $[0 ; N-1] T_{c}$ e perfil atraso-potência com $\mathbb{E}\left[\beta_{k, 1}^{2}\right]=0,652$ e $\mathbb{E}\left[\beta_{k, 2}^{2}\right]=0,348, \forall k$ e carregamento variável com o número de usuários ativos $K=[1,5,10,20]$, resultando em um carregamento $3,23 \% \leq K / N \leq 64,5 \%$, conforme tabela 5.4 .

Para os parâmetros do canal, adotou-se o modelo de Jakes modificado (DENT; BOTTOMLEY; CROFT, 1993), com frequência da portadora $f_{c}=2 \mathrm{GHz}$, número de osciladores $N_{d}=36$, velocidades de deslocamento dos móveis uniformemente distribuídas entre 0 e $120 \mathrm{~km} / \mathrm{h}$.

Utilizou-se a relação $\bar{\gamma}$ variável no intervalo $\bar{\gamma}=[0 ; 15] d B$ para decodificação Turbo.

Na especificação do CDMA2000 (TIA/EIA/IS-2000-2, 1999), o entrelaçador é cuidadosamente projetado visando evitar o mapeamento de bits em posições vizinhas dentro da mesma janela de processamento. As linhas são embaralhadas de acordo com uma regra, e os elementos dentro de cada linha são permutadas de acordo com uma sequência linear específica. Por fim, os endereços de saída são lidos por coluna. No entanto, neste trabalho, utilizou-se uma estrutura simplificada para o entrelaçador. O entrelaçador utilizado realiza a permutação dos bits de forma aleatória, sendo as posições sorteadas a cada quadro de $I=196$ bits transmitidos.

Além desses parâmetros do sistema, adotou-se a matriz geradora dos códigos Turbo da forma:

$$
G(E)=\left[1, \frac{g_{0}(E)}{d(E)}, \frac{g_{1}(E)}{d(E)}\right]=\left[1, \frac{1+E+E^{3}}{1+E^{2}+E^{3}}, \frac{1+E+E^{2}+E^{3}}{1+E^{2}+E^{3}}\right]
$$

ou $[1,15 / 13,17 / 13]$ em octal, conforme apresentado na tabela 5.4.

Tabela 5.4: Polinômios da codificação Turbo e cenários do sistema.

\begin{tabular}{c|c|c|c|c}
\hline $\begin{array}{c}\text { Taxa } \\
1 / n\end{array}$ & $\begin{array}{c}\text { Número de } \\
\text { Registradores } Q\end{array}$ & $\begin{array}{c}\text { Polinômio de } \\
\text { Realimentação } d\end{array}$ & $\begin{array}{c}\text { Polinômio } \\
g_{0}\end{array}$ & $\begin{array}{c}\text { Polinômio } \\
g_{1}\end{array}$ \\
\hline \hline $1 / 3$ & 3 & 13 & 15 & 17 \\
\hline \multicolumn{5}{c}{} \\
\hline Cenário & $\mathbf{S 1}$ & $\mathbf{S 2}$ & $\mathbf{S 3}$ & $\mathbf{S 4}$ \\
\hline usuários $K$ & 1 & 5 & 10 & 20 \\
\hline
\end{tabular}


Analisou-se o desempenho dos algoritmos Turbo para taxa de codificação $1 / 3$, acarretando em uma taxa básica de transmissão e tamanho dos pacotes que podem ser observados na tabela 5.5.

Tabela 5.5: Parâmetros da decodificação Turbo.

\begin{tabular}{c|c|c}
\hline \multicolumn{3}{|c}{ Turbo } \\
\hline $1 / n$ & $I$ & $R_{b}$ \\
\hline $1 / 3$ & 186 & $9600 \mathrm{bps}$ \\
\hline
\end{tabular}

A figura 5.10.a apresenta o desempenho do decodificador Turbo com 5 iterações considerando diferentes índices de carregamento (sistemas 1, 2, 3 e 4) conforme tabela 5.4 na ausência de estratégias heurísticas. Observa-se que para garantir uma BER $<10^{-4}$ e considerando $K<10$ usuários, é necessário apenas uma relação de $\bar{\gamma}<16 \mathrm{~dB}$. No entanto, quando aumenta-se o carregamento o desempenho é degradado proporcionalmente, mostrando que a estratégia Turbo é sensível ao aumento do número de usuários no sistema.

Portanto, quando aumenta-se o carregamento deve-se utilizar de forma combinada uma maior taxa de codificação, uma melhor estratégia para o entrelaçador e desentrelaçador, um maior número de iterações visando atingir a BER desejada ou alguma forma de deteç̧ão multiusuário para minimizar a interferência à entrada do decodificador. Assim, observa-se na figura 5.10.b que o uso das estratégias heurísticas resultam em desempenho significativamente superior, pois obtém-se patamares próximos ao desempenho quando não há interferência de múltiplo acesso $(K=1)$, evidenciando a aplicabilidade de tais técnicas. Observase, que para as mesmas condições de sistema, consegue-se uma $B E R \approx 3,8 \times 10^{-3}$ para $K=31$ usuários, $\bar{\gamma}=10 \mathrm{~dB}$ considerando topologia sem algoritmos heurísticos enquanto consegue-se uma $B E R \approx 9,3 \times 10^{-5}$ com a utilização de estratégias heurísticas, um incremento de desempenho em termos da BER da ordem de $\approx 1,6$ décadas.

Além disso, os algoritmos heurísticos apresentaram os mesmos patamares de desempenho considerando 50 gerações para os algoritmos GA e EP-C e 60 iterações para os algoritmos SA, STTS, RTS e HH para todos os cenários simulados.

\subsubsection{Detecção em sistemas com codificação LDPC}

Para todas as simulações realizadas nesta seção os seguintes parâmetros de sistema foram adotados: sequências de espalhamento aleatórias com ganho de processamento $N=31$; modulação BPSK, canal com dois percursos e desva- 

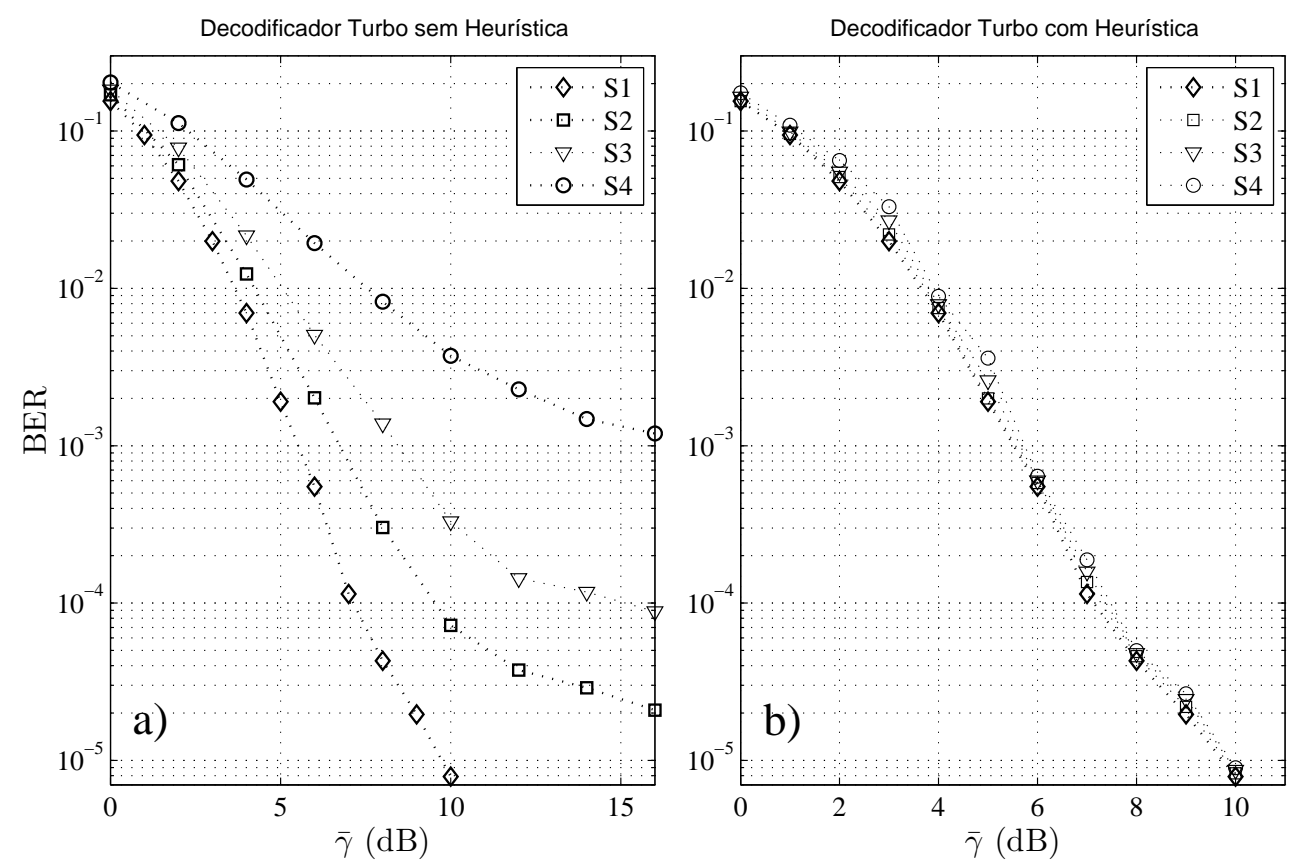

Figura 5.10: Desempenho para decodificação Turbo a) sem a utilização e b) com a utilização das estratégias heurísticas.

necimento lento seguindo a distribuição Rayleigh com atrasos aleatórios ordenados no intervalo $[0 ; N-1] T_{c}$ e perfil atraso-potência com $\mathbb{E}\left[\beta_{k, 1}^{2}\right]=0,652$ e $\mathbb{E}\left[\beta_{k, 2}^{2}\right]=0,348, \forall k$ e carregamento variável com o número de usuários ativos $K=[1,5,10,20]$, resultando em um carregamento $3,23 \% \leq K / N \leq 64,5 \%$.

Novamente, adotou-se o modelo de Jakes modificado para os parâmetros do canal, considerando frequência da portadora $f_{c}=2 \mathrm{GHz}$, número de osciladores $N_{d}=36$, velocidades de deslocamento dos móveis uniformemente distribuídas entre 0 e $120 \mathrm{~km} / \mathrm{h}$.

Utilizou-se a relação $\bar{\gamma}$ variável no intervalo $\bar{\gamma}=[0 ; 10] d B$ para decodificação em sistemas com codificação LDPC $(204,102)$ curta (MACKAY; NEAL, 1997). O decodificador utilizado foi o BP - Belief Propagation Decoder (LUCAS et al., 2000) com 20 iterações.

A figura 5.11.a descreve o desempenho do decodificador BP em sistemas com codificação LDPC e ausência de estratégias heurísticas, enquanto a figura 5.11.b descreve o desempenho do decodificador BP em sistemas com codificação LDPC e presença de estratégias heurísticas.

A figura 5.11.a e figura 5.11.b apresentam o desempenho do decodificador BP em cenários com codificação LDPC com 20 iterações considerando diferentes índices de carregamento (sistemas 1, 2, 3 e 4) conforme tabela 5.4. Note que para 

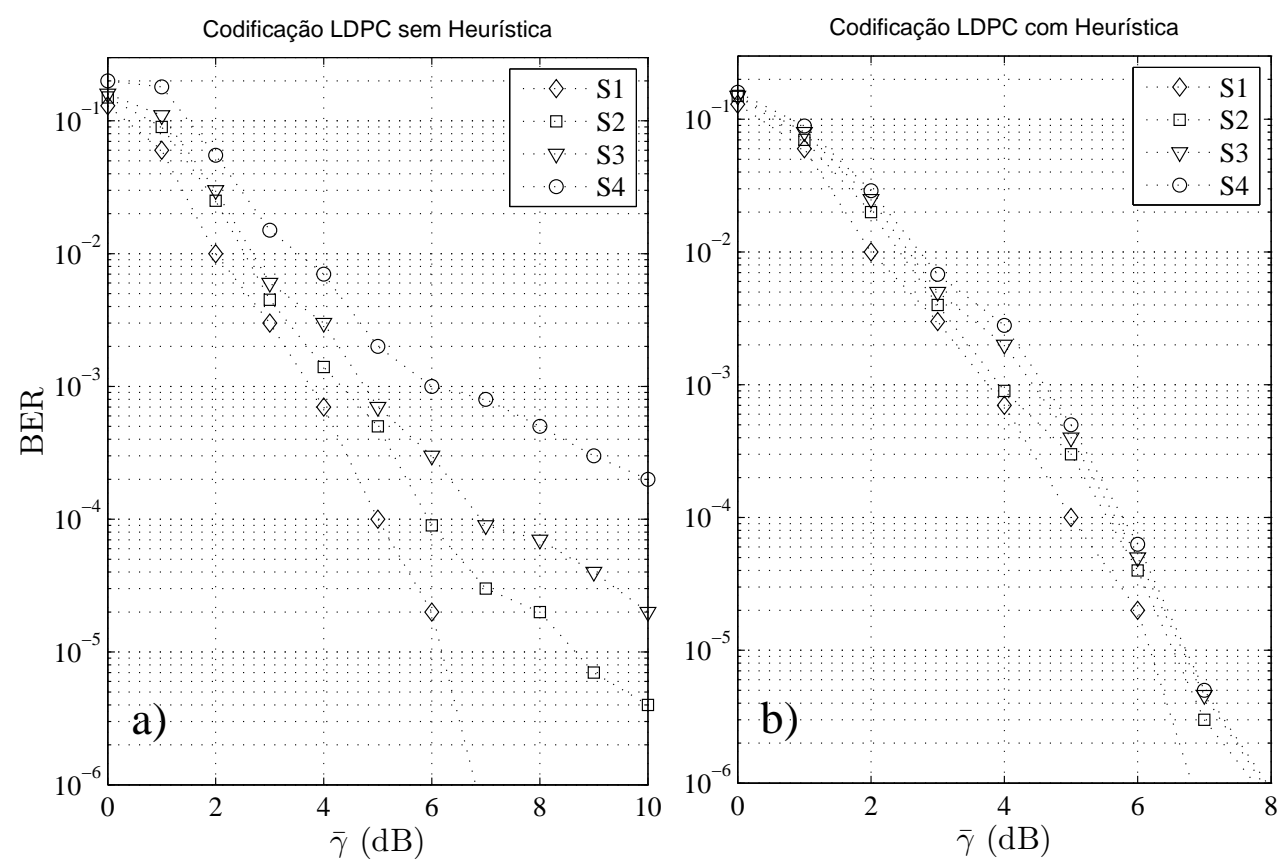

Figura 5.11: Desempenho para codificação LDPC a) sem a utilização e b) com a utilização das estratégias heurísticas.

garantia de uma BER $<10^{-4}$, conforme figura 5.11.a, e considerando $K<10$ usuários, é necessário uma relação de $\bar{\gamma}<7$ dB. No entanto, quando aumentase o carregamento o desempenho é degradado, evidenciando que o aumento do número de usuários no sistema também limita o desempenho para sistemas sem estratégias heurísticas.

Novamente, observa-se na figura 5.10.b que o uso das estratégias heurísticas resultam em desempenho significativamente superior, pois indicam obtenção de desempenho próximos ao limite quando não há interferência de múltiplo acesso $(K=1)$, evidenciando a aplicabilidade de tais técnicas para estes cenários. Observa-se que o desempenho obtido para $K=31$ usuários, $\bar{\gamma}=8 \mathrm{~dB}$ é de $B E R \approx 5 \times 10^{-4}$ considerando topologia sem algoritmos heurísticos enquanto consegue-se uma $B E R \approx 1 \times 10^{-6}$ com a utilização de estratégias heurísticas, um incremento de desempenho em termos da BER da ordem de $\approx 2,7$ décadas para as mesmas condições de sistema.

Vale ressaltar que foram consideradas 50 gerações para os algoritmos GA e EP-C e 60 iterações para os algoritmos SA, STTS, RTS e HH para os cenários simulados nesta seção, sendo que todos os algoritmos heurísticos apresentaram desempenho iguais após convergência. 


\subsubsection{Detecção em sistemas multitaxa DS/CDMA}

Esta seção considera sistemas onde os usuários podem transmitir em diferentes taxas, ou seja, simulando diferentes tipos de serviços de telecomunicações. Neste momento, não estão sendo consideradas as demais possibilidades de exploração de diversidade.

Nas simulações computacionais para sistemas multitaxa foram adotadas sequências de canalização do tipo Walsh-Hadamard de comprimento $N_{C}=8$ e sequências de embaralhamento do tipo aleatória com $N=50$.

Considerou-se que a mobilidade (velocidade) de todos os $K$ usuários pode ser modelada por uma distribuição estatística uniforme no intervalo $\left[0 ; v_{\max }\right]$, resultando em uma frequência Doppler máxima $f_{D}=\frac{v_{\max }}{\lambda_{c}} \approx 185 \mathrm{~Hz}$ para uma frequência da portadora de $f_{c}=2 G H z$; a diversidade do receptor Rake adotada é $D=L=3$, perfil atraso-potência uniforme e a largura de banda do sistema adotada é igual a $B W=3,84 M H z$.

Para simular os diferentes tipos de serviços oferecidos, considerou-se dois sistemas onde os usuários transmitem utilizando as taxas relativas de $8 R, 4 R$, $2 R$ e $R$, onde a taxa básica é $R=9,6 \mathrm{kbps}$, conforme descrito na tabela 5.6. Para o sistema simulado, o número total de usuários virtuais foi fixado em $\mathcal{K}_{v}=m^{(1)} K^{(1)}+m^{(2)} K^{(2)}+m^{(3)} K^{(3)}=24$ devido ao elevado tempo de simulação em outras condições considerando um número maior de usuários.

Tabela 5.6: Principais parâmetros para o sistema multitaxa.

\begin{tabular}{|c|c|c|}
\hline Serviço & Usuários Físicos & Taxa \\
\hline S1 & $K^{(1)}=8$ & $R$ \\
\hline $\mathrm{S} 2$ & $K^{(2)}=2$ & $4 R$ \\
\hline S3 & $K^{(3)}=1$ & $8 R$ \\
\hline & Sistema 1 & \\
\hline
\end{tabular}

Visando comparação, os desempenhos do receptor Rake e do limite SuB (com taxa de bit $R$ ) foram incluídos (PROAKIS, 1995). Em todas as simulações, os algoritmos heurísticos processam e otimizam um conjunto de $D \mathcal{K}_{v} I$ bits por vez, sendo $I=5 \mathrm{bits} /$ usuário virtual e o número de gerações / iterações $G_{t}=50$ para todos os algoritmos heurísticos.

A figura 5.12 apresenta a curva de convergência dos algoritmos heurísticos nas condições do sistema 1. Este gráfico expressa a evolução de desempenho do algoritmo heurístico em direção à solução ótima, em função do aumento do número de gerações/iterações computadas. Evidencia-se a rápida convergência para próximo 
do limite SuB dos respectivos desempenhos para os 3 grupos multitaxa. Percebese que com pouquíssimas gerações/iterações $(\approx 25)$, os algoritmos são capazes de encontrar boas soluções, implicando em uma enorme redução da complexidade quando comparada à do OMuD. Vale ressaltar que a convergência dos algoritmos para um bom resultado ocorre em aproximadamente 25 gerações/iterações. No entanto, visando garantir estabilidade e qualidade das soluções, observou-se que o número mínimo de gerações deve ser de 50 gerações/iterações. Assim, optou-se pela utilização dos valores já mencionados.

Numericamente, esta redução de complexidade pode ser obtida verificando o número de soluções candidatas testadas (universo de busca visitado), por exemplo, pelos detectores baseados no GA e EP-C que ao final de $G_{t}=50$ gerações, testam $p . G_{t}=7000$ soluções candidatas, enquanto que para o $\mathrm{OMuD}$ seriam necessários $2^{\mathcal{K}_{v} \cdot I}=1,4.10^{36}$ testes $^{5}$.

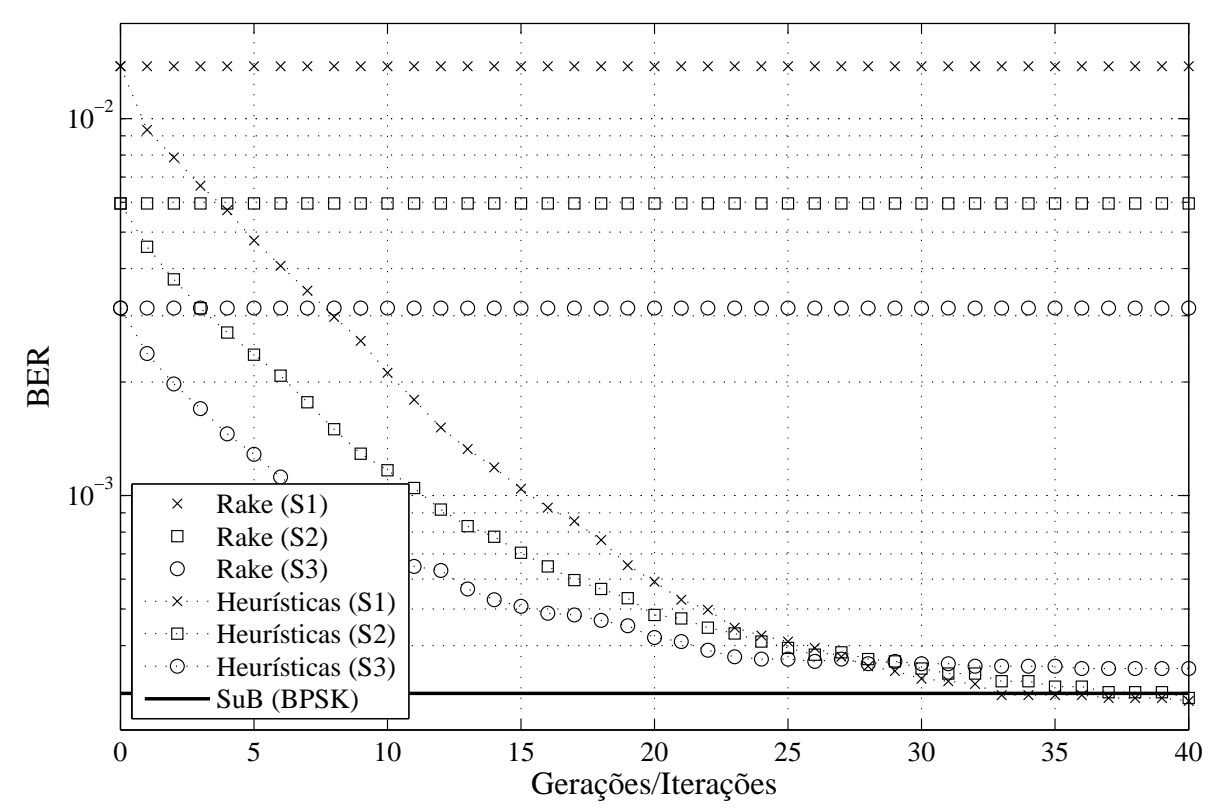

Figura 5.12: Convergência dos algoritmos heurísticos para sistema 1 e

$$
\bar{\gamma}=16 d B \text {. }
$$

A figura 5.13 apresenta o desempenho do sistema multitaxa em função da relação sinal-ruído $(\bar{\gamma})$. Note que a BER para as estratégias heurísticas aproximam-se do desempenho $\mathrm{SuB}$, evidenciando um enorme ganho de desempenho em relação ao detector Rake para todos os 3 grupos multitaxa avaliados. Assim, mesmo para o grupo de alta taxa obteve-se desempenho próximo ao limiar, reforçando a

\footnotetext{
${ }^{5}$ Não computados, devido à impossibilidade de realização utilizando o computador pessoal de alto desempenho e capacidade de armazenamento já citado. Por esta razão, compara-se o desempenho dos detectores heurísticos com o SuB.
} 
possibilidade de utilização das técnicas heurísticas propostas para os sistemas de telecomunicações sem fio vindouros.

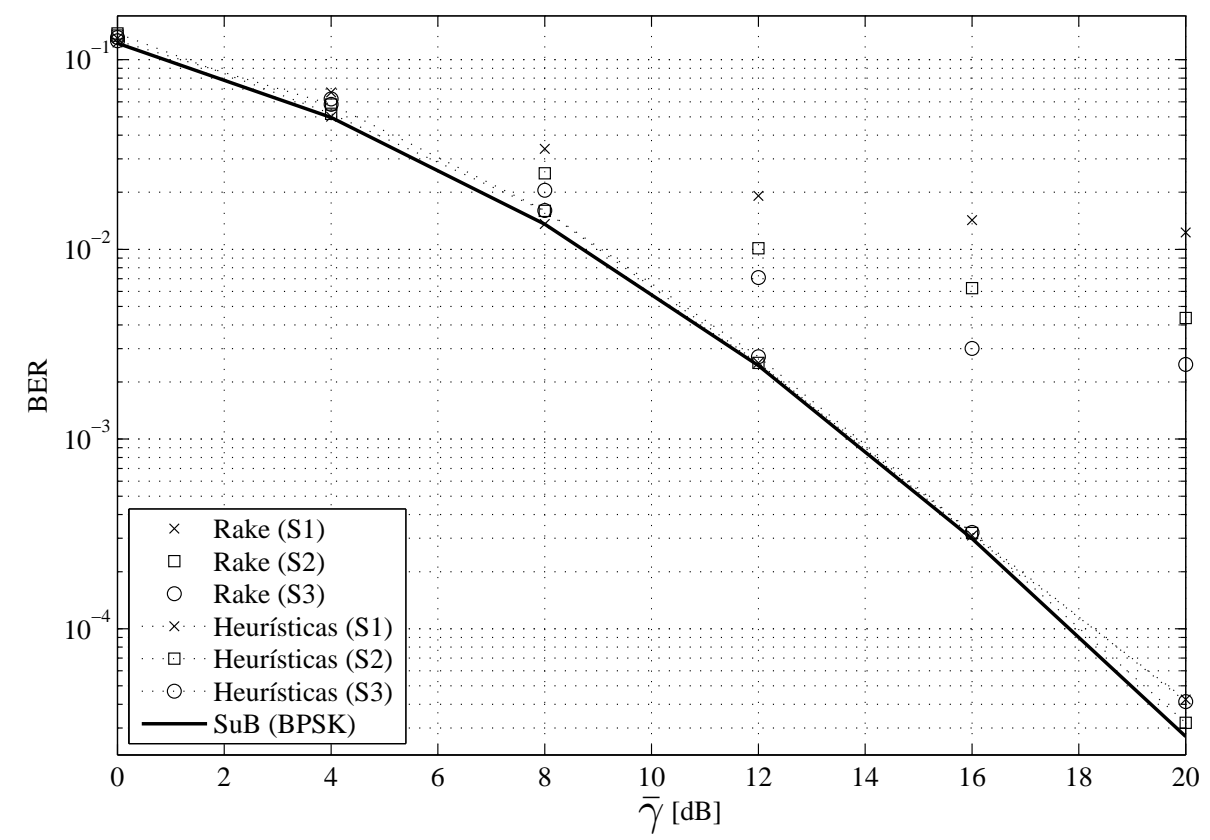

Figura 5.13: BER para o receptor Rake e estratégias heurísticas para sistema 1.

Por fim, vale ressaltar que foram realizadas outras simulações em diferentes cenários e para todas as simulações realizadas as conclusões apresentadas nesta seção são as mesmas. Assim, optou-se por inserir apenas um resultado significativo de simulação.

\subsubsection{Detecção em sistemas multiportadora DS/CDMA}

Esta seção considera sistemas multiportadora do tipo MC DS/CDMA, conforme apresentado na seção 2.1.4.1, onde a informação é espalhada no domínio da frequência de forma adicional ao espalhamento no domínio do tempo utilizando um número $M$ de subportadoras. Desta forma, pode-se explorar a presença de diversidade em frequência através de técnicas de recepção baseadas em heurísticas.

Nas simulações computacionais para sistemas multiportadora foram adotadas sequências aleatórias de comprimento $N=32$ e um número de subportadoras $M=8$. Considerou-se, também, que a mobilidade (velocidade) de todos os $K$ usuários pode ser modelada por uma distribuição estatística uniforme no intervalo $\left[0 ; v_{\max }\right]$, resultando em uma frequência Doppler máxima $f_{D}=\frac{v_{\max }}{\lambda_{c}} \approx 150 \mathrm{~Hz}$ 
para uma frequência da portadora de $f_{c}=2 G H z$; a diversidade do receptor Rake adotada é $D=L=2$ e a largura de banda do sistema adotada é igual a $B W=3,84 M h z$.

Além disso, considerou-se modulação BPSK, canal com dois percursos e desvanecimento lento seguindo a distribuição Rayleigh com atrasos aleatórios ordenados no intervalo $[0 ; N-1] T_{c}$ e perfil atraso-potência com $\mathbb{E}\left[\beta_{k, 1}^{2}\right]=0,652 \mathrm{e}$ $\mathbb{E}\left[\beta_{k, 2}^{2}\right]=0,348, \forall k$ e carregamento variável com o número de usuários ativos $K=[1,5,10,20]$, resultando em um carregamento $3,23 \% \leq K / N \leq 64,5 \%$.

Para os sistemas multiportadora simulados, assumiu-se nula a correlação entre os desvanecimentos de duas subportadoras quaisquer. Vale ressaltar que os resultados de simulação deste trabalho foram comparados com expressões analíticas de desempenho apresentadas em (YANG; HANZO, 2002; ANGéLICO, 2005) e mostraram-se coincidentes, validando as rotinas desenvolvidas.

A figura 5.14 apresenta o desempenho do sistema multiportadora em função da relação sinal-ruído $(\bar{\gamma})$ e diferentes condições de carregamento do sistema. Note que a BER para as estratégias heurísticas aproximam-se do desempenho para usuário único, evidenciando um enorme ganho de desempenho em relação ao detector convencional para todos os valores de carregamento avaliados. Assim, mesmo para carregamento médio/alto obteve-se desempenho próximo ao limiar, enquanto o desempenho para o receptor convencional é degradado consideravelmente quando o número de usuários aumenta.

Para ilustrar o ganho de desempenho de forma numérica, observa-se da figura 5.14 que o desempenho obtido para $K=20$ usuários, $\bar{\gamma}=25 \mathrm{~dB}$ é de $B E R \approx 3,3 \times 10^{-2}$ considerando topologia sem algoritmos heurísticos enquanto consegue-se uma $B E R \approx 3 \times 10^{-4}$ com a utilização de estratégias heurísticas, um incremento de desempenho em termos da BER da ordem de $\approx 2$ décadas para as mesmas condições de sistema.

Vale ressaltar que todos os algoritmos heurísticos resultaram no mesmo patamar de desempenho sendo consideradas 10 gerações para $K \leq 10$ para os algoritmos e 20 gerações/iterações para $10<K \leq 20$ para os cenários simulados nesta seção. No entanto, observou-se que a convergência para valores razoáveis de desempenho ocorreram em $G_{t}=8$ para os algoritmos GA e EP-C e em $I_{t}=7$ para os algoritmos SA, STTS, RTS e HH, não sendo apresentados. 

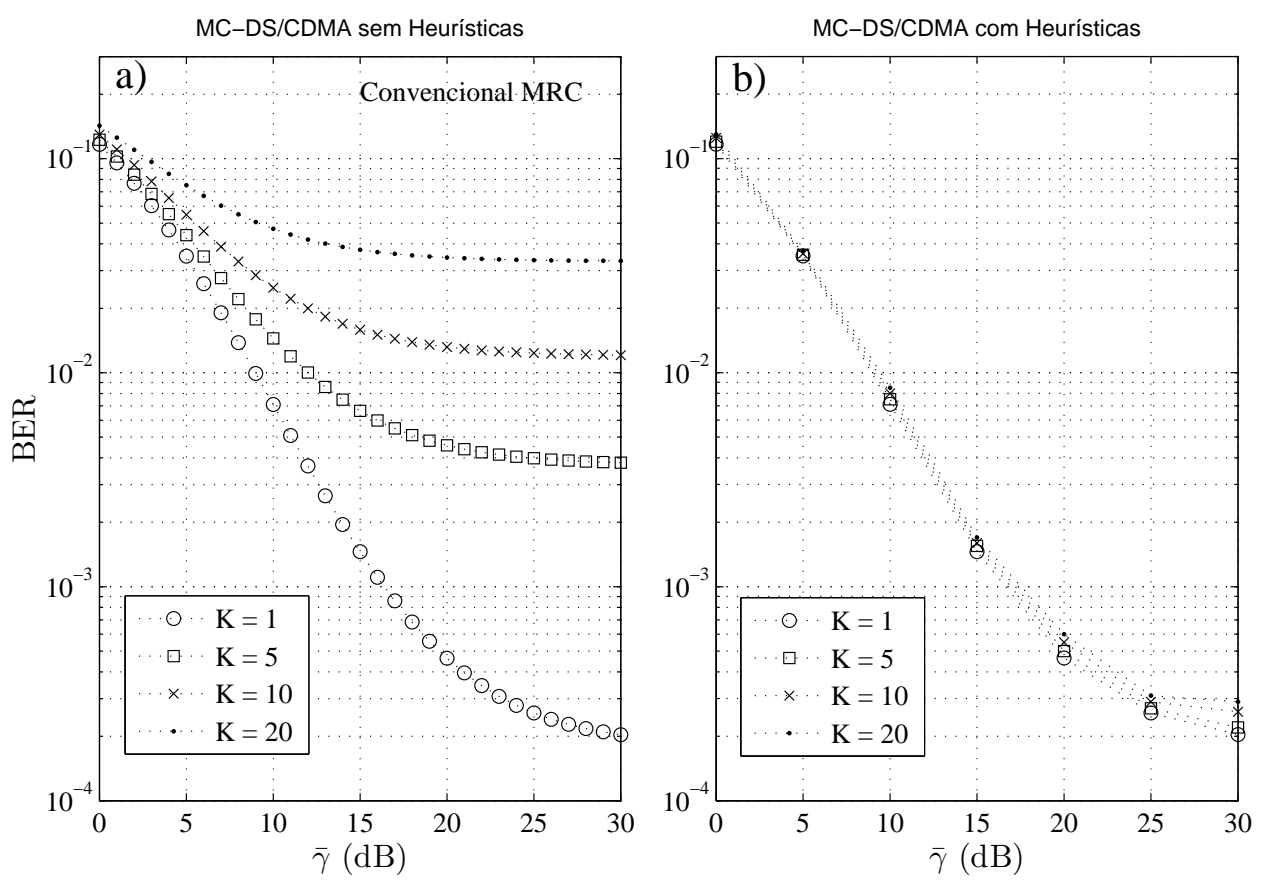

Figura 5.14: BER para o sistema multiportadora MC DS/CDMA com a) recepção convencional e b) estratégias heurísticas.

\subsubsection{Detecção em sistemas DS/CDMA com diversidade multidimensional}

Esta seção contempla alguns resultados obtidos em cenários com exploração de vários tipos de diversidade. Primeiramente, apresentam-se resultados para um sistema SIMO MC-DS/CDMA, ou seja, que possui diversidade em frequência e espaço, devido ao emprego de multiportadoras e múltiplas antenas de recepção. Em um segundo momento, considera-se um cenário com diversidade de código (codificação LDPC) e diversidade espacial considerando múltiplas antenas de recepção e/ou transmissão.

Desta forma, procurou-se evidenciar a aplicabilidade das técnicas heurísticas em sistemas com exploração de diversidade considerando poucas dimensões e a expansão da análise em cenários mais complexos que possuem um número grande de tipos de diversidade, sendo apresentadas na seção 5.1.5.3 até a seção 5.1.6.1.

\subsubsection{Detecção em sistemas multiportadora e com múltiplas antenas}

Para esta seção, são considerados sistemas com diversidade de frequência e espaço, em cenários SIMO MC-CDMA. Os principais parâmetros do sistema e dos coeficientes de canal são apresentados na tabela 5.7. Em todas as simulações, considera-se um ganho de processamento $N=8$ e número de subportadoras 
$M=4$. Considerou-se que os parâmetros de canal são perfeitamente conhecidos no receptor e cada subportadora apresenta desvanecimento plano em frequência.

Tabela 5.7: Parâmetros do canal e do sistema multiportadora com múltiplas antenas.

\begin{tabular}{ll}
\hline Parâmetros & Valores Adotados \\
\hline \# Antenas Rx & $A_{R x}=1$ a 5 \\
\# Usuários & $K=5 ; 10 ; 15 ; 20 ; 25 ; 32$ \\
Sequências & aleatórias, $N=8$ \\
Subportadoras & $M=4$ \\
Período de Bit,$T_{b}$ & $300 \mu \mathrm{s}$ \\
SNR recebida & $\bar{\gamma} \in[0 ; 18] \mathrm{dB}$ \\
Max. freq. Doppler & $f_{\mathrm{D}}=100 \mathrm{~Hz}$ (canal lento) \\
\hline
\end{tabular}

As simulações Monte Carlo realizadas indicaram que os algoritmos GA, SA, RTS, STTS, EP-C e HH aplicados a um cenário multiportadora e múltiplas antenas de recepção resultam em um mesmo desempenho em termos de qualidade da solução encontrada após a convergência. No entanto, apresentam complexidade distintas.

A figura 5.15 apresenta o desempenho que todos os algoritmos atingiram após convergência, mostrando igualdade entre as técnicas neste aspecto. Neste caso, foram consideradas distintas soluções iniciais para os algoritmos e todos alcançaram um desempenho sensivelmente superior ao detector convencional. No entanto, o número de gerações/iterações para convergência mostrou-se diferente, resultando em distintas complexidades ${ }^{6}$. Note que o aumento do número de antenas receptoras resulta em uma melhoria significativa de desempenho para um carregamento médio e baixa relação sinal-ruído.

A figura 5.16 apresenta o desempenho para carregamento médio $(K=20)$ e um número de antenas de recepção $A_{R x}=1$ a 5 . Nestas condições, obtémse uma $\mathrm{BER}=10^{-5}$ para um número moderado de antenas receptoras e SNR. Assim, nota-se o ganho de desempenho das estratégias heurísticas em relação ao detector convencional quando do aumento do número de antenas para uma relação sinal-ruído na faixa de 0 a $18 \mathrm{~dB}$.

No entanto, na figura 5.17 pode-se verificar o desempenho para cenários com carregamento total $(K=32)$ e um número de antenas de recepção $A_{R x}=1$ a 3. Embora apresente desempenho superior ao detector convencional, nota-se a degradação de desempenho quando o carregamento do sistema aumenta. Esta situação pode ser melhorada com o aumento da SNR, com o aumento do número de antenas no receptor ou com o aumento do comprimento da sequência de espa-

\footnotetext{
${ }^{6} \mathrm{~A}$ complexidade é discutida na seção 5.3 .
} 

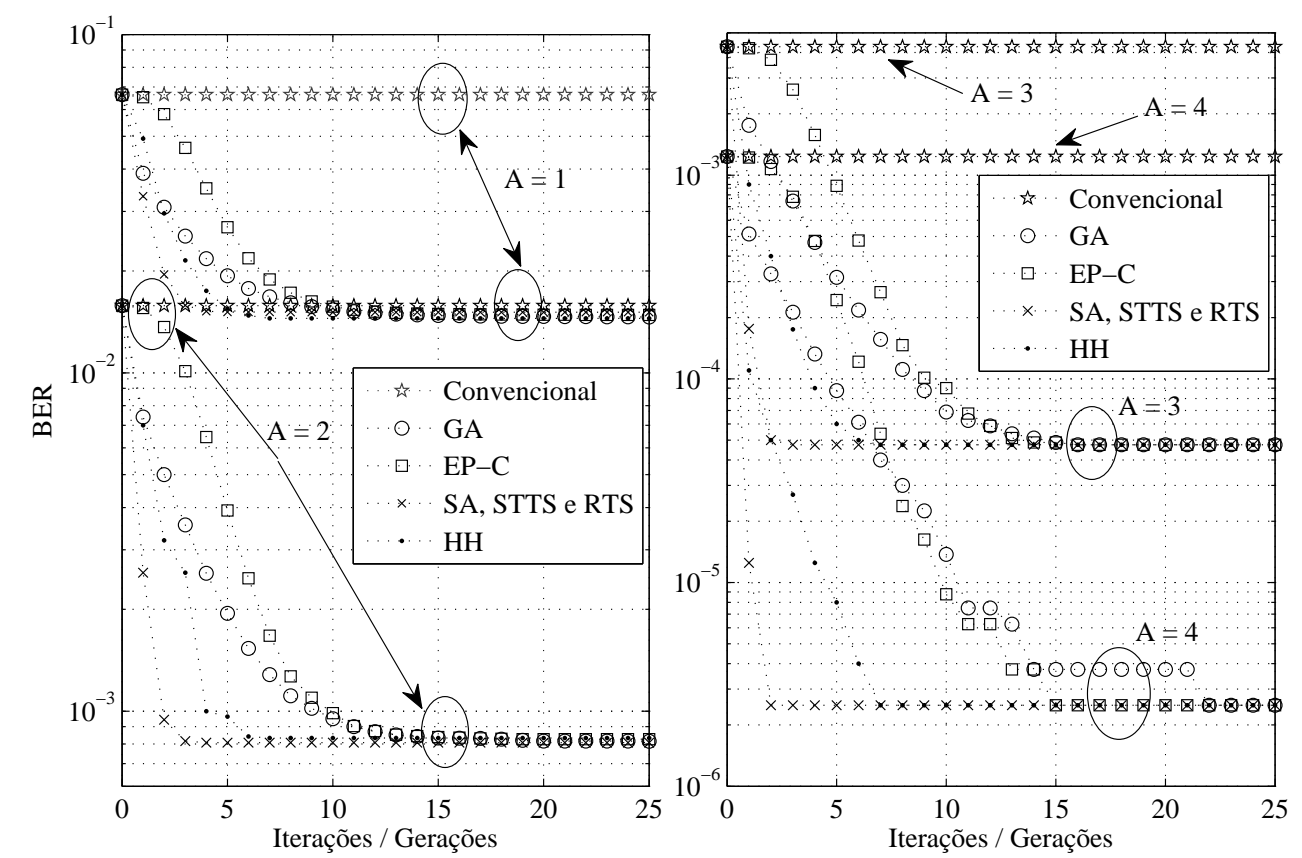

Figura 5.15: Convergência para o detector convencional e algoritmos Heurísticos em cenários SIMO MC-CDMA para $E_{b} / N_{0}=9 \mathrm{~dB}, K=20$.

lhamento, garantindo uma condição mais favorável de interferência de múltiplo acesso. Em ambos os cenários (carregamento médio e total), o desempenho dos algoritmos heurísticos mostra-se superior quando comparado ao detector convencional.

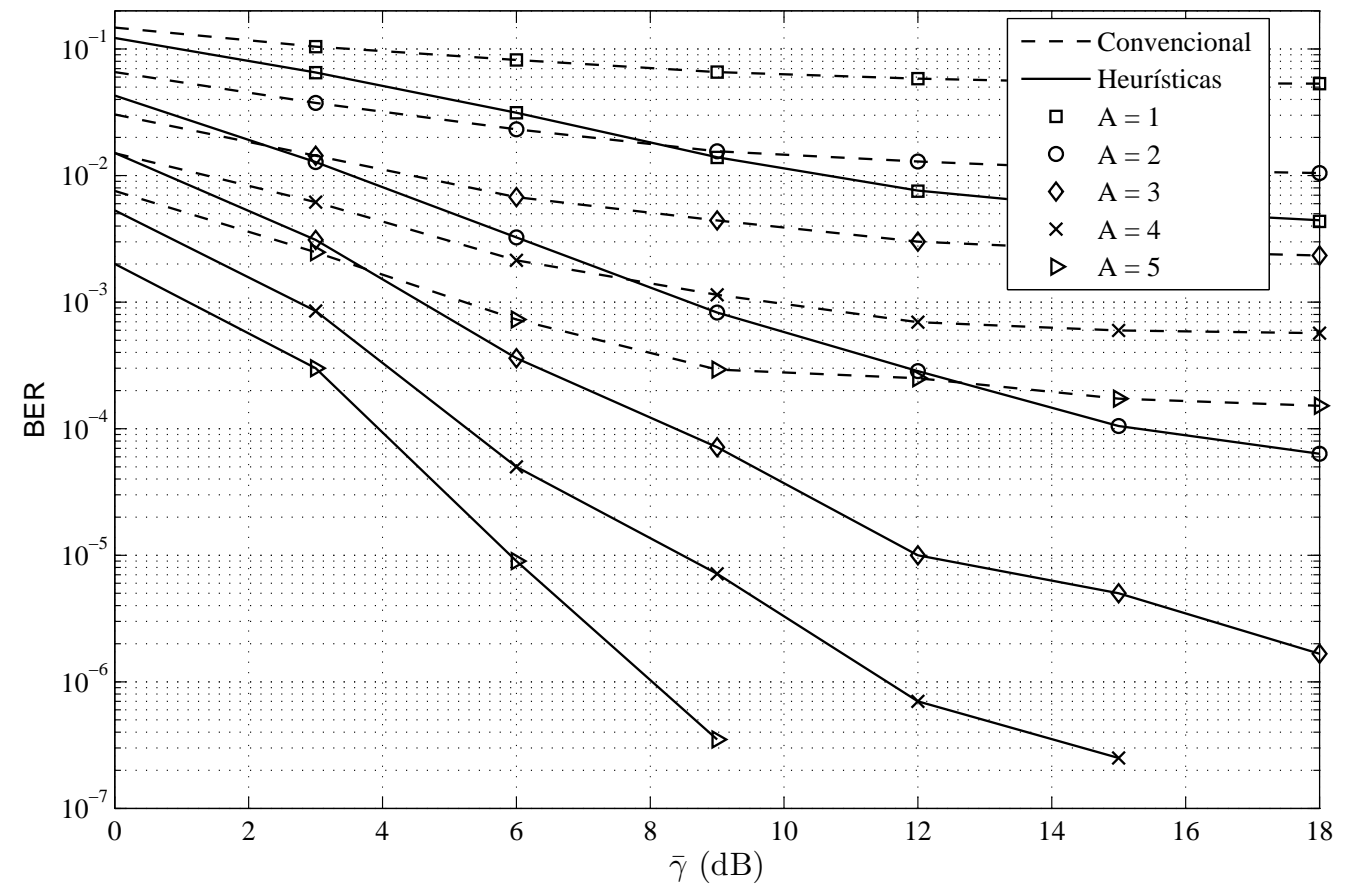

Figura 5.16: Desempenho em termos da BER para os algoritmos heurísticos em cenário SIMO MC-CDMA para $K=20$. 


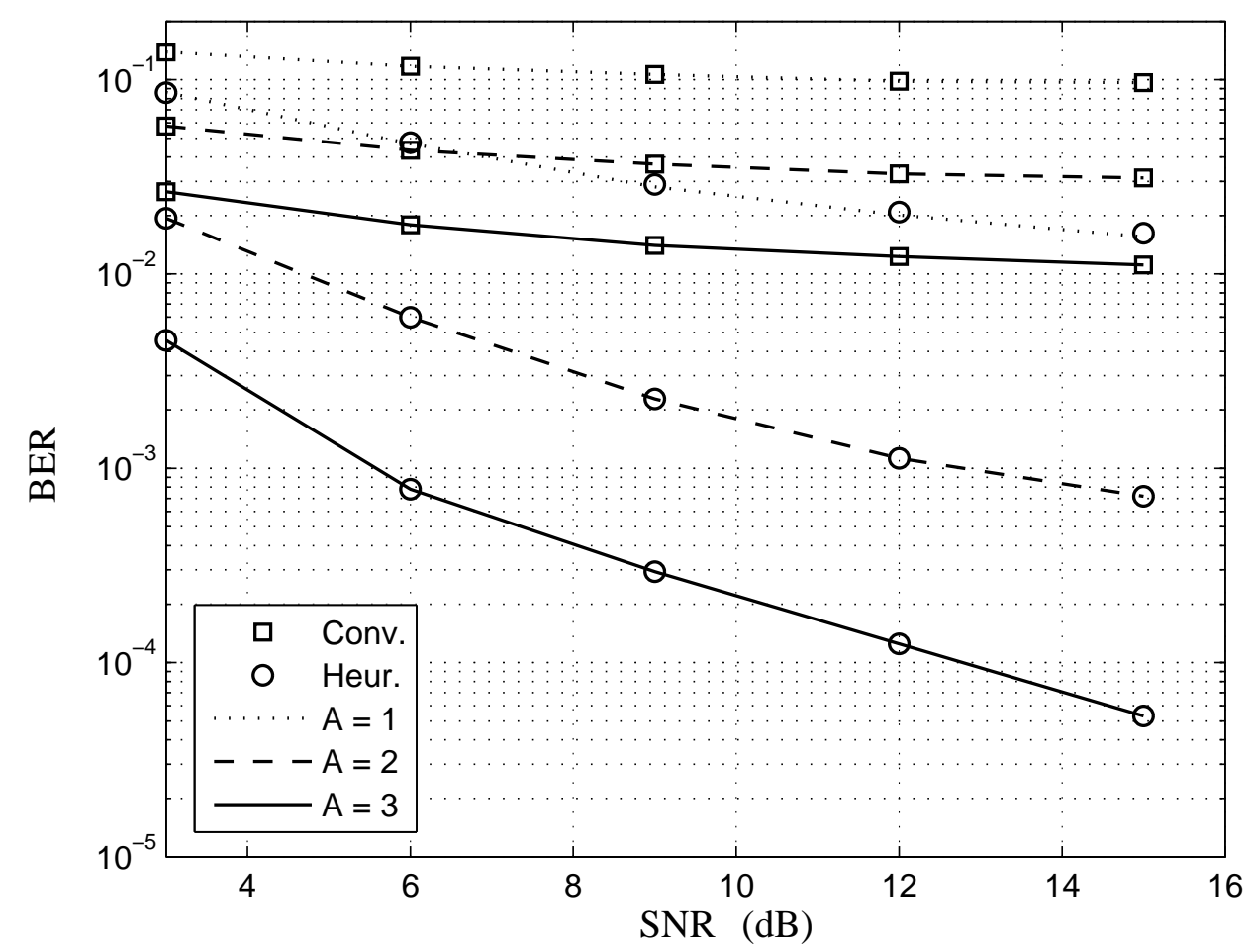

Figura 5.17: Desempenho em termos da BER para os algoritmos heurísticos em cenário SIMO MC-CDMA para $K=32$.

de usuários ativos. A figura 5.18 apresenta o desempenho dos algoritmos heurísticos em função do número de usuários $K=[5,30]$. O aumento no carregamento do sistema provoca uma degradação da BER, mas o desempenho dos heurísticos aponta superioridade significativa em relação ao convencional, incluindo as condições de alto carregamento. Esse desempenho é melhorado à medida que o número de antenas, SNR ou o ganho de processamento aumenta. Além disso, para baixo carregamento do sistema ( $K=5$ usuários), o desempenho dos heurísticos mostra-se muito próximo do desempenho para usuário único, mostrando a aplicabilidade das estratégias heurísticas propostas neste trabalho.

Vale ressaltar que todos os algoritmos heurísticos resultaram no mesmo patamar de desempenho sendo consideradas 10 gerações / iterações para os algoritmos heurísticos nos cenários simulados nesta seção.

\subsubsection{Detecção em sistemas codificados e com múltiplas antenas}

Esta seção contempla uma análise de sistemas com múltiplas entradas e múltiplas saídas (MIMO) com codificação STBC, pois apresentam-se como uma solução promissora frequentemente incorporada em normas comerciais como o Wimax, por exemplo. Além disso, pode-se obter um melhor compromisso desempenho $\times$ 


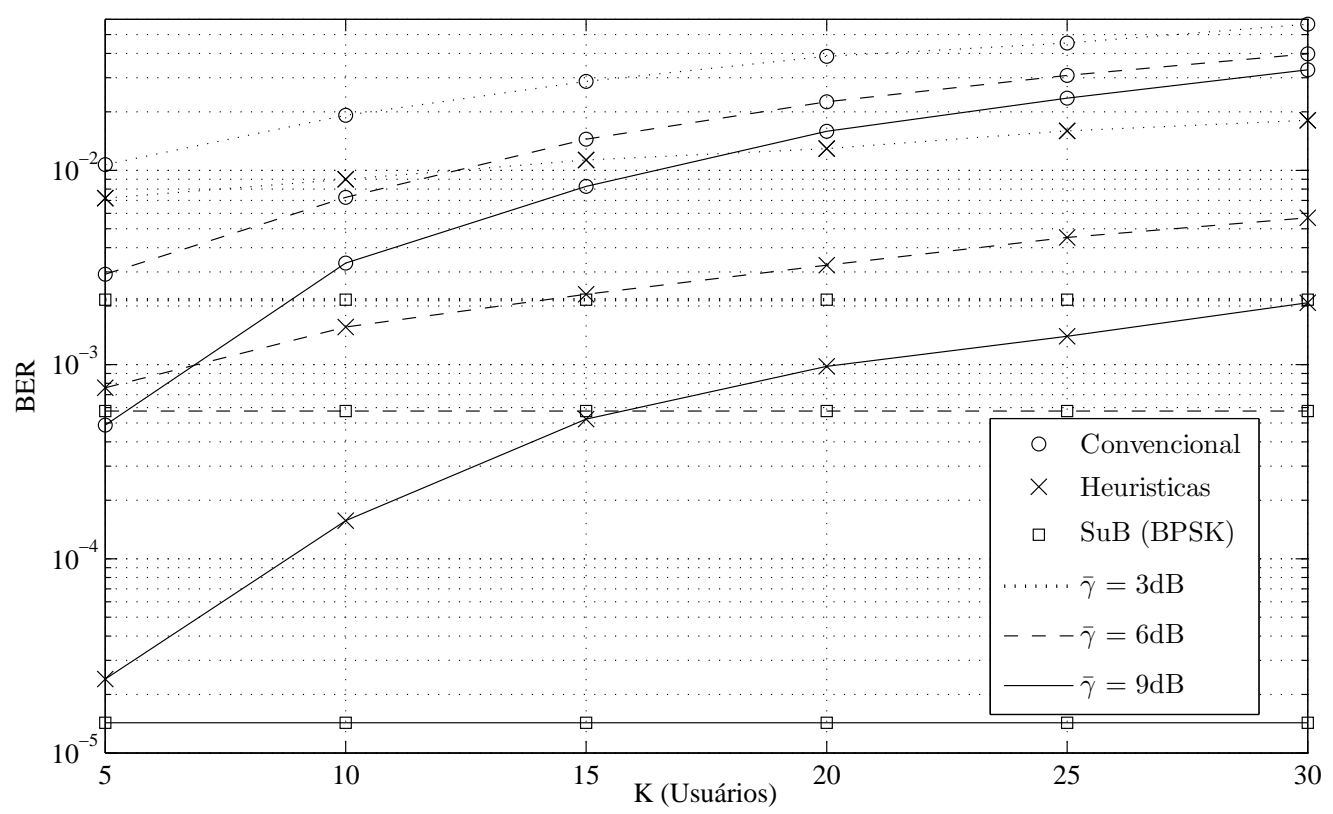

Figura 5.18: Desempenho em termos da BER para detector convencional e estratégias heurísticas em sistemas SIMO MC-CDMA em função do carregamento do sistema $\operatorname{com} Q=2$ antenas de recepção.

complexidade através da utilização de códigos de verificação de paridade de baixa densidade (LDPC). A escolha da topologia STBC deve levar em conta critérios de desempenho como o ganho de codificação, ganho de diversidade, o ganho de multiplexação e, obviamente, da complexidade do decodificador. Notadamente, estes tópicos não são o cerne deste trabalho e, por isso, maiores informações podem ser obtidas nas referências (ALAMOUTI, 1998; JAFARKHANI, 2005; YUEN; GUAN; TJHUNG, 2005; PAU; TAYLOR; MARTIN, 2008; KIM; CHEUN, 2008).

O sistema MIMO considerado para demonstração contém $A_{T x}=4$ antenas de transmissão e $A_{R x} \geq 1$ antenas de recepção, sendo 4 símbolos transmitidos simultaneamente. Adicionalmente, considera-se $A_{T x} A_{R x}$ canais com desvanecimentos planos em frequência e estatisticamente independentes, modulação $M$-ária QAM, esquema QO-STBC de taxa 1 (JAFARKHANI, 2005), LDPC curto $(204,102)$, conhecimento perfeito das informações do canal, sequências aleatórias de comprimento $N=32$ e dois cenários de carregamento com $K=1$ e $K=32$ usuários.

A figura 5.19 apresenta o comportamento em termos da BER $\times$ SNR à entrada do receptor para diferentes constelações de modulação e considerando $A_{T x}=4$ e $A_{R x}=1$ antenas. Nota-se que o desempenho para usuário único converge $^{7}$ mais rapidamente do que para carregamento total (com $K=32$ usuários). No entanto, observa-se que com um acréscimo pequeno na SNR (entre 2 a $3 \mathrm{~dB}$ ) para sistemas com carregamento alto é possível obter BER muito baixas, prin-

\footnotetext{
${ }^{7}$ Após um valor de SNR o desempenho melhora de forma abrupta.
} 
Tabela 5.8: Sistema MIMO e parâmetros do canal.

\begin{tabular}{ll}
\hline & Sistema MIMO QO-STBC \\
\hline \# Tx antenas & $A_{T x}=4$ \\
\# Rx antenas & $A_{R x}=1$ ou 4 \\
Modulação & $M$-QAM: $M=4,16,64,256$ \\
Código QO-STBC & Taxa $1, R_{\text {stbc }}=1(\mathrm{JAFARKHANI}, 2005)$ \\
SNR por antena Rx & $S N R \in[-2.5 ; 30] \mathrm{dB}$ \\
Vazão & $\Theta=1.0,2.0,3.0,4.0[\mathrm{bits} /$ período de símbolo] \\
\hline & \multicolumn{1}{c}{ Códigos $L D P C$} \\
\hline Tipo & LDPC curto $(\mathrm{MACKAY}, 1999)$ \\
Taxa & LDPC $(204,102), \Rightarrow R_{\mathrm{stbc}}=\frac{1}{2}$ \\
Decodificador BP & It $t_{B P} \leq 20$ iterações \\
\hline & \multicolumn{1}{c}{ Canal Rayleigh } \\
\hline tipo de canal & quasi-estático (lento), $L=4$ \\
\hline
\end{tabular}

cipalmente para modulação 4-QAM. No entanto, topologias do tipo 256-QAM possibilitam a transmissão de mais bits por período de símbolo e, em caso de possibilidade de aumento da SNR, pode-se considerar sistemas mais eficientes em termos de vazão (throughput). Além disso, a perda de desempenho pelo aumento do carregamento mostra-se pequena, viabilizando a utilização da topologia com algoritmos heurísticos em sistemas de múltiplo acesso.

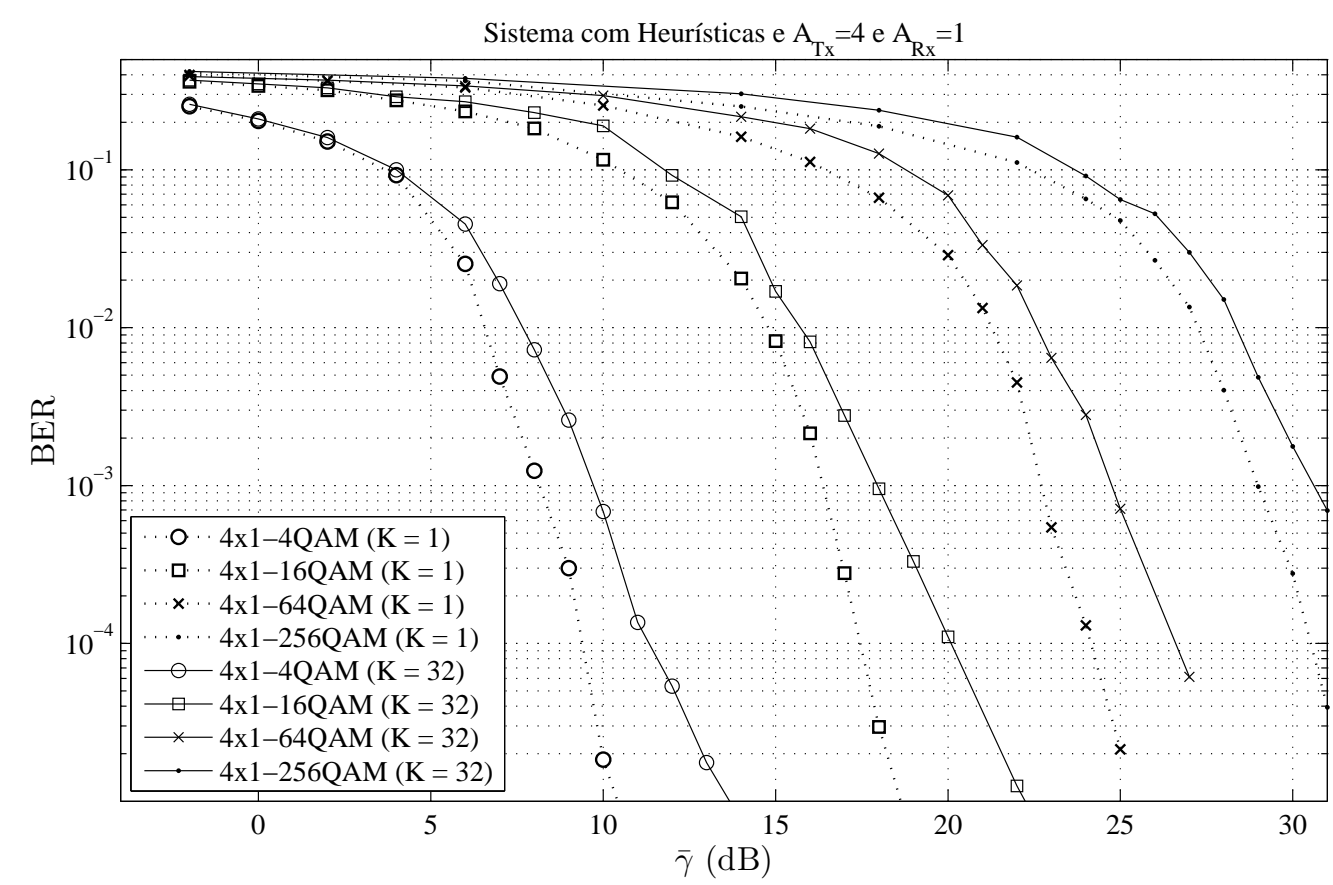

Figura 5.19: Comparação de desempenho entre os decodificadores baseados em heurísticas para sistemas QO-STBC MIMO com codificação LDPC $(204,102)$ curto, $A_{T x}=4$ e $A_{R x}=1$ antenas e $K=1$ e $K=32$ usuários.

Finalmente, a figura 5.20 compara o desempenho em termos da BER $\times$ SNR à entrada do receptor para diferentes constelações de modulação e considerando $A_{T x}=4$ e $A_{R x}=4$ antenas. Observa-se o mesmo comportamento apresentado na 
figura 5.19. Mas neste caso o número de antenas receptoras foi aumentada para $A_{R x}=4$, resultando em melhoria significativa de desempenho, da ordem de $10 \mathrm{~dB}$ na SNR, para a obtenção de desempenhos semelhantes. Nota-se, novamente, que a perda de desempenho pelo aumento do carregamento é pequena, podendo-se considerar sua utilização em cenários de múltiplo acesso.

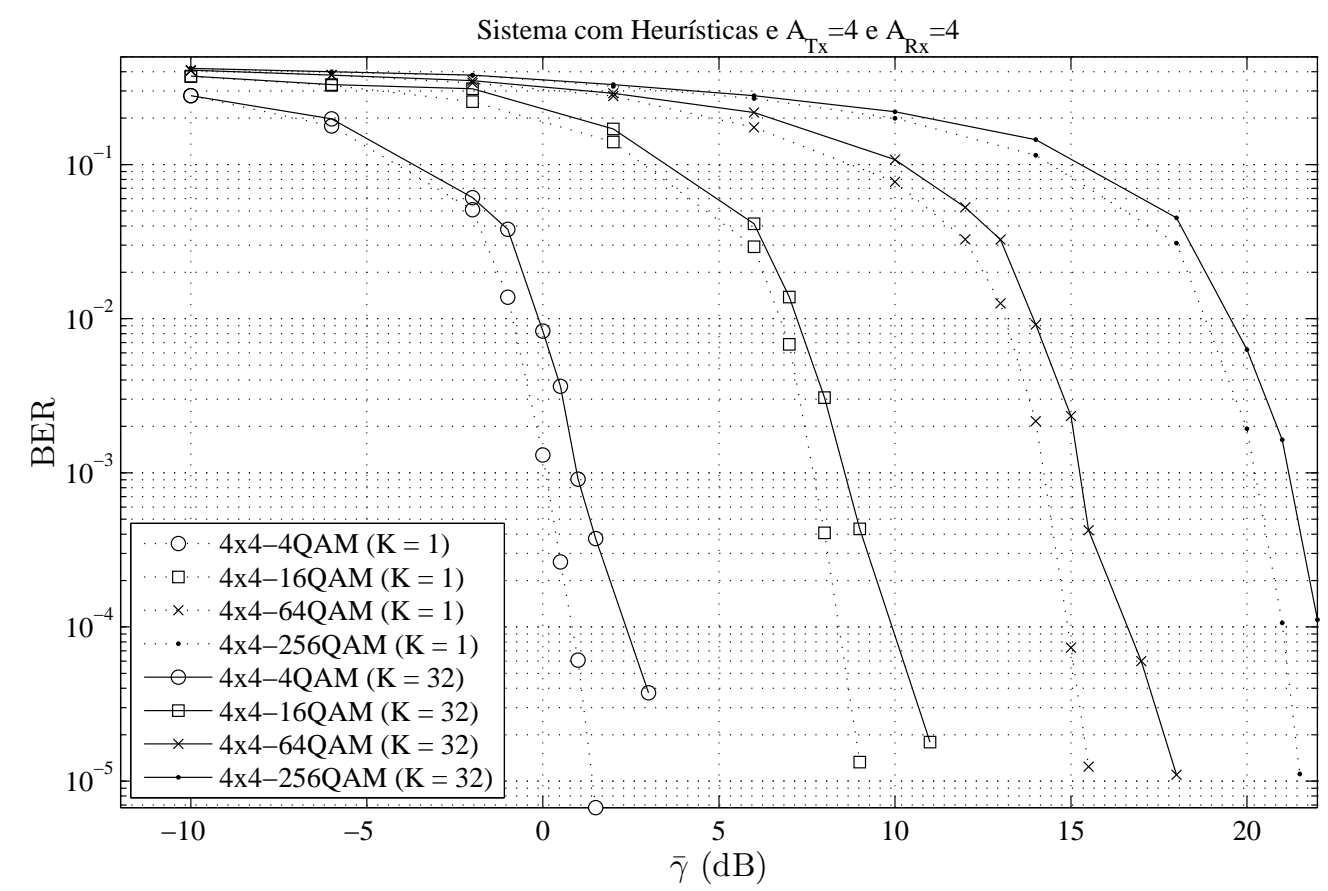

Figura 5.20: Comparação de desempenho entre os decodificadores baseados em heurísticas para sistemas QO-STBC MIMO com codificação LDPC (204,102) curto, $A_{T x}=4$ e $A_{R x}=4$ antenas e $K=1$ e $K=32$ usuários.

Vale ressaltar que foram testados todos os algoritmos heurísticos e estes apresentaram mesmo patamar de desempenho quando consideradas 40 gerações para os algoritmos GA e EP-C e 45 iterações para os algoritmos SA, STTS, RTS e $\mathrm{HH}$.

\subsubsection{Detecção em sistemas com diversidade de código, tempo, frequên- cia e espaço}

Esta seção contempla uma análise de sistemas com vários tipos de diversidade, considerando um sistema com múltiplas entradas e múltiplas saídas (MIMO), codificação STBC, sistema multiportadora DS-CDMA e codificação decodificação turbo. Esta topologia ${ }^{8}$ foi adotada para representar uma topologia com grande exploração de diversidade, possibilitando a obtenção de excelente desempenho em termos da BER mesmo para baixa relação sinal-ruído. Assim, evidencia-se esta topologia como promissora para adoção como padrão comercial.

\footnotetext{
${ }^{8}$ Diversas outras topologias multidimensionais podem ser consideradas para análise.
} 
Vale ressaltar que topologias distintas da escolhida para apresentação dos resultados podem ser analisadas, considerando, por exemplo, codificação de canal do tipo convolucional ou LDPC e diversidade espacial com outras configurações. No entanto, o objetivo da seção consiste em validar a aplicação dos métodos heurísticos em cenários com diversidade multidimensional e não comparar topologias e configurações de sistema.

Desta forma, na tabela 5.9 são apresentados os principais parâmetros do sistema e dos coeficientes de canal. Em todas as simulações, considera-se um ganho de processamento $N=64$ e um número de subportadoras $M=64$. Considerou-se também que os parâmetros de canal são perfeitamente conhecidos no receptor e que cada subportadora apresenta desvanecimento plano em frequência.

Tabela 5.9: Parâmetros do canal e do sistema multidimensional.

\begin{tabular}{ll}
\hline Parâmetros & Valores Adotados \\
\hline \# Usuários & $K=64$ \\
\# Antenas Tx & $A_{T x}=1$ a 2 \\
\# Antenas Rx & $A_{R x}=1$ a 2 \\
Códigos & aleatórios, $N=64$ \\
Subportadoras & $M=64$ \\
Taxa básica,$R$ & $9600 \mathrm{bps}$ \\
Modulação & BPSK \\
Max. freq. Doppler & $f_{\mathrm{D}}=30 \mathrm{~Hz}$ (canal lento) \\
\hline
\end{tabular}

A figura 5.21 compara os sistemas considerando cenários com arranjos de 1x1 antenas e $2 \times 2$ antenas ${ }^{9}$ sem codificação de canal e eficiência espectral de $1 \mathrm{bps} / \mathrm{Hz}$ para detectores baseados em heurísticas e no MMSE. Observa-se o ganho de desempenho quando do aumento do arranjo de antenas de transmissão e recepção para ambos os detectores. Além disso, a topologia baseada em heurísticas apresentou desempenho sensivelmente superior ao método baseado no MMSE, principalmente para arranjo de antenas 1x1. Mesmo para arranjos de antenas $2 \times 2$, o detector com heurísticas mostrou-se mais eficiente para toda a faixa de relação sinal-ruído, aproximando-se do limite para usuário único.

Mas vale ressaltar que esta simulação não contempla os benefícios de desempenho oriundos da codificação de canal. Assim, optou-se por apresentar o desempenho obtido por uma topologia com codificação de canal em separado.

A figura 5.22 apresenta o desempenho considerando os mesmos cenários da figura 5.21 mas com a inclusão de codificação de canal através de codificação e decodificação Turbo de taxa 1/2, resultando em uma eficiência espectral de

\footnotetext{
${ }^{9}$ Arranjo com $n \times m$ antenas corresponde a um arranjo com $n$ antenas de transmissão e $m$ antenas de recepção.
} 


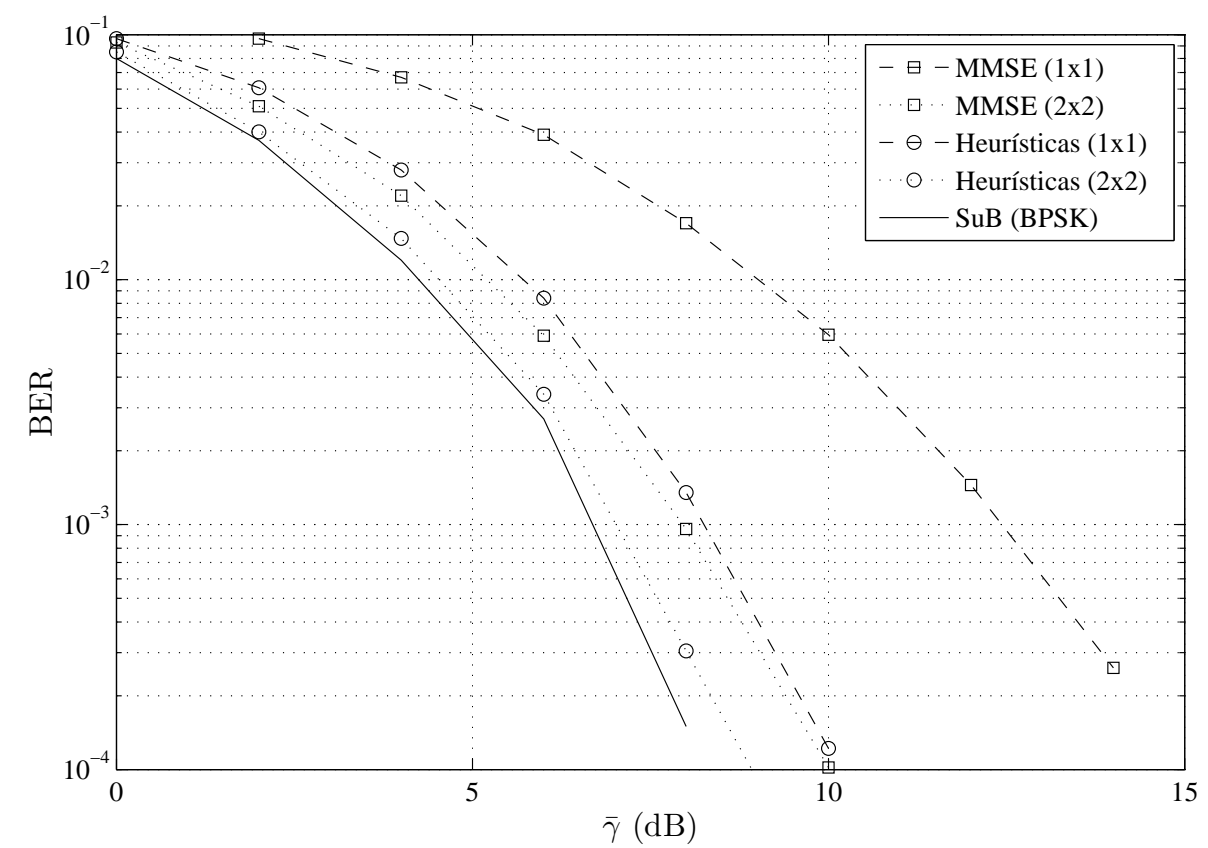

Figura 5.21: Comparação da BER $\times$ relação sinal-ruído para um sistema sem codificação de canal.

0,5bps/Hz. Novamente, observa-se o ganho de desempenho quando do aumento do arranjo de antenas de transmissão e recepção para ambos os detectores. Outro aspecto importante consiste na obtenção de BER extremamente baixas para $\bar{\gamma} \leq 3 \mathrm{~dB}$ com topologias baseadas em heurísticas mesmo em um arranjo de antenas 1x1. Com o aumento do arranjo de antenas, configuração 2 x2 e código de Alamouti (ALAmouti, 1998), obteve-se desempenho de $B E R \leq 10^{-4}$ mesmo para $\bar{\gamma} \leq 2 \mathrm{~dB}$. Assim, o desempenho obtido pela topologia baseada em heurísticas aproxima-se do limite para usuário único, evidenciando sua aplicabilidade em sistemas e padrões comerciais de comunicação sem fio de alto desempenho.

Vale ressaltar que foram testados todos os algoritmos heurísticos e estes apresentaram mesmo patamar de desempenho quando consideradas 100 gerações para os algoritmos GA e EP-C e 120 iterações para os algoritmos SA, STTS, RTS e $\mathrm{HH}$.

Por fim, os resultados de desempenho apresentados na seção 5.1.1 até a seção 5.1.5.3 evidenciam, para diversos tipos de cenários de telecomunicações com pouca ou grande exploração de diversidade, a aplicabilidade das técnicas heurísticas propostas, pois estas resultaram sempre em melhoria significativa da BER. Assim, a seção 5.3 visa quantificar a complexidade computacional das estratégias com uma posterior discussão sobre quais técnicas são factíveis para implementação considerando o poder de processamento dos computadores atuais. 


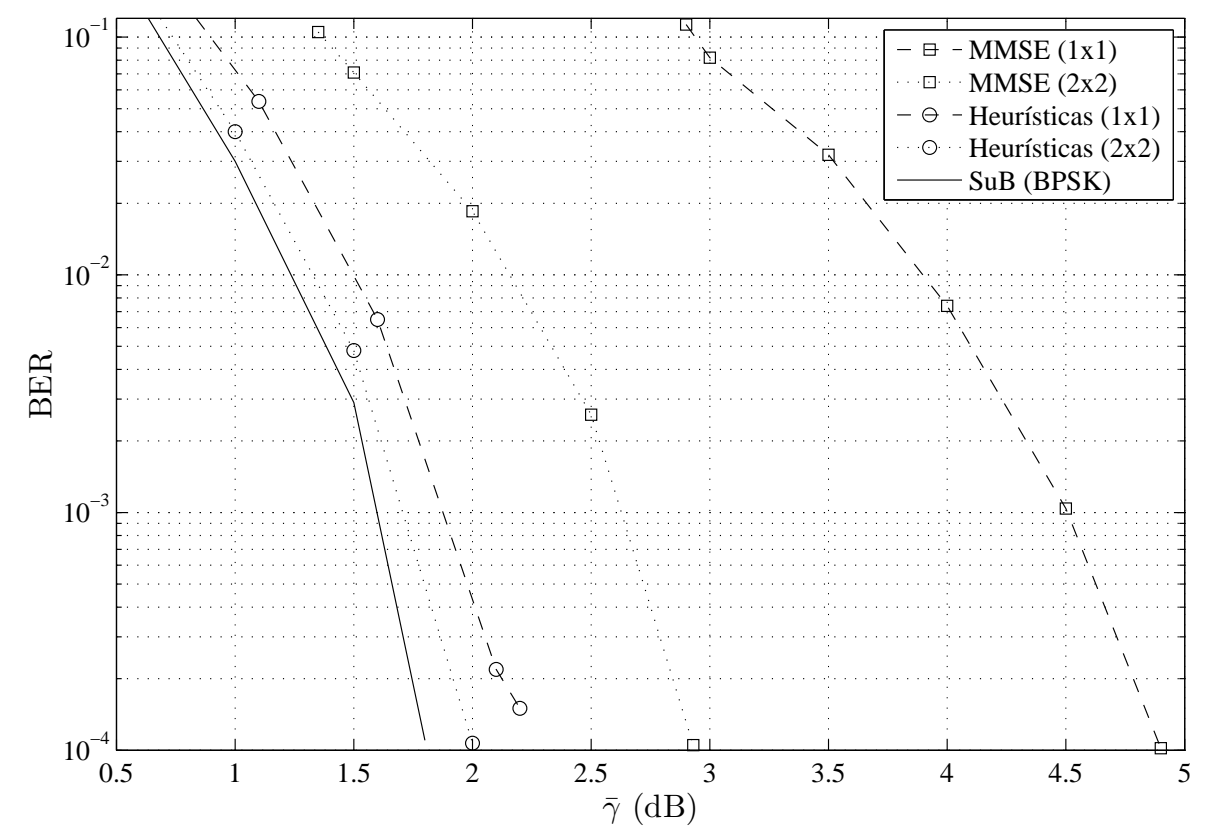

Figura 5.22: Comparação da BER $\times$ relação sinal-ruído para um sistema com codificação de canal do tipo turbo.

\subsubsection{Sistema 3D iterativo}

Esta seção visa expandir a análise de desempenho realizada anteriormente para sistemas com diversidade multidimensional em malha aberta considerando uma estrutura de recepção iterativa. Com isso, existirá realimentação do sinal decodificado em estruturas de múltiplos estágios, visando à realização de iterações na busca de melhoria de desempenho. Assim, a recepção é realizada de forma conjunta e iterativa, onde dois ou mais estágios do receptor trocam informações buscando melhorar o desempenho individual e, consequentemente, em um nível mais geral, a cada nova iteração.

Conforme apresentado no capítulo 2, encontram-se poucos trabalhos que consideram a utilização de otimização multidimensional de forma iterativa ${ }^{10}$, e somente com o trabalho recente de (LU, 2011) foi apresentado a possibilidade de expansão para exploração conjunta e iterativa com mais de 2 dimensões, resultando em uma estrutura (3D) ${ }^{11}$.

Desta forma, a seção 5.1.6.1 considera a topologia apresentada na figura 2.10 baseada no trabalho de (LU, 2011), onde a detecção ocorre primeiramente no domínio S e posteriormente na busca do símbolo ótimo considerando a diversidade

\footnotetext{
${ }^{10}$ Os resultados apresentados indicam similaridade de desempenho em relação às técnicas tradicionais de detecção individuais em malha aberta com diminuição da complexidade.

${ }^{11}$ Exploração conjunta e iterativa da diversidade tempo-frequência-espaço em uma estrutura 1D seguida de uma estrutura 2D, resultando em três possibilidades de arranjos.
} 
temporal e em frequência de forma conjunta (estratégia $S-F T$ ).

\subsubsection{Detecção no domínio S-FT}

Visando a comparação de resultados das topologias baseadas em heurísticas propostas, adotou-se parâmetros próximos ao adotado em (LU, 2011). A tabela 5.10 apresenta os principais parâmetros do sistema e dos coeficientes de canal. Assim, em todas as simulações desta seção considera-se um ganho de processamento $N=9$, um número de subportadoras $M=12$, parâmetros de canal perfeitamente conhecidos no receptor, cada subportadora apresenta desvanecimento plano em frequência, e realização de três iterações $\left(I_{S-F T}=3\right)$ para a estratégia iterativa S-FT.

Vale ressaltar que o objetivo desta seção consiste em apresentar a aplicabilidade das técnicas heurísticas propostas para a detecção mesmo considerando estruturas multidimensionais iterativas, visando diminuir a complexidade de uma topologia SFT conjunta (otimização multiobjetivo ${ }^{12}$ ). Além disso, como a estrutura iterativa considera as dimensões S-FT, optou-se pela não inclusão de diversidade oriunda da codificação de canal, bem como disponibilidade de transmissão em taxas distintas. Assim, evidencia-se o desempenho das técnicas heurísticas em comparação com o detector MMSE descrito em (LU, 2011). No entanto, análises de topologias considerando a estratégia iterativa S-FT e exploração de outros tipos de diversidade mostram-se como promissoras, sendo indicadas na seção 6.1 como trabalhos futuros.

Tabela 5.10: Parâmetros do sistema e do canal.

\begin{tabular}{ll}
\hline Parâmetros & Valores Adotados \\
\hline \# Usuários & $K=40$ e $K=100$ \\
$\#$ Antenas Tx & $A_{T x}=1$ \\
$\#$ Antenas Rx & $A_{R x}=4$ e $A_{R x}=8$ \\
\# iterações S-FT & 3 iterações \\
Sequências & aleatórias, $N=9$ \\
Subportadoras & $M=12$ \\
Modulação & BPSK \\
Max. freq. Doppler & $f_{\mathrm{D}}=20 \mathrm{~Hz}$ (canal lento) \\
\hline
\end{tabular}

A figura 5.23 apresenta o desempenho obtido pelos detectores MMSE e baseados em heurísticas em um cenário S-FT iterativo para $K=40$, figura 5.23.a, e $K=100$ usuários, figura 5.23.b, número de subportadoras $M=12, A_{R x}=4$

\footnotetext{
${ }^{12}$ Topologias multiobjetivo geralmente resultam em funções custo que apresentam uma complexidade computacional muitas vezes superior à soma das complexidades individuais.
} 
antenas de recepção e ganho de processamento $N=9$. Nota-se que o desempenho obtido pelas estratégias baseadas em heurísticas mostra-se muitas vezes superior à estratégia MMSE para os dois valores de carregamento do sistema, aproximando-se do limite de usuário único a medida que o carregamento do sistema diminui.

Para ilustrar o ganho de desempenho de forma numérica, observa-se da figura 5.23.a que o desempenho obtido para $K=40$ usuários, $\bar{\gamma}=10 \mathrm{~dB}$ é de $B E R \approx 2,2 \times 10^{-2}$ considerando detector MMSE enquanto consegue-se uma $B E R \approx 5,9 \times 10^{-4}$ com a utilização de estratégias heurísticas, um incremento de desempenho em termos da BER da ordem de $\approx 1,6$ décadas para as mesmas condições de sistema. Com o aumento do número de usuários, figura 5.23.b, o incremento para a mesma relação sinal-ruído é da ordem de $\approx 1$ década.
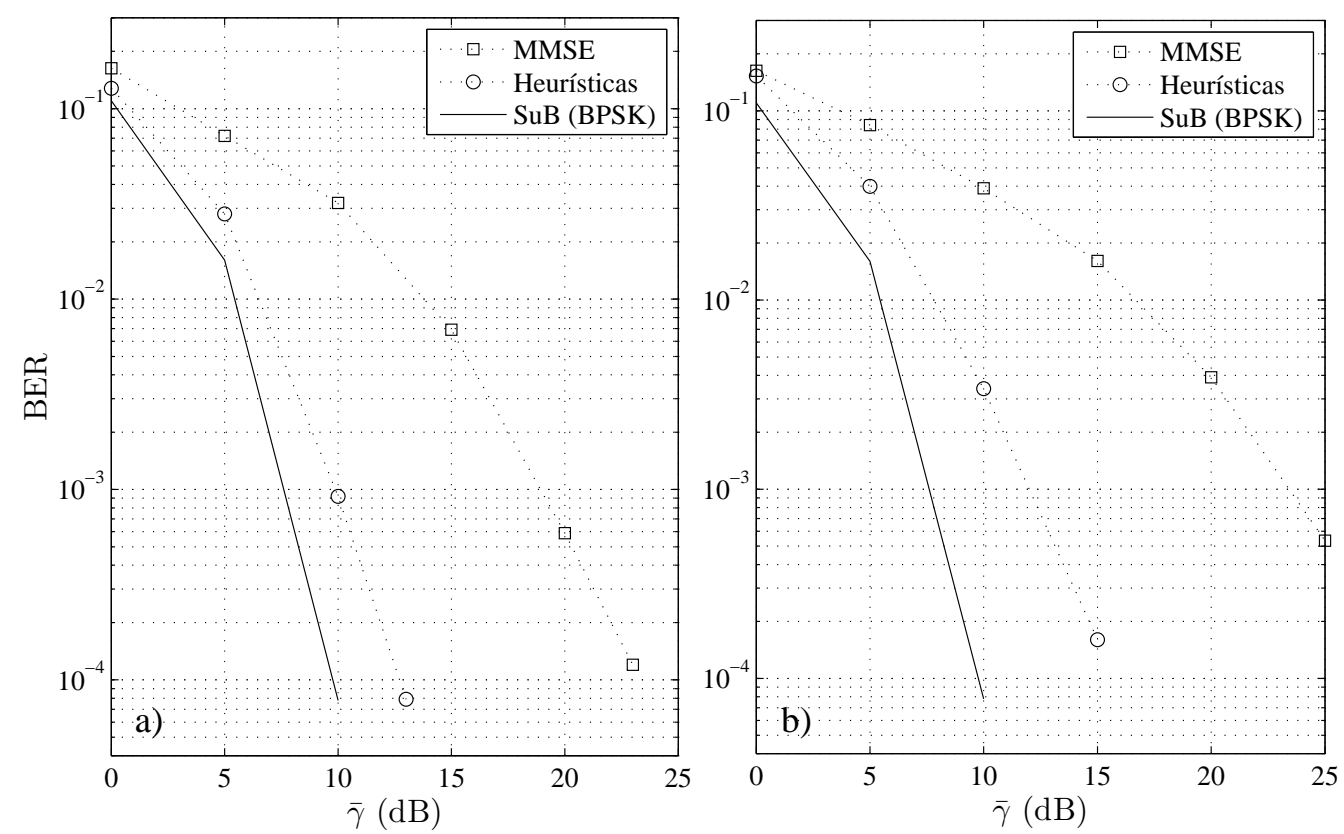

Figura 5.23: Comparação da BER $\times$ relação sinal-ruído para a) $K=40$ usuários e b) $K=100$ usuários; $A_{R x}=4, M=12$ e $N=9$.

A figura 5.24 apresenta o desempenho obtido pelos detectores MMSE e baseados em heurísticas aumentando-se o número de antenas receptoras, sendo adotado $A_{R x}=8$. Novamente, o desempenho das estratégias baseadas em heurísticas mostra-se muitas vezes superior à estratégia MMSE para os dois valores de carregamento do sistema. Assim, evidencia-se a aplicabilidade das técnicas propostas neste trabalho em cenários multidimensionais iterativos.

Visando quantificar esta melhoria, nota-se da figura 5.23.a que o desempenho obtido para $K=40$ usuários, $\bar{\gamma}=10 \mathrm{~dB}$ é de $B E R \approx 3,2 \times 10^{-2}$ considerando detector MMSE enquanto resulta em $B E R \approx 8,9 \times 10^{-4}$ com a utilização de 
estratégias heurísticas. Esta melhoria em termos da BER é da ordem de $\approx 1,5$ décadas para as mesmas condições de sistema. Com o aumento do número de usuários, figura 5.23.b, o incremento para a mesma relação sinal-ruído é da ordem de $\approx 1$ década.
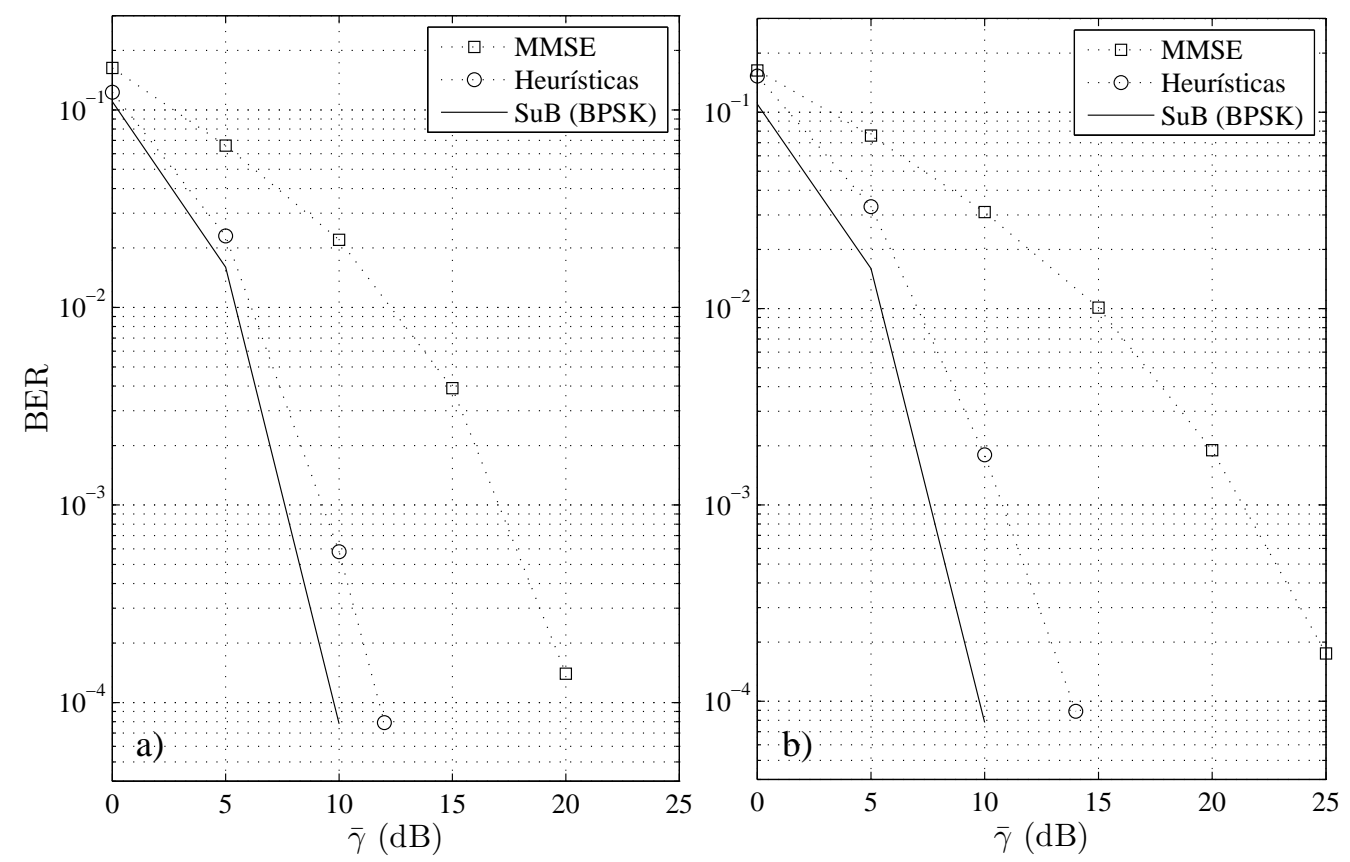

Figura 5.24: Comparação da BER $\times$ relação sinal-ruído para a) $K=40$ usuários e b) $K=100$ usuários; $A_{R x}=8, M=12$ e $N=9$.

Vale dizer que é possível alcançar melhores patamares de desempenho com o aumento do ganho de processamento $(N>9)$, reduzindo a MAI existente e possibilitando aos detectores um melhor desacoplamento dos usuários (baseados na técnica MMSE ou na técnica de máxima verossimilhança). No entanto, o tempo de simulação necessário torna-se excessivo com o aumento do ganho de processamento, dificultando tal análise. Uma forma de análise similar consiste na diminuição do número de usuários, mantendo-se os demais parâmetros adotados. Com isso, foram realizadas simulações incluindo outros valores para o número de usuários $(K=[1,20,60,80])$ resultando em uma análise da BER $\times K$, sendo apresentada na figura 5.25.

A figura 5.25 apresenta o desempenho dos algoritmos heurísticos e do MMSE em função do número de usuários. O aumento no carregamento do sistema provoca uma degradação da BER, mas o desempenho dos heurísticos aponta superioridade significativa em relação ao método MMSE para toda a faixa simulada. Esse desempenho é melhorado para ambos os detectores à medida que o número de antenas e SNR aumenta, aproximando-se rapidamente do limite para usuário único quando o ganho de processamento aumenta ou carregamento diminui. 


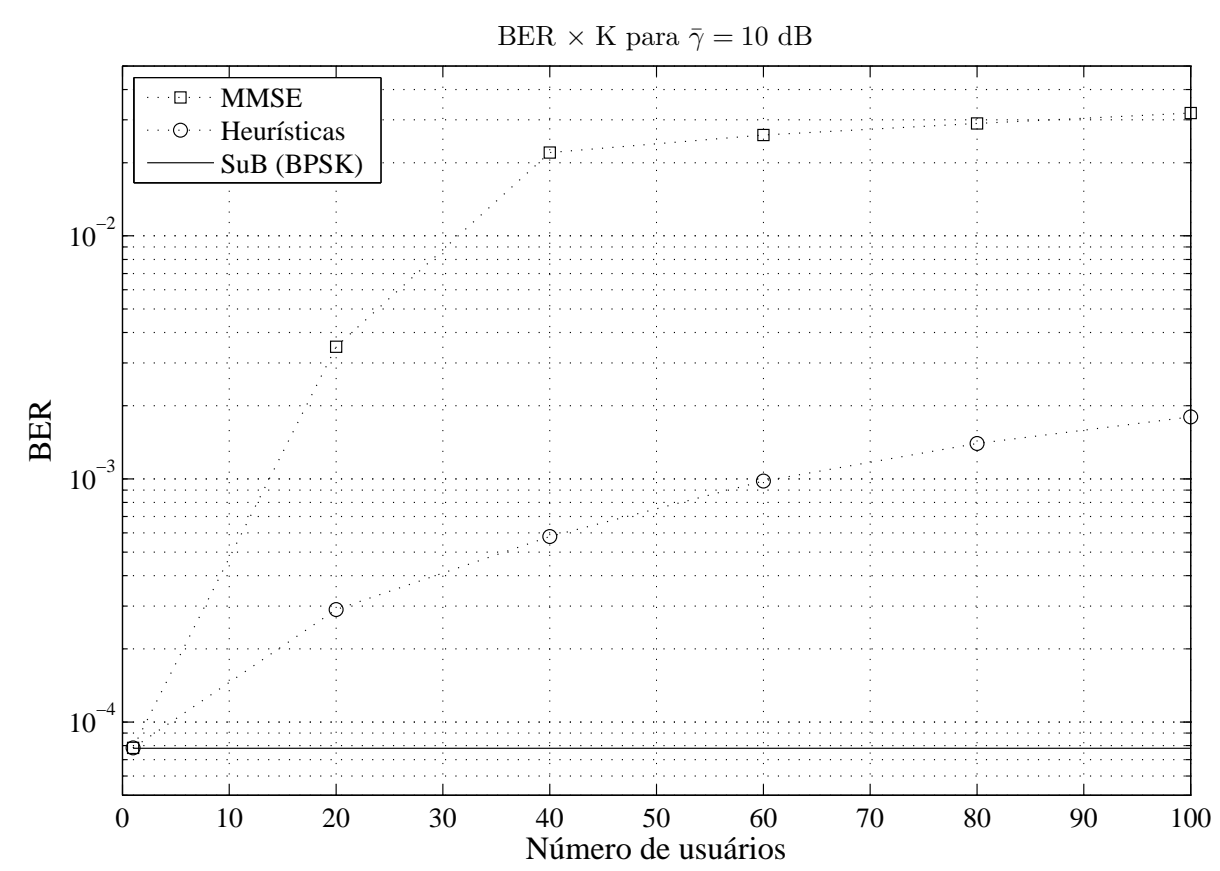

Figura 5.25: Comportamento da BER em relação ao aumento do número de usuários do sistema para $\bar{\gamma}=10 \mathrm{~dB}, A_{R x}=8, M=12$ e $N=9$.

\subsection{Estimativa de Parâmetros para Sistemas Mul- tidimensionais}

Esta seção visa demonstrar a aplicabilidade da técnica baseada nos algoritmos heurísticos, validados no capítulo 4, na busca de estimativas confiáveis (próximas às verdadeiras) para a resposta do canal para que posteriormente estas sejam utilizadas na etapa de detecção utilizando os algoritmos heurísticos aplicados ao problema $\mathrm{MuD}$. Os resultados de simulação indicaram viabilidade das topologias heurísticas em operar de forma conjunta à etapa de detecção via detector multiusuário heurístico. Como resultado, tem-se a detecção final da informação a partir do emprego das estimativas, relativamente precisas, dos coeficientes de canal.

Devido ao tempo computacional exigido nas simulações foram adotados, no contexto desta seção, os seguintes parâmetros para as simulações Monte-Carlo: sequências aleatórias com ganho de processamento $N=16$; número de usuários ativos $K=8 ; E_{b} / N_{0}=10 d B$; canal Rayleigh lento com dois percursos e atrasos uniformemente distribuídos no intervalo $[0 ; N-1] T_{c}$ e perfil de potência uniforme com $\mathbb{E}\left[\beta_{k, 1}^{2}\right]=\mathbb{E}\left[\beta_{k, 2}^{2}\right]=\ldots=\mathbb{E}\left[\beta_{k, D}^{2}\right]=1 / D, \forall k$. Para a mobilidade, considerou-se perfis de velocidades uniformemente distribuídas no intervalo $\left[0 ; v_{\max }\right]$, resultando em uma máxima frequência Doppler de $f_{D}=\frac{v_{\max }}{\lambda_{c}}=17 \mathrm{~Hz}$, para uma frequência da portadora de $f_{c}=\frac{1}{\lambda_{c}}=2 G H z$ e um número de gerações/iterações $=200$ para todos os algoritmos heurísticos. A tabela 5.11 sintetiza 
os principais parâmetros das condições de operação dos sistemas.

Tabela 5.11: Principais parâmetros do sistema para o problema MuChE.

\begin{tabular}{|c|c|c|c|c|c|c|c|c|}
\hline Sistema & $K$ & Sequência & $N$ & $I$ & $L$ & $\bar{\gamma}$ & $f_{c}$ & $f_{D}$ \\
\hline$\overline{\text { S1 }}$ & $\overline{10}$ & Aleatória & 20 & 10 & 2 & $10 \mathrm{~dB}$ & $2 \mathrm{Ghz}$ & $17 \mathrm{~Hz}$ \\
\hline $\mathrm{S} 2$ & 5 & Aleatória & 20 & 10 & 3 & $10 \mathrm{~dB}$ & $2 \mathrm{Ghz}$ & $17 \mathrm{~Hz}$ \\
\hline S3 & 10 & Aleatória & 20 & 10 & $\leq 2$ & $10 \mathrm{~dB}$ & $2 \mathrm{Ghz}$ & $17 \mathrm{~Hz}$ \\
\hline
\end{tabular}

As principais figuras de mérito para a estimativa da resposta do canal (desempenho) foram medidas através do erro quadrático médio normalizado (MSE - Mean Squared Error) e do erro percentual médio (MEP - Mean Error Percentage). Para o $i$-ésimo intervalo de bit, a medida de MSE é definida por:

$$
\zeta_{G A}^{(m)}=\frac{\left\|\hat{\mathbf{z}}_{G A}^{(m)}-\mathbf{z}\right\|^{2}}{\|\mathbf{z}\|^{2}}
$$

onde $\|\cdot\|$ indica operador norma vetorial e $\mathbf{z}$ é definido conforme equação (2.134).

Já o erro percentual médio (MEP) considera a diferença percentual entre o valor verdadeiro do coeficiente e o valor estimado, considerando a fase e módulo separadamente. Com isso, a figura de mérito MEP para o módulo e fase é definida por:

$$
\begin{aligned}
& \left|\xi_{G A}^{(m)}\right|=\frac{\left|\hat{\mathbf{z}}_{G A}^{(m)}\right|-|\mathbf{z}|}{|\mathbf{z}|} \times 100 \quad[\%] \\
& \measuredangle \xi_{G A}^{(m)}=\frac{\measuredangle \hat{\mathbf{z}}_{G A}^{(m)}-\measuredangle \mathbf{z}}{\measuredangle \mathbf{z}} \times 100 \quad[\%]
\end{aligned}
$$

Inicialmente, visando comparar as estratégias heurísticas com outros estimadores (GD e ML), considerou-se apenas a figura de mérito MSE, pois os trabalhos encontrados na literatura consideram essa medida de desempenho para análise. No entanto, a medida de erro quadrático médio apresenta apenas o efeito conjunto de erros no módulo e fase dos coeficientes, não indicando a precisão das estimativas separadamente. Vale ressaltar que os receptores multiusuário mostram-se mais sensíveis a erros na fase dos coeficientes do que no módulo (CIRIACO; ABRÃO; JESZENSKY, 2005a; CIRIACO, 2006). Portanto, utilizar apenas a medida de MSE para quantificar a precisão (acurácia) do estimador que será utilizado à entrada dos detectores baseados em heurísticas demonstra imprecisão, pois não é possível analisar os erros na fase e módulo separadamente. Com isso, em uma segunda etapa de análise, considerou-se a figura de mérito MEP na avaliação de desempenho, pois com esse resultado (valores de erro percentual no módulo e fase) é possível quantificar de forma mais precisa o desempenho dos detectores heurísti- 
cos através de simulação.

Portanto, a análise inicial (figuras 5.26 e 5.27), considera apenas o valor de MSE, pois essa análise visa comparar a eficiência dos métodos de estimação baseada em heurísticas em relação aos métodos tradicionais ML e GD.

A figura 5.26 apresenta o MSE (sobre 30 simulações) em relação ao tamanho da janela de processamento $I$, considerando os estimadores ML, o baseado no gradiente com $\mu=0,002$ de (BHASHYAM; AAZHANG, 2002) e o estimador baseado em heurísticas com codificação tipo ${ }^{13}$, considerando canais com desvanecimento multipercurso variantes no tempo $\left(f_{D}=17 \mathrm{~Hz}\right)$. Resultados prévios de simulação indicaram que todos os algoritmos heurísticos indicados no capítulo $2^{14}$ apresentaram mesmo desempenho em termos da MSE após convergência. No entanto, conforme apresentado adiante, existe um pequena diferença de desempenho entre as técnicas utilizando-se a figura de mérito MPE, além do número de gerações/iterações que os algoritmos necessitam para alcançar tais patamares.

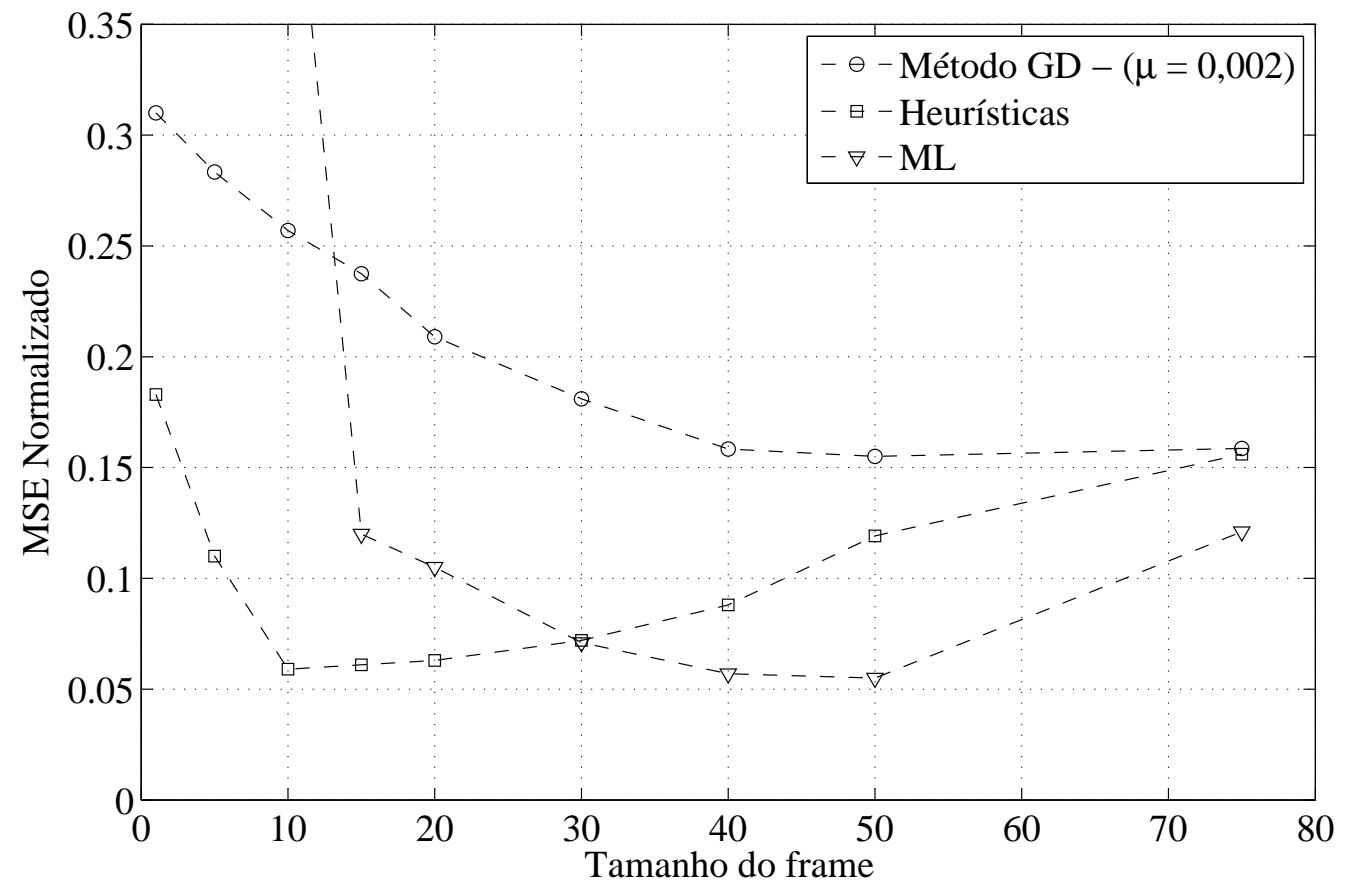

Figura 5.26: Evolução do MSE normalizado para $K=10$ usuários com 2 percursos em função do tamanho do frame $I$.

Os resultados de simulação mostraram que o estimador ML e o estimador baseado em heurísticas atingem o mesmo desempenho em termos do MSE normalizado, encontrando o valor de $\bar{\zeta}_{\text {Heur }} \approx \bar{\zeta}_{M L} \approx 0,055$, para $10<I_{\text {Heur. }}<20 \mathrm{e}$ $40<I_{M L}<50$, respectivamente, enquanto que o estimador GD atingiu um MSE

\footnotetext{
${ }^{13} \mathrm{~A}$ análise para as demais estratégias de codificação é realizada posteriormente.

${ }^{14}$ Algoritmos GA, EP-C, STTS, RTS e HH.
} 
normalizado de $\approx 3 \times \bar{\zeta}_{\text {Heur. }}$, para $50<I_{G D}<60$. Nota-se que para tamanho de preâmbulos realistas espera-se um valor de MSE normalizado $\bar{\zeta} \leq 0,1$ (10\%). O estimador baseado em heurísticas conseguiu atingir esse desempenho com a utilização de um preâmbulo de apenas $I=10$ bits, reduzindo a complexidade computacional e possibilitando a utilização de poucos bits de treinamento.

A figura 5.27 ilustra uma evolução típica do MSE normalizado, $\zeta^{(m)}$, considerando 20 percursos ( $K=10$ usuários e $L=2$ percursos lentamente variáveis, $f_{D}=17 \mathrm{~Hz}$ ) ao longo de $G_{t}=200$ gerações de otimização do $\mathrm{GA}^{15}$. Nota-se que para a estimativa dos coeficientes para o primeiro período de bit $T$, $\zeta_{G A}^{(1)}$, não existem estimativas prévias, sendo necessário um número maior de gerações para a obtenção de um $\zeta_{G A}^{(1)}$ aceitável.

Após as 10 primeiras estimativas, o MSE normalizado tende a um valor médio, neste caso, $\left|\zeta_{G A}^{(m)}\right|=0,08$. Logicamente, outros valores ainda menores para o MSE normalizado podem ser obtidos. Essa afirmação pode ser verificada através da curva $\zeta_{G A}^{(197)}$.

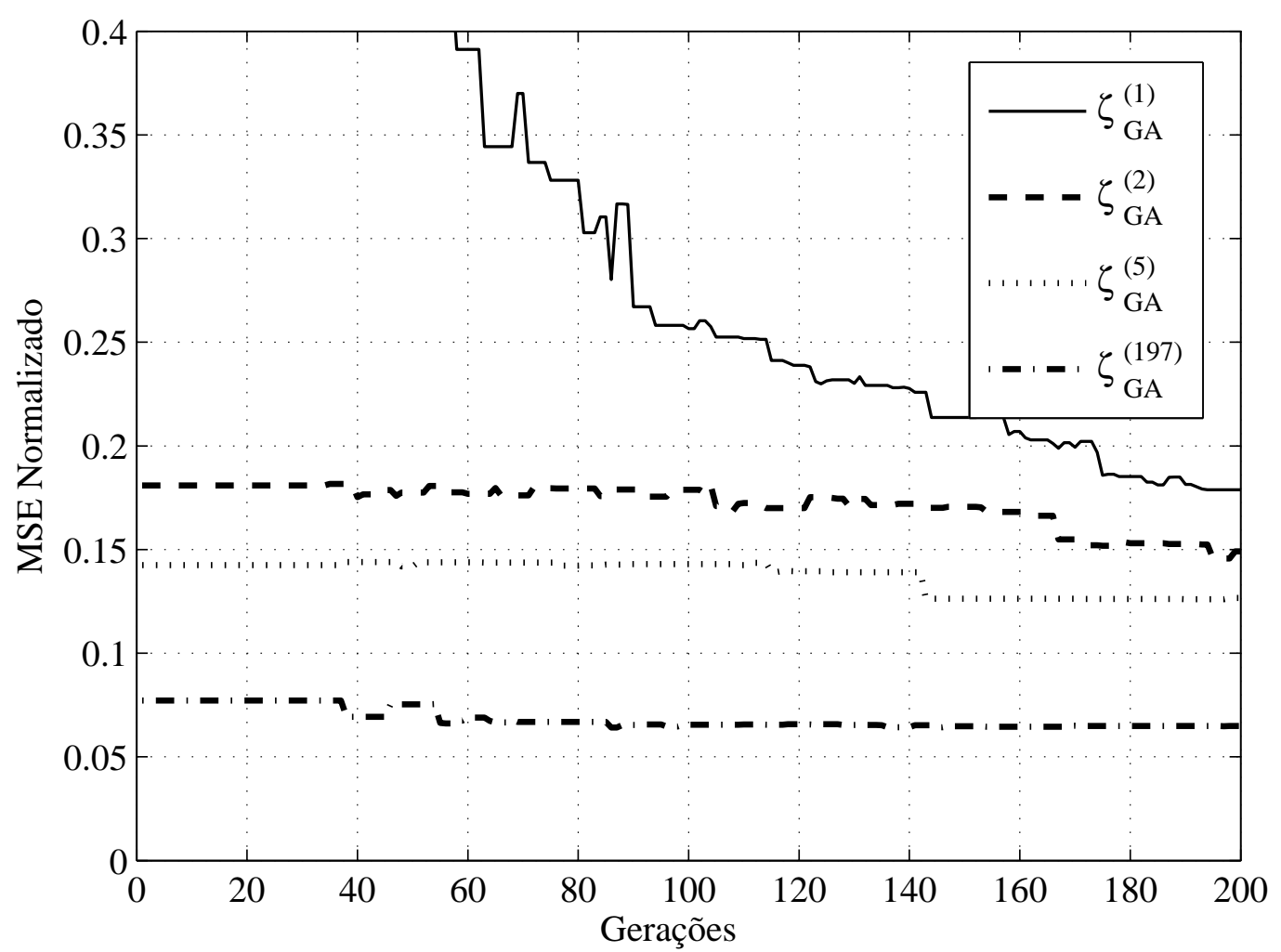

Figura 5.27: Evolução típica do MSE normalizado, considerando $K=8$ usuários em função do número de gerações $G_{T}$; são apresentados o MSE normalizado para os coeficientes iniciais e para um coeficiente intermediário (197), de um grupo de 670 estimativas.

\footnotetext{
${ }^{15}$ Apenas para ilustrar uma convergência típica, podendo-se verificar similaridade para os demais algoritmos heurísticos considerados neste trabalho.
} 
Na figura 5.28 e figura 5.29 é apresentado a acurácia das estimativas para os coeficientes de canal típicos para quatro usuários via algoritmos heurísticos, considerando $\bar{\gamma}=10 d B$ e $f_{D}=17 \mathrm{~Hz}$. A estimativa dos coeficientes foi realizada por um período de 670 bits. O tamanho do frame utilizado foi $I=10$ bits e assumiram-se conhecidos os bits de informação ao longo dessa janela de processamento. Pode-se verificar que as estratégias heurísticas com codificação tipo I são capazes de estimar de forma relativamente precisa as variações dos coeficientes de canal. As observações das estimativas para os outros percursos dos demais usuários também demonstraram a mesma acurácia e capacidade no acompanhamento nas variações de canal multipercurso Rayleigh lento.

Após análise do desempenho em termos do MSE, considerou-se a figura de mérito MEP, visando quantificar o valor de erro percentual médio para a fase e módulo dos coeficientes separadamente.

Para facilitar a compreensão, optou-se por apresentar a figura 5.30 que permite a comparação das três codificações propostas na seção 3.1.2 através da função densidade de probabilidade do erro médio percentual (MEP) para o estimador baseado no GA sob condição de operação de sistema S1. Observa-se que a codificação tipo I resulta em melhor desempenho, pois atinge menores valores de MEP para as estimativas do módulo e fase dos coeficientes. Além disso, resultou em um menor desvio padrão quando comparado às codificações do tipo II e III. Por fim, os valores para a média e desvio padrão do erro percentual médio do módulo e da fase simulados para o GA e demais algoritmos heurísticos podem ser visualizados na tabela 5.12 .

Vale ressaltar que foram realizadas médias em 100 simulações para cada algoritmo e tipo de codificação considerando um período de 670 bits por simulação e tamanho do frame de $I=10$ bits.

Com isso, adotou-se a codificação tipo I para as demais figuras de desempenho, pois esta resulta em menores valores de MEP para o módulo e fase dos coeficientes.

A tabela 5.13 apresenta o MEP para os sistemas $\mathbf{S 1}$ e $\mathbf{S 2}$, visando analisar a diminuição ou não do MEP quando há uma maior diversidade de percursos (de $L=2$ em $\mathbf{S} 1$ para $L=3$, em $\mathbf{S} 2$ ). Nota-se que o resultado encontrado apresenta um menor valor para o erro médio percentual quando comparado ao sistema S1 para todos os algoritmos heurísticos, indicando uma melhoria na acurácia do estimador na condição de incremento da diversidade multipercurso. Além disso, percebe-se que há uma diminuição do desvio padrão do erro, realçando 

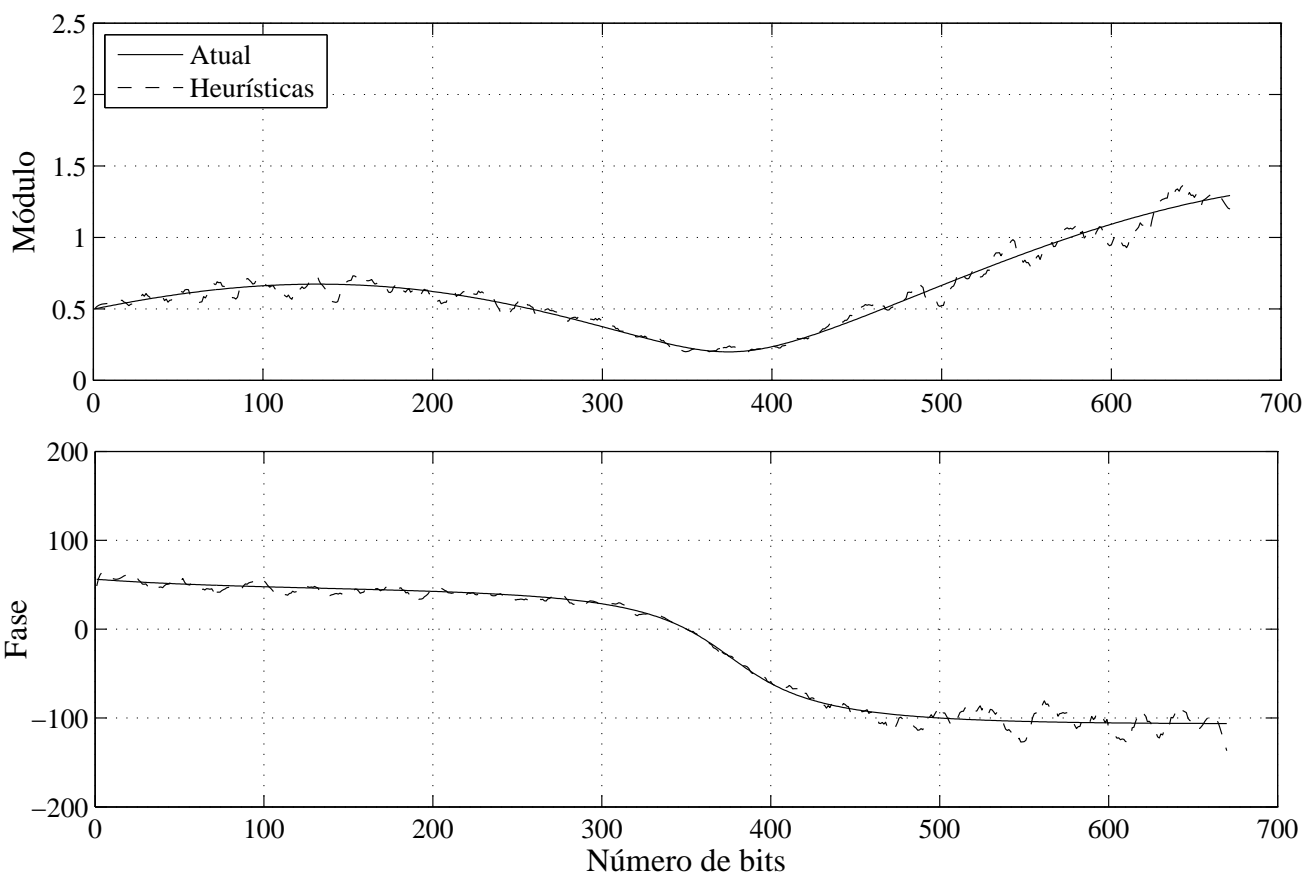

(a)
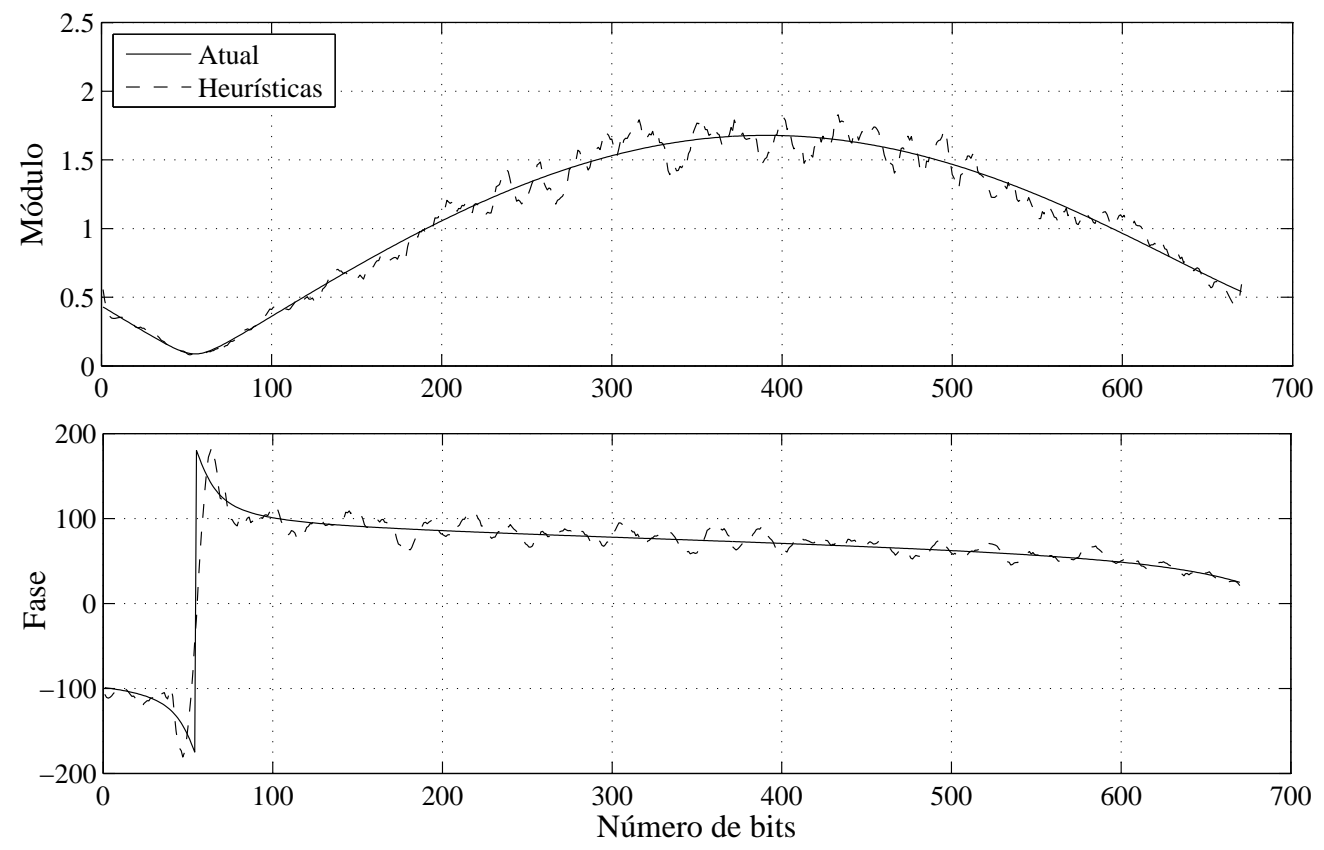

(b)

Figura 5.28: Acurácia das estimativas de canal (módulo e fase) sobre os 670 bits para quatro usuários distintos; sistema com $K=10$ usuários, $L=2$ percursos, espalhamento Doppler $f_{D}=17 \mathrm{~Hz}, N F R=0 \mathrm{~dB}$ e tamanho do preâmbulo $I=10$ bits. (a) usuário 1 , percurso 1 e (b) usuário 3, percurso 1 . 

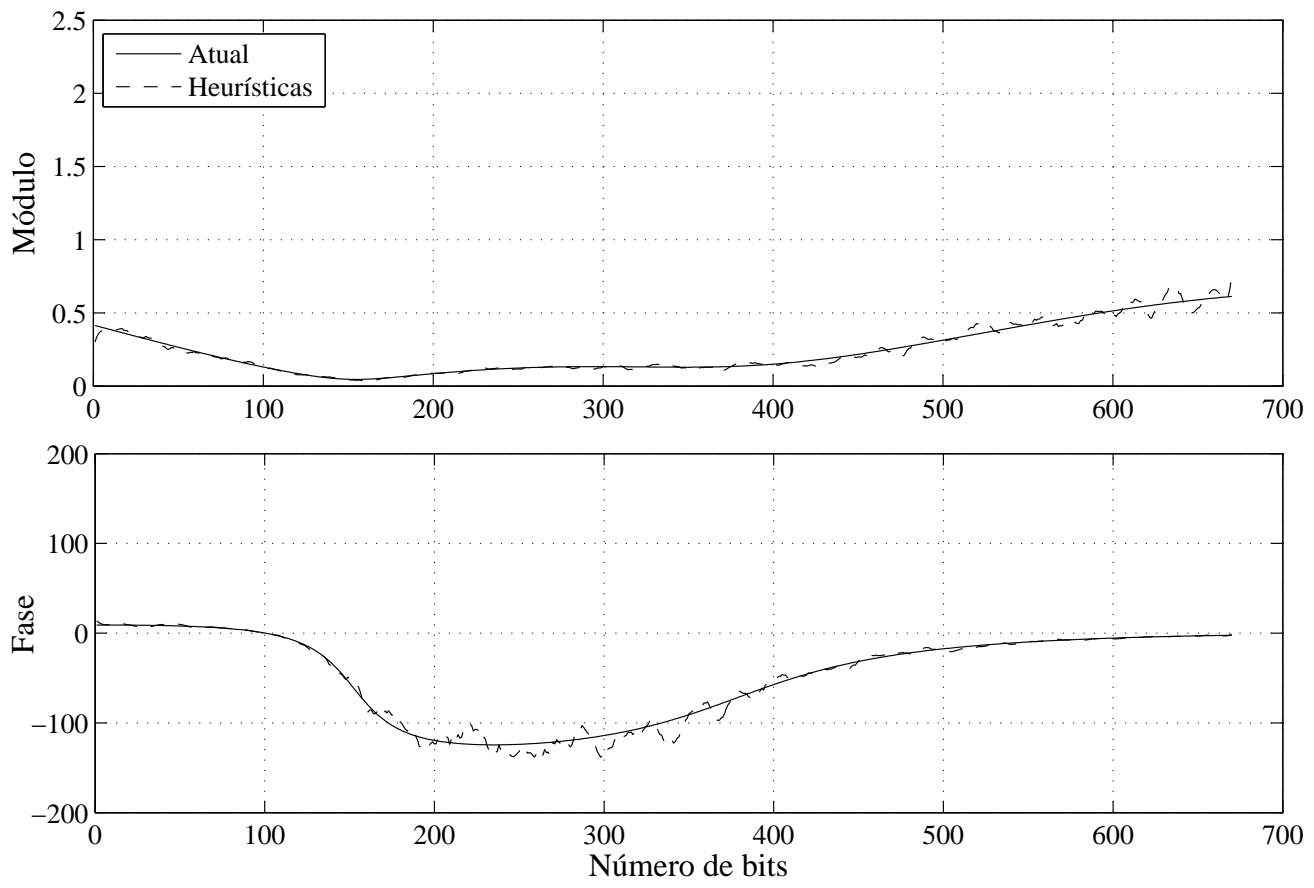

(a)
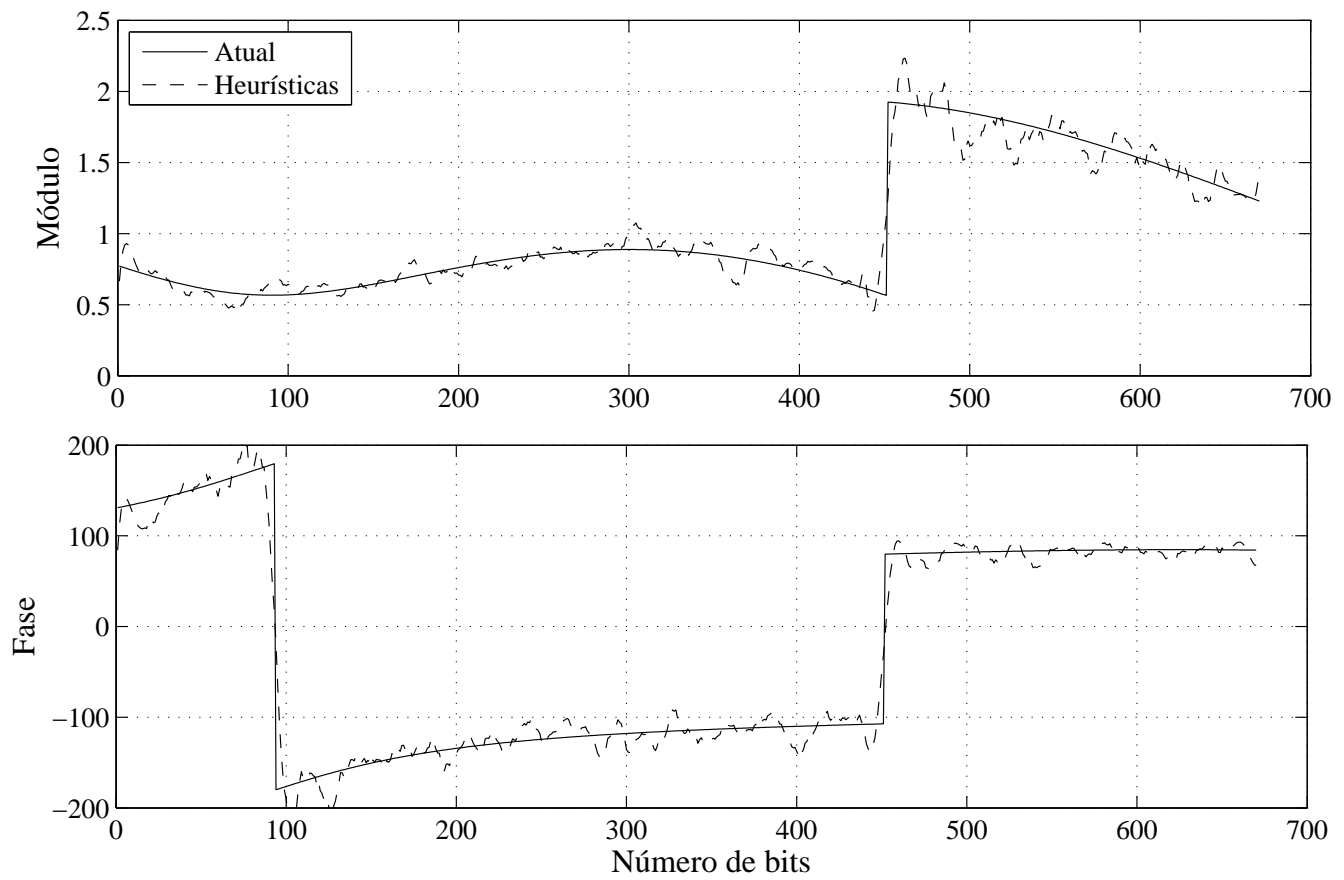

(b)

Figura 5.29: Acurácia das estimativas de canal (módulo e fase) sobre os 670 bits para quatro usuários distintos; sistema com $K=10$ usuários, $L=2$ percursos, espalhamento Doppler $f_{D}=17 \mathrm{~Hz}, N F R=0 \mathrm{~dB}$ e tamanho do preâmbulo $I=10$ bits. (a) usuário 7, percurso 2 e (b) usuário 10, percurso 2 . 


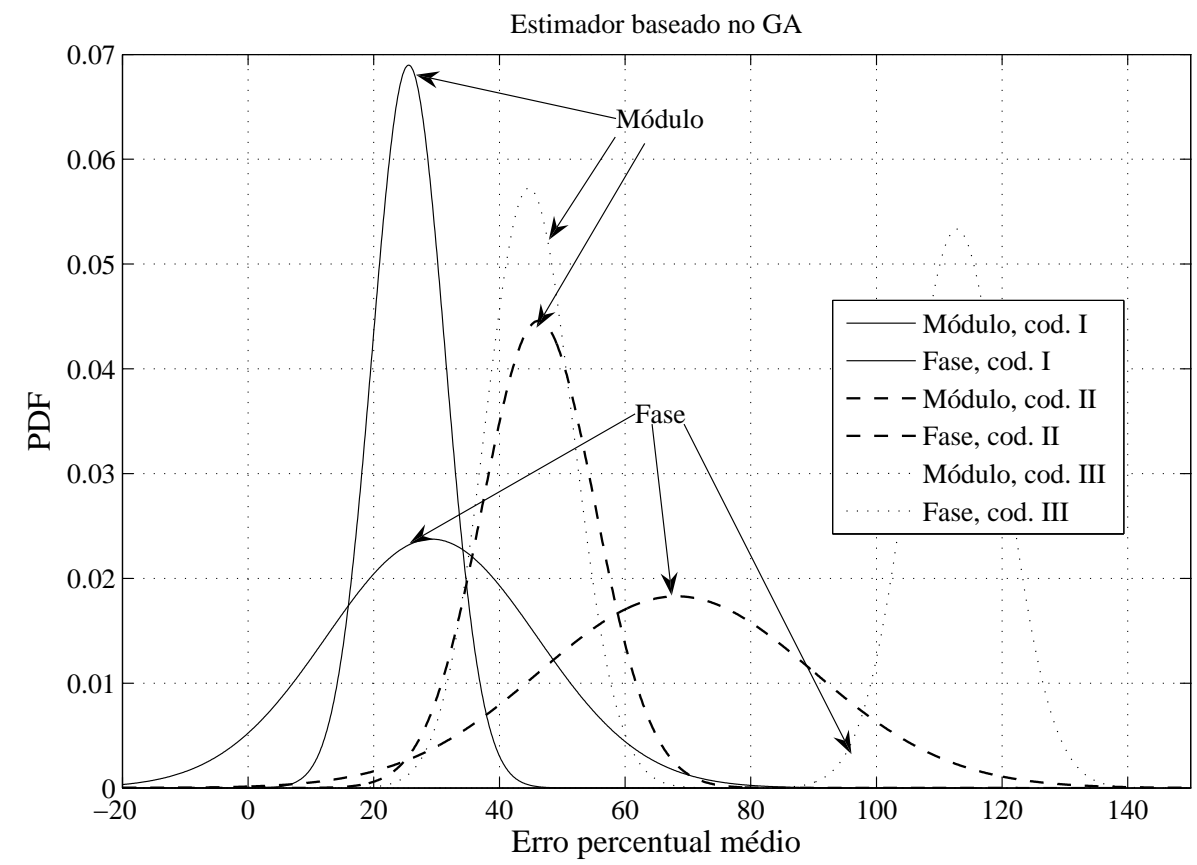

Figura 5.30: PDF do erro percentual médio (MEP) para as três codificações tipo I, II e III, considerando sistema S1.

a melhoria da precisão do estimador. Assim, os valores para a média e desvio padrão das estimativas do módulo e fase podem ser visualizados na tabela 5.13. No entanto, deve-se ressaltar que a complexidade dos algoritmos heurísticos cresce com o aumento da diversidade devido ao número de operações para o cômputo da função custo ${ }^{16}$, devendo ser considerado na etapa de implementação do sistema.

Observa-se da tabela 5.13 que os algoritmos apresentam desempenhos próximos, com vantagem para a estratégia $\mathrm{HH}$, pois esta contempla um maior número de estratégias para escape de mínimos locais ao mesmo tempo em que agrega técnicas de intensificação devido ao uso dos diversos algoritmos heurísticos indicados.

Nota-se que para o sistema S3, o desempenho para todos os algoritmos não mostra-se satisfatório. Por isso, a figura 5.31 apresenta a perda de precisão (acurácia) das estimativas para o estimador baseado no GA quando há possibilidade de existirem percursos não resolvíveis ${ }^{17}$, pois a estratégia de estimação considera que é possível estimar apenas um percurso para cada posição do vetor $\mathbf{z}_{k}$, descrito na equação (2.133). Assim, quando ocorrer sobreposição de percursos, o desempenho do estimador é degradado consideravelmente ${ }^{18}$. Essa perda é claramente

\footnotetext{
${ }^{16}$ Esse crescimento da complexidade com o aumento da diversidade de percursos é quantificada na seção 5.3 .

${ }^{17}$ Apresentam mesmo atraso, não sendo possível separá-los.

${ }^{18}$ Esta característica também foi observada para os demais algoritmos, conforme apresentado na tabela 5.13 .
} 
Tabela 5.12: Valores de MEP obtidos para cada codificação e algoritmo.

\begin{tabular}{|c|c|c|c|c|c|}
\hline Algoritmo & Codificação & $\operatorname{MEP} \mid \xi^{(m)}$ & $\sigma_{\left|\xi^{(m)}\right|}$ & MEP $\measuredangle \xi^{(m)}$ & $\sigma_{\measuredangle \xi^{(m)}}$ \\
\hline \multirow{3}{*}{ GA } & Tipo I & $24,35 \%$ & 5,31 & $25,11 \%$ & 7,54 \\
\hline & Tipo II & $43,11 \%$ & 7,47 & $59,73 \%$ & 19,63 \\
\hline & Tipo III & $42,24 \%$ & 6,71 & $106,43 \%$ & 7,14 \\
\hline \multirow{3}{*}{$\mathrm{EP}-\mathrm{C}$} & Tipo I & $24,41 \%$ & 5,46 & $26,37 \%$ & 14,49 \\
\hline & Tipo II & $42,35 \%$ & 8,13 & $63,74 \%$ & 20,92 \\
\hline & Tipo III & $44,27 \%$ & 6,11 & $108,63 \%$ & 7,32 \\
\hline \multirow{3}{*}{$\mathrm{SA}$} & Tipo I & $23,76 \%$ & 5,37 & $25,32 \%$ & 8,13 \\
\hline & Tipo II & $41,42 \%$ & 7,24 & $62,51 \%$ & 19,18 \\
\hline & Tipo III & $43,53 \%$ & 5,74 & $102,17 \%$ & 6,68 \\
\hline \multirow{3}{*}{ STTS } & Tipo I & $24,01 \%$ & 5,86 & $24,98 \%$ & 9,16 \\
\hline & Tipo II & $44,76 \%$ & 9,07 & $61,37 \%$ & 17,41 \\
\hline & Tipo III & $44,13 \%$ & 7,13 & $108,65 \%$ & 8,89 \\
\hline \multirow{3}{*}{ RTS } & Tipo I & $23,55 \%$ & 5,78 & $29,21 \%$ & 16,78 \\
\hline & Tipo II & $45,38 \%$ & 8,94 & $68,18 \%$ & 21,81 \\
\hline & Tipo III & $45,28 \%$ & 6,61 & $107,35 \%$ & 7,07 \\
\hline \multirow{3}{*}{$\mathrm{HH}$} & Tipo I & $22,36 \%$ & 4,17 & $23,62 \%$ & 6,96 \\
\hline & Tipo II & $41,34 \%$ & 6,83 & $51,17 \%$ & 11,91 \\
\hline & Tipo III & $40,73 \%$ & 5,77 & $97,34 \%$ & 6,10 \\
\hline
\end{tabular}

observada através das PDF's para o módulo e fase para o sistema S3. Neste caso, nas simulações, considerou-se a sobreposição temporal entre multipercursos de diferentes usuários como também a auto sobreposição de multipercursos. Vale ressaltar novamente que se forem garantidas as condições de não sobreposição temporal, como também aumento da imunidade à interferência de múltiplo acesso $^{19}$ a acurácia dos estimadores baseados em heurísticas é garantida.

Para finalizar a análise dos estimadores, optou-se pela comparação de acurácia dos estimadores baseados no $\mathrm{GA}^{20}$ e na técnica ML através da função densidade de probabilidade do erro médio percentual em sistema S1. Observa-se que a estratégia baseada no GA resulta em melhor desempenho em relação ao estimador ML, pois atinge menores valores de MEP para as estimativas do módulo e fase dos coeficientes. Este resultado é completamente justificável quando se observa a figura 5.32 e tabela 5.13, pois percebe-se que o estimador ML atinge patamares de MSE aceitáveis apenas na condição de grandes preâmbulos (na faixa de 50 bits). Além disso, o estimador GA resultou em um menor desvio padrão quando comparado ao estimador ML. Os valores para a média e desvio padrão do erro médio percentual, para módulo e fase simulados podem ser visualizados na tabela 5.14.

Neste momento, torna-se importante ressaltar que as técnicas utilizadas atu-

\footnotetext{
${ }^{19}$ Pela utilização de sequências determinísticas, pelo aumento do ganho de processamento, pelo aumento da resolução do estimador em submúltiplos de $T_{c}$, ou uma combinação destes.

${ }^{20}$ Pode-se realizar a mesma análise para os demais algoritmos heurísticos utilizados, conforme apresentado na tabela 5.13.
} 


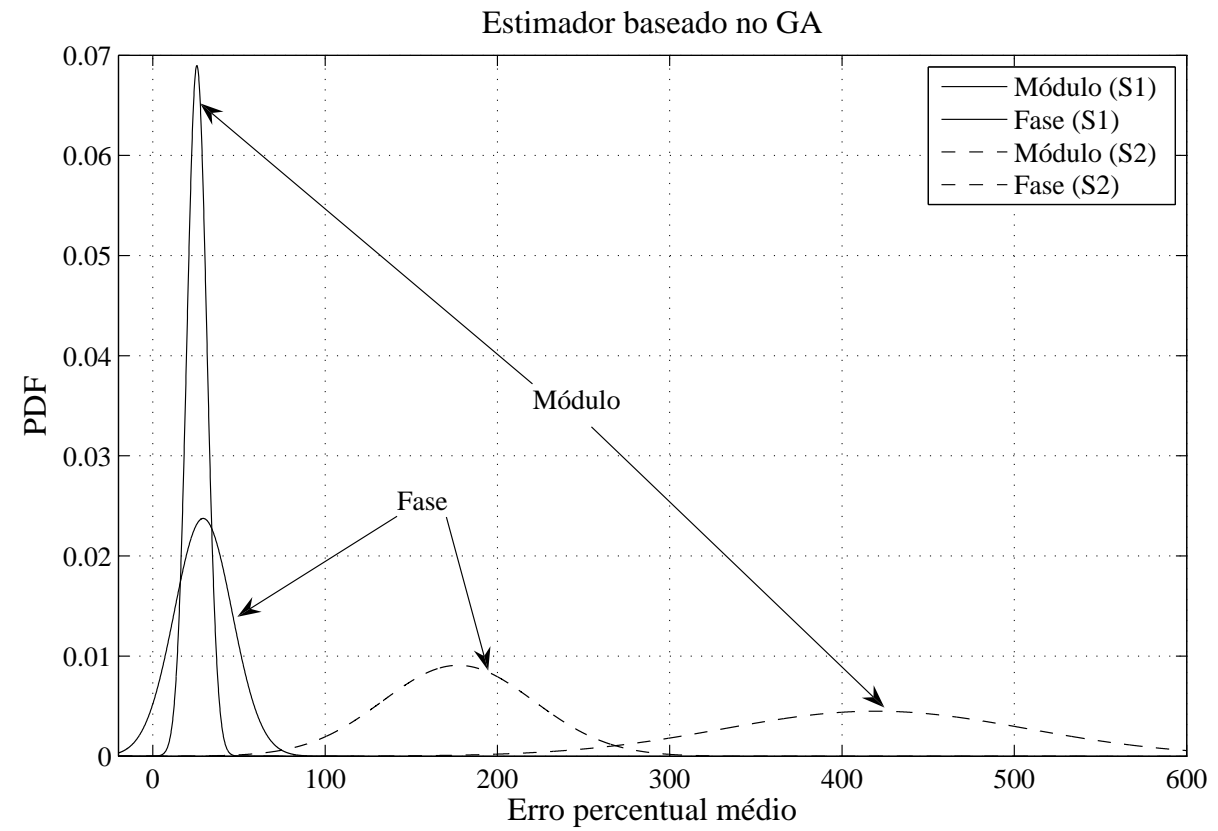

Figura 5.31: PDF do erro percentual médio (MEP) para os sistemas S1 e S3 e estimador GA, considerando a possibilidade de percursos não resolvíveis no receptor.

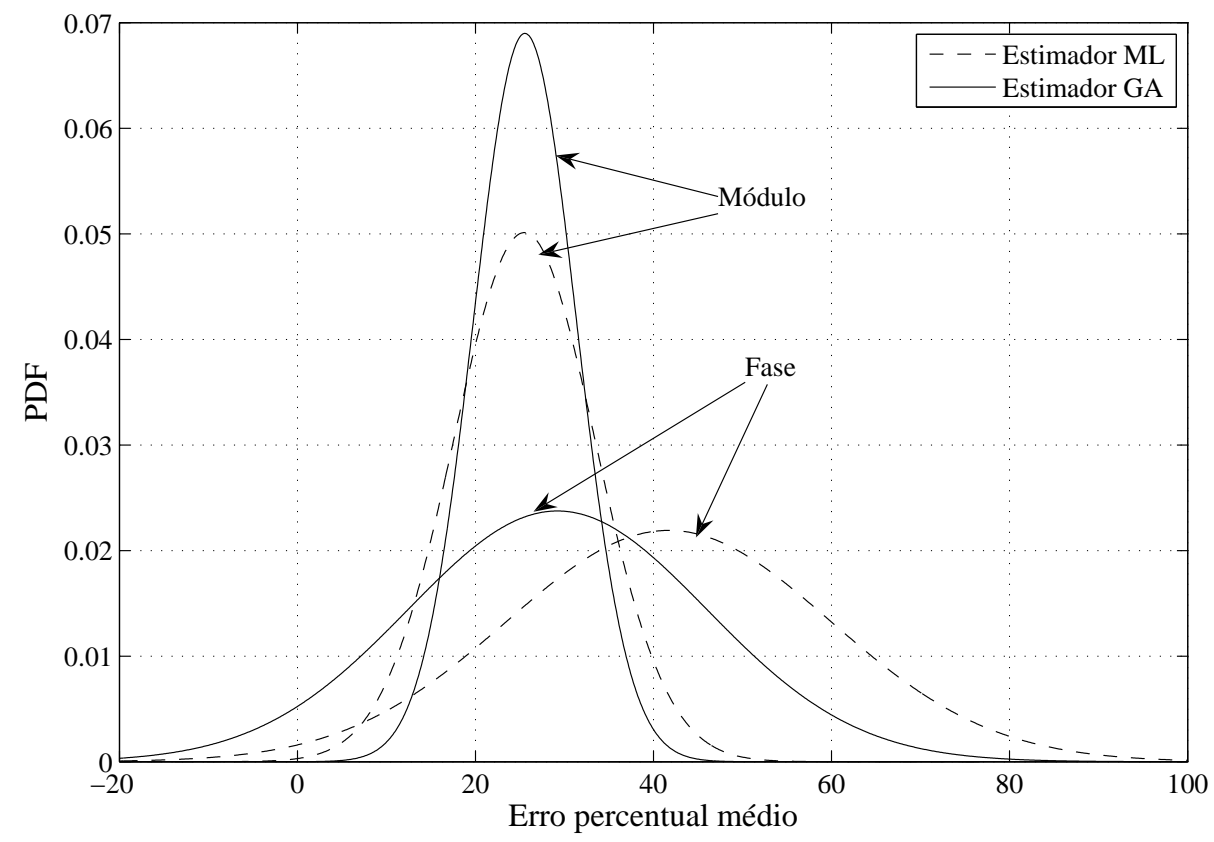

Figura 5.32: Comparação entre as PDF's do erro percentual médio (MEP) para os estimadores GA e ML, considerando sistema $\mathbf{S 1 .}$ 
Tabela 5.13: Valores de MEP obtidos para cada sistema com codificação Tipo I.

\begin{tabular}{|c|c|c|c|c|c|}
\hline Algoritmo & Sistema & $\mathrm{MEP} \mid \xi^{(m)}$ & $\sigma_{\xi^{(m)}}$ & $\mathrm{MEP} \measuredangle \xi^{(m)}$ & $\sigma_{\measuredangle \xi^{(m)}}$ \\
\hline \multirow{3}{*}{ GA } & S1 & $24,35 \%$ & 5,31 & $25,11 \%$ & 7,54 \\
\hline & $\mathrm{S} 2$ & $22,33 \%$ & 3,93 & $21,64 \%$ & 5,99 \\
\hline & S3 & $407,11 \%$ & 80,32 & $165,41 \%$ & 40,97 \\
\hline \multirow{3}{*}{ EP-C } & S1 & $24,41 \%$ & 5,46 & $26,37 \%$ & 14,49 \\
\hline & $\mathrm{S} 2$ & $22,68 \%$ & 4,04 & $22,03 \%$ & 6,87 \\
\hline & S3 & $411,25 \%$ & 82,91 & $167,63 \%$ & 38,24 \\
\hline \multirow{3}{*}{ SA } & S1 & $23,76 \%$ & 5,37 & $25,32 \%$ & 8,13 \\
\hline & S2 & $23,02 \%$ & 3,61 & $20,46 \%$ & 6,04 \\
\hline & S3 & $413,37 \%$ & 85,46 & $139,52 \%$ & 36,27 \\
\hline \multirow{3}{*}{ STTS } & S1 & $24,01 \%$ & 5,86 & $24,98 \%$ & 9,16 \\
\hline & $\mathrm{S} 2$ & $23,13 \%$ & 3,47 & $22,18 \%$ & 6,45 \\
\hline & S3 & $416,55 \%$ & 86,74 & $173,92 \%$ & 39,68 \\
\hline \multirow{3}{*}{ RTS } & S1 & $23,55 \%$ & 5,78 & $29,21 \%$ & 16,78 \\
\hline & $\mathrm{S} 2$ & $22,77 \%$ & 3,88 & $22,35 \%$ & 6,38 \\
\hline & S3 & $415,98 \%$ & 83,22 & $186,12 \%$ & 41,49 \\
\hline \multirow{3}{*}{$\mathrm{HH}$} & S1 & $22,36 \%$ & 4,17 & $23,62 \%$ & 6,96 \\
\hline & $\mathrm{S} 2$ & $20,52 \%$ & 2,34 & $18,86 \%$ & 4,67 \\
\hline & S3 & $402,24 \%$ & 52,41 & $105,76 \%$ & 31,13 \\
\hline
\end{tabular}

Tabela 5.14: Comparação do MEP para o estimador ML e GA em sistema S1.

\begin{tabular}{|c|c|c|c|c|}
\hline Estimador & $\operatorname{MEP}\left|\xi^{(m)}\right|$ & $\sigma_{\xi^{(m)}}$ & MEP $\measuredangle \xi^{(m)}$ & $\sigma_{\measuredangle \xi^{(m)}}$ \\
\hline $\mathrm{GA}$ & $24,35 \%$ & 5,31 & $25,11 \%$ & 7,54 \\
\hline ML & $25,49 \%$ & 7,96 & $41,70 \%$ & 18,21 \\
\hline
\end{tabular}

almente na etapa de aquisição são capazes de estimar os atrasos dos percursos com um erro menor ou igual a $1 T_{c}$. Com isso, as simulações realizadas para os estimadores consideraram esse erro na etapa de aquisição. No entanto, para todos os testes realizados as estratégias heurísticas foram capazes de realizar a etapa de tracking de forma precisa, encontrando os atrasos para todos os percursos. Nota-se que, neste trabalho, foram adotados somente atrasos múltiplos inteiros de $T_{c}$ para a obtenção das estimativas. Portanto, em casos práticos, a etapa de tracking realizada pelos heurísticos deve ser feita em submúltiplos de $T_{c}$, para tornar possível a obtenção precisa do atraso na condição de $\tau_{k, \ell}<T_{c}$. Além disso, observa-se que as amplitudes recebidas dos usuários são estimadas juntamente com o coeficiente de canal correspondente, ou seja, $z_{k, \ell}=A_{k}^{\prime} c_{k, \ell}$, como apresentado na equação (2.134).

Visando apresentar o desempenho de uma topologia conjunta de deteç̧ão e estimação dos parâmetros de canal, considerou-se o sistema S1 e os algoritmos GA e HH, pois representam uma estratégia de desempenho médio e de melhor desempenho, respectivamente. Nota-se, na figura 5.33, que o desempenho al- 
cançado pelas estratégias conjuntas baseadas no GA e no HH são superiores ao desempenho do receptor Rake mesmo na condição de estimativa perfeita, evidenciando o enorme ganho de desempenho das estruturas propostas. Além disso, observa-se que se melhores estimativas de coeficientes puderem ser realizadas ${ }^{21}$, o desempenho em termos da BER também será incrementado.

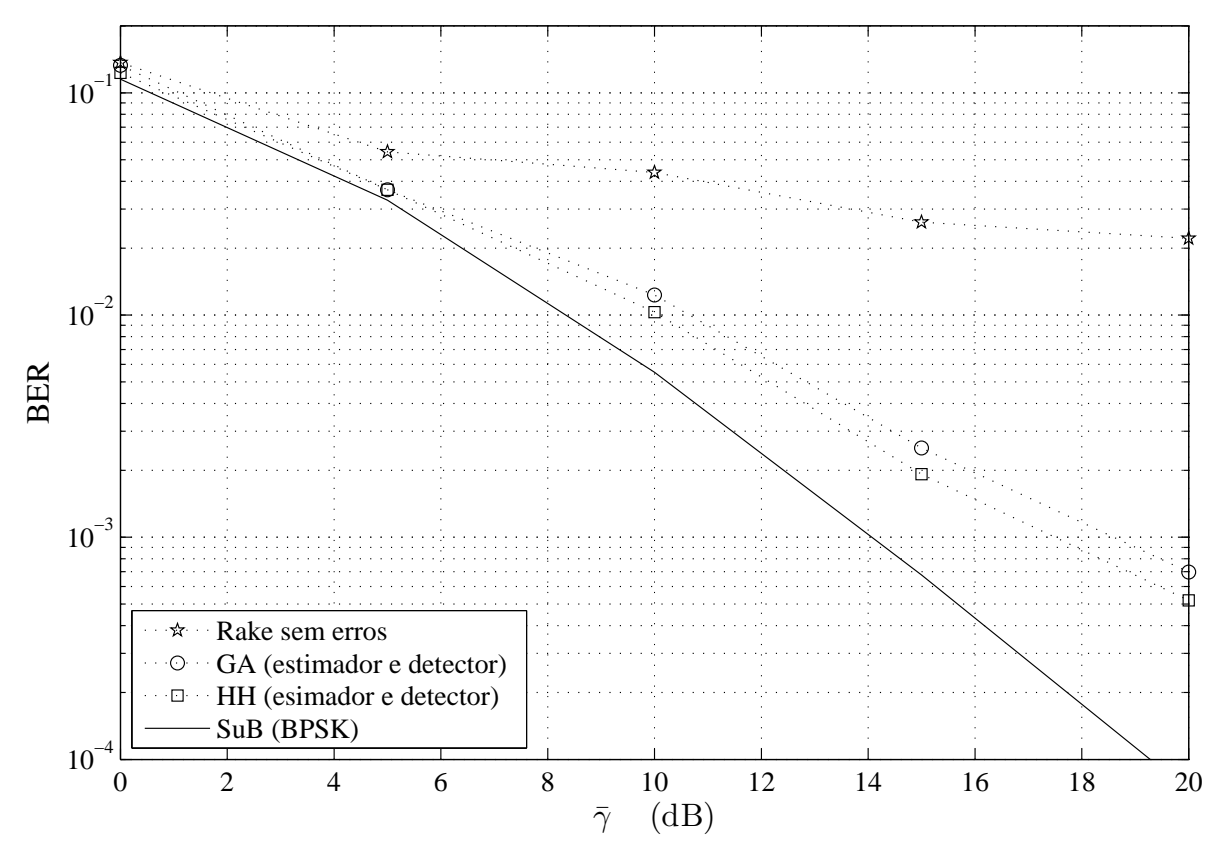

Figura 5.33: BER para as estratégias heurísticas GA e HH como estimador de canal e detector conjunto considerando sistema $\mathbf{S} 1$.

Portanto, as estratégias heurísticas mostram-se como uma opção atrativa, pois atingem patamares de desempenho muito superiores aos obtidos com o receptor Rake na ausência de erros nas estimativas, além de manter o desempenho próximo ao $\mathrm{SuB}$ quando estimativas confiáveis puderem ser obtidas.

\subsection{Discussão sobre Qualidade, Estabilidade e Com- plexidade em Sistemas de Telecomunicações}

Conforme apresentado no capítulo 4, utilizou-se uma figura de mérito para quantificar a estabilidade e qualidade das soluções obtidas pelos algoritmos heurísticos baseada nos critérios de gráfico de controle e medidas ACI para um regime controlado de simulações pelo uso das funções de otimização F1 a F10.

Desta forma, quantificou-se a estabilidade e qualidade dos resultados possibilitando a escolha de topologias apropriadas para aplicação nos problemas $\mathrm{MuD}$

\footnotetext{
${ }^{21}$ Aumentando-se os bits para a codificação e/ou a imunidade à MAI através de sequências determinísticas ou o ganho de processamento.
} 
e MuChE. Os algoritmos GA, EP-C, SA, STTS, RTS e HH com o uso dos parâmetros otimizados foram as topologias que apresentaram desempenho e níveis de estabilidade satisfatórios.

No entanto, em cenários de telecomunicações, torna-se muito difícil a obtenção de medidas numéricas de qualidade e estabilidade conforme método realizado no capítulo 4 devido à não previsibilidade dos efeitos aleatórios das interferências existentes e tampouco dos sinais que são transmitidos e que influenciam no desempenho em termos da BER ou MSE e MPE para o sistema. Além disso, cada topologia de sistema com sua respectiva configuração de parâmetros resulta em um cenário muito particular e de difícil definição de um critério justo e plausível de qualidade e estabilidade das soluções.

Iniciando a discussão pelo problema da detecção multiusuário e visando exemplificar, sabe-se que o melhor desempenho em termos da BER para sistemas DS/CDMA multitaxa, conforme apresentado na seção 5.1.3, é obtido através do detector ótimo baseado em máxima verossimilhança (VERDÚ, 1998). Para realizar a otimização de desempenho apresentada na figura 5.12, por exemplo, o detector ótimo necessita de aproximadamente $1,4.10^{36}$ testes da função custo ${ }^{22}$. Vale ressaltar que o número de operações necessários é de ordem ainda maior, pois cada teste da função custo necessita de um número de operações superior à unidade. Assim, torna-se impossível a realização de simulações para o detector ótimo aplicado aos sistemas de telecomunicações considerados neste trabalho utilizando um computador pessoal de alto desempenho e capacidade de armazenamento apresentado na seção 4.4.5.

Desta maneira, para todos os problemas de detecção considerados neste trabalho considerou-se para comparação o limite de desempenho quando o sistema encontra-se na configuração de usuário único $(\mathrm{SuB})$.

Além disso, sabe-se que o desempenho do detector ótimo, na presença de interferência de múltiplo acesso, é degradado à medida que esta interferência aumenta. Por isso, comparar o desempenho dos algoritmos heurísticos com o $\mathrm{SuB}$ em cenários de múltiplo acesso ${ }^{23}$ mostra-se como uma métrica injusta e impossível de se quantificar em termos de ACI ou gráfico de controle. Utilizando analogia, sabe-se que os detectores lineares baseados em cancelamento de interferência (SIC e PIC) possuem uma parcela cumulativa de ruído devido ao cancelamento imperfeito a cada iteração. Neste caso, o desempenho é afetado quando o número de usuários (leia-se carregamento) aumenta. Vale ressaltar que as etapas de can-

\footnotetext{
${ }^{22}$ Teste de todas as possibilidades existentes.

${ }^{23}$ Principalmente em cenários com alto carregamento.
} 
celamento de interferência consideram uma operação linear (ABRÃO, 2001). No caso da métrica baseada em máxima verossimilhança, busca-se a minimização da equação (2.83) através da diferença quadrática ou, de forma equivalente, da minimização da equação (2.86). No entanto, a medida que o número de usuários aumenta, observa-se que a resultante é crescente e não nula devido à imprecisão das estimativas dos símbolos recebidos (termo $\mathcal{Y}$ ). Assim, da mesma forma que para os detectores lineares, existe um limitante para o desempenho da estratégia ML (detector ótimo) em cenários de múltiplo acesso ${ }^{24}$.

Mas, embora apresente limitações, esta comparação pode ser utilizada para indicação de algumas observações e conclusões:

- Se o desempenho é próximo ao SuB independente do número de usuários, é certo que o algoritmo proposto está otimizando a função custo.

- Se o desempenho mostra-se um pouco afastado do SuB, mas apresenta a mesma tendência/inclinação de melhoria conforme a relação sinal-ruído aumenta, é certo que o algoritmo proposto está otimizando a função custo e este patamar mostra-se como o limite que o detector ótimo resultaria.

Assim, se alguma das observações citadas estiverem presentes nas figuras de desempenho, considera-se que o algoritmo analisado apresenta estabilidade e qualidade nas soluções encontradas.

Outra observação e conclusão importante diz respeito a curva de convergência dos algoritmos $(\mathrm{BER} \times$ gerações/iterações). Se a curva de convergência do algoritmo proposto atingir um patamar de desempenho e não melhorar após um número razoável de gerações / iterações, é certo que o algoritmo atingiu o limite para o detector ótimo e o aumento do número de gerações / iterações não alterará o resultado.

Vale ressaltar que para todos os cenários considerados, as curvas de convergência para a BER mostraram que os algoritmos alcançam um mesmo patamar após um determinado número de gerações/iterações ${ }^{25}$. Alguns testes foram realizados para um número razoavelmente superior de gerações e iterações e o desempenho dos algoritmos continuou apresentando os mesmos limites e a convergência continuou ocorrendo, na média e respectivamente para cada algoritmo, para o mesmo número de gerações/iterações.

\footnotetext{
${ }^{24}$ Esta degradação em termos da BER é muito inferior quando comparada a de outros detectores sub-ótimos.

${ }^{25}$ Este resultado foi observado quando as entradas dos algoritmos são as mesmas, indicando que todos os algoritmos atingiram a convergência após um número de gerações / iterações.
} 
Portanto, para os problemas de detecção multiusuário apresentados neste trabalho conclui-se que os algoritmos heurísticos propostos são capazes de encontrar a solução ótima ou muito próxima com um número reduzido de testes da função custo, aproximando-se do desempenho do detector ótimo desde que um número adequado e suficiente de gerações / iterações seja escolhido.

Esta discussão aponta para uma análise qualitativa a respeito das características da função custo para os problemas de detecção multiusuário apresentados neste trabalho ${ }^{26}$, indicando que as funções custo não apresentam muitos pontos de descontinuidade, com presença de poucos ou nenhum vale, ou seja, poucos ou ausência de mínimos locais, facilitando a busca pelos algoritmos heurísticos. Consequentemente, por apresentarem mesmo desempenho, a escolha do algoritmo heurístico para problemas de detecção multiusuário deve considerar aquele que apresentar a menor complexidade.

Por fim, a diferença encontrada entre o desempenho para usuário único e na presença de interferência multiusuário em algumas simulações apresentadas neste capítulo não pode ser vista como uma limitação dos métodos heurísticos propostos, mas sim como o limitante de desempenho que o detector ótimo é capaz de atingir quando aumento do nível de interferência e relação sinal-ruído ${ }^{27}$.

Para o problema de estimativa de parâmetros apresentado na seção 5.2, observa-se que os algoritmos apresentaram mesmo desempenho em termos do MSE e compatível com o estimador baseado em ML, mas com uma diminuição do tamanho do preâmbulo de $I=40$ do ML para apenas $I=10$ bits para os heurísticos. No entanto, considerando a figura de mérito MEP, os algoritmos heurísticos apresentaram pequenas diferenças, mesmo após convergência, indicando uma necessidade de análise e pontuação para a definição da melhor alternativa.

Vale ressaltar que todos os resultados de simulação indicaram que os algoritmos heurísticos apresentam melhor desempenho que a estratégia baseada em ML considerando tamanho de preâmbulo $I=10$, conforme figura 5.26 e tabela 5.14 . Nota-se que se o tamanho do preâmbulo for $I=40$, o desempenho do estimador ML tenderá ao mesmo encontrado pelos heurísticos para $I=10$, principalmente para a figura de mérito MSE.

Desta forma, a tabela 5.15 apresenta a pontuação escalonada ${ }^{28}$ para as estra-

\footnotetext{
${ }^{26}$ Para os diversos cenários de telecomunicações considerados nas simulações apresentados na seção 5.1 .

${ }^{27}$ Qualquer outro método ou algoritmo aplicado a estas condições de sistema resultará, no máximo, no mesmo desempenho obtido pelos algoritmos heurísticos.

${ }^{28}$ As notas foram escalonadas na faixa de 0 a 100 pontos considerando o algoritmo de maior pontuação com nota 100.
} 
tégias heurísticas considerando os sistemas $\mathbf{S 1}$, S2 e S3 e os critérios de desempenho MEP e seus respectivos desvios-padrões.

Tabela 5.15: Pontuação obtida para cada sistema e algoritmo heurístico em problemas MuChE.

\begin{tabular}{|c|c|c|c|c|c|c|c|}
\hline Sist. & MEP & $\overline{G A}$ & EP-C & $\overline{\mathrm{SA}}$ & STTS & $\overline{\mathrm{RTS}}$ & $\overline{\mathrm{HH}}$ \\
\hline \multirow{4}{*}{ S1 } & $\left|\xi^{(m)}\right|$ & $24,35 \%$ & $24,41 \%$ & $23,76 \%$ & $24,01 \%$ & $23,55 \%$ & $22,36 \%$ \\
\hline & $\sigma_{\xi^{(m)}}$ & 5,31 & 5,46 & 5,37 & 5,86 & 5,78 & 4,17 \\
\hline & $\measuredangle \xi^{(m)}$ & $25,11 \%$ & $26,37 \%$ & $25,32 \%$ & $24,98 \%$ & $29,21 \%$ & $23,62 \%$ \\
\hline & $\sigma_{\measuredangle \xi^{(m)}}$ & 7,54 & 14,49 & 8,13 & 9,16 & 9,16 & 6,96 \\
\hline \multirow{4}{*}{ S2 } & $\left|\xi^{(m)}\right|$ & $22,33 \%$ & $22,68 \%$ & $23,02 \%$ & $23,13 \%$ & $22,77 \%$ & $20,52 \%$ \\
\hline & $\sigma_{\xi(m)}$ & 3,93 & 4,04 & 3,61 & 3,47 & 3,88 & 2,34 \\
\hline & $\measuredangle \xi^{(m)}$ & $21,64 \%$ & $22,03 \%$ & $20,46 \%$ & $20,46 \%$ & $22,35 \%$ & $18,86 \%$ \\
\hline & $\sigma_{\measuredangle \xi^{(m)}}$ & 5,99 & 6,87 & 6,04 & 6,04 & 6,38 & 4,67 \\
\hline \multirow{4}{*}{ S3 } & $\left|\xi^{(m)}\right|$ & $407,11 \%$ & $411,25 \%$ & $413,37 \%$ & $415,98 \%$ & $415,98 \%$ & $402,24 \%$ \\
\hline & $\sigma_{\xi(m)}$ & 80,32 & 82,91 & 85,46 & 86,74 & 83,22 & 52,41 \\
\hline & $\measuredangle \xi^{(m)}$ & $165,41 \%$ & $167,63 \%$ & $139,52 \%$ & $173,92 \%$ & $186,12 \%$ & $105,76 \%$ \\
\hline & $\sigma_{\measuredangle \xi(m)}$ & 40,97 & 38,24 & 36,27 & 39,68 & 41,49 & 31,13 \\
\hline \multicolumn{2}{|c|}{ Pontuação } & 80 & 67 & 78 & 64 & 62 & 100 \\
\hline \multicolumn{2}{|c|}{ Colocação } & $2^{o}$ & $4^{o}$ & $3^{o}$ & $5^{o}$ & $6^{o}$ & $1^{o}$ \\
\hline
\end{tabular}

Nota-se que o algoritmo HH apresenta o melhor desempenho e consequentemente a maior pontuação quando comparado aos demais algoritmos heurísticos. Além disso, os patamares de desempenho dos algoritmos para os problemas $\mathrm{Mu}$ ChE apresentaram diferença sutil, validando todos os métodos heurísticos propostos, principalmente quando comparados ao estimador ML.

Novamente, esta discussão aponta para uma análise qualitativa a respeito das características da função custo para os problemas de estimativa de parâmetros do canal apresentados neste trabalho. Como o desempenho apresenta diferenças, indica-se que as funções possuem diversos mínimos locais, dificultando a busca pelos algoritmos heurísticos. Consequentemente, por apresentarem desempenho diferentes, a escolha do algoritmo heurístico para problemas de estimativa de parâmetros deve considerar uma das seguintes premissas:

- Escolha pelo melhor desempenho.

- Escolha pela menor complexidade.

- Escolha pelo compromisso desempenho $\times$ complexidade.

Portanto, antes da definição das topologias mais promissoras segundo as premissas acima para o problema de estimativa de parâmetros é necessário a análise da complexidade computacional dos algoritmos propostos. 


\subsubsection{Complexidade Computacional}

Conforme apresentado na seção 4.4, a complexidade dos algoritmos pode ser obtida através da notação $\mathcal{O}$, que representa a ordem de grandeza da complexidade, do número de instruções computadas e do tempo computacional médio necessário para uma determinada otimização.

Assim, esta seção tem por finalidade apresentar a complexidade computacional das topologias propostas visando a indicação das mais eficientes para aplicação nos problemas de detecção e estimativa de parâmetros inerentes aos sistemas de comunicação sem fio.

Vale ressaltar que na tabela 4.10 são apresentadas as complexidades computacionais dos algoritmos considerando o número de instruções necessárias ao cômputo e a figura 4.26 apresenta o tempo médio $\mu$ que cada algoritmo necessita conforme o aumento do tamanho do indivíduo. Assim, esta seção utiliza estas informações para quantificar a complexidade em cenários de telecomunicações.

\subsubsection{Número de Operações}

Como a complexidade para os algoritmos em termos do número de operações já foi determinado, pode-se determinar a complexidade destes em cada cenário de telecomunicações considerando a complexidade para o cálculo da função custo.

Assim, deve-se determinar a complexidade computacional para a função custo considerando os seguintes cenários:

1. Detecção multiusuário em sistemas DS/CDMA

2. Detecção em sistemas codificados DS/CDMA

3. Detecção em sistemas multitaxa DS/CDMA

4. Detecção em sistemas multiportadora DS/CDMA

5. Detecção em sistemas DS/CDMA com diversos tipos de diversidade

6. Detecção no domínio S-FT

7. Estimativa de parâmetros de canal

Para os cenários de 1 a 5 a função custo é a mesma devido ao sistema em malha aberta ${ }^{29}$. Mas os dois conjuntos de operações da função custo, definida pela

\footnotetext{
${ }^{29}$ Será apresentado apenas a complexidade computacional das etapas de detecção e estimativa
} 
equação (2.86), $\mathcal{F}_{1}=\mathcal{C}^{H} \mathcal{A Y}$ e $\mathcal{F}_{2}=\mathcal{C} \mathcal{A} \mathbf{R} \mathcal{A C} \mathcal{C}^{H}$ podem ser obtidos antes do laço de otimização de cada algoritmo. Assim, para cada teste de uma solução candidata, computam-se $\mathcal{B}^{T} \mathcal{F}_{1}$ e $\mathcal{B}^{T} \mathcal{F}_{2} \mathcal{B}$, que em termos de operações é equivalente à $(\text { K.I.D })^{2}+4$ K.I.D operações. Para o detector OMuD, o número de operações cresce exponencialmente com o número de usuários, i.e., $\mathcal{O}\left(2^{K . I}(K . I . D)^{2}\right)$. São necessárias $2^{K . I}$ gerações de bits de ordem K.I.D e $2^{K . I}$ cálculos da função custo para a detecção simultânea do frame constituído por $I$ bits dos $K$ usuários em um sistema com detecção MuD em canal com desvanecimento. Para canal puramente aditivo, a matriz de coeficiente de canal reduz-se a $\mathcal{C}=\mathbf{I}$; para canal síncrono, a dimensão da matriz de correlação simplifica-se a $K \times K$. Vale ressaltar que $K$ compreende o número de usuários total (virtuais ou não) do sistema.

Para o cenário 6, a função custo é descrita pela equação (2.124). Assim, para cada teste de uma solução candidata para todos os usuários, computamse K.I.D $\left(2 A_{R x} \cdot(M . N+1)+3 M . N\right)$. Nota-se que para a detecção iterativa os parâmetros do tamanho da sequência de espalhamento temporal e em frequência e o número de antenas de recepção afetam o número de operações necessárias.

Por fim, a função custo para o estimador de parâmetros é apresentada na equação (2.147). Nota-se, neste caso, que a operação $\mathcal{U} \mathbf{B}_{i}$ pode ser realizada antes do laço de otimização dos algoritmos. Assim, um simples teste de um vetor candidato necessita de aproximadamente $4 K . I . N^{2}+6 N$ operações.

De forma resumida, a tabela 5.16 apresenta a complexidade aproximada em termos do número de operações para o cálculo de uma função custo.

Tabela 5.16: Número de operações para o cálculo de uma função custo.

\begin{tabular}{c}
\hline Função custo \\
\hline Detecção multiusuário \\
Detecção iterativa \\
Estimativa de parâmetros \\
\hline
\end{tabular}

\begin{tabular}{c}
\hline Número de operações \\
\hline $\mathcal{O}_{F C}=(K I D)^{2}+4 K I D$ \\
$\mathcal{O}_{F C}=K I D\left(2 A_{R x}(M N+1)+3 M N\right)$ \\
$\mathcal{O}_{F C}=4 K I N^{2}+6 N$ \\
\hline
\end{tabular}

Com isso, torna-se possível calcular o número de operações para cada cenário simulado. Observando os resultados de simulação apresentados na seção 5.1.1 até a seção 5.2, nota-se a presença de 32 cenários de telecomunicações distintos para detecção multiusuário, 7 cenários de detecção iterativa e 3 cenários para o problema de estimativa de parâmetros. Consequentemente, a escolha das topologias mais promissoras deve considerar uma comparação e posterior pontuação para os 42 cenários existentes.

de parâmetros através dos algoritmos heurísticos, desconsiderando a complexidade das demais etapas. 
A tabela 5.17 sintetiza estes cenários e os principais parâmetros que influenciam no cálculo da complexidade em termos do número de operações.

Desta maneira, obteve-se a complexidade em termos do número de operações para cada cenário e algoritmo heurístico proposto. A tabela 5.18 apresenta a complexidade indicando a estratégia com a menor complexidade por cenário através do sistema de pontuação adotado neste trabalho. Vale ressaltar que optou-se por escalonar a pontuação em uma escala de 0 a 100 pontos e considerando o de maior valor com pontuação igual a 100. Nota-se que a ordem de grandeza envolvida é apresentada ao lado do número do cenário simulado.

Com isso, conclui-se que o algoritmo EP-C apresenta o melhor desempenho de complexidade em termos do número de operações. Nota-se, também, que os algoritmos heurísticos possuem uma complexidade muito inferior aos métodos de deteç̧ão e estimativa de parâmetros baseados na estratégia ML. Por fim, para a detecção iterativa, indicou-se a complexidade do detector sub-ótimo MMSE, sendo esta menor que a complexidade dos algoritmos heurísticos por um fator de 10000. No entanto, embora possua uma complexidade menor, o desempenho em termos da BER para a estratégia MMSE mostra-se muito inferior ao disponibilizado pelos algoritmos propostos, validando a proposta do uso de estratégias heurísticas.

\subsubsection{Tempo Computacional}

Para finalizar a análise de complexidade dos algoritmos heurísticos aplicados aos cenários de telecomunicações considerados neste trabalho torna-se necessário estimar a complexidade em termos do tempo computacional que cada estratégia necessita para otimização e classificar os algoritmos conforme respectivas pontuações. Ao final, conforme realizado na seção 4.4.5, considera-se uma estratégia para definição de qual algoritmo resulta na melhor opção.

O tempo computacional pode ser obtido através da equação (4.49). Conforme figura 4.26, o tempo $\mu$ para os algoritmos já foi estabelecido. Portanto, deve-se quantificar o tempo para o cálculo de uma função custo conforme cenários de telecomunicações apresentados de forma resumida na tabela 5.17.

A figura 5.34 apresenta o tempo computacional para as diferentes funções custo consideradas neste trabalho sendo descritas através da equação (2.86), equação (2.124) e da equação (2.147), respectivamente.

Através da figura 5.34 percebe-se que o tempo para o cálculo da função custo 
Tabela 5.17: Cenários utilizados nas simulações considerados para o cálculo do número de operações.

\begin{tabular}{|c|c|c|c|c|c|c|c|c|}
\hline Cenário & $K$ & $D$ & $I$ & $N$ & $M$ & $A_{R x}$ & $G_{t} / I_{t}$ & Fig./Tab. \\
\hline \multicolumn{9}{|c|}{ Detecção Multiusuário } \\
\hline 1 & 10 & 1 & 7 & 31 & - & - & $25 / 25$ & figura 5.2 \\
\hline 2 & 10 & 2 & 7 & 31 & - & - & $25 / 25$ & figura 5.3 \\
\hline 3 & 10 & 3 & 7 & 31 & - & - & $25 / 25$ & figura 5.4 \\
\hline 4 & 20 & 2 & 7 & 31 & - & - & $45 / 45$ & figura 5.5 \\
\hline 5 & 1 & 1 & 192 & 31 & - & - & $50 / 60$ & figura 5.8 \\
\hline 6 & 10 & 1 & 192 & 31 & - & - & $50 / 60$ & figura 5.8 \\
\hline 7 & 15 & 1 & 192 & 31 & - & - & $50 / 60$ & figura 5.8 \\
\hline 8 & 20 & 1 & 192 & 31 & - & - & $50 / 60$ & figura 5.8 \\
\hline 9 & 25 & 1 & 192 & 31 & - & - & $50 / 60$ & figura 5.8 \\
\hline 10 & 31 & 1 & 192 & 31 & - & - & $50 / 60$ & figura 5.8 \\
\hline 11 & 1 & 2 & 196 & 31 & - & - & $50 / 60$ & figura 5.10 \\
\hline 12 & 5 & 2 & 196 & 31 & - & - & $50 / 60$ & figura 5.10 \\
\hline 13 & 10 & 2 & 196 & 31 & - & - & $50 / 60$ & figura 5.10 \\
\hline 14 & 20 & 2 & 196 & 31 & - & - & $50 / 60$ & figura 5.10 \\
\hline 15 & 1 & 2 & 200 & 31 & - & - & $50 / 60$ & figura 5.11 \\
\hline 16 & 5 & 2 & 200 & 31 & - & - & $50 / 60$ & figura 5.11 \\
\hline 17 & 10 & 2 & 200 & 31 & - & - & $50 / 60$ & figura 5.11 \\
\hline 18 & 20 & 2 & 200 & 31 & - & - & $50 / 60$ & figura 5.11 \\
\hline 19 & 24 & 3 & 5 & 50 & - & - & $50 / 50$ & figura 5.13 \\
\hline 20 & 1 & 2 & 8 & 32 & 8 & - & $10 / 10$ & figura 5.14 \\
\hline 21 & 5 & 2 & 8 & 32 & 8 & - & $10 / 10$ & figura 5.14 \\
\hline 22 & 10 & 2 & 8 & 32 & 8 & - & $20 / 20$ & figura 5.14 \\
\hline 23 & 20 & 2 & 8 & 32 & 8 & - & $20 / 20$ & figura 5.14 \\
\hline 24 & 5 & 1 & 4 & 8 & 4 & - & $10 / 10$ & figura 5.18 \\
\hline 25 & 10 & 1 & 4 & 8 & 4 & - & $10 / 10$ & figura 5.18 \\
\hline 26 & 15 & 1 & 4 & 8 & 4 & - & $10 / 10$ & figura 5.18 \\
\hline 27 & 20 & 1 & 4 & 8 & 4 & - & $10 / 10$ & figura 5.18 \\
\hline 28 & 25 & 1 & 4 & 8 & 4 & - & $10 / 10$ & figura 5.18 \\
\hline 29 & 32 & 1 & 4 & 8 & 4 & - & $10 / 10$ & figura 5.18 \\
\hline 30 & 1 & 4 & 200 & 32 & - & - & $40 / 45$ & figura 5.20 \\
\hline 31 & 32 & 4 & 200 & 32 & - & - & $40 / 45$ & figura 5.20 \\
\hline 32 & 64 & 1 & 192 & 64 & 64 & - & $100 / 120$ & figura 5.22 \\
\hline \multicolumn{9}{|c|}{ Detecção Iterativa } \\
\hline 33 & 40 & 1 & 12 & 9 & 12 & 4 & $150 / 100$ & figura 5.23 \\
\hline 34 & 100 & 1 & 12 & 9 & 12 & 4 & $150 / 100$ & figura 5.23 \\
\hline 35 & 40 & 1 & 12 & 9 & 12 & 8 & $150 / 100$ & figura 5.24 \\
\hline 36 & 100 & 1 & 12 & 9 & 12 & 8 & $150 / 100$ & figura 5.24 \\
\hline 37 & 20 & 1 & 12 & 9 & 12 & 8 & $150 / 100$ & figura 5.25 \\
\hline 38 & 60 & 1 & 12 & 9 & 12 & 8 & $150 / 100$ & figura 5.25 \\
\hline 39 & 80 & 1 & 12 & 9 & 12 & 8 & $150 / 100$ & figura 5.25 \\
\hline \multicolumn{9}{|c|}{ Estimativa de Parâmetros } \\
\hline 40 & 10 & 2 & 10 & 20 & - & - & $200 / 130$ & tabela 5.13 \\
\hline 41 & 5 & 3 & 10 & 20 & - & - & $200 / 130$ & tabela 5.13 \\
\hline 42 & 10 & $\leq 2$ & 10 & 20 & - & - & $200 / 130$ & tabela 5.13 \\
\hline
\end{tabular}


Tabela 5.18: Número de operações necessárias para otimização dos cenários 1 a 42 apresentados de forma resumida na tabela 5.17.

\begin{tabular}{|c|c|c|c|c|c|c|c|}
\hline Cenário & GA & $\overline{\mathrm{EP}-\mathrm{C}}$ & $\overline{\mathrm{SA}}$ & STTS & RTS & $\mathrm{HH}$ & $\mathrm{OMuD}$ \\
\hline $1\left(10^{6}\right)$ & 7,506 & 7,016 & 9,441 & 9,507 & 9,509 & 8,599 & $6,20.10^{18}$ \\
\hline $2\left(10^{7}\right)$ & 3,672 & 3,604 & 3,566 & 3,572 & 3,572 & 3,598 & $2,40.10^{18}$ \\
\hline $3\left(10^{7}\right)$ & 10,297 & 10,209 & 7,902 & 7,909 & 7,909 & 8,845 & $5,33.10^{18}$ \\
\hline $4\left(10^{8}\right)$ & 3,652 & 3,617 & 5,037 & 5,041 & 5,041 & 4,478 & $1,11.10^{39}$ \\
\hline $5\left(10^{8}\right)$ & 1,795 & 1,746 & 4,402 & 4,414 & 4,414 & 3,496 & $2,37.10^{54}$ \\
\hline $6\left(10^{10}\right)$ & 5,017 & 5,003 & 42,622 & 42,633 & 42,633 & 27,983 & $>10^{300}$ \\
\hline $7\left(10^{11}\right)$ & 1,376 & 1,373 & 14,368 & 14,370 & 14,370 & 9,281 & $>10^{300}$ \\
\hline $8\left(10^{11}\right)$ & 2,813 & 2,809 & 34,036 & 34,040 & 34,040 & 21,773 & $>10^{300}$ \\
\hline $9\left(10^{11}\right)$ & 4,970 & 4,964 & 66,452 & 66,459 & 66,459 & 42,258 & $>10^{300}$ \\
\hline $10\left(10^{11}\right)$ & 8,347 & 8,339 & 126,663 & 126,674 & 126,674 & 80,007 & $>10^{300}$ \\
\hline $11\left(10^{8}\right)$ & 9,452 & 9,386 & 18,325 & 18,337 & 18,337 & 15,521 & $1,56.10^{56}$ \\
\hline $12\left(10^{10}\right)$ & 5,212 & 5,205 & 22,652 & 22,655 & 22,655 & 16,093 & $3,94.10^{291}$ \\
\hline $13\left(10^{11}\right)$ & 3,004 & 3,002 & 18,096 & 18,097 & 18,097 & 12,300 & $>10^{300}$ \\
\hline $14\left(10^{12}\right)$ & 1,662 & 1,661 & 14,467 & 14,467 & 14,467 & 9,478 & $>10^{300}$ \\
\hline $15\left(10^{8}\right)$ & 9,837 & 9,770 & 19,465 & 19,477 & 19,477 & 16,390 & $2,60.10^{57}$ \\
\hline $16\left(10^{10}\right)$ & 5,628 & 5,620 & 24,066 & 24,069 & 24,069 & 17,140 & $4,30.10^{297}$ \\
\hline $17\left(10^{11}\right)$ & 3,128 & 3,126 & 19,226 & 19,228 & 19,228 & 13,037 & $>10^{300}$ \\
\hline $18\left(10^{12}\right)$ & 1,762 & 1,762 & 12,809 & 12,809 & 12,809 & 8,390 & $>10^{300}$ \\
\hline $19\left(10^{8}\right)$ & 7,947 & 7,907 & 7,884 & 7,888 & 7,888 & 7,903 & $1,75.10^{33}$ \\
\hline $20\left(10^{5}\right)$ & 12,489 & 11,145 & 2,792 & 2,839 & 2,847 & 6,413 & 8,60 \\
\hline $21\left(10^{6}\right)$ & 4,316 & 4,181 & 2,738 & 2,747 & 2,747 & 3,346 & $7,48.10^{9}$ \\
\hline $22\left(10^{7}\right)$ & 4,349 & 4,277 & 4,238 & 4,244 & 4,245 & 4,271 & $3,19.10^{21}$ \\
\hline $23\left(10^{8}\right)$ & 2,322 & 2,303 & 3,333 & 3,336 & 3,336 & 2,926 & $1,52.10^{45}$ \\
\hline $24\left(10^{5}\right)$ & 2,154 & 1,818 & 1,090 & 1,115 & 1,117 & 1,459 & $5,24.10^{3}$ \\
\hline $25\left(10^{5}\right)$ & 8,931 & 8,035 & 7,540 & 7,630 & 7,634 & 7,958 & $1,98.10^{10}$ \\
\hline $26\left(10^{6}\right)$ & 2,274 & 2,106 & 2,415 & 2,435 & 2,435 & 2,334 & $4,50.10^{15}$ \\
\hline $27\left(10^{6}\right)$ & 4,597 & 4,328 & 5,572 & 5,606 & 5,607 & 5,144 & $8,22.10^{21}$ \\
\hline $28\left(10^{6}\right)$ & 6,946 & 6,610 & 10,705 & 10,758 & 10,759 & 9,158 & $1,33.10^{28}$ \\
\hline $29\left(10^{7}\right)$ & 1,288 & 1,238 & 2,212 & 2,221 & 2,221 & 1,836 & $5,79.10^{35}$ \\
\hline $30\left(10^{9}\right)$ & 4,390 & 4,382 & 5,794 & 5,795 & 5,795 & 5,451 & $1,03.10^{57}$ \\
\hline $31\left(10^{13}\right)$ & 2,569 & 2,569 & 18,877 & 18,878 & 18,878 & 12,483 & $>10^{300}$ \\
\hline $32\left(10^{13}\right)$ & 1,028 & 1,027 & 22,277 & 22,278 & 22,278 & 13,860 & $>10^{300}$ \\
\hline Cenário & GA & EP-C & $\overline{\mathrm{SA}}$ & STTS & RTS & $\mathrm{HH}$ & MMSE \\
\hline $33\left(10^{12}\right)$ & 1,256 & 0,770 & 24,804 & 26,954 & 26,954 & 16,015 & $2,99.10^{-4}$ \\
\hline $34\left(10^{12}\right)$ & 4,962 & 3,041 & 155,023 & 168,460 & 168,460 & 99,465 & $7,48.10^{-4}$ \\
\hline $35\left(10^{12}\right)$ & 3,454 & 2,082 & 92,765 & 101,365 & 101,365 & 59,844 & $2,99.10^{-4}$ \\
\hline $36\left(10^{12}\right)$ & 13,677 & 8,243 & 579,779 & 633,528 & 633,528 & 372,315 & $7,49 \cdot 10^{-4}$ \\
\hline $37\left(10^{12}\right)$ & 1,223 & 0,737 & 23,191 & 25,341 & 25,341 & 15,038 & $1,49.10^{-4}$ \\
\hline $38\left(10^{12}\right)$ & 6,352 & 3,828 & 208,721 & 228,070 & 228,070 & 134,342 & $4,49 \cdot 10^{-4}$ \\
\hline $39\left(10^{12}\right)$ & 9,784 & 5,897 & 371,059 & 405,458 & 405,458 & 238,504 & $5,99.10^{-4}$ \\
\hline Cenário & GA & EP-C & $\mathrm{SA}$ & STTS & RTS & $\mathrm{HH}$ & ML \\
\hline $40\left(10^{9}\right)$ & 2,929 & 2,906 & 4,598 & 4,602 & 4,602 & 3,519 & $7,18.10^{60}$ \\
\hline $41\left(10^{9}\right)$ & 1,140 & 1,131 & 1,151 & 1,151 & 1,151 & 0,986 & $2,79.10^{27}$ \\
\hline $42\left(10^{9}\right)$ & 2,929 & 2,906 & 4,598 & 4,602 & 4,602 & 3,519 & $7,18.10^{60}$ \\
\hline Pontuação & 87 & 100 & 83 & 72 & 56 & 85 & - \\
\hline Colocação & $2^{o}$ & $1^{o}$ & $4^{o}$ & $5^{\circ}$ & $6^{\circ}$ & $3^{\circ}$ & - \\
\hline
\end{tabular}



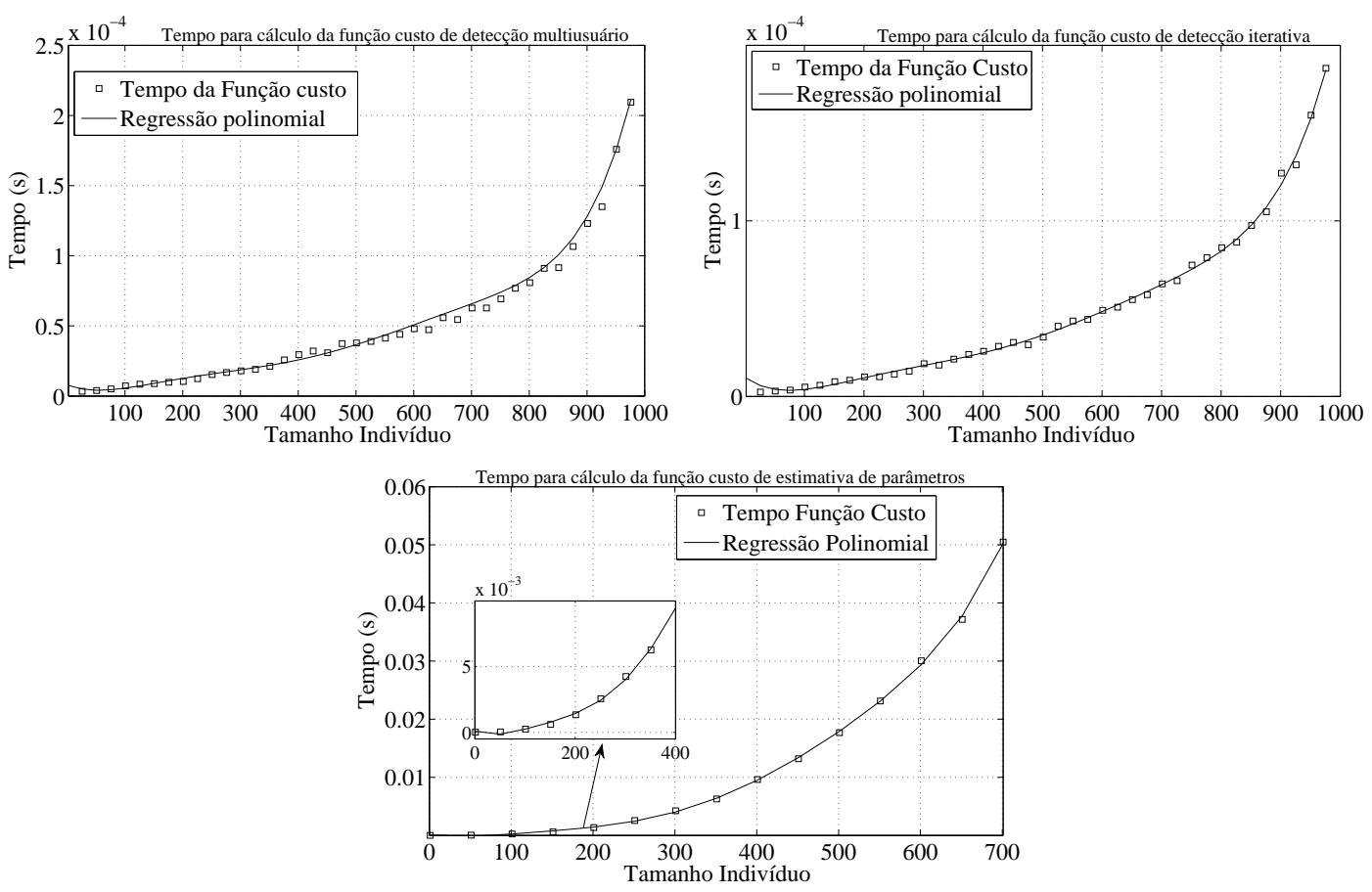

Figura 5.34: Tempo médio para o cálculo das funções custo e tempo por aproximação polinomial.

para o problema de estimativa de parâmetros cresce mais rapidamente a medida que aumenta o tamanho do indivíduo. Com isso, utilizando-se das equações obtidas via regressão polinomial para os tempos $\mu$ e $\varpi$ dos algoritmos e das funções custo, é possível calcular o tempo médio necessário à otimização para cada cenário de telecomunicações considerado.

A tabela 5.19 apresenta o tempo médio necessário para otimização em cada cenário para os algoritmos considerados neste trabalho, bem como classifica-os através da pontuação obtida.

Com isso, conclui-se novamente que o algoritmo EP-C apresenta o melhor desempenho de complexidade em termos do tempo computacional. Nota-se, também, que todos os algoritmos heurísticos possuem uma complexidade muito próxima, tanto em termos do número de operações quanto do tempo computacional. Desta forma, pode-se adotar quaisquer topologias sem perda significativa de compromisso desempenho $\times$ complexidade, validando a proposta do uso de estratégias heurísticas otimizadas conforme parâmetros indicados na tabela 4.7. 
Tabela 5.19: Tempo médio em segundos para otimização dos cenários 1 a 42 apresentados de forma resumida na tabela 5.17.

\begin{tabular}{|c|c|c|c|c|c|c|}
\hline Cenário & GA & EP-C & $\overline{\mathrm{SA}}$ & STTS & RTS & $\mathrm{HH}$ \\
\hline 1 & 0,0782 & 0,0756 & 0,1005 & 0,1013 & 0,1014 & 0,0911 \\
\hline 2 & 0,143 & 0,1388 & 0,2547 & 0,2559 & 0,256 & 0,2124 \\
\hline 3 & 0,2304 & 0,2241 & 0,4739 & 0,4755 & 0,4758 & 0,3859 \\
\hline 4 & 0,5536 & 0,539 & 1,354 & 1,3582 & 1,3592 & 1,0749 \\
\hline 5 & 0,0524 & 0,0506 & 0,0455 & 0,0428 & 0,0428 & 0,0521 \\
\hline 6 & 0,2656 & 0,2576 & 0,489 & 0,4916 & 0,4919 & 0,4221 \\
\hline 7 & 0,3741 & 0,3636 & 0,8938 & 0,8973 & 0,8978 & 0,7304 \\
\hline 8 & 0,5562 & 0,5413 & 1,4065 & 1,4111 & 1,412 & 1,1432 \\
\hline 9 & 0,7094 & 0,6906 & 2,0227 & 2,0289 & 2,0304 & 1,6165 \\
\hline 10 & 0,9074 & 0,8837 & 2,9169 & 2,9254 & 2,9278 & 2,2974 \\
\hline 11 & 0,0806 & 0,0778 & 0,0801 & 0,0799 & 0,0799 & 0,0865 \\
\hline 12 & 0,2656 & 0,2576 & 0,489 & 0,4916 & 0,4919 & 0,4221 \\
\hline 13 & 0,5562 & 0,5413 & 1,4065 & 1,4111 & 1,412 & 1,1432 \\
\hline 14 & 1,3232 & 1,2891 & 4,6628 & 4,6755 & 4,6794 & 3,64 \\
\hline 15 & 0,081 & 0,0782 & 0,0861 & 0,0861 & 0,0861 & 0,0905 \\
\hline 16 & 0,2757 & 0,2675 & 0,5485 & 0,5512 & 0,5515 & 0,4647 \\
\hline 17 & 0,5857 & 0,5701 & 1,6001 & 1,6052 & 1,6063 & 1,2841 \\
\hline 18 & 1,4315 & 1,3949 & 5,4526 & 5,467 & 5,4715 & 4,2159 \\
\hline 19 & 0,8844 & 0,8612 & 2,2955 & 2,3023 & 2,3041 & 1,8156 \\
\hline 20 & 0,0158 & 0,0153 & 0,0095 & 0,0092 & 0,0092 & 0,0118 \\
\hline 21 & 0,039 & 0,0378 & 0,0474 & 0,0477 & 0,0477 & 0,0436 \\
\hline 22 & 0,1401 & 0,1362 & 0,2488 & 0,2498 & 0,25 & 0,208 \\
\hline 23 & 0,297 & 0,2892 & 0,7509 & 0,7532 & 0,7538 & 0,5948 \\
\hline 24 & 0,016 & 0,0154 & 0,0114 & 0,0113 & 0,0113 & 0,0131 \\
\hline 25 & 0,0225 & 0,0217 & 0,0217 & 0,0219 & 0,0219 & 0,0218 \\
\hline 26 & 0,0301 & 0,0291 & 0,0335 & 0,0338 & 0,0339 & 0,0319 \\
\hline 27 & 0,039 & 0,0378 & 0,0474 & 0,0477 & 0,0477 & 0,0436 \\
\hline 28 & 0,0422 & 0,0409 & 0,0633 & 0,0637 & 0,0638 & 0,0549 \\
\hline 29 & 0,0547 & 0,0531 & 0,0894 & 0,0898 & 0,0899 & 0,076 \\
\hline 30 & 0,4638 & 0,4515 & 1,1704 & 1,1741 & 1,1749 & 0,9414 \\
\hline 31 & 128,126 & 128,001 & 914,891 & 914,876 & 914,906 & 609,049 \\
\hline 32 & 5,2576 & 5,1283 & 24,0933 & 24,1408 & 24,1608 & 18,2711 \\
\hline 33 & 3,9382 & 3,8359 & 7,6996 & 7,7208 & 7,7273 & 6,0153 \\
\hline 34 & 44,0421 & 43,6815 & 157,764 & 157,798 & 157,839 & 109,461 \\
\hline 35 & 3,9382 & 3,8359 & 7,6996 & 7,7208 & 7,7273 & 6,0153 \\
\hline 36 & 44,0421 & 43,6815 & 157,764 & 157,798 & 157,839 & 109,461 \\
\hline 37 & 1,6444 & 1,5997 & 2,3053 & 2,313 & 2,3145 & 1,8755 \\
\hline 38 & 7,2883 & 7,1064 & 17,4017 & 17,4388 & 17,4534 & 13,2976 \\
\hline 39 & 12,9355 & 12,6666 & 37,4885 & 37,5334 & 37,5595 & 27,7526 \\
\hline 40 & 33,4291 & 33,3777 & 52,7542 & 52,7633 & 52,765 & 40,4025 \\
\hline 41 & 5,7205 & 5,6892 & 5,736 & 5,7416 & 5,742 & 4,9276 \\
\hline 42 & 33,4291 & 33,3777 & 52,7542 & 52,7633 & 52,765 & 40,4025 \\
\hline Pontuação & 88 & 100 & 73 & 66 & 56 & 80 \\
\hline Colocação & $2^{o}$ & $1^{o}$ & $4^{o}$ & $5^{\circ}$ & $6^{o}$ & $3^{\circ}$ \\
\hline
\end{tabular}




\subsection{Escolha das Topologias e Discussão sobre Im- plementabilidade}

Conforme realizado na seção 4.4.5, optou-se pela média entre as pontuações de complexidade (número de operações e tempo computacional) evitando, assim, uma análise injusta entre as estratégias de otimização ou possíveis viés existentes.

A tabela 5.20 apresenta um resumo das pontuações e colocação final obtida pelos algoritmos heurísticos considerando pesos iguais entre as características.

Tabela 5.20: Resumo das pontuações e colocação dos algoritmos para os cenários de telecomunicações considerados.

\begin{tabular}{c|c|c|c|c|c|c}
\hline Pontuação & GA & EP-C & SA & STTS & RTS & HH \\
\hline Número de operações & 87 & 100 & 83 & 72 & 56 & 85 \\
Tempo computacional & 88 & 100 & 73 & 66 & 56 & 80 \\
\hline Média Complexidade & 88 & 100 & 78 & 69 & 56 & 83 \\
\hline \multicolumn{7}{|c}{} \\
\hline Qualidade e Estabilidade & 80 & 67 & 78 & 64 & 62 & 100 \\
\hline Pontuação Final Média & 84 & 83 & 78 & 66 & 59 & 91 \\
Colocação & $2^{o}$ & $3^{o}$ & $4^{o}$ & $5^{\circ}$ & $6^{\circ}$ & $1^{o}$ \\
\hline
\end{tabular}

Portanto, adotando-se a métrica de pesos iguais entre as características de qualidade/estabilidade e complexidade computacional, conforme tabela 5.20, resultará, para os problemas de detecção multiusuário, detecção iterativa e estimativa de parâmetros, nas seguintes escolhas:

- Escolha pelo melhor desempenho: Algoritmo HH

- Escolha pela menor complexidade: Algoritmo EP-C

- Escolha pelo compromisso desempenho $\times$ complexidade: Algoritmo HH (com média geral de 91 pontos)

\subsubsection{Discussão sobre Implementabilidade dos Algoritmos Heurísticos}

Esta seção não tem por objetivo analisar uma arquitetura para implementação das estratégias heurísticas em DSP, mas sim realizar uma discussão sobre o quão passível de implementação nos dias atuais essas técnicas são. Para isso, utilizouse os valores de complexidade computacional (em número de operações ou flops) 
que as estratégias propostas necessitam para estimar e/ou detectar, conforme tabela 5.17 .

Para o pior caso, ou seja, o maior valor em termos do número de operações necessários, a grandeza envolvida aponta $10^{12}$ flops. Considerando o valor exato, necessita-se de 634 Tflops (cenário 36). Esta configuração de sistema compreende a detecção iterativa para $K=100$ usuários, $Q_{R x}=8$ antenas, $N=9$ e $M=12$ considerando o algoritmo STTS. Nota-se que todos os outros cenários apresentam número de operações inferior e, por isso, não serão consideradas para discussão.

Ilustrativamente, analisando a utilização de DSP's específicos como os modelos de DSP's da Texas Instruments, família TMS320C6670, capazes de realizar 19,2 Gflops por núcleo em precisão de 32 bits, percebe-se, claramente, que não seria possível utilizá-los para essa tarefa. No entanto, a topologia permite o arranjo em múltiplos núcleos e caso seja possível paralelizar o cômputo, seriam necessários mais de 33000 DSP's dessa família para realizar todas as operações necessárias à otimização. Nota-se que o número de DSP's necessários torna-se impraticável à medida que o número de usuários, taxa de transmissão e demais parâmetros aumenta.

Contudo, caso sejam utilizados superprocessadores, como os poderosos SX-9 da $\mathrm{NEC}^{30}$ capazes de fornecer mais de 100 Gflops por CPU com uma precisão de 64 bits e um desempenho de aproximadamente 1,6 Tflops em apenas um nó com 16 CPU's, seria possível estimar e/ou detectar certo número de usuários, sendo necessários 396 nós SX-9 para o atendimento total dos cenários considerados neste trabalho. O limite de nós em um arranjo desta série é de 512 nós, totalizando 819 Tflops. Essa capacidade seria suficiente para a implementação das estratégias baseadas em heurísticas para aplicação em tempo real. Todavia, o custo e a dimensão da solução ainda impossibilitam tal prática.

Em 2008, a IBM apresentou um supercomputador chamado Roadrunner, sendo o primeiro a quebrar a barreira de desempenho de $1 \mathrm{Pflops}^{31}$, alcançando 1,7 Pflops.

Em novembro de 2011, a empresa Fujitsu anunciou o lançamento do supercomputador PRIMEHPC FX10, capaz de fornecer um desempenho de 23,2 Pflops. Desta forma, assumirá a liderança em termos de capacidade de processamento superando o atual supercomputador K Computer system. O novo recordista é constituído de 98304 nós com um processador SPARC64 IXfx com 16 núcleos

\footnotetext{
${ }^{30}$ Empresa multinacional japonesa de tecnologia da informação conhecida até 1983 como Nippon Electric Company.

${ }^{31} 1$ Petaflop $=10^{15}$ flops.
} 
cada. Cada processador SPARC64 IXfx é capaz de realizar 236,5 Gflops.

Dado a corrida pelo avanço de desempenho, existe uma estimativa que os supercomputadores serão capazes de realizar 1 Eflops ${ }^{32}$ em 2019 (SHAH, 2011). Segundo a lei de Moore (MOORE, 1965), os computadores dobram de capacidade a cada 2 anos, aproximadamente. Em teoria, os supercomputadores serão capazes de realizar 1 Zflops $^{33}$ em 2030.

A lei de Moore e a economia de escala são fatores dominantes para o desenvolvimento de supercomputadores. Claramente, percebe-se que topologias que foram desenvolvidas para supercomputadores do passado e que apresentaram custos elevados, estão gradualmente sendo incorporadas ao computadores para uso civil. Assim, o custo de produção em escala diminui substancialmente, mostrando que os avanços no ramo dos supercomputadores acabam sendo incluídos após um determinado tempo aos computadores de escala a preços acessíveis.

Mas, infelizmente, ainda não existe na atualidade um computador pequeno e de baixo custo capaz de realizar a estimativa e deteç̧ão para todos os cenários. No entanto, a crescente evolução por poder de processamento mostra que a evolução dos processadores pode, em um futuro muito próximo, garantir a implementação das estruturas heurísticas propostas em sistemas 3G e 4G de alta capacidade.

Neste momento, torna-se importante ressaltar também que a utilização de qualquer forma de paralelização para o cômputo das operações traz uma diminuição do tempo total necessário. Além disso, na literatura especializada, por exemplo, (GOLUB; VAN LOAN, 1996; HORN; JOHNSON, 1999), pode-se encontrar a teoria que descreve as propriedades das matrizes que são utilizadas no cálculo da função custo para a estimação e detecção. Com isso, pode-se utilizar algoritmos altamente eficientes para as multiplicações matriciais e vetoriais visando diminuir a complexidade do cálculo da função custo para ambos os problemas. Por exemplo, em (GOLUB; VAN LOAN, 1996), encontram-se algoritmos eficientes para o cálculo de multiplicação de matrizes que são Tridiagonais e/ou Toeplitz por blocos, reduzindo substancialmente ${ }^{34}$ o número de flops necessários. Note-se que as matrizes $\mathbf{R}$ e $\mathcal{U} \mathbf{B}_{i}$ possuem essas características, indicando a utilização de tais algoritmos. Com isso, se forem utilizados algoritmos eficientes, capazes de reduzir a complexidade para a faixa de dezenas de Tflops, já seria possível implementar a estratégia de detecção conjunta nos dias atuais utilizando poucos

\footnotetext{
${ }^{32} 1$ Exaflops $=10^{18}$ flops.

${ }^{33} 1$ Zettaflops $=10^{21}$ flops.

${ }^{34}$ Comumente diminui a complexidade polinomial em uma ordem, ou até mesmo a transforma em uma complexidade linear com o tamanho da matriz. Para complexidades já lineares, comumente há uma redução em uma casa decimal.
} 
clusters $^{35}$ de processamento.

Por fim, caso haja a intenção de implementar a estratégia proposta, deve-se realizar um estudo aprofundado sobre algoritmos de baixa complexidade para multiplicação de matrizes que possuem propriedades de simetria como também de arquiteturas passíveis de realizar processamento em paralelo.

${ }^{35}$ Conjunto com vários processadores em paralelo. 


\section{Principais Conclusões e Trabalhos Futuros}

Este trabalho analisou diversas técnicas heurísticas para otimização combinatória aplicadas aos problema da detecção multiusuário e estimativa de parâmetros em sistemas de múltiplo acesso, em diversos cenários e dimensões de diversidade (tempo, frequência, espaço e código), em canais Rayleigh visando aumentar a capacidade do sistema e oferecer uma diversidade de serviços multimídia, garantindo a sua qualidade em termos da taxa de erro de bit.

Os principais cenários analisados considerando o problema da detecção multiusuário em sistemas DS/CDMA foram:

- Detecção multiusuário em sistemas convencionais

- Detecção em sistemas codificados

- Detecção em sistemas multitaxa

- Detecção em sistemas multiportadora

- Detecção em sistemas com diversos tipos de diversidade

- Detecção no domínio S-FT iterativo

Nestes cenários, os algoritmos heurísticos propostos apresentaram desempenho muito próximo ao limite $\mathrm{SuB}$ para a maioria das condições de sistema simulados e muito superior a outros métodos apresentados em algumas figuras de desempenho. Nota-se que os algoritmos oferecem uma vantagem de redução drástica de complexidade computacional em relação ao $\mathrm{OMuD}$ com uma perda de desempenho apenas marginal, mesmo em condições severas de canal e carregamento. Assim, os resultados confirmaram a boa qualidade das soluções obtidas com a garantia de estabilidade após um determinado número de gerações / iterações, validando a metodologia de otimização dos parâmetros, etapas e pontuação dos algoritmos. 
Portanto, para o problema de detecção, pode-se concluir que os algoritmos heurísticos propostos atingiram patamares de desempenho satisfatórios para todos os cenários considerados tanto para deteç̧ão em malha aberta como para cenários com detecção iterativa 3D. Neste caso, a escolha do melhor algoritmo deve considerar o que possuir a menor complexidade, o melhor desempenho ou o melhor compromisso desempenho $\times$ complexidade, sendo indicados o EP-C e o $\mathrm{HH}$, respectivamente.

Para o problema MuChE, foram analisados os algoritmos heurísticos na busca de estimativas confiáveis para a resposta do canal visando utilização na etapa de detecção. Os resultados de simulação indicaram viabilidade das topologias heurísticas em operar de forma conjunta à etapa de detecção via detector multiusuário heurístico. Como resultado, tem-se a deteç̧ão final da informação a partir do emprego das estimativas, relativamente precisas, dos coeficientes de canal. Vale ressaltar que foram utilizadas as principais figuras de mérito para a estimativa da resposta do canal através do erro quadrático médio normalizado (MSE) e erro percentual médio (MEP).

Além disso, realizou-se uma comparação das três codificações propostas através da função densidade de probabilidade do erro médio percentual. Assim, concluiu-se que a codificação tipo I resulta em melhor desempenho, pois atinge menores valores de MEP para as estimativas do módulo e fase dos coeficientes quando comparado às codificações do tipo II e III.

Em canais Rayleigh lentamente variantes no tempo, os estimadores heurísticos com codificação tipo I apresentaram uma grande acurácia nas estimativas dos coeficientes do canal, considerando alguns cenários com carregamento médio. Além disso, o processo de otimização dos algoritmos é realizado no domínio binário, podendo-se controlar a complexidade computacional e a resolução do desempenho através dos parâmetros $Q_{\text {int }}$ e $Q_{\text {frac }}$, resultando em um compromisso complexidade $\times$ acurácia nas estimativas que pode acompanhar a evolução das tecnologias DSP.

Resultados de simulação mostraram que os estimadores baseados em heurísticas atingiram uma MSE similar ao do ML, com uma expressiva redução no custo computacional e no tempo de latência (pequenos tamanhos de frame).

Para este problema, os algoritmos indicados para utilização por possuírem a menor complexidade e o melhor desempenho / compromisso são o EP-C e o $\mathrm{HH}$, respectivamente. Essas indicações foram possíveis através da metodologia baseada em pontuação. 
Portanto, considerando uma topologia conjunta (estimativa e detecção), as estratégias heurísticas mostram-se como uma opção atrativa, pois atingem patamares de desempenho muito superiores aos obtidos com o receptor Rake na ausência de erros nas estimativas, além de manter o desempenho próximo ao $\mathrm{SuB}$ quando estimativas confiáveis puderem ser obtidas.

Além disso, como uma das principais contribuições deste trabalho, cita-se a obtenção e indicação de parâmetros otimizados bem como a definição das melhores estratégias para as etapas dos algoritmos heurísticos propostos. A análise de qualidade e estabilidade baseada em pontuação nas condições otimizadas foi realizada e verificada através do uso de diversas funções de testes utilizadas comumente na literatura, evidenciando o nível de otimização obtido. Vale ressaltar que os parâmetros otimizados e a definição das etapas dos algoritmos foram apresentados visando facilitar a compreensão e a consulta. Os resultados em cenários de telecomunicações demonstraram que os algoritmos heurísticos são capazes de encontrar excelentes soluções para todos os cenários simulados, validando a etapa de otimização dos parâmetros e escolha das estratégias intrínsecas aos algoritmos.

Assim, o método de classificação das topologias através de pontuação mostrouse adequada, pois possibilitou quantificar o nível de otimização dos parâmetros e posterior qualidade e estabilidade das soluções encontradas.

Outra contribuição importante consiste na determinação e análise da complexidade computacional para os algoritmos heurísticos propostos e para todos os 42 cenários de telecomunicações simulados. Desta forma, é possível utilizar as equações apresentadas e a metodologia para determinar e comparar outras técnicas de otimização em diversos cenários.

Também foi discutido o nível de implementabilidade das estratégias nos dias atuais, indicando que a crescente evolução no poder de processamento pode, em um futuro muito próximo, garantir a implementação destas estruturas heurísticas em sistemas $3 \mathrm{G}$ e $4 \mathrm{G}$.

Por fim, durante o desenvolvimento do trabalho, alguns temas mostraram-se interessantes e serão considerados em trabalhos futuros.

\subsection{Trabalhos Futuros}

Como trabalhos futuros, as seguintes direções são sugeridas:

1. Análise e comparação da complexidade de implementação dos algoritmos 
em DSP, levando em consideração a utilização de algoritmos eficientes para realizar as operações matriciais e a capacidade de paralelização de cada processo.

2. Análise da aplicabilidade de outros algoritmos heurísticos, como o de colônia de formigas e PSO, entre outros, visando determinar parâmetros e escolha das etapas de forma ótima, tornando ainda mais robusta a confecção do algoritmo HH através da incorporação de tais técnicas.

3. Definição e análise de outras topologias para o algoritmo HH, considerando o método de construção de heurísticas para posterior aplicação ao problemas $\mathrm{MuD}$ e MuChE.

4. Utilização das técnicas heurísticas em outras configurações de sistema, principalmente com parâmetros de topologias comercias, evidenciando os ganhos oriundos das técnicas heurísticas utilizadas.

5. Utilização dos algoritmos para outros tipos de problemas combinatórios existentes em sistemas DS/CDMA, como é o caso da otimização de sequências de espalhamento, alguns procedimentos de controle de potência, alocação dinâmica de recursos e garantia da qualidade de serviço (QoS) para os diversos tipos de serviços oferecidos.

6. Desenvolvimento de um modelo que considera uma metodologia iterativa e conjunta para a exploração total da diversidade disponível no receptor. Esta topologia considera a modelagem multidimensional com 5 dimensões distintas, conforme figura 6.1. Novamente, os algoritmos heurísticos deverão ser utilizados para otimização das funções custo, visando o desempenho de máxima verossimilhança individual e, consequentemente, desempenho ótimo global.

7. Análise para determinação teórica do número de gerações / iterações adequado à otimização dependente apenas dos parâmetros convencionais do sistema a ser otimizado. 


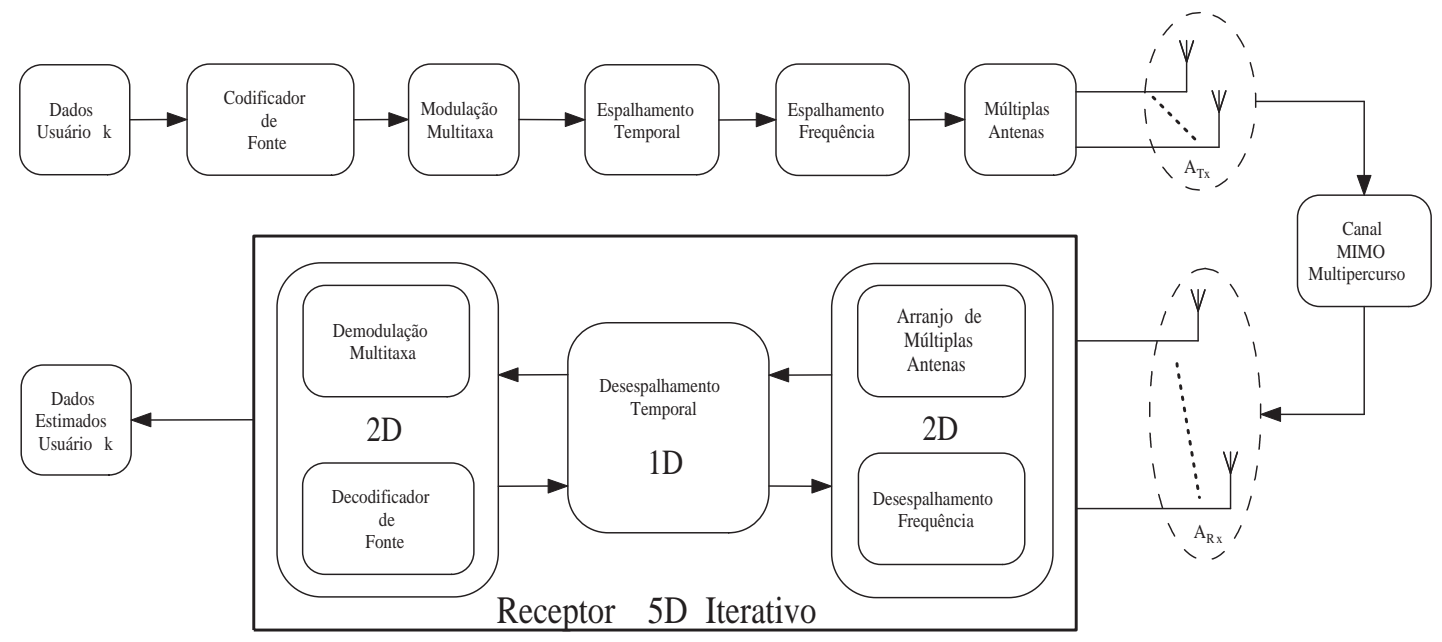

Figura 6.1: Sistema proposto para o transmissor e receptor com diversidade iterativa $5 \mathrm{D}$ 


\section{Apêndice A - Trabalhos Relevantes sobre Utilização de Algoritmos Heurísticos em Sistemas CDMA}

Visando manter o texto autocontido e ao mesmo tempo não cansativo, optouse por apresentar os principais trabalhos não citados anteriormente ou rapidamente comentados no presente apêndice. Além disso, considera-se importante a descrição dos principais avanços oriundos da utilização de algoritmos heurísticos na otimização de problemas inerentes aos sistemas sem fio DS/CDMA. Assim, evidencia-se o esforço da comunidade científica na proposição de topologias de deteç̧ão baseadas em heurísticas que agregam excelente compromisso desempenho $\times$ complexidade além de reforçar que trata-se de uma área de pesquisa relativamente nova, pois o primeiro artigo em periódico foi publicado em 1997.

O primeiro detector multiusuário baseado no algoritmo genético (GAMuD) foi proposto por Juntti et al. (JUNTTI; SCHLOSSER; LILLEBERG, 1997), sendo a análise realizada para um sistema CDMA síncrono através de um canal AWGN. Os autores concluíram que era necessário a utilização de boas soluções iniciais para que o algoritmo atingisse um desempenho razoável.

Posteriormente, Ergün et al. (ERGUN; HACIOGLU, 2000) propuseram uma estratégia GAMuD híbrida para um sistema AWGN assíncrono que utiliza um detector de cancelamento de interferência de múltiplos estágios (IC) como parte dos processos do GA, na tentativa de melhorar a taxa de convergência e reduzir a complexidade computacional.

No entanto, incorporando um elemento de busca local à estratégia do GAMuD, (YEN; HANZO, 2000) mostraram que o desempenho do algoritmo heurístico híbrido tende ao limite single-user ( $\mathrm{SuB}$ ) com uma diminuição significativa da complexidade computacional. Após, o algoritmo de Programação Evolucionária (EP) foi empregado pela primeira vez no problema da detecção multiusuário em canal AWGN síncrono (LIM; VENKATESH, 2003). Em seguida, Abrão et al. 
(ABRÃO; CIRIACO; JESZENSKY, 2004) sugeriram uma versão modificada para o algoritmo EP, incorporando procedimentos de clonagem e mutação adaptativa aplicados ao problema MuD.

Trabalhos considerando o efeito do canal multiplicativo com desvanecimento do tipo plano síncrono incluem (YEN; HANZO, 2001; CIRIACO; ABRÃO; JESZENSKY, 2004) e plano assíncrono (ERGUN; HACIOGLU, 2000; CIRIACO, 2004).

Detectores heurísticos híbridos combinando estratégias Clássicas e Analógicas têm sido propostos nos últimos 8 anos. Em (LIM; VENKATESH, 2003), utilizou-se um detector baseado no algoritmo de busca local $k$-opt considerando sistemas CDMA e canais assíncronos AWGN. Os resultados apresentaram-se como promissores, pois o desempenho obtido através de simulações estava próximo ao ótimo e a complexidade do algoritmo podia ser controlada através da diminuição ou aumento da vizinhança conforme variações da relação sinal-ruído. Em (LIM; VENKATESH, 2004) foi proposto um detector combinando o algoritmo EP para a fase inicial de otimização e o algoritmo $k$-opt para a fase final de refinamento do processo de deteç̧ão multiusuário para canal AWGN assíncrono.

Em 2004, Yen et al. (YEN; HANZO, 2004) utilizaram a estratégia GAMuD para estender os resultados de (YEN; HANZO, 2001) para um sistema DS/CDMA assíncrono transmitindo através de um canal com desvanecimento composto por 2 percursos, considerando os dois raios com mesma energia. Para reduzir a complexidade do detector e aumentar a velocidade de convergência, os autores aplicaram uma técnica de janelamento, resultando na detecção de apenas um símbolo por vez de todos os usuários. Em (TAN; RASMUSSEN, 2004), diversos métodos de otimização foram comparados considerando o problema de detecção multiusuário em cenários não muito realistas, i.e., canais AWGN síncronos. No entanto, a contribuição consistiu na comparação entre as diversas técnicas de otimização utilizadas (relaxações e heurísticas), podendo-se citar o algoritmo Branch and Bound (técnica exata), Busca Tabu e algoritmos de Busca Local (técnicas heurísticas). Desta forma, evidenciou-se a supremacia das técnicas heurísticas em termos de desempenho quando do aumento do número de usuários.

Em 2005, foi utilizado pela primeira vez o algoritmo de otimização baseado em nuvem de partículas (PSO - Particle Swarm Optimisation) em detecção multiusuário (EL-MORRA; SHEIKH; ZERGUINE, 2005). Considerou-se canais síncronos AWGN e comparou-se o desempenho em relação ao detector descorrelacionador. No entanto, não foram realizadas comparações de complexidade ou de desempenho com outras técnicas heurísticas. Em (EL-MORRA; SHEIKH; ZERGUINE, 2006), 
o mesmo autor utilizou os algoritmos de busca local e de busca Tabu de forma combinada na tentativa de diminuir a complexidade computacional e garantir um desempenho próximo ao ótimo. Os resultados apresentaram um ganho de desempenho e diminuição da complexidade quando comparados ao descorrelacionador e às estratégias de otimização utilizadas de forma individual. No entanto, o modelo de sistema considerava canais síncronos e apenas ruído AWGN.

Em (SHAH et al., 2006), uma ampla pesquisa sobre os avanços na área de detecção multiusuário foi realizada, considerando a utilização de detectores lineares (Descorrelacionador e o MMSE), detectores não-lineares (Cancelamento Sucessivo, Cancelamento Paralelo e Decisão realimentada), algoritmos heurísticos (Busca Local, Busca Tabu, Algoritmo Memético ${ }^{1}$ e Algoritmo Genético) e baseados em Redes Neurais. Embora tenha sido realizada uma descrição das topologias dos algoritmos e também das possibilidades de otimização, o trabalho não apresentou resultados numéricos de simulação, considerando apenas comparações subjetivas ou para casos particulares.

Neste mesmo ano, (OLIVEIRA et al., 2006) considerou a utilização de duas estratégias para o algoritmo PSO aplicados aos sistemas CDMA assíncronos e canais com desvanecimento plano em frequência. Neste mesmo cenário, expandiu-se a comparação de desempenho e complexidade considerando os algoritmos genéticos e de programação evolucionária com clonagem. Todos os algoritmos utilizados apresentaram desempenho muito próximo ao ótimo com uma redução drástica da complexidade computacional ${ }^{2}$. Evidenciou-se também, a sensibilidade das estratégias de detecção baseadas em heurísticas quando estimativas de parâmetros de canal não são obtidas de forma precisa.

Em (CIRIACO; ABRAO; JESZENSKY, 2006), pela primeira vez, foi considerado a utilização de algoritmos heurísticos (algoritmo genético) para a deteç̧ão multiusuário considerando sistemas DS/CDMA multitaxa em canais seletivos em frequência. Além disso, comprovou-se a aplicabilidade da estratégia heurística mesmo na condição de alto carregamento e com erros nas estimativas de parâmetros de canal. A redução na complexidade computacional foi apresentada comparando-a com a complexidade do detector ótimo.

Como resultado das pesquisas realizadas no período de 2002 a 2006, em (CI-

\footnotetext{
${ }^{1}$ Metaheurística pertencente à classe dos algoritmos populacionais com um processo evolutivo que tenha a busca local como parte decisiva na evolução. A ideia principal consiste na exploração da vizinhança das soluções obtidas por um algoritmo genético e caminhar em busca do ótimo local através de otimização por busca local (MOSCATO; PLATA; NORMAN, 1992).

${ }^{2} \mathrm{O}$ algoritmo genético apresentou a menor complexidade computacional dentre os algoritmos utilizados.
} 
RIACO, 2006) é analisado a técnica de otimização combinatória baseada no algoritmo genético aplicada aos problemas de detecção multiusuário e de estimativa de parâmetros (coeficientes de canal) em sistemas DS/CDMA unitaxa e multitaxa por códigos múltiplos sujeitos ao desvanecimento multipercurso. Distintas configurações para o sistema DS/CDMA foram analisadas, considerando distintos carregamentos de sistema, taxa de transmissão, perfil atraso-potência, entre outros. Além disso, avaliou-se a robustez dos algoritmos face as variações nos parâmetros de sistema e a perda de desempenho na ocorrência de erros nas estimativas de canal. A complexidade dos algoritmos foi analisada em termos da ordem de complexidade, do número de operações necessárias para se atingir a convergência e, para alguns casos, do tempo necessário à otimização e, posteriormente, comparadas às demais complexidades das estratégias mais utilizadas para cada um dos problemas.

Em (QIN; CAI; ZOU, 2007), de forma pioneira, apresentou-se uma estratégia baseada em heurística de busca local para o problema de decodificação iterativa SISO (Soft-Input Soft-Output) considerando a redução de complexidade em comparação aos algoritmos tradicionais baseados em probabilidade a posteriori $(\mathrm{APP})^{3}$. A complexidade resultante demonstrou-se ser muitas vezes menor do que a utilização do algoritmo APP e o desempenho resultante demonstrou-se viável, com possibilidade de evolução a medida que outros estudos fossem realizados.

No mesmo período, (LAIN; LAI, 2007) propuseram um detector multiusuário baseado no algoritmo de colônia de formigas (ACO - Ant Colony Optimisation) considerando diversidade espacial na recepção. O desempenho apresentado evidencia a possibilidade de utilização de técnicas heurísticas para otimização e exploração de diversos tipos de diversidade.

Em (AN; XU, 2008), utilizou-se o algoritmo PSO na deteç̧ão multiusuário em sistemas MIMO com codificação de bloco espaço-tempo (STBC). Novamente, tornou-se evidente a possibilidade e viabilidade em termos de desempenho e complexidade da utilização de estratégias heurísticas na exploração da diversidade.

No trabalho de (ABRAO et al., 2008a), analisa-se o compromisso desempenho $\times$ complexidade de três estratégias heurísticas (Recozimento Simulado, Busca Local e Nuvem de Partículas) aplicados a sistemas MIMO e multitaxa. Simulações demonstraram que o desempenho dos três algoritmos heurísticos após a convergência eram idênticos e com uma redução significativa da complexidade computacional $^{4}$. Além disso, em (OLIVEIRA et al., 2008) analisou-se o algoritmo

\footnotetext{
${ }^{3} \mathrm{~A}$ complexidade cresce exponencialmente com o número de usuários.

${ }^{4}$ Neste estudo, a estratégia baseada em Busca Local 1-opt apresentou o melhor compromisso.
} 
PSO e o de busca local 1-opt na detecção multiusuário em sistemas DS/CDMA com modulação de alta ordem, particularmente M-QAM. Os resultados apresentados demonstraram-se promissores, pois o desempenho obtido encontrava-se próximo ao ótimo e a complexidade foi reduzida drasticamente.

Em (ARIFIANTO et al., 2007; XU et al., 2008; XU, 2008; QIN; ZOU; CAI, 2008), foram propostas topologias utilizando o algoritmo Genético e o PSO para a redução da complexidade do receptor multiusuário turbo em sistemas com STBC, multiportadora (OFDM) e MIMO considerando canais com desvanecimento. Novamente, a utilização de estratégias heurísticas na otimização e exploração da diversidade em sistemas DS/CDMA mostrou-se atraente, pois agrega excelente desempenho (próximo ao ótimo ${ }^{5}$ ) com redução significativa da complexidade inerente ao processo de detecção.

Uma comparação em termos de desempenho e complexidade entre os principais algoritmos heurísticos em sistemas com multiportadora e multitaxa foi realizada em (ABRAO et al., 2008b), pois comparou-se os algoritmos genéticos, recozimento simulado e lista Tabu.

Em (LIU; SONG, 2009), apresentou-se um detector multiusuário baseado na otimização multiobjetivo através da utilização do algoritmo genético. Considerouse a otimização para um sistema com multiportadora e codificação de bloco espaço-tempo (STBC MC-CDMA). Para resolver a função multiobjetivo considerouse a região de Pareto. As análises de simulação indicaram que o esquema proposto atingiu um excelente compromisso desempenho $\times$ complexidade.

Por fim, em (ZHANG; HANZO, 2010) foi proposto um novo esquema no receptor em sistemas DS/CDMA considerando a estimativa iterativa conjunta de coeficientes de canal, detecção multiusuário e decodificação utilizando uma estratégia heurística chamada de Busca Harmônica (Harmony Search). Os resultados de simulação demonstraram ser próximos ao ótimo e com uma complexidade inerente muito inferior.

Desta forma, fica evidente que trata-se de uma área com espaço para contribuições, principalmente trabalhos focados na utilização de técnicas heurísticas em sistemas atuais $3 \mathrm{G}$ e posteriormente $4 \mathrm{G}$ visando o aumento de qualidade, taxa de transmissão, aumento no número de usuários ativos, disponibilidade de diversos serviços entre outros benefícios.

\footnotetext{
${ }^{5} \mathrm{O}$ desempenho é significativamente melhorado devido à exploração quase total da diversidade disponível.
} 


\section{Apêndice B - Resumo das Principais Publicações}

Este apêndice tem por objetivo apresentar as pesquisas realizadas que possibilitaram ao candidato propor e posteriormente desenvolver este trabalho. Assim, considera-se que os últimos nove anos de estudo do autor, sendo os dois primeiros realizados ainda na graduação, dois no período de desenvolvimento do mestrado e cinco anos no período de doutoramento, na área de telecomunicações, especificamente na área de detecção multiusuário e estimativa de parâmetros utilizando algoritmos heurísticos em sistemas sem fio com espalhamento espectral foram essenciais para a confecção do trabalho atual, sendo cronologicamente descritos a seguir.

\section{B.1 Trabalhos Anteriores}

Inicialmente, os estudos em detecção multiusuário circunscreveram-se ao que já estava bem estabelecido na literatura, como os detectores multiusuário lineares e os canceladores de interferência. Posteriormente, iniciou-se uma procura de possíveis melhorias para as estratégias já conhecidas na literatura e buscou-se novos receptores multiusuário no intuito de promover um aumento no desempenho e uma diminuição da complexidade. Nesta etapa, observou-se uma possível, e atraente, aplicabilidade de técnicas heurísticas na diminuição da complexidade do detector multiusuário ótimo sem que o desempenho fosse degradado consideravelmente, iniciando, a partir daí, uma nova etapa de estudos das possíveis técnicas heurísticas passíveis de adaptação ao problema da detecção multiusuário para sistemas DS/CDMA.

As análises iniciais de técnicas heurísticas aplicadas ao problema MuD, baseadas em trabalhos esparsos encontrados na literatura da época, consideravam canais não muito realistas, ou seja, canais síncronos puramente AWGN. Mas os resultados obtidos mostraram-se promissores, tanto do ponto de vista de desempenho quanto do ponto de vista da complexidade computacional. 
Por isso, as análises foram estendidas para canais mais realistas, plano síncrono e assíncrono e por fim, canais multipercurso. Observou-se que mesmo em canais mais realistas e complexos, os resultados obtidos apresentaram um desempenho muito próximo ao ótimo com uma enorme redução da complexidade em relação ao $\mathrm{OMuD}$.

O único inconveniente das técnicas de detecção baseadas em heurísticas é a necessidade de se "conhecer" alguns parâmetros do sistema, como coeficientes de canal, amplitude (potência) dos usuários e atraso dos multipercursos. Logicamente, isso não deve ser visto como uma limitação da estratégia, já que existem diversas técnicas para obter essas estimativas e os outros receptores multiusuário encontrados na literatura também necessitam de tais parâmetros. No entanto, as técnicas utilizadas para estimar esses parâmetros do sistema, na maioria das vezes, são complexas, além de não apresentarem um desempenho ótimo. A seguir, apresenta-se um resumo das principais publicações em congressos/revistas nacionais e internacionais relacionadas ao desenvolvimento desse trabalho. Este estudo foi realizado pelo autor no período de sua graduação (2000 - 2004) e mestrado (2005 - 2006) em Engenharia Elétrica pela Universidade Estadual de Londrina, PR.

Vale ressaltar que no período de 2005 a 2006, dentro do programa de mestrado, os esforços continuaram na análise e busca de um detector com desempenho quase ótimo de baixa complexidade; adicionalmente, procurou-se o desenvolvimento de um estimador de parâmetros para o sistema DS/CDMA utilizando a mesma estrutura do algoritmo de detecção. Esse estimador também deveria agregar as qualidades de baixa complexidade computacional e excelentes figuras de mérito.

Nesse ponto da investigação alguns caminhos surgiram e novas metas foram estabelecidas, considerando:

1. Análise de desempenho (BER) para sistemas multitaxa.

2. Análise da "sensibilidade" das técnicas heurísticas quando da ocorrência de erros nas estimativas dos parâmetros do sistema.

3. Análise das técnicas heurísticas para a obtenção dos seguintes parâmetros do sistema: coeficientes de canal, amplitude dos sinais recebidos e atrasos dos multipercursos.

O trabalho de mestrado permitiu que essas metas fossem cumpridas. Os 
resultados dessas análises podem ser encontrados nas publicações em congressos/revistas nacionais e internacionais, relacionadas a seguir:

- Ciriaco , F. ; Abrão, Taufik ; Jeszensky, Paul Jean E. DS/CDMA Multiuser Detection With Evolutionary Algorithms. International Journal Of Foundations Of Computer Science, v. 12, n. 4, p. 450-480, 2006.

- Ciriaco , F. ; Heringer, Lisiane ; Albuquerque, Luiz Carlos ; Abrão, Taufik ; Jeszensky, Paul Jean E. Detectores Multiusuário Adaptativos Para DSCDMA. Semina. Ciências Exatas E Tecnológicas, v. 27, p. 63-78, 2006.

- Ciriaco , F. ; Abrão, Taufik ; Jeszensky, Paul Jean E. . Multirate Multiuser Ds/Cdma With Genetic Algorithm Detection In Multipath Channels. In: 2006 IEEE International Symposium On Spread Spectrum Techniques And Applications, 2006, Manaus.

- Ciriaco , F. ; Abrão, Taufik ; Jeszensky, Paul Jean E. . Genetic Algorithm Applied To Multipath Multiuser Channel Estimation In DS/CDMA Systems. In: 2006 IEEE International Symposium On Spread Spectrum Techniques Ans Applications, 2006, Manaus.

- Oliveira, Leonardo Dagui De ; Ciriaco , F. ; Abrão, Taufik ; Jeszensky, Paul Jean E. . Particle Swarm And Quantum Particle Swarm Optimization Applied To DS/CDMA Multiuser Detection In Flat Rayleigh Channels. In: 2006 IEEE International Symposium On Spread Spectrum Techniques Ans Applications, 2006, Manaus.

- Ciriaco , F. ; Oliveira, Leonardo Dagui De ; Abrão, Taufik ; Jeszensky, Paul Jean E. . Algoritmos Swarm, Genético E Programação Evolucionária Aplicados À Detecção Multiusuário DS/CDMA. Semina. Ciências Exatas E Tecnológicas, v. 26, p. 195-209, 2005.

- Ciriaco , F. ; Abrão, Taufik ; Jeszensky, Paul Jean E. . Sistemas DS/CDMA Multitaxa Com Detector Heurístico-Genético Em Canais Multipercurso. Semina. Ciências Exatas E Tecnológicas, v. 26, p. 155-166, 2005.

- Ciriaco , F. ; Abrão, Taufik ; Jeszensky, Paul Jean E. . Genetic Algorithm Multiuser Detection In Fading Channel With Parameters Errors Estimates. International Microwave \& Optoeletronics Conference, 2005.

- Ciriaco , F. ; Abrão, Taufik ; Jeszensky, Paul Jean E. . Detecção Multiusuário Utilizando Algoritmos Heurísticos Evolucionários E De Busca Local. Semina. Ciências Exatas E Tecnológicas, v. 25, p. 145-162, 2004. 
- Ciriaco , F. ; Abrão, Taufik ; Jeszensky, Paul Jean E. . Algoritmos Heurísticos Aplicados À Deteç̧ão Multiusuário DS/CDMA. Revista Da Sociedade Brasileira De Telecomunicações, v. 20, n. 2, p. 37-51, 2004.

- Ciriaco , F. ; Abrão, Taufik ; Jeszensky, Paul Jean E. . Análise De Desempenho De Detectores Multi-Usuários Lineares Para Sistemas DS/CDMA. Semina. Ciências Exatas E Tecnológicas, Londrina - Paraná, v. 25, p. 69-82, 2004.

- Ciriaco , F. ; Abrão, Taufik ; Jeszensky, Paul Jean E. . Algoritmos Heurísticos Evolucionários Aplicados À Detecção Multiusuário DS/CDMA. In: XXI Simpósio Brasileiro De Telecomunicações-Sbt 04, 2004, Belém.

- Abrão, Taufik ; Ciriaco , F. ; Jeszensky, Paul Jean E. . Evolutionary Programming With Cloning And Adaptive Cost Function Applied To MultiUser. In: 2004 IEEE International Symposium On Spread Spectrum Techniques Ans Applications, 2004, Sydney.

- Ciriaco , F. ; Abrão, Taufik . Desempenho De Detectores Multi-Usuários Lineares Para Sistemas DS/CDMA. In: 56 a Reunião Anual Da Sbpc, 2004, Cuiabá.

- Ciriaco , F. ; Abrão, Taufik . Deteç̧ão Multiusuário Utilizando Algoritmos Heurísticos Evolucionários E De Busca Local. In: XIII Encontro Anual De Iniciação Científica, 2004, Londrina.

- Ciriaco , F. ; Abrão, Taufik . Algoritmos Heurísticos Aplicáveis À Detecção Multiusuário. In: XII Congresso De Iniciação Científica Da UFSCAR, 2004, São Carlos.

- Ciriaco , F. ; Abrão, Taufik . Desempenho De Detectores Multi-Usuários Lineares Para Sistemas DS/CDMA. In: XII EAIC - Encontro Anual De Iniciação Científica, 2003, Foz Do Iguaçu.

\section{B.2 Trabalhos Atuais}

A partir de 2007, dentro do programa de Doutorado em Engenharia Elétrica da Escola Politécnica da Universidade de São Paulo, buscou-se a investigação envolvendo a aplicação de algoritmos heurísticos aos sistemas de comunicação de telefonia celular de terceira e quarta gerações, redes pessoais, locais e metropolitanas sem fio que utilizam as técnicas de multiportadoras, espalhamento espectral 
por sequência direta (DSSS), múltiplas antenas de transmissão e/ou recepção (sistemas SISO, SIMO, MISO e MIMO) e sistemas codificados no tempo (Turbo, LDPC) ou no espaço-tempo (STBC). Objetivou-se utilizar algoritmos heurísticos na proposição de novas estruturas de transmissão e/ou recepção, particularmente para a detecção e estimação de parâmetros, tendo em vista o aumento de desempenho, agregando melhoria da qualidade de serviço e eficiência espectral com uma reduzida complexidade computacional, considerando nas simulações condições de propagação realistas.

Para isso, alguns tópicos e investigações tornaram-se necessários como um processo evolutivo para a descoberta de novas estruturas de recepção e utilização de algoritmos heurísticos, podendo-se citar os principais:

1. Análise de detectores heurísticos em sistemas com multiportadoras.

2. Análise de detectores heurísticos em sistemas codificados no tempo (Turbo, LDPC) e no espaço-tempo (STBC).

3. Análise de estimadores e detectores de forma conjunta em sistemas multitaxa DS/CDMA.

4. Análise de desempenho de algoritmos heurísticos em sistemas com múltiplas antenas (MIMO).

5. Análise de desempenho e complexidade de diversos algoritmos heurísticos para os cenários acima descritos e utilização destes algoritmos em alguns cenários com mais de uma diversidade combinada, i.e., com diversidade espacial (sistemas MIMO) e diversidade de frequência (multiportadoras), com diversidade espacial e codificação espaço-tempo (STBC), entre outras, resultando em topologias inéditas de recepção.

6. Utilização de algoritmos heurísticos na construção de sequências otimizadas para sistemas multitaxa do tipo MPG QS-CDMA.

Desta forma, no período de 2007 a 2011, dentro do programa de doutorado, os esforços continuaram e as investigações realizadas resultaram em diversas publicações em congressos/revistas nacionais e internacionais abaixo relacionadas. Assim, fica evidente o avanço das investigações para cenários mais realistas e com possibilidade de implementação em sistemas que necessitam de uma crescente melhoria da qualidade de serviço e aumento da eficiência espectral considerando topologias de reduzida complexidade computacional. 
- Kuramoto, A. S. R. ; Ciriaco , F. ; Abrão, Taufik ; Jeszensky, Paul Jean E. . Sequence Design For Mpg Qs-Cdma Systems Based On Heuristic Combinatorial Optimization. Wireless Communications And Mobile Computing, v.12, p. $236-247,2012$.

- Abrão, Taufik ; Suzuki, I. ; Ciriaco , F. ; Angelico, B. A. ; Jeszensky, Paul Jean E. ; Casadevall, F. . Reduced Cluster Search ML Decoding For Qo-STBC M-QAM Mimo Systems. International Journal Of Satellite Communications Policy And Management, v. 1, n.1, p. 15 - 30. 2011.

- Ciriaco , F. ; Abrão, Taufik ; Toledo, A. F. ; Jeszensky, Paul Jean E. . Jointly Multi-User Detection And Channel Estimation With Genetic Algorithm. Wireless Communications And Mobile Computing, v. 11, p. 767-782, 2011.

- Okano, Wagner ; Ciriaco , F. ; Abrão, Taufik . Confiabilidade Do Canal Em Codificação Turbo DS/CDMA Sujeito A Desvanecimento Rayleigh E Interferência De Múltiplo Acesso. Revista IEEE América Latina, v. 8, p. $1-8,2010$.

- Oliveira, Leonardo D. ; Ciriaco , F. ; Abrão, Taufik ; Jeszensky, Paul Jean E. . Local Search Multiuser Detection. Aeü. International Journal Of Electronics And Communications, v. 63, p. 259-270, 2009.

- Abrão, Taufik ; Oliveira, Leonardo Dagui De ; Ciriaco , F. ; Angelico, B. A. ; Jeszensky, Paul Jean E. ; Casadevall, F. . S/MIMO MC-CDMA Heuristic Multiuser Detectors Based On Single-Objective. Wireless Personal Communications, v. 49, p. 529-553, 2009.

- Okano, Wagner ; Ciriaco , F. ; Abrão, Taufik . Confiabilidade Do Canal Em Sistemas DS/CDMA Com Codificação Turbo Sujeitos Ao Desvanecimento Lento E Seletivo Em Frequência E Interferência De Múltiplo Acesso. Semina. Ciências Exatas E Tecnológicas, v. 28, p. 101-113, 2007.

- Suzuki, I. ; Abrão, Taufik ; Ciriaco , F. ; Angelico, B. A. ; Jeszensky, Paul Jean E. ; Casadevall, F. . Reduced Cluster Search ML Decoding For QoSTBC Systems. In: Spacomm - International Conference On Advances In Satellite And Space Communications, 2009, Colmar.

- Ciriaco , F. ; Okano, Wagner ; Abrão, Taufik ; Jeszensky, Paul Jean E. - Estratégia Heuristica De Baixa Complexidade Aplicada À Decodificação Multiusuário Em Sistemas DS/CDMA. In: XXVII Simpósio Brasilieiro De Telecomunicações, 2009, Blumenau. 
- Jacob, J. L. ; Suzuki, I. ; Ciriaco , F. ; Angelico, B. A. ; Abrão, Taufik ; Jeszensky, Paul Jean E. . Decodificação De Sistemas Qo-STBC Baseada Em Máxima Verossimilhança E Agrupamento Reduzido. In: XXVII Simpósio Brasileiro De Telecomunicações, 2009, Blumenau.

- Stábile Filho, M ; Durand, Fábio Renan ; Ciriaco , F. ; Abrão, Taufik . Controle De Potência Em Redes Ocdma Estrela De Múltiplo Acesso Via Modelo De Verhulst. In: XXVII Simpósio Brasileiro De Telecomunicações, 2009, Blumenau.

- Abrão, Taufik ; Oliveira, Leonardo Dagui De ; Ciriaco, Fernando ; Angelico, B. A. ; Jeszensky, Paul Jean E. ; Casadevall, F. . Weighting Particle Swarm Optimization Simo Mc-Cdma Multiuser Detectors. In: ISSSTA 2008 - 10th International Symposium On Spread Spectrum Techniques And Applications, 2008, Bologna.

- Abrão, Taufik ; Ciriaco, Fernando ; Oliveira, Leonardo Dagui De ; Angelico, B. A. ; Jeszensky, Paul Jean E. ; Casadevall, F. . Weighting Particle Swarm, Simulation Annealing And Local Search Optimization For S/MIMO MCCDMA Systems. In: IEEE Swarm Intelligence Symposium, 2008.

- Okano, Wagner ; Ciriaco, Fernando ; Abrão, Taufik . Channel Reliability In Turbo-Coded Ds/Cdma Systems Under Rayleigh Fading Channels. In: 2nd International Conference On Signal Processing And Communication Systems, 2008, Gold Cost.

- Abrão, Taufik ; Ciriaco, Fernando ; Oliveira, Leonardo Dagui De ; Angelico, B. A. ; Jeszensky, Paul Jean E. ; Casadevall, F. . GA, SA, and TS Near-Optimum Multiuser Detectors For S/MIMO MC-CDMA Systems. In: Fourth Ieee Conference On Wireless Communication And Sensor Networks, 2008, Allahabad (U.P.).

- Abrão, Taufik ; Suzuki, I. ; Ciriaco, Fernando ; Oliveira, Leonardo Dagui De - Reduced Tree-Search, Heuristic And Linear Decoupler Low-Complexity Mimo Detectors. In: Fourth Ieee Conference On Wireless Communication And Sensor Networks, 2008, Allahabad (U.P.).

- Okano, Wagner ; Ciriaco , F. ; Abrão, Taufik . Confiabilidade Do Canal Em Sistemas DS/CDMA Com Codificação Turbo Sujeitos Ao Desvanecimento Lento E Seletivo Em Frequência. In: XXV Simpósio Brasileiro De Telecomunicações, 2007, Recife. 
- Heringer, Lisiane ; Ciriaco , F. ; Angelico, B. A. ; Abrão, Taufik ; Jeszensky, Paul Jean E. . Desempenho-Complexidade De Sistemas DS-UWB Em Canais Multipercursos Densos. In: Simpósio Brasileiro De Telecomunicações, 2007, Recife.

Note que os trabalhos desenvolvidos consideraram sistemas mais realistas, mas, no entanto, a otimização não é realizada de forma conjunta e iterativa. Desta forma, com o andamento da investigação algumas novas ideias surgiram e diferentes caminhos foram estabelecidos, considerando:

1. Construção de um modelo para o sistema sem fio que apresente a possibilidade de otimização baseado no princípio de máxima verossimilhança considerando diversas dimensões de diversidade e possibilidade de otimização conjunta e iterativa.

2. Busca de uma estrutura de recepção única e iterativa baseada em algoritmos heurísticos capaz de otimizar os diferentes problemas em sistemas com mais de uma diversidade envolvida de forma conjunta, trazendo benefícios de otimização da exploração da diversidade disponível.

3. Análise, formalização e sistematização da aplicação de algoritmos heurísticos em problemas de telecomunicações, demonstrando seus limiares de desempenho e de convergência para sistemas com várias dimensões de diversidade.

Portanto, de forma resumida, a proposta de pesquisa de doutorado procurou expandir as análises realizadas nos trabalhos anteriores, considerando a aplicação de algoritmos heurísticos não somente em sistemas DS/CDMA (telefonia celular) mas também em outras tecnologias de comunicação utilizadas nas redes locais e metropolitanas sem fio (multiportadora, MIMO, STBC, Decodificação Turbo, LDPC, entre outras), indicando topologias inéditas para melhorar a qualidade da transmissão/recepção desses sistemas.

Por fim, vale ressaltar que o background adquirido pelo candidato no período de investigação apresentado e a expansão deste nos últimos dois anos foi essencial para a proposição de aplicabilidade de estratégias de otimização multidimensional baseadas em heurísticas em sistemas com grande aproveitamento de diversidade e alto desempenho, além da consolidação da aplicabilidade das estratégias heurísticas para estes problemas. 


\section{Apêndice C - Canais de Rádio Móveis}

O canal pode ser entendido como uma variável não envolvida nos processos de transmissão e recepção, mas que, de alguma forma, influencia na informação.

Em sistemas CDMA, o canal é representado como o bloco intermediário entre a transmissão e recepção de um sinal espectralmente espalhado, comumente dividido em: ruído aditivo ${ }^{1}$, constituído pela contribuição das antenas de transmissão e recepção e pelo ruído térmico gerado nos primeiros estágios do receptor, e o ruído multiplicativo, constituído do canal físico de propagação.

Contudo, o estudo dos canais de rádio móveis é muito amplo e este trabalho não tem intenção de fazê-lo em profundidade. O que se pretende é apresentar alguns conceitos básicos essenciais ao estudo dos receptores e assim justificar o modelo matemático considerado nas simulações.

\section{C.1 Ruído Multiplicativo - Meio Físico de Propa- gação}

O canal pode ser explicado através de características físicas, como fenômenos atmosféricos e composição gasosa, juntamente com a característica de mobilidade entre transmissor e receptor.

As ondas de rádio de alta frequência interagem com as superfícies presentes no canal, sendo comum a identificação de fenômenos como reflexão, difração e dispersão. Como mudanças de características atmosféricas e de posição relativa entre antenas de transmissão e recepção ocorrem constantemente, a resposta impulsiva do canal é do tipo variante no tempo. Isto causa flutuações na amplitude e forma de onda do sinal, sendo chamado de desvanecimento ou fading. Assumese aqui que o desvanecimento do canal é lento o suficiente para que o coeficiente de canal possa ser considerado constante durante o período de bit.

\footnotetext{
${ }^{1}$ Também denominado de ruído térmico ou ruído de fundo.
} 
Quando as condições de propagação mudarem, devido por exemplo à mobilidade do transmissor e/ou receptor, fazendo com que as amplitudes recebidas variem com o tempo (efeito Doppler), porém sem a introdução de distorção nas formas de onda do sinal, ter-se-á um canal com Desvanecimento Plano em Frequência.

A frequência de deslocamento Doppler é definida como o deslocamento Doppler associado à velocidade relativa entre o receptor e o transmissor:

$$
f_{D}=f_{c} \frac{v_{\max }}{c_{l u z}}
$$

onde $f_{c}$ é a frequência da portadora, $v_{\max }$ é a velocidade do móvel e $c_{l u z}$ é a velocidade da luz no vácuo. Devido à mudanças nas características do canal de rádio móvel, este é modelado através de processos estocásticos, utilizando funções densidade de probabilidade específicas.

Neste trabalho foi empregado um modelo de canal cujo efeito sobre a envoltória do sinal recebido pode ser descrito por uma distribuição estatística caracterizada pela função densidade de probabilidade de Rayleigh:

$$
p_{d f}(r)=r e^{-\frac{r^{2}}{2}}
$$

para $r \geq 0$, onde $r$ é a amplitude do sinal.

No intuito de compreender o efeito que o desvanecimento exerce sobre o sinal recebido e como simular estes efeitos em banda base, descreve-se abaixo um modelo para canal Rayleigh, neste caso, plano em frequência, amplamente utilizado em simulações de sistemas DS/CDMA. No entanto, nas simulações para canais multipercursos, o canal não é plano em frequência, e sim seletivo. Para simular esse efeito, normaliza-se os coeficientes gerados pelo perfil atraso-potência adotado nas simulações. Para cada percurso são gerados coeficientes estatisticamente independentes e posteriormente são normalizados pelo perfil atraso-potência.

Por fim, o modelo adotado neste trabalho foi baseado no modelo de Jakes Modificado (JAKES, 1974; DENT; BOTTOMLEY; CROFT, 1993).

\section{C.1.1 Modelo de Jakes Modificado}

Originalmente proposto em (JAKES, 1974) e posteriormente modificado por (DENT; BOTTOMLEY; CROFT, 1993), o modelo de Jakes é um método determinístico para a simulação de canal com desvanecimento Rayleigh com formas de onda descorrelacionadas no tempo. 
Este método é baseado na composição de sinais de algumas dezenas de osciladores senoidais de mesma frequência com fases e ângulos de chegada distintos, sendo às vezes denominado de método multitom. O modelo assume que $N_{d}$ sinais (ondas planas) de mesma intensidade chegam a um receptor móvel com ângulos de incidência, $\alpha_{n}$, uniformemente distribuídos, resultando em distintas frequências de deslocamento Doppler, $w_{d}$. A forma de onda contínua para o desvanecimento é dada por:

$$
C(t)=\sqrt{\frac{2}{N_{d}}} \sum_{n=1}^{N_{d}} e^{j w_{n} t+\phi_{n}}
$$

onde: $N_{d}$ é o número de osciladores, inteiro tal que $\frac{N_{d}-2}{4}$ resulta um número inteiro; $w_{n}=w_{d} \cos \alpha_{n} ; w_{d}=2 \pi f_{c} v_{d} / c_{l u z}$ é a máxima frequência angular de deslocamento Doppler; $v_{\max }$ é a velocidade de deslocamento do móvel; $f_{c}$ é a frequência da portadora e $c_{l u z}$ é a velocidade da luz; $\alpha_{n}=2 \pi \frac{n}{N_{d}}$ é o ângulo de incidência, uniformemente distribuído em $\left(n=1, \ldots, N_{d}\right)$ e $\phi_{n}$ é a fase inicial para cada oscilador $\left(n=1, \ldots, N_{d}\right)$.

Em processos com desvanecimento deseja-se que os sinais em fase e quadratura tenham potências idênticas e não sejam correlacionados:

$$
\begin{gathered}
\mathbb{E}\left[\left|\Im\left\{C(t)^{2}\right\}\right|\right]=\mathbb{E}\left[\left|\Re\left\{C(t)^{2}\right\}\right|\right]=1 / 2 \\
\mathbb{E}[\Im\{C(t)\} . \Re\{C(t)\}]=0
\end{gathered}
$$

Se os termos fase inicial e final dos osciladores forem escolhidas arbitrariamente na equação (C.3), têm-se que as duas condições acima não serão satisfeitas simultaneamente. Para satisfazer ambas as condições, pode-se aumentar o número total de osciladores ou então modificar os ângulos de incidência, $\alpha_{n}$.

Esta foi a modificação feita por Dent, (DENT; BOTTOMLEY; CROFT, 1993) no modelo de Jakes. Esta modificação introduziu uma rotação nos ângulos de incidência dos osciladores de $\pi / N_{d}$, satisfazendo simultaneamente a equação (C.4) e equação (C.5). Com tal modificação, os ângulos de chegada tornam-se $\alpha_{n}=$ $2 \pi \frac{(n-0,5)}{N_{d}}$, com $n=1, \ldots, N_{d}$, eliminando-se os ângulos críticos de incidência $0^{\circ} \mathrm{e}$ $180^{\circ}$, resultando nas seguintes formas de onda para os coeficientes:

$$
\begin{aligned}
C(t) & =\sqrt{\frac{2}{N_{\text {osc }}}} \sum_{n=1}^{N_{\text {osc }}}\left[e^{j\left(w_{n} t+\phi_{n}\right)}+e^{-j\left(w_{n} t+\phi_{-n}\right)}\right] \\
& =\sqrt{\frac{2}{N_{\text {osc }}}} \sum_{n=1}^{N_{o s c}} e^{j \phi_{n}} \cos \left(w_{n} t+\theta_{n}\right)
\end{aligned}
$$

com $N_{o s c}=N_{d} / 4 ; \phi_{n}=\pi n / N_{o s c} ; \theta_{n}=$ fases iniciais para cada um dos $N_{\text {osc }}$ 
osciladores; impondo fases iniciais aleatórias com distribuição uniforme em $[ \pm \pi]$ obtêm-se as formas de onda para os coeficientes que seguem distribuição Rayleigh para o $|C(t)|$ e distribuição uniforme para a $\measuredangle C(t)$.

Como exemplo da validade do modelo na obtenção dos coeficientes do canal, foi utilizado $N_{o s c}=36$ para o número de osciladores; $f_{c}=2 G H z$ para a frequência da portadora e $v_{\max }=120 \mathrm{Km} / \mathrm{h}$ para a velocidade máxima do móvel. Isto resulta numa frequência Doppler máxima, $\underset{\max }{f_{D}}=222,2 \mathrm{~Hz}$.

Conjuntos de amostras obtidos por simulação mostraram que as componentes em fase e em quadratura dos coeficientes têm aproximadamente a mesma energia, $\mathbb{E}\left[\left|\Re\left\{C(t)^{2}\right\}\right|\right] \approx \mathbb{E}\left[\left|\Im\left\{C(t)^{2}\right\}\right|\right]$, e não são correlacionadas, $\mathbb{E}[\Im\{C(t)\} \Re\{C(t)\}]=$ 0, figura C.1.
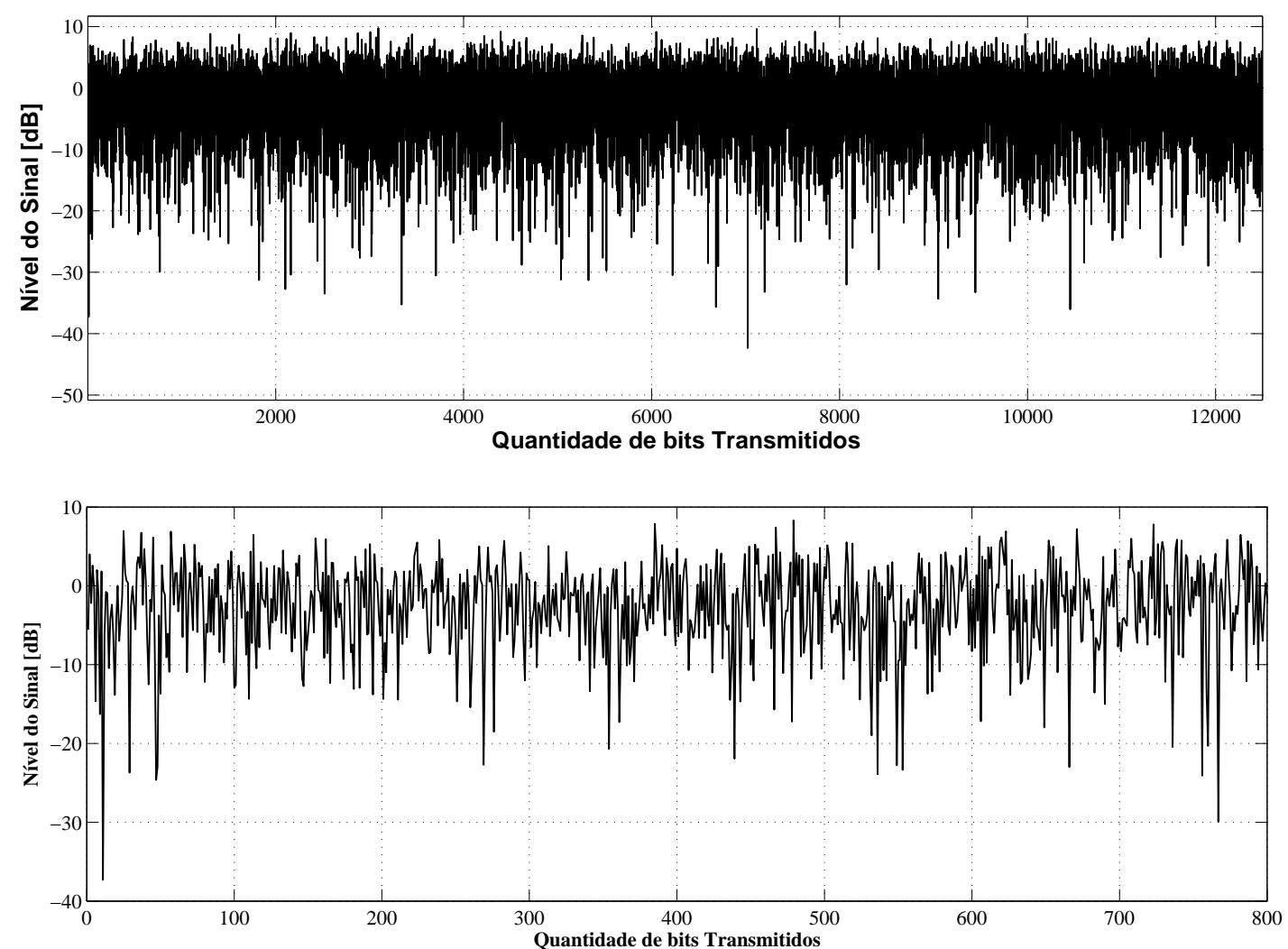

Figura C.1: Coeficientes de um canal Rayleigh Plano com 12500 amostras e com zoom em 800 amostras

Os valores obtidos para a energia e correlação, nesta simulação, foram:

$$
\begin{gathered}
\mathbb{E}\left[\left|\Re\left\{C(t)^{2}\right\}\right|\right]=0,5101 \\
\mathbb{E}\left[\left|\Im\left\{C(t)^{2}\right\}\right|\right]=0,4919 \\
\mathbb{E}[\Im\{C(t)\} . \Re\{C(t)\}]=0,0053
\end{gathered}
$$


A amplitude e fase das amostras apresentaram distribuição estatística de Rayleigh e uniforme, respectivamente, como ilustrado na figura C.2. Neste caso, foi considerado uma número de amostras igual a 12500.
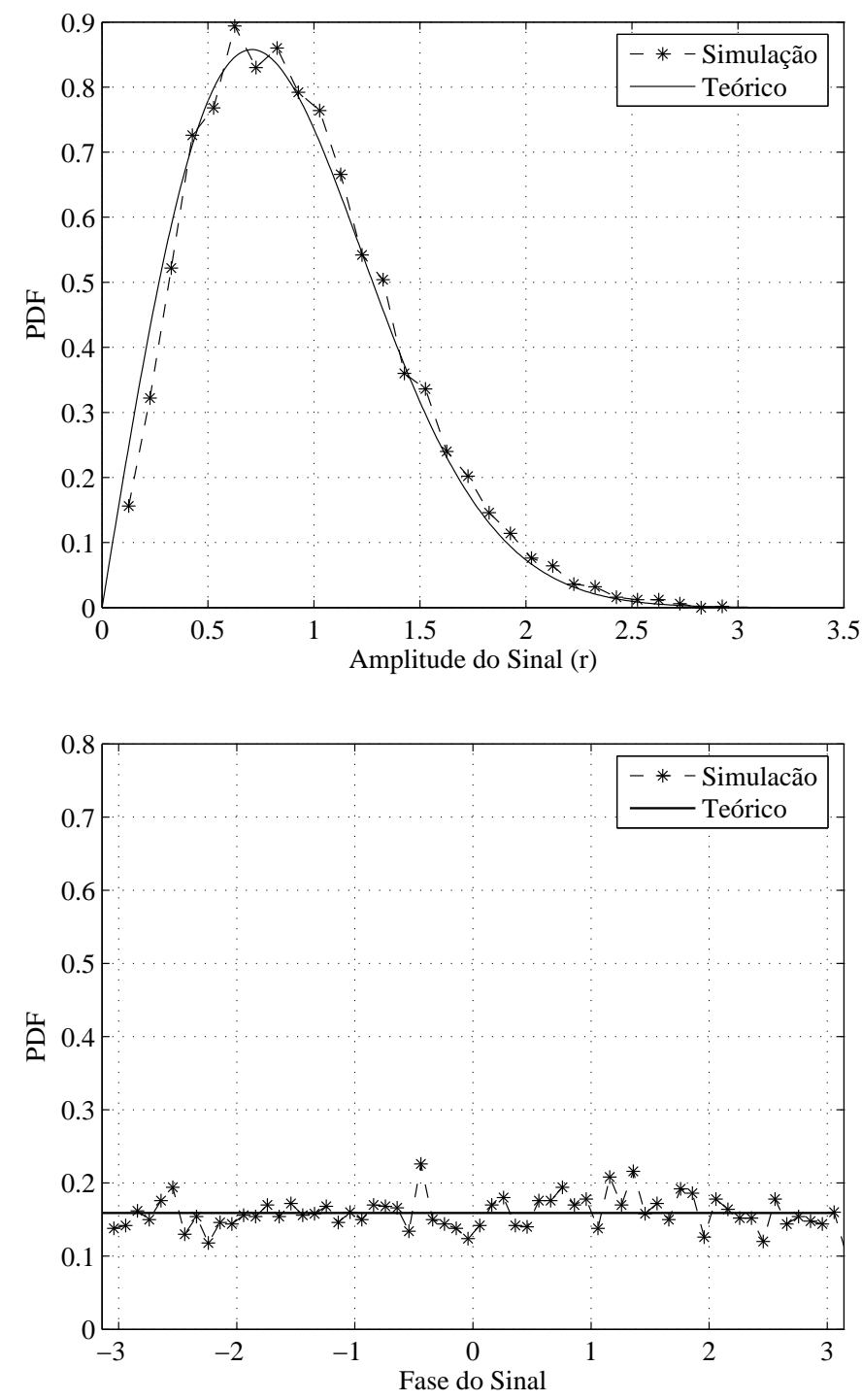

Figura C.2: Distribuição para amplitude e fase para coeficientes de um canal com desvanecimento Rayleigh implementado a partir modelo de Jakes modificado.

Evidencia-se, portanto, a aplicabilidade e validade do modelo de Jakes Modificado utilizado neste trabalho.

\section{C.2 Ruído de Fundo}

Além de distorcerem os sinais transmitidos, os canais de rádio móveis possuem uma parcela ruidosa. Esse sinal ruidoso é em grande parte gerado pela antena de recepção e pelos primeiros estágios amplificadores do circuito receptor. 
Nos circuitos receptores o sinal ruidoso é gerado internamente, sendo proveniente do movimento de elétrons em seus componentes devido unicamente à energia térmica, sendo chamado de ruído térmico.

Comumente, este ruído é modelado como um processo estocástico com distribuição normal de média zero e com função densidade espectral de potência constante ao longo de uma banda muito larga ${ }^{2}$, sendo que este ruído é adicionado ao sinal transmitido espectralmente espalhado.

Nestas condições, o ruído recebe a denominação de ruído aditivo branco com distribuição Gaussiana (AWGN). Sua função densidade de probabilidade é dada por:

$$
p_{d f}(x)=\frac{1}{\sqrt{2 \pi \sigma^{2}}} \cdot e^{\left(-\frac{x^{2}}{\sigma^{2}}\right)}
$$

onde $\sigma^{2}=N_{0}$ é a variância do ruído.

A adição de AWGN ao conjunto de sinais transmitidos deve seguir algumas relações visando ajustar corretamente o nível de potência deste ruído. Para tanto, adotou-se os seguintes procedimentos de simulação Monte Carlo na geração e adição do AWGN ao sinal.

Em um sistema CDMA com modulação BPSK, códigos curtos e formatação de pulsos retangulares, com 1 amostra/chip, a relação entre as energias de bit e a de ruído é:

$$
\frac{E_{b}}{N_{0}}=\frac{P_{b} \cdot T}{N_{0}}=\frac{P_{b} \cdot T_{c} \cdot N}{N_{0}}
$$

onde $\frac{N_{0}}{2}$ é a densidade espectral de potência bilateral do AWGN; $E_{b}$ é a energia de bit de dados; $N$ é o ganho de processamento; $P_{b}$ é a potência de bit recebida; $T$ é o período de $\mathrm{bit}^{3}$, que para código curto vale $N . T_{c}$, com $T_{c}$ sendo o período de chip.

Considerando $B$ a largura de banda unilateral do sinal espalhado em banda base $\left(B=1 / T_{c}\right)$, a potência do AWGN (variância) será:

$$
\sigma^{2}=\frac{N_{0} \cdot B}{2}=\frac{N_{0}}{2 T_{c}}
$$

Portanto, a equação (C.8) é equivalente a:

$$
\frac{E_{b}}{N_{0}}=\frac{P_{b} \cdot T_{c} \cdot N}{N_{0}}=\frac{P_{b} \cdot N}{2 B \cdot N_{0}}=\frac{P_{b} \cdot N}{2 \sigma^{2}}=\frac{S N R \cdot N}{2}
$$

onde $\frac{P_{b}}{\sigma^{2}}=S N R$ é a relação entre as potências de sinal e de ruído.

\footnotetext{
${ }^{2}$ Teoricamente infinita.

${ }^{3}$ Considerado, sem perda de generalidade, normalizado.
} 
Sem perda de generalidade, considerando potência recebida igual a $P_{b}=$ $A^{2} / R_{n}$, sendo $A$ a amplitude do sinal recebido e $R_{n}$ a resistência de entrada do sistema receptor normalizada em $1 \Omega$, têm-se:

$$
P_{b}=2 \sigma^{2} \frac{E_{b}}{N_{0} \cdot N}=A^{2}
$$

Existem duas maneiras para se calibrar adequadamente a relação $E_{b} / N_{0}$ : uma pela amplitude do sinal $(A)$ e outra pela variância do ruído $\left(\sigma^{2}\right)$. Neste trabalho escolheu-se a normalização pela variância $\left(\sigma^{2}=1\right)$.

Sendo assim, a média do processo Gaussiano será igual a 0 e a variância do AWGN será dada por:

$$
\sigma_{n}^{2}=\frac{N_{0} N A^{2}}{2 E_{b}}=\frac{N A^{2}}{2 E_{b} / N_{0}}=1
$$

E, portanto:

$$
A=\sqrt{\frac{2 E_{b}}{N_{0} N}}
$$

Geralmente o parâmetro de entrada é a relação $E_{b} / N_{0}$, ou de forma equivalente, $S N R^{4}$, encontrando, assim, a amplitude do sinal do usuário. Como exemplo, gerou-se um vetor de 60000 amostras de ruído AWGN, considerando uma relação $\frac{E_{b}}{N_{0}}=15 \mathrm{~dB}$ e ganho de processamento $N=32$. A figura C.3 apresenta uma comparação obtida numericamente entre a função densidade de probabilidade obtida por simulação e a teórica (equação (C.7)), considerando os parâmetros acima.

Os valores, teóricos e numéricos, para os momentos estatísticos de $1^{a}$ e $2^{a}$ ordem, média e variância respectivamente, são apresentados na tabela C.1, indicando ter boa concordância com os valores teóricos, validando, assim, o método de simulação e possibilidade de uso nas simulações de desempenho apresentadas no capítulo 5 .

Tabela C.1: Momentos estatísticos, teóricos e numéricos, de $1^{a}$ e $2^{a}$ ordem para um processo AWGN

\begin{tabular}{ccc}
\hline momentos estatísticos & numérico & teórico \\
\hline $\mathbb{E}[\mathbf{x}]$ & 0,0010 & 0 \\
$\mathbb{V}[\mathbf{x}]=\sigma^{2}$ & 0,5100 & $\frac{32}{2.10^{1,5}}=0,50596$ \\
\hline
\end{tabular}

\footnotetext{
${ }^{4}$ No caso CDMA há uma diferença $>3 \mathrm{~dB}$, pois $\left.\frac{E_{b}}{N_{0}}\right|_{d B}=\left.S N R\right|_{d B}+\left.N\right|_{d B}-3$, como indicado na equação (C.10).
} 


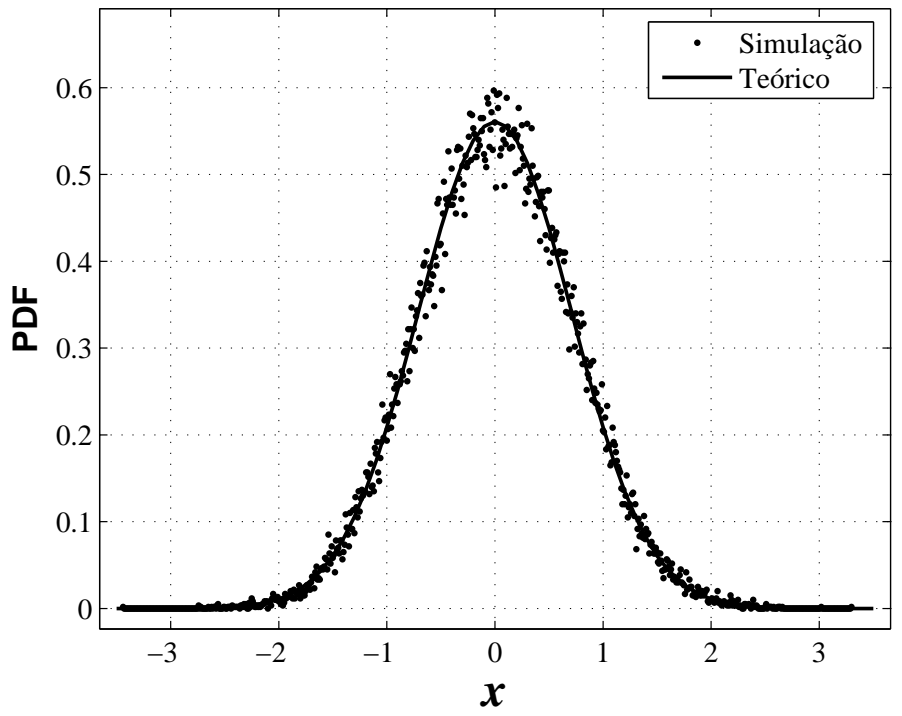

Figura C.3: Função densidade de probabilidade para um conjunto de 60000 amostras representando um processo AWGN, em comparação com a $p d f$ teórica, dada pela equação (C.7). 


\section{Apêndice D - Método de Simulação Monte Carlo}

O método de simulação computacional empregado neste trabalho foi o método Monte Carlo. O método de simulação Monte Carlo (MCS), refere-se a um conjunto de técnicas de cálculo de probabilidade que faz uso de eventos aleatórios. O nome origina-se de Monte Carlo, em Mônaco, onde há uma grande quantidade de cassinos com jogos de azar, cuja essência está toda baseada na teoria das probabilidades (SOBOL, 1975).

Este método aplica-se a vários contextos, sendo largamente utilizado em telecomunicações quando não for possível determinar a probabilidade de erro de bit analiticamente e numericamente ou ainda quando se estiver investigando a validade de expressões (semi-) analíticas para o desempenho de novas estruturas e/ou sistemas de comunicação. O MCS é simplesmente um conjunto de sequências de Bernoulli onde são computados os números de sucessos ou erros dividido pelo número de realizações.

Neste trabalho, o método MCS é utilizado para a caracterização do desempenho dos sistemas considerados em termos da BER. O modelo empregado nas simulações é representado na figura D.1.

Nesta figura, $n_{\text {erros }}$ representa o número de erros mínimo computado para o cálculo da BER em cada ponto desejado. O cômputo do erro é feito comparando o sinal recebido com o enviado. Cada vez que um erro é detectado, o contador de erros é incrementado até atingir o valor especificado em $n_{\text {erros }}$. Quanto maior o valor de $n_{\text {erros }}$, mais confiável se torna o resultado obtido, pois aumenta-se o número necessário de trials, sendo trials o número de vezes em que os dados aleatórios são gerados de forma independente e utilizados na transmissão.

Desta maneira, a BER estimada é calculada da forma:

$$
\widehat{P}_{e}=\frac{n_{\text {erros }}}{\text { trials }}
$$




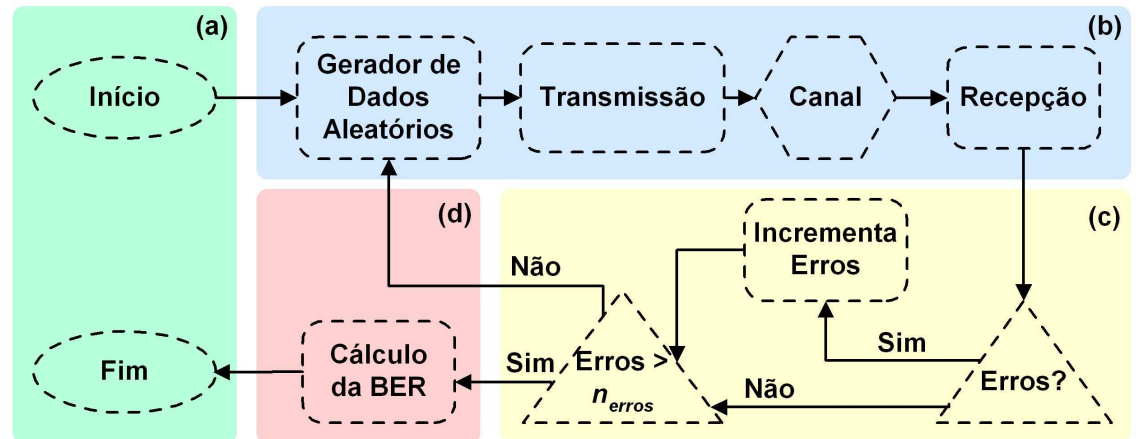

Figura D.1: (a) Inicialização dos parâmetros do sistema e Finalização da simulação com obtenção de gráficos de desempenho em termos da BER; (b) Geração, Transmissão e Recepção de Dados; (c) Estratégia Monte-Carlo de Parada e (d) Estimador da BER

Quando trials $\rightarrow \infty$ a razão que define $P_{e}$ converge, mas adotar computacionalmente trials $\rightarrow \infty$ é inviável devido ao tempo de simulação necessário. Portanto, emprega-se um número tal de trials ou $n_{\text {erros }}$ que conduza a um resultado dentro de um intervalo de confiança esperado mantendo o tempo de simulação factível. O menor número para $n_{\text {erros }}$ utilizado nas simulações foi de 100 erros por ponto para faixas de baixa e média SNR e 10 erros por ponto para a faixa de alta SNR. Este trabalho considerou alta SNR todos os valores que resultam em BER inferior a $10^{-4}$ e baixa e média SNR os demais valores que resultam em BER superior a $10^{-4}$. de forma ilustrativa, para uma $P_{e}$ esperada de $10^{-3}$, por exemplo, exige-se no mínimo $10^{5}$ realizações, pois está na faixa estipulada como de baixa e média SNR e para uma $P_{e}$ esperada de $10^{-5}$, exige-se no mínimo $10^{6}$ realizações, pois está dentro da faixa considerada como de alta SNR.

Para estimar o tempo necessário para uma simulação adotou-se os valores de desempenho obtido pelos limiares inferiores teóricos de desempenho ${ }^{1}$, ou seja, o melhor desempenho possível na condição do sistema. Assim, com $n_{\text {erros }}$ e $P_{e}$ pode-se estimar o número total de trials necessários à simulação. Nos algoritmos, realiza-se um número de iterações pré-definido pelo programador ${ }^{2}$ com medição do tempo para execução. Após, com o número total de trials e o tempo medido para a execução de um percentual deste, obtém-se uma boa estimativa do tempo total de simulação. Para ilustrar, algumas simulações necessitaram de poucas horas (2 a 3 horas) enquanto as mais onerosas chegaram a 13 dias contínuos. Por diversas vezes os parâmetros de sistema resultaram em tempo estimado de simulação não factível (acima de 20 dias) e, por isso, os parâmetros utilizados no capítulo 5 para

\footnotetext{
${ }^{1}$ Obtidos da literatura.

${ }^{2}$ Por exemplo de 10, 50 ou 100 iterações.
} 
os sistemas de telecomunicações foram limitados a algumas unidades ou poucas dezenas de usuários visando garantir confiabilidade nos resultados.

Por isso, considerando diversos valores de trials (ou de forma equivalente $\left.n_{\text {erros }}\right)$, têm-se um intervalo de confiança que segue a figura D.2 (ABRÃO, 2001).

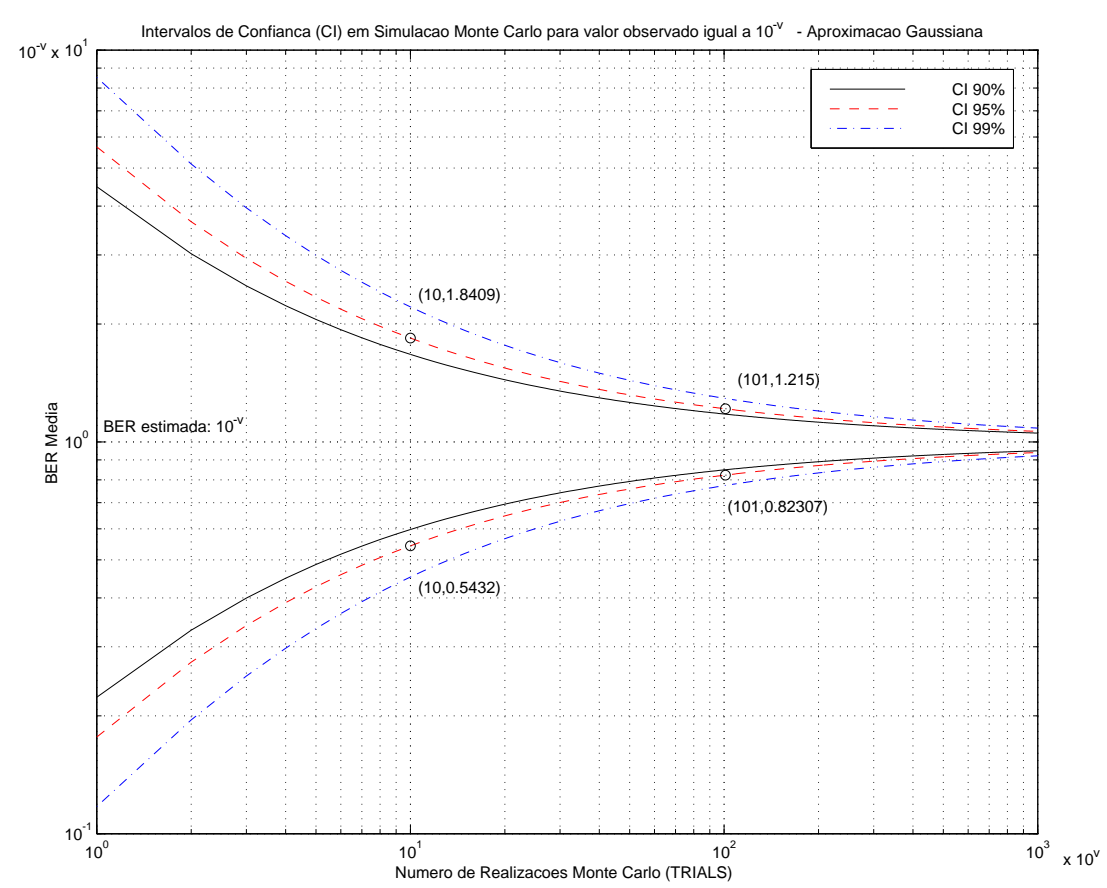

Figura D.2: Intervalos de Confiança sobre a BER quando o valor observado for igual a $P_{e}=10^{-v}$

Observe-se que adotando $n_{\text {erros }}=100$, e intervalo de confiança igual a $95 \%$, assegura-se que a $\widehat{P}_{e}$ estará na faixa entre 0,823 a 1,215 da $P_{e}$ verdadeira, ou seja:

$$
\text { @ c.i. }=95 \% \Rightarrow \widehat{P}_{e} \subset[0,823 ; 1,215] P_{e}
$$

E adotando-se $n_{\text {erros }}=10$, e intervalo de confiança igual a 95\%, assegura-se que a $\widehat{P}_{e}$ estará na faixa entre 0,5432 a 1,809 da $P_{e}$ verdadeira, ou seja:

$$
@ \text { @.i. }=95 \% \Rightarrow \widehat{P}_{e} \subset[0,5432 ; 1,809] P_{e}
$$

Estes são os menores valores de precisão e exatidão adotados para os resultados de simulação apresentados no capítulo 5 . 


\section{Referências}

AARTS, E. H. L.; KROST, J. H. M. Simulated Annealing and Boltzmann Machine. Chichester: John Wiley, 1989.

AARTS, E. H. L.; LENSTRA, J. K. Local Search in Combinatorial Optimization. Chichester: John Wiley, 1996.

ABEDI, S.; TAFAZOLLI, R. Genetically modified multiuser detection for code division multiple access systems. IEEE Journal on Selected Areas in Communications, v. 20, n. 2, p. 463-473, February 2001.

ABRAO, T.; CIRIACO, F.; OLIVEIRA, L. D.; ANGEliCO, B. A.; JESZENSKY, P.; CASADEVALL, F. Ga, sa, and ts near-optimum multiuser detectors for s/mimo mc-cdma systems. In: Fourth International Conference on Wireless Communication and Sensor Networks (WCSN). [S.l.: s.n.], 2008. p. 173-178.

ABRAO, T.; CIRIACO, F.; OLIVEIRA, L. D.; ANGELICO, B. A.; JESZENSKY, P.; CASADEVALL, F. Weighting particle swarm, simulation annealing and local search optimization for s/mimo mc-cdma systems. In: IEEE Swarm Intelligence Symposium (SIS). [S.l.: s.n.], 2008. p. 1-7.

ABRÃO, T. Canceladores de Interferência Multiusuário Aplicados a Sistemas DS/CDMA de Múltipla Taxa. 364 p. Tese (Doutorado) — Escola Politécnica da Universidade de São Paulo - EPUSP, São Paulo - SP, 2001.

ABRÃO, T.; CIRIACO, F.; JESZENSKY, P. J. E. Evolutionary programming with cloning and adaptive cost funciton applied to multi-user ds-cdma systems. In: 2004 IEEE International Symposium on Spread Spectrum Techniques and Applications. Sydney: Australia, 2004. p. 160-163. ISBN 0-7803-8408-3.

ABRÃO, T.; JESZENSKY, P. J. E. Multistage hybrid interference canceller for asynchronous multirate ds-cdma systems in awgn and flat rayleigh channels. In: IEEE Seventh International Symposium on Spread Spectrum Techniques and Applications. Prague: Czech Republic, 2002. p. 283-287.

ABRÃO, T.; StAnCANELli, E. M. G.; KURAMOTO, A. S.; ROCHA, A. F. da; ANGéLICO, B.; JESZENSKY, P. J. E. Esquemas multitaxa para sistemas cdma. Revista do INATEL, v. 8, n. 2, p. 1 - 22, 2005.

ACKLEY, D. H. A connectionist machine for genetic hillclimbing. Boston: Kluwer Academic Publishers, 1987.

AHN, C. W.; RAMAKRISHNA, R. S. A genetic algorithm for shortest path routing problem and the sizing of populations. IEEE Transactions on Evolutionary Computation, v. 6, n. 6, p. 566-578, December 2002. 
AKAN, A.; EDEMEN, C. Path to $4 \mathrm{~g}$ wireless networks. In: IEEE International Symposium on Personal, Indoor and Mobile Radio Communications Workshops (PIMRC). [S.l.: s.n.], 2010. p. 405-407.

AL-SAWAFI, M. M. S.; JERVASE, J. A. A micro-genetic algorithm-based cdma multi-user detector. In: Second Annual Conference on Communication Networks and Services Research. Fredericton: Canada, 2004.

ALAMOUTI, S. M. A simple transmit diversity technique for wireless communications. IEEE Journal on Selected Areas in Communications, v. 16, n. 8, p. 1451-1458, October 1998.

ALENCAR, M. S. Sistemas de Comunicações. 1. ed. São Paulo: Ed. Érica, 2001.

ALIAS, M. Y.; CHEN, S.; HANZO, L. Genetic algorithm assisted minimum bit-error rate multiuser detection in multiple antenna aided ofdm. In: Proc. IEEE Vehicular Technology Conf. (VTC-Fall). Los Angeles: USA, 2004. p. $548-552$.

AN, J.; XU, B. Multiuser detection in stbc-mimo systems based on pareto optimality particle swarm optimization algorithm. In: Fourth International Conference on Natural Computation (ICNC). [S.l.: s.n.], 2008. v. 5, p. $237-241$.

ANDREWS, M.; KUMARAN, K.; RAMANAN, K.; STOLYAR, A. L.; VIJAYAKUMAR, R.; WHITING, P. Providing quality of service over a shared wireless link. IEEE Communications Magazine, v. 39, p. 150-154, 2001.

ANGéLICO, B. Sistemas CDMA Multiportadora. 162 p. Dissertação (Mestrado) - Universidade de São Paulo, São Paulo - SP, 2005.

ANGéLICO, B. Sistemas de Banda Ultralarga com Pré-Processamento. 129 p. Tese (Doutorado) - Escola Politécnica da Universidade de São Paulo - EPUSP, São Paulo - SP, 2010.

ARIFIANTO, M. S.; CHEKIMA, A.; BARUKANG, L.; HAMID, M. Y.; VISWACHEDA, D. V. Stbc mc-cdma with genetic algorithm based mud for wireless multimedia communications. In: International Conference on Computational Intelligence and Multimedia Applications. [S.l.: s.n.], 2007. v. 4, p. 298-305.

ARMSTRONG, E. H. A method of reducing disturbances in radio signaling by a system of frequency modulation. Proceedings of the IEEE, v. 72, n. 8, p. 1042-1062, August 1984.

BAHL, L. R.; COCKE, J.; JELINEK, F.; RAVIV, J. Optimal Decoding of Linear Codes for Minimizing Symbol Error Rate. IEEE Transactions on Information Theory, IT-20, p. 284-287, Mar. 1974.

BAI, D.; PARK, C.; LEE, J.; NGUYEN, H.; SINGH, J.; GUPTA, A.; PI, Z.; KIM, T.; LIM, C.; KIM, M.; KANG, I. Lte-advanced modem design: challenges and perspectives. IEEE Communications Magazine, v. 50, p. 178-186, February 2012 .

BARBUleSCU, A.; PIETROBON, S. S. Interleaver Design for Turbo Codes. IEE Electronics Letters, v. 30, p. 2107-2108, Dec. 1994. 
BARBUleSCU, A.; PIETROBON, S. S. Turbo codes: A tutorial on a new class of powerful error correcting coding schemes: Part 1: Code structure and interleaver design. Journal of Electrical and Electronics Engineering, v. 19, p. 129-142, September 1999.

BASILIO, C. The us government versus alexander graham bell: An important acknowledgment. Bulletin of Science Technology Society, v. 22, p. 426 - 442, 2002 .

BATTITI, R.; TECCHIOLI, G. The reactive tabu search. ORSA, Journal of Computing, v. 6, p. 126-140, 1994.

BAUDINO, J. E.; KITTROSS, J. M. Broadcasting's oldest stations: An examination of four claimants. IEEE Journal of Broadcasting, p. 61-82, 1977.

BENDER, P.; BLACK, P.; GROB, M.; PADOVANI, R.; SINDHUSHAYANA, N.; VITERBI, A. Cdma/ hdr: a bandwidth-efficient high-speed wireless data service for nomadic users. IEEE Communications Magazine, p. 70-77, July 2000.

BENEDETTO, S.; DIVSAlAR, D.; MONTORSI, G.; POLLARA, F. A soft-input soft-output maximum a posteriori (map) module to decode parallel and serial concatenated codes. In: The Telecommunications and Data Acquisition Progress Report 42-127. [S.l.: s.n.], 1996.

BEnEDETTO, S.; DIVSAlAR, D.; MONTORSI, G.; POLLARA, F. Soft-output decoding algorithms in iterative decoding of turbo codes. In: The Telecommunications and Data Acquisition Progress Report 42-124. [S.l.: s.n.], 1996. p. 63-87.

BENEDETTO, S.; DIVSAlAR, D.; MONTORSI, G.; POLLARA, F. Design of Serially Concatenated Interleaved Codes. IEEE International Conference on Communications, v. 2, p. 710-714, Feb. 1997.

BEnEDETTO, S.; MONTORSI, G. Design of Parallel Concatenated Convolutional Codes. IEEE Transactions on Communications, v. 44, No.5, p. 591-600, May 1996.

BEnEDETTO, S.; MONTORSI, G. Unveiling Turbo Codes: Some Results on Parallel Concatenated Coding Sschemes. IEEE Transactions on Information Theory, v. 42, p. 409-428, Mar. 1996.

BENEDETTO, S.; MONTORSI, G.; DIVSALAR, D. Concatenated convolutional codes with interleavers. IEEE Communications Magazine, v. 41, n. 8, p. 102-109, 2003.

BENSLEY, S. E.; AAZHANG, B. Subspace-based channel estimation for code division multiple access communication systems. IEEE Transactions on Communications, v. 44, n. 8, p. 1009-1020, August 1996.

BENSLEY, S. E.; AAZHANG, B. Maximum-likelihood synchronization of a single user for code-division multiple-access communication systems. IEEE Transactions on Communications, v. 46, n. 3, p. 392-400, March 1998.

BERROU, C.; GLAVIEUX, A. Near Optimum Error Correcting Coding and Decoding: Turbo Codes. IEEE Transactions on Communications, v. 44, p. 1261-1271, Oct. 1996. 
BERROU, C.; GLAVIEUX, A.; THITIMAJSHIMA, P. Near shannon limit error-correcting coding and decoding. In: IEEE International Conference on Communications (ICC). [S.l.: s.n.], 1993. p. 1064-1070.

BHASHYAM, S.; AAZHANG, B. Multiuser channel estimation and tracking for long-code cdma systems. IEEE Transactions on Communications, v. 50, n. 7, p. 1081-1090, July 2002.

BIGLIERI, E.; CALDERBANK, R.; CONSTANTINIDES, A.; GOLDSMITH, A.; PAULRAJ, A.; POOR, H. V. MIMO Wireless Communications. [S.1.]: Cambridge University Press, 2007.

Bluetooth Special Interest Group. Specification of the bluetooth system, version 1.2. 2002.

BOBER, W.; TSAI, C. T.; MASORY, O. Numerical and analytical methods with MATLAB. [S.l.]: CRC Press, 2009. (CRC series in computational mechanics and applied analysis).

BOLCSKEI, H.; GESBERT, D.; PAPADIAS, C.; VEEN, A. J. V. D.; CIPRIANO, A. M. Space-Time Wireless Systems: From Array Processing to MIMO Communications. [S.1.]: Cambridge University Press, 2006.

BRENNER, P. Tesla against marconi: The dispute for the radio patent paternity. In: 2009 IEEE Eurocon. Saint-Petersburg: Russia, 2009. p. 1035-1042.

BREYFOGLE, F. W. Implementing Six Sigma: Smarter Solutions Using Statistical Methods. New York: John Wiley \& Sons Ltda, 1999.

BURKE, E.; CURTOIS, T.; HYDE, M.; KENDALL, G.; OCHOA, G.; PETROVIC, S.; RODRIGUEZ, J. A. V.; GENDREAU, M. Iterated local search vs. hyper-heuristics: Towards general-purpose search algorithms. In: IEEE Congress on Evolutionary Computation (CEC). [S.1.: s.n.], 2010. p. 1-8.

BURKE, E. K.; CURTOIS, T.; HYDE, M.; KENDALL, G.; OCHOA, G.; PETROVIC, S.; VAZQUEZ-RODRIGUEZ, J. A. Towards the decathlon challenge of search heuristics. In: Genetic and Evolutionary Computation Conference (GECCO). [S.l.: s.n.], 2009. p. 2205-2208.

BURKER, E. K.; HYDE, M.; KENDALL, G.; OCHOA, G.; AZCAN, E.; WOODWARD, J. R. A classification of hyper-heuristic approaches. In: HILliER, F. S.; GENDREAU, M.; POTVIN, J.-Y. (Ed.). Handbook of Metaheuristics. [S.1.]: Springer US, 2010. v. 146, p. 449-468.

BURKER, E. K.; KENDALL, G.; SOUBEIGA, E. A tabu-search hyperheuristic for timetabling and rostering. Journal of Heuristics, v. 9, n. 6, p. 451-470, 2003.

BURR, A. Turbo-codes: the ultimate error control codes? Electronics \& Communication Engineering Journal, p. 155-165, August 2001.

CASELLA, I. R. S. Estruturas Espaço-Temporais de Múltiplas Entradas e Múltiplas Saídas para a Transmissão de Dados de Alta Taxa em Sistemas W-CDMA. 418 p. Tese (Doutorado) — Escola Politécnica da Universidade de São Paulo - EPUSP, São Paulo - SP, 2004. 
CASTRO, L. N.; VON ZUBEN, F. J. Learning and optimization using the clonal selection principle. IEEE Transactions on Evolutinary Computation, v. 6, p. 239-251, June 2002.

CERNY, V. Minimization of continuous functions by simulated annealing. Research Institute for Theoretical Physics, University of Helsinki, 1985.

CERNY, V. Thermodynamical approach to the traveling salesman problem: an efficient simulation algorithm. Journal of Optimization Theory and Applications., v. 45, p. $41-51,1985$.

CHAN, T. M.; KWONG, S.; MAN, K. F.; TANG, K. S. Sequences optimization in ds/cdma systems using genetic algorithms. In: IEEE Region 10 International Conference on Electrical and Electronic Technology. Phuket Island: Singapore, 2001. v. 2, p. $728-731$.

CHEN, S.; WU, Y. Maximum likelihood joint channel and data estimation using genetic algorithms. IEEE Transactions Signal Processing, v. 46, p. 1469-1473, May 1998.

CHILDRESS, D. H.; TESLA, N. As fantásticas Invenções de Nikola Tesla. 1. ed. São Paulo: Ed. Madras, 2004.

CHO, H. J.; OH, S. Y.; CHOI, D. H. Population-oriented simulated annealing technique based on local temperature concept. Electronics Letters, v. 34, n. 3, p. 312 - 313, February 1998.

CHUNG, S. Y.; FORNEY, G. D.; RICHARDSON, T. J.; URBANKE, R. On the design of low-density parity-check codes within $0.0045 \mathrm{db}$ of the shannon limit. IEEE Communications Letters, v. 5, n. 2, p. 58-60, February 2001.

CIRIACO, F. Algoritmos Heurísticos Aplicados à Detecção Multiusuário DS-CDMA. Brasil: [s.n.], 2004. 117 p. Trabalho de Conclusão de Curso em Engenharia Elétrica. Universidade Estadual de Londrina.

CIRIACO, F. Detecção Multiusuário e Estimativa de Parâmetros em Sistemas DS/CDMA Utilizando Algoritmos Genéticos. 167 p. Dissertação (Mestrado) Universidade Estadual de Londrina, Londrina - PR, 2006.

CIRIACO, F.; ABRAO, T.; JESZENSKY, P. J. E. Multirate multiuser ds/cdma with genetic algorithm detection in multipath channels. In: IEEE Ninth International Symposium on Spread Spectrum Techniques and Applications (ISSSTA). [S.l.: s.n.], 2006. p. 128-132.

CIRIACO, F.; ABRÃO, T.; JESZENSKY, P. J. E. Algoritmos heurísticos evolucionários aplicados à detecção multiusuário ds-cdma. In: XXI Simpósio Brasileiro de Telecomunicações. Belém: Brasil, 2004. (Espalhamento Espectral).

CIRIACO, F.; ABRÃO, T.; JESZENSKY, P. J. E. Genetic algorithm multiuser detection in fading channel with parameters errors estimates. In: International Microwave \& Optoeletronics Conference. Brasilia: Brazil, 2005.

CIRIACO, F.; ABRÃO, T.; JESZENSKY, P. J. E. Sistemas ds/cdma multitaxa com detector heurístico-genético em canais multipercurso. Semina. Ciências exatas e tecnológicas, v. 26, n. 2, p. 155 - 166, 2005. 
CIRIACO, F.; ABRÃO, T.; JESZENSKY, P. J. E. Ds/cdma multiuser detection with evolutionary algorithms. Journal of Universal Computer Science - J.UCS, v. 12 , n. 4 , p. $450-480,2006$.

CIRIACO, F.; ABRÃO, T.; JESZENSKY, P. J. E. Genetic algorithm applied to multipath multiuser channel estimation in ds/cdma systems. In: 2006 IEEE International Symposium on Spread Spectrum Techniques and Applications. Manaus: Brazil, 2006.

CIRIACO, F.; ABRÃO, T.; JESZENSKY, P. J. E. Multirate multiuser ds/cdma with genetic algorithm detection in multipath channels. In: 2006 IEEE International Symposium on Spread Spectrum Techniques and Applications. Manaus: Brazil, 2006.

CIRIACO, F.; OKANO, W.; ABRÃO, T.; JESZENSKY, P. J. E. Estratégia heurística de baixa complexidade aplicada à decodificação multiusuário em sistemas ds/cdma. In: XXVII Simpósio Brasileiro de Telecomunicações. Blumenau: Brasil, 2009. (Espalhamento Espectral).

CLARK, G. C.; CAIN, J. B. Error-Correction Coding for Digital Communications. New York: Plenum Press, 1983.

CONRAD, R. B. Mobile communications and the federal telecommunications system. IRE Transactions on Vehicular Communications, v. 13, n. 1, p. 19-23, September 1959.

COWLING, P.; KENDALL, G.; SOUBEIGA, E. A hyperheuristic approach for scheduling a sales summit. In: International Conference on the Practice And Theory of Automated Timetabling (PATAT). Konstanz - Germany: [s.n.], 2000. p. $176-190$.

CUI, T.; TELLAMBURA, C. Power delay profile and noise variance estimation for ofdm. IEEE Communications Letters, v. 10, n. 1, p. 25-27, January 2006.

DARWIN, C. R. On The Origin of Species by Means of Natural Selection. London: John Murray, 1859. ISBN 0-517-12320-7.

DARWIN, C. R. On The Origin of Species by Means of Natural Selection. London: Elibron Classics, 2000. ISBN 1421289911.

DENT, P.; BOTTOMLEY, G. E.; CROFT, T. Jakes fading model revisited. IEEE Electronics Letters, v. 29, n. 3, p. 1162-1163, June 1993.

DENZINGER, J.; FUCHS, M.; FUCHS, M. High performance atp systems by combining several ai methods. In: International Joint Conference on Artificial Intelligence (IJCAI). [S.l.: s.n.], 1997. p. 102-107.

DHOLAKIA, A. Introduction to Convolutional Codes. Boston: Kluwer Academic Publishers, 1994.

DIGGAVI, S. N.; AL-DHARIR, N.; STAMOUliS, A.; CALDERBANK,

A. R. Great expectations: the value of spatial diversity in wireless networks. Proceedings of the IEEE, v. 92, n. 2, p. 219-270, February 2004.

DIVSALAR, D.; POLLARA, F. Turbo codes for deep-space communications. JPL TDA Progress Report, February 1995. ISSN 42-120. 
DIXON, L. C.; SZEGO, G. P. The optimization problem: An introduction, Towards Global Optimization II. New York: North Holland, 1978.

DIXON, R. C. Spread spectrum systems. New York: John Wiley, 1976.

DONG, L.; YOUYUN, X.; WENTAO, S.; HANWEN, L.; XINGZHAO, L. Genetic algorithm based multiuser detection for cdma systems. In: Proceedings of the IEEE 6th Circuits and Systems. Shanghai: China, 2004. v. 1, p. 321-324.

DORAN, R. W. The gray code. Journal of Universal Computer Science, v. 13, n. 11, p. 1573-1597, November 2007.

DU, Y.; CHAN, K. T. Feasibility of applying genetic algorithms in space-time block coding multiuser detection systems. In: Proc. IASTED Int. Conf. Wireless and Optical Communications. Banff: Canada, 2003. p. 469-473.

DUECK, G.; SCHEUER, T. Threshold accepting: A general purpose optimization algorithm appearing superior to simulated annealing. Journal of Computer Physics, v. 90, p. 161-175, 1990.

DUEL-HALLEN, A. Decorrelating decision-feedback multiuser detector for synchronous cdma channel. IEEE Transactions on Communications, v. 41, n. 2, p. 285-290, February 1993.

DUEL-HALLEN, A. A family of multiuser decision-feedback detectors for asynchronous cdma channels. IEEE Transactions on Communications, v. 43, p. 421-434, 1995.

DUEL-HALlEN, A.; HOLTZMAN, J.; ZVONAR, Z. Multiuser detection for cdma systems. IEEE Personal Communications, p. 46-58, April 1995.

EASTWOOD, L.; MIGALDI, S.; QIAOBING, X.; GUPTA, V. Mobility using ieee 802.21 in a heterogeneous ieee 802.16/802.11-based, imt-advanced (4g) network. IEEE Wireless Communications, v. 15, n. 2, p. 26-34, April 2008.

EDELKAMP, S.; SCHRöDL, S. Heuristic Search - Theory and Applications. Waltham: Morgan Kaufmann, 2012.

EL-MORRA, H. H.; SHEIKH, A. U.; ZERGUINE, A. Application of particle swarm optimization algorithm to multiuser detection in cdma. In: IEEE 16th International Symposium on Personal, Indoor and Mobile Radio Communications (PIMRC). [S.l.: s.n.], 2005. v. 4, p. 2522-2526.

EL-MORRA, H. H.; SHEIKH, A. U.; ZERGUINE, A. Application of heuristic algorithms for multiuser detection. In: IEEE International Conference on Communications (ICC). [S.1.: s.n.], 2006. v. 7, p. 3157-3161.

ELIAS, P. Coding for noisy channels. IRE Convention Record, p. 37-47, 1955.

ENGST, A.; FLEISHMAN, G. The Wireless Networking Starter Kit. [S.1.]: Peachpit Press, 2005. ISBN 8534615322.

ERFANIAN, J. A.; PASUPATHY, S.; GULAK, G. Reduced Complexity Symbol Detectors with Parallel Structures for ISI Channels. IEEE Transactions on Communications, v. 42, p. 1661-1671, Feb. 1994. 
ERGUN, C.; HACIOGLU, K. Multiuser detection using a genetic algorithm in cdma communications systems. IEEE Transactions on Communications, v. 48, p. $1374-1382,2000$.

ETTEN, W. V. An optimum linear receiver for multiple channel digital transmission systems. IEEE Transactions on Communications Technology, v. 23, n. 8, p. 828-834, August 1975.

FAN, M.; HOFFMANN, C.; SIU, K. Y. Error-rate analysis for multirate ds-cdma transmission schemes. IEEE Transactions on Communications, p. 1897-1909, November 2003.

FANO, R. M. A Heuristic Discussion of Probabilistic Decoding. IEEE Transactions on Information Theory, v. 9, n. 2, p. 64-74, Apr 1963.

FCC Part15. FCC 15.517 Rule - Technical Requirements for Indoor UWB Systems. 2003.

FERRARI, A. M. Telecomunicações, Evolução e Revolução. 9. ed. São Paulo: Ed. Érica, 2005.

FERTL, P.; MATZ, G. Channel estimation in wireless ofdm systems with irregular pilot distribution. IEEE Transactions on Signal Processing, v. 58, n. 6, p. 3180-3194, June 2010.

FISHER, H.; THOMPSON, G. L. Probabilistic learning combinations of local job-shop scheduling rules. In: Factory Scheduling Conference. Carnegie Institute of Technology: [s.n.], 1961. p. 10-12.

FITZPATRICK, J. M.; GREFENSTETTE, J. J. Genetic algorithms in noisy environments. Machine Learning, n. 3, p. 101-120, 1988.

FLORAC, W. A.; CARLETON, A. D. Measuring the Software Process:

Statistical Process Control for Software Process Improvement. Beijing: China: Tsinghua University Press, 2001.

FOGEL, D. B. An introduction to simulated evolutionary optimization. IEEE Transactions on Neural Networks, v. 5, p. 3-13, 1994.

FORNEY, G. D. The Viterbi Algorithm. Proceedings of the IEEE, v. 61, n. 3, p. 268-278, March 1973.

FOSCHINI, G. J. Layered space-time architecture for wireless communication in a fading environment when using multiple antennas. Bell Labs System Technical Journal, v. 1, p. 41-59, March 1996.

FOSCHINI, G. J.; GANS, M. J. On limits of wireless communications in a fading environment when using multiple antennas. Wireless Personal Communications, v. 6, n. 3, p. 311-335, March 1998.

GALLAGER, R. G. Low density parity check codes: Construction based on finite geometries. IRE Transactions on Information Theory, v. 8, n. 1, p. 21-28, 1962.

GALLAGER, R. G. Low-Density Parity-Check Codes. Tese (Doutorado) - MIT Press, Cambridge, 1963. 
GAMAL, A. A. E.; HEMACHANDRA, L. A.; SHPERLING, I.; WEI, V. K. Using simulated annealing to design good codes. IEEE Transactions on Information Theory, IT-33, n. 1, p. 116-123, 1987.

GESBERT, D.; BOLCSKEI, H.; GORE, D.; PAUlRAJ, A. Mimo wireless channels: Capacity and performance prediction. In: IEEE Global Telecommunications Conference (GLOBECOM). [S.l.: s.n.], 2000. p. 1083-1088.

GLOVER, F. Heuristic for integer programming using surrogate contraints. Decision Sciences, v. 8, p. 156-166, 1977.

GLOVER, F. Future paths for integer programming and links to artificial intelligence. Computers and Operations Research, v. 13, p. 533-549, 1986.

GLOVER, F. Tabu search methods in artificial intelligence and operations research. ORSA, Artificial Intelligence Newsletter, v. 1, 1987.

GLOVER, F.; LAGUNA, M. Tabu Search. Boston: Kluwer Academic Publishers, 1997.

GOFF, S. L.; GLAVIEUX, A.; BERROU, C. Turbo-Codes and High Spectral Efficiency Modulation. in Proceedings of IEEE International Conference on Communications (ICC 94), New Orleans, LA, USA, v. 2, p. 645-649, May 1994.

GOLDBARG, M. C.; LUNA, H. P. L. Otimização Combinatória e Programação Linear. Rio de Janeiro: Campus, 2000. 649 p.

GOLDBERG, D. E. Genetic Algorithms in Search Optimization and Machine Learning. Nova York: AddisonWesley, 1989.

GOLDBERG, D. E.; DEB, K.; CLARK, J. H. Genetic algorithms, noise, and the sizing of populations. Complex Systems, v. 6, p. 333-362, 1992.

GOLDBERG, D. E.; RUDNICK, M. Genetic algorithms and the variance of fitness. IlliGAL Report, n. 91001, 1991.

GOLDEN, G. D.; FOSCHINI, G. J.; VALENZUELA, R. A.; WOLNIANSKY, P. W. Detection algorithm and initial laboratory results using v-blast space-time communication architecture. IEEE Electronics Letters, v. 35, p. 14-16, January 1999.

GOLUB, G. H.; VAN LOAN, C. F. Matrix Computations. 3. ed. Baltimore: The John Hopkins University Press, 1996.

GRANT, E. L.; LEAVENWORTH, R. S. Statistical Quality Control. Seventh. Beijing: China: Tsinghua University Press, 1999.

GREFEnstetTe, J. J.; GOPAL, R.; ROSMAitA, B. J.; Van Gucht, D. Genetic algorithms for the traveling salesman problem. In: International Conference on Genetic Algorithms and their Applications. Hillsdale: New Jersey, 1985. p. 160-168.

GROBLER, J.; ENGELBRECHT, A. P.; KENDALL, G.; YADAVALLI, V. S. S. Alternative hyper-heuristic strategies for multi-method global optimization. In: IEEE Congress on Evolutionary Computation (CEC). [S.l.: s.n.], 2010. p. 1-8. 
GUI, X.; NG, T. S. Performance of asynchronous orthogonal multicarrier cdma system in frequency selective fading channel. IEEE Transactions on Communications, v. 47, n. 7, p. 1084-1091, July 1999.

HAARDT, M.; KLEIN, A.; KOEHN, R.; OESTREICH, S.; PURAT, M.; SOMMER, V.; ULRICH, T. The td-cdma based utra tdd mode. IEEE Journal on Selected Areas in Communications, v. 18, p. 1375-1385, 2000.

HAGENAUER, J. Source-Controlled Channel Decoding. IEEE Transactions on Communications, v. 43, No.9, p. 2449-2457, Sep. 1995.

HAGENAUER, J.; HOEHER, P. A Viterbi Algorithm with Soft-Decision Outputs and Its Applications. in Proceedings of IEEE Global Telecommunications Conference (GLOBECOM'89), Dallas, Texas, p. 47.1.1-47.1.7, Nov. 1989.

HAGENAUER, J.; OFFER, E.; PAPKE, L. Iterative decoding of binary block and convolutional codes. IEEE Transactions on Information Theory, v. 42, p. 429-445, March 1996.

HALEY, D.; GRANT, A.; BUETEFUER, J. Iterative encoding of lowdensity parity-check codes. In: IEEE Global Telecommunications Conference (GLOBECOM). [S.l.: s.n.], 2002.

HALL, E. K.; WILSON, S. G. Design and analysis of turbo codes on rayleigh fading channels. IEEE Journal Selected Areas Communications, v. 16, p. 160-174, February 1998.

HANSEN, P.; MLEDANOVIC, N. An Introduction to Variable Neighborhood Search. [S.l.], February 1998.

HARA, S.; PRASAD, R. Overview of multicarrier cdma. IEEE Communications Magazine, v. 35, n. 12, p. 126-133, December 1997.

HARIK, G.; CANTú-PAZ, E.; GOLDBERG, D. E.; MILlER, B. L. The gambler's ruin problem, genetic algorithms, and the sizing of populations. Evolutionary Computations, v. 7, n. 3, p. 231-253, 1999.

HARLOW, A. F. Old Wires and New Waves. 1. ed. New York: D. Appleton-Century Company, 1936.

HAYKIN, S. Adaptive Filter Theory. 3rd edition. ed. New Jersey: Prentice Hall, 1996.

HELLER, J.; JACOBS, I. Viterbi Decoding for Satellite and Space Communication. IEEE Transactions on Communication Technology, San Diego, CA, USA, COM-19, n. 5, p. 835-848, Oct. 1971.

HIGHAM, N. J. Accuracy and Stability of Numerical Algorithms. Philadelphia, PA: SIAM, 1996.

HOLLAND, J. H. Robust algorithms for adaptation set in a general formal framework. In: IEEE Symposium on Adaptive Processes Decision and Control. Austin: Texas, 1970. v. 27.

HOLLAND, J. H. Genetic algorithms and the optimal allocations of trial. SIAM - Journal on Applied Mathematics, v. 2, n. 2, p. 88-105, 1973. 
HOLLAND, J. H. Adaptation in Natural and Artificial Systems. Ann Arbor: University of Michigan Press, 1975.

HONARY, B.; HERAVI, B. M.; KARIYAWASAM, S.; PANDYA, N. Design, implementation and applications of low-complexity ldpc codes. In: International Conference on Signal Processing and Communication Systems (ICSPCS). [S.l.: s.n.], 2008.

HONIG, M.; MADHOW, U.; VERDÚ, S. Blind adaptive multiuser detection. IEEE Trans. Information Theory, v. 41, p. 944-960, July 1995.

HONIG, M. L. Advances in multiuser detection. [S.l.]: John Wiley \& Sons, 2009. 497 p. ISBN 978-0-471-77971-1.

HORN, R. A.; JOHNSON, C. R. Matrix Analysis. UK: Cambridge University Press, 1999.

IEEE 802.15 Working Group for WPAN. Ieee 802.15 std. specification. 2002.

IEEE 802.15.4a. PART 15.4:Wireless Medium Access Control (MAC) and Physical Layer (PHY) Specifications for Low-Rate Wireless Personal Area Networks (LR-WPANs): Amendment to add alternate PHY (Amendment of IEEE Std 802.15.4). 2007.

IEEE 802.15.4b. Part 15.4b: Wireless Medium Access Control (MAC) and Physical Layer (PHY) Specifications for Low Rate Wireless Personal Area Networks (WPANs) (Amendment of IEEE Std 802.15.4-2003). 2006.

IEEE 802.15.5. Part 15.5: Mesh Topology Capability in Wireless Personal Area Networks (WPANs). 2008.

IEEE Std. 802.11. Wireless LAN Medium Access Control (MAC) and Physical Layer (PHY) specifications. 1997.

IEEE Std. 802.11a. Wireless LAN Medium Access Control (MAC) and Physical Layer (PHY) specifications: High-speed Physical Layer in the 5GHz Band. 1999.

IEEE Std. 802.11b. Wireless LAN Medium Access Control (MAC) and Physical Layer (PHY) specifications: High-speed Physical Layer Extension in the 2.4GHz Band. 1999.

IEEE Std. 802.11g. Wireless LAN Medium Access Control (MAC) and Physical Layer (PHY) specifications: Amendment 4: Further Higher Data Rate Extension in the 2.4 GHz Band. 2003.

IEEE Std. 802.11g-2003. Wireless LAN Medium Access Control (MAC) and Physical Layer (PHY) Specifications. Amendment 4: Further Higher Data Rate Extension in the 2.4GHz band. 2006.

IEEE Std. 802.11n. Wireless LAN Medium Access Control (MAC) and Physical Layer (PHY) Specifications Amendment 5: Enhancements for Higher Throughput. 2009.

IEEE Std. 802.15.1. Part 15.1: Wireless Medium Access Control (MAC) and Physical Layer (PHY) Specifications for Wireless Personal Area Networks (WPANs(tm)). 2005. 
IEEE Std. 802.15.2. Part 15.2: Coexistence of Wireless Personal Area Networks with Other Wireless Devices Operating in Unlicensed Frequency Band. 2003.

IEEE Std. 802.16. Part 16: Air Interface for Fixed Broadband Wireless Access Systems. 2001.

IEEE Std. 802.16. Part 16: Air Interface for Fixed Broadband Wireless Access Systems - Revision. 2004.

IEEE Std. 802.16. Part 16: Air Interface for Broadband Wireless Access Systems. 2009.

IEEE Std. 802.16.2. Coexistence of Fixed Broadband Wireless Access Systems. 2004.

IEEE Std. 802.16a. Part 16: Air Interface for Fixed Broadband Wireless Access Systems - Amendment 2: Medium Access Control Modifications and Additional Physical Layer Specifications for 2-11 GHz. 2003.

IEEE Std. 802.16c. Part 16: Air Interface for Fixed Broadband Wireless Access Systems - Amendment 1: Detailed System Profiles for 10-66 GHz. 2002.

IEEE Std. 802.16f. Part 16: Air Interface for Fixed Broadband Wireless Access Systems - Amendment 1: Management Information Base. 2005.

IEEE Std. 802.16g. Air Interface for Fixed and Mobile Broadband Wireless Access Systems - Amendment 3: Management PLANe Procedure and Services. 2007.

ILTIS, R. A. A digital receiver for demodulation of cdma waveforms with a-priori unknown delays and amplitudes. In: IEEE Military Communications. McLean: Virginia, 1991. p. 113-116.

INGBER, L.; ROSEN, B. Genetic algorithms and very fast simulated reannealing: A comparison. Mathematical Computer Modeling, v. 16, n. 11, p. $87-100,1992$.

JAFARKHANI, H. Space-Time Coding: Theory and Practice. [S.l.]: Cambridge University Press, 2005.

JAKES, W. C. Microwave Mobile Communications. New York: Wiley, 1974. ISBN 0-471-43720-4.

JAMIL, M.; SHAIKH, S. P.; SHAHZAD, M.; AWAIS, Q. 4g: The future mobile technology. In: IEEE Region 10 Conference (TENCON). [S.l.: s.n.], 2008. p. 1-6.

JESZENSKY, P. J. E. Sistemas Telefônicos. 2. ed. São Paulo: Ed. Manole, 2004.

JESZENSKY, P. J. E.; STOLFI, G. Cdma systems sequences optimization by simulated annealing. In: IEEE 5th International Symposium on Spread Spectrum Techniques and Applications. Sun City: South Africa, 1998. v. 3, p. 706-708.

JIANG, M.; AKHTMAN, J.; HANZO, L. Iterative joint channel estimation and multi-user detection for multiple-antenna aided ofdm systems. IEEE Transactions on Wireless Communications, v. 6, n. 8, p. 2904-2914, August 2007. 
JIANG, M.; HANZO, L. Multiuser mimo-ofdm for next-generation wireless systems. Proceedings of the IEEE, v. 95, n. 7, p. 1430-1469, 2007.

JOHANNESSON, R.; ZIGANGIROV, K. S. Fundamentals of Convolutional Coding. New York: IEEE Press, 1999.

JOHANSSON, A. L. Interference Cancellation for DS/CDMA systems in flat fading channels. Dissertação (Mestrado) - Chalmers University of Technology, Sweden, March 1996.

JOHANSSON, A. L. Sucessive Interference Cancellation in DS-CDMA Systems. Tese (Doutorado) - Chalmers University of Technology, Göoteborg - Sweden, 1998.

JONG, K. A. D. An analysis of the behavior of a class of genetic adaptive systems. Tese (Doutorado) - Department of computer and Communication Sciences, University of Michigan, Ann Arbor - Michigan, 1975.

JUNTTI, M. J.; SCHLOSSER, T.; LILLEBERG, J. O. Genetic algorithms for multiuser detection in synchronous cdma. In: IEEE International Symposium on Information Theory. Ulm: Germany, 1997. p. 492-492.

KATAYAMA, K.; NARIHISA, H. Performance of simulated annealing-based heuristic for unconstrained binary quadratic programming problem. European Journal of Operational Research, v. 134, p. 103-119, 2001.

KAYE, A. R.; GEORGE, D. A. Transmission of multiplexed pam signals over multiple channel and diversity systems. IEEE Transactions on Communication Technology, v. 18, n. 5, p. 520-526, October 1970.

KIM, J.; CHEUN, K. An efficient decoding algorithm for qo-stbcs based on iterative interference cancellation. IEEE Communications Letters, v. 12, n. 4, p. 292-294, April 2008.

KIRKPATRICK, S.; GELLAT, C. D.; VECCHI, M. P. Optimization by simulated annealing. Science, v. 220, p. 671-680, 1983.

KNUTH, D. Big omicron and big omega and big theta. SIGACT News, ACM, New York, NY, USA, v. 8, n. 2, p. 18-24, April 1976.

KNUTH, D. The Art of Computer Programming, Volume 1: Fundamental Algorithms. Third. [S.1.]: Addison-Wesley, 1997. (CRC series in computational mechanics and applied analysis).

KOCH, W.; BAIER, A. Optimum and Sub-Optimum Detection of Coded Data Disturbed by Time-Varying Inter-Symbol Interfrence. IEEE GLOBECOM'90, v. 3, p. 1679-1684, Dec. 1990.

KRENIK, B. 4g wireless technology: When will it happen? what does it offer? In: IEEE Asian Solid-State Circuits Conference (A-SSCC). [S.l.: s.n.], 2008. p. 141-144.

KURAMOTO, A. S. R.; CIRIACO, F.; ABRãO, T.; JESZENSKY, P. J. E. Sequence design for mpg qs-cdma systems based on heuristic combinatorial optimization. Wireless Communications and Mobile Computing, John Wiley \& Sons, Ltd., 2010. ISSN 1530-8677. Disponível em: <http://dx.doi.org/10.1002/wcm.953>. 
KURAmOTO, A. S. R.; JESZENSKY, P. J. E.; ABRÃO, T. Projeto de seqüências para sistemas qs-cdma multitaxa mpg. In: XXI Simpósio Brasileiro de Telecomunicações. Belém: Brasil, 2004.

LAARHOVEN, P. J. M.; AARTS, E. H. L. Simulated Annealing: Theory and Applications. Dordreech, Holanda: D. Reidel Publishing Company, 1985.

LAIN, J. K.; LAI, J. J. Ant colony optimisation-based multiuser detection for direct-sequence cdma systems with diversity reception. IET Communications, v. 1, n. 4, p. 556-561, August 2007.

LARSSON, E. G.; STOICA, P.; GANESAN, G. Space-Time Block Coding for Wireless Communications. New York: Cambridge University Press, 2003.

LEE, E. A.; MESSERSCHMITT, D. G. Digital Communication. Second. Horwell, MA: Kluwer Academic Publishers, 1994. ISBN 0792393910.

LEE, J. S.; MILLER, L. E. CDMA Systems Engineering Handbook. [S.l.]: Artech House Publishers, 1998.

LIM, H. S.; RAO, M. V. C.; TAN, A. W. C.; CHUAH, H. T. Multiuser detection for ds-cdma systems using evolutionary programming. IEEE Communications Letters, v. 7, p. 101-103, March 2003.

LIM, H. S.; VENKATESH, B. An efficient local search heuristics for asynchronous multiuser detection. IEEE Communications Letters, v. 7, p. 299-301, June 2003.

LIM, H. S.; VENKATESH, B. An effective memetic algorithm for the optimum multiuser detection problem. In: IEEE International Symposium on Spread Spectrum Techniques and Applications. Sydney: Australia, 2004. p. 885-889.

LIN, S.; COSTELLO, D. J. Error Control Coding: Fundamentals and Applications. Englewood Cliffs: Prentice-Hall, 1983.

LINDBOM, L. A Wiener Filtering Approach to the Design of Tracking Algorithms with Applications in Mobile Radio Communications. Tese (Doutorado) — Uppsala University, Sweden, 1995.

LIU, H.; SONG, G. A multiuser detection based on multi-objectives optimization-genetic algorithm. In: International Conference on Networks Security, Wireless Communications and Trusted Computing (NSWCTC). [S.l.: s.n.], 2009. v. 2, p. 286-289.

LIU, X.; CHONG, E. K. P.; SHROFF, N. Opportunistic transmission scheduling with resource sharing constraints in wireless networks. IEEE Journal on Selected Areas in Communications, v. 19, October 2001.

LOPS, M.; BUZZI, S.; TUlinO, A. M. Mmse multiuser detection for asynchronous dual-rate direct sequence cdma communications. In: The Ninth IEEE International Symposium on Personal, Indoor and Mobile Radio Communications. Boston: USA, 1998. p. 8-11.

LU, H. Y. Iterative multiuser detectors for spatial-frequency-time-domain spread multi-carrier ds-cdma systems. IEEE Transactions on Vehicular Technology, v. 60, n. 4, p. 1640-1650, May 2011. 
LU, H. Y.; FANG, W. H. Soft information assisted space-time multiuser detection for highly loaded cdma. IEEE Transactions on Wireless Communications, v. 8, n. 2, p. 662-667, February 2009.

LUBY, M.; MITZENMACHER, M.; SHOKROLLAHI, A.; SPIELMAN, D. Improved low- density parity-check codes using irregular graphs. IEEE Transactions Information Theory, v. 47, n. 2, p. 585-598, 2001.

LUCAS, R.; FOSSORIER, M. P. C.; KOU, Y.; LIN, S. Iterative decoding of one-step majority logic deductible codes based on belief propagation. IEEE Transactions on Communications, v. 48, n. 6, p. 931-937, June 2000.

MACKAY, D. Good error-correcting codes based on very sparse matrices. IEEE Transactions on Information Theory, v. 45, n. 2, p. 399-431, March 1999.

MACKAY, D.; NEAL, R. M. Near shannon limit performance of low density parity check codes. Electronic Letters, v. 33, n. 6, p. 457-458, March 1997.

MADKOUR, M. F.; GUPTA, S. C. Performance analysis of a wireless multirate ds-cdma using fast walsh transformation and decorrelating detection. IEEE Transactions on Communications, p. 1405-1412, August 2000.

MARZETTA, T. L.; HOCHWALD, B. M. Capacity of a mobile multiple antenna communication link in rayleigh flat fading. IEEE Transactions on Information Theory, v. 45, n. 1, p. 139-157, January 1999.

MASSEY, J. L. Threshold Decoding. Massachusetts, USA: M.I.T. Press, Cambridge, 1963.

MAVRIDOU, T. D.; PARDALOS, P. M. Simulated annealing and genetic algorithms for the facility layout problem: A survey. Computational Optimization and Applications, v. 7, p. 111-126, 1997.

MCCABE, T. J. A complexity measure. IEEE Transactions on Software Engineering, v. 2, n. 4, p. 308 - 320, 1976.

METROPOLIS, N.; ROSENBLUTH, A. W.; ROSENBLUTH, M. N.; TELLER, A. H.; TELLER, E. Equation of state calculations by fast computing machine. Journal Chemical and Physical, v. 21, p. 1087-1092, 1953.

MüHLENBEIN, H.; SCHOMISCH, D.; BORN, J. The parallel genetic algorithm as function optimizer. Parallel Computing, n. 17, p. 619-632, 1991.

MICHALEWICZ, Z. A hierarchy of evolution programs: an experimental study. In Evolutionary Computation, v. 1, p. 51-76, 1993.

MICHALEWICZ, Z. Genetic Algorithms + Data Structures = Evolution Programs. Berlin: Springer-Verlag Berlin Heideberg, 1996.

MIETZNER, J.; SCHOBER, R.; LAMPE, L.; GERSTACKER, W. H.; HOEHER, P. A. Multiple-antenna techniques for wireless communications a comprehensive literature survey. IEEE Communications Surveys Tutorials, v. 11, n. 2, p. 87-105, 2009. 
MILLER, S. Y.; SCHWARTZ, S. C. Parameter estimation for asynchronous multiuser communications. In: Conference on Information Sciences and Systems. Boston: Massachusetts, 1989.

MITCHELL, M. An Introduction to Genetic Algorithms. Cambridge: MIT Press, 1998.

MONTGOMERY, D. C. Introduction to statistical quality control. [S.l.]: Wiley, 1996.

MOORE, G. E. Cramming more components onto integrated circuits. Electronics Magazine, v. 38, n. 8, 1965.

MOSCATO, P.; PLATA, L.; NORMAN, M. G. A memetic approach for the traveling salesman problem. In: In Proceedings of the International Conference on Parallel Computing and Transputer Applications. [S.l.]: IOS Press, 1992. p. $177-186$.

MOSHAVI, S. Multi-user detection for ds-cdma communications. IEEE Communications Magazine, v. 34, p. 124-136, October 1996.

MOUSTAFA, M.; HABIB, I.; NAGHSHINEH, M. N. Efficient radio resource control in wireless networks. IEEE Transactions on Wireless Communications, v. 3, p. 2385-2395, November 2004.

NAGUIB, A.; TAROKH, V.; SESHADRI, N.; CALDERBANK, A. R. A space-time coding modem for high-data-rate wireless communications. IEEE Journal on Selected Areas in Communications, v. 16, p. 1459-1477, October 1998.

NATARAJAN, B.; DAS, S.; STEVENS, D. An evolutionary approach to designing complex spreading codes for ds-cdma. IEEE Transactions on Wireless Communications, v. 4, n. 5, p. 2051-2056, September 2005.

NICKL, H.; HAGENAUER, J.; BURKETT, F. Approaching Shannon's Capacity Limit by $0.27 \mathrm{~dB}$ Using Simple Hamming Codes. IEEE Communications Letters, v. 1, p. 130-132, Sep. 1997.

OHHASHI, A.; OHTSUKI, T. Performance analysis and code design of low-density parity-check (ldpc) coded space-time transmit diversity (sttd) system. In: IEEE Global Telecommunications Conference (GLOBECOM). [S.l.: s.n.], 2004. v. 5, p. 3118-3122.

OJANPERA, T.; PRASAD, R. An overview of air interface multiple access for umts/ imt-2000. IEEE Communications Magazine, v. 36, p. 82-95, 1998.

OKANO, W.; CIRIACO, F.; ABRãO, T. Confiabilidade do canal em codificação turbo ds/cdma sujeito a desvanecimento rayleigh e interferência de múltiplo acesso. Revista IEEE América Latina, v. 8, p. 1-8, 2010.

OLIVEIRA, L. D.; ABRAO, T.; JESZENSKY, P. J. E.; CASADEVALL, F. Particle swarm optimization assisted multiuser detector for m-qam ds/cdma systems. In: IEEE Swarm Intelligence Symposium (SIS). [S.l.: s.n.], 2008. p. 1-8. 
OLIVEIRA, L. D.; CIRIACO, F.; ABRAO, T.; JESZENSKY, P. J. E. Particle swarm and quantum particle swarm optimization applied to ds/cdma multiuser detection in flat rayleigh channels. In: IEEE Ninth International Symposium on Spread Spectrum Techniques and Applications (ISSSTA). [S.l.: s.n.], 2006.

OPPERMANN, I.; HäMäLäINEN, M.; IINATTI, J. UWB Theory and Applications. [S.l.]: John Wiley \& Sons, 2004. 233 p. ISBN 0-470-86917-8.

ORNDORFF, A. M. Transceiver Design for Ultra-Wideband Communications. 126 p. Dissertação (Mestrado) - Virginia Polytechnic Institute and State University, Blacksburg, VA, 2004.

OSMAN, I. H.; KELLY, J. P. Meta-Heuristics: Theory and Applications. Boston: Kluwer, 1996. 571-587 p.

OSMAN, I. H.; LAPPORT, G. Metaheuristics: A bibliography. Annals of Operations Research on Metaheuristics, Baltzer, v. 63, 1996.

OSMAN, I. H.; POTTS, C. N. Simulated annealing for permutation flowshop scheduling. Omega, v. 17, p. 551-557, 1989.

OTTOSSON, T. Multirate schemes and multiuser decoding in DS/CDMA systems. Dissertação (Mestrado) - Chalmers University of Technology, Göoteborg - Sweden, 1995.

OTTOSSON, T. Coding, Modulation and Multiuser Decoding for DS-CDMA Systems. Tese (Doutorado) — Chalmers University of Technology, Göoteborg Sweden, November 1997.

OTTOSSON, T.; SVEnSSON, A. Performance of different multirate schemes in ds/cdma systems. In: Nordic Radiosymposium on Radio Communication Networks. Linköping: Sweden, 1994. p. 15-18.

PAPADIMITRIOU, C. H.; STEIGLITZ, K. Combinatorial Optimization Algorithms and Complexity. 2. ed. [S.1.]: Dover, 1998. 496 p. ISBN 0-486-40258-4.

PARKVALL, S.; FURUSKäR, A.; DAHLMAN, E. Evolution of lte toward imt-advanced. IEEE Communications Magazine, v. 49, p. 84-91, February 2011.

PATEL, P.; HOLTZMAN, J. M. Analysis of a single sucessive interference cancellation scheme in a ds/cdma system. IEEE Journal on Selected Areas in Communications, v. 12, p. 796-807, June 1994.

PAU, N. S. J.; TAYLOR, D. P.; MARTIN, P. A. Robust high throughput space time block codes using parallel interference cancellation. IEEE Transactions on Wireless Communications, v. 7, n. 5, p. 1603-1613, May 2008.

PAULRAJ, A.; NABAR, R.; GORE, D. Introduction to Space-Time Wireless Communications. 1. ed. New York: Cambridge University Press, 2008.

PAULRAJ, A. J.; KAILATH, T. Increasing capacity in wireless broadcast systems using distributed transmission/directional reception. USA: U.S. Patent no. 5345599, 1994. 
PEREZ, L. C.; SEGHERS, J.; COSTELLO, D. J. A Distance Spectrum Interpretation of Turbo Codes. IEEE Transactions on Information Theory, v. 42, No.6, p. 1698-1709, Nov. 1996.

PETERSON, R. L.; ZIEMER, R. E.; BORTH, D. E. Introduction to Spread Spectrum Communications. 1. ed. New Jersey: Prentice Hall, 1995.

PICKHOLTZ, R. L.; SCHILlinG, D. L.; MILSTEIN, L. B. Theory of spread spectrum communication - a tutorial. IEEE Transactions on Communications, v. 30, n. 5, p. 855-884, May 1982.

POOR, H. V. On parameter estimation in ds/ssma formats. In: Int. Conf. Advances in Commun. Contr. Syst. Baton Rouge: Louisiana, 1988. v. 1, p. 98-109.

POOR, H. V.; VERDÚ, S. Probability of error in mmse multi-user detection. IEEE Transactions on Information Theory, v. 43, n. 3, p. 858-881, May 1997.

PROAKIS, J. G. Digital Communications. 2. ed. New York: McGraw-Hill, 1995. (Electrical Engineering. Communications and Signal Processing). ISBN 0-07-050937-9.

PYNDIAH, R. M. Near-Optimum Decoding of Product Codes: Block Turbo Codes. IEEE Transactions on Communications, v. 46, No.8, p. 1003-1010, Aug. 1998.

QIN, Z.; CAI, K.; ZOU, X. Turbo multiuser detection based on local search algorithms. In: IEEE International Conference on Communications (ICC). [S.l.: s.n.], 2007. p. 5987-5992.

QIN, Z.; ZOU, X.; CAI, K. Turbo multiuser detection based on simulated annealing. In: IEEE Conference on Industrial Electronics and Applications (ICIEA). [S.l.: s.n.], 2008. p. 1858-1863.

RADOVIC, A.; AAZHANG, B. Iterative algorithms for joint data detection and delay estimation for code division multiple access communication systems. In: 31st Annual Allerton Conference on Communication, Control, and Computing. Monticello: Illinois, 1993. p. 1-10.

RALEIGH, G. G.; CIOFFI, J. M. Spatio-temporal coding for wireless communication. IEEE Transactions on Communications, v. 46, n. 3, p. 357-366, March 1998.

RAMAKRISHNA, J.; HOLTZMAN, S. A comparison between single code and multicode transmission schemes in a cdma system. In: Vehicular Technology Conference. Ottawa: Canada, 1998. p. 791-795.

RAPELI, J. Umts: Targets, system concept, and standardization in a global framework. IEEE Personal Communications, p. 20-28, February 1995.

RAPPAPORT, T. S. Comunicações Sem Fio: Princípios e Práticas. 2. ed. São Paulo: Pearson Prentice Hall, 2009.

RASTRIGIN, L. A. The convergence of the random search method in the extremal control of a many parameter system. Automation and Remote Control, v. 24, n. 10, p. 1337-1342, 1963. 
RAYWARD-SMITH, V. J.; OSMAN, I. H.; REEVES, C. R.; SMITH, G. D. Modern Heuristic Search Techniques. Chichester: John Wiley, 1996.

RECHENBERG, I. Evolution strategy: Optimization of technical systems by means of biological evolution. [S.l.]: Stuttgart: Fromman-Holzboog, 1973.

REEVES, C. Modern Heuristic techniques for combinatorial problems. Oxford: Blackwell Scientific, 1993.

RICHARDSON, T. J.; SHOKROLLAHI, M.; URBANKE, R. Design of capacityapproaching irregular low-density parity-check codes. IEEE Transactions on Information Theory, p. 619-637, February 2001.

RICHARDSON, T. J.; URBANKE, R. The capacity of low-density parity-check codes under message-passing decoding. IEEE Transactions on Information Theory, p. 599-618, February 2001.

RICHARDSON, T. J.; URBANKE, R. Efficient encoding of low-density parity-check codes. IEEE Transactions on Information Theory, p. 638-656, February 2001.

RICHARDSON, T. J.; URBANKE, R. Codes defined on graphs. IEEE Communications Magazine, v. 41, n. 8, p. 126-131, 2003.

ROBERTSON, P.; VILLEBRUN, E.; HOEHER, P. A compararison of optimal and sub-optimal map decoding algorithms operating in the log domain. In: IEEE International Conference on Communications (ICC). [S.l.: s.n.], 1995. p. 1009-1013.

ROBERTSON, P.; WORZ, T. Bandwidth-Efficient Turbo Trellis-Coded Modulation Using Punctured Component Codes. IEEE Journal on Selected Areas in Communications, v. 16, No.2, p. 206-218, Feb. 1997.

ROCHA, A. F. da. Esquemas de multitaxa para sistemas cdma de banda larga. Dissertação (Mestrado) - Escola Politécnica da Universidade de São Paulo, São Paulo - Brasil, Setembro 2002.

ROSENBROCK, H. H. An automatic method for finding the greatest or least value of a function. The Computer Journal, v. 3, n. 3, p. 175-184, 1960.

ROSS, J. The Book of Wi-Fi. [S.l.]: Alta Books, 2003.

ROY, R.; KAILATH, T. Esprit - estimation of signal parameters via rotational invariant techniques. IEEE Trans. Acoust., Speech, Signal Processing, v. 37, n. 7, p. 984-995, July 1989.

SALZ, J. Digital transmission over cross-coupled linear channels. ATEST Technical Journal, v. 64, n. 6, p. 1147-1159, July 1985.

SAQUIB, M. Quality of Service for Multi-Rate DS/CDMA Systems with Multiuser Detection. Tese (Doutorado) - The State University of New Jersey, New Jersey - USA, January 1998.

SCHAFFER, J. D.; CARUANA, R.; ESHELMAN, L. J.; DAS, R. A study of control parameters affecting online performance of genetic algorithms for function optimization. In: Proceedings of the 3rd International Conference on Genetic Algorithms. [S.l.: s.n.], 1989. p. $51-60$. 
SCHLEGEL, C.; GRANT, A. Coordinated Multiuser Communications. [S.1.]: Springer, 2006. 270 p.

SCHLEGEL, C. B.; PéREZ, L. C. Trellis and Turbo coding. [S.l.]: A John Wiley \& Sons, 2004.

SCHMIDT, R. O. Multiple emitter location and signal parameter estimation. IEEE Trans. Antennas Propagation, v. 34, p. 276-280, March 1986.

SCHWARTZ, M. History of communications. IEEE Communications Magazine, v. 46, n. 8, p. 26-29, August 2008.

SCHWEFEL, H. P. Numerical Optimization of Computer Models. Tese (Doutorado) - Birkhäuser Verlag, traduction by John Wiley and Sons in 1980, Basel, 1977.

SENGUPTA, C.; CAVAllaro, J. R.; AAZHANG, B. On multipath channel estimation for cdma using multiple sensors. IEEE Transactions on Communications, v. 49, p. 543-553, March 2001.

SENGUPTA, D.; PALMA, M. S.; OLINER, A.; MAILLOUX, R.; SARKAR, T. Nikola Tesla and His Contributions to Radio Development. [S.1.]: John Wiley and Sons, 2006. 267-289 p.

SERBETLI, S.; YENER, A. Mimo-cdma systems: signature and beamformer design with various levels of feedback. IEEE Transactions on Signal Processing, v. 54, n. 7, p. 2758-2772, July 2006.

SHAH, A. Intel plan to speed supercomputers 500 times by 2018. ComputerWorld, June 2011.

SHAH, S. I.; NAEEM, M.; SHEIKH, A. U. H.; JAMAL, H.; AHMAD, J. A survey of advances in multi-user detection in ds-cdma. In: IEEE International Conference on Computer Systems and Applications. [S.l.: s.n.], 2006. p. 730-737.

SHAKOURI, H.; SHOJAEE, K.; BEHNAM, M. Investigation on the choice of the initial temperature in the simulated annealing: A mushy state sa for tsp. In: Control and Automation, 2009. MED '09. 17th Mediterranean Conference on. [S.l.: s.n.], 2009. p. $1050-1055$.

SHANNON, C. E. A mathematical theory of communication. Bell System Technical Journal, v. 27, p. 379-423 and 623-656, July and October 1948.

SHAYESTEH, M. G.; MENHAJ, M.; NOBARY, B. G. A new modified genetic algorithm for multiuser detection in ds/cdma systems. In: 12th IEEE International Symposium on Personal, Indoor and Mobile Radio Communications. San Diego: California, 2001. v. 1, p. B-11-14.

SHEWART, W. A. Economic control of Quality of Manufactured Product. New York: Van Nostrand Reinhold Co., 1931.

SHIN, H.; KIM, S.; LEE, J. H. Turbo decoding in a rayleigh fading channel with estimated channel state information. In: IEEE Vehicular Technology Conference Fall (VTC Fall). [S.l.: s.n.], 2000. p. 1358-1363. 
SILVA, M. C. D.; MOREIRA, I. C. A introdução da telegrafia elétrica no brasil (1852-1870). Revista da Sociedade Brasileira de História e Ciência, v. 5, p. 47-62, January 2007.

SKLAR, B. A primer on turbo codes concepts. IEEE Communications Magazine, v. 35, p. 94-102, December 1997.

SOBOL, I. M. The Monte Carlo Method. Moscow: MIR, 1975.

SOHN, A. Parallel n-ary speculative computation of simulated annealing. Parallel and Distributed Systems, IEEE Transactions on, v. 6, n. 10, p. 997 1005, October 1995.

SOLEYMANI, M. R.; GAO, Y.; VILAIPORNSAWAI, U. Turbo Coding for Satellite and Wireless Communications. [S.l.]: Kluwer Academic Publishers, 2002.

SOUROUR, E. A.; NAKAGAWA, M. Performance of orthogonal multicarrier cdma in a multipath fading channel. IEEE Transactions on Communications, v. 44, n. 3, p. 356-367, March 1996.

STARR, T.; CIOFFI, J. M.; SILVERMAN, P. J. Understanding digital subscriber line technology. New Jersey: Prentice Hall Communications Engineering and Emerging Technologies Series, 1999.

STRÖM, E. G.; PARKVALL, S.; MILleR, S. L.; OTTERSTEN, B. E. Propagation delay estimation in asynchronous direct sequence code division multiple access systems. IEEE Transactions on Communications, v. 44, n. 1, p. 84-93, January 1996.

SUNG, C. W.; KWAN, H. Y. Heuristic algorithms for binary sequence assignment in ds-cdma systems. In: IEEE International Symposium on Personal, Indoor and Mobile Radio Communications. [S.l.: s.n.], 2002. v. 5, p. 2327-2331.

TAN, P. H. Multiuser detection in CDMA-Combinatorial optimization Methods. 93 p. Dissertação (Mestrado) — Chalmers University of Technology, Göteborg, 2001.

TAN, P. H.; RASMUSSEN, L. K. Multiuser detection in cdma - a comparison of relaxations, exact, and heuristic search methods. Wireless Communications, IEEE Transactions on, v. 3, n. 5, p. 1802 - 1809, September 2004.

TAN, T. H.; HUANG, Y. F.; HSU, L. C.; WU, C. H. Joint channel estimation and multi-user detection for mc-cdma system using genetic algorithm and simulated annealing. In: IEEE International Conference on Systems Man and Cybernetics (SMC). [S.l.: s.n.], 2010. p. 249-256.

TAROKH, V.; JAFARKHANI, H.; CALDERBANK, A. R. Space-time block codes from orthogonal designs. IEEE Transactions on Information Theory, v. 45, n. 5, p. 1456-1467, July 1999.

TAROKH, V.; NAGUIB, A.; SESHADRI, N.; CALDERBANK, A. R. Space-time codes for high data rate wireless communication: Performance criteria in the presence of channel estimation errors, mobility, and multiple paths. IEEE Transactions on Communications, v. 47, p. 199-207, February 1999. 
TAROKH, V.; SESHADRI, N.; CALDERBANK, A. R. Space-time codes for high data rate wireless communication: Performance criterion and code construction. IEEE Transactions on Information Theory, v. 44, n. 2, p. 744-765, March 1998.

TEBO, J. The early history of telecommunications: The first hundred years. IEEE Communications Society, v. 14, p. 12-21, June 1976.

TELATAR, E. Capacity of multi-antenna gaussian channels. European Transactions on Telecommunications, v. 10, p. 585-595, November 1999.

TIA/EIA/IS-2000-2. Physical Layer Standard for cdma2000 Spread Spectrum Systems. USA: Telecommunications Industry Association with Electronic Industries Alliance, August 1999.

TORRIERI, D. J. Principles of secure communication systems. USA: Artech House, 1985. (Artech House communication and electronic defense library).

TUDE, E.; BERNAL, H.; MELlO, J. B.; SOUZA, J. L. D.; MARTINS, V. A. Telefonia Celular. January 2011. http://www.teleco.com.br.

UNGERBOECK, G. Trellis-Coded Modulation with Redundant Signal Sets Part I: Introduction. IEEE Communications Magazine, v. 25, No.2, p. 5-11, Feb. 1987.

UNGERBOECK, G. Trellis-Coded Modulation with Redundant Signal Sets Part II: State of the Art. IEEE Communications Magazine, v. 25, No.2, p. 12-21, Feb. 1987.

VARANASI, M. K.; AAZHANG, B. Multistage detection in asynchronous cdma communications. IEEE Transactions on Communications, v. 38, p. 509-519, April 1990.

VASCONCELOS, J. A.; RAMíREZ, J. A.; TAKAHASHI, R. H.; SALDANHA, $\mathrm{R}$. R. Improvementas in genetic algorithms. IEEE Transactions on Magnetics, v. 37, n. 5, p. 3414-3417, September 2001.

VERDÚ, S. Minimum probability of error for asynchronous gaussian multipleaccess channels. IEEE Transactions on Information Theory, v. 32, p. 85-96, January 1986.

VERDÚ, S. Optimum multiuser asymptotic efficiency. IEEE Transactions on Communications, p. 890-897, September 1986.

VERDÚ, S. Computational complexity of optimum multiuser detection. Algorithmica, v. 4, p. 303-312, 1989.

VERDÚ, S. Multiuser Detection. USA: Cambridge University Press, 1998. ISBN 0-521-59373-5.

VIKALO, H.; HASSIBI, B.; STOICA, P. Efficient joint maximum-likelihood channel estimation and signal detection. IEEE Transactions on Wireless Communications, v. 5, n. 7, p. 1838-1845, July 2006. 
VITERBI, A. Error bounds for convolutional codes and an asymptotically optimum decoding algorithm. IEEE Transactions on Information Theory, v. 13, n. 2, p. 260-269, April 1967.

VOB, S. Meta-heuristics: The state of art. In: NAREYEK, A. (Ed.). Local Search for Planning and Scheduling. [S.l.]: Springer-Verlag Berlin Heidelberg, 2001. p. 1-23.

WACHSMANN, U.; HUBER, J. Power and Bandwidth Efficient Digital Communications Using Turbo Codes in Multilevel Codes. European Transactions on Telecommunications (ETT), v. 6, p. 557-567, Sep. - Oct. 1995.

WHALEN, D. J. The worldwide history of telecommunications - book review. IEEE Technology and Society Magazine, v. 24, p. 54-55, Janeiro 2005.

WHITLEY, D.; MATHIAS, K.; RANA, S.; DZUBERA, J. Building better test functions. In: Proceedings of the Sixth International Conference on Genetic Algorithms. [S.l.: s.n.], 1995. p. 239-246.

WICKER, S. B. Error Control Systems for Digital Communications and Storage. First. Upper Saddle River, NJ, USA: Englewood Cliffs: Prentice-Hall, 1995. ISBN 0-13-200809-2.

WINTERS, J. H. Optimum combining in digital mobile radio with cochannel interference. IEEE Transactions on Vehicular Technology, v. 33, n. 3, p. 144-155, August 1984.

WINTERS, J. H. The diversity gain of transmit diversity in wireless systems with rayleigh fading. IEEE Transactions on Vehicular Technology, v. 47, n. 1, p. 1119-1123, February 1998.

WITTNEBEN, A. Basestation modulation diversity for digital simulcast. In: IEEE Vehicular Technology Conference. [S.1.: s.n.], 1991. p. 848-853.

WITTNEBEN, A. A new bandwidth efficient transmit antenna modulation diversity scheme for linear digital modulation. In: IEEE International Conference on Communications (ICC). [S.l.: s.n.], 1993. v. 3, p. 1630-1634.

WOLFGAnG, A.; AHMAD, N. N.; CHEN, S.; HANZO, L. Genetic algorithm assisted minimum bit-error rate beamforming. In: Proc. IEEE Vehicular Technology Conf. (VTC-Spring). Milan: Italy, 2004. p. 142-146.

WONG, K. L.; CONSTANTINIDES, A. G. Speculative parallel simulated annealing with acceptance prediction. Computers and Digital Techniques, IEE Proceedings, v. 143, n. 4, p. 219 - 223, July 1996.

WOODARD, J. P.; HANZO, L. Comparative study of turbo decoding techniques: An overview. IEEE Transactions on Vehicular Technology, v. 49, n. 6, p. 2208-2234, November 2000.

WOZENCRAF, J. M. Sequential Decoding for Reliable Communication. IRE Conventional Record, v. 5, n. 2, p. 11-25, 1957.

WOZENCRAFT, J. M.; REIFFEN, B. Sequence Decoding. Cambridge, MA, USA: MIT Press, 1961. 
WU, X.; CHUAH, T. C.; SHARIF, B. S.; HINTON, O. R. Adaptive robust detection for cdma using a genetic algorithm. IEE Proceeding Communications, v. 150, n. 6 , p. 437-444, December 2003.

XIAO, Y. Ieee 802.11n: Enhancements for higher throughput in wireless lans. IEEE Wireless Communications, p. 82-91, December 2005.

XIE, Z.; RUSHFORTH, C. K.; SHORT, R. T.; MOON, T. K. Joint signal detection and parameter estimation in multiuser communications. IEEE Transactions on Communications, v. 41, n. 7, p. 1208-1215, August 1993.

XIN, L.; JIAN-HUA, W.; JONG, X. Methods for obtaining cir based on ifft in mimo-ofdma mobile communication systems. In: International Conference on Wireless Communications, Networking and Mobile Computing (WiCOM). [S.l.: s.n.], 2008. p. 1-4.

XU, B. Particle-swarm-optimization based turbo multiuser detection for stbc mc-cdma systems. In: IEEE 19th International Symposium on Personal, Indoor and Mobile Radio Communications (PIMRC). [S.l.: s.n.], 2008. p. 1-5.

XU, B.; AN, J.; ZHOU, R.; WANG, A. Turbo multiuser detection for stbc mc-cdma uplink systems using hybrid particle swarm optimization algorithm. In: Third International Conference on Communications and Networking in China (ChinaCom). [S.1.: s.n.], 2008. p. 987-991.

YANG, L.; GIANNAKIS, G. B. Ultra-wideband communications: An idea whose time has come. IEEE Signal Processing Magazine, v. 21, p. 26-54, November 2004 .

YANG, L. L. Multicarrier communications. [S.l.]: John Wiley \& Sons Ltda, 2009 .

YANG, L. L.; HANZO, L. Performance of generalized multicarrier ds-cdma over nakagami-m fading channels. IEEE Transactions on Communications, v. 50, n. 6, p. 956-966, June 2002.

YANG, L. L.; HANZO, L. Multicarrier ds-cdma: A multiple-access scheme for ubiquitous broadband wireless communications. IEEE Communications Magazine, v. 41, n. 10, p. 116-124, 2003.

YANG, L. L.; HUA, W.; HANZO, L. A multicarrier ds-cdma system using both time-domain and frequency-domain spreading. In: IEEE Vehicular Technology Conference Fall (VTC Fall). [S.l.: s.n.], 2003.

YANG, L. L.; HUA, W.; HANZO, L. Multiuser detection assisted time-and frequency-domain spread multicarrier code-division multiple-access. IEEE Transactions on Vehicular Technology, v. 55, n. 1, p. 397-404, January 2006.

YEN, K.; HANZO, L. Hybrid genetic algorithm based multiuser detection schemes for synchronous cdma systems. In: 51th IEEE Vehicular Technology Conference. Tokyo: Japan, 2000. p. 1400-1404.

YEN, K.; HANZO, L. Genetic algorithm assisted joint multiuser symbol detection and fading channel estimation for synchronous cdma systems. IEEE Journal on Selected Areas in Communications, v. 19, n. 6, p. 985-998, June 2001. 
YEN, K.; HANZO, L. Antenna-diversity-assisted genetic-algorithm-based multiuser detection schemes for synchronous cdma systems. IEEE Transactions on Communications, v. 51, n. 3, p. 366-370, 2003.

YEN, K.; HANZO, L. Genetic-algorithm-assisted multiuser detection in asynchronous cdma communications. IEEE Transactions on Vehicular Technology, v. 53, n. 5, p. 1413-1422, September 2004.

YIP, P. P. C.; PAO, Y. H. Combinatorial optimization with use of guided evolutionary simulated annealing. IEEE Transactions on Neural Networks, v. 6, n. 2, p. 290 - 295, March 1995.

YUEN, C.; GUAN, Y. L.; TJHUNG, T. T. Quasi-orthogonal stbc with minimum decoding complexity: further results. In: IEEE Wireless Communications and Networking Conference. [S.l.: s.n.], 2005. v. 1, p. 483-488.

ZEXIAN, L.; LATVA-AHO, M. Spatial transmit diversity techniques for mc-cdma systems. In: International Symposium on Spread Spectrum Techniques and Applications (ISSSTA). [S.1.: s.n.], 2002. v. 1, p. 155-159.

ZHANG, Q. L. Metrics for meta-heuristic algorithm evaluation. In: International Conference on Machine Learning and Cybernetics. [S.l.: s.n.], 2003. v. 2, p. 1241-1244.

ZHANG, R.; HANZO, L. Harmony search aided iterative channel estimation, multiuser detection and channel decoding for ds-cdma. In: IEEE Vehicular Technology Conference Fall (VTC Fall). [S.1.: s.n.], 2010. p. 1-5.

ZHAO, W.; LU, M. Cdma downlink rate allocation for heterogeneous traffic based on utility function: Ga-sa approach. In: Second Annual Conference on Communication Networks and Services Research. Fredericton: Canada, 2004. p. 156-162.

ZHONG, H.; ZHANG, T. Block-ldpc: a practical ldpc coding system design approach. IEEE Transactions on Circuits and Systems I: Regular Papers, v. 52, n. 4, p. 766-775, April 2005.

ZHOU, J.; CHEN, J.; KIKUCHI, H.; SASAKI, S.; MURAMATSU, S. Convergence rate evaluation of a ds-cdma cellular system with centralized power control by genetic algorithms. In: IEEE Wireless Communications and Networking Conference. Orlando: Florida, 2002. v. 1, p. 177-182.

ZIEMER, R. E.; PETERSON, R. L. Introduction to Digital Communication. 2. ed. New Jersey: Prentice Hall, 2001. 